\title{
India's Competition Regimes and Informal Business Institutions: \\ Interaction, Conflict and Accommodation
}

\author{
Derek Ireland
}

A thesis submitted to the Faculty of Graduate Studies and Research

In partial fulfillment of the requirements for the degree of

Doctor of Philosophy

School of Public Policy

Carleton University

Ottawa, Ontario

December 2008 


$\begin{array}{ll}\begin{array}{l}\text { Library and } \\ \text { Archives Canada }\end{array} & \begin{array}{l}\text { Bibliothèque et } \\ \text { Archives Canada }\end{array} \\ \begin{array}{l}\text { Published Heritage } \\ \text { Branch }\end{array} & \begin{array}{l}\text { Direction du } \\ \text { Patrimoine de l'édition }\end{array} \\ \begin{array}{l}\text { 395 Wellington Street } \\ \text { Ottawa ON K1A 0N4 } \\ \text { Canada }\end{array} & \begin{array}{l}\text { 395, rue Wellington } \\ \text { Ottawa ON K1A 0N4 } \\ \text { Canada }\end{array}\end{array}$

Your file Votre référence ISBN: 978-0-494-47467-9 Our file Notre référence ISBN: 978-0-494-47467-9

NOTICE:

The author has granted a nonexclusive license allowing Library and Archives Canada to reproduce, publish, archive, preserve, conserve, communicate to the public by telecommunication or on the Internet, loan, distribute and sell theses worldwide, for commercial or noncommercial purposes, in microform, paper, electronic and/or any other formats.

The author retains copyright ownership and moral rights in this thesis. Neither the thesis nor substantial extracts from it may be printed or otherwise reproduced without the author's permission.
AVIS:

L'auteur a accordé une licence non exclusive permettant à la Bibliothèque et Archives Canada de reproduire, publier, archiver, sauvegarder, conserver, transmettre au public par télécommunication ou par l'Internet, prêter, distribuer et vendre des thèses partout dans le monde, à des fins commerciales ou autres, sur support microforme, papier, électronique et/ou autres formats.

L'auteur conserve la propriété du droit d'auteur et des droits moraux qui protège cette thèse. $\mathrm{Ni}$ la thèse ni des extraits substantiels de celle-ci ne doivent être imprimés ou autrement reproduits sans son autorisation.
In compliance with the Canadian Privacy Act some supporting forms may have been removed from this thesis.

While these forms may be included in the document page count, their removal does not represent any loss of content from the thesis.
Conformément à la loi canadienne sur la protection de la vie privée, quelques formulaires secondaires ont été enlevés de cette thèse.

Bien que ces formulaires aient inclus dans la pagination, il n'y aura aucun contenu manquant.

\section{Canada}




\title{
India's Competition Regimes and Informal Business Institutions: Interaction, Conflict and Accommodation
}

\author{
Derek Ireland
}

\section{A thesis submitted to the Faculty of Graduate Studies and Research}

In partial fulfillment of the requirements for the degree of

Doctor of Philosophy

School of Public Policy

Carleton University

Ottawa, Ontario

December 2008 


\begin{abstract}
This dissertation conducts analysis on the evolution of India's competition regimes from 1965 to the present day. The central research question is: How have India's competition regimes interacted and conflicted with and accommodated themselves to the country's informal business institutions? Special attention is given to the country's traditional family-based business groups, which predate its formal competition rules by many decades.
\end{abstract}

Two time-dependent arguments and a comparative case study approach are employed. The approach predicts that the interactions would be very different before 1991, compared with the post-1991 period when new business interests emerged, economic liberalization accelerated, and detailed discourse, debate and analysis took place on a new formal competition regime for India.

The dissertation adds to the comparatively little academic research on competition policy in India over the past two decades. It as well illustrates the benefits from applying to competition policies in developing economies a competition regime approach and a more comprehensive conceptual framework that encompasses recent advances in new institutional economics and related economics literatures.

Informal business institutions proved to be a good prism for analysing the evolution of India's competition regimes over a four decade period that experienced dramatic changes in the country's economic performance and the broader economic policy regime and discourse. India's traditional family-based business groups continue to be very important to India's private economy. As predicted, the number, quality and outcomes from the interactions, conflicts and accommodations between India's competition regimes and informal business institutions are very different after 1991 compared with before. These differences made an important contribution to the improved performance of the Indian economy after 1991.

At the same time, the empirical story is richer and more complex than presumed by the two arguments. A single direction argument for the pre-1991 period -- that well established informal business institutions would prevent the competition regime from achieving its objectives -- was enriched by assessing the strategic responses of business groups in order to avoid the high transactions costs and risks of dealing with the pre-1991 competition regime. Consistent with path dependence, past interactions are presenting difficult challenges for the new competition regime. 


\section{Acknowledgement}

First and foremost, I would like to thank my supervisor, Bruce Doern, and the two members of my PhD Committee, Stephan Schott and Christopher Stoney, all of Carleton University, Ottawa Canada, for their guidance, professionalism, diligence, patience and encouragement over an extended period, in keeping me "on track", enriching the analysis, and helping to make my overly long early drafts more concise, understandable and readable. I would as well like to thank the many other professors and staff and my fellow students and colleagues at the School of Public Policy, Carleton University, for their continuous support and in teaching me how to apply political-economic ideas in new ways to complex research and economic policy problems.

I also wish to extend my appreciation to the many friends and colleagues in government, international institutions, the academic community, and the legal and business communities in Canada and many other developed and developing countries who, many years ago, first taught me about competition policy and law, and then encouraged me to first begin and then complete a PhD at a comparatively advanced age.

In this regard, I would particularly like to acknowledge the assistance and support of CUTS International (the Consumer Unity and Trust Society) of Jaipur India, which was the host for my Indian field research throughout the summer of 2006. I particularly valued the assistance and advice of Pradeep S. Mehta, the CUTS Secretary General, and of Manish Agarwal and Nitya Nanda who at that time were senior officers at the CUTS Centre for Competition, Investment and Economic Regulation. Their excellent expertise, information, advice, and encouragement both during and after the field work in India played a pivotal role in the successful completion of my $\mathrm{PhD}$ dissertation. In addition, my extensive and highly valuable field research in India would not have been possible without a very generous and timely Doctoral Fellowship Award from SSHRC, the Social Sciences and Humanities Research Council of Canada.

Finally and most importantly, I would like to thank my wife Ruby, my two children Naomi and Kevin, and my two grandchildren Danielle and Gabrielle, for their constant encouragement, patience and support over the five plus years that I needed to fully complete the PhD program at the School of Public Policy of Carleton University. 


\section{Table of Contents}

$\begin{array}{lc} & \text { Page } \\ \text { Abstract } & \text { ii } \\ \text { Acknowledgement } & \text { iii } \\ \text { Glossary of Terms and Abbreviations } & \text { ix } \\ \text { India Map } & \text { xi } \\ \text { Introduction } & \mathbf{1} \\ \text { Part I: Context, Economics Literatures Engaged and Conceptual } & 15 \\ \text { Framework } & \\ \text { Chapter 1: Competition Policy and Law in India and Other Countries } & 15 \\ \text { 1.1 Purpose } & 15 \\ \text { 1.2 Competition Policy and Law in Other Countries } & 15 \\ \text { 1.3 History of Competition Policy and Law in India } & 22 \\ \text { 1.4 Conclusions } & 43\end{array}$

Chapter 2: Economic Literatures Engaged to Construct the Conceptual 46 Framework

2.1 Purpose

46

2.2 Placing New Institutional Economics into a Broader Economic Theory 47 Context

2.3 Major Features of New Institutional Economics (NIE) 56

2.4 Williamson's Transactions Cost Economics (TCE) Model and Its 59

Implications for the Conceptual Framework and Empirical Analysis

2.5 Importance of NIE Concepts to Developing Economies 65

2.6 Extensions to the Williamson Model Relevant to the Conceptual 68

Framework

2.7 Overlaps, Synergies and Differences between New Institutional Economics $\quad 83$

(NIE) and New Industrial Organization (NIO) Economics

2.8 Conclusions

Chapter 3: Conceptual Framework and Methodology 92

3.1 Purpose $\quad 92$

3.2 Expanding on the Purpose and Central Question 92

3.3 The Two Time-Dependent Arguments That Support the Comparative Case $\quad 97$

Study Approach

3.4 Assessing the Number and Quality of and the Outcomes from These

107

Interactions and Accommodations

3.5 Summary of the Methodology

3.6 Three Major Challenges in Applying the Conceptual Framework and Model

3.7 Preparation and Application of the Research Questions and Related

Interview Methods

3.8 Conclusions 
Part II: Empirical Analysis of the Interactions, Conflicts and

Accommodations Between India's Competition Regimes and Informal

Business Institutions

Chapter 4: Competition Regimes and Informal Business Institutions in

India's Economic and Business History

4.1 Purpose

125

4.2 Importance of Informal Business Institutions in India's Business and

125

Economic History

4.3 The Role of Informal Business Institutions in Balancing Competition and

126

Cooperation in Pre-Colonial India

4.4 Evolution of India's Business Groups and Other Informal Business

Institutions

4.5 Changes in Business Culture and Relationships under British Colonial Rule

4.6 Potential for the Pre-Colonial Competition Culture to Have Some

Resonance in Modern India

4.7 Conclusions

151

Chapter 5: India's Competition Regimes and Informal Business Institutions Within The Country's Broader Economic Policy Regimes

5.1 Purpose

5.2 India's Post Independence License Raj and its Implications Up To 1991

5.3 Implications of the License Raj for Domestic Competition and

International Competitiveness Before and After 1991

5.4 Liberalization and Trade Reforms Which Started in the 1980s and

Accelerated After 1991

5.5 Implications of Liberalization for Economic Growth, Equity and the

Quality of Life

5.6 Summary of the Current Discourse on the Benefits and Costs of

Liberalization

5.7 Conclusions

Chapter 6: Interactions, Conflicts and Accommodations Between India's

Did Not Reduce Industrial Concentration and Promote Competition

6.4 Interactions, Conflicts and Accommodations From the Perspective of India's Business Groups and Other Informal Business Institutions and Arrangements 
6.5 Broader Consequences of the Interactions and Accommodations for

Competition, Market Structure, Business Conduct and Performance From 1965

to 1991

6.6 The MRTPA Legacy for the New Post-1991 Competition Law and Regime

Chapter 7: Interactions, Conflicts and Accommodations Between India's

Still Evolving Competition Regime and Informal Business Institutions From 1991 to the Present Day

7.1 Purpose

7.2 Limited Interaction with, Accommodation to, and Influence of Traditional

Business Groups and Other Key Domestic and External Stakeholders

Regarding India's Post 1991 Liberalization Program

7.3 Interactions and Accommodations with India's Traditional Business

Groups and Other Non-Government Stakeholders in Designing the New

Competition Law and Regime

7.4 Summary of the Major Interactions, Accommodations and Outcomes and Their Implications from the Competition Regime Perspective

7.5 Role of Business Groups and the Business Lobby in Delaying Enforcement of the New Competition Law

7.6 The Continuing MRTPA Legacy and its Implications for Current and

Future Interactions, Conflicts and Accommodations

7.7 Conclusions

Chapter 8: Analysis of the Post-1991 Interactions, Conflicts and

Accommodations From the Perspective of India's Traditional Business Groups and New Economy Informal Business Institutions

8.1 Purpose

8.2 Accommodations and Strategic Responses of the Business Groups and

Other Informal Business Institutions to the Opportunities, Challenges and Pressures of the Post-1991 Competition Regime

8.3 Interactions Designed to Respond to and Capitalize on the Remaining

Deficiencies in the Post-1991 Competition Regime

8.4 Implications of Interactions and Accommodations for the Future of India's Traditional Business Groups

8.5 Responses of New Economy Industries, Companies and Informal Business Institutions and Arrangements

8.6 Conclusions

Chapter 9 Comparing the 1965-1991 and Post-1991 Case Studies

9.2 Comparing the Interactions and Accommodations Between the Two Time

Periods from the Competition Regime Perspective 
9.3 Comparing the Interactions and Accommodations Between the Two Time

Periods from the Perspective of India's Informal Business Institutions

9.4 Conclusions

Chapter 10: Conclusions

10.1 Contributions of the Dissertation

10.2 Purpose of the Dissertation

10.3 The Central Question and Three Kinds of Interactions

10.4 The Two Time Dependent Arguments and Case Studies

10.5 Research Implications and Areas for Future Research

\section{List of Exhibits}

Exhibit I: Competition Regimes and the Informal Business Institutions of India Exhibit II: Overview of the Conceptual Framework

Exhibit IV: Major Milestones in the Evolution of India's Competition Regimes

Exhibit V: Comparing the New Competition Commission of India (CCI) with for this Dissertation

Exhibit VII: Rise and Fall of Business Groups and Similar Business Arrangements

Exhibit VIII: Accommodations and Interactions Between India's Competition

Regime and Informal Business Institutions From 1965 to 1991

Exhibit IX: Accommodations and Interactions Between India's Competition

Regime and Informal Business Institutions From 1991 to the Present

Exhibit X: Translating Informal Business Institutions Into Rules of Business

Conduct and Business Arrangements, Groups and Networks

Exhibit XI: Continuity and Change in India's Informal Business

Institutions and Arrangements for Over 2000 Years

Exhibit XII: Stylized Family-Based Indian Business Group/Conglomerate

Exhibit XIII: Evolution of the Competition Regimes and Culture and Their

Interactions with and Implications for India's Informal Business Institutions from the Pre-Colonial Period to the Present Day

Exhibit XIV: Comparison of the Three Broader Economic Policy Regimes

And Their Outcomes and Consequences

Exhibit XVI: Summary of the Enforcement History of the MRTPA and 
Exhibit XVII: Summary of Post-1991 Interactions and Accommodations

And Their Anticipated Outcomes and Consequences

Exhibit XVIII: Comparing the Interactions and Accommodations Between the

Two Time Periods

Exhibit XIX: Accommodations and Responses of India's Traditional

Business Groups to Changes in the Competition Regime

\section{List of Appendices}

Appendix 1: Key Definitions Used Throughout the Dissertation

Appendix 2: Specifications for the "Equations" in the "Conceptual Model" on

the Interactions and Accommodations between India's Competition Regimes and Its Informal Business Institutions and Arrangements

Appendix 3: Research Instrument and Questions Used for the Field Research Interviews and the Literature Review

Appendix 4: List of Research Participants: From the Fieldwork in India During the Summer of 2006

Appendix 5: Major Events and Milestones in the Evolution of India's Competition Regimes

Appendix 6: Major Developments and Events in Indian History Relevant to This Thesis

Appendix 7: Comparing The Gross Revenues of Major Business Groups

With India's Gross National Income (GNI) for 2005

Appendix 8: Analysis of Selected MRTPA Cases and Their Possible Impacts On Corporate Structure, Behaviour and Attitudes

Appendix 9: Comparisons of the Two Case Studies and Competition Regimes In Terms of the Strategic Accommodations and Responses of the Traditional Business Groups 


\section{Glossary of Terms and Abbreviations}

$\begin{array}{ll}\text { ADB } & \text { Asian Development Bank } \\ \text { AOD } & \text { Abuse of Dominance } \\ \text { APEC } & \text { Asia Pacific Economic Cooperation (Forum) } \\ \text { ASSOCHAM } & \begin{array}{l}\text { Associated Chambers of Commerce and Industry of India (generally had } \\ \text { strong participation from foreign invested and owned companies) }\end{array} \\ \text { BOP } & \text { Balance of Payments } \\ \text { BPO } & \text { Business Process Outsourcing } \\ \text { CAT } & \text { Competition Appellate Tribunal (of India) under the Competition } \\ & \text { Amendment Act 2007 } \\ \text { CCI } & \text { Competition Commission of India } \\ \text { C-CIER } & \text { CUTS Centre for Competition, Investment, and Economic Regulation- } \\ \text { CII } & \text { established in Jaipur India in 2003 } \\ \text { CIRC } & \text { Confederation of Indian Industry } \\ \text { COPRA } & \text { CUTS Institute for Regulation and Competition established in 1983 in } \\ & \text { the Indian State of Jaipur Rajasthan } \\ \text { Consumer Protection Agency - established in 1986 and overlaps to a } \\ \text { CSR } & \text { considerable degree with the UFT provisions under the MRTPA } \\ \text { CUTS } & \text { amendments of 1984 } \\ & \text { Corporate Social Responsibility } \\ \text { Consumer Unity and Trust Society of India - the Host for the Author's } \\ \text { DFID } & \text { Field Work in India } \\ \text { EU } & \text { Department for International Development (of the United Kingdom) } \\ \text { FDI } & \text { European Union } \\ \text { FERA } & \text { Foreign Direct Investment } \\ \text { FICCI } & \text { Foreign Exchange Regulation Act (of 1973) } \\ \text { GDP } & \text { Federation of Indian Chambers of Commerce and Industry } \\ \text { GNP } & \text { Gross Domestic Product } \\ \text { GOI } & \text { Gross National Product } \\ & \text { Government of India } \\ \text { ICP } & \text { Indian Congress Party (also called the Indian National Congress or INC) } \\ \text { IFIs } & \text { International Financial Institutions - the International Monetary Fund } \\ \text { IMF } & \text { (IMF), World Bank, Asian Development Bank etc. } \\ \text { IO } & \text { International Monetary Fund } \\ \text { IP } & \text { Industrial Organization } \\ \text { IPRs } & \text { Intellectual Property } \\ \text { IT } & \text { Intellectual Property Rights } \\ \text { ICT } & \text { Information Technology } \\ \text { MNCs } & \text { Information and Communications Technology } \\ \text { MRTPA } & \text { Multi-National Corporations } \\ \text { MRTPC } & \text { Monopolies and Restrictive Trade Practices Act } \\ \text { MTP } & \text { Monopolies and Restrictive Trade Practices Commission } \\ \text { Monopolistic Trade Practices (under the MRTPA) }\end{array}$




\begin{tabular}{|c|c|}
\hline NAFTA & North American Free Trade Agreement \\
\hline NCE & Neoclassical Economics \\
\hline NEIO & New Empirical Industrial Organization (Economics) \\
\hline $\mathrm{NGO}$ & Non-Government Organization \\
\hline NIE & New Institutional Economics \\
\hline NIO & New Industrial Organization (Economics) \\
\hline NPC & National People's Congress of China \\
\hline OECD & Organization for Economic Cooperation and Development \\
\hline PRC & People's Republic of China \\
\hline PSUs & Public Sector Undertakings \\
\hline RBPs & Restrictive Business Practices \\
\hline Rs & Indian Rupees \\
\hline RTPs & $\begin{array}{l}\text { Restrictive Trade Practices (under the MRTPA and in the UNCTAD } \\
\text { competition policy and law literature) }\end{array}$ \\
\hline SCP & $\begin{array}{l}\text { Structure/Conduct/Performance model for assessing market competition } \\
\text { (in the traditional IO) }\end{array}$ \\
\hline SOEs & State-Owned Enterprises \\
\hline TCE & Transactions Cost Economics \\
\hline TELCO & Tata Engineering and Locomotive Company \\
\hline TFP & Total Factor Productivity \\
\hline TISCO & Tata Steel \\
\hline TOR & Terms of Reference \\
\hline UTPs & $\begin{array}{l}\text { Unfair Trade Practices (under the amended MRTPA of } 1984 \text { - these are } \\
\text { usually addressed under consumer protection laws, and were not included } \\
\text { in the new Competition Act 2002) }\end{array}$ \\
\hline UNCTAD & $\begin{array}{l}\text { United Nations Conference on Trade and Development -- which has } \\
\text { responsibility for restrictive business practices, competition policy and } \\
\text { competition law within the UN System }\end{array}$ \\
\hline WTO & World Trade Organization \\
\hline
\end{tabular}




\section{ADMINISTRATIVE MAP OF INDIA}

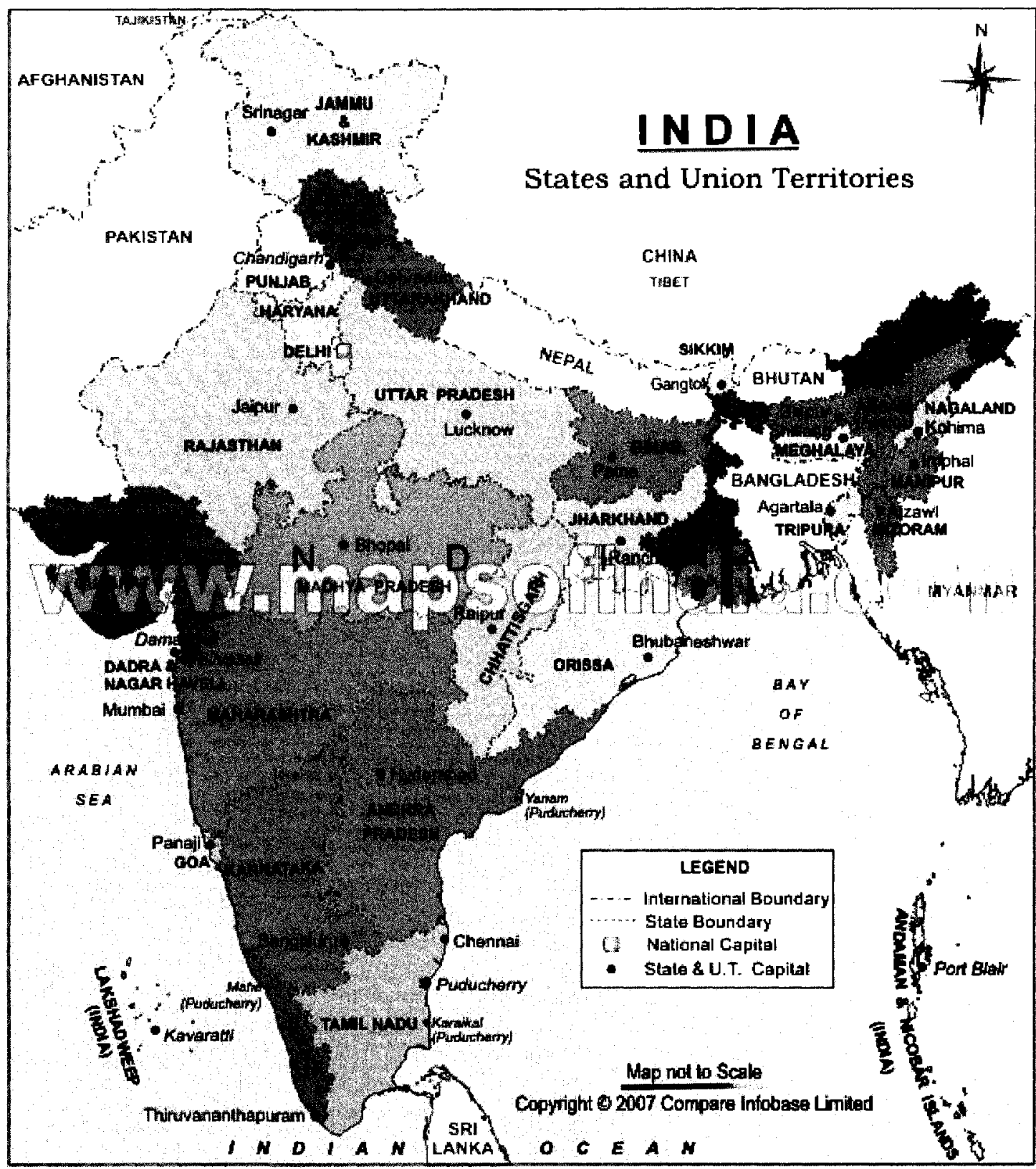




\section{Introduction}

\section{Purpose and Literatures Engaged}

The purpose of this dissertation is to analyze the evolution of India's competition regimes from 1965 up to the present day. The thesis examines the interactions, conflicts and accommodations between India's competition regimes and the country's informal business institutions, informal rules of business conduct and informal business arrangements (see Exhibit I on the next page). The research has been conducted from the perspective that the evolution of competition regimes within India cannot be fully explained and understood without as well developing a thorough understanding of the country's informal business institutions, including its informal business practices, norms ${ }^{1}$, values, and rules of conduct and arrangements. Because they predate formal competition rules by many decades and even centuries, these informal business institutions are well established and embedded within India's economy and society and therefore have shaped the evolution of the formal and informal components of its competition regimes throughout the country's long and complex economic history up to the present day. Other forces and institutions, that have also had an influence on India's competition regimes, are addressed where relevant as part of the empirical story in Chapters $4-10$, rather than as significant elements in the conceptual framework described in Chapter 3.

\section{Exhibit I: Competition Regimes and the Informal Business Institutions of India}

\footnotetext{
${ }^{1}$ Throughout this dissertation, the term norm refers to an obligation that directs behaviour, not just a social regularity which is more like a convention or custom (as per Cooter 1994, p. 220).
} 


\begin{tabular}{|c|c|}
\hline $\begin{array}{l}\text { India's Competition Regimes } \\
\text { 1. Formal competition law and the competition agency } \\
\text { that enforces that law. } \\
\text { 2. More direct formal competition policies based on the } \\
\text { enforcement activities, voluntary compliance programs, } \\
\text { and education, advocacy and partnership building } \\
\text { efforts of the competition agency, working with its } \\
\text { partners in and outside government. } \\
\text { 3. Other formal policy and regulatory regimes - trade, } \\
\text { industrial, innovation, competitiveness, intellectual } \\
\text { property, corporate governance, bankruptcy, consumer } \\
\text { protection, sectoral regulation etc. -- that influence } \\
\text { competition in a positive or negative way } \\
\text { 4. Directive principles in the Indian Constitution on the } \\
\text { distribution of material resources and the concentration } \\
\text { of wealth and means of production } \\
5 \text {. India's "competition culture": informal business and } \\
\text { other institutions, rules, conduct, practices, routines, } \\
\text { attitudes, rhetoric, and organizations (including } \\
\text { business arrangements) of Indian private and state- } \\
\text { owned companies, of government officials/agencies } \\
\text { and other Indian elites, consumers and other economic } \\
\text { agents that have positive and negative influences on } \\
\text { competition and market incentives and outcomes. }\end{array}$ & $\begin{array}{l}\text { Informal Business } \\
\text { Institutions and } \\
\text { Arrangements } \\
\text { 1. India's traditional } \\
\text { business groups, the } \\
\text { merchant and industrial } \\
\text { houses and managing } \\
\text { agencies of the past, and } \\
\text { the new economy informal } \\
\text { business institutions and } \\
\text { arrangements that have } \\
\text { emerged particularly } \\
\text { during the post-1991 } \\
\text { liberalization period. } \\
\\
\text { 2. And the informal } \\
\text { business institutions and } \\
\text { rules of business conduct } \\
\text { that led to their } \\
\text { establishment and have } \\
\text { helped them to persist, } \\
\text { continue to be functional, } \\
\text { and to provide benefits to } \\
\text { their member companies } \\
\text { up to the present day. }\end{array}$ \\
\hline
\end{tabular}

Note: For the most part, from 1965 on, competition regimes relate to the formal legal, policy and regulatory components. However, there is some overlap between the informal component of the competition regime in the left-hand side box, and the informal business institutions in the right hand side box. This overlap involves the informal business institutions, conduct, practices and attitudes of Indian businesses that influence market competition on the left side, and the informal institutions, rules of business conduct and arrangements of India's business groups and other informal business arrangements and networks on the right side. The latter is essentially a subset of and thus influences the former, the country's informal "competition culture". This informal component of the competition regime is particularly important to the pre-1965 analysis.

The competition regime is a subset of the broader economic policy environment and regime which was dominated by the "License Raj" before 1991 and India's liberalization program after 1991 -- see Appendices 1 and 2, section 7.1, and the text and footnote 247 in section 8.1. As discussed there, the competition regime before 1991 embodied a relatively identifiable and well articulated set of policies, laws and regulations that influenced competition and business entry and exit (generally in a negative manner). The boundaries of the post-1991 competition regime are more difficult to identify. This is mainly because the new competition law and policy are not yet being administered and enforced. The result is that the post-1991 competition regime used in this analysis is a "work-in-progress", which largely encompasses the weakening of the old competition law, the elimination of many but not all of the pre-1991 policies, laws and regulations, and the introduction of new policies and regulatory regimes in the areas of sectoral regulation, international trade, innovation and competitiveness. These new policies and regimes were designed to achieve other objectives but have important and often, but not always, positive consequences for competition. 
To achieve the research purpose, the thesis draws on three main streams of literature: literature on competition policy, law and regimes (which provides the context in Chapter 1); literature on Indian economic and business history and the Indian political economy (discussed in Chapters 1, 4 and 5 and employed selectively in the remaining empirical chapters); and literature on the new institutional economics, as discussed in Chapter 2. In particular, the conceptual framework for the thesis in Chapter 3 is anchored in new institutional economics (NIE), as developed by such scholars as North (1990) and Williamson (1975, 1985, 1986, 2000:1 and 2000:3).

For new institutional economists and other institutional scholars, history, path dependence, and formal and informal institutions - including the informal rules of business conduct - are important to past economic performance and current economic and political outcomes. The conceptual framework gives particular attention to the work of Oliver Williamson who raised serious questions about how formal competition regimes should be designed and enforced based on his transactions cost economics model. His insights on transactions costs and informal business institutions and practices and their implications for market competition, incentives and outcomes raise significant technical, analytical and information challenges for new competition agencies in India and other developing and emerging market economies. The economics conceptual literature review in Chapter 2 and the conceptual framework in Chapter 3 encompass as well NIE's extensions into and overlaps with related economic literatures, including traditional and new industrial organization economics, behavioral, information and innovation economics, new endogenous growth theory, and theories on institutional change. 


\section{Contributions of the Dissertation}

The dissertation contributes to research and analysis in three ways. Comparatively little academic research has been conducted on competition policy, law and related business practices in India, and on the formal and informal institutions and other forces that have both shaped and been influenced by the country's competition regimes over the past forty years. In particular, India's academic and policy communities have given much less attention to competition policy and law since 1991 compared with the three previous decades. This thesis contributes to filling this analytical gap.

A second contribution is that the thesis adds to our understanding of the evolution of modern competition regimes ${ }^{2}$ in developing and transition economies. Unlike many other developing and transition countries that adopted more modern competition regimes over the past two decades, discourse on, and development of, more modern competition regimes in India over the past four decades are driven by domestic pressures, ideas, informal and formal institutions, and business and government interests. In contrast, foreign influences, interests and pressures such as multinational corporations, IMF and World Bank requirements for structural reform, or obligations in trade agreements play a relatively minor role. The emphasis in this analysis on the interactions, conflicts and accommodations between two very different domestic institutional entities: competition regimes that include formal and informal components, and informal institutions of business rules, conduct and arrangements; represents a significant departure from previous research and studies on India and virtually all other competition law jurisdictions. The previous research has emphasized for the most part the interactions of

\footnotetext{
${ }^{2}$ As defined in Appendix 1.
} 
formal competition policy and law with other formal economic institutions and policy regimes of government.

The third contribution of the analysis centres on the fact that, by applying a competition regime approach, new institutional economics (NIE) and the transactions cost economics (TCE) model, the dissertation offers further conceptual insights that may be particularly relevant to future competition research and policy formulation in developing and transition economies. Past analysis has largely focused on the legal design and economic rationale for the new competition law and agency, and has given little attention to existing policies, informal business and other institutions, and attitudes towards competition and fair trading.

\section{$\underline{\text { Research Methodology }}$}

The methodology employed to conduct the analysis required the collection, interpretation, comparison and integration of qualitative data and to a lesser degree quantitative data from a large number of sources. Major sources included: the growing theoretical, empirical, economic policy, and legal literatures on the role of markets, governments, competition, cooperation, and related policy and institutional regimes that are available from academic, national and international sources; and the many Indian economic and business histories, which give considerable attention to the informal institutions of business rules of conduct and arrangements - particularly India's unique family-based business groups. These were augmented by such Indian sources as official government planning and policy documents, the academic literature, position papers by interest groups and research institutes, media reports, specific competition law 
enforcement cases under the Monopolies and Restrictive Trade Practices Act $1969^{3}$, the enforcement policies and guidelines under the old and new competition acts, and other India based archival material. Finally, personal interviews were conducted with 35 key research participants from government, business, the academic community and nongovernment organizations, who were and are involved in past and current debates on India's competition policy, broader economic liberalization program and related fields (see Appendix 4).

\section{Background to the Dissertation}

Formal competition regimes in India have a fairly short and checkered history going back about forty years to the mid-1960s. Based on the recommendations of the Monopolies Inquiry Commission established in 1965, the 1969 Monopolies and Restrictive Trade Practices Act and Commission (MRTPA and MRTPC) were established to regulate the growing concentration of economic and monopoly power in India' private economy. As discussed in Chapters 4 and 6, most Indian competition experts have concluded that the 1969 Act was not effective in promoting competition and reducing industrial concentration.

Competition policy (broadly defined) and the need to open up India's markets to greater competition from domestic and foreign suppliers played a fairly prominent role in discourse on and the design of India's liberalization program from 1991 to the present day. Analysis and debate on a new formal competition regime for India began in the

\footnotetext{
${ }^{3}$ When the author began work on the dissertation five years ago, the expectation was that merger and other guidelines, some completed cases and other enforcement related evidence under the new Competition Act 2002 would be available for this thesis. However, for reasons described in chapters one and seven, the substantive provisions of the new competition law had not been enacted at the time of his field work in India in the summer of 2006, and full enforcement in fact had not started as of December 2008 when the dissertation was completed.
} 
mid-1990s, and in October 1999, the Government of India established a High Level Committee to provide advice on a new competition law in line with international developments. After consultations with the Indian business and NGO communities, review by a Parliamentary Standing Committee, and modest debate in and approval by the Indian Parliament, the 1969 MRTP Act was to be replaced by the India Competition Act of 2002, which established the new Competition Commission of India (CCI).

However, the composition of the new Competition Commission (CCI) was challenged before India's Supreme Court soon after the CCI was established in 2003. The Competition Amendment Bill designed to address the Supreme Court's and other concerns was passed by both houses of the Indian Parliament without debate in September 2007, but current expectations (as of December 2008) are that the new Competition Commission will not be fully staffed and enforcement of the new act will not begin until mid-year 2009.

\section{The Central Research Question}

The central research question of the thesis is as follows. How have India's competition regimes interacted with, conflicted with and accommodated themselves to the country's informal business institutions? In answering this question, special attention is given to the regimes' interactions with the country's traditional family-based business groups, which in many cases were established well before the country's formal competition rules.

Informal business institutions in the NIE literature lie between market exchange and firm hierarchy. The traditional business groups of India and other Asian and developing countries are a particular form of informal business institution. Business groups are less 
"bound together" than the divisions legally consolidated within a single corporation, and more "bound together" than short-term strategic alliances and R\&D partnerships. The generic definition used by most business group scholars is that a business group is a set of legally independent affiliated companies that are linked together by a variety of economic and social instruments that allow them to operate in a coordinated and mutually beneficial manner over an extended period of time (Chung 2001 p. 721 and Granovetter 1995, p. 95). This definition is further explored in Appendix 1 and the various instruments used to coordinate activities across the affiliated companies of a business group are addressed in Chapters 2 and 4, particularly Exhibit XII on pp.141-142.

The verbs "interact" and "accommodate" have been selected on purpose because of the different kinds of interactions that are implied by the concept of accommodation. The term accommodation denotes a two-way street where causation can be in both directions, sometimes in the same transaction (see Exhibit II on the next page).

The first kind of interaction, which draws from the NIE and related institutional and political economy literatures (see Chapters 2, 4 and 5), involves whether, how and to what degree the country's competition regimes had to find policy space for itself within, and accommodate and adapt itself to, India's informal business institutions. These institutions go back decades and even centuries, often (but not always) have been problematic for competition, inter-firm rivalry, and fair trading, and are supported by India's broader policy environment. 


\section{Exhibit II: Overview of the Conceptual Framework}

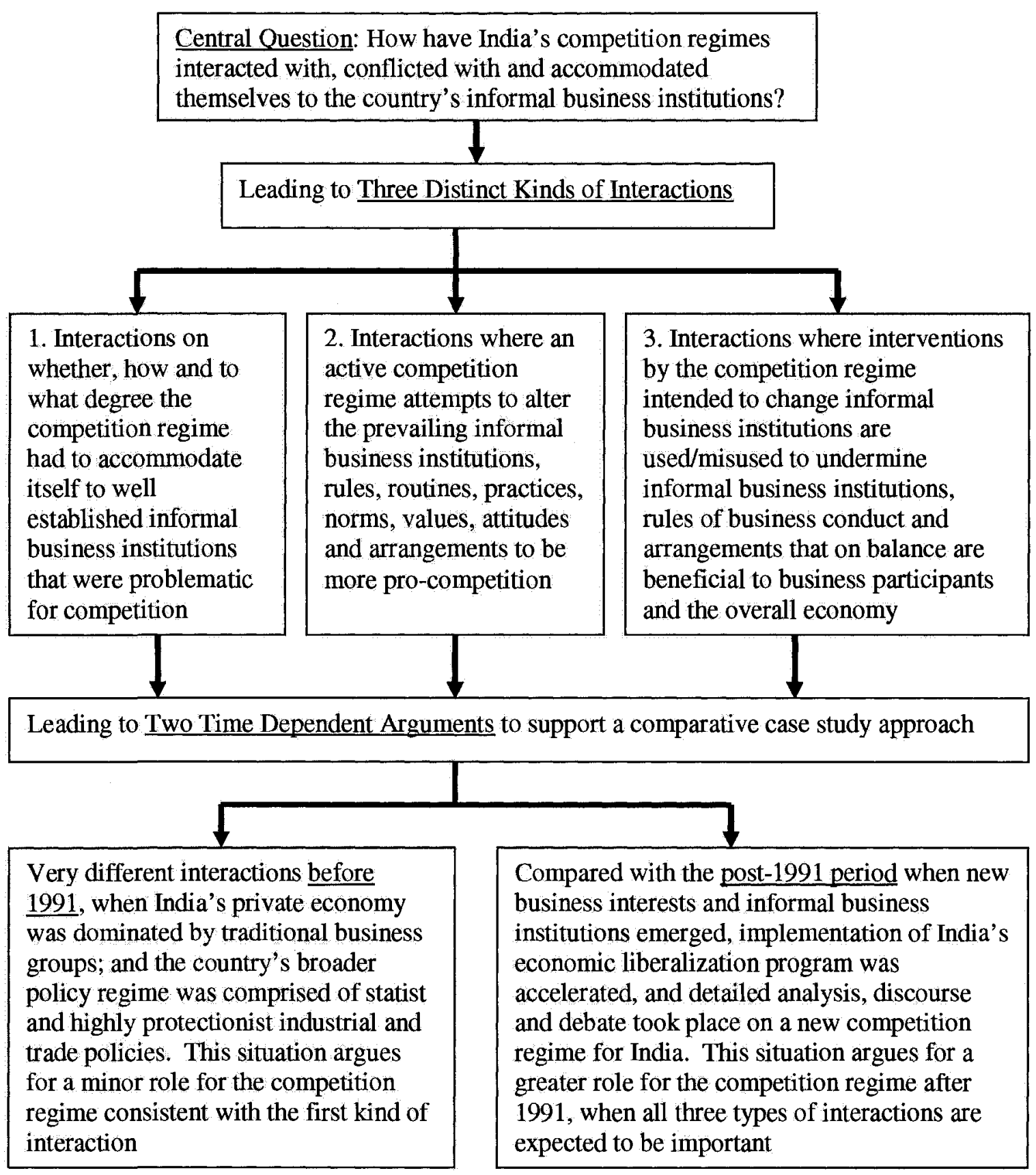

Causation is in the opposite direction under the second kind of interaction, which is broadly consistent with the conventional competition policy and law literature (see Chapter 1). Under the second kind of interaction, the competition regime, through its enforcement, voluntary compliance, and competition education and advocacy activities, 
directly addresses the existing nexus of informal business institutions and attempts to alter the prevailing business practices, rules, norms, values, attitudes and arrangements to be more supportive of competition and therefore more consistent with the competition regime.

The concept of accommodation also encompasses a third kind of interaction which draws heavily from the transaction cost economics model of Oliver Williamson and his colleagues (see Chapter 2). Under this third set of interactions, the efforts of the competition regime to change the prevailing informal business institutions pose the danger that India's formal competition regime is used or misused to undermine informal business institutions, rules of business conduct, arrangements and networks that: economize on transaction and production costs; promote various kinds of technological and managerial innovations; and, on balance are beneficial to business participants and the overall economy.

Leading to Two Main Time Dependent Arguments to Support a Comparative Case Study Approach

The two time dependent arguments at the bottom of Exhibit II provide the basis for the two-period comparative case study approach within a single country that is employed in Chapters 6 to 9. The conceptual framework and empirical analysis is based on the contention that the interactions, conflicts and accommodations between India's competition regimes and the country's informal business institutions were quite different before and after liberalization which started in 1991. Before 1991, India's private economy was dominated by traditional business groups, and the broader policy environment (called the "License Raj") was comprised of statist and protectionist industrial and trade policies that on balance hurt competition. This pre-1991 situation 
would be expected to make the competition regime a relatively minor player consistent with the first kind of interaction.

In contrast, after 1991, new business interests and informal business institutions started to emerge, implementation of India's economic liberalization and market opening program was accelerated, and detailed analysis, discourse and debate took place on a new formal competition regime for India. This post-1991 situation suggests a greater role for the competition regime after 1991, when all three kinds of interactions are expected to be important. The empirical evidence in Chapters 6 to 9 indicate that, because of the new institutional economics (NIE) concepts of path dependence and institutional inertia found in both informal and formal business institutions, the differences between the two periods are not as great as anticipated; and the interactions and accommodations in each period are richer and more subtle and complex than suggested by the two arguments.

Nonetheless, the two time dependent arguments proved to be useful instruments for conducting comparative analysis of the evolution, role and influence of India's competition regimes and informal business institutions, and of the interactions and accommodations between them, during two quite different time periods and under two quite different broader economic policy environments. The two arguments were particularly helpful in illuminating the complexity of India's competition regimes and informal business institutions over the past four decades.

\section{Structure of the Dissertation}

The structure of the dissertation is summarized in Exhibit III at the end of this chapter. Part I provides the context and conceptual framework for the empirical chapters through analyzing trends in competition policy and law in India and other countries over 
the past several decades, reviewing the economic literatures and theories that are most relevant to the research with emphasis on new institutional economics and the Williamson TCE model, and describing the conceptual framework and methodology employed in collecting, analysing, interpreting and integrating the empirical evidence.

Part II tells the empirical story. Because history and path dependence play such an important role in new institutional economics, the story begins in Chapter 4 with a brief description of the evolution of India's competition regimes and informal business institutions, and the interactions, conflicts and accommodations between them, through the country's long and complex economic and business history. Most of the pre-1965 historical story in this chapter explores interactions, accommodations and the many overlaps between informal competition regimes and informal business institutions (see Exhibit I). Chapter 5 briefly analyses and compares the broader institutional and economic policy environments in the pre- and post 1991 periods. This analysis recognizes that India's competition regimes and informal business institutions, and the interactions, conflicts and accommodations between them, are embedded within and influenced by these broader institutional and policy environments.

The empirical story then moves on to the two time dependent case studies described earlier. Chapter 6 presents the empirical evidence on the interactions, conflicts and accommodations from 1965 to 1991 . Special attention is given to the interactions between India's first competition law, the Monopolies and Restrictive Trade Practices Act (MRTPA) and the traditional business groups. Chapter 7 explores the empirical evidence on interactions, conflicts and accommodations largely from the perspective of the still evolving post-liberalization competition regime from 1991 to the present day. 
Chapter 8 investigates the post-1991 interactions, conflicts and accommodations in greater detail from the perspective of India's traditional business groups and the country's new economy informal business institutions and arrangements. The major findings from these three chapters are then used to briefly compare the two time-period case studies in Chapter 9.

Compared with Chapter 4, Chapters 6-9 give greater attention to interactions, conflicts and accommodations that involve India's formal competition regimes. However, the informal components as captured in India's "competition culture" are also important to the empirical narrative and case study comparison. The author's major conclusions regarding the contributions, purpose, central question, and two main arguments of the dissertation are summarized in the final chapter. The material in the nine Appendices is referenced and explained as appropriate in the main text. 


\section{Exhibit III: Structure of the Dissertation}

Introduction: Purpose, Literatures Engaged, Contributions, Central Question, Two Main Arguments, and Thesis Structure - Setting out the Roadmap for the Dissertation

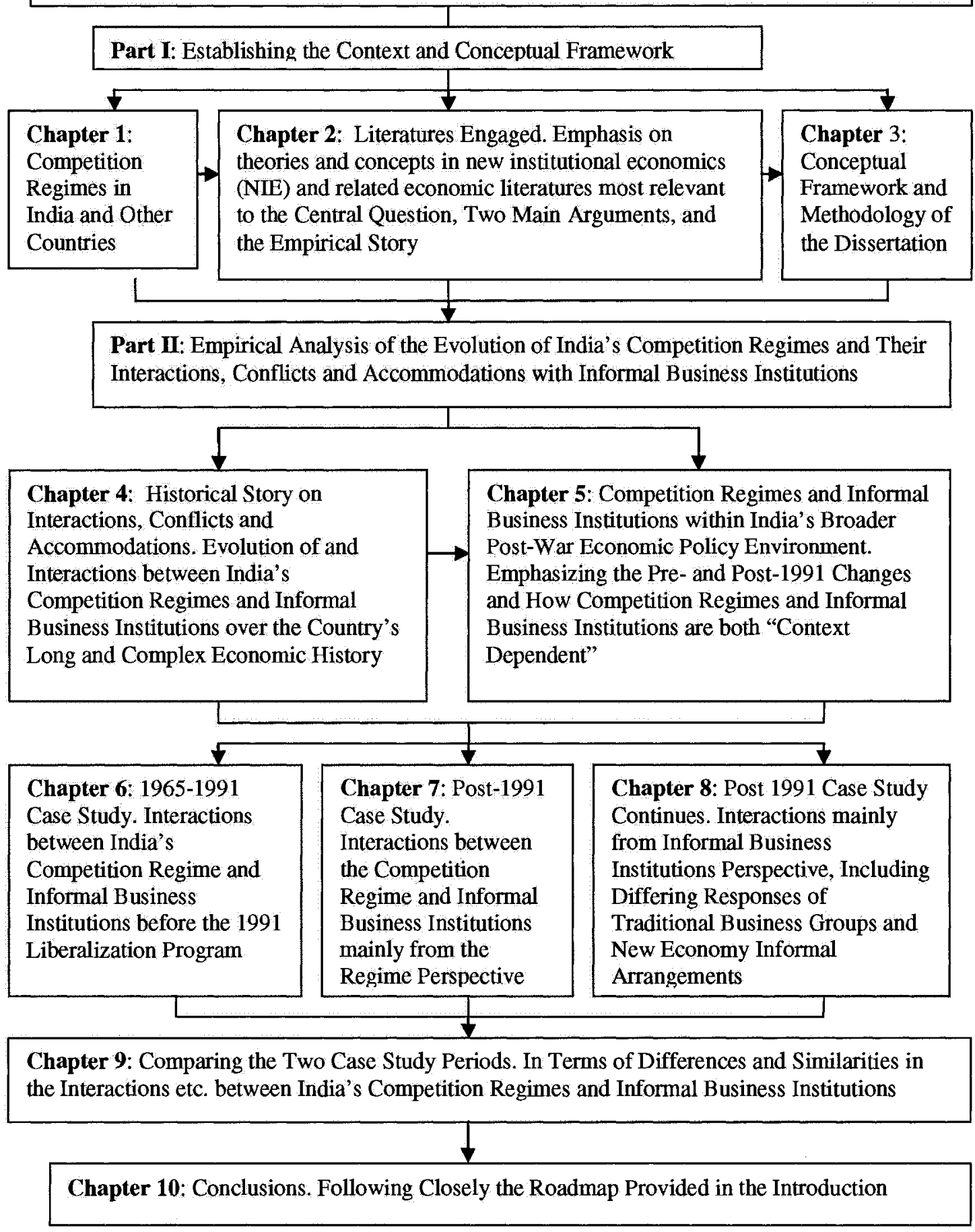




\section{Part I: Context, Economics Literatures Engaged, and Conceptual Framework}

\section{Chapter 1: Competition Policy and Law in India and Other Countries}

\subsection{Purpose}

This chapter establishes the context for this dissertation, which comprises: the role and importance of competition policy, law and regimes in the economic histories and development of other countries; and, the relatively short history of formal competition regimes in India from 1965 to the present day. The next section explores the empirical evidence on the importance of proactive competition policies and actively enforced competition laws to the progress and prosperity of the more advanced OECD economies and more recently to the development and modernization of the many developing and transition countries that have adopted more modern competition regimes over the past two decades. Similar to India, the adoption of a modern competition regime by other developing economies is often one component of a more comprehensive economic liberalization and market opening program. The third section then describes the modern history of competition policy and law in India over the past four decades, with emphasis on the continuing and still unresolved debates on the new competition regime and its role in India's economic development and liberalization program. The final section presents the major conclusions and implications for the rest of this dissertation.

\subsection{Competition Policy and Law in Other Countries}

Competition policy and law have a relatively short history in the global economy, going back to 1889 when the first Canadian competition law was established (Khemani and Stanbury 1991) and, more importantly, back to 1890 when the Sherman Act was enacted in the United States. While most of the more advanced OECD economies had 
adopted a modern competition law by the early 1980 s, many of these same countries went through long periods when their competition laws were quite inactive and ineffective.

In fact, for most of this 115 year period, only the United States has had an actively enforced and relatively effective competition regime for the entire period (Levinsohn 1994, p. 9). Since 1980, there has been a virtual explosion of new competition laws in the global economy. The number of countries with some kind of competition policy, law and agency has expanded from about 30 in 1980 to over 115 countries, including better than 80 developing countries at the present time. Nevertheless, the industrialized and developing economies that have long histories with proactive competition policies and effectively enforced competition laws, and therefore could provide helpful models for developing economies such as India, are relatively few in number.

One reason is that there have been relatively few countries and jurisdictions where the introduction of competition rules took place within a broader political economy, policy and institutional environment that could be called accommodating and supportive of competition policy principles and competition law enforcement. This was the case in the United States with the Sherman Act in 1890; with the competition rules in the European Treaty of Rome where vigorously enforced competition rules were needed to promote the single European Market; and in Germany after the Second World War when competition rules particularly against cartels had broad based political support because of the role played by the German cartels, monopolies and larger firms in supporting the Nazi regime and the German war effort. Some analysts argue as well that the revival of the Japanese economy in the 1950s and 1960s, and the emergence of leading Japanese global 
companies in the automotive, electronics and selected other export industries can be credited to a significant degree to the introduction of a modern competition regime during the American occupation (Porter 1990, and Amsden and Singh, 1994).

Competition regimes in several other countries and jurisdictions, including Canada, Australia, the United Kingdom, the Nordic Countries, and many other EU countries have made significant progress in the past 25 years, as part of their broader economic liberalization, trade and regulatory reform and market integration programs. Before then, competition policy and law had a relatively limited role because investment and other economic and business decisions were based less on markets and more on governments working closely with the corporate sector, trade unions and other strong economic interests. The scope for competition rules expanded in these OECD countries as markets took on greater importance in allocating investment, workers and other resources and in providing information and incentives to and disciplining the conduct of businesses and other economic agents.

Despite recent progress in reforming their formal competition regimes and in providing a more supportive institutional environment for competition law enforcement, the performance of competition regimes in most OECD countries has been mixed and variable over the six decades since the Second World War. Nonetheless, empirical evidence from the competition literature indicates that industrial customers and final consumers in the United States have benefited over an extended period from the lower prices, higher quality products, greater product choice and dynamic efficiencies made possible by the country's proactive competition regime, effectively enforced competition law, and strong competition culture. Businesses and consumers in the EU, Canada, 
Australia and other OECD countries have received similar benefits in more recent years from more effective competition policies and laws and a more pro-competition policy environment ${ }^{4}$. Canada for example up to the first quarter of 2008 has enjoyed seventeen years of sustained economic growth with no recessions and low inflation since it adopted a more open and pro-competition policy and regulatory regime.

Most of the competition laws in the eighty or so developing and emerging market countries with relatively modern competition regimes were established since 1990 (Singh 2004, p. 2). The result is that developing country experience and success with competition law enforcement is still very limited. With a few important exceptions such as South Africa, Brazil, Mexico, South Korea, China Taiwan, and the new EU members in central and eastern Europe, comparatively few developing and transition countries are actively enforcing their current competition laws and effectively applying competition policy and law (World Bank 2002). The national economic policy framework in many cases still involves considerable intervention and coordination by governments, as well as cooperation between government, industry and other non-government groups.

Therefore, in many of these countries, the prevailing economic policy and institutional environments continue at best to be ambivalent, complex and problematic for competition policy and law enforcement. As a consequence, many international competition policy experts are now arguing that formal competition regimes in developing and transition economies should be better tailored to the specific conditions and requirements of each country; and thus should take full account of the prevailing policy, institutional and business environments including existing policy and regulatory

\footnotetext{
${ }^{4}$ Depending on the country, such an environment includes complementary policy initiatives such as the reduction in external and internal trade and investment barriers, regulatory reform, deregulation and privatization, and more proactive and pro-competition science, technology and innovation policies.
} 
regimes and informal business institutions and arrangements. This would allow greater space for flexibility and innovation in the design of competition policies, laws, authorities, enforcement practices and analytical methods that are more suitable to the special conditions, needs and development objectives of developing and transition countries (Berkovitz et al 1999, Dutz, Ordover and Willig 2000, Anderson and Jenny 2005, Gal 2004, World Bank 2004 and Fox 2007) ${ }^{5}$.

The exceptions listed earlier, where some progress in competition law enforcement has been made, are all relatively more advanced developing and transition countries where recent policy and other reforms have provided on balance a more hospitable institutional environment for competition policy and law. These countries have recognized that their economic reform programs need to be supported by a more proactive competition regime, in order to achieve broader economic and social objectives and in some cases international obligations related to: economic liberalization, market opening, the elimination of external and internal trade barriers, and EU membership; greater dependence on markets instead of government intervention and command-andcontrol regulation; and, greater equality in access to employment and business opportunities and in the distribution of income and wealth.

The history of competition policy and law in other countries raises two issues that are important to this dissertation. Despite the relatively limited effectiveness and success described above, there is a rapidly expanding international competition advocacy

\footnotetext{
${ }^{5}$ Similar concerns are being raised in the legal institutional literature (see e.g. Banerjee etc. 2003 and Berkowitz et al 1999). Too much emphasis on efficient institutions, based on harmonization towards international standards, benchmarks and "best practices", would mean that legal institutions would be left with no significant and independent non-economic values, particularly cultural values, embedded within them. In addition, transplanting laws with little change from other jurisdictions, with no effort to tailor the transplanted laws to local conditions, results in less effective legal institutions, which in turn is associated with reduced economic growth and development.
} 
literature on the role that market competition and modern competition regimes potentially can and should play in economic development and modernization (UNCTAD 1997, World Bank 2002, Mehta 2005, Anderson and Jenny 2005, Brook 2005 and 2007, and Khemani 2007). This international literature stresses the potential economic and social benefits from more competitive markets and more active competition policy and law for growth performance, economic development, innovation, and institutional development in developing and transition economies. However, given the empirical evidence that these benefits have rarely been fully realized, making competition policy and law truly functional and effective for the development of emerging market economies continues to be a challenge for India and most other developing and transition economies (Mehta 2006 and 2007).

The second major issue important to this dissertation and to the economic development of India and many other Asian economies is the past and current importance of informal business institutions, groups, networks and similar arrangements to these economies. These arrangements include the zaibatsu and keiretsu of Japan, the chaebol of South Korea, and the expanding Overseas Chinese business networks that are now encompassing and becoming increasingly centered on the People's Republic of China (Redding 1993 and 1995, Granovetter 1995 and 2005, and Zhuang 2006). As described in Chapter two, these informal business institutions and arrangements employ cooperation, trust, reciprocity of trust, reciprocal obligations, and informal governance systems in order to save on information, transactions and other costs, and allow member companies to better capitalize on their complementary assets, and better protect their intellectual property and other property rights and assets. These attributes, which were 
particularly important when these countries were at an early stage in the development of their formal institutional capacities, continue to be relevant up to the present day (Williamson, 1975 and 1985; Fukuyama 1995; Dobson 1998, Bostock and Stoney 1997 and Khanna 2000). Indian business groups, networks and other informal business institutions share many of the same characteristics as the business groups and networks in East Asia (Dobson 1998).

These informal business arrangements generally have been treated in a permissive manner by the relevant competition authorities in East Asian countries (Khanna 2000) ${ }^{6}$. At the same time, this permissive treatment over the past two decades has been the source of trade policy frictions, complaints and actions by in particular the United States and the European Union against Japan (Lawrence 1991), and to a lesser degree against South Korea. These trade actions were based on allegations that informal business arrangements have restricted foreign entry and market access by means of imports and direct investment. Informal business arrangements in India have not received similar international scrutiny. This is partly because the Indian market until quite recently has played a comparatively minor role in the corporate and marketing strategies of OECD country exporters and international corporations and investors. This situation is now changing, as India becomes more integrated into the global economy and receives increasing attention from international corporations, investors and business media.

\footnotetext{
${ }^{6}$ In sharp contrast, the business groups and industrial houses of India were subjected to significant government regulation designed to regulate their business activities and to control and reduce their growth and market, economic and political power especially from the late 1960s to the mid-1980s (see Chapters 5 and 6.
} 


\subsection{History of Competition Policy and Law in India}

India's formal competition regimes of competition policies and law have a fairly checkered history going back about forty years to the mid 1960s. Exhibit IV below lists the post 1965 milestones that are most important to this research, while Appendix 5 provides a more detailed chronology of the major events and milestones in the history of India's competition regimes starting in the 1920s.

\section{Exhibit IV: Major Milestones in the Evolution of India's Competition Regimes From 1965 to 2008}

\section{Milestone}

Report of the Monopolies Inquiry Commission (MIC)

Monopolies and Restrictive Trade Practices Act (MRTPA) and Commission 1969

Report of the High Powered Committee on Companies and the MRTP Act 1978

Amendments to the MRTPA to include Unfair Trade Practices (UFTs)

MRTPA Amendment Act as part of the GOI's Liberalization Program.

Including Removal of the Licensing and Related Control Provisions Applied to Business Groups and Other Larger Companies (the "MRTPA Monopoly Companies") and Significant Weakening of the Merger Control Provisions

Report of the Raghavan (High Level Committee) on India's Competition

Establishment of the New Competition Commission of India (CCI)

Enforcement - Expected in Mid-Year 2009

\subsubsection{The Monopolies and Trade Practices Act of 1969}

Starting from the early 1960 s, there were growing concerns in India that the industrial licensing requirements in place since 1951 were inhibiting rather than encouraging competition, private business entry and the broadening of India's entrepreneurial base. 
As a consequence, economic power, major industries, and most industrial and consumer markets in the country were becoming increasingly concentrated. Traditional business groups and other larger privately owned firms were using and often manipulating the licensing system, and their contacts and influence with government agencies, the commercial banks ${ }^{7}$ and the state-owned development finance institutions, in order to prevent entry by potential competitors and to retard the growth of small and medium scale enterprises (Fulda and Till 1968, Debroy 2004). There were as well allegations and some anecdotal evidence of price-fixing and other anti-competitive practices by business groups, other larger firms and industry associations.

These concerns led to studies of the industrial licensing system and, most importantly for this research, the establishment and report of the Monopolies Inquiry Commission (MIC) in 1965. The MIC report focused on the concentration of economic and monopoly power in India's private economy as illustrated by the prominent role played by the large business groups led by Tata and Birla (Till and Fulda 1968). The Commission estimated that the assets of India's 75 largest business concerns in 1964 amounted to $47 \%$ of total private corporate assets. When combined together, the two largest business groups, Tata and Birla, accounted for $11 \%$ of these total assets.

The Commission considered the concentration of economic power ${ }^{8}$ to be the main problem, and that monopolistic, restrictive and other anti-competitive trade practices were the direct consequence of concentrated economic power (Dasgupta and Sengupta 1981, pp. 95-96). The MIC was particularly concerned with the "exorbitant prices"

\footnotetext{
${ }^{7}$ Which prior to their nationalization in 1969 were often owned by the larger business groups (see Chapters 5 and 6).

${ }^{8}$ Defined to include (i) product, industry and market specific concentration which typically is addressed by competition law, as well as (ii) country-wide economic concentration which typically is addressed by other policy instruments.
} 
charged by monopolists and oligopolists, and with the efforts of large firms and business groups to shut out competitors by means of monopolistic trade practices and abuses of dominant position (Fulda and Till 1968, p. 389). The Commission concluded as well that the industrial licensing system significantly favoured large business incumbents, and significantly impeded entry and growth by new entrepreneurs and small and medium sized enterprises.

The Government of India of the day, led by Indira Gandhi, decided that -- rather than reforming or eliminating the industrial licensing system" -- the "monopoly" business groups and other larger companies that were benefiting from the licensing system should be further regulated and controlled. This was to be accomplished through adding yet another layer of regulation to an already very complex regulatory regime of licenses and other permissions, approvals and business controls (Debroy 2004). Therefore in 1969, the Monopolies and Restrictive Trade Practices (MRTP) Act was enacted, and the MRTP Commission was established to enforce the new law. The Act's three objectives were: (i) to control and regulate the concentration of economic power to the common detriment, (ii) to control monopolies and monopolistic trade practices, and (iii) to prohibit restrictive trade practices unless any of these can be justified to be in the public interest (Dasgupta and Sengupta 1981, p. 94) ${ }^{10}$.

Establishment of the new Indian competition law in the late 1960s appears similar in rationale to passage of the Canadian anti-combines law in 1889 (Khemani and Stanbury

\footnotetext{
${ }^{9}$ Which was the advice of the best known Indian economic scholars of the day (see e.g. Bhagwati and Srinivasan 1975).

${ }^{10}$ The provisions on restrictive trade practices were essentially borrowed from similar provisions of the United Kingdom's competition law at that time, leading to criticisms that the MRTPA was for the most part a foreign import that took little account of Indian economic conditions and development needs (Dasgupta and Sengupta 1981, p. 107).
} 
1991, particularly Chapter 1). The 1969 Indian law was needed to justify and validate, and to deflect criticism away from, the highly protectionist policies of the Government of India $^{11}$, just as the 1889 Canadian anti-combines legislation was enacted to validate and deflect criticism away from the national policy of the Canadian government of that period. The intent of the 1969 MRTP Act was less to promote competition and efficiency and more to regulate (but not prevent) the growth of larger Indian business groups and other private businesses. Future growth of these groups and companies was allowed as long as the company was not in a dominant market position and company expansion was needed to achieve economies of scale.

The MRTP Act was amended several times after 1969 and was reviewed in detail by the "High Powered Committee on Companies and the MRTP Act" that was established by the Government of India in June 1977 and reported in August 1978. The Committee made a number of major recommendations for improving the effectiveness of the MRTPA (Paranjape 1980). The more important for this analysis is as follows. All important cases under Chapter III of the Act, which addressed the substantial expansion of business groups and other larger companies ${ }^{12}$, should be automatically referred to the MRTP Commission rather than decided on by the government. Decisions of the Commission should be binding and should not be open to modification by the government. Improvements should be made in the restrictive trade practices provisions in order to more easily establish market dominance in cases involving a business group or closely connected undertakings (typically within business groups). The market threshold

\footnotetext{
${ }^{11}$ Fulda and Till $(1968$, p. 376) in fact questioned why such a highly regulated Indian economy needed an antitrust policy and competition law, except to anticipate future market reforms and liberalization (which as noted in chapter 5 only began in any meaningful fashion in the early 1980s).

${ }^{12}$ Called undertakings under the MRTPA.
} 
level for establishing a dominant undertaking and market position should be dropped from one-third to one-quarter. Government undertakings (that is, state-owned companies) should be brought within the scope of the restrictive trade practices provisions of the MRTPA ${ }^{13}$. Finally, all orders of the Commission regarding restrictive trade practices as well as monopolistic trade practices should be final, subject only to an appeal to the Supreme Court.

Some of the recommendations of the 1978 High Powered Committee, that were designed to increase the scope, independence and effectiveness of the MRTPA and the MRTPC, were included in later amendments to the MRTPA that were enacted during the 1980s (see Appendix 5). However, many others were not adopted by the Government of India until the new Competition Act of 2002. The failure to adopt some of the more procompetition and anti-business group proposals of the Committee in the 1980s is consistent with the 180 degree shift in the economic policies and the policy rhetoric of the second Indira Gandhi government in favor of stronger economic growth and private business investment (Rodrik and Subramanian 2005). Furthermore, Indian central governments up to the present day have never been enthusiastic about decreasing its discretion and increasing the independence of its competition and other regulatory agencies. This Committee also recommended that the Act should be expanded to include a separate chapter on unfair trade practices that are designed to mislead and misinform consumers (Rao and Sastry 1987). In response, the Government of India amended the

\footnotetext{
${ }^{13}$ From 1969 to 1991 , state-owned companies and other public undertakings were not covered by the Act. Instead, it was simply presumed that state-owned firms would operate in a manner that was consistent with the public interest (however defined). This recommendation of the Commission was implemented as part of the liberalization reforms of the early 1990s. The new competition law of 2002 also fully covers stateowned corporations in all their various management and ownership forms. However, state owned companies and other public undertakings continue to enjoy preferences in government procurement, which decreases their incentives to be more efficient and to compete on price and quality (Chakravorty 2006:2, p. 48).
} 
MRTPA in 1984 to include provisions on five categories of unfair trade practices: false representation, misleading bargain prices, gifts and promotional contests, product safety standards, and hoarding.

\subsubsection{Competition Policy and Law Developments during the 1990s}

The final MRTPA amendments in 1991 removed from the Act the controls on business groups and larger companies (the so-called MRTPA monopoly companies), and significantly diluted its merger control provisions. The purpose of both sets of amendments was to improve the Act's consistency with economic liberalization and related reforms, which began to be implemented in the same year (see Chapter 5). In its Statement of Objects and Reasons appended to the 1991 MRTPA Amendment Bill, the Government of India in 1991 recognized that: the pre-entry restrictions had outlived their usefulness and had become a hindrance to the speedy implementation of industrial projects; and the elimination of the time-consuming procedures of prior approval facilitated participation by all segments of society in maximizing production. The Statement therefore recognized explicitly the significant impact of these restrictions and procedures on both business entry and on business transaction costs.

The government statement further indicated that, from this point forward, the MRTPA would focus on monopolistic, restrictive and unfair trade practices, which largely involve business conduct rather than market structure and concentration. The amendments as well included measures to enlarge the scope of enquiry of the MRTPC to more effectively curb and regulate those practices that are detrimental to the public interest (Government of India 2000 - the Raghavan Committee Report, p. 60). 
Competition law's major contribution to the liberalization reforms was the substantial weakening of the MRTP Act's merger provisions, which eliminated a competition based statutory barrier to mergers, consolidations and the establishment of national champions in key industries. The consequence was that, from 1991 on, concentrations of economic power could only be addressed under a residual provision of the MRTPA that remained in the Act, which allowed the government to order the division of an undertaking (essentially a divestiture) or the severance of interconnections between undertakings (that is, links between partner companies in e.g. a business group, joint venture or strategic alliance). This provision in fact has never been used by the MRTP Commission (Bhattacharjea 2003:2, p. 207). The result of the MRTPA merger amendments was a major increase in horizontal merger activity in India. The resulting merger wave encompassed many larger transactions that involved foreign firms and raised the kinds of competition issues that normally led to merger investigations in other competition law jurisdictions (Bhattacharjea 2003:2, pp. 207-209, and Agarwal 2006:1).

Other events and decisions during the 1990s and the early 2000s raised additional questions regarding the effectiveness of India's old competition law and the MRTP Commission during a period of globalization and increasing competition in both domestic and international markets. A July 2002 decision by the Indian Supreme Court severely qualified the application of the effects doctrine under the MRTPA ${ }^{14}$ (Bhattacharjea 2003:2, pp. 213-214). This decision made it almost impossible for the MRTPC to take enforcement actions against transborder anti-competitive business practices, and

\footnotetext{
${ }^{14}$ Section 14 of the MRTPA had a provision that was similar to the effects doctrine employed in Europe and the United States. Under this doctrine, foreign firms involved e.g. in international cartels, potentially could be prosecuted by the MRTP Commission for violations of the MRTP Act that had adverse effects within India.
} 
therefore to participate in the emerging international consensus on information sharing and cooperative enforcement across competition law jurisdictions against international cartels and other anti-competitive arrangements. The decision also meant that the restrictive business practices of foreign firms exporting to India were immune from MRTPC investigation and penalties. In contrast, the same practices by Indian firms, including Indian companies with foreign operations that were importing the same goods into the Indian market, were not immune (Bhattacharjea 2003:1, p. 8). For these and other reasons discussed in greater detail in Chapters 6 and 7, there was growing debate and consensus during the 1990s that the MRTP Act was not adequate to deal with the new policy environment of economic reform, trade and investment liberalization and India's integration into the global economy.

\subsubsection{India's New Competition Law of 2002}

In October 1999, the Government of India established a High Level Committee (generally called the Raghavan Committee) to provide advice on a new competition law in line with international developments. Based on the Committee's recommendations, a draft concept bill to facilitate consultations was placed on the web site of the Department of Company Affairs ${ }^{15}$ in 2000. Once the consultations were completed, a draft competition law was prepared and presented to the Government in November 2000. This bill was passed by the Indian Parliament with limited debate in December 2002.

\footnotetext{
${ }^{15}$ One of the positive developments of the current decade is the improved position of Company Affairs within the GOI. At the time the Competition Bill was introduced into Parliament in 2001, the Department of Company Affairs (which at that time had the company law and the MRTPA) was under the Ministry of Law and Justice. After that, it was under the Ministry of Finance. More recently the Department has become a full Ministry of Company (now Corporate) Affairs, with responsibilities for company law and the new amended competition act. This may increase the Ministry's and competition law's political clout, but this will depend to some degree on the Minister's interests, agenda and political influence and strength within the government:
} 
The Raghavan Committee offered a number of substantive reasons for why the old MRTPA should be fully repealed and a new competition law should be prepared to replace the old act. Other countries and jurisdictions such as Canada, Australia, UK, and the EU had repealed old competition laws and replaced them with more modern ones. The MRTPA does not clearly address competition and anti-competitive practices, contains no definitions, and in many cases not even any mention, of certain key anticompetitive practices important to modern competition law. MRTPA decisions and case law on anti-competitive practices are inconsistent. The thrust of the MRTPA was not on promoting competition, competitiveness and the consumer interest, but rather to apply a legalistic approach (rather than an economic rule of reason approach) to regulate and control industrial and economic concentration, monopolies and oligopolies in the private sector $^{16}$, and monopolistic, restrictive, and unfair trade practices.

As noted above, the MRTPA no longer had merger review provisions, and its provisions to address concentration and dominance were also substantially weakened by the 1991 amendments (Government of India 2000, p. 60). There were overlaps with the Consumer Protection Act of 1986. Finally, the Committee stressed that the old Act generated binding rulings from the Supreme Court and MRTPC decisions that would have to be incorporated into any amendments. Given its many other inadequacies, the MRTPA would virtually have to be rewritten in any event.

The Raghavan Committee concluded therefore that the MRTPA is inadequate for: fostering competition, reducing anti-competitive practices, promoting the country's domestic and international trade and competitiveness, and addressing India's current and

\footnotetext{
${ }^{16}$ As noted earlier, state-owned enterprises and other public undertakings were not covered under the MRTPA until 1991.
} 
future competition related WTO obligations (Government of India 2000, p. 57). The Committee recommended therefore that the MRTPA should be replaced with a totally new competition statute.

The major driver for the new competition law was the perception that the business groups and other larger private companies, whose size and expansion were to be controlled under the MRTPA, were in fact too small to compete successfully in global markets. As India became more integrated into the global economy, India's traditional business groups and other "MRTPA monopoly companies" would need to expand and merge with other companies in and outside India in order to compete on more equal terms with the much larger international corporations. In this manner, the MRTPA monopoly companies of the pre-1991 competition regime became the national champions of the current competition regime.

After consultations on the draft bill and debate in Parliament, the 1969 Act was to be replaced by the India Competition Act of 2002, which in turn established the new Competition Commission of India. In line with the new thinking on market competition (Church and Ware, 2000 and Chapter 2), the new Indian competition law emphasizes for the most part a conduct, behavioral, and "rule of reason" approach over the MRTPA's structural and legalistic approach that emphasized business group and company size. The preamble to the 2002 Act highlights the following four major objectives: (i) prevention of practices that have an adverse effect on competition; (ii) promoting and sustaining competition in markets; (iii) protecting the interests of consumers; and, (iv) ensuring freedom of trade carried out by participants in Indian markets. 
The preamble also stresses that competition policy should be designed to support the country's overall development path, and therefore by implication India's broader industrial, innovation, economic development, and poverty reduction goals, policies and programs ${ }^{17}$. The new Competition Act as well outlines a statement of objects and reasons for the new competition law. These include globalization, trade liberalization, and the need to open up the Indian economy, remove regulatory controls, and force Indian companies to face competition both within and outside the country. Another was the requirement to modernize India's competition rules in light of recent international developments in competition law ${ }^{18}$.

Most commentators agree that the Indian Competition Act represents a significant improvement over the MRTPA (see Bhattacharjea 2003:1, Singhi 2003, and the Comparison Table at the end of Appendix 5). Furthermore, as indicated in Exhibit $\mathrm{V}$ on the next page, the GOI is expected to provide the new Commission with substantially greater human and financial resources compared with the MRTPC. The 2002 Act provides for the most part a modern framework for regulating competition, through three separate enforcement sections that explicitly deal with three kinds of competition concerns: (i) anti-competitive practices; (ii) abuses of dominant position; and (iii) the regulation of business combinations, including mergers, amalgamations, acquisitions and acquisitions of control.

\footnotetext{
${ }^{17}$ This is similar to a broader public interest objective (see Chapter 7 and Chakravorty 2006:1, p. 60).

${ }^{18}$ Recent developments stressed by analysts and research participants included recent improvements to the EU's competition rules and the modernization of the UK's competition statutes to be consistent with the EU rules.
} 


\section{Exhibit V: Comparing the New Competition Commission of India (CCI) with the Previous Monopolies and Restrictive Trade Practices Commission (MRTPC)}

\begin{tabular}{|c|c|c|}
\hline Indicator & MRTPC & CCI (Projected) \\
\hline Total Staff & $\begin{array}{l}\text { Total staff of } 152 \text { as of } 2000 / 2001 \text {, } \\
\text { with } 4 \text { MRTPC members, } 23 \\
\text { professionals, and } 125 \text { support staff }\end{array}$ & $\begin{array}{l}\text { Professional staff projected to be } 240 \\
\text { in the first year, rising to } 480 \text { by year } \\
\text { five of operations }{ }^{19} \text {. This suggests } \\
\text { total employment would be many } \\
\text { times greater than the total staff of the } \\
\text { current MRTPC }\end{array}$ \\
\hline $\begin{array}{l}\text { Staff } \\
\text { Capability }\end{array}$ & $\begin{array}{l}\text { Only } 3 \text { of } 23 \text { professionals had } \\
\text { backgrounds in economics, commerce } \\
\text { and finance and only two were } \\
\text { lawyers }\end{array}$ & $\begin{array}{l}\text { It is proposed that } 40 \% \text { of } \\
\text { professional staff would be } \\
\text { economists, another } 40 \% \text { would be } \\
\text { lawyers. and the remaining } 20 \% \\
\text { would be financial analysts, financial } \\
\text { management experts, and chartered } \\
\text { accountants etc. }\end{array}$ \\
\hline $\begin{array}{l}\text { Annual } \\
\text { Budget }\end{array}$ & $\begin{array}{l}\$ \text { US } 723,600 \text { in } 2000 \text {, of which staff } \\
\text { costs account for } 66 \% \text {. }\end{array}$ & $\begin{array}{l}\text { No figures available, but will clearly } \\
\text { be many times larger than current } \\
\text { MRTPC budget }\end{array}$ \\
\hline $\begin{array}{l}\text { As \% of Total } \\
\text { Government } \\
\text { Expenditures }\end{array}$ & $\begin{array}{l}\text { Less than } 0.001 \% \text {. With no change } \\
\text { through the last half of the } 1990 \mathrm{~s} \\
\text { despite liberalization. And well } \\
\text { below all other competition agencies } \\
\text { surveyed in the CUTs sources - } \\
\text { including Kenya, Pakistan, South } \\
\text { Africa (the second highest at } 0.03 \% \text { ) } \\
\text { Sri Lanka, Tanzania, Zambia (the } \\
\text { highest at } 0.06 \% \text { ) and the United } \\
\text { States (at } 0.01 \% \text { ) when FTC and the } \\
\text { Anti-Trust Division of DOJ are added } \\
\text { together }\end{array}$ & $\begin{array}{l}\text { Calculations not been made, but } \% \\
\text { will be more in line with other } \\
\text { competition jurisdictions; and after } 5 \\
\text { years of operation could approach the } \\
\text { US figure of } 0.01 \% \text { which the CUTS } \\
\text { studies use as a benchmark (see } \\
\text { CUTS International } 2003 \text {, Table B). }\end{array}$ \\
\hline $\begin{array}{l}\text { Commission } \\
\text { Structure }\end{array}$ & $\begin{array}{l}\text { The MRTP Act provides for a } \\
\text { Chairman and up to } 8 \text { Commission } \\
\text { members. The sources used to } \\
\text { develop this Exhibit did not provide } \\
\text { any further information on the } \\
\text { MRTPC's structure }\end{array}$ & $\begin{array}{l}\text { As proposed by IMB (see sources } \\
\text { below), would include a Chairperson, } \\
6 \mathrm{CCI} \text { members }{ }^{21} \text {, and Senior } \\
\text { Officials/Groups responsible for } \\
\text { Economic Analysis, Financial } \\
\text { Analysis, Legal, Investigations, and } \\
\text { the CCI Secretariat }\end{array}$ \\
\hline $\begin{array}{l}\text { Location } \\
\text { within the } \\
\text { Government } \\
\text { of India }\end{array}$ & $\begin{array}{l}\text { Semi-independent regulatory agency } \\
\text { under the Department of Company } \\
\text { Affairs (with relatively little actual } \\
\text { autonomy), which for most of the } \\
\text { period up to the current decade was }\end{array}$ & $\begin{array}{l}\text { Semi-independent regulatory agency } \\
\text { under the Ministry of Corporate } \\
\text { Affairs (with comparatively more } \\
\text { autonomy than the MRTPC), which is } \\
\text { a full Ministry led by a Cabinet }\end{array}$ \\
\hline
\end{tabular}

\footnotetext{
${ }^{19}$ At the start of 2008, the Ministry of Corporate Affairs had proposed recruitment of 250 professionals and executives for the CCI (Business Line 2008).

${ }^{20}$ And therefore in time will soon surpass the total number of employees at the Canadian Competition Bureau which currently is reported to be about 400 employees.

${ }^{21}$ At the time the research for this dissertation was completed in the Fall of 2008, the permanent Chairperson and six Commissioners for the CCI had not yet been appointed by the Government of India.
} 


\begin{tabular}{|c|l|l|}
\hline Indicator & \multicolumn{1}{|c|}{ MRTPC } & \multicolumn{1}{c|}{ CCI (Projected) } \\
\hline & $\begin{array}{l}\text { part of a larger ministry including the } \\
\text { Ministry of Law and Justice and more } \\
\text { recently the Ministry of Finance }\end{array}$ & $\begin{array}{l}\text { Minister, and is responsible for } \\
\text { competition and corporate law } \\
\text { administration and enforcement and } \\
\text { related activities that regulate the } \\
\text { functioning of the corporate sector }\end{array}$ \\
\hline
\end{tabular}

Sources: CUTS International (2002, 2003 and 2007), Business Line (2008) and "Material Regarding the Proposed CCI Organization" on the Commission's Website, which is based on a study conducted for the CCI by the Institute of Management in Bangalore (IMB).

Similar to Canadian, European and most other OECD country competition laws, dominant positions are not strictly prohibited. However, abusive conduct designed to maintain and generate excessive supra-competitive profits from a dominant position is under the purview of the new Act and Commission.

Among its other more positive features, the new Act as amended in September 2007: clearly defines many anti-competitive practices, places predatory pricing under the section on the abuse of a dominant position, lists criteria for determining the relevant geographical or product antitrust market for purposes of competition analysis, and provides for substantial fines and other penalties. The new Act as well avoids such MRTPA type areas as monopolistic pricing and control of firm size. Penalties for noncompliance with the law include: fines of up to $10 \%$ of the violating company's average turnover for its last three financial years, the division (divestiture of assets) of dominant enterprises, and the "demerger" of mergers and amalgamations that adversely affect competition.

The new Competition Act provides broad coverage in terms of the markets, industries and kinds of companies that can be investigated by the Competition Commission of India. The definitions at the outset of the legislation describe an enterprise as a person or department of the Government engaged in commercial activities. A later definition of 
person includes an individual, company, firm, association, any corporation established by or under any Central, State or Provincial Act or a Government company as defined in section 617 of the Companies Act 1956, any body corporate incorporated by or under the laws of a country outside India, a cooperative society, and a local authority. In short, state owned companies, government departments, local authorities and other public undertakings that are involved in commercial activities in product markets are fully covered under the new competition law. This represents a significant improvement over the original MRTPA under the 1965-1991 competition regime, which fully exempted state-owned companies and other public undertakings until the 1991 MRTPA amendments.

The statute does not have a separate section on specific exemptions and exceptions, but it does contain: an export cartel exemption (section 3.(5) (ii) of the Act); partial exceptions for patents and other intellectual property rights; and what are essentially efficiency defences for joint ventures and other kinds of combinations and amalgamations (essentially mergers and strategic alliances). Moreover, while there is no explicit small firm exception, any smaller firm with a small market share of a relevant competition/antitrust market ${ }^{22}$ would be exempt through the application of the "appreciable adverse effect on competition within India" rule (see section 3 (1) of the 2002 Act).

\footnotetext{
${ }^{22}$ The concept of the relevant competition (or antitrust) market is referenced quite often in the dissertation. This concept is based on the "hypothetical monopolist" test for an antitrust market, which is applied in merger review and other competition cases. "The basic idea of the hypothetical monopolist test is to find for each of the products of the merging firms what would be the smallest group of products that if owned by a single monopolist could profitably increase price by a non-trivial amount. The term hypothetical arises because, of course, one firm does not control all of these products - in fact it is the market power of the merging firm that is of concern, not that of the market as a whole. The purpose of this exercise is to find a gap in the chain of substitute products, so that the merging products are contained in the resulting self-defined "market" (Church and Ware p. 727; see as well Chapter 19 of the same textbook).
} 
The Government as well can provide exemptions under the Act for such purposes as state security, the public interest, meeting India's treaty obligations, and to any enterprise "which performs a sovereign function on behalf of the central Government or a State Government" (Chakravorty 2006:1, p. 65). These exemptions taken together appear similar to the regulatory conduct defense in Canada and other countries. India's new Competition Act as well provides some leniency provisions, whereby the first participant or whistle blower in e.g. a conspiracy case would receive a reduced penalty for his/her information that is used to break a conspiracy (Chakravorty 2006:1, p. 58).

The amended Competition Act also: provides for mandatory notification of mergers above a high size threshold ${ }^{23}$; allows for cooperation between the CCI and foreign competition agencies; and reinstates the "effects" doctrine to cover foreign anticompetitive practices that negatively affect Indian markets (Bhattacharjea 2003:2, pp. 221-222). There are as well specific provisions on competition advocacy that mandates the Competition Commission to conduct activities designed to create a culture of competition in India. However, competition advocacy can take place only at the government's direct request. The advocacy and enforcement sections and provisions are broadly consistent with modern competition laws in the OECD jurisdictions. With repeal of the MRTPA of 1969 and elimination of the MRTP Commission, all pending cases under the MRTPA were to be transferred to the CCI except for those relating to unfair trade practices, which were to be transferred to the relevant forums established under the Consumer Protection Act (COPRA) 1986. Accordingly, unfair trade practices are no

\footnotetext{
${ }^{23}$ Merger notification was voluntary in the original 2002 Act. This change to the 2002 Act, which has garnered considerable media attention and business opposition, is addressed in some detail in Chapter 7 .
} 
longer part of India's competition law but rather are now consolidated into the country's consumer protection legislation.

The Parliament of India approved the new competition bill during its winter session that ended in December 20, 2002, and the new law received the assent of the Indian President early in 2003. The press release indicating Parliamentary approval and Presidential assent noted that: the Competition Commission of India (the CCI) would function as a regulator like other GOI regulators; the new competition law gives effect to the second generation of economic reforms in India on the pattern of the global standards set by the United Kingdom, the United States and the European Commission; and, the provisions of the Competition Act would be implemented in three phases from dates to be notified in each case by the Government through the Department of Company Affairs (now the Ministry of Corporate Affairs). The investigation of cases under the first two sections on anti-competitive agreements and abuse of dominance was to begin in the second year, and merger review was to begin in the third year. Phased implementation was intended to give the Indian corporate sector adequate time to familiarize themselves with the new law before the CCI is formally constituted and enforcement of specific competition cases begin.

\subsubsection{Continuing Debate and Contestation on India's Competition Act 2002 and Still Evolving Competition Regime}

However, full implementation and enforcement of the new competition law has been delayed by six years (and still counting), and the new Commission's activities have been limited over that period to competition policy advocacy, education, training and since September 2007 staffing. This delay was largely the result of public interest litigation by two lawyers from Chennai (Madras) who argued that, as a quasi-judicial body, the 
Competition Commission of India (CCI) should be chaired by a judge or former judge rather than a competition, commercial and/or trade law expert. This case which began in 2003 was concluded more than a year later when the Indian Supreme Court decided in January 2005 that changes were needed to the composition of the $\mathrm{CCI}$ before full implementation of the new law could begin. Further delays resulted from the time needed by the GOI to prepare amendments to the Competition Act which were first tabled in India's Parliament in March of 2006, revised and tabled again in August 2007, and then finally passed by both houses of the Indian Parliament without debate in September 2007 (see Appendix 5). During this period up to the present day, the old MRTP Act and Commission have continued to function in a relatively low-key but not inconsequential manner (see Chapters 6 and 7); and will continue to function until the major provisions of the amended Competition Act are notified and enforcement begins. The new Competition Commission of India is expected to be fully staffed and enforcement of the new law is expected to begin by mid-year 2009 .

Interviews with research participants and other sources indicate that a number of major issues regarding the design and enforcement of the Act continue to be contested up to the present time (Bhattacharjea 2003:2, Mehta 2005, 2006, and 2007, A. Agarwal 2005, and M. Agarwal 2006:2). Concerns that the new competition law and regime will not be significantly different from the MRTPA continue to be raised by competition policy advocates as well as business opponents and sceptics. Competition policy advocates question whether the GOI has the political will to allow the CCI to effectively enforce the new law. Over the past year and a half (up to December 2008), large domestic and international corporations and their trade associations and legal counsel 
have expressed major concerns that mandatory notification and review of large merger transactions will significantly delay the corporate restructuring needed to compete in global markets.

More generally, some business opponents and sceptics contend that external trade liberalization is all that is needed to ensure reasonably competitive and contestable domestic markets in India. Therefore, a new competition law is seen as redundant and, similar to the MRTPA, would simply add to business transaction and other costs while providing few if any competition benefits. This perspective was argued quite persuasively by some of the more influential members of the Raghavan Committee who expressed minority views in the Committee's report.

Concerns of a more operational nature were also expressed by many research participants. These concerns addressed the technical capacity of India and the new Commission to conduct analytically sound and credible competition analysis and to successfully administer and enforce a more modern competition law and regime ${ }^{24}$. Participants also questioned the GOI's commitment and the CCI's capability in establishing and maintaining the independence of the new Competition Commission, They emphasized in this regard the discretion retained by the government in providing direction to the CCI, in setting competition policy, in determining the issues for competition policy advocacy, and in extending competition law exceptions and exemptions to businesses and industries in the future.

These concerns were exacerbated by the government's intention to simply transfer MRTPC officers to the new Commission, in order to provide them with continuing

\footnotetext{
${ }^{24}$ The definition for a "modern competition regime" is provided at the beginning of Appendix 1.
} 
employment; and the still quite limited financial and personnel resources and competition policy and law expertise to be provided to the Commission by the government ${ }^{25}$. These questions lead to the related concern of both competition advocates and business sceptics that competition policy analysts trained in neo-classical economics and traditional industrial organization theory - who in many cases worked for the previous MRTP Commission -- would apply a legalistic and structural approach, would place too much weight on company size, market structure and industrial concentration, and would give too little attention to business conduct, corporate strategy, static and dynamic efficiencies, and superior competitive performance.

Serious questions remain therefore regarding the quality of the Commission's staff, the need for training and capacity building in the Commission and whether the GOI and the new Commission will allocate sufficient resources to staff training and capacity building, and to voluntary compliance, education and related training and communication programs directed towards business, government, NGOs and other stakeholders ${ }^{26}$. These more operational concerns are shared by business representatives as well as competition policy advocates and experts.

There are as well continuing debates about whether the amended Competition Act will in fact satisfy the concerns of the Supreme Court, the judiciary and India's very active and highly litigious legal community (Agarwal 2006:2 and Chaudhuri 2005); and about the relationships and interactions between the new Commission and the much

\footnotetext{
${ }^{25}$ Despite the significant improvements compared with the MRTPC as outlined in Exhibit $\mathrm{V}$ above.

${ }^{26}$ This would include building industrial organization and competition policy and law expertise in the academic, consulting and research institute communities. In this context, research participants and other sources emphasized India's comparatively few highly trained economists either in or outside government who have interest and expertise in new industrial economics and related economic disciplines and their application to competition policy and law.
} 
better established and (often) better resourced sectoral regulators which in some cases have well articulated competition mandates (Uppal 2006 and Ireland 2007:2). Many research participants noted the danger of overlap, conflicts and conflicting competition decisions between the new competition law and commission and the sectoral regulators ${ }^{27}$.

Some competition policy advocates question whether the new competition law, which emphasizes conduct, behaviour, and abuses of dominance over business group and company size, market structure, dominance, and corporate concentration, will be adequate to the task of addressing and providing remedies for the anti-competitive practices of Indian business groups and other larger companies and of very large transnational corporations (Chandrasekhar 2003). Related concerns are directed at specific provisions in the new statute, including: the very limited attention in the Act to the anti-competitive abuses that can result from intellectual property rights; and the very high asset and turnover thresholds that must be exceeded before a merger can be reviewed by the Commission. There are concerns as well that the removal of unfair trading practices (consumer protection provisions) from the Competition Act will significantly limit the extent to which the new Act can be applied to local marketplace issues and can be used to build political and public support for competition law, competitive markets, and fair business practices within Indian states, urban municipalities and rural areas.

\footnotetext{
${ }^{27}$ For example, there are concerns that the merging parties involved in an electricity generation or telecom merger that falls below the size thresholds of the new competition law will be able to successfully argue that the transaction cannot be reviewed under the competition provisions of the electricity or telecom regulator; and/or that a transaction above the competition law thresholds would be reviewed by both the $\mathrm{CCI}$ and the sectoral regulator - adding greatly to the delays, transactions costs, risks and uncertainty of the merging parties. As the traditional business groups move into recently deregulated sectors such as financial services, telecom, and electricity generation, these overlaps and conflicts could have significant implications for these groups' transaction costs and their interactions and accommodations with and strategic responses to the still evolving competition regime which encompasses both the $\mathrm{CCI}$ and the sectoral regulators.
} 
More generally, the author's field work in the summer of 2006 identified limited support for, understanding of and even interest in the new competition law and commission from politicians, government, the bureaucracy, business, the academic community, labour, civil society and other stakeholders. This was the combined result of the delay of six years in launching full enforcement of the new Competition Act and the continuing enforcement of the truncated and discredited MRTPA (section 7.5 of Chapter $7)^{28}$.

In this manner, concerns and contestation about the many weaknesses of the MRTP Act and Commission have carried over into discourse on the new Act and Commission. Critics on both sides of the debate are worried that the government, policy and business environments that negatively influenced the enforcement and effectiveness of the MRTPA before 1991 have not changed fundamentally since then - despite 17 years of liberalization (see Chapters 6-8). One irony is that many business opponents and other sceptics of a new competition law argued in the early years of this decade that passage of the new Act should be delayed; or, if passed by Parliament, enforcement of the substantive provisions should be delayed for a number of years. The Commission would then focus in the intervening period on competition advocacy and education and recruiting and training their new officers ${ }^{29}$. This in fact is exactly what has taken place from January 2003 through to December 2008 (see Appendix 5).

\footnotetext{
${ }^{28}$ The GOI and the Planning Commission attempted to address this problem through incorporating a separate section on consumer protection and ambitious proposals for a national competition policy in its major $11^{\text {th }}$ Five-Year Plan publication (see Government of India 2007:1, pp. 282-289). It is too early to tell whether this and related GOI efforts are resulting in greater understanding of and interest in India's new competition regime.

${ }^{29}$ See e.g. Bombay Chamber of Commerce and Industry 2000, pp. 2 and 3, plus dissenting opinions in the Raghavan Committee Report, Government of India 2000, pp. 73-74, and Agarwal 2005.
} 
These debates on the need for, relevance and impact of, and ability to administer a more modern competition regime at India's current stage of economic and institutional development, will influence how the new law is accepted by India's business, government, academic and other elites, and is enforced by the CCI and the Government of India. Research participants stressed that, in order to gain support from competition policy advocates and respect from the private business sector, it is essential that the CCI and its partners in and outside government have some early successes in enforcing the new law and in advocating and promoting greater competition in key sectors of the India economy.

\subsection{Conclusions}

This chapter has established the context for this dissertation, which encompasses the large number of advanced and developing countries that have introduced new competition laws or modernized their existing competition laws and regimes over the past three decades, and the limited success of India and most other developing countries in enforcing their competition statutes.

Discourse on the reform of India's competition regime starting in 1995 has taken place during a period of dramatic change both in global competition policy and in India's broader economic policy regime. During this period, India joined about 80 other developing and transition economies in establishing a new more modern competition regime. Competition law models from other countries were helpful in designing India's new Competition Act. However, designing a new competition law by referencing other countries' statutory models is the easy part. In enforcing its new competition law and designing and administering a broader competition policy and regime, the case selection 
procedures, analytical methods and enforcement practices of the better established competition regimes in the OECD countries offer only general guidance to the Competition Commission of India.

While there is near unanimity within the international competition policy advocacy network $^{30}$ that almost any country can benefit from establishing a modern competition regime, there is much less agreement and even less guidance on how a modern competition law should be enforced and on how recent advances in new industrial organization economics should be applied in India and other developing and transition economies that now have new competition statutes and agencies, There are legitimate concerns that applying without significant modification the competition analysis methods, enforcement practices and related techniques of OECD countries could more often hurt than help competition in developing countries. Moreover, other developing and transition economies, that are somewhat similar to India in their economic and institutional development, offer few successful models that can guide India in enforcing its new competition law and implementing a broader competition policy and regime.

The experience, enforcement practices and analytical methods of India's previous competition law and agency are also thought to be of little value to the new law and agency. In fact, the MRTPA and MRTPC are often seen as threats by competition law critics and advocates alike. This is because of the MRTPA's poor case law, weak track

\footnotetext{
${ }^{30}$ This network, which has become increasingly active and influential over the past 15 years, is led by the OECD's Competition Law and Policy Committee, the work of UNCTAD on Restrictive Business Practices, the International Competition Network (ICN), the section of the World Bank that focuses on competition, privatization and regulatory reform, the EU's competition law section, and the two most important American antitrust agencies, the Federal Trade Commission and the Antitrust Division of the Department of Justice.
} 
record and even weaker credibility and the likely transfer of many of the MRTPC's officers to the new agency (see Chapters 6 and 7).

Finally, the court challenges and delays of the past six years have meant that no experience, progress and successes have been achieved in enforcing the new law. The delay provided additional opportunity to debate and question India's competition law and policy; and, has led many potential advocates to lose interest and confidence in India's ability to effectively enforce its new competition law. The result is that, while the amended Competition Act 2007 in its legal wording appears in theory to be a fairly modern and "enforceable" statute, there is no actual real-world experience and evidence after nearly six years that it will work in practice.

India's new Competition Commission is not quite starting from scratch, but it will be facing many difficult and even daunting challenges once enforcement begins in 2009. These challenges and what they mean for the interactions between India's new and still evolving competition regime and the country's old and new informal business institutions and arrangements are addressed in detail in Chapters 7 and 8. 


\section{Chapter 2: Economic Literatures Engaged to Construct the Conceptual Framework}

\subsection{Purpose}

This chapter describes the economics conceptual literatures that have been engaged in preparing the conceptual framework in Chapter 3 and the empirical chapters in Part II of the dissertation. The thesis is anchored for the most part in new institutional economics (NIE) and in particular the transaction cost economics (TCE) model of Oliver Williamson (1975 and 1985). For new institutional economists and other institutional scholars, history, path dependence ${ }^{31}$, and formal and informal institutions - including informal business institutions, rules of business conduct and arrangements - are important to past and future economic performance and to current economic and political outcomes. NIE and the transactions cost model of Williamson and his colleagues illustrate through both economic theory and empirical research that businesses and other economic agents often establish formal and informal institutions and select between the various institutional options that are available to them in order to mitigate or avoid transaction costs.

Like many other developing and transition economies, India has been and continues to be a high transactions cost economy ${ }^{32}$. Therefore, while most competition analysis is anchored in traditional and new industrial organization economics, the author decided to employ new institutional economics and its various extensions in this role. This decision was based largely on NIE's capacity to enrich our understanding of the evolution of competition regimes and informal business institutions in developing and transition

\footnotetext{
${ }^{31}$ The concept of path dependence is particularly important to NIE and other institutional literatures. "Path dependence means that the process by which we arrive at today's institutions is relevant and constrains future choice, with the result that one can observe persistent poor economic performance and long-run divergent patterns of development" (Platteau 1994:2 p. 787, and North 1990, p. 93). Path dependence is caused and strengthened by increasing returns, which in turn are linked to self-reinforcing mechanisms, large initial set-up costs when an institution is first established, learning and coordination effects, and adaptive expectations (Platteau 1994:2 p. 787).

${ }^{32}$ See e.g. Lewis 2004, World Bank 2007:1 and 2008, and section 3.4.
} 
economies. The next section provides the theoretical and empirical context for new institutional economics through briefly discussing relevant advances in related economic literatures. The chapter then describes the new institutional economics literature, with emphasis on informal business institutions, rules of business conduct, and business arrangements, the transactions cost economics (TCE) model of Oliver Williamson (1975 and 1985), the importance of NIE and TCE to developing economies, and the extensions to the Williamson model developed over the past two decades by Williamson's supporters and critics. The synergies and major differences between new institutional economics and new industrial organization economics (NIEO) that are most important to the conceptual framework are then summarized. The chapter ends with a discussion of the major conclusions and implications that are most important to the following chapters.

\subsection{Placing New Institutional Economics into a Broader Economic Theory Context}

This section briefly describes related economic literatures that provide the context for the fuller description of NIE in the rest of this Chapter. New institutional economics and related recent advances in economic theory and empirical economics over the past four decades were developed in response to the criticism and limited empirical support for many of the assumptions and conditions that need to be satisfied for neoclassical economics to be fully operational and to provide unambiguous predictions, conclusions, and policy recommendations. Most economists recognize that these assumptions and conditions do not accord with economic reality ${ }^{33}$, and therefore have been relaxing them

\footnotetext{
${ }^{33}$ Therefore, a good microeconomics textbook now explores the implications of these limitations to the NCE model in some detail (see e.g. Friedman 2002). Relaxing the major assumptions and conditions of the NCE model is used as the reference point for this section. Despite the major advances in economic theory and empirical research over the past four decades, many economists involved in competition theory and analysis continue to employ the assumptions, conditions and unambiguous predictions of neoclassical economics as their "Weberian ideal type" for assessing divergences from perfectly competitive markets and for recommending competition remedies. This is particularly true for officials with competition
} 
in order to explore the implications for business conduct, market structure and outcomes, competition and consumer and social welfare.

A good starting point is traditional industrial organization economics, which relaxed the NCE assumption of perfect competition in order to investigate: how market power is established and maintained; the social welfare implications of various monopoly, oligopoly and monopolistic competition models when compared with perfect competition; the importance of market structure that in the traditional IO literature essentially dictates firm conduct and performance, market prices and quantities, and the extent of market competition; and, how barriers to entry prevent industries and markets from being more competitive. This traditional approach to industrial organization is called the Structure-Conduct-Performance (SCP) paradigm and is generally associated with the work of J.S. Bain on barriers to entry in the 1950s (Church and Ware 2000, p. 10; and Bain, 1956 and 1959) ${ }^{34}$. The SCP model assumed that there was a stable, causal and uni-dimensional relationship between industry structure, firm conduct and business performance that could be readily applied across all markets, industries, countries and time periods (Schmalensee 1989).

The traditional IO literature was highly sceptical and even hostile towards nonstandard forms of contracting and firm organization such as vertical restraints, vertical

responsibilities in developing and transition economies. Many research participants stressed that the limited economics training of competition agency officers is one reason for the difficult interactions between competition regimes and informal business institutions in India over the past forty years.

${ }^{34}$ Traditional IO was criticized for placing too much emphasis on the height, strength and sustainability of entry barriers, and too little emphasis on how these barriers can be significantly reduced and at times eliminated through market forces, inter-firm rivalry, product and process innovations, consumer and competitor learning, and improved government policies designed to reduce rent-seeking and corruption and to favour competition over specific competitors (Baker 2002). However, in Bain's defense, high and sustainable barriers to entry remain relevant to developing and transition economies such as India. Entry barriers and their links to informal business institutions therefore are given some prominence in the conceptual framework and the empirical chapters. 
integration and non-merger horizontal arrangements such as business groups and networks and research partnerships that often involve company rivals in the same product markets. Cooperation between suppliers and customers and especially between competitors was assumed to be only for the purpose of fixing prices and extending and abusing market power in other ways - rather than for helping to solve information, coordination, transactions cost, R\&D and other microeconomic and macroeconomic "puzzles" where the solutions could enhance economic efficiency and consumer welfare (Williamson 1975, 1985 and 2003 and Cooper 1999).

New industrial organization economics employs advances in non-cooperative game theory in order to address these concerns with the SCP model, its emphasis on entry barriers, and the treatment of non-standard forms of contracting and business organization $^{35}$ (Tirole 1988, Church and Ware 2000 and Baker 2002). New IO focuses greater attention on firm behavior and conduct and on the strategic interactions between producers and their competitors, suppliers, industrial customers and to some degree final consumers. New IO economics therefore relaxed the neoclassical economics assumption of perfect anonymity across all economic agents and of no contact, interaction, bargaining, negotiation, haggling, interdependence and/or mutual adjustment and adaptation between market participants (Hirschman 1982, p. 1473).

In questioning the uni-directional SCP model, the new IO literature contends that, in an oligopoly market, the market shares and the exercise of market power of one company are determined in response to other firms' conduct and strategy, production costs, and the number of firms entering the market under various equilibrium conditions. Therefore,

\footnotetext{
${ }^{35}$ Which were raised not only by new IO economists using non-cooperative game theory but also by new institutional economist led by Williamson (1975 and 1985). The NIE contributions are further described in section 2.7 .
} 
market structure and concentration and to some degree barriers to entry are endogenous not exogenous variables and thus are internal to rather than external to the firm, market and industry. Some markets with only two or three competitors can be reasonably competitive and contestable ${ }^{36}$, while others with e.g. ten suppliers can experience less competition because of history, business conduct and strategy and exogenous and endogenous entry barriers (see e.g. Baumol 1982).

In summarizing the new approaches to IO theory, Church and Ware (2000) concluded as follows on p. 451. "The complexity of firm conduct and its determinants in many markets, problems with interpretation, measurement errors, and conceptual difficulties suggest that SCP studies are unlikely to establish convincing causal or structural relationships between structure and performance variables across industries. Instead as Schmalensee (1989) has argued, they might provide evidence on empirical regularities broad descriptions of how markets look, but not how they work." These concerns with the traditional SCP approach are particularly relevant to new competition laws and agencies in developing and transition economies like India.

The new IO concepts that are most important to this dissertation include: the theory of the firm as a governance structure and strategic player rather than as a passive production

\footnotetext{
${ }^{36}$ The concept of a contestable market, which was first developed by Baumol and his colleagues (see e.g. Baumol 1982 and Church and Ware 2000, pp. 507-513), is applied quite extensively in this analysis. A market approaches "contestability" when the barriers to entry and exit are negligible and therefore the costs of entry and exit are very low. A contestable market does not require a large number of suppliers to generate competitive market outcomes. Duopoly markets and markets with one dominant supplier and an active competitive fringe can be sufficient as long as entry and exit barriers are low. This is because the fear of future entry and competition forces incumbents to price their products and provide product quality in a manner that is broadly consistent with competitive outcomes.
}

Like a perfectly competitive market, a perfectly contestable market is an ideal type that is rarely found in the real world. However, by focusing on the entry and exit conditions needed for reasonably competitive outcomes in markets with few suppliers, contestability provides a useful concept and reference point to developing and transition economies, which have relatively small national and regional markets that can support only a few plants at minimum efficient scale, and where entry and exit barriers are often the direct and indirect result of government policies and regulations that of course can be reformed. 
function (Williamson 1985, 1986 and 2002:2); entry barriers that are endogenous and thus the consequence of firm strategy and conduct; and the entry deterrence strategies of firms in oligopoly markets in order to discourage entry. These strategies include investments in excess capacity, research and development, intellectual property, advertising, building the brand name (including the family business group name), and lobbying government for entitlements and protection from potential competitors. Some consideration is given as well to other more specific types of strategic behaviour such as learning-by-doing, predatory pricing, raising rivals costs and the switching costs of business customers and final consumers, and the bundling or tying of two or more products (Church and Ware 2000, Chapters 15-21).

Other new IO concepts important to the analysis are the potential role in some product and geographic markets of small firms called the "competitive fringe", which can generate market outcomes that might approach those of perfect competition; and as noted earlier the concept of contestable markets (Baumol 1982). In markets with adequate contestability, the threat of so-called "hit-and-run" (i.e. uncommitted) entry can constrain the behaviour of incumbents and help to eliminate market power even when there are only a few suppliers (Baker 2002). A final new IO concept is the work of some new IO economists on multimarket contact. This is particularly important to the competition analysis of larger business groups in developing and transition economies that compete against other business groups and non-affiliated companies in multiple markets. Multimarket contact with the same companies makes cartels and tacit forms of collusion more stable, and adds to the credibility of threats of price wars, predation and other entry deterrence and anti-competitive strategies more credible directed at competitors and 
potential entrants (Church and Ware 2000 pp. 346-348, Weigelt and Camerer 1988, and Bernheim and Whinston1990).

These new IO departures from the conventional economic model are particularly important in comparing the competition regimes, and the interactions, accommodations and responses of India's traditional business groups and other informal business institutions, between the two case study periods (see Chapters 5-9). New IO theories of the firm as governance structure and strategic player, which are based to an important degree on the transactions cost economics model of Oliver Williamson (see sections 2.3 to 2.5 below), help to explain the establishment, boundaries and conduct of India's traditional business groups, and the differences in business group strategy between the two time periods. Entry barriers and deterrence strategies were largely the result of government policy before 1991, but are increasingly the consequence of the strategies of business groups and other larger companies after 1991.

During the post-liberalization period, Indian markets have become somewhat more competitive and contestable; "hit-and-run" entry has become feasible in some but not all industries; and the country's middle class consumers have become more influential and demanding. The result is that, since 1991, business group strategies designed to promote learning-by-doing and to increase customer loyalty through advertising, building the brand name, product tying, and increasing business customer and final consumer switching costs, have taken on greater importance for both traditional business groups and India's new economy companies (Chapter 8).

In contrast, over the full forty year period covered by the analysis, the potential in India for small firms to become a "competitive fringe", which would allow smaller Indian 
markets to be reasonably competitive despite only e.g. two or three major players, has been limited by the government's small enterprise reservation policies that prevented smaller firms from expanding to medium scale (see Chapter 5); and the dependence of small firms on their sales to and purchases from business groups and other larger companies. Current more proactive government policies under India's Eleventh FiveYear Plan are designed to reduce these constraints. However, to date the impact on small firm growth and their ability to provide an effective "competitive fringe" against larger firms has been modest.

Compared with before 1991, many of these new IO concepts are now more important to explaining market structure, business conduct and strategy, the performance of business groups and other privately owned companies, and the extent of competition in Indian markets; and will likely take on even greater importance as India's broader liberalization program is completed and the post-1991 competition regime becomes more firmly established (Chapters 5 and 8).

The major strength of the new industrial organization economics, compared with the neo-classical economic model (NCE) and the simple models of monopoly and oligopoly based on the SCP approach, is that the new IO literature provides a more realistic picture of how firms actually compete against each other in the marketplace. Its greatest challenge is that the regularities and universal laws of NCE are replaced by a great deal of contingency, where the same market structure can lead to vastly different competition outcomes in markets and industries depending on: firm conduct and strategy; the height of entry barriers particularly barriers that result from government policy; and at least implicitly the country, industry, business group and company and their stage of 
development. The information requirements and analytical challenges of the resulting case-by-case, rule of reason approach are much greater and more daunting, particularly for new inexperienced competition agencies in developing and transition countries. These challenges are especially troublesome because most of the new thinking on industrial organization economics has been developed for and applied to firms, industries and markets in the more advanced OECD countries.

Turning briefly to other economic disciplines used selectively in this dissertation, recent advances in information economics investigates the importance of information gaps, asymmetries and uncertainty particularly regarding future events, which lead to adverse selection and moral hazard ${ }^{37}$. Information constraints can result in less competitive and less efficient outcomes in financial and other markets even when a market has a relatively large number of suppliers and customers (Akerlof 1970 and Stiglitz 2001). Experimental and behavioral economics uses laboratory and field research, including historical and anthropological case studies, in order to question the NCE assumptions of perfect rationality and unbounded self-interest. Behavioral economics thus employs empirical evidence, rather than deductions from economic theory, to analyse the actual behavior, transactions, and other interactions of consumers, firms and other economic agents in real markets. Using a multi-disciplinary approach that encompasses insights from psychology, sociology and anthropology, behavioral

\footnotetext{
${ }^{37}$ Moral hazard (or nonobservability of the agent's action) in law and economics is the name given to the risk that one party to a contract can change its behaviour to the detriment of the other party to the contract once the contract has been signed and starts to be implemented. Moral hazard leads to higher monitoring costs and costs of incentive schemes. Adverse selection, also called anti-selection, involves a precontract informational advantage for one of the parties that leads to high signalling and screening costs. Adverse selection is used in economics where e.g. in the case of insurance, the people who take out a life insurance policy are more likely to make a claim than the population of people used by the insurer to set their rates (Dixit 1996, pp, 54-55); and, in the case of used cars, the seller of the used car knows the quality, performance and defects much better than the buyer -- leading in both cases to the market for lemons of Akerlof (1970).
} 
economics can for example help to explain how "bounded rationality", associated with the limitations of time, imperfect and asymmetric information, foresight, cognitive and computational capacities, discipline, and self-interest/selfishness, can result in behavioral biases and mistakes by, and less satisfactory outcomes for, consumers, companies and their employees, suppliers and business customers, and government law-makers, regulators and other decision-makers (see e.g. Jolls et al 1998, Kahneman 1994, and Kahneman and Tversky 1979) ${ }^{38}$.

Recent advances in innovation economics and new endogenous growth theory question the NCE and traditional growth theory emphasis on static over dynamic efficiencies and the assumption that technological change is exogenous to the economic system (see e.g. Langlois and Robertson 1995, Robertson and Yu 2001, and Aghion and Howitt 2006). These recent advances ${ }^{39}$ explore through theory, case studies, econometric modelling and other empirical research how technology development responds to: market signals, incentives and forces; the extent of market competition; and other formal and informal institutions. Particular attention is given to how and why producers interact and often cooperate with their competitors, suppliers, business customers and final consumers; in order to: determine the level and allocation of research and development expenditures of companies and industries; identify and co-invent the product and process innovations to be created and marketed; and establish the innovation winners and losers

\footnotetext{
${ }^{38}$ In recent years, bounded rationality and bounded self-interest, and the insights from experimental, behavioral and information economics, are starting to be employed in the new industrial organization models (see Ellison 2006, Foss 2003 and Klemperer 1995), as well as in innovation economics (see below).

${ }^{39}$ This also encompass the evolutionary theory of the firm (see e.g. Nelson 1991), which emphasizes as well the $R \& D$, innovation and related capabilities of the firm in a Schumpeterian context.
} 
at all levels -- the company, industry, national economy and the international marketplace ${ }^{40}$.

\subsection{Major Features of New Institutional Economics (NIE)}

New institutional economics has influenced, borrowed from and been integrated into these other recent advances that question the core assumptions and conditions of the neoclassical economics model. New institutional economics has developed over the past 35 years and is associated with such scholars as North (1990), Olson and Kahkonen (2000), Williamson (1975, 1985, 2000:1 and 2000:3), Stiglitz (2001), Mantzavinos (2001) and Greif $(1996,1997: 1,1997: 2$ and 2004).

This dissertation places particular emphasis on how the new institutional economics treats informal business institutions, rules of business conduct and informal business arrangements such as business groups and networks, research partnerships, strategic alliances, long-term supplier-customer relationships and national and global supply chains between independent companies. Oliver Williamson (1985 and 1991:2, p. 80) calls these arrangements non-standard (or hybrid) forms of contracting and organization that lie between hierarchy within a firm and arms-length market relationships between independent and often anonymous companies and other economic agents; and therefore have characteristics of both markets and hierarchical within-firm relationships.

Most NIE scholars accept some of the major assumptions, conditions and concepts of the neo-classical economics (NCE) model -- particularly those related to the importance of scarcity, competition and inter-firm rivalry to economize on resource use and the costs of production and transactions, and to create the incentives needed for greater efficiency,

\footnotetext{
${ }^{40}$ Leading to the Schumpeterian processes of dynamic competition and creative destruction (Schumpeter 1934 and 1976).
} 
innovation, productivity and adaptability for firms, industries and the total economy (Williamson 1975 and 1985, Best 1990). At the same time, NIE scholars question some of the core assumptions of traditional economic theory in order to explore the role of informal business institutions and arrangements in helping businesses and other economic agents to address and reduce the negative effects of real-world transaction related problems. The resulting analysis often points out the need for the appropriate mix between competition and cooperation in order to achieve business goals and promote greater efficiency and innovation in the economy (Kreps 1990, Best 1990, Fukuyama 1995 and 1999, and Ostrom and Walker 2003).

The NIE literature therefore helps us to understand why and how business communities in advanced and developing economies establish business groups and networks and other informal institutions, rules, and arrangements, that, on the one hand, place constraints on the decisions and conduct of individual member companies and their senior managers; and, on the other hand, allow businesses to deal with the many challenges listed above. NIE encompasses many different (albeit related) approaches and sub-literatures (Richter 2002). The economics conceptual literature review and conceptual framework for this dissertation particularly emphasize the transaction cost economics (TCE) model of Williamson (1975, 1985 and 1986) and to a lesser degree in Chapter 4 the NIE of economic history associated with North and Greif (Richter 2002, pp. 13-14). A 1992 article by Douglass North (p. 1) summarizes the key aspects of the NIE literature that have been engaged in preparing the conceptual framework for this thesis. 
"The new institutional economics is an attempt to incorporate a theory of institutions into economics. However, in contrast to many earlier attempts to overturn or replace neo-classical theory, the new institutional economics builds on, modifies and extends neo-classical theory to permit it to come to grips and deal with an entire range of issues heretofore beyond its ken. What it retains and builds on is the fundamental assumption of scarcity and hence competition - the basis of the choice theoretic approach that underlies micro-economics. What it abandons is instrumental rationality - the assumption of neoclassical economics that made it an institution-free theory ... In a world of instrumental rationality, institutions are unnecessary; ideas and ideologies don't matter; and efficient markets - both economic and political -- characterize economies.

In fact, we have incomplete information and limited mental capacity by which to process information. Human beings, in consequence, impose constraints on human interaction in order to structure exchange. There is no implication that the consequent institutions are efficient. In such a world ideas and ideologies play a major role in choices and transaction costs result in imperfect markets ... Individuals possess mental models to interpret the world around them. These are in part culturally derived - that is, produced by the intergenerational transfer of knowledge, values and norms which vary radically among different ethnic groups and societies".

Informal business and other institutions are especially needed when states and the court system that are supposed to create and enforce the formal rules are weak or nonexistent. Informal institutions however continue to be important in strong states because of the time, expense and uncertainty of adjudicating disputes before the formal courts (Williamson 2005:1). NIE emphasizes that the preparation of the formal rules on 
competition and related economic policy regimes should take full account of the existing informal business and other institutions that likely predate the more formal rules by decades and even centuries. This is particularly essential in preparing formal business rules in developing and transition countries such as India that have long and complex economic and business histories (Scott 1998 and Williamson 2000:1 and 2000:3).

\subsection{Williamson's Transactions Cost Economics (TCE) Model and Its Implications for the Conceptual Framework and Empirical Analysis}

The conceptual framework in Chapter 3 and the empirical chapters is based to an important degree on the transactions cost economics model of Oliver Williamson (1975, 1985, 1986 and 2005:1). Williamson argues that transactions costs, not technology, are more important to determining the existence and boundaries of the firm (and by inference the business group), how work is organized, and how and where transactions are conducted. The later options encompass market exchange; corporations/hierarchy; hybrids/longer-term relational contracts, and/or business groups and networks, which are largely hybrid arrangements but often also contain elements of markets and hierarchy (Williamson 1980 and 2002:2). The aspects of Williamson's research and insights that are most important to this dissertation on the evolution of competition regimes and informal business institutions in India are summarized in Exhibit VI on the next page and described in the following paragraphs.

\section{Exhibit VI: Williamson Transactions Cost Economics (TCE) Model: Modified for this Dissertation}




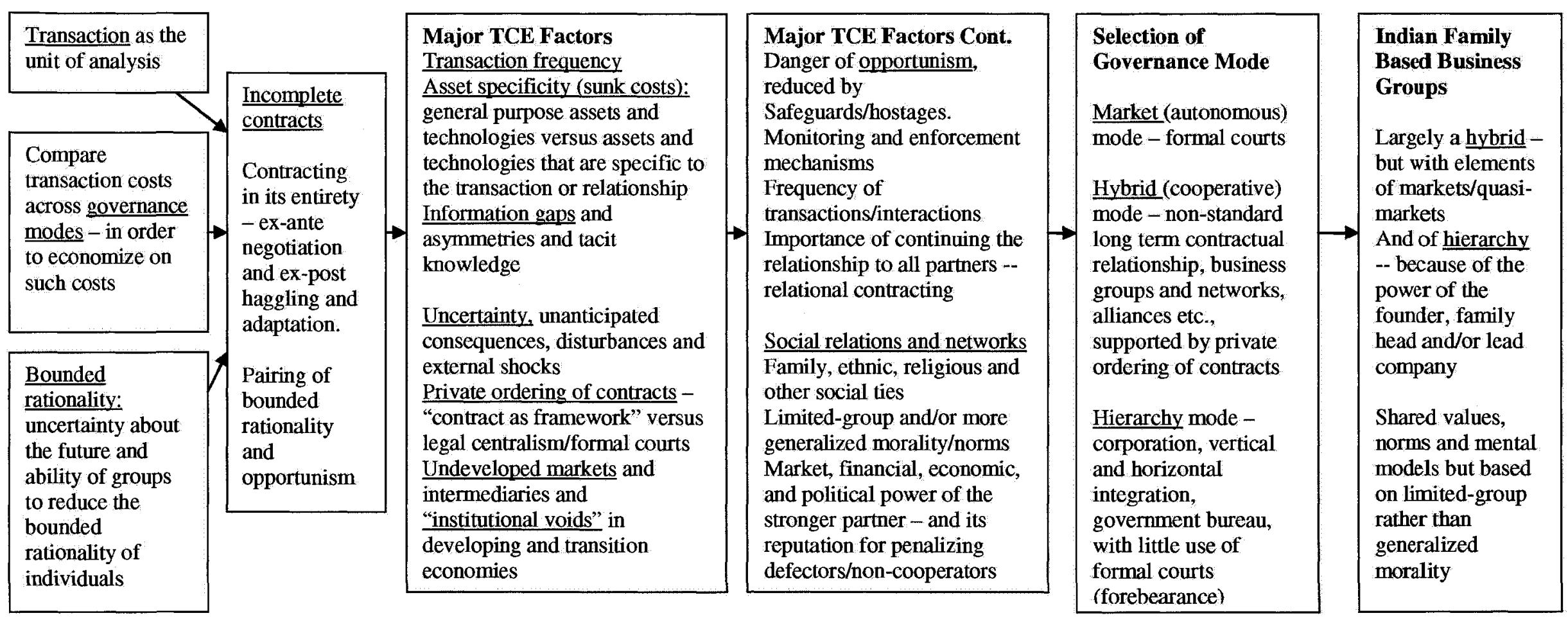

Possible TCE explanations for emergence and persistence of business groups in India and other developing and transition countries. (i) Greater information failures, risk and uncertainty about the future leading to more incomplete contracts and more opportunities for opportunism outside business groups. (ii) Under-developed markets, intermediate services and other "institutional voids" -- making more assets transaction specific and transactions outside the group more costly and risky.

(iii) Family, ethnic, religious and related social links and solidarity (limited-group morality), and the power of the family/group leader, providing social and economic penalties to punish defectors (non-cooperators) and those who refuse to punish defectors. (iv) Economizing on scarce information and reducing opportunism and governance, monitoring, enforcement and other transaction costs within the group. (v) Weakness of generalized morality in India: makes transactions within the group less costly and risky compared with transactions with other groups and companies. (vi) Transactions within business group favoured over long-term relationships with non-member companies because of high costs and uncertainty of courts, litigious nature of Indian society outside business groups, and little experience with "contract as framework". (vii) formal competition and other business institutions/rules that favour within-group transactions over transactions between independent firms. 
Williamson and his NIE colleagues stress the importance of non-standard forms of contracting and organization (such as business groups and networks) that lie between market transactions and hierarchical relationships within the firm or government bureau $^{41}$. Bounded rationality ${ }^{42}$ and uncertainty about the future mean that most contracts between two or more companies in a long-term business relationship are incomplete. Incomplete contracts add greatly to the significance of and problems with transaction specific assets (including technologies and social and human capital) to business transactions and informal business arrangements. Transaction specific assets when combined with bounded rationality, information asymmetries and gaps ${ }^{43}$, uncertainty about the future, and incomplete contracts lead to greater opportunities for strategic behaviour and opportunism by one or more parties to the transaction (Williamson 1985 , p. 72$)^{44}$.

Bounded rationality and the behavioral biases identified in experimental and behavioral economics are particularly important to the modified TCE model developed for this dissertation. The behavioral constraints and biases that are most important are information gaps, asymmetries and uncertainties particularly regarding future events, outcomes and the strategies of other companies; and the "constraints" to perfect

\footnotetext{
${ }^{41}$ Business groups in India and other developing and transition economies are defined as non-standard forms of contracting for purposes of this dissertation (see the definitions in Appendix 1). Khanna (see various references in the bibliography) adopts a similar approach in his extensive research program on business groups in India and other countries.

${ }^{42}$ For example, Williamson (1986, p. 110), states as follows. "Economizing on transaction costs essentially reduces to economizing on bounded rationality ..." See as well Conlisk 1996, p. 675 and pp. 690-691.

${ }^{43}$ Williamson introduced the concept of "information-impactedness" to cover all aspects of information gaps, limitations and asymmetry (Dixit 1996, p. 54). However, this dissertation will generally use the terms information gaps, information asymmetries and associated market failures to avoid confusion and to be consistent with the terminology used in information economics (see e.g. Stiglitz 2001).

${ }^{44}$ What Williamson (1985) calls "self-interest with guile".
} 
rationality and unbounded self-interest that result from social preferences and family, clan, ethnic, religious, local community and other social pressures and obligations ${ }^{45}$.

Vertical or horizontal integration is one governance option to mitigate opportunism and related transaction problems. However, economizing on transactions costs often requires the establishment of informal governance of business relationships - what Williamson calls "hybrids" and the private ordering of contracts ${ }^{46}$ - which often is preferred to both: internal governance/hierarchy; and market exchange and the court ordering of contracts. The private ordering of contracts can often be preferred to formal court ordering because of the high costs: of court litigation, of negotiating "complete" contracts, and of "haggling" after the contract is signed, costs that can be disproportionate to the expected benefits from the arrangement ${ }^{47}$. As well, the formal courts can cause delays and can generate inappropriate decisions.

The advantages of hierarchy and hybrids over markets are illustrated by Williamson's analysis of "contracting in its entirety" when two or more companies establish a long-

\footnotetext{
${ }^{45}$ Bounded self-interest recognizes that producers, consumers, markets and the economy are embedded within a broader society (Granovetter 1985). Some attention in the empirical chapters is also given to time constraints that result in the application of heuristics, rules of thumb and organizational routines to the dayto-day operations and decisions of businesses.

Time constraints can be particularly important to large and expanding family owned and operated business groups where key corporate and group decisions remain centralized in the family leader and a few other senior family members (see Chapter 8). In contrast, less attention is given to the cognitive, computational and related psychology-based constraints that are explored in the behavioral economics and related literatures. Cognitive constraints are not analysed in any detail in the Indian business group literature reviewed for this dissertation, and are likely no more important (i) to Indian companies than companies based in other countries, and (ii) to Indian business groups than other Indian companies.
}

\footnotetext{
46. Williamson defines the private ordering of contracts as follows. "Whatever the rules of the game, the lens of contract is also usefully brought to bear on the play of the game. This latter is what I refer to as private ordering, which entails efforts by the immediate parties to a transaction to align incentives and to craft governance structures that are better attuned to their exchange needs" (Williamson 2002, p. 172 italics in the original).
}

${ }^{47}$ A major exception in OECD countries is patent law where the payoffs from successful court cases can be very large and thus can justify expensive court cases. Patent law and related intellectual property disputes and strategies will take on greater importance in India as the economy modernizes and places greater emphasis on knowledge, human capital, innovation (see Chapter 8 ). 
term informal business relationship. Contracting in its entirety addresses both ex-ante conditions before the contract is signed (when there is greater competition and choice for both parties) and ex-post conditions and contingencies -- when the partners are locked into a bilateral monopoly relationship of mutual dependence (Williamson 1985, p. 63). This ex-post business relationship exacerbates the problems of: information asymmetries and gaps, uncertainty about the future, bounded rationality, and asset specificity; which lead to greater opportunism, shirking and other strategic behaviour of one or both parties that are designed to appropriate all of the profits from the relationship. At the same time, successfully working together and making joint investments of time and money to find and implement solutions to these ex-post problems can make business groups and networks and other informal business arrangements (including anti-competitive cartels) more stable and sustainable than was presumed in traditional micro-economics and industrial organization theory (Church and Ware 2000, Chapter 10).

The Williamson transactions cost model especially emphasizes the interactions between opportunism and bounded rationality for the stability and sustainability of, and mutual benefits from, informal business institutions and arrangements. All contractual problems and most transactions costs would disappear without the pairing of bounded rationality and opportunism. Without bounded rationality (which would mean that all current and future matters relevant to the contract are totally knowable and known to all parties), comprehensive contingent claims contracting would be sufficient. Without opportunism, contract as promise (whereby all parties would promise to deal fairly with, and take full account of the interests of, all other parties) would be sufficient (Williamson 1985, pp. 64-67). 
The risk of opportunism is positively related to market size, depth and development. Williamson contends that opportunism poses little risk when there are competitive exchange relations involving large numbers of potential buyers and sellers and the purchaser has a number of product and supplier choices. However, under the Williamson TCE model, the risk of opportunism becomes greater as the number of qualified bidders declines, such as when contracts are to be renewed, when markets are under developed and fragmented, and/or when high transport costs limit markets to confined geographic $\operatorname{areas}^{48}$. The opportunities for strategic behaviour - and the methods for controlling and decreasing such behaviour through for example business groups -- become especially significant in developing and transition economies. Opportunism and other forms of strategic behaviour made possible by information asymmetries and bounded rationality, especially regarding future outcomes, mean that informal business relationships must include safeguards. Safeguards are in place when both parties make investments in physical, human and/or social capital and assets ${ }^{49}$ that are specific to the transaction and therefore are non-redeployable and cannot be easily reallocated to an alternative use at minimum cost.

Finally, Williamson emphasizes that informal business arrangements can become very problematic in business environments characterized by high levels of risk, uncertainty and institutional immaturity. Risk and uncertainty for example are

\footnotetext{
${ }^{48}$ Williamson's treatment of opportunism is contested by many other institutional and business strategy scholars. Their arguments and the implications of this debate for India are explored in a later section of this chapter.

${ }^{49}$ Safeguards can encompass joint investments in social capital, including the time and effort to develop shared values, norms, knowledge particularly tacit knowledge, experiences, successes and "mental models". Social capital, which is very important to successful business groups, is not readily redeployed to an alternative use and therefore typically is a sunk cost (Fukuyama 1995 and 1999, Annen 2003, and Ostrom and Ahn 2001).
} 
particularly serious for informal business arrangements based on research, development and innovation, where transaction specific assets are normally very important (Williamson 1985, p. 143) and predicting future benefits is very difficult ${ }^{50}$. By its very nature, innovation ${ }^{51}$ is a high risk, uncertain enterprise where information asymmetries and gaps and bounded rationality about future events and outcomes are substantial.

Williamson was especially concerned that the need to economize on transactions costs - and the role of non-standard (or hybrid) forms of contracting and organization in minimizing such costs -- was not well understood by competition and other government regulators. Competition, corporate governance and other policies and laws may ignore the important efficiencies provided by non-standard forms of contracting and organization, including implicitly the horizontal and vertical transactions and relationships between member companies that take place within business groups and networks (Khanna 2000 and Khanna and Palepu 1999), strategic alliances, research partnerships (Agrawal 2005), national and global supply chains, industrial districts (Oughton and Whittam 1997), and technology clusters (Prashantham 2004, Chen 2003 and Porter 2001). This issue is further explored in the following sections.

\subsection{Importance of NIE Concepts to Developing Economies}

While Williamson $(1975,1985$, and 1986) based his TCE model on the United States and other more advanced OECD countries, the major NIE concepts described in Exhibit VI may be even more important to reducing transactions costs, and achieving static and

\footnotetext{
${ }^{50}$ Later NIE scholars emphasize in particular the ex-post governance problems that need to be faced by informal business arrangements based on R\&D and innovation (Reur etc. 2002).

${ }^{51}$ In the literature and this dissertation, innovation is defined to encompass technological change as well as managerial, organizational and governance innovations needed e.g. by companies and business groups in developing and transition economies to adapt successfully to a rapidly changing and highly contingent external environment. Later chapters emphasize that India's traditional business groups have been more adept at managerial than technological innovations.
} 
dynamic efficiencies and the gains from trade in developing and transition countries. In developing and transition economies like India, markets and the formal court system and other formal institutions are less developed and less trusted by businesses, consumers and other market participants. Information, transport, telecom, market exchange and other transactions costs are often higher and more important than production costs. Markets are more fragmented (in both product and geographic space); and language, ethnic, religious and other social differences can further fragment markets and the private business sector through increasing information asymmetries, misunderstandings, distrust, transactions costs, and opportunism across different business groups, other businesses, and business communities (see Chapter 4). Finally, rapid economic, technological, social and organizational change exacerbates information uncertainties and asymmetries and place additional bounds on rationality and the ability of economic agents to predict the future. Under the Williamson TCE model used in this dissertation, these conditions provide additional opportunities for opportunism and other forms of strategic behaviour in India and other developing and transition economies.

The pairing of bounded rationality and opportunism in the TCE model is especially helpful to understanding the establishment, persistence and continuing success of traditional business groups in India and other developing and transition economies. Business groups reduce the negative impacts of bounded rationality on its affiliated companies through specialization, sharing information from multiple products, markets and market experiences (Langlois and Robertson 1995 and Williamson 1998 ${ }^{52}$ ), and

\footnotetext{
${ }^{52}$ Williamson (1998, pp. 6-7) notes that business organizations, including business groups and networks, can reduce the negative effects of limited knowledge, foresight, skill and time and other cognitive limitations of individual human beings, through a mix of simple aggregation, sharing information, learning and experiences, developing shared "mental models", and specialization/division of labour. The ability of
} 
through building shared learning, trust, reciprocity of trust, experience, successes and mental models. These and other mechanisms also significantly reduce opportunism within traditional business groups.

Particularly important in this regard are the consequent reductions in information asymmetries, bounded rationality, and the "unbounded self-interest" of affiliated company members and their managers and employees; and the greater trust and reciprocity of trust within business groups, especially when compared with transactions between different business groups and with other unaffiliated companies that often have different ethnic, religious and/or social backgrounds and "mental models". Opportunism is further controlled through the strong leadership of the group leader/head of family; and through imposing business, family and other social norms and penalties on noncooperators. This allows the business group and its leaders to apply the concept of "contract as promise" as described in the TCE model outlined earlier.

The TCE model therefore underlines the importance in developing and transition economies of business groups and networks and other informal business institutions and arrangements in reducing bounded rationality and opportunism and thus increasing the net gains from trade within the group, network and arrangement. When the business groups are based on family, religious, ethnic and other social ties, transactions costs, information failures, opportunism, risk and uncertainty are further monitored, controlled and reduced. These TCE and NIE concepts are particularly important to the design and enforcement of modern competition regimes in developing and transition economies. Using these concepts would allow developing and transition countries to avoid the

business groups and other forms of business organization to control and reduce the bounded rationality of individual employees is particularly relevant to rapidly expanding and changing developing economies where risk and uncertainty are high and the ability to predict the future is limited. 
mistakes (embodied in the third kind of interaction in Exhibit II) that can result from the doctrinaire application of the neo-classical model and traditional industrial organization economics based on the structure/conduct/performance model (Williamson 1986, chapters 10 and 11 and Williamson 2002:1 and 2002:2) ${ }^{53}$.

\subsection{Extensions to the Williamson Model Relevant to the Conceptual Framework}

Subsequent economic, business and other theorists in the NIE tradition have employed, conducted empirical research on, extended and filled some of the gaps in Williamson's transactions cost model ${ }^{54}$. The following stresses extensions that are most important to understanding the establishment and persistence of business groups and other informal business institutions and arrangements and their interactions with competition regimes in India and other developing and transition countries.

\subsubsection{Combining Price, Authority and Trust}

Bradach and Eccles (1989, p. 101) start from the transaction cost model but then argue that price, authority and trust - which correspond quite closely to the ideal types of markets, firm hierarchy, and hybrids/relational contracting in the Williamson model - are not mutually exclusive alternatives but, instead, can be combined with each other in a variety of ways. Business groups and networks in India and elsewhere likely employ all three modes of governance depending on the context. Three more specific examples are:

${ }^{53}$ Expanding on this point, the competition issues posed by: (i) price discrimination, resale price maintenance, and other vertical restraints, (ii) vertical and horizontal integration, (iii) short-term and longterm contractual relationships including between horizontal competitors, (iv) business groups and networks, (v) duopoly and oligopoly markets and conglomerate forms of organization, that are generally considered to be anti-competitive when traditional micro-economic and IO theory and the SCP are applied, become less clear-cut and more nuanced and contingent when the TCE and NIE concepts reviewed above are added to the competition analysis (Williamson 1975, 1986 and 2002:2). At the same time, traditional business groups can raise serious competition issues because of their participation in multiple product and geographic markets and their ability to use shared norms, values and mental models and both social and commercial penalties to sustain cartels and other formal and tacit anti-competitive agreements for an extended period (see Chapter 8).

${ }^{54}$ Many of these extensions were acknowledged and accepted by Williamson in his later writings during the 1990s and the current decade (see e.g. Williamson 1998 and 2000:1 and Hodgson 1998). 
trust/relational contracting to reduce disputes and information and other transaction costs in transactions and other exchanges between group companies; control mechanisms/hierarchy to coordinate the investment and other decisions of affiliated companies and to share profits between family members and the senior managers of group companies in order to minimize family conflicts (Das 2002); and markets (or quasi-markets), prices, profit centres and other market incentives to facilitate intra-group transactions and to determine which affiliated company is to receive internal venture capital funds or new managers trained in the group's management training facility.

This NIE extension also helps to explain why and under what circumstances business groups or networks will use plural or mixed market/hierarchy forms such as employing both make and buy options in purchasing key inputs or new technology from affiliated companies and unaffiliated (including smaller) suppliers, or in using both internal and external commercial financing for project investments (Bradach and Eccles, p. 113). These mixed forms can be applied in order to acquire information and experience, to create competition between within group and outside sources, and to better control both internal and outside suppliers.

\subsubsection{Multi-Product Firms and Business Groups}

Teece (1980) applied the transactions cost model to explore the major elements of an efficiency based theory of the multi-product (or conglomerate) firm. The article stresses the importance of the recurrent use of specialized proprietary know-how of various kinds (e.g. technological, managerial and marketing know-how, good will and brand loyalty) and specialized and indivisible physical assets to the establishment and efficient operation of multi-product enterprises. Khanna, Palepu and other authors have extended 
these arguments to examine why business groups and other conglomerate/multi-product corporate entities continue to be appropriate corporate forms for India and other emerging market economies (see e.g. Khanna and Palepu 1997, 1999 and 2000:2, Fisman and Khanna 2004, and Lensink et al 2003).

In some respects, the business groups of India and other developing and transition countries - which are groupings of nominally independent companies (see Appendix 1) may combine together the features of the market, hybrid and hierarchy governance modes in a manner that is appropriate to their needs and stage of development. The business group affiliated companies achieve economies of scale by selling to each other; and economies of scope through sharing know-how, business and government contacts, specialized and indivisible physical assets, and the family/brand name, and through establishing joint ventures between member companies in order to meet some of their most critical input requirements that cannot be satisfied by under-developed "external" markets (Rey and Tirole 2001 and Khanna and Palepu 2004:2). At the same time, business groups may avoid some of the high governance costs and risks and the weaker incentives associated with vertical integration and large conglomerate firms, as well as some of the dangers of opportunism and abuses of power associated with the leaders of large multi-division corporations (Dow 1987). This is because the business group member companies are nominally independent and make at least some of their own purchasing and other day-to-day decisions.

\subsubsection{Relational Norms and Contracts}

Another important extension, and to some degree criticism, of the treatment of opportunism in the original TCE model, address the limited attention that Williamson 
gives to the role of relational norms and shared values in reducing opportunism and transactions costs in non-standard contracting. Theoretical work and empirical evidence indicate that relational norms and shared values and mental models that develop over time, through the frequent interactions that take place in long-term contractual relationships, partnerships, strategic alliances and business networks ${ }^{55}$ between independent companies, reduce opportunism, shirking, strategic behaviour, and transactions $\operatorname{costs}^{56}$. These reductions take place even when there is significant asset specificity and uncertainty about the future (Dore 1983, Heide and John 1992, Gulati 1995, Nooteboom et al 1997, Nee 1998, Artz and Brush 2000) ${ }^{57}$.

A number of factors that provide evidence of relational norms in a business arrangement between two or more independent companies are relevant to the persistence and continuing success of India's business groups. These are: the extent of information sharing, joint planning and forecasting, the use of non-coercive rather than coercive communication and negotiation strategies (Artz and Brush 2000 p. 346), and flexibility and adaptability. Also important are the emergence of shared expectations that the relationship will continue for many years into the future, and, related to this, a sense of solidarity, where the parties to the relationships see the problems of one party as joint problems to be solved together and perceive a shared responsibility for maintaining the

\footnotetext{
${ }_{55}^{55}$ Including from previous relationships between the two parties (see e.g. Agrawal 2005)

${ }^{56}$ Including the costs of negotiating contracts ex-ante and the costs of monitoring, managing and modifying contracts ex-post.

${ }^{57}$ These extensions to the NIE and TCE models explore many dimensions of asset specificity that can be important to business groups, including investments in physical, human and social capital that are discussed earlier, and the temporal dimension when e.g. the buyer is highly dependent on timely performance by the supplier because of limited supplier alternatives and the supplier is highly dependent on timely payment by the buyer because the buyer is a major customer (Artz and Brush 2000, pp. 342-343). Mutual dependence can lead through repeated interactions to mutual obligations, shared information and learning, and greater trust and reciprocity of trust.
} 
relationship. Empirical research indicates that cooperation, trust, reciprocity of trust and relational norms reduce transaction costs both directly and through their interactions with asset specificity ${ }^{58}$ and to a lesser degree with uncertainty (Artz and Brush 2000, p. 357).

These critics believe that Williamson has under estimated the risk of opportunism in market transactions, when economic agents are often anonymous and transact infrequently, and thus there is no opportunity for shared learning and building trust and reciprocity of trust through repeated interactions. They also believe that the TCE model has exaggerated the risk of opportunism in long-term supplier and related non-standard contracting relationships, where shared learning and values and mutual dependence, obligations and trust can significantly lower opportunism and the cost of monitoring and governing the relationship.

This author has taken a middle course on this debate. The arguments of Williamson's critics are important to understanding: transactions and transaction cost minimization within India's business groups and other informal business institutions; and the preference for this kind of informal governance structure over market transactions. This preference is associated with India's high information costs, large geographic size, highly fragmented markets, and social and other divisions, which combine together to increase the risks of opportunism in market exchange. At the same time, consistent with the Williamson TE model, opportunism is still seen as a serious constraint to the establishment of mutually beneficial long-term contractual relationships between different business groups and between business groups and non-affiliated companies

\footnotetext{
${ }^{58}$ For example, a relationship based on cooperation, trust, reciprocity of trust, and relational norms more generally lowers transaction costs for a given level of asset specificity, and as well may encourage the partners to make greater investments in efficiency-enhancing relationship specific assets. In short, causation can operate in several directions (Artz and Brush 2000, p. 358).
} 
within the Indian private business sector. The higher risk of opportunism from these informal contractual relationships are the result of the ethnic, religious, language, social and regional differences between business groups and different business communities, the long history of strong rivalry (and "unfair competition") between groups for state entitlements before 1991 and for market share after 1991, and the weaknesses of India's court system and other formal business institutions. These issues are further explored in Chapter 4 (see e.g. the end of section 4.4) and Chapter 8 (sub-section 8.4.2)

\subsubsection{Resource-Based Perspective on the Firm and Business Group.}

Business theorists have extended Williamson's TCE model to give greater attention to the internal capabilities and resources of the firm, as captured in what the business literature calls the resource-based theory of the firm (Hodgson 1998, Madhok 2002, Garrouste and Saussier 2005, and Carter and Hodgson 2006). This approach does not ignore transactions costs, but places greater weight on production costs and on how these are related to the differing capabilities and the organizational and production routines of firms within the same industry (Nelson and Winter 1982, Nelson 1991, and Langlois and Robertson 1995). Under this theory, firms and by extension business groups are superior to markets not only because they economize on transactions costs; but also because firms possess production cost minimizing and productivity enhancing factors associated with their resources, capabilities, skills, knowledge, organizational and production routines, business practices and informal business arrangements with other firms. These factors can make one firm or business group more competitive than another firm or group in the same industry and market (Nelson 1991). 
Under the resource-based theory, informal business arrangements are especially beneficial in innovation and related market environments that are undergoing rapid change. Rapid change makes the firm's past resources, capabilities and organizational routines less valuable. As a consequence, informal business arrangements with trusted business partners are needed to fill these emerging resource gaps through e.g. sharing information, learning, and technology including patent sharing and cross-licensing. Nonstandard forms of contracting and inter-firm collaboration more generally allow the company to: have access to complementary resources; overcome constraints in their own resources, capabilities and routines, and thereby improve productivity, product quality and competitive advantage (Madhok 2002, pp. 542-545).

The resource-based theory thus provides additional reasons why informal inter-firm business arrangements are often preferred to hierarchy and the market in the highly dynamic and uncertain situations found in rapidly developing transition economies like India (Madhok 2002, pp. 542-543) ${ }^{59}$. Inter-firm collaboration based on both complementary resources and transaction cost minimization can better explain the importance of building shared relational norms, values, social capital and mental models between the member companies of a business group or network. The resulting shared mental models and social capital helps to further reduce opportunism, shirking and governance, monitoring, enforcement and other transactions costs (Madhok 2002, p. 546). This leads in turn to greater investments in mutually beneficial transaction specific

\footnotetext{
${ }^{59}$ For example, India's extensive but incomplete post-1991 liberalization program has resulted in underdeveloped and fragmented markets and limited availability of many intermediate goods and services, leading to numerous "institutional voids" (see Khanna and Rivkin 2001 and Khanna and Palepu 2004:1, 2004:2 and 2004:3) that often need to filled through inter-firm collaboration within and between business groups.
} 
investments by members of the business group, and the generation of greater total and net benefits from the business arrangement for its members and (perhaps) the total economy.

In sum, bringing together the transactions costs (TCE) model with the resource-based theory of the firm in the Indian context: further explains the importance of business groups and other informal business institutions and arrangements both historically and currently; demonstrates their potential importance to India's future development; and, further illustrates how poorly designed and enforced competition regimes could undermine pro-competitive business groups and other informal business arrangements.

\subsubsection{Innovation and Endogenous Growth}

These competition issues are explored in greater detail in the expanding innovation economics literature on the competition law treatment of informal business arrangements such as research partnerships and strategic alliances that are established to conduct joint research and development programs and to commercialize new product and process innovations. This literature is often associated with the work of Jorde and Teece (1992) and their colleagues in the early 1990s (see as well Langlois and Robertson 1995 and Robertson and $\mathrm{Yu}$ 2001). These scholars voiced serious concerns that treating innovation markets the same as traditional markets for goods and services had led to the overly rigorous and negative treatment of $\mathrm{R} \& \mathrm{D}$ and innovation based informal business arrangements under competition laws in the United States, the European Union and other OECD countries. These competition law approaches were discouraging research, development and innovation by companies of all sizes. Similar to the concerns of Williamson (1985), these critics argued that competition rules can readily be misused to prevent vertical and horizontal arrangements such as research joint ventures and 
partnerships that can generate economies of scale in research and production, and can promote dynamic efficiencies, product and process innovations, greater competition and consumer welfare over the longer term (Jorde and Teece 1992, and Scotchmer 1998).

There is still the danger that cooperation between independent companies in research and innovation can lead to collusion and abuse of dominant positions when the resulting innovations are commercially sold in product markets. At the same time, research partnerships and other informal business arrangements can generate greater financial and economic returns compared with large vertically integrated companies, formal horizontal mergers, and conglomerate forms of corporate governance. This can be particularly true in industries where generic multi-purpose enabling technologies and time to market are important and product life cycles are short. Informal business arrangements for example can be preferable to large companies when the latter are burdened by complex decisionmaking processes and long periods of time for information to first flow vertically before it flows horizontally (Teece 1992, pp. 21 and 22). Similar to large multi-division and conglomerate firms in other countries, some of India's larger traditional business groups are also known for their rigidity, weak within-group information flows and slow and complex decision-making (Das 2002) ${ }^{60}$.

The new (Schumpeterian) endogenous growth models of Aghion, Howitt and their colleagues (2006) also apply a more dynamic framework to assess competition and related formal and informal business institutions. Their growth models indicate that countries, sub-national regions and firms that are closer to their technological frontiers

\footnotetext{
${ }^{60}$ The solutions can be long-term relationships between affiliated companies within two or more business groups, and between business group affiliates and smaller unaffiliated companies that are more flexible, nimble and innovative but lack the financial and human resources to commercialize new product and process innovations. Informal business relationships with smaller more innovative companies can also protect larger incumbents from the Schumpeterian process of creative destruction.
} 
are more likely to benefit from higher firm exit, entry and turnover and competition promoting improvements in formal and informal institutions ${ }^{61}$. Applying this model to India indicated that the more technologically advanced industries and firms and the more highly developed regional states with more pro-business policies -- which are all closer to their technological frontiers -- are more likely to respond positively to and thus benefit from liberalization than the less advanced industries, firms and regional states (Aghion Burgess et al 2003 and 2005:1 and 2005:2).

\subsubsection{Extending the TCE Model to Politics and Public Administration}

The TCE model has been extended by Williamson and others into the world of politics and government administration. Some of the major NIE concepts can lead to even higher transactions costs and more uncertain outcomes in the political and bureaucratic world (see in particular Dixit 1996, Williamson 1999:1 and Stiglitz 2003). A partial listing of these NIE concepts would include bounded rationality, information asymmetries and gaps, the weak incentives of government officials because of limited competition across government agencies, the commitment and coordination failures of government, and opportunism, shirking and other forms of strategic behaviour.

This extension of TCE to politics and government bureaucracies is helpful to explaining the high transactions costs, uneasy relationships, and difficult interactions with uncertain outcomes over the past four decades between, on the one hand, Indian governments and their more formal competition, business licensing, and related business regulation agencies, and, on the other, the country's business groups and their more informal institutions and rules of business conduct (described in Chapters 6-8)

${ }^{61}$ Technological frontiers can be defined to encompass not only product and process technologies and innovations but as well human capital, social capital, and organizational innovations including improvements to formal and informal business institutions. 


\subsubsection{Theories of Institutional Change}

Finally, NIE and the TCE model have been extended into theories on how and why institutions change. Theories of institutional change are important to assessing how India's informal business institutions first became established, have evolved through the centuries in response to foreign influences and incursions, more domestically oriented shocks and changes, and pressures and changes that are internal to the traditional business groups and their member companies. Because of history, path dependence, and institutional inertia, institutions change slowly, and informal business and other institutions often change more slowly than formal institutions that are under the control of government and can be altered through government edict.

Therefore, much of the literature on informal institutional change stresses the importance of major external economic and political shocks to bring about fundamental changes in informal institutions. These shocks include war, occupation, colonial rule, revolution and global depression, or more significant domestic changes such as major shifts in the domestic policy environment. India and its informal business institutions and arrangements have experienced nearly all of these shocks and changes over the past three centuries (see Chapters 4 and 5).

In contrast, other theories of informal institutional change emphasize the role of small, incremental and endogenous factors within the broader society and economy that over time can have a cumulative effect that brings about slow but fundamental institutional change. Theories on endogenous institutional change also address factors that are internal to the company, business group, network, community and culture such as expansions in the number of members and in their diversity in terms of ethnic, religious 
and social composition, attitudes, and cultural beliefs (Greif 1996, 1997:1, 1997:2 and 2004).

Three kinds of endogenous incremental change are germane to the conceptual framework for this thesis. Informal business institutions and arrangements can be highly successful for a period of time, and attract more members and establish and acquire new companies in e.g. unfamiliar product and geographic markets. Over time however, the arrangement may become too large, complex and diverse ${ }^{62}$ to be effectively monitored and enforced using the old rules and informal governance systems. The result is more free-riding and less investment by members in the institutions, rules of business conduct and shared facilities that made the arrangement a success in the first place ${ }^{63}$. The Tata, Birla, Ambani/Reliance and other Indian business groups that are now entering global markets through significant acquisitions of Indian and foreign companies and thus becoming larger, more complex and more diverse, could be facing these problems in the years ahead.

There is the alternative danger that the business group, network or community and its institutions become so entrenched, self-satisfied and impressed with its own success and the extent of consensus within the group or community -- that it is no longer able to adapt to and capitalize on changes in the external environment that pose new and unfamiliar opportunities, threats and risks. This can particularly take place within family, ethnic, language and religion based business groups and communities that exclude outsiders with

\footnotetext{
${ }^{62}$ For example, in terms of ethnicity, firm size, and/or the interests of affiliated companies and their managers (Schmitz 1995).

${ }^{63}$ See e.g. Humphrey and Schmitz (1998, pp. 52-54) for a discussion of how social ties become less effective as an industrial cluster grows in size and complexity. These two authors discuss two examples of industrial clusters in Brazil and Pakistan. Similar forces are likely at play as India's business groups become larger and more complex and diverse through domestic and foreign mergers and acquisitions, greenfield investments outside India, and related global competitiveness strategies.
} 
new energy and ideas (Bowles and Gintis 2002). There is anecdotal evidence that these factors help to explain the decline and disappearance of the Indian business groups that have failed to respond effectively to globalization and liberalization (see Chapters 6-8) ${ }^{64}$.

The third kind of endogenous change may be more relevant to changes in formal competition regimes and to how they respond to alterations in the external environment ${ }^{65}$. This institutional literature emphasizes endogenous, incremental but ultimately fundamental changes in institutional outcomes through the processes of what are called institutional drift, layering, conversion, displacement and erosion ${ }^{66}$. These kinds of formal institutional change are highly relevant to the competition law experience of India that has had a competition law, the Monopolies and Restrictive Trade Practices Act, for four decades but until recently has displayed little capacity and political will to enforce the country's competition law (see e.g. section 7.6).

The literature on institutional change is particularly important to developing a better understanding of how informal business and related institutions and rules of the game in a society and economy ${ }^{67}$ are first established (see e.g. Axelrod 1986, Moore 1994 and 1997 and Cooter 1994), and are then translated into better articulated and more specific but still informal rules of business conduct and into informal business arrangements, networks

\footnotetext{
${ }^{64}$ The reader should note the tension and conflict between the first and second sources of institutional change and weakening. The first describes the risk of too many members and too much diversity and the second describes the risk of a "closed shop" with too few members and too little entry, exit, and diversity. In many respects, India's more successful business groups are trying to find the middle path between these two sources of institutional risk and change (see Chapter 8).

${ }^{65}$ Including to the strategies of business groups and other informal business institutions - and their political and bureaucratic supporters (further explored in Chapter 5-8).

${ }^{66}$ See e.g. Hacker 2003, Crouch and Keune 2003, Streeck and Thelen 2004, Culpepper 2001, Pierson and Skocpol 2003, and Lindner and Rittberger 2003. While these concepts are typically applied to formal institutions, some of them are also relevant to business groups and other informal institutions and arrangements in India and other developing economies.

${ }^{67}$ Which to repeat are associated in the institutional literatures with cooperation, trust, reciprocating trust, reciprocal obligations and building/investing in reputations for being trustworthy (see the Ostrom references in the bibliography).
} 
and groups. Oughton and Whittam (1997) provide some important insights on this "translation" process ${ }^{68}$. These two authors contend that inter-firm cooperation emerges because of the mutually reinforcing impacts of rational profit maximization and of institutional and cultural environments that encourage cooperation, trust and the reciprocity of trust. The two authors especially focus on collective external economies, which arise when firms cooperate over input activities including research and technological development, finance, marketing, export promotion, and other business services, often through the pooling of fixed $\operatorname{costs}^{69}$. Business groups and other forms of informal inter-firm collaboration thus provide benefits to their members both through various kinds of economies of scale and scope, and through the establishment of a complex web of inter-firm and repeated interactions that are economic and social in nature, and that are strongly influenced by an equally complex web of social conventions and norms that further promote inter-firm cooperation.

\footnotetext{
${ }^{68}$ See as well Smith-Doerr and Powell 2005, and Aspers 1999.

${ }^{69}$ In other words, using. Williamson's terminology, companies make shared investments in physical, human and social capital and therefore establish safeguards and "hostages" to their collaborative relationship that reduces opportunism and defection. Collective external economies shift the average cost curve downward and increase the survival prospects of participating firms (Oughton and Whittam 1997, p. 27).
}

Collective external economies are external to the firm but internal to the business group or network, and thus require the active involvement of participating firms through e.g. joint investments of time and money. Free-riding can be minimized through cost-effective monitoring and enforcement mechanisms, shared belief systems and "mental models" that value cooperation over opportunism, and the frequency of economic and social transactions and other interactions.

In terms of game theory, this process involves a finitely repeated game with imperfect information and bounded rationality. This means that the players do not know when the game will end and have to address the very real possibility that the game will continue indefinitely. This situation can lead to trigger strategies (which discourage defection because defectors are severely punished) and tit-for-tat strategies where players will cooperate as long as other players cooperate (Ostrom and Walker 1994 and Axelrod 1984). The result can be cooperative outcomes that avoid the prisoners dilemma type outcomes of conventional economic theory and non-cooperative game theory. 


\section{Exhibit VII: Rise and Fall of Business Groups And Similar Business Arrangements}

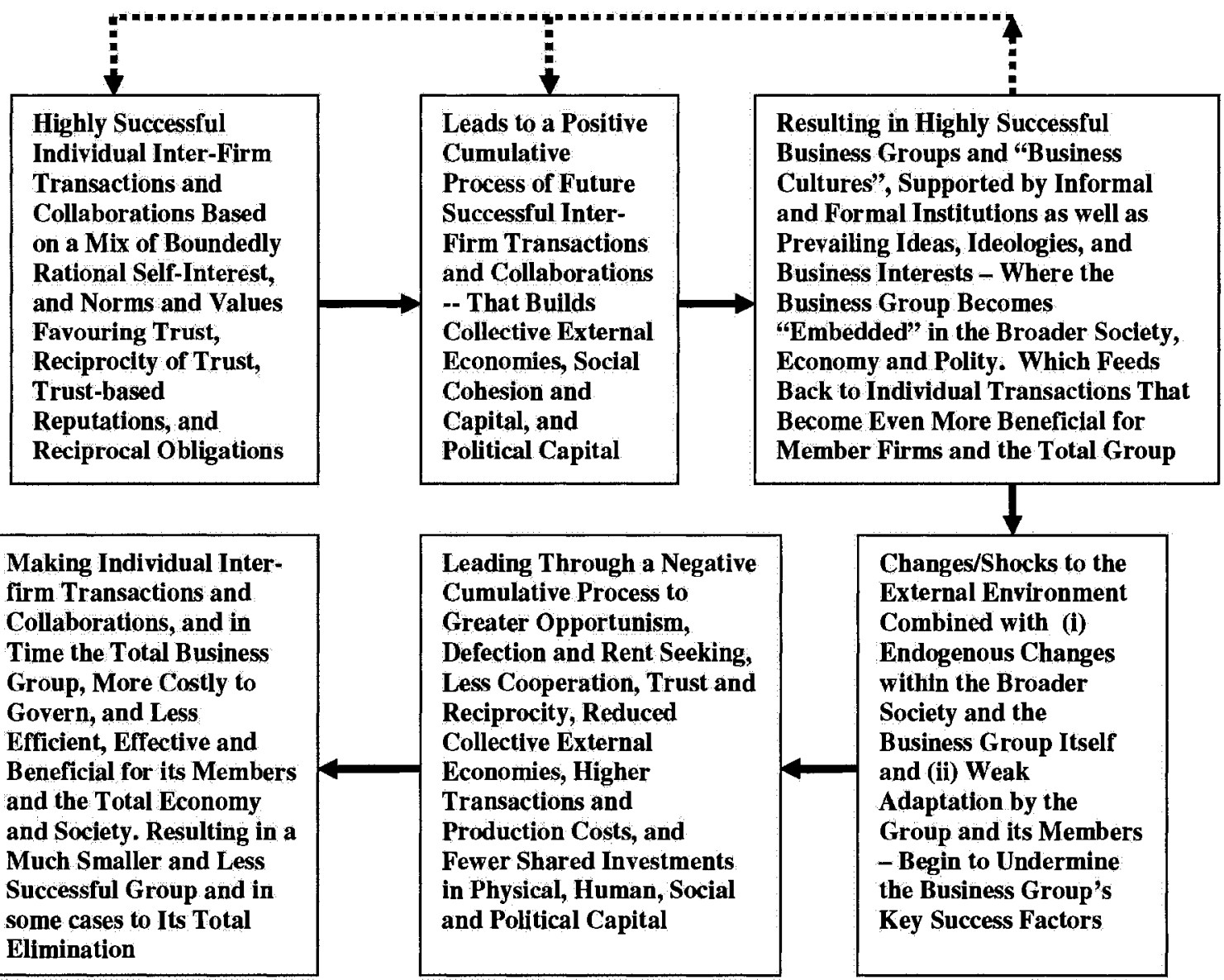

Based on this literature on informal institutional change, ${ }^{70}$ one could postulate the evolution of a distinct set of informal business institutions, rules of business conduct, business arrangements, groups and networks that when combined together can first grow and then decline in size and effectiveness ${ }^{71}$. The core elements of such a theory for business groups and other informal arrangements are summarized in Exhibit VII on the previous page. This exhibit is used extensively in Chapter eight in describing the

\footnotetext{
${ }^{70}$ Including the conditions and concepts set out in the Oughton and Whittam article, as well as the many references on common pool resources, common property and social capital in the bibliography associated with Ostrom and her colleagues.

${ }^{71}$ See as well Platteau, 1994:1 and 1994:2 and Grabowski 1999.
} 
evolution of India's traditional business groups as well as the emergence of the new economy informal business arrangements.

2.7 Overlaps, Synergies and Differences between New Institutional Economics (NIE) and New Industrial Organization (NIO) Economics

\subsubsection{Broader Similarities and Differences Between the Two Economic Literatures}

Because of the importance of new industrial organization (NIO) economics to competition analysis and the design and enforcement of formal competition regimes, special attention needs to be given to the overlaps, synergies and differences between NIE and new IO economics that are most important to the conceptual framework in Chapter 3. The new industrial organization and new institutional economics literatures start from quite different foundations. However, they are now starting to converge through addressing common themes and many of the same limitations of the NCE model. One major unifying theme in the two literatures is that more competition and suppliers are usually preferred to less competition and fewer competitors in order to improve allocative and dynamic efficiencies, economize on production and transactions costs, and make businesses, industries and the total economy more adaptable to new opportunities, risks and threats (North 1992) ${ }^{72}$.

Despite this convergence, there are still some important differences between the two literatures. Whereas NIE stresses path dependence and history (time and place), the new industrial organization literature maintains for the most part the ahistorical perspective of the NCE model. The regularities of industry and market structure, business conduct and

\footnotetext{
${ }^{72}$ While most economists would consider this to be an obvious statement, behavioral economics in recent years has conducted empirical research that has uncovered many situations when too many choices, leading to information and product choice overload, can mean for consumers, businesses and other economic agents: (i) decision paralysis - as agents prefer to avoid making a decision, (ii) staying with the status quo e.g. continuing to use the incumbent supplier when lower cost options are available, or (iii) making product and vendor switching decisions that are sub-optimal for consumers and social welfare (see Gans 2005:1 and 2005:2, Wilson and Waddams Price 2005, and Botti and Iyengar 2006).
} 
business performance found in specific OECD country markets and industries are expected to be relevant as well to developing and transition economies regardless of their economic histories and current stage of development. The new IO therefore presumes for the most part that the competition challenges and analytical requirements of formal competition regimes in developing and transition economies are similar to the challenges and requirements faced by more mature competition regimes such as the United States and the European Union.

In sharp contrast, the NIE concepts and findings are more sensitive to and contingent on time and place and thus more relevant to different countries, especially to developing and transition economies at different stages of development. The NIE literature gives much greater attention to the unique challenges and needs of developing and transition economies and the differences in business, market and other institutions, and in the institutional gaps between countries. These differences mean that the same industry can generate significantly different industrial structures and business conduct, strategies, arrangements, and performance depending on the country and its stage of development (Khanna and Rivkin 2001, Khanna and Palepu 2004:1, 2004:2 and 2004:3 and Williamson 2000:1 $1^{73}$ ). For new institutional economists, industries, markets, institutions, the country and its stage of development (time and place) are all important and interact together in determining market and industry structure, business conduct and performance, and competitive and anti-competitive outcomes.

The second consideration that sets NIE apart from the new industrial organization economics is the more explicit modeling in NIE of bounded rationality and imperfect information and what these imply for: incomplete contracts; opportunism, shirking and

${ }^{73}$ As well as the articles by Bardhan, Cooter, and other NIE theorists in Olson and Kahkonen (2000). 
defection; coordination and institutional failures; and, the potential for conventions, ethical norms, and moral values associated with and in support of cooperation, trust and reciprocity to address and offset opportunism in many (although not all) economic and social contexts (see. e.g. Artz and Brush 2000, and Heide and John 1992).

\subsubsection{More Specific Contributions of the Williamson TCE Model to Competition Law Analysis and Enforcement}

Many of the overlaps and synergies between NIE and the new IO result from the contributions of Oliver Williamson who made major contributions to both economic literatures. This section closes with a more detailed discussion of three contributions of Williamson's transactions cost model to the new IO literature, which has influenced competition regimes throughout the world including in India.

As noted earlier, Williamson (1985 and 1986) expressed serious concerns that nonstandard forms of contracting and business organization have too often been viewed with suspicion by competition authorities as simply new ways to fix prices, form cartels and exercise market power (see e.g. Blake 1973). His analysis indicates that competition law should treat business groups and other non-standard forms of contracting and informal business organization the same as formal business arrangements such as mergers and equity-based research joint ventures. His proposals are especially important to competition policy and law in developing economies such as India. Businesses in these countries need to be given sufficient latitude to build on their informal institutional histories and experiences and to experiment with new non-standard forms of contracting, business organization and other organizational innovations that in many cases are efficiency enhancing. Based on Williamson's analysis, special attention needs to be given to the interactions between asset specificity, prices, and safeguards when 
competition authorities investigate resale price maintenance, product tying ${ }^{74}$, territorial restrictions, other vertical restraints, price discrimination and related competition issues raised by an informal business arrangement (Williamson 1985, 1986 and 2002:2) ${ }^{75}$

The second contribution of Williamson's transactions cost model to the competition literature is the so-called Williamson efficiencies trade-off for assessing the net economic benefits of mergers and other formal and informal business arrangements (Williamson 1968). This trade-off proposes that a merger to monopoly should be permitted under competition law when the transaction generates net economic benefits because e.g. the decrease in industry-wide production, transactions and other costs is greater than the loss in consumer surplus ${ }^{76}$. This efficiencies defense argument was later extended by other competition and innovation theorists to include the long-term dynamic efficiencies that result from R\&D expenditures and process and product innovations ${ }^{77}$.

\footnotetext{
${ }^{74}$ Where a customer who wishes to purchase one product such as computer hardware is required to purchase a second product such as the operating system and other computer software.

${ }^{75}$ For example, when safeguards are in place in a vertical relationship with one customer and not in place with a second customer, the prices charged to the second customer need to be higher because the risks of opportunism and related transaction costs are higher in the relationship with the second customer. The application of the price discrimination, resale price maintenance or abuse of dominance provisions to the relationship with the second customer would reduce not increase economic efficiency and consumer welfare (Williamson 1985, pp. 15-42).

More generally, competition agencies in developing and transition countries should assess organizational innovations in terms of the economic benefits and costs of alternative feasible arrangements rather than against the hypothetical ideals of perfect competition and welfare maximization. Non-standard forms of contracting and organization therefore should be addressed under competition law only when there is clear evidence of the abuse of market power (Williamson 1985, p. 286).
}

This is the concept of remediableness that Williamson applies in all of his writings (2000, p. 102). Williamson argues that a policy puzzle or problem must be "remediable" by government or some other group. A problem is deemed to be "remediable" when the government or other group are able to take practical and feasible actions that result in improvements compared with the status quo/the "do-nothing" option. Comparing a problem with an ideal such as perfect competition and the universal claim of "get the prices right" under NCE and "get the property rights right" by e.g. shifting assets from government to private ownership under one branch of NIE called neo-institutional economics (Eggertsson 1990), is in his view not helpful to decision-makers or society.

\footnotetext{
${ }^{76}$ Also see the Canadian Competition Bureau (2004).

${ }^{77}$ These innovation proposals were based on the Schumpeterian perspective (Schumpeter 1934 and 1976) that large oligopolistic firms are better positioned to conduct extensive R\&D and innovation programs
} 
Third, Williamson (1975) uses an institutions-based transactions cost approach -- that places considerable weight on first-mover advantages, path dependence, institutional inertia and market imperfections -- to argue that dominant positions in mature industries can become so entrenched that these positions can no longer be disciplined, reduced and ultimately eliminated by ordinary market forces. More recent research has raised similar concerns for highly entrenched dominant positions in network and related industries (see e.g. Church and Ware 1998) ${ }^{78}$. Companies in these industries extensively employ patents, other intellectual property rights, technical standards, and cross-licensing with other companies, in order to strengthen informal business arrangements and their market power. As a consequence, high degrees of concentration can continue in many mature and new economy industries despite significant growth in market demand (Kwotka and White 2000). Williamson argues that dominant market positions that result from the breakdown of the self-policing properties of markets (Williamson 1975, p. $208^{79}$ ) should not be allowed to continue for an indefinite period.

The only defences and exceptions for sustaining a dominant market position would be, first, dominant positions that are required to achieve the benefits of economies of scale in a small market, leading to a natural monopoly where some kind of regulatory intervention by government would be needed; and, second, dominant positions that result directly from business acumen and superior efficiency and competitive performance that

compared with small and medium sized enterprises that operate on smaller profit margins, have less financial and technical resources to undertake expensive research programs, have limited access to commercial financing, and are less able to appropriate to themselves the benefits of the resulting research (Church and Ware 2000, pp. 148-149).

${ }^{78}$ In addition, Dutz, Ordover and Willig (2000) apply these IO issues of monopolization and foreclosure to the special conditions faced by entrepreneurs in developing and transition economies.

${ }^{79}$ Such breakdowns can be associated with chance events (uncertainty), the incompetence of competitors (default failure), and discontinued business acumen (that is, business acumen and superior competitive performance that took place many years in the past). 
is currently taking place and continues to generate consumer and other economic benefits up to the present time ${ }^{80}$.

A more limited monopoly/dominance "right" under competition law would make dominance cases more analytically straightforward and transparent; would lead to a more straightforward and effective remedy, the dissolution through divestiture of the dominant firm into two or more new companies that would compete in the same market; and would allow a more permissive efficiencies-based process for the review of mergers, strategic alliances, research partnerships and other informal business arrangements ${ }^{81}$. Perhaps most importantly, a more limited dominance right would address the risk that the market power of the dominant firm can be further extended and abused through translating market power into political influence and power in a manner that entrenches the company's dominant position at the expense of consumers, workers and other stakeholders (Williamson 1975). These arguments in favour of a more limited "dominance right" under competition law are particularly relevant to developing economies such as India where competition agencies have limited experience with complex abuse of dominance cases, and where dominant firms have become entrenched through a combination of: effective informal business institutions and arrangements;

\footnotetext{
${ }^{80}$ The Chicago School and other new IO theorists argue that dominant market positions should be permitted under competition law as long as these positions are the result of superior efficiency, business acumen and competitive performance by the dominant company. Williamson agrees with this position, but contends as well that dominance based on past superior performance that is no longer generating benefits for consumers and the economy should be challenged by competition authorities. As discussed in Chapters 7 and 8, these theoretical debates are highly relevant to the treatment of India's traditional business groups and new economy informal business arrangements under the country's new competition law.

${ }^{81}$ This is because the competition authority and affected businesses know that a strong abuse provision is available if the merger etc. subsequently leads to monopoly/market dominance "in perpetuity". Abuse cases as well are easier to investigate and analyse than mergers and other horizontal arrangements because abuse cases involve analysis of actual market structure, business conduct, performance, and market outcomes, rather than future conjectures and predictions about structure, conduct, performance and outcomes after the merger transaction is completed.
} 
close government-business relationships; preferred access to external financing; policy and regulatory support from government leading to "regulatory capture"; and rentseeking by government and business.

Bringing these three contributions together, the Williamson TCE model argues for: (i) more permissive competition rules to allow companies to innovate and experiment with non-standard forms of contracting and organization; (ii) more permissive merger review processes to facilitate approval of mergers and other horizontal arrangements that potentially can generate static and dynamic efficiencies; and (iii) more rigorous competition rules to address entrenched monopolies and dominant positions so that companies cannot benefit from first-mover advantages, path dependence and mergers to monopoly "in perpetuity".

A strong and relatively simple abuse of dominance provision therefore would be available in the event that the organizational innovation or merger permitted under the first two Williamson arguments later led under the third argument to market dominance that could not be disciplined through normal market forces. The existence of a strong abuse provision could as well discourage businesses from organizational innovations and mergers that are likely to be anti-competitive over the longer term. The major danger with this integration of the three Williamson arguments is that, as described in chapter one, governments in India and many other developing and transition economies have traditionally had little appetite for using competition law to break up large, dominant and politically well connected business groups, networks and individual companies through forced divestiture and other structural remedies ${ }^{82}$.

\footnotetext{
${ }^{82}$ In fairness, the reader should note that breaking up large dominant companies and conglomerates has also been unpopular and used very infrequently in Canada and other more advanced OECD competition
} 


\subsection{Conclusions}

There are a number of reasons why new institutional economics (NIE) and the transaction cost economics (TCE) model of Oliver Williamson, including the later extensions of other economists, were selected as the principal economics literature for this dissertation. NIE emphasizes the implications of time, place, history, path, dependence, the political economy context, and institutions/the "rules of the game" for competition, market dynamics, structure and outcomes, economic and institutional development, and business organization and strategy. India was and remains a high transactions cost economy (see section 3.4), and therefore economizing on transactions costs continues to be important to economic performance and business strategy in this country. The major attention given by Williamson and his colleagues to business governance and organization, including non-standard forms of contracting and informal business institutions and arrangements that lie between market exchange and firm hierarchy, make NIE and the TCE model particularly relevant to this dissertation.

Williamson's TCE model has also made important contributions to new industrial organization economics, which is the theoretical foundation for modern competition analysis, policy and law. Compared with the neo-classical model, new institutional economics together with related advances in the new IO and other economics literatures provide a more realistic picture of competition dynamics and outcomes. At the same time, these literatures generate more ambiguous results and predictions that are contingent on time, place, context, institutions and a host of other factors (Rumelt et al 1991 and Williamson 1968, 1975, 1985 and 2000:1).

\footnotetext{
law jurisdictions, with the partial exception of the United States -- as illustrated by the break-up of AT\&T (the "Ma Bell" system) in 1982-1984 (Robinson 1986).
} 
Most importantly for this analysis, NIE micro-analytics and empirical research on the linkages between incomplete contracts, bounded rationality (including information uncertainties and social pressures and obligations), opportunism, and transaction specific assets (sunk costs) greatly enhance our understanding of why and how informal business institutions, including India's traditional business groups, are established, evolve, and have survived and prospered despite rapid technological change, liberalization, and the modernization of formal institutions including competition regimes.

These same NIE concepts and micro-analytics are also important to explaining the interactions, conflicts and accommodations between competition regimes and informal business institutions, and why these interactions and their outcomes for competition and economic performance can vary significantly: between countries, through time in the same country, and between regions in the same country. These sub-national dimensions are especially important for large continental and sub-continental economies such as India, which have numerous business groups, networks and communities with different regional and national experiences, histories, state-business relationships and competition cultures (Sinha 2005:1). These concepts provide the foundation for the two-time dependent cases studies, the differences between India's traditional business groups and new economy informal arrangements, and other components of the conceptual framework that are described in the next chapter. 


\section{Chapter 3: Conceptual Framework and Methodology}

\subsection{Purpose}

This chapter brings together the major insights from the competition policy and law literature and context in Chapter one and the economics conceptual literature review in Chapter two in order to more fully describe the conceptual framework and methodology, which was summarized in the Introduction and employed in completing the empirical analysis in Part II of this dissertation. The next three sections expand on the purpose, central question and two time dependent arguments in Exhibit II, in order to further describe their central role in the conceptual framework and model (see as well Appendix 2), in preparing the research questions (Appendix 3), and in identifying some of the key hypotheses and conjectures that are tested in the two time-period case studies that are central to the empirical analysis. Sections 5-7 summarize the methodology and the more difficult methodological issues encountered in completing the empirical analysis. Concluding comments are provided in section 8 .

\subsection{Expanding on the Purpose and Central Question}

As described in Exhibit II in the Introduction, the purpose of this dissertation is to analyse the evolution of the competition regimes in India over the past four decades from 1965 to the present day. This is accomplished through examining the interactions between India's competition regimes and its informal business institutions, rules of business conduct and business arrangements that have existed in India for many decades.

The central question of the dissertation research is as follows. How have India's competition regimes interacted with and accommodated themselves to the country's informal business institutions? In answering this central question, the analysis in the 
empirical chapters, particularly in Chapter 5, also explores the business interests, ideas and ideologies, and more formal policy and regulatory regimes and institutions, which have formed around, influenced and been influenced by India's informal business institutions and arrangements.

Three different kinds of interaction are captured by the concept of accommodation. These different interactions demonstrate that accommodation denotes a two-way street where causation can be in both directions ${ }^{83}$. The first kind of interaction involves whether, how and to what degree the country's competition regimes have had to find policy space for itself within, and thus accommodate and adapt itself to, India's informal business institutions. These institutions embody norms, values and attitudes that often (but not always) have been problematic for competition and inter-firm rivalry. This first kind of interaction, which draws from new institutional economics, historical institutional and related institutional and political economy literatures (see Chapters 2 and 5), addresses the reality that formal competition regimes (see Exhibit I) have been part of India's economic and political history for a relatively few decades.

Competition policy and law therefore has had to seek accommodations with - and to find space for itself within -- existing informal business institutions and related formal and supporting institutions, ideologies, ideas and interests. These informal institutions predate India's formal competition regimes by decades and in many ways are unique to India. In this manner, the direction of causation is from the informal business institutions

${ }^{83}$ This can sometimes take place in the same transaction or interaction. For example, in a meeting between a business group and the competition agency, the business group may agree to make a small change to a merger or business practice in response to a competition issue raised by the competition agency (interaction two and sometimes interaction three in Exhibit II), while the competition agency agrees to apply the competition law in a more flexible manner to other aspects of the merger transaction or business practice (interaction one). This is a normal part of the "give and take" that takes place between a competition agency and company in order to fix a competition problem, while avoiding the high costs and long delays for both sides of a full investigation and adjudication before a tribunal or court. 
to the design and enforcement of competition rules. The two time dependent arguments provided in the Introduction (see Exhibit II) suggest that this direction of causation may have been particularly important in the period from 1965 to 1991.

The concept of accommodation can encompass a second kind of interaction where causation is in the opposite direction. In this case, the competition regime directly addresses the existing framework of informal business institutions and attempts to alter the prevailing norms, values, attitudes and arrangements in favor of competition and more effective competition law enforcement. Consistent with the conventional competition policy and law literature summarized in Chapter 1, these pro-competition outcomes are achieved by a competition agency through information, education and voluntary compliance programs, investigating and prosecuting high visibility enforcement cases, and building coalitions with those elements of the private business sector that favor competition, inter-firm rivalry and fair trading.

The second kind of interaction can involve various kinds of accommodations and outcomes. India's business groups and other informal business institutions and arrangements could alter their conduct and strategies as a direct consequence of competition law enforcement, competition advocacy, education and the information activities of the competition agency. These same activities can result as well in changes in business attitudes that favor competition. Informal business institutions could also be modified and informal business arrangements could alter their strategies as an indirect consequence of the competition regime. These modifications, for example, could be done in order to avoid the transactions and other costs, including embarrassment and the loss of reputation, of being investigated and prosecuted under the competition law. 
Informal business institutions as well could change in anticipation of the establishment of a new competition regime, such as from 1965 to 1969 when India's first competition law was being prepared and debated, and from 1995 to the present day in anticipation of India's new competition law and regime. For example, the merger wave since 1991 when the MRTPA's merger provisions were eliminated (Agarwal and Bhattacharjea, 2006) anticipated the reintroduction of merger review rules under a new competition law.

Finally, the central question covers a third kind of interaction where the efforts of the competition regime to change the prevailing informal business institutions results in the competition law being misused. This misuse would be conducted in a manner that undermined informal business institutions, rules of business conduct, and arrangements that economize on transactions and production costs, promote product, process and organizational innovations, and on balance are beneficial to business participants and the overall economy. This kind of interaction, which draws heavily from the Williamson TCE model in Chapter 2, can place individual business groups and other informal arrangements at risk, and at the extreme, could threaten informal business institutions as a generic form of governance. The third interaction covers as well the situation where business groups adopt sub-optimal strategies, governance modes and informal business institutions including with other companies in order to avoid scrutiny by a competition regime that is emphasizing business group and company size and industrial concentration and is not applying an efficiencies test (see below and Chapter 6).

All of the interactions and accommodations that are captured by the central question are important to the conceptual framework and the empirical story developed in Part II. In exploring the accommodations and interactions between India's competition regimes 
and the country's informal business institutions and arrangements, emphasis is placed on India's traditional business groups. This is the result of: the business groups' long history over many decades going back to the last half of the $19^{\text {th }}$ century; their dominant role in the country's private business sector up to the liberalization reforms of 1991; and their continuing importance after that. In particular, the business groups were the major driver in the establishment of the Monopolies and Restrictive Trade Practices Act and Commission (the MRTPA and MRTPC) of 1969; and, continue to be very important to economic and political discourse on liberalization, national competitiveness, and competition policy and law in India up to the present day. The conceptual framework is also used to explore the introduction in India's new economy sectors of new forms of informal business institutions and arrangements in response to globalization, technological change, and India's greater integration into the global economy after 1991 liberalization.

In addressing these interactions, conflicts and accommodations, priority is given to mergers, monopolies, abuse of dominance, monopolistic trade practices and related competition rules and violations that address the existence, exercise and misuse of market power and therefore are highly relevant to India's business groups and other larger companies. The emphasis on market power and India's business groups and other informal business institutions is fully consistent with the priority given to industrial concentration and monopoly power throughout the relatively brief history of formal competition regimes in India from 1965 on. 


\subsection{The Two Time Dependent Arguments That Support the Comparative Case Study Approach}

This section further describes the two time dependent arguments summarized in Exhibit $I$ in the Introduction that provide the foundation for the two-period comparative case study approach in Chapters 6-9. The analysis emphasizes the interactions, conflicts and accommodations between India's competition regimes and the country's informal business institutions and arrangements particularly India's business groups. As a consequence, neither the competition regimes nor informal business institutions can play the role of a single dependent variable in the analysis. Rather, the number of, quality of and outcomes from the interactions between the two at different points in time are the combined result of what could be called a simultaneous qualitative simulation model of various equations. Under this model, competition regimes and informal business institutions and arrangements are "determined" together in an interactive and "endogenous" manner through their interactions, conflicts and accommodations with each other (see Appendix 2).

The conceptual framework and empirical analysis is based on the contention that the interactions between India's competition regimes and the country's informal business institutions were quite different between two time periods. The first is the period from 1965 to 1991 when India's private economy was dominated by traditional business groups, and the broader economic policy regime was comprised of statist and highly protectionist industrial and trade policies under the "License Raj that on balance discouraged business entry and competition. This situation would be expected to make the competition regime more a "policy taker" consistent with the first kind of interaction. The interactions before 1991 can be compared with the post-1991 period, when the new 
economy business interests and new informal business institutions started to emerge, implementation of India's economic liberalization and market opening program has accelerated, and when detailed analysis, discourse and debate took place on a new formal competition regime for India. Major outcomes important to the second argument are the new Indian Competition Law and Competition Commission passed in 2002 and amended in 2007, with enforcement to begin in 2009 , and the proposals for a National Competition Policy in India's $11^{\text {th }}$ Five-Year Plan (Government of India 2007:1, pp. 282-289). This suggests a greater role for the competition regime after 1991 when all three types of interactions are expected to be important.

The first argument contends therefore that the pre-1991 interactions, conflicts and accommodations are relatively straightforward, stable and predictable. These interactions largely centered on India's traditional business groups, which provided the major rationale for and driver of India's first competition law, the Monopolies and Restrictive Trade Practices Act (MRTPA) of 1969, and in many respects for India's broader economic policy regime that was first established in the early 1950s and became even more interventionist from 1969 through to end of the 1970s. The first argument indicates a subordinate role for India's competition regime before 1991, when the strength of informal business institutions, rules of business conduct, and arrangements and their political and bureaucratic supporters, left little or no space for an independent and effective formal competition regime. This is captured at the bottom of Exhibit VIII by the much wider and bolder line from informal business institutions to the enforcement of India's competition regime from 1965 to 1991. 


\section{Exhibit VIII: Accommodations and Interactions Between India's Competition Regime and Informal Business Institutions From 1965 to $1991^{84}$}

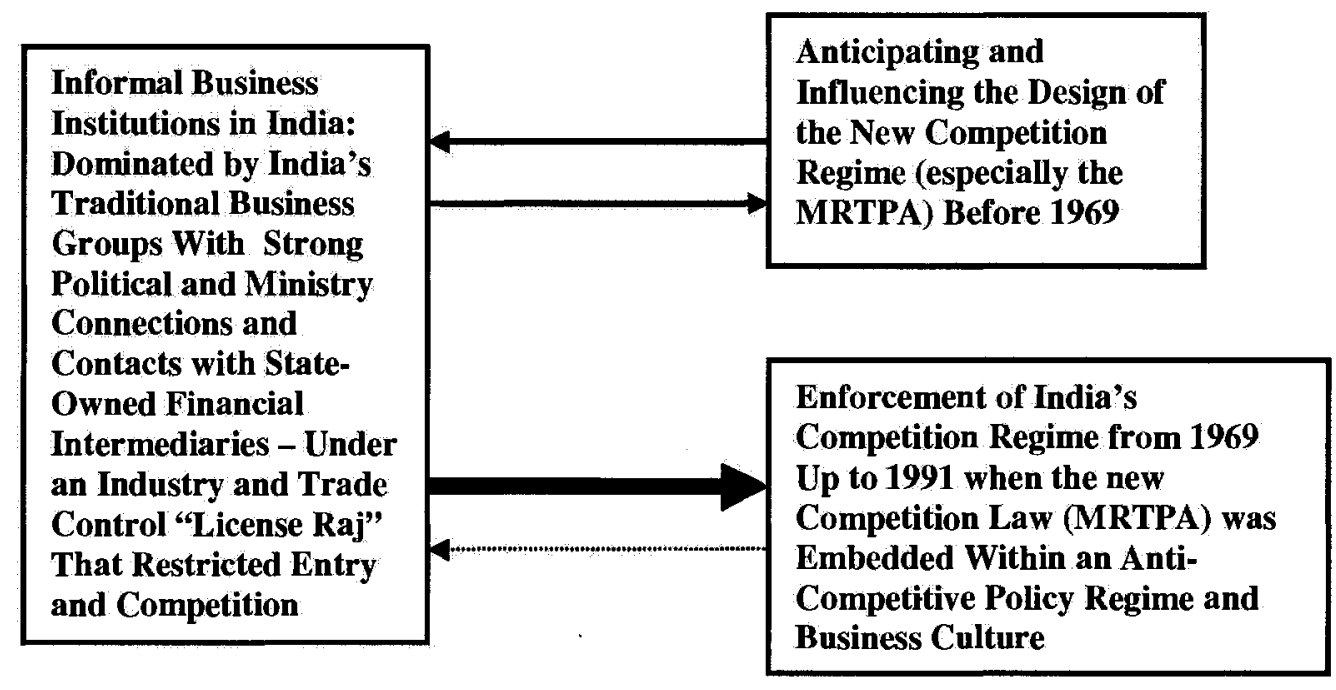

In sharp contrast, the second argument suggests a greater role for India's competition regime during the post 1991 liberalization period, when policy discourse placed greater emphasis on market opening, innovation, business entry and inter-firm rivalry to promote international competitiveness and greater competition, product and vendor choice, and consumer welfare in domestic markets. During the post-1991 period, there is greater opportunity for India's competition regime to influence the country's informal business institutions in a pro-competition manner. There is as well greater risk that the competition regime could undermine informal business institutions that on balance advance economic efficiency, competition and the gains from trade (interactions two and three in Exhibit II). Accordingly, the accommodations and interactions in the post 1991

\footnotetext{
${ }^{84}$ While the MRTPA and other major components of the 1965-1991 competition regime were established from 1969 to 1973 , the starting year for the first case study is 1965 in order to cover business group efforts to influence the design of the new competition regime and to anticipate the MRTPA and the other components in other ways.
} 
liberalization period appear to be much less straight-forward and predictable, and more complex and contingent (see Exhibit IX).

\section{Exhibit IX: Accommodations and Interactions \\ Between India's Competition Regime and Informal Business Institutions From 1991 to the Present}

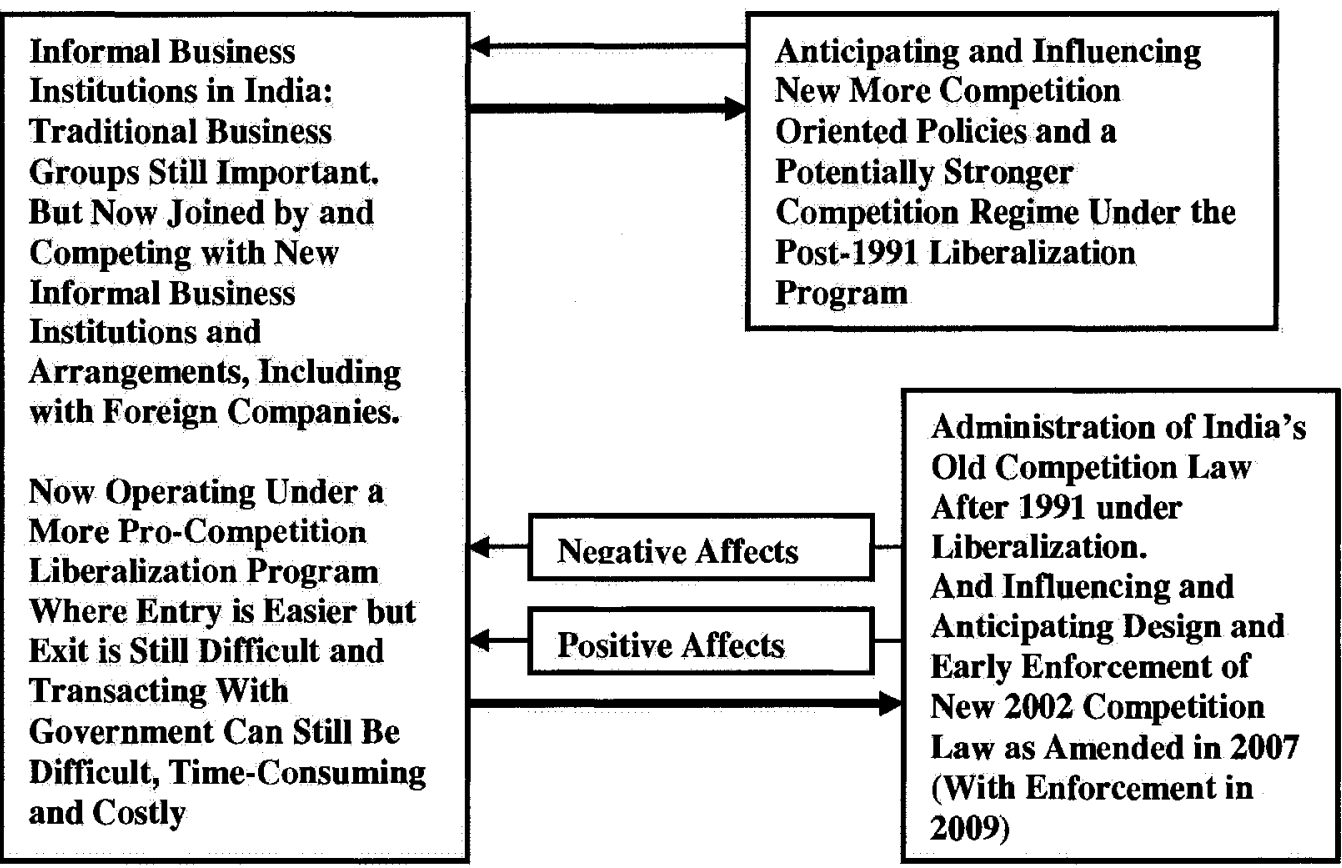

Multiple interactions, accommodations and outcomes are now possible. India's traditional business groups, other business interests old and new, and the industry and trade associations that represent these diverse business interests, could attempt to influence the design and administration of the business entry and exit, import, foreign investment, foreign technology and other competition related aspects of the 1991 liberalization program. These same groups could as well attempt to influence discourse on and the design of the new competition law and commission from 1995 on.

Major changes in corporate strategy can be anticipated by traditional business groups and unaffiliated private companies in response to the opportunities, constraints and risks posed by globalization, rapid technological change and the post-1991 liberalization 
program that on balance is more pro-competition. Shifting interests and changing coalitions could take place within and across traditional business groups, between traditional business groups and new business interests, and between business and political, bureaucratic and other elites, regarding the competition regime that best meets their business needs. In contrast to pre-1991 when the traditional business groups dominated India's private economy and discourse on the competition regime, there is expected to be greater uncertainty, unpredictability and contingency in the post-1991 analysis regarding the future role and importance of India's traditional business groups; and whether these groups will respond positively to the fundamental changes now taking place in the competition regime and the broader liberalization program, within which the competition regime is embedded.

On the positive side, compared with the MRTPA of 1969, the new competition law passed in 2002 and amended in September 2007 is much less directed at economic concentration, market power and the strategic interests of the business groups (see Chapter 1). On the negative side, globalization, rapid technological change, incomplete liberalization, and India's integration into the global economy can result in greater uncertainty, unpredictability, instability, coordination failures, and information asymmetries and failures, and new and often unfamiliar challenges and opportunities for business groups as well as other Indian businesses. Therefore, the literature on institutional change and adaptation reviewed in section 6 of chapter 2 is important to the empirical story and comparative case study in Part II.

Field research in India was conducted later in the analysis and thus only after: the economic theories and conceptual literatures in Chapter 2 had been reviewed; the 
conceptual framework was quite well developed; virtually all secondary sources and archival material available from a Canadian location had been assembled and reviewed thoroughly; construction of the business group database was well advanced (see section 3.5); and, the research questions had been finalized ${ }^{85}$. This allowed the author to: prepare conjectures and hypotheses based on the economic theories and literature review in Chapter 2 and the other sources cited in Chapters 4 and 5, and then to use the personal and telephone interviews and the other data collection in India in order to further explore the conceptual framework and model described above and in Appendix 2 and the questions in Appendix 3, test the key hypotheses, and fill in the major gaps in the empirical evidence.

Many of the hypotheses prepared before the field research involved the possible differences in the interactions, conflicts and the accommodations between India's competition regimes and informal business institutions, especially its traditional family based business groups, before and after liberalization in 1991. It was found that the $25 \%$ rule proved to be a good reference point for preparing and testing in the empirical chapters many of these hypotheses on the differences between the two case study periods. Under this $25 \%$ rule $^{86}$, a business group or company before 1991 could not have more than a $25 \%$ market share of any one industry's production or of any one market's

\footnotetext{
${ }^{85}$ Preparations for the field work were assisted greatly by the author's first visit to India in early 2005 in order to participate and speak at an international conference on "Moving Forward the Competition Policy Agenda in India" held in New Delhi by CUTS International. Participation at this conference was very helpful in lining up a host for the field work, namely CUTS, identifying the key issues to be addressed in the interviews and future analysis, and selecting potential research participants in terms of individuals and agencies.

${ }^{86}$ Called the $25 \%$ market share limit rule in the rest of this dissertation. These hypotheses and conjectures regarding the implications of the 25\% rule before 1991 and of its elimination after 1991 are addressed quite extensively in many places in the empirical chapters including: Exhibit XIV on p. 156 in Chapter 5; pp. 192 and 211-219 in Chapter 6, pp. 268-271 and p. 277 in Chapter 8 and in particular pp. 322-323 in Chapter 9.
} 
revenues. The $25 \%$ rule was then eliminated together with the rest of the "License Raj" in the post-1991 liberalization program (see Chapters 5 and 6).

The 25\% market share limit rule was fully consistent with the traditional IO Structure-Conduct-Performance model (see section 2.2 above) that was the theoretical foundation for the MRTPA. The premise was that, by guaranteeing a minimum of four suppliers in every product market, the rule would ensure a reasonable level of competition and consumer choice throughout the Indian economy. However, the $25 \%$ rule ignored business conduct and recent advances in the new IO, new institutional economics and related economics literatures reviewed in Chapter 2. These advances emphasized that business conduct is just as important as market structure in determining the extent of competition in product markets. These recent theoretical and empirical advances suggest that the $25 \%$ market share limit rule would do less to promote competition and pro-competition behaviour by informal business institutions before 1991; and its elimination would have fewer impacts on competition, concentration and business conduct and strategy after 1991, than would be presumed by traditional IO economists and the officials who designed the 1965-1991 competition regime.

These recent advances therefore provided the following five conjectures and hypotheses regarding the $25 \%$ market share limit rule for the pre-1991 case study period. Every industry and market (however defined) should have a minimum of four competitors. Most suppliers were forced to operate plants at below minimum efficient scale because of the combined effects of the $25 \%$ rule and the small size of most Indian markets, which at that time were experiencing limited growth. Suppliers at the $25 \%$ maximum (which appeared to be the norm for business group members) had no incentive 
to increase market share and revenues through producing a higher quality product and thereby attracting business away from competitors ${ }^{87}$. Business groups would establish duplicate companies and plants in different Indian locations when they could convince the licensing authorities that the industries and markets were regional and therefore separate from each other. Finally, business groups would diversify into both related and totally unfamiliar products, industries and markets when they had achieved the $25 \%$ market share limit in their current markets, and when these various markets were deemed to be national in scope by the licensing authority and the MRTPC ${ }^{88}$.

A related and more general hypothesis was that, since the $25 \%$ rule made high market shares and market dominance impossible, business groups would use license pre-emption and hoarding strategies, broad industry specialization strategies and tacit economy-wide market sharing agreements in order to: stay out of each others key markets; avoid expensive head-to-head competition; and ensure price leadership and supra-competitive profits from each group's most important markets (see Chapters 5 and 6). Business groups as well would be expected to export very little because of their high production and transactions costs, stable revenues and supra-competitive profits from their domestic sales, and lack of experience in directly competing with foreign companies, which combined together, resulted in the export pessimism that prevailed in the pre-1991 period.

\footnotetext{
${ }^{87}$ For firms at the $25 \%$ limit, the only way to increase profits was to reduce production, governance and other transactions costs. And because the market share limit was typically based on sales rather than the number of units produced i.e. cars or widgets, there was no incentive to improve quality and the price and profit for each unit as occurred under the voluntary export restraints imposed by the United States on Japan's motor vehicle manufacturers in the 1980s.

${ }^{88}$ It was further presumed that business groups could secure external financing for diversification into unfamiliar products and markets because of their good repayment records on past loans and strong connections with key government ministries and financial intermediaries (which were largely government owned after 1970).
} 
Under the post-1991 competition regime, the $25 \%$ rule was eliminated together with the rest of the "License Raj" (see Chapter 5); barriers to imports and foreign direct investment were reduced leading to more competitive and contestable markets in some industries and markets; and merger review and the regulation of business groups and other larger companies were removed from the Monopolies and Restrictive Trade Practices Act. The conceptual economics literatures in Chapter 2 suggested that the possible responses of business groups to the removal of the $25 \%$ rule and other components of the post-1991 competition regime might include the following. Business groups could conduct within group mergers to bring duplicate companies and plants together into a single company and at times into a single plant in order to reduce costs and achieve economies of scale and scope. Business groups as well could conduct strategic horizontal mergers with companies in other business groups and with independent companies in order to increase market share (beyond the pre-1991 25\% limit) and market power in key markets and industries where the business group is deemed to have a long-term competitive advantage. The third response would be restructuring and divestitures to move out of industries and markets where the business group does not have a long-term competitive advantage.

Finally, the business groups could implement strategies designed to achieve high market shares and dominance in each group's core market - suggesting the potential for a new but less stable form of tacit economy-wide market sharing agreement across business groups $^{89}$. In the absence of foreign entry through imports and direct investment (which in fact has taken place in only some industries and markets up to 2008), the removal of the

\footnotetext{
${ }^{89}$ These tacit agreements would be less stable because of the greater potential for foreign and domestic entry after 1991, and in the future, because the higher market shares and greater opportunities for market dominance may attract the attention of the new competition law and agency (see Chapters 7 and 8 ).
} 
$25 \%$ rule almost guarantees that India's post- 1991 industries and markets would be more concentrated than before $1991^{90}$.

More generally, the removal of the $25 \%$ rule and other post-1991 changes to the competition regime indicate that Schumpeterian type models of dynamic competition, industry churning ${ }^{91}$, and creative destruction would be more relevant to the post-1991 period (Aghion and Howitt 1992 and 2006). Less certainty in domestic markets, combined with the restructuring and reduced costs made possible by eliminating the $25 \%$ rule, should mean that the larger and more successful business groups would drop the export pessimism of the past and export more goods and services to foreign markets. These conjectures and hypotheses regarding the traditional business groups played an important role in preparing the questions prior to the field research in India during the summer of 2006, and in interpreting the data from the field research and preparing the empirical chapters (see Appendix 3 and Chapters 5-9).

A final important difference between the two time periods based on the literature review and other sources is that India's traditional business groups dominated the country's private economy before 1991; but were joined after 1991 by India's information technology and other new economy industries and companies, which are more innovative and globally competitive, are better prepared for liberalization, are likely operating closer to their technological frontiers (see the Aghion etc. references in Chapter 2, pp. 76-77), and often receive more favorable government and business media attention.

\footnotetext{
${ }^{90}$ Elimination of the $25 \%$ market share limit rule would also remove an important barrier to the expansion of medium-sized companies that are dependent on a single or a few products and markets. Other things being equal, these unaffiliated companies would be expected to benefit more from the elimination of the $25 \%$ rule than the affiliated companies of business groups. The empirical evidence regarding this hypothesis is addressed in footnote 328 on p. 323 in Chapter 9.

${ }^{91}$ Which means significant entry and exit, as well as substantial and almost continuous changes in market shares among the current suppliers.
} 
This led to separate hypotheses and questions for the new economy companies and higher technology industries to be addressed during the field research and in preparing the post1991 empirical chapters (see Appendix 3 and Chapters 7 and 8).

\subsection{Assessing the Number of, Quality of, and the Outcomes from These Interactions and Accommodations}

As noted above, the conceptual framework and model (see Appendix 2) analyse and compare the two-case study periods in terms of both the quantity/number of interactions between the competition regime and informal business institutions, and the quality of those interactions in terms of the anticipated outcomes for the participants as well as for the Indian economy. Not surprisingly, the data sources did not provide any actual counts of the number of meetings, requests for licenses, subsidies, tax relief and other approvals, contested hearings and other interactions that took place between the agencies and officials representing India's competition regime and the country's traditional business groups and other informal business institutions.

As a consequence, discussion of the number of interactions is based on a qualitative analysis - and comparative analysis of the two time periods - which uses and interprets information from secondary sources, from the interviews, and from analysis of e.g. the number of approvals required by a company to secure a production, import, technology or other kind of license or MRTPA approval (see chapter 5). Fortunately, the approval processes under the License Raj before 1991 and the remaining government licenses and approvals after liberalization are well documented by the secondary sources reviewed for

this dissertation (see e.g. Debroy 2004 and Sinha 2005:1), and were often discussed by research participants during the interviews. 
Similarly, the research did not uncover any comprehensive and quantified social welfare analyses of the quality of, and outcomes from, these interactions for government, business participants, competition, consumers and the total economy. Instead, the quality and outcomes analysis is based on the secondary sources, the interview results, and the application of the insights from the literature review and conceptual framework which provide indications of direction and to a lesser degree of magnitude. Particularly important in this regard were the modified Williamson transaction cost economics model described in Exhibit VI and discussed in sections 2.4 and 2.5.

Fortunately, the social welfare, economic efficiency, competition, competitiveness, and distributional effects and implications of India's competition and broader economic policy regimes, traditional business groups and more recently new economy informal arrangements, have played a prominent role in the country's economic research and economic and political discourse since the country's independence in 1947. The author brought together these various sources; compared findings, rhetoric and the biases of researchers; and then developed his judgements, findings and conclusions on the quality and outcomes of interactions between the competition regime and informal business institutions during the two case study time-periods.

One of the major implications of and outcomes from these interactions is that India has been and continues to be a high transactions cost economy, despite domestic and external trade reforms and market opening since 1991. The costs of transacting with government and with other businesses and economic agents are particularly high for business groups and other larger companies operating in the formal sector. The literature reviewed for this dissertation did not identify any sources that provided quantified 
estimates indicating e.g. that transaction costs as a proportion of GDP are higher in India than in other developing, transition and advanced countries. Rather, this judgment is based on qualitative evidence and inferences from research participants and other sources, which are then interpreted using the modified Williamson TCE model in Chapter two and the conceptual model in Chapter 2.

These sources indicate a number of reasons for the high costs of transactions and market exchange in India. Many sources emphasized the country's still large government bureaucracies, complex and multi-layered business policy and regulatory regimes, large number of public sector undertakings (state-owned enterprises), and high levels of government intervention in the economy despite liberalization (Debroy 2004 and Sinha 2005:1). These and other sources also discussed the time, expense and many steps required to establish a new private business even though the "License Raj" has been dismantled (World Bank 2007:1); and, the very high cost of business restructuring, reducing payrolls and/or closing a business in India (Debroy 2004 and World Bank 2007:1). Sources as well identified the continuing high cost of the "inspection raj" at the regional state government levels, especially for medium and large scale manufacturers in the formal sector that are not covered by the small enterprise reservation system (Sinha 2005:1).

Other factors are the time, expense and uncertainty of taking a business dispute to court, combined with the limited availability of alternative dispute resolution mechanisms (Debroy 2004); and the high incidence of corruption and other forms of rent seeking which diverts scarce resources to unproductive activities (Goldsmith 1999) ${ }^{92}$. In

\footnotetext{
${ }^{92}$ As a consequence, India typically ranks in the middle or bottom half of the many indices and country rating systems that are now in place to assess the extent of corruption, rent-seeking, costs of doing business
} 
addition, the Indian regional states, with more business friendly economic policy regimes that lower the cost of transacting with government, have enjoyed more rapid economic growth in the post-liberalization period (see e.g. Aghion et al 2003 and 2005:1 and Sinha 2005:1). This evidence is consistent with the business group strategies described in Chapters 6-9, which are intended to reduce the costs and risks of transacting with government and other economic agents that are not members of their business group. These strategies now include business group investments in special economic zones similar to those established in China over the past three decades (see Chapter 8, p. 289).

Other relevant considerations include: the major costs, risks and uncertainties of transportation, telecommunications, logistics, and trade facilitation including customs and border delays (Das and Pohit 2006); India's underdeveloped financial markets and the time, expense and connections needed to secure external financing (see Chapter 5); and, the new opportunities for transactions cost investments provided by domestic and external liberalization and regulatory reform. The latter encompass the time and expense of securing a telecommunications, electricity generation, air transport or insurance license, and anti-dumping, countervail and other import relief. All of these involve high transaction costs for the business applicant, government and the total economy.

The continuing high costs of transacting with government and other economic agents are shaping India's comparative advantage in favour of more skill and technology intensive information technology and related services, and away from more labour and

and other indicators of transactions costs and related barriers. One of the best known is the "Corruption Perceptions Index" of Transparency International. In this index, India placed $85^{\text {th }}$ out of 180 countries in 2008. A second is the composite "ease of doing business" index of the World Bank. In this indicator, India placed $122^{\text {nd }}$ out of 181 countries in 2007-2008. Within this composite index, India's ranking was particularly low in the following "ease of doing business" indicators: dealing with construction permits $136^{\text {th }}$; paying taxes $-169^{\text {th }}$; enforcing contracts $-180^{\text {th }}$; and closing a business $-140^{\text {th }}$. These low rankings are consistent with India's incomplete liberalization and many "institutional voids" that are discussed in Chapters 5, 7, and 8. 
resource intensive secondary and resource based manufacturing - where India should have significant export strength based on its resource endowments (see e.g. Kochhar et al 2006). High transactions costs as well are placing specific Indian industries at a competitive disadvantage compared with other Asian and developing countries, such as the small-scale industrial sector (Ramamurthy 1995), the country's sugar industry (Chhauhan 2003), the financial sector (Rabi 1997), and the electricity distribution sector (Debroy 2004, p. 194); and as noted above are providing competitive advantages to regional states and urban regions that successfully reduce these transaction costs through establishing special economic development zones and other measures ${ }^{93}$.

\subsection{Summary of the Methodology}

The dissertation involved the collection, comparison and detailed analysis of qualitative data and, to a lesser degree, quantitative data from many different sources and perspectives. These sources include the growing theoretical, academic, policy, legal and international literature on the role of markets, governments, competition, cooperation, competition policy, and related economic policy regimes that is available from academic, national and international sources; and the many Indian economic, business and political economy histories covering different periods in the country's economic development, which give considerable attention to the informal institutions of business rules, conduct and arrangements. Other Indian sources analysed by the author encompass official Government of India planning, policy and consultation documents, the extensive Indian academic literature, position papers by interest groups and research institutes, media

\footnotetext{
${ }^{93}$ The interviews and other sources indicated that reducing the cost of transacting with government plays a major role in the investment attraction and private business development strategies of Gujarat, Maharashtra, Tamil Nadu and Karnataka, the urban regions of Mumbai, Bangalore and Chennai, and other higher growth and more prosperous Indian regions.
} 
reports, specific competition law enforcement cases, the enforcement policies and related material on the old and new competition acts, the report of the parliamentary committee on the Competition Bill 2001, and other archival material. In addition, the author conducted personal interviews -- and when necessary, based on time and location, telephone interviews and Email correspondence -- with key participants from government, business, the academic community and non-government organizations who were and are involved in past and current debates on India's competition regimes, broader economic liberalization program and related fields.

One technique and intermediate output from the data collection and analysis was the construction of a quite detailed database of qualitative and quantitative information on 29 major business groups in India. All of the most important groups at different times in India's business history over the past century were included, as well as examples of smaller traditional groups and of the more important new economy business groups that have emerged in the past 20-40 years. Emphasis in constructing the data base was placed on business groups with longer histories; therefore the database includes a few groups that are less prominent today than in e.g. the pre-independence period. To provide continuity, the larger groups that have recently been divided up among sons and other relatives were treated as a single group to the greatest extent possible.

The database includes information on: the group name, the year of establishment and the headquarters location of each group; the group's employment and sales/turnover at different points in time, including the most available data; the group's major industries and markets and the various goods and services produced by each business group -including those produced in the past and those produced at the present time; the group's 
past and current foreign operations; each group's ethnic, religious, regional, and/or social composition at the time it was established (Marwari, Chettiar, Parsi etc. - see Chapter 4); and, each business group's history and past and current corporate strategies, with emphasis on the strategies employed when first established and on the group's strategic responses to liberalization, globalization, rapid technological change and the new competition regime since 1991 .

The information contained in, and the insights provided by, the business group database, are used extensively in the empirical chapters in Part II. The database was developed over an extended three year period and was based on a wide range of primary and secondary sources including: (i) interviews held during the fieldwork in India; (ii) the websites of each business group which in most cases now contain quite detailed information on a group's revenues, employment, current goods and services, expected new goods and services (product diversification plans), and marketing and broader corporate strategies; (iii) media reports reviewed particularly in India and other material found on the Internet; and (iv) a wide range of secondary sources on the business histories of different business groups ${ }^{94}$.

A second technique and intermediate output was to conduct detailed word-for-word analysis and comparisons of the Raghavan Committee Report of 2000, the Competition Bill of 2001, the Competition Act of 2002 and the amended Competition Act 2007. The purpose of this analysis and the comparisons was to identify substantive changes as well

\footnotetext{
${ }^{94}$ Secondary sources include: HR Folks International (2004), Dorin (2003 in particular Appendix I), Tripathi (2004, in particular Appendix II), the many other Tripathi references in the bibliography, Ghoshal et al (2001), Piramal (1996, particularly the Appendix), UN Volunteers et al, 2004, Das (2002), Ghemawat and Khanna (1998), Khanna and Palepu (1997, 2004:1, 2004:2 and 2004:3), Swaminathan (1992), Taknet 1986, Timberg (1969), as well as information on some business groups from Wikepedia, and the list of Indian companies provided by Answers.com.
} 
as smaller changes and additions to legal wording, which resulted from the many interactions and accommodations between government/the competition regime and the business groups and their trade associations from the late 1990s to the present day. The results from this detailed analysis were then combined with the findings from the interviews and other sources in order to explore the implications for the post-1991 competition regime from its interactions, conflicts and accommodations with India's traditional business groups and other informal business institutions in Chapters 7-9.

\subsection{Three Major Challenges in Applying the Conceptual Framework and Methodology}

The first challenge was to collect evidence on the existence and effects of informal business institutions in India and more specifically evidence regarding their influences on the evolution of India's competition regimes from 1965 to the present day. The existence and influences of informal business institutions and rules of conduct by their very nature are not well documented, and at times are not even well articulated and understood by the people who use them in their day-to-day business operations ${ }^{95}$. Because these informal institutions and rules of conduct are tacit rather than codified in law and regulation (as is the case for formal rules), informal institutions are better understood by "insiders" (that is, by the members of the specific business group or business community based on ethnicity, language, religion, location etc.) than by outsiders.

Evidence on India's informal business institutions was found in the country's economic, business and political economy histories, in more recent literature on the country's business sector and political economy, other archival material noted earlier, and

\footnotetext{
${ }^{95}$ Informal business institutions are a good example of the unobservable but causally important factors that are emphasized by the methodological realists such as Sayer (1984 - see as well Sinha 2005:1). This issue is further explored in later paragraphs.
} 
from personal interviews conducted in India. Literature on other countries also provided some insights that were assessed and tested in relation to India's experience. Finally, the insights from the literature review and conceptual framework were used to develop inferences from and interpret the available information from these information sources including the information placed in the business group database.

While the field work in India comprised about 35 substantive interviews with representatives of government and the business, non-government organization (NGO) and academic communities, limited time, resources and business contacts resulted in only two interviews with research participants who had worked for an extended period in one of the largest business groups. These two business group are among the more progressive and influential of India's many business groups and pride themselves as modernization leaders. As well, the two research participants were knowledgeable and open regarding the post-liberalization strategies of not only their own groups but also of some of the other major Indian business groups. Based on these two interviews, the author prepared and then shared and confirmed with the research participants the current strategies of their groups. This strategy was then used as the reference point for assessing the current strategies of other larger business groups developed from their websites, the interviews, and secondary and other sources.

In addition, the leading companies in the business groups were often the largest and most influential members of the many industry and trade associations that were active and knowledgeable participants in the research program (see Appendix 4). Finally, Indian economic and other historians - particularly histories on state-business relations and the interactions, conflicts and accommodations between business and government -- 
place considerable weight on the role and importance of informal business institutions, norms, rules of conduct and arrangements throughout the country's long and complex business history (see in particular Chapter 4). India's economic and business histories thus provide many interesting conjectures, ideas and hypotheses that could be applied and tested in reviewing more recent literature, data and other evidence, and in interviewing key research participants.

Nonetheless, evidence on India's informal business institutions proved for the most part to be limited, qualitative, anecdotal, judgmental, and based on inferences from and interpretation of related information, using the conceptual economics literatures and framework. At times, the evidence was hidden within broader discourse on formal economic institutions and policy regimes, ideology, business and other economic interests, and on the unique features of India's culture, society and current stage of development. Because of these information constraints, great care was taken to collect and compare evidence from different primary and secondary sources - employing multiple lines of evidence, triangulation and discourse analysis to the greatest degree possible.

Triangulation was applied through time. The quite numerous secondary sources that were available in Canada were analysed and compared, and the differences between them and the reasons for those differences, were identified and assessed prior to the field research in India in the summer of 2006. The results from these secondary sources were then compared thoroughly and critically against the findings and insights from the research participant interviews and other data and secondary sources collected in India including the insights from the many individual MRTPA cases that were reviewed in 
India. Finally, in preparing the empirical chapters, the insights and findings from the multiple lines of evidence described above based on the author's earlier Canadian and Indian research were brought together and compared against the insights, interpretations and inferences from the economics conceptual literatures and conceptual framework and model reviewed in Chapter 2, this chapter and Appendix 2. In this manner, the analysis, findings and conclusions in the empirical chapters are developed and finalized through integrating empirical data from multiple sources with the theoretical insights provided by the economics conceptual literatures and conceptual framework. This approach is particularly useful to the analysis of informal business institutions and rules, and their interactions with competition regimes, that are difficult to observe and measure directly from the empirical data but are important to the empirical story ${ }^{96}$.

In reviewing documents and the results from personal interviews, the author employed as well the guidance and constraints provided by different forms of discourse analysis, including: critical discourse analysis which emphasizes context; and rhetoric analysis, which focuses on competing alternatives and undermining alternative cases and perspectives. Rhetoric analysis was particularly helpful in analysing, interpreting and comparing evidence from: academic articles and books from scholars associated with different parts of the political and economic spectrum; other written documents such as the government's policy statements, submissions from business associations and civil society groups, and business media articles; and research participants on different sides of India's liberalization debate (see Chapter 5) ${ }^{97}$.

\footnotetext{
${ }^{96}$ This approach therefore is consistent with the emphasis on qualitative over quantitative data and on the "causal importance of the unobservable and the not yet observed" in the realist method of Sayer (1984).

${ }^{97}$ The term "discourse", as defined by Michel Foucault as a system of ideas or knowledge as inscribed in a specific vocabulary (e.g. the vocabulary of economics), is used quite extensively in the empirical chapters
} 
The same sources and techniques were also applied to address the second and related challenge. This is the difficult issue of how informal business and related institutions ("the more general rules of the game") in a society and economy, which for the most part are based on a country's history, culture, social traditions, conventions, norms and values, are translated in the Indian context into more specific but still informal, rules of business conduct, and into informal business arrangements. Exhibit $\mathrm{X}$ attempts to summarize this translation process and its implications for the research questions that arise from the literature review and conceptual framework and that are applied in the empirical chapters in Part II of the text.

\section{Exhibit X: Translating Informal Business Institutions Into Rules of Business Conduct and Business Arrangements, Groups and Networks}

\begin{tabular}{|c|c|c|}
\hline $\begin{array}{l}\text { 1. Informal Business } \\
\text { Institutions. Based } \\
\text { on Broader Norms } \\
\text { and Values of Society } \\
\text { Related to } \\
\text { Cooperation, Trust, } \\
\text { Reciprocity of Trust } \\
\text { and Reputation (or } \\
\text { Lack Thereof) That } \\
\text { Are Difficult to } \\
\text { Identify Particularly } \\
\text { Through Applying } \\
\text { Research Questions } \\
\text { in Interviews. }\end{array}$ & $\begin{array}{l}\text { 2. Better Articulated But } \\
\text { Still Informal Rules of } \\
\text { Business Conduct Related } \\
\text { to Cooperation versus } \\
\text { Opportunism in } \\
\text { Transactions and Informal } \\
\text { Business Arrangements, } \\
\text { Fair versus "Cut-Throat" } \\
\text { Competition, Fair Dealing, } \\
\text { Market-Sharing } \\
\text { Agreements and Other } \\
\text { Forms of Collusion and } \\
\text { Rent Seeking. The Basis } \\
\text { for Many Research } \\
\text { Questions in the } \\
\text { Dissertation. }\end{array}$ & $\begin{array}{l}\text { 3. Informal Business } \\
\text { Arrangements: Business } \\
\text { Groups and Networks, } \\
\text { Research Partnerships, } \\
\text { Strategic Alliances, Long- } \\
\text { Term Supply } \\
\text { Relationships, Membership } \\
\text { in National and Global } \\
\text { Supply Chains, Business } \\
\text { Communities, Technology } \\
\text { Clusters, Industrial } \\
\text { Districts, and Business } \\
\text { "Cultures". Stressed in the } \\
\text { Literature and also the } \\
\text { Basis for Many Research } \\
\text { Questions. }\end{array}$ \\
\hline
\end{tabular}

because of the important influence that changes through time in India's "economic policy discourse" have had on (i) the country's competition regimes especially its informal attitudes towards competition, as captured in the concept of "competition culture" (see Exhibit I) as well as (ii) the attitudes of Indian elites, the media and the general public towards business groups, "big business", the private business sector more generally, and state-business relations. 
How informal business institutions are translated into more specific rules of business conduct and informal business arrangements plays an important role in understanding and determining the numbers and quality of and market outcomes from the interactions and accommodations between India's competition regimes and informal business institutions and arrangements over the past four decades. This translation process is also important to understanding how India's traditional business groups survived and prospered before 1991 (an important topic in chapter 6); and whether these same groups will continue to endure and prosper in the post-1991 liberalization period (an important question in chapters 7 and 8 ).

Nonetheless, this translation process is far from obvious. Collecting and interpreting research participant and other information on more specific rules of business conduct and on informal business arrangements and how they function (boxes two and three above) is comparatively easy. In sharp contrast, for the reasons described earlier, research questions on more general and conceptual informal business institutions associated with trust and related social norms and values are more difficult to formulate and apply, particularly in an interview setting ${ }^{98}$. Therefore, research participant and other information on more specific but still informal rules of business conduct were interpreted to provide some of the links between the more conceptual and general informal business institutions and the more concrete informal business arrangements that are more easily observed.

\footnotetext{
${ }^{98}$ For example, questions about the extent of trust in the country's business transactions and other commercial relationships generated significantly different responses depending on the research participant's function (e.g. business association versus academic or civil society member) and/or the participant's broader views regarding the contributions of India's private business sector to the country's development. The application of discourse analysis was particularly helpful in assessing these responses.
} 
The third challenge throughout the analysis was to control the research scope in light of the large size and complexity of the Indian economy and society, its rich economic and business history, and the large size, breadth and complexity of the new institutional economics and related literatures that are engaged by the author. Research scope was controlled in five ways. The analysis maintains a clear focus on the central question, the three kinds of interactions and two time dependent arguments as described above and in Exhibit II. Emphasis is given to one conceptual economics literature, new institutional economics and more specifically the transaction cost economics model of Williamson. The thesis emphasizes the key interactions and directions of causation between competition regimes and informal business institutions that are identified in the conceptual framework and Appendix 2. Business groups and other informal business institutions are used as a prism for selecting and assessing the other forces related to ideas, ideology and interests that also influenced the evolution of India's competition regimes.

Finally, regional factors, associated with informal business institutions and relevant ideas and interests, are considered only when these regional factors influenced national discourse on India's competition regimes. The fourth and fifth methods for controlling scope meant that ideology, ideas, interests, other formal economic institutions and policy regimes $^{99}$, and regional forces were treated as part of the empirical story rather than as key components of the conceptual framework.

\footnotetext{
${ }^{99}$ Such as other policy regimes in the areas of industrial, investment and trade policies, innovation, intellectual property rights, regulatory reform, and consumer protection that could influence competition.
} 


\subsection{Preparation and Application of the Research Questions and Related Interview Methods}

The context and literature review chapters and conceptual framework and resulting conceptual model summarized in this chapter, were then employed to prepare a set of research questions to facilitate information collection and analysis. These are listed in Appendix 3. The research questions were grouped under four broad themes. The first was the importance, role, growth and evolution of informal business institutions in the development of the Indian economy over an extended period. The second was the interactions and accommodations between India's competition regimes and the country's informal business institutions, including how business groups and other informal business institutions should be treated under the new competition regime. The third theme was how informal business institutions and rules of business conduct are translated into business groups, networks and communities, leading to theories, conjectures and questions relevant to the rise and fall of informal business institutions and the resulting business groups, networks, communities and distinct "business cultures"; while the final these was the major structural, market and cultural factors that help to explain whether a set of informal business institutions and resulting business groups and networks are anticompetitive or pro-competitive.

The research questions listed in Appendix 3 were applied both in interviews with research participants (Appendix 4), and in the collection and review of secondary sources and other documents and information that took place in Canada and during the field mission in India in 2006. Semi-structured in-person and telephone interviews took place in various Indian locations in order to capture emerging regional perspectives and differences that are important to the analysis of the evolution of India's national 
competition regimes. These locations included: the national capital, New Delhi; Jaipur in Rajasthan state, which is the location for the main office of the author's host for the field research, the Consumer Unity and Trust Society (CUTS); Mumbai (Bombay) in Maharashtra state which is the business and financial capital of India; Ahmedabad in Gujarat state which has a long trading and industrial history and is still one of India's major industrial cities; Bangalore in Karnataka state, the location for India's largest information technology cluster; and Chennai (Madras) in Tamil Nadu and Hyderabad in Andhra Pradesh which also have large and rapidly expanding IT technology clusters. Limited time and resources, and the limited number of possible research participants with a strong interest in competition policy and law, prevented visits to Kerala State, Kolkata (previously Calcutta) and Pune, which also is an important industrial and information technology centre in Maharashtra State.

In total, thirty-five substantive interviews were completed with representatives of government and the business, NGO and academic communities, while further evidence and insights were gathered through informal meetings and discussions with the officials and associates of the host agency and other groups. After each interview, the author prepared a note on the key findings, which was then forwarded to the research participant for verification and his/her own use. About one-quarter of the participants responded with changes, comments and additional ideas.

All research participants were promised strict confidentiality and therefore the results and insights from each interview were "blended in" with the findings from other participant interviews and the results from the various non-interview sources. The insights from research participants often confirmed and enriched the major findings from 
the non-interview sources. Many of these key findings in the empirical chapters begin with the phrase "research participants and other sources indicated that" or similar wording. The result is that most of the major findings and conclusions in the empirical chapters, especially Chapters 6-9 on the two time-period case studies, are supported by evidence from both the research participants and the non-interview sources ${ }^{100}$.

\subsection{Conclusions}

Drawing on the competition policy and law literature context in Chapter 1 and the economics conceptual literature review in Chapter 2, the conceptual framework and methodology for this dissertation have been designed to address and interpret the interactions, conflicts and accommodations between India's competition regimes and informal business institutions in a manner that is both comprehensive and flexible. This approach is needed because of: the major differences between the two case study time periods in terms of their competition and broader economic policy regimes and information availability, and the inherent difficulties in finding "hard evidence" on informal institutions and the interactions and accommodations between two different sets of institutions.

The conceptual framework has been designed to accept, compare and interpret information from many different sources, and to develop inferences and judgements from the economic theories in the literature review that can assist in turning this information into findings and conclusions. The analysis, findings and conclusions in the empirical chapters are therefore developed through bringing together: inferences from economic

\footnotetext{
${ }^{100}$ At the end of the field work in India in late August 2006, the author made a major presentation on the key findings and conclusions from the interviews to CUTS officials and invited guests at the CUTS office in Jaipur. This presentation and the comments and validation received from the attendees formed the basis for many of the major findings and conclusions in this dissertation.
} 
theory; the findings of previous researchers; the author's interpretation of official documents; analysis and interpretation based on the conceptual models, data bases and selected quantitative data on economic trends that the author developed for this dissertation; and the rich but anecdotal evidence provided by the thirty-five research participants. Multiple lines of evidence, triangulation and discourse analysis are employed to the greatest degree possible throughout the empirical chapters. Special attention has been given to the evidence from the research participants, which was often used to verify the insights, inferences, conjectures, interpretations and preliminary findings from the other sources. 


\section{Part II: Empirical Analysis of the Interactions, Conflicts and Accommodations Between India's Competition Regimes and Informal Business Institutions}

\section{Chapter 4: Competition Regimes and Informal Business Institutions in India's Economic and Business History}

\subsection{Purpose}

This chapter provides a brief description of the evolution of India's competition regimes and informal business institutions, and the interactions and accommodations between them, through India's pre-colonial and colonial periods and the first two decades of independence up to the mid-1960s. In contrast to the remaining empirical chapters, this chapter addresses for the most part the interactions between the country's informal competition regimes (or competition attitudes/culture) and informal business institutions (see Exhibit I in the Introduction).

History and path dependence are important to new institutional economics. The interactions, conflicts and accommodations between India's competition regimes and informal business institutions over the past four decades are influenced by: the evolution and importance of informal business institutions and arrangements within India's private business sector ${ }^{101}$ and total economy over the country's long and complex economic history, the subject of sections 2-4 of this chapter; and, whether these institutions and arrangements functioned within and contributed to a business culture that on balance was

\footnotetext{
101 Throughout this thesis, the term private business sector rather than business community is used to denote all privately owned business groups and unaffiliated companies "in aggregate". The term business community is applied only to more specific business communities, such as the Marwari business community, that are based on a shared ethnicity, religion, language, location, occupation or other socioeconomic factor. In addition, the term private business sector clearly indicates that the analysis covers only privately owned business groups and other companies, not India's many state-owned enterprises and other public sector undertakings. The latter also make important contributions to the Indian economy but their strategies, conduct, motivation and interactions with the competition regime are likely quite different from privately owned groups and companies.
} 
supportive of competition, inter-firm rivalry and fair trading practices, the subject of sections 5 and 6 . These two chapters emphasize the differences between the pre-colonial and colonial periods. The chapter concludes with a discussion of the implications of these historical developments for the interactions, conflicts and accommodations after 1965. Appendix 6 provides a brief chronology of the developments and events in India's economic and political history that are most relevant to this dissertation.

\subsection{Importance of Informal Business Institutions in India's Business and Economic History}

India's informal business institutions and arrangements have played an important and even pivotal role in the Indian economy at all stages of the country's economic development for over 2000 years. In the pre-colonial period, the importance of these informal institutions and arrangements are underlined by the strong association between India's merchants groups and networks - which in many ways were the forerunners for the business groups of today - and India's strong and often dominant position in global industry, trade and commerce for an extended period from about 1400 up to 1800 . By the start of the $16^{\text {th }}$ century, the merchant communities of India, led by the Gujarati network located on the west coast of India, had taken over the sub-continent's transoceanic trade with other Asian regions. Indian dominance was in part the consequence of the withdrawal of the Chinese under the Ming dynasty from Indian Ocean trade, as well as the decline of the Arab traders (Bouchon 1999, p. 43).

The pattern of Asian trade indicates that India for most of this period was among the most advanced and cost-competitive "industrialized" trading countries in Asia (Prakash 
1985, p. 5). Within the sub-continent, Bengal ${ }^{102}$ was the regional leader for both withinIndia trade as well as trade between India and other Asian countries. Compared with Europe where the political and economic achievements of the Greek and Roman empires were followed by the "dark ages" that lasted several centuries, pre-colonial India for over 2000 years had a long and virtually uninterrupted history of textiles, apparel and other high quality (pre-industrial revolution) manufacturing and handicraft production, and virtually uninterrupted inter-regional trade within the Indian sub-continent and international trade with China, Southeast Asia, the Gulf/Middle East and indirectly with Europe.

As late as the end of the $17^{\text {th }}$ century, India controlled $25 \%$ of global trade in textiles, had the world's leading manufacturing sector and a large commercial sector with a sophisticated market and credit structure, had developed an indigenous banking system, and contributed over $20 \%$ to the world's gross domestic product ${ }^{103}$. In many ways, the rapid economic development of China and India over the past two to three decades is simply returning these two countries to the powerful positions they enjoyed within the global economy for most of the last two millennia up to 1800 . For the citizens of China and India, the current re-emergence is a "return to normal" (Das 2002, Gernet 2002).

India's pre-eminent position was achieved with little support from the state, in particular the Mughal empire, that controlled (or tried to control) much but not all of India for a quite extended period from 1550 to the late 1700s. The Mughal Empire

\footnotetext{
${ }^{102}$ Which Prakash (1985) and other historians define as the very large territory now covered by Bangladesh plus the Indian states of West Bengal, Bihar and Orissa.

${ }^{103}$ At this time, India's agriculture sector supported a population of over 100 million people, generated a significant financial surplus, and, in terms of productivity, yields and financial returns, likely compared favourably with agriculture in other countries including the countries of Western Europe (Das 2002, pp. 5556). "It is not surprising, then, that English travelers to India found an economy that was dynamic and commercial, not stagnant and backward" (Das 2002, p. 56).
} 
focused on state administration, revenue collection and staying in power, not on nation building through state protected and regulated trade and industry ${ }^{104}$. Before full British colonial rule after 1857, India's quite well-developed trade and industry, and sophistication in dealing with money and credit, were based on informal business institutions and personal relationships between businesses and business people rather than on formal policies and institutions that were guaranteed, protected and promoted by a strong state authority. The period from 1500 (when European traders first arrived in India) to 1800 (when British dominance became more firmly established) is characterized by historians as one of healthy competition and cooperation between Indian and European business equals. Indian merchants and traders and the country's manufactured goods remained important and competitive even during the initial decades of the British colonial period under the British East India Company that began in 1750 .

To summarize, during the four hundred year period up to about 1800 , the Indian private business sector experienced quite considerable growth, incremental change, innovation, entrepreneurship, inter-firm rivalry and cooperation. The sector responded with quite considerable success, and with little help from the central government authority, to the external conditions, shocks and opportunities caused by the rise and fall of the Mughal Empire and the arrival and growth of European businesses and of European political and military power. The expansion and growing capabilities of India's merchant houses and other businesses were particularly pronounced during the period from 1750 to the early 1800s when the Mughal Empire was in decline but before

\footnotetext{
104 This is the approach of mercantilism and monopoly that was being adopted over this period by the emerging nation states in Europe in particular Portugal, Spain, the Netherlands, France, and latterly and most successfully Great Britain. India in fact never had a relatively "strong state" until full British colonial rule when direct rule from London was established after 1857.
} 
British colonial rule was fully established (Bayly 1983). During this period, Indian merchants were on a par with the great European merchant houses and competed on equal terms with European merchants from Portugal, the Netherlands, France, and Great Britain.

The British East India Company monopoly only started to have a significant impact after 1750 - when Indian merchants, traders, money-lenders and artisans/manufacturers increasingly were placed in a more subordinate position relative to British and other European businesses. Even then, Mughal decline, British rule and the British East India Company monopoly had a larger influence on some Indian regions starting with Bengal, and on some aspects of India's internal and international trade, compared with other regions and trading relationships. Bengal, Madras/South India, western India centered on Bombay/Mumbai and the current states of Maharashtra and Gujarat, and central India centered on Delhi, all to some degree have different political, military, economic, and business histories and experiences -- including experience with British imperialism and institutions. While India is more than a geographical expression, these different regional histories and experiences have shaped their regional economies, attitudes towards private enterprise, entrepreneurship, markets and competition, and the informal business institutions and arrangements that have been and continue to be important to each regional economic unit within India (Sinha 2005:1 and Chapter 8).

Through the British colonial period, Indian traders, merchants, and (pre-industrial revolution) manufacturers remained important and successful either working closely with British business interests, which of course had the support and protection of the Empire, or on their own in areas where British interests and influence were more limited. While 
India is considered to be a late industrializer, industrialization made its first steps in India in the mid- $19^{\text {th }}$ century and therefore earlier than in many other British colonies such as Canada and Australia. India in the Asian context was in fact a relatively early industrializer. India established its first cotton mill, jute mill and small railway system in the second half of the $19^{\text {th }}$ century at about the same time that the Japanese after the Meiji Restoration began to industrialize (Bowonder 1998, p. 623). "From the 1850s, when the first major industries were started, to 1914, India had the world's largest jutemanufacturing industry, a modern iron and steel manufacturing industry, and the third largest railway network" (Prakash 2001, p. 34).

India therefore has a long, complex, productive and distinguished economic and business history that continues to influence the country's informal business institutions, rules of business conduct and business arrangements up to the present day. The themes of continuity and change, and of incremental, subtle but still quite significant economic, business, institutional and social adaptation, progress and innovation -- taking place beneath the surface of the major external shocks of European arrival, Mughal decline and British colonial rule -- provide the historical context for the emergence, persistence and continuing success of India' traditional business groups and other informal business institutions from the mid- $19^{\text {th }}$ century through to the first years of the $21^{\text {st }}$ century.

\subsection{The Role of Informal Business Institutions in Balancing Competition and Cooperation in Pre-Colonial India}

India's trade up to about 1800 often involved cooperative and mutually beneficial informal business institutions and arrangements, which could encompass larger merchant houses as well as smaller traders/petty peddlers, artisans and smaller manufacturers (Chaudhury and Morineau 1999 and Palat et al 1999). Therefore, the appropriate mix of 
cooperation, fair trading and competition characterized Indian manufacturing and trade and the relationships between non-Indian and Indian companies during this period (see e.g. Tripathi 2004). The capability of Indian merchants, traders and other enterprises to both compete and cooperate in this manner was a competitive strength of the Indian merchant houses, traders and small-scale artisans and industrialists centered especially in Bengal, Gujarat, and southern India.

Cooperation between European companies such as the Dutch East India Company and local Indian merchants in conducting trade within the sub-continent as well as Asian trade took various forms. These included cooperation in hiring freight space and the chartering of vessels for particular voyages; European use of the Indian banking system; and cooperation between individual European and Indian merchants in financing voyages to and from various Asian ports. "The strength of the Indian merchant evidently lay in his lower overhead costs and a much more intimate familiarity with the mechanics of the markets both at home and at the ports of destination" (Prakash 1985, p. 259) ${ }^{105}$.

Until the middle of the $18^{\text {th }}$ century, the interest of the European trading companies was mainly commercial not political, as they all competed fiercely with each other and with the local Indian merchants for the coveted Indian cargos in textiles, raw silk, saltpetre and other goods (Prakash 1985). Trade and commerce within India and between India and other Asian and non-Asian countries in the pre-British colonial period were supported by: the establishment of the money economy -- facilitated in part by imports of precious metals as a major means for Europeans to pay for the high quality textiles and other Indian goods demanded by high income Europeans; growth in relatively modern

\footnotetext{
${ }^{105}$ In sum, these merchants were successful in minimizing their transactions costs (consistent with the Williamson TCE model in Chapter 2).
} 
money lending and banking firms and the hundi system ${ }^{106}$ and other methods for settling accounts across long distances; and the strong merchant houses in India and other Asian countries. Other factors included appropriate and supportive property and class relations; and a fair degree of individualism and of equality in kinship systems and temple sects (Das 2002, p. 301), which resulted in significant entrepreneurial activity in trade, commerce and money lending and banking.

Most importantly for this analysis, India's impressive commercial and economic capabilities through the pre-colonial period were supported by a wide range of informal business institutions, rules of business conduct and arrangements that minimized transactions costs and on balance favoured fair trading and the appropriate balance between cooperation and competition over collusion, monopolies, and rent-seeking. These informal business institutions and arrangements likely were not optimal in the Pareto sense, since they were designed to facilitate trade between a relatively narrow group of merchants and traders based on family, ethnicity, religion, location and frequency of transactions. However, these institutions and arrangements were functional and perhaps even relatively efficient (compared with the readily available governance alternatives ${ }^{107}$ ) for the business participants as well as the broader Indian economy.

There are many reasons for the development in India at this time of a business culture that balanced fair trading, competition and cooperation in a manner reminiscent of modern business and economic development strategy (Best 1990, Porter 1990, and Jorde

\footnotetext{
106 The hundi system was a type of bill of exchange between the two parties to the transaction, which was carefully drafted in order to minimize the dangers of fraud or impersonation (Tripathi 2004, p. 18). The hundi system meant that transfers of cash were not needed. While the remittance charges were quite understandably high, the system was viewed with such significant credibility that it was used throughout India and a secondary market for saleable hundis was starting to emerge in the early 1700 s. The hundi network was particularly important during the period of Mughal decline as the successor states became major clients of India's merchant houses.

${ }_{107}$ Therefore, these institutions satisfied the remediableness test of Williamson (2000:1, p. 102).
} 
and Teece 1992). Traditional Indian economic thought, which was first developed over 2000 years ago, emphasized the importance of fair trading and provided explicit prohibitions against price-fixing, other forms of collusion and exploitation of market power, usury and overly high prices (what we now call price gouging) (Spengler 1971). Until the British colonial period, India did not have a "strong state" to provide state protection, entitlements and monopolies, and to enforce formal commercial rules of business conduct. Pre-colonial business transactions involved a combination of both high risks and high rewards, the consequence of: virtually no formal commercial laws that could be readily enforced by a strong state authority; and the high risks at that time of long distance trading, particularly during periods of political uncertainty, warfare, and the rise and fall of empires.

Therefore, trade and industry and the business transactions of merchants, small artisans and industrialists and other businesses required informal business institutions, rules of business conduct and informal business arrangements based on cooperation, trust, reciprocity of trust, reciprocal obligations when an agent in one transaction becomes the principal in the next, and building reputations for being trustworthy (see Chapter 2). These informal business institutions and rules for many centuries functioned through: guilds, occupational, religious and caste groups; long-term supplier-customer arrangements between Indian merchant houses, artisans and small manufacturers that at times cut across caste, religious, ethnic and other social and occupational divisions; and similar long-term arrangements between Indian merchant houses and non-Indian merchants located in India and other countries. The result was the development of informal business groups, networks, alliances, relational contracts, and other longer-term 
arrangements between merchants, traders, money lenders and manufacturers/handicraft producers.

\subsection{Evolution of India's Business Groups and Other Informal Business Institutions}

India's business histories emphasize continuity, stability and path dependence in the country's informal business institutions, which begin with the merchant and trader guilds, networks and related groups of the pre-colonial period, with their long-term relationships with artisans and pre-modern manufacturers; move through to the managing agencies and industrial houses of the colonial period and the first two decades of independence; and culminate with today's traditional business groups and new informal business arrangements in the new economy sectors (see Tripathi and Mehta 1990, Tripathi 2004 and Exhibit XI below). The business groups and other informal business arrangements of today embody attributes of the managing agencies as well as India's pre-colonial informal business institutions and arrangements.

Exhibit XI: Continuity and Change in India's Informal Business Institutions and Arrangements for Over 2000 Years

\begin{tabular}{|c|c|c|c|c|}
\hline $\begin{array}{l}\text { Informal } \\
\text { Business } \\
\text { Institutions } \\
\text { Based on the } \\
\text { Guilds, Other } \\
\text { Occupational } \\
\text { Groups, } \\
\text { Merchant } \\
\text { Houses, and } \\
\text { Smaller } \\
\text { Traders of the } \\
\text { Pre-European } \\
\text { Period -- That } \\
\text { go back over } \\
1500 \text { years }\end{array}$ & $\begin{array}{l}\text { Emergence of } \\
\text { the Major } \\
\text { Indian } \\
\text { Merchant } \\
\text { Houses (the } \\
\text { Indian } \\
\text { Merchant } \\
\text { Princes) and } \\
\text { Informal } \\
\text { Merchant } \\
\text { Networks } \\
\text { after 1400, } \\
\text { which } \\
\text { continued to } \\
\text { be important } \\
\text { up to at least } \\
1800\end{array}$ & $\begin{array}{l}\text { Establishment } \\
\text { of the British } \\
\text { and Indian } \\
\text { Owned } \\
\text { Managing } \\
\text { Agencies - } \\
\text { starting in the } \\
\text { mid-19 } \\
\text { century } \\
\text { through to } \\
1970 \text { when } \\
\text { the system } \\
\text { was formally } \\
\text { abolished by } \\
\text { the GOI }\end{array}$ & $\begin{array}{l}\text { Transformation } \\
\text { of the } \\
\text { Managing } \\
\text { Agencies into } \\
\text { the Industrial } \\
\text { Houses of the } \\
\text { Inter-War } \\
\text { Period and the } \\
\text { Business } \\
\text { Groups after } \\
\text { Independence in } \\
\text { 1947-that } \\
\text { remain in place } \\
\text { to the present } \\
\text { day }\end{array}$ & $\begin{array}{l}\text { Emergence of } \\
\text { New Kinds of } \\
\text { Informal } \\
\text { Business } \\
\text { Institutions } \\
\text { and } \\
\text { Arrangements } \\
\text { - in response } \\
\text { to post-1991 } \\
\text { liberalization, } \\
\text { rapid } \\
\text { technological } \\
\text { change/the } \\
\text { new } \\
\text { economy, and } \\
\text { globalization }\end{array}$ \\
\hline
\end{tabular}


Discussions of path dependence in India's business histories give special attention to the continuing importance of the Marwari business community after many centuries (Taknet 1986, Tripathi 2004), and the most important counterfactual to institutional continuity and path dependence - the Hindu and Muslim business communities of Bengal. Both developments and the synergies between them are important to understanding the historical evolution of India's informal business institutions up to the present day. As noted previously, Bengal was the center of Indian trade and industry before British colonial rule, and was considered to be the major prize in the conflicts between the European colonial powers in the Indian sub-continent prior to the British takeover in 1757 (see e.g. Prakash 1985).

However, the traditional Bengal business communities suffered major setbacks in both the mid- $18^{\text {th }}$ and $19^{\text {th }}$ centuries and virtually disappeared to be replaced by "outsiders", mainly the Marwaris from Rajasthan state near New Delhi, from 1850 on (Tripathi 2004, Sinha 2005:1, chapter 6 and Timberg 1969). The fall of Bengal's indigenous business class had major repercussions for business attitudes and strategies on both sides of the British/India ethnic divide. These Bengali developments influenced state-private business relations up to and after India's independence in 1947. This is the because of the importance of Bengal to India's pre-colonial trade and industry and its political, economic and business histories; state-business relations and economic policy discourse, and the business attitudes of political, government, media and other elites, policy-influencers and decision-makers in post-independence India.

A major irony and tragedy of the collapse of the Bengali business class in the mid$19^{\text {th }}$ century is that Bengal was virtually the only Indian region where British business 
interests attempted to establish partnerships and joint ventures with their Bengali business colleagues on roughly equal terms. These more equal partnerships between British and Bengali business interests had virtually disappeared by 1850 . This was also one of the few times during the $19^{\text {th }}$ century when Brahmins and other members of India's upper castes played prominent roles in the establishment and operation of new business ventures. Upper caste Indians had the self-confidence, education, political connections, and status in society to deal with the British on more equal terms. The failure of these prominent business arrangements in Bengal may have discouraged many upper caste Indians from establishing businesses in the future; and may have reinforced their preferences to work in the professions, the civil service and religious and cultural occupations, preferences that have continued to the present day.

While the leading merchant and industrial houses and business groups changed through time, many of the business groups of today have links to the managing agencies of pre-independence and early post-independence, and in some cases have some links with the important merchant houses and trader groups that go back to India's pre-colonial period. The managing agencies cover the period from the mid-1800s to 1970 , when they were eliminated by the Government of India as an artefact of the colonial period (see Chapter 6). Under this system, the managing agency controlled a large number of firms that were active in a range of industries. This system, which reportedly was unique to India, "entrusted the management of a corporation -- subject to only a formal control by the board of directors -- to another corporation or a partnership firm or an individual working as a management agent, in return for payment for services" (Ghosh, 1974:2, p. 852). 
Because managerial and entrepreneurial skills in the early years of India's industrial development were in short supply, many British business houses became managing agents of large numbers of individual companies that were incorporated in India. For similar reasons, Indians with financial capital, entrepreneurial interests, business acumen and talent for management also established managing agencies. The result was that over time a large number of nominally independent Indian companies were managed by managing agencies (Ghosh 1974:2 and 1974:3). The typical managing agency did not have controlling shares in their companies. Rather, the older companies of the managing agency made sufficient investments to ensure that the new companies were under the $d e$ facto management control of the managing agency. The British and Indian owned managing agencies thus created their own business empires with relatively limited investment (Tripathi 2004 and Mehta 1990, pp. 26-27). The result was management control by proxy that economized on limited financial, management and entrepreneurial resources in India. This form of management control continued under the industrial houses and business groups of post-independence India ${ }^{108}$.

The continuity, stability and path dependence of India's informal business institutions and arrangements can be compared with - and to some degree was probably necessitated by - the many external shocks and fundamental changes to the more formal institutions and policy regimes that have characterized India's economic and political history for a long period up to the present day. Two other developments facilitated institutional continuity and path dependence within India's informal business institutions and private business sector through the British colonial period. Information asymmetries favoured

\footnotetext{
${ }^{108}$ This system is only now starting to come under pressure in part because of the recent emergence of the market for corporate control in India, resulting in the threat of hostile takeovers of a business group's larger and more profitable company affiliates (see Chapter 8).
} 
traditional local businesses and local government and political leaders over the new British rulers (Roy 2000, p. 31). This meant that British businesses and the colonial government were dependent on their Indian officers and on Indian-owned businesses. The second development is that British hegemony and the disruptive influence of British institutions were much stronger in some parts of the sub-continent than in others.

India's traditional business groups are now being joined (but not replaced) by new forms of informal business institutions, arrangements and inter-firm cooperation that are more consistent with India's liberalization program and emerging knowledge-based economy, including its competitive strengths in information technology, biotechnology and other new economy sectors. These new forms include joint ventures, strategic alliances and partnerships between Indian based and offshore companies including companies run by Indian ex-patriots in Silicon Valley and other high technology clusters in more advanced OECD countries. These informal arrangements provide access to venture and other forms of risk capital, technology, management skills, global supply chains and markets (Van Dijk et al 2003, Balasubramanyam et al 2000 and Das 2002 p. $335)$.

In addition, arrangements between smaller and larger firms are now emerging. These capitalize on the complementary resources and capabilities of different sized companies and are used by the larger partner to e.g. respond to large and unanticipated increases in demand without making major investments to increase their own production capacity (Patibandla 1998). There is as well greater use: of informal relationships between smaller artisans, manufacturers and traders in the same urban neighbourhood and industrial district; and of modern franchising which is now being used quite extensively by both 
foreign and domestically owned firms in some service sectors such as restaurant chains as well as computer training centers (Das 2002, p. 249) ${ }^{109}$.

Informal business institutions and arrangements therefore are now being found in new contexts to meet new business needs and customer demands (see. e.g. Dorin 2003, Patibandla and Petersen 2001, Van Dijk 2003 and Benjamin 2000). Many of these new informal business arrangements in the new economy sectors such as information technology involve the active participation of traditional business groups such as the Tatas, Birlas and Mahindra \& Mahindra. The emergence of these new forms of informal business institutions and arrangements suggests that India's traditional business groups are not "crowding out" new (and potentially more efficient) institutions and arrangements; but rather are making a modest contribution to the establishment of these new forms of inter-firm cooperation. The challenges posed by these adjustments are explored in greater detail in Chapter 8.

Informal business institutions and arrangements have thus played a major role in the development of India's private economy and are taking on even greater importance in the high-risk, high-reward knowledge-based economy now emerging in India. For the reasons indicated by the transactions costs economics model in Chapter 2, informal business institutions and arrangements remain important despite modern competition, intellectual property (IP), company, contract and other formal institutions/policy,

\footnotetext{
109 This thesis emphasizes India's traditional business groups and the new economy informal business arrangements which have become more important since 1991. These two informal governance modes have been emphasized because of their importance to India's competition regimes. The informal networks of smaller manufacturers and the other kinds of informal business institutions described in this paragraph are also important to India's industrial and export performance but their implications for competition are less important or at least less evident. Nonetheless, given their continuing importance and the likely expansion in their linkages with India's traditional business groups (see Chapter 8 above), these informal networks of smaller manufacturers and other informal governance forms should be given greater attention in future research on informal business institutions and India's competition regimes.
} 
regulatory and legal regimes. The stability and mutual benefits from these long-term business relationships are reinforced by two other inter-related considerations.

Many, although not all, transactions take place within the same ethnic, religious, language, merchant caste or other occupational group. Furthermore, many of these more successful business communities and informal business arrangements from pre-colonial India to the present day are based on caste, occupational, religious, regional, and ethnic minority groups that were considered to be "outsiders" of lower rank under India's caste and social systems. Being considered as and perceiving your group as an outsider tends to increase within group solidarity and is often associated with business success in Asia (see e.g. Taknet 1986, Redding 1993 and 1995).

There are some similarities between informal business institutions and arrangements in India and those in other Asian and developing countries. However, India's institutions and arrangements involve an interesting mix of cooperative, coercive/hierarchical and quasi-market factors that appear to be unique to India's traditional business groups and other informal institutions and arrangements and to be reflective of - and thus embedded within - the enduring features of India's history, society and culture. Building on the previous two chapters (see in particular Exhibit VI as well as the conceptual model in Appendix 2), Exhibit XII starting on the next page attempts to summarize in a stylized manner the structure, routines and rules of business conduct of a "typical" larger business group in India.

One theme from the historical evidence that is consistent with the NIE and related literatures reviewed in Chapter 2 and is important to later empirical analysis is the extensive and apparently well monitored and enforced cooperation: within India's 
traditional business groups; within certain broader ethnic, religious and caste-based business communities led by the Marwaris; and, within the caste based guilds, and the long-term commercial relationships between merchant houses and other groups of the past. In sharp contrast, there appears to be some, but more limited and less sustained cooperation, across different business groups and business communities ${ }^{110}$. Religious, ethnic, caste, regional and other social differences have tended to divide business groups and communities between insiders and outsiders -- where the business rules of cooperation and fair trading are more strongly applied and enforced in transactions and dealings with other insiders than with outsiders ${ }^{111}$.

\subsection{Changes in Business Culture and Relationships under British Colonial Rule}

In sharp contrast to the pre-colonial period, 200 years of British colonial rule had a negative influence on India's competition culture, which has resonated to the present day. British colonial rule replaced business relationships based on trust, reciprocity of trust, reciprocal obligations, cooperation, equality and fair competition, with relationships based on hierarchy, one-way principal-agent transactions, and exploitation and unequal bargaining power between the British and Indian business parties.

\section{Exhibit XII: Stylized Family-Based Indian Business Group/Conglomerate}

\footnotetext{
${ }^{110}$ An important exception to this conclusion is the complementary and mutually beneficial trading institutions and arrangements between Hindu and Muslim traders in medieval port towns that have supported religious tolerance and integration in many of these towns up to the present day (Jha 2005).

${ }^{111}$ This inclusiveness is one of the dangers of informal institutions and arrangements that are emphasized in the new institutional economics and related literatures (see e.g. Bowles and Gintis, 1998 and 2002 and the many Ostrom references in the bibliography). The implications for the future strategies and governance of traditional business groups are further analysed in Chapter 8.
} 
Leading Company: iron and steel mill, managed by the head of family (the managing agency before 1970)

Lean

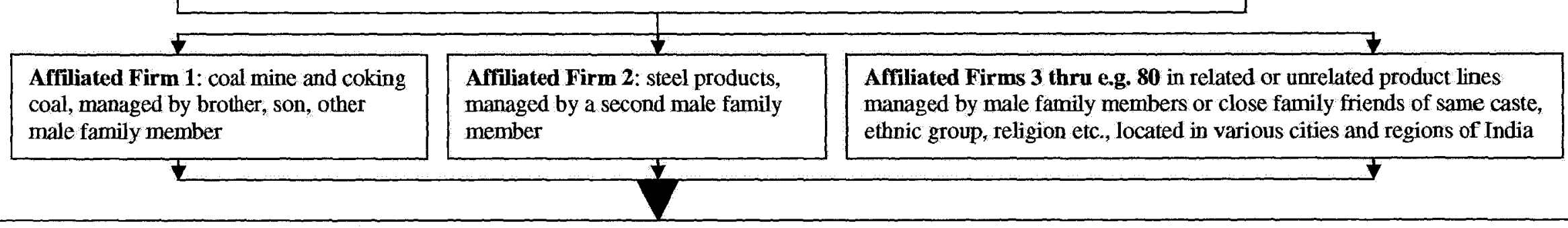

Held together, managed and made functional and effective by a wide range of instruments, routines and rules of business conduct:

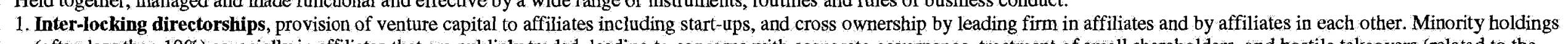

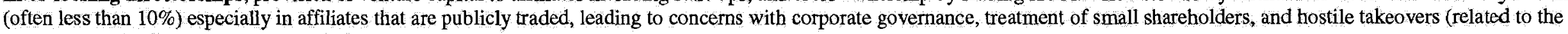
emerging market for corporate control in India).

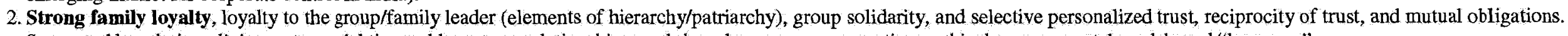
Supported by ethnic, religious, etc. social ties and long-term relationships, and shared successes, conventions, ethical norms, mental models and "language".

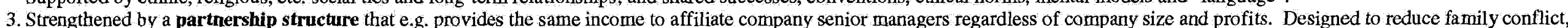

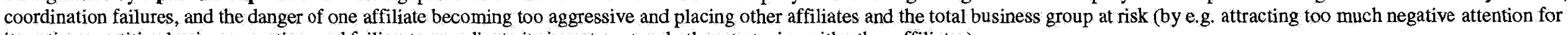
its anti-competitive business practices and failing to coordinate its investment and other strategies with other affiliates).

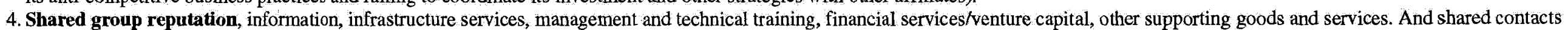

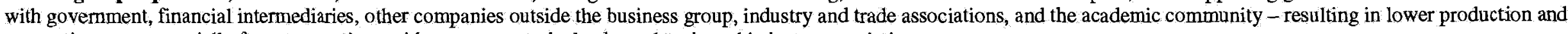
transaction costs especially from transactions with government, the banks and trade and industry associations.

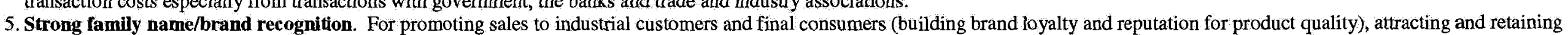

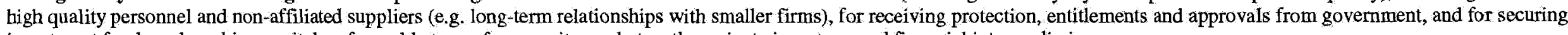
investment funds and working capital on favorable terms from equity markets, other private investors, and financial intermediaries.

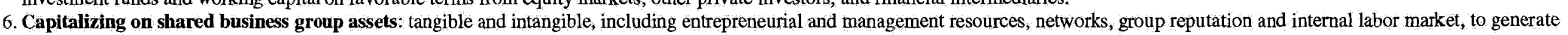
profits and other advantages for all affiliated companies.

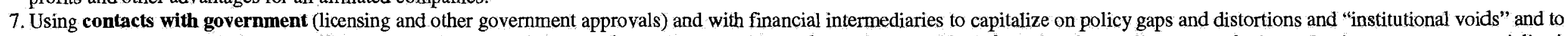

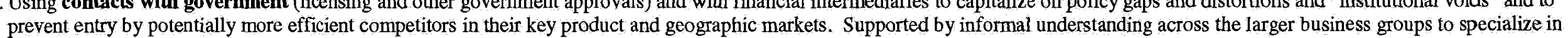

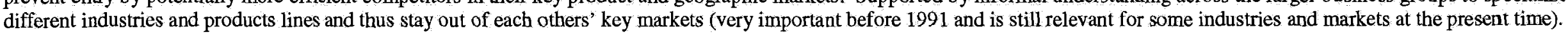

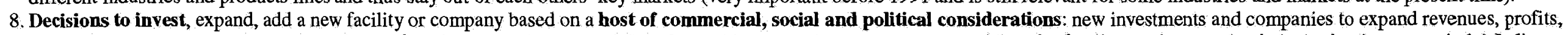

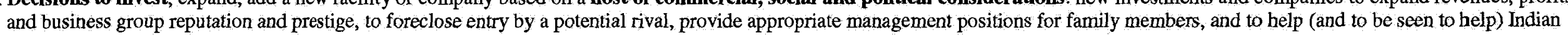
governments to achieve industrial, regional, and other policy objectives.

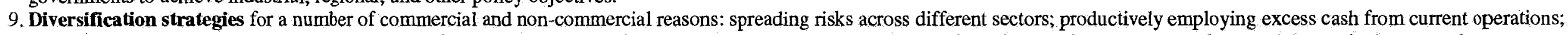

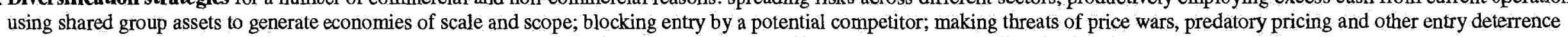
strategies more credible (since these strategies can be applied in multiple markets); and providing senior management jobs for family members.

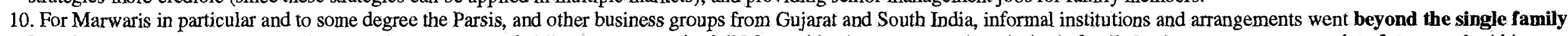

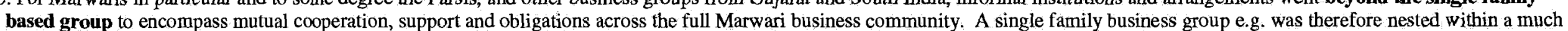

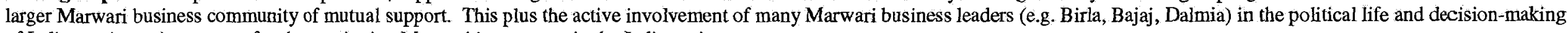
of India are the major reasons for the continuing Marwari importance in the Indian private sector. 
This change in business culture is strongly associated with the British East India Company monopoly. Rule of much of India by a private company for nearly a century resulted in even greater exploitation and disruption of traditional business practices than direct rule by a colonial power which began only after 1857 . Other factors included: state promotion and protection of British businesses including monopolies in jute, shipping and other key sectors; the system of discriminating protectionism after the First World Warr ${ }^{112}$; and exploitation of India for the benefit of British businesses and the home economy. All of these activities were conducted in the name of free trade and markets, minimal intervention by the state, and laissez-faire (at least for British owned businesses).

In addition, India's traditional informal business, banking, money lending, village and other informal institutions, and its decentralized systems of rule making, compliance monitoring and dispute resolution, were replaced by more centralized formal court systems and other formal institutions. The result was an overly centralized system of government administration that was needed to rule a colony, and too many laws together with too little governance (Kranton and Swamy 1999, and Debroy 2004, p. 111). India's business and economic histories provide many examples of changes under British colonial rule that negatively affected the country's development trajectory and competition regime after independence. The following paragraphs provide only a few illustrations.

\footnotetext{
${ }^{112}$ Discriminating protectionism was a particularly pernicious form of trade protection that badly distorted India's external trade relationships and competition within India's domestic markets. This system discriminated in favour of British industrial and trading interests and their Indian associates and led to higher consumer prices for most labourers and farmers and greater profits for certain individual industrialists (Das 2002, p. 87). The system therefore favoured imports from British-based factories, prevented imports from third countries, impeded entry by new mainly Indian owned businesses and entrepreneurs, and resulted in much higher prices in India. Accordingly, it provided few if any of the domestic benefits in the form of new Indian investment, businesses and jobs that are typically identified with import substitution strategies, and arguably deepened and extended the Great Depression in India (Rothermund 1993, Chapter 8).
} 
In the pre-colonial period in southern India (Madras), Indian merchants advanced funds to weavers. This however was not the "putting out system" in the strict sense of this term. Rather, the weavers were free to sell their product to other merchants based on the best price then available in the market. The first merchant who advanced the money to the weaver was then repaid from the sale proceeds. The arrival of European traders at first led to increased competition and prices that favoured the weavers. However, once British power was firmly established in southern India in the later years of the $18^{\text {th }}$ century, the British East India Company decided to control this system directly through its own officers. The British East India Company's officers controlled production, made cash advances, controlled the delivery of the goods to the Company, and enforced quality control (leading to significant volumes of rejections). Under this hierarchical system, prices were fixed arbitrarily by the company - rather than by competition in the market as under the pre-colonial system - and corruption and extortion were reported to be common. This transformed the independent weavers into what were essentially the Company's "coolie workers" (Tirumalai 1986).

Similar changes, where hierarchy and economic and political power replaced markets, fair trading and mutually beneficial commercial transactions, took place in Bengal after the British takeover in 1757. During the first half of the $18^{\text {th }}$ century in Bengal, trade in commodities for which the state had established a monopoly, such as salt, opium and saltpetre, were farmed out to Indian merchants from the Hindu, Muslim, Armenian and other business communities through public auction, under quite a modern system that we would now call "competition for the market". However, soon after the British takeover in 1757 , all commercial privileges over the key monopolies and the control of state 
revenues were transferred to British business interests, and there were no auctions or other competitive methods that would have allowed other ethnic business communities to compete for the business (Tripathi 2004, p. 38).

As a final example, the hundi network of bills of exchange that had served Indian and British merchants very well up to 1800 was replaced by a more "modern" (but less functional) banking system that was designed to serve British colonial interests and lacked the scale, financial depth, and modern financing instruments to support the investment and other credit needs of India's industrialists and economic development. The result was that India entered its post-independence period with a relatively small and under-developed banking sector. This is only one of many illustrations where the British colonial regime over time undermined India's traditional informal institutions, but did not replace these with strong formal institutions to serve India's long-term development requirements (Tripathi 2004, pp. 39-41, Roy 2000, p. 174, and Debroy 2004).

Wherever British political leverage increased on the sub-continent, the rival European merchants nearly always became marginalized, and coercion and exploitation of Indian merchants, artisans and other economic agents replaced the level playing field and the market forces of supply and demand (Prakash 2001). These unfavourable changes took place despite public assurances from the British East India Company to Indian merchants and artisans and the rival European merchants that free trade and fair competition were still the "law of the land" (Prakash 2001, pp. 17-18). Regardless of the British rhetoric, free trade was "managed" to promote British commercial interests and the home economy throughout the 200 years of British colonial rule. 
More fundamentally, the British colonial regime replaced to a significant degree the collectivist beliefs of India's pre-colonial business culture with the more individualist beliefs associated with the business cultures of the United Kingdom and other "AngloSaxon" economies. Collectivist cultural beliefs promote reciprocal obligations that can economize on transactions costs ${ }^{113}$. In sharp contrast, under the individualist cultural beliefs promoted by British colonial rule, merchants were always merchants and agents were always agents or subordinates carrying out the directions of the British principal (Greif 1993 and 1994, pp. 925-930).

The dominance of one-way principal-agent relationships between British and Indian business people was the result of several interrelated factors: British familiarity and greater trust in their own "modern" rules of business conduct; the ability of the colonial ruler to "impose" their "superior" individualist business rules on their Indian subjects; and the importance of access to the colonial regime. Not surprisingly, British businesses had much better connections with key officials in the colonial government compared with their Indian counterparts (Tripathi 2004). One lasting and quite costly consequence of this change in business culture under British colonial rule is that modern India is not too far below the United States as one of the more litigious countries in the global economy.

\footnotetext{
${ }^{113}$ In the pre-colonial period, reciprocal obligations helped Indian merchants to be cost competitive with their European counterparts. In a collectivist society with reciprocal obligations, merchants can pay agents a lower commission, whereas, in individualist societies, agents need to be paid a premium in order to buy and maintain their loyalty and minimize opportunism and shirking (Greif 1994, pp. 925-930). This is a good illustration of how trust, reciprocity of trust, and building reputations for being trustworthy can minimize transactions costs.
} 
In sum, the British, with only a little help from the Dutch, Portuguese and French ${ }^{114}$, introduced into India's business culture, and made more popular and profitable, state protection, monopolies, collusion, rent seeking, predatory behaviour, short-term get-richquick business strategies, and currying favor with governments, politicians and bureaucrats. These changes in business culture associated with 200 years of British colonial rule placed India on a different development trajectory with respect to competition, fair trading and state-private business relations. After independence, following the proposals recommended by the private business sector in the Bombay Plan of 1944, the business groups and other larger Indian owned companies generally supported: the establishment of a mixed economy in India; a major role for government investment, ownership and management in heavy and other capital intensive industries; and, at least some degree of state planning, business regulation and government intervention.

As noted (and perhaps over-stated) by one economic historian: "Indian capitalists were probably unique in the third world in demanding a planned economy" (Chattopadhyay 1991, p. 308). This was viewed as an acceptable compromise as long as incumbent Indian businesses replaced British business interests as the major beneficiaries of state preferences, protection, subsidies and other entitlements -- as first the British colonial regime in 1947 and then British businesses over the next two decades "quit India” (Tripathi 2004 and Chibber 2003:1 and 2003:2).

\footnotetext{
${ }^{114}$ While the Portuguese were the first to introduce monopoly concessions into India's trade with other countries starting in the middle of the $16^{\text {th }}$ century, (Prakash 1999, pp. 178-180), the Portuguese and then the Dutch monopoly companies and the French merchants generally co-existed, competed fairly against and at times cooperated with the Indian merchant houses through to the $18^{\text {th }}$ century. This was largely because their major interest was commercial not political.
} 
Whether the arrival of the Europeans and the establishment of the British colonial regime were on balance positive or negative factors in India's economic development and in promoting more modern business and market institutions continues to be contested up to the present day. Leaving that question aside, a stronger case can be made that British colonialism was a negative force in the creation of a pro-competition culture in India. What the British colonial regime taught India about the dark, predatory side of trade, commerce, industry, markets and globalization has strongly influenced Indian discourse on economic development and the role of private business, competition, and markets in the country's development since 1947 (Basu 2003, p. 11).

\subsection{Potential for the Pre-Colonial Competition Culture to Have Some Resonance in Modern India}

Despite the negative effects of British colonial rule on attitudes towards competition and fair trading, the new institutional economics concepts of continuity, path dependence and institutional inertia suggest that the spirit of competition, fair trading, mutually beneficial cooperation, reciprocal obligations, and entrepreneurship without state protection that characterized the pre-colonial period may still resonate today in some sectors and regions.

India's information technology (IT) "miracle" occurred in South India with relatively modest government support, but as well with little government hindrance and interference. Research participants emphasized that it is not just chance that India's IT miracle started in a region of the sub-continent where: the British influence was more limited and benign; the wars, chaos and the rise and fall of northern India's many empires had a more limited impact on business attitudes, norms, entrepreneurship and risk-taking; and participation in the global economy through trade with and direct investment in other 
Asian countries by South Indian owned firms had continued nearly without interruption for many centuries including through the British colonial period ${ }^{115}$. South India benefited as well from its later start in industrialization and modernization, which only gained some momentum during the inter-war period when the British colonial government had more balanced policies between British and Indian-business interests (Tripathi 2004 and Mahadevan 1992).

Finally, South India on balance had more positive experiences (compared with Bengal and Calcutta) with mutually beneficial collaborations between British and Indian owned managing agencies/business groups and other businesses both before and after independence. This more positive, stable and entrepreneurial business history helps to explain the rise of Bangalore in Karnataka state, Chennai in Tamil Nadu state, Hyderabad in Andhra Pradesh, and other parts of South India since 1991 as national leaders in computer software, information technology outsourcing and related services, other the new economy sectors, and in establishing modern informal business arrangements with overseas companies, investors and entrepreneurs (see sections 4.4 and 8.5).

Compared with Bengal, the opportunities for Indian businesses were also comparatively greater in the Bombay Regency ${ }^{116}$. In these Western India regions, Indian producers and merchants continued to play quite important and independent roles in

115 Southern India had established strong trading relationships with Southeast Asia that were in place for over 1000 years before the arrival of the Portuguese and other foreign traders. Compared with northern and eastern India especially Bengal, this international trade was less affected by European trade and merchants from 1500 to 1800 when the hegemony of the British East India Company was being established throughout many parts of the sub-continent, including some parts of the south (Tirumalai 1986 and Raychaudhuri et al 1982, pp. 17-18).

${ }^{116}$ The Bombay Regency covered the modern states of Maharashtra and Gujarat where the Indian owned textile producers were first established (Tripathi 2004, and Tripathi and Mehta 1990). Maharashtra and Gujarat continue to be among the strongest industrial and economic performers among the Indian regional states through to the preset time (Sinha, 2005:1). 
industry, trade and commerce throughout the British colonial period. In addition, rural industries in various parts of the sub-continent prospered during the 1930 s, including oil presses, rice mills and motor vehicles. Growth in these industries was based on investments by more prosperous rural entrepreneurs and investors, who invested their surplus funds in food processing and motor transport that could compete with the railways (Rothermund 1993, Chapter 8, p. 113). Finally, British and other foreign traders were more important in India's international trade, particularly with Europe, leaving more room for Indian merchants to profit from India's internal trade and its trade with other Asian countries.

Timing appears to be particularly important. Bengal had the most numerous and negative interactions with British business interests when: India was still ruled by the British East India Company, and British business practices appeared to be most exclusionary (and arguably racist), short-term, rent seeking, and anti-competitive ${ }^{117}$. South India, the Bombay Regency and other Western regions largely developed their modern commercial and industrial sectors after the start of direct British rule in 1857, when the colonial regime still favoured British business interests but was somewhat more even handed. Therefore, generalizations on the negative attitudes of Indian businesses towards competition and fair trading that resulted from British colonial rule must be appropriately qualified because of the size and complexity of the Indian economy, society and geography (Tripathi 2004). For every tendency towards collusion, rent seeking, state protection, and other forms of cooperation that are anti-competitive, one finds counter tendencies and counter-factual examples of entrepreneurship, innovation, and intense

${ }^{117}$ As illustrated by the Bengal-based jute cartel that was in place up to independence and was dominated by Scottish owned companies (Tripathi and Mehta 1990, p. 110 and Tripathi 2004). 
rivalry involving India's business groups, other informal business arrangements, and other companies $^{118}$.

As a consequence, the pre-colonial attitudes and experiences which favoured competition and fair trading still appear to be part of India's business culture and heritage (Das 2002 and Debroy 2004). Exhibit XIII on the next page summarizes how competition regimes and the business attitudes towards competition and fair trading ${ }^{119}$ have evolved through the period covered in this and later empirical chapters. The dotted arrows from the first three historical boxes to the later periods are designed to indicate how attitudes and interactions of the pre-colonial and colonial periods have influenced and continue to influence business attitudes towards and interactions, conflicts and accommodations with India's competition regimes up to the present day.

\subsection{Conclusions}

The pre-1965 evolution of India's largely informal competition regimes and informal business institutions, and the interactions, conflicts and accommodations between them, are very important to understanding the more recent interactions and accommodations explored in later chapters -- which compared to this chapter give greater attention to the formal components of the competition regime described in Exhibit I. Informal business institutions and arrangements have dominated the country's private business sector and contributed significantly to India's economic and business development for over 2000 years.

\footnotetext{
${ }^{118}$ Regrettably, in perhaps too many cases, entrepreneurship and inter-firm rivalry were played out in the offices of politicians and bureaucrats rather than in markets (see Chapters 6-9). This in fairness is the expected result in a "mixed economy" with extensive government influence, intervention and meddling in business affairs.

${ }^{119}$ This is essentially the informal component/competition culture dimension of competition regimes in Exhibit $I$ in the Introduction.
} 
Exhibit XIII: Evolution of the Competition Regimes and Culture and Their Interactions with and Implications for India's Informal Business Institutions

$$
\text { From the Pre-Colonial Period to the Present Day }
$$

1. Up to About 1800: Appropriate mix of competition, cooperation and fair trading. Result of a weak state, no formal business laws and regulations, high risks and benefits of long-distance trading, highly competitive (pre-industrial revolution) manufacturing, comparatively efficient informal business and banking institutions developed over an extended period, and traditional Indian economic thought.

2. 1800-1920: Rent-seeking, collusion, and other anti-competitive business practices of the British colonial regime (all in the name of "free trade and laissez faire") -which India's informal business institutions accommodated, learned from, adapted to, and when possible either capitalized on or avoided. With greater competition and fair trading in industries and regions with more limited British business involvement.

3. 1920-1947: As captured in the Bombay Plan of 1944, positioning the traditional business groups and other Indian owned businesses to benefit from independence, through better access to and use of state protection and entitlements provided by the colonial regime (learning-by-doing before independence) and lobbying within and financial support to aspects of the independence movement (especially groups/events controlled by Gandhi).

4. 1947 to early 1970s: Design and implementation of business compromise with political, government and bureaucratic elites, which offered business groups and other India-owned businesses fairly significant space within a mixed economy (that was more socialist in rhetoric than reality) and provided benefits of state protection and entitlements (transferred from British businesses) that on balance were greater than the costs of state regulation, interference and meddling.

5. Early 1970s to 1991: Growing recognition that the transactions and other costs and risks of the business compromise were becoming greater, and the benefits smaller and more contingent - leading to business hopes of domestic industrial reforms and maintaining the "status-quo" protections from imports and foreign direct investment (hopes that were realized to a significant degree in the 1980s).

6. Early 1990s to Present Day: Among traditional business groups, grudging acceptance of trade liberalization, market opening and greater competition in domestic markets encouraged in part by new business voices in industries and regions less influenced by, interested in and dependent on the state protections and entitlements of the pre-1991 competition regime; and, through path dependence, influenced by the more procompetition informal business institutions and traditional Indian economic thought of the past. 
The business groups and other informal business institutions and arrangements continue to be a credible, adaptable, reasonably efficient and "remediable" response to the many transaction and other costs, challenges and "institutional voids" associated with India's economic development trajectory. Order-of-magnitude estimates indicate the continuing importance of business groups to the Indian economy; these groups still account for about one-third of India's non-agricultural gross national income (GNI) in the formal economy ${ }^{120}$. Informal business institutions and arrangements have been important at all stages of India's economic and institutional development up to the present day; and were fundamental to India's ascendancy as the global leader in the production, trade and financing of high quality (pre-industrial revolution) manufactured goods from before 1500 to nearly 1800 . Over that period, India's business culture and informal competition regime had the appropriate mix between competition, fair trading and cooperation. This business culture changed markedly under British colonial rule, which introduced state protection and entitlements and anti-competitive business practices into the Indian economy and business culture. However, the impressive economic, business and technological advances enjoyed by the Indian economy since the start of liberalization in the early 1980 s suggest that many of the more positive aspects of the earlier more procompetition business culture of the pre-colonial period may still resonate within important segments of the country's private business sector.

\footnotetext{
${ }^{120}$ The gross revenue (or turnover) of the three largest groups - the Reliance, Birla and Tata Groups currently constitute about $14 \%$ of India's non-agricultural gross national income (GNI) in the formal economy, while the 28 business groups identified in Appendix 7 combined together account for about $27 \%$ of the country's total non-agricultural GNI in the formal economy. Since the appendix lists only some of the business groups now operating in India, the revenue of all business groups and other informal business arrangements combined together likely account for about one-third of the country's non-agricultural gross domestic product in the formal economy. Moreover, when the contributions of state-owned enterprises and other public sector undertakings are removed from the denominator, the contributions of India's business groups to India's non-agricultural GNI in the formal private sector economy would be much higher, likely in excess of $60 \%$.
} 


\section{Chapter 5: India's Competition Regimes and Informal Business Institutions Within the Country's Broader Economic Policy Regimes}

\subsection{Purpose}

This chapter builds on the historical analysis in Chapter 4 in order to assess and compare the broader economic policy discourse and regimes in the 1965-1991 and post 1991 case study periods. India's competition regimes and informal business institutions, and the interactions, conflicts and accommodations between them, are embedded within and influenced by the country's broader economic policy regimes, which have changed significantly over the forty-year period covered by this analysis. Particularly important is India's economic liberalization program, which began in a tentative manner in the early 1980s, and then accelerated after the country's balance of payments crisis in 1991. Post1991 liberalization continues to dominate economic policy discourse, formulation and implementation in India up to the present day ${ }^{121}$.

The following sections in this chapter: (i) assesses the pre-1991 License Raj and compares it to the post-1991 liberalization program, (ii) summarizes the implications of the License Raj for India's economic performance, (iii) analyses India's broader post1991 liberalization program, which is both comprehensive and incomplete, and (iv) investigates the discourse and empirical evidence regarding the design and economic and equity implications of India's post-1991 liberalization.

The chapter concludes with discussions of the implications of the dramatic shifts in India's broader policy environment, and the continuing debates on the post 1991 liberalization program, for the evolution of the country's competition regime and

\footnotetext{
${ }^{121}$ As noted by La Croix et al (2000): "A history of competitive political parties reaching back nearly a century and a tradition of socialist rhetoric extending over more than five decades have made Indian economic restructuring particularly contentious." India's federal system adds to the complexity and contested nature of the country's liberalization program.
} 
informal business institutions, and for the interactions, conflicts and accommodations between them.

\subsection{India's Post Independence License Raj and its Implications Up To 1991}

Exhibit XIV below provides a brief summary and comparison of the three broader economic policy regimes that are relevant to the evolution of India's competition regimes and informal business institutions from 1965 to the present day. India's first competition law was debated and introduced in the last half of the 1960's as an extension to the "License Raj", which was dominated by highly interventionist command-and-control industrial and trade policies that promoted import substitution and self-sufficiency over competition in domestic markets and competitiveness in international markets (GaneshKumar et al 2003, p. 9). In many respects, the policies and instruments of economic planning developed by the British in the 1920s, 1930s and 1940s were simply taken over by the new Indian government after independence (Rothermund 1993, and Anant and Goswami 1995). The regime of "discriminating protectionism" established by the British colonial government in the 1920 s and 1930 s became even more rigid and bureaucratic by means of the rationing controls established by the British colonial regime during the Second World War. Many of these controls were continued and made even more restrictive over the next four and a half decades following the armistice and India's independence (Anant and Goswami 1995, pp. 238-239, and Debroy 2004). Competition in domestic markets was highly regulated - and in a very real sense restricted -- by policies, laws and regulations that strictly controlled the establishment, operations, growth, product lines, product diversification and production locations of non-financial firms (Ganesh-Kumar et al 2003, pp. 16-18). 
Exhibit XIV: Comparison of the Three Broader Economic Policy Regimes

\begin{tabular}{|c|c|c|}
\hline $\begin{array}{l}\text { Policy Regime and } \\
\text { Time Period }\end{array}$ & Major Features of Each Policy Regime & $\begin{array}{l}\text { Implications for Competition, Consumers } \\
\text { and Competitiveness }\end{array}$ \\
\hline $\begin{array}{l}\text { Early 1980s to } \\
1991 . \\
\text { Partial pro- } \\
\text { business industrial } \\
\text { policy reforms. } \\
\text { But limited and }\end{array}$ & $\begin{array}{l}\text { Partial, ad-hoc and at times non-transparent domestic industrial } \\
\text { policy reforms largely designed to benefit existing business } \\
\text { incumbents, not new firms. Including: removal of } 25 \text { industries, } \\
\text { medium-sized firms and some other production units from the } \\
\text { "License Raj". Greater flexibility to larger firms for expansion } \\
\text { and diversification. Removing a large number of items from }\end{array}$ & $\begin{array}{l}\text { Higher private business entry, growth, } \\
\text { investment and profits, leading to higher but } \\
\text { unsustainable economic growth because of } \\
\text { large government deficits. But little benefit to } \\
\text { competition, consumers and competitiveness, } \\
\text { as tariffs and the effective rates of protection }\end{array}$ \\
\hline
\end{tabular}




\begin{tabular}{|c|c|c|}
\hline $\begin{array}{l}\text { Policy Regime and } \\
\text { Time Period }\end{array}$ & Major Features of Each Policy Regime & $\begin{array}{l}\text { Implications for Competition, Consumers } \\
\text { and Competitiveness }\end{array}$ \\
\hline $\begin{array}{l}\text { ineffective trade } \\
\text { policy reforms. }\end{array}$ & quantitative import controls; and incentives to encourage exports. & $\begin{array}{l}\text { increased in many industries. Therefore, } \\
\text { foreign trade as \% of output decreased. }\end{array}$ \\
\hline $\begin{array}{l}\text { From 1991 On. } \\
\text { More fundamental } \\
\text { and } \\
\text { comprehensive but } \\
\text { still gradual and } \\
\text { incomplete pro- } \\
\text { market and pro- } \\
\text { competition } \\
\text { industrial and } \\
\text { trade policy } \\
\text { reforms. } \\
\text { Accelerated } \\
\text { and/or justified by } \\
\text { the } 1991 \text { balance } \\
\text { of payments crisis. }\end{array}$ & $\begin{array}{l}\text { Virtual elimination of the licensing regime. Much lower (but still } \\
\text { relatively high) import duties. Removal of import quotas/ } \\
\text { quantitative restrictions. } \\
\text { Significant reduction of most (formal) foreign investment } \\
\text { restrictions - allowing majority foreign ownership and "automatic } \\
\text { entry" into } 34 \text { industries; and significant devaluation of the Rupee. } \\
\text { Lower taxes and a simpler tax system. Industries reserved for the } \\
\text { state sector decreased from } 18 \text { to 3. Significant financial market } \\
\text { liberalization later in the } 1990 \text { s; and the opening of capital markets } \\
\text { to international portfolio investors. } \\
\text { Removal of MRTPA merger review and of prior approvals for the } \\
\text { "MRTPA monopoly companies". } \\
\text { "Liberation" of the Internet from government control in } 1998 \text {. }\end{array}$ & $\begin{array}{l}\text { Liberalization remains incomplete - the small } \\
\text { firm reservation policies are still largely in } \\
\text { place and reforms in labour market regulation, } \\
\text { bankruptcy law, corporate governance, } \\
\text { infrastructure, health and education have been } \\
\text { modest and/or ineffective. } \\
\text { Nonetheless, business entry and innovation } \\
\text { have accelerated, imports and exports are } \\
\text { much higher, consumer choice is much } \\
\text { greater, many markets are more contestable, } \\
\text { and competition and competitiveness have } \\
\text { been enhanced. } \\
\text { As evidenced by India's strong economic } \\
\text { growth and surging exports at record levels } \\
\text { during the current decade. }\end{array}$ \\
\hline
\end{tabular}


The major legislation that comprised the "License Raj" was the Industries (Development and Regulation) Act of 1951, the Industrial Policy Resolutions of 1956 and 1959, the Monopolies and Restrictive Trade Practices Act (MRTPA) of 1969, and the Foreign Exchange Regulation Act (FERA) of 1974. By the early 1970s when the License Raj reached its pinnacle, an Indian business group or larger company planning to establish a new facility, expand its existing facility or diversify its product line would be required to apply for and receive approvals from a large number of Indian ministries before receiving the industrial license required to proceed with its plans.

Approvals could be required for the following purposes from various government agencies. A partial listing would include approvals for: capital goods imports -- from the Chief Controller of Imports and Exports under the Ministry of Commerce, subject to approval from the Ministry of Industry; a proposal for a collaboration with a foreign company -- from the Ministries of Finance and Industry; access to the capital market -from the Controller of Capital Issues in the Ministry of Finance; and, the monopoly and concentration aspects under the MRTPA -- from the Department of Company Law and Company Affairs. In addition, any foreign ownership and foreign exchange aspects would need to be approved under the Foreign Exchange Regulation Act - from the Department of Company Affairs and the Reserve Bank of India. Only after these and likely many other approvals had been received could the company submit its letter of intent for the preparation and receipt of an industrial capacity license (Anant and Goswami 1995, p. 240).

The five major objectives of the industrial licensing regime were to: (i) channel investment into priority industries as outlined in India's development plans; (ii) avoid the 
growth of monopolies; (iii) encourage the dispersal of industries to backward regions in order to promote more balanced regional development; (iv) encourage medium and small industries and prevent "unhealthy competition" between large-scale and small-scale enterprises; and (v) promote the optimum use of scarce foreign exchange resources (Datt 1971).

Each regulatory approval step had a public purpose. However, the License Raj, which layered one complex regulatory regime on top of another, provided significant opportunities for regulation shopping, for corruption and rent seeking to both public and private sector officials, and to politically well connected business groups and other large firms to manipulate the licensing regime to prevent entry by potentially more efficient business rivals, both foreign and domestic (Cheung 1996). The consequence was higher production costs and in particular higher transactions costs for India's business groups and other larger companies. Only the smallest companies were exempt from these licensing requirements.

As well, most public utilities and basic and strategic industries were exclusively reserved for the state to own and operate, while the Monopolies and Restrictive Trade Practices Act (MRTPA) of 1969 stipulated that all firms over a certain comparatively small size threshold were permitted to enter only selected industries and then only on a case by case basis, with each case to be reviewed by the MRTP Commission.

Therefore, after 1969, all investment proposals by business groups and other larger firms deemed to be "MRTPA monopoly companies" required not only industrial licenses and related permits from several government agencies, but as well needed separate approvals from the Department of Company Affairs, the government agency responsible 
for administering the MRTPA. Just as the MRTPA of 1969 regulated and controlled market entry, expansion and product diversification of India's business groups and other larger firms, the Foreign Exchange Regulation Act (FERA) of 1973 provided a similar regulatory regime for foreign joint ventures ${ }^{122}$. In this manner, the GOI established a form of competition (or "anti-competition") policy that encompassed quite formidable government imposed barriers to entry. These restrictions were particularly directed at foreign firms and domestic business groups and other larger companies. However, they affected to some degree all but the smallest Indian private firms, which enjoyed (and continue to enjoy) special privileges, protections, access to credit and other incentives under the small enterprise reservation system (Anant and Goswami 1995, pp. 240 and 241).

\subsection{Implications of the License Raj for Domestic Competition and International Competitiveness Before and After 1991}

The impact of the "License Raj" on economic concentration, market power, competition in domestic markets, and India's competitiveness in foreign markets was debated throughout the pre-1991 period (Chapter 6). Many analysts addressed why Indian industrial policy from 1947 to 1991 was less successful than similar policies in South Korea ${ }^{123}$ and other East Asian "success stories" in promoting competitiveness,

\footnotetext{
122 The 1973 FERA: (i) provided the regulatory framework for controlling the commercial and manufacturing activities of foreign companies in India, (ii) specified the list of industries where foreign firms would be allowed to operate, (iii) required that foreign ownership be limited to $40 \%$ of company equity -- because of this ownership restriction, some of the largest multinationals with wholly foreign owned subsidiaries, such as Coca Cola and IBM, decided to leave India, only to return a decade or so later in response to liberalization and higher economic growth and consumer spending; and (iv) stipulated that all new investments and substantial expansions by foreign firms required separate approval from the Department of Company Affairs.

${ }^{123}$ South Korea was often used as a reference point for Indian writers, because the two countries were at similar levels of economic, export and institutional development in the mid-1960s (Chibber 2003:2 and Morris 2005). Now, the Peoples Republic of China provides the benchmark for critics of India's post-1991
} 
export performance, innovation and higher economic growth and per capita incomes. One interpretation is that industrial policy in India was less successful than in South Korea, and in other East Asian economies including latterly China, because the "carrot" of state protection and support in India was not matched by the "stick" of forcing company beneficiaries to meet export, productivity, innovation and other standards that were established and enforced by the state. These "sticks" in other countries forced companies quite early in the industrial development process to export and thus face competition from, and to learn from, better established foreign suppliers especially from the OECD countries (Chibber 2003:2, Mahmood and Singh 2003, and the World Bank 1993).

South Korean success, which closely followed the earlier Japanese model (Porter 1990), was the combined result of industrial policy targeting, technical and financial support, temporary protection from imports and FDI, and aggressive competition and competitiveness policies that encouraged strong competition among South Korea's large and diversified business groups and forced the business groups and other South Korean companies to become globally competitive at a comparatively early stage of the country's development (Amsden and Singh, 1994). Other Asian tigers such as Malaysia, Thailand, Taiwan, Hong Kong, Singapore and more recently the Peoples Republic of China have had similar competition-driven export oriented policies and broadly similar export and economic development success.

Indian industrial policy until the 1991 liberalization program therefore had all of the "carrots" of state support, entitlements and protection from imports and entry by

liberalization and growth performance (Khanna 2007, Lemoine and Unal-Kesenci (2007), Morris 2005, Khan 2004, Lewis 2004, Srinivasan 2004, Henley 2004, and Huang and Khanna 2003). 
potentially more efficient domestic and foreign investors, but none of the "sticks" of domestic competition and of innovation and export performance standards. Furthermore, the export and innovation standards that were established on a case-by-case basis were often not seriously enforced by the Indian government (Swaminathan 1992). Domesticled growth, self-sufficiency, export pessimism and limited integration into the global market meant that the disciplines, incentives information and learning that competition provides for product prices and quality, efficiency, cost reduction, productivity, and innovation, ${ }^{124}$ were largely absent from the Indian economy until after 1991 (Rothermund 1993, Chapters 12-14, Chibber 2003:1 and 2003:2, Srinivasan 2003, and Goldar 1986).

Larger firms and business groups had little interest in or incentive to export because of their preferred access to government entitlements and the monopoly and oligopoly profits generated by their sales to highly protected and concentrated domestic markets. In fact, in many industries, small and medium sized industries were more active in export markets than the business groups and other larger firms (Patibandla 1995 and 1998) ${ }^{125}$. India therefore became a very minor player in global markets at a time when international trade was expanding rapidly. India's share of world exports fell from $2.2 \%$ in 1948 to a low of $0.4 \%$ in the early 1980 s, rising slightly to $0.5 \%$ in 1990 (Srinivasan 2003 , p. 4$)^{126}$. The License Raj as well discouraged technological and organizational innovation, leading to the adoption of inefficient and inappropriate technologies and product designs in

\footnotetext{
${ }^{124}$ That in other Asian countries resulted from foreign direct investment (FDI) and from competing in domestic markets with other domestic suppliers and in foreign markets against stronger international competitors.

${ }^{125}$ The literature and the interviews conducted in 2006 indicated that independent small and medium sized enterprises are often still more export-oriented than many of the traditional business groups and other larger enterprises (see Chapters 7 and 8).

${ }^{126}$ Based on World Bank data (World Bank 2007:2), India's contribution to global exports was about $1 \%$ in 2006, which represents a sharp improvement over the 1990 figure but is still well below China's contribution of $8 \%$.
} 
India's engineering goods and other industries. This further held back export performance, innovation and technological change (see Frankena, 1971, Desai et al 1999 and Sen 2002).

Another major consequence of the License Raj before 1991 was that India became an even higher transaction cost economy, which for many firms and industries, more than offset the production cost advantages provided by low-cost labour, raw materials and other inputs. The more successful Indian companies and business groups were those that were able to minimize their transactions costs and to generate the greatest benefits from their transaction "investments" with government, financial intermediaries, and affiliated and other businesses. Lower prices and production costs, greater efficiency, technology creation and adoption, and higher quality more innovative products, were much less important to business group and private enterprise success. Furthermore, because of institutional inertia and the length of the investment cycle, the high transaction costs that resulted from the License Raj distorted markets and depressed business group and other companies' competitiveness well beyond 1991. Investments made in the 1970s and 1980s to economize on transactions costs and capitalize on the "License Raj" have remained in place long after the start of liberalization.

Concerns about the international competitiveness and investment performance of India's business groups and other larger private sector firms only started to resonate among Indian political, government, academic and business elites in the late 1970s. Some analysts argue that import substitution policies up to 1965 had been quite successful in building and diversifying India's manufacturing base, and therefore had moved the Indian economy closer to the global technological frontier compared with 
before independence (Aghion and Howitt 2006). They contend, and the current author concurs that, if the "sticks" of domestic competition and export performance standards had been applied at that time, India's growth performance through the late sixties and seventies would have been more impressive (Denoon 1998, Mukherji 2000, Chibber 2003:2 and Morris 2005). Instead, the Government of India continued to apply an economic development model driven by import substitution, self-sufficiency and export pessimism for another nearly two decades. As a result, India fell further behind its competitors and moved further away from the technological frontier.

\subsection{Liberalization and Trade Reforms Which Started in the 1980s and Accelerated After $1991^{127}$}

\footnotetext{
${ }^{127}$ The starting point for liberalization in India continues to be contested. Some scholars focus on 1991 and ignore previous developments. Some stress the quite transparent but highly selective 1985 reforms of the Rajiv Gandhi government. And some scholars believe that the reform process began with the policy rhetoric of the Indira Gandhi Government of 1980 that stressed private investment and business growth over redistribution, and implemented "under-the-table" reforms on a selective and highly politicized basis (Rodrik and Subramanian 2005), what a few critics have called "economic reform by stealth" (Pani 2006).
}

The improved policy environment in the early 1980s led to stronger economic and business growth and higher private investment compared to the previous decade (see e.g. Rodrik and Subramanian 2005). Furthermore, econometric evidence indicates that firms and industries which were under the License Raj in previous decades and then experienced de-licensing and greater domestic competition in the 1980s registered greater productivity growth both in the 1980s and in the 1990s when selective domestic reforms were augmented with more extensive domestic and external reforms (Sharma 2006). The more selective 1980s reforms helped to prepare the affected firms and industries for, and added to the effectiveness of, the more comprehensive liberalization program from 1991 on (Sharma 2006, pp. 33-34).

Nevertheless, the later empirical chapters in this dissertation - while recognizing the role and importance of the pre-1991 reforms -- continue to use 1991 as the base year for the reform process. This is because the post-1991 balance of payments crisis reforms: (i) were more comprehensive and fundamental, (ii) were more pro-market and pro-competition compared to the earlier reforms that involved selective domestic industrial policy reforms and were more pro-business than pro-market, (iii) were seen as irreversible by government and in time by the bureaucracy, business, labour and other key communities and elites -- the government's commitment to reform was perceived as credible by the private business sector and other elites by the mid-1990s and this credible commitment has survived many changes in the national government over this period., (iv) represented an important departure in India's political economy discourse in favour of markets, competition, business groups and other larger companies, and the development of national champions in the private business sector (Panagariya 2004), and (v) resulted in economic growth that is less fragile and more sustainable over the longer term as evidenced by the Indian economy's strong GDP gains in recent years (Panagariya 2003 and Chapter 5). These issues are further explored in the rest of this Chapter and the empirical chapters to follow. 
The Indian economic development model came under extensive scrutiny and criticism from both domestic and foreign commentators starting in the later 1970s. In response, liberalization began to take place in a modest and ad-hoc manner in the early to mid1980 s, with the reform of domestic business entry restrictions. This reform involved the gradual relaxation of the extensive, complex and dysfunctional system of industrial investment licensing that had been in force since the 1950s (Bhattacharjea 2003:2, pp. 203-204). These relatively small reforms led to quite significant improvements in India's private investment and economic performance through the 1980s (Rodrik 2001, and Rodrik and Subramanian 2005) ${ }^{128}$.

India's domestic and external liberalization and market opening program accelerated quite dramatically during the 1990 s after the 1991 balance of payments crisis. While much remains to be done, the industrial licensing regime, which was the dominant feature of the Indian economic development model for nearly four decades, has been virtually eliminated, and other government-imposed domestic entry barriers are much lower today compared with the early 1980s. Compared with the reform of the industrial licensing regime, external trade liberalization through the 1990s was implemented at a somewhat slower pace with some back-tracking because of lobbying from business interests and their supporters within government (Bhattacharjea 2003:2, p. 205).

\footnotetext{
${ }^{128}$ This led to debates on how relatively small policy, regulatory and institutional reforms can have quite major investment and growth impacts. Rodrik (2001, p. 9) states as follows. "Determinants of development such as institutions and geography change slowly or hardly at all. Yet countries like China and India have gone through remarkable transformations during the last two decades in their economic performance, while many others have experienced sharp deteriorations.
}

This suggests that modest changes in country specific circumstances (policies and institutional arrangements), often interacting with the external environment, can produce discontinuous changes in economic performance, which in turn set off virtuous or vicious cycles. In-depth country studies can highlight these important interactions in ways that cross-country empirics cannot". One reason why small changes in policy led to quite large increases in investment and economic growth in the 1980s in India is the country's long history of business development, international trade, entrepreneurship, fair trading, competition and functional informal business institutions and arrangements (Tripathi 2004). 
Import licensing for intermediate and capital goods was eliminated in stages during the 1980s and 1990s. However, some trade barrier reductions were reversed during the $1990 \mathrm{~s}^{129}$; the substantial real depreciation of the Indian rupee from 1985 to 1993 (which continued through the 1990s and the first years of the current decade) dampened import competition; and Indian tariffs up to the present day continue to be higher than the levels in most other developing countries. India as well is now one of the most active users in the global economy of anti-dumping and other trade remedy laws, which further reduces import competition and prevents domestic industry from feeling the full effects of stronger foreign competition that would otherwise result from external liberalization. Moreover, while the stringent quantitative restrictions on consumer goods imports were first relaxed and then abolished in $2001^{130}$, the high tariffs and non-tariff barriers that remain in place on consumer goods, when combined with significant reductions in the tariffs on intermediate inputs, mean that the effective protection afforded to domestic producers of most consumer goods is still very high.

Despite the gradual "two-steps forward one-step back" approach in the 1990s, external trade liberalization has still made considerable progress, with some acceleration during the current decade as India implemented its WTO obligations and thus "locked in" the trade policy reforms of the 1990 s through international treaty ${ }^{131}$. The result in the

\footnotetext{
${ }^{129}$ For example, while tariffs declined significantly from an imported weighted average of $73 \%$ in 1991-92 to $25 \%$ in 1996-97, this percentage moved upward again to $35 \%$ in 2001-02 (Srinivasan 2003, p. 4).

${ }^{130}$ In 2001, India lost its WTO case for retaining these quantitative restrictions because of balance of payments concerns.

${ }^{131}$ A good measure of the height of tariff barriers is the effective rate of protection provided to the Indian manufacturing sector. These rates (in percentage terms) have been estimated as follows (Balakrishnan et al 2006, p. 56). The table indicates significant decreases but still high levels particularly in consumer goods products, where many of the business groups and other larger Indian private companies are very active. Continuing high effective rates of protection, when combined with the devaluation of the Rupee, suggests that business groups and other suppliers in India's domestic markets still enjoy quite high levels of protection from imports despite the important trade policy reforms under the 1991 liberalization program.
} 
current decade is somewhat more contestable Indian domestic markets and greater availability of capital and consumer goods for many businesses and consumers. Nonetheless, the high tariffs and even higher levels of effective protection on many consumer goods significantly diminish competition in domestic consumer goods markets, including markets important to lower income rural and urban consumers. This will pose major challenges for India's new competition regime and its future interactions with the country's traditional business groups that are the dominant suppliers in many consumer goods markets.

\subsection{Implications of Liberalization for Economic Growth, Equity and the Quality of Life}

India's liberalization and market opening program is associated in the economic literature and business media with a quite large number of positive outcomes. The domestic benefits include: significantly higher economic growth rates particularly during the current decade; higher living standards for many Indian households; an expanding Indian middle (or consuming) class that now numbers well over a hundred million and could approach 200 million in the near future according to some forecasts; and a somewhat more integrated and less fragmented domestic economy ${ }^{132}$.

\begin{tabular}{|l|l|l|l|}
\hline & $\mathbf{1 9 8 6 - 1 9 9 0}$ & $\mathbf{1 9 9 1 - 1 9 9 5}$ & $\mathbf{1 9 9 6 - 2 0 0 0}$ \\
\hline Intermediate Goods & $149.2 \%$ & $87.6 \%$ & $40.1 \%$ \\
\hline Capital Goods & $78.5 \%$ & $54.2 \%$ & $33.3 \%$ \\
\hline Consumer Goods & $111.6 \%$ & $80.6 \%$ & $48.2 \%$ \\
\hline
\end{tabular}

\footnotetext{
${ }^{132}$ Liberalization, market opening, the major but still incomplete improvements in transportation, telecommunications and other infrastructure sectors, and increases in consumer purchasing power are associated with significant declines in consumer price differences in major commodities across Indian states and major urban centers between 1994 and 2004. While full integration (based on the "law of one price" throughout the national market) has not been achieved and may not be possible given the geographic size and complexity of the Indian economy, spatial market integration has improved significantly since the start of liberalization (Virmani and Mittal 2006).
} 
Liberalization on the external side is associated with the creation of a small but rapidly expanding and globally competitive high technology sector based on information technology, computer software, and biotechnology including bio-pharmaceuticals; and a comparatively more open Indian economy for foreign $\operatorname{trade}^{133}$ and foreign direct investment, which has led to somewhat greater integration into the global economy, some improvements in the international competitiveness of Indian produced manufactured goods, and improvements in India's trade performance and ability to attract foreign direct investment, particularly during the current decade (Ganesh-Kumar et al, 2003 and Dholakia 2002). A number of sources emphasize the emergence of Indian corporate brand names, leaders and managers (Tata, Birla, Ambani/Reliance, Mahindra, Bajaj, Maruti, Infosys, Wipro, Mittal, Hindustan Lever etc.) that are receiving greater global attention and respect each year.

Liberalization as well is associated with increased business entry first by domestic companies and then by foreign firms, some reductions in industry concentration and price-cost margins, and more competitive domestic markets and efficient enterprises (Krishna and Mitra 1998, Sen and Chand 1999, Goldar and Aggarwal 2004), and Kambhampati and Parikh 2003) ${ }^{134}$. While R\&D activity in general and average R\&D spending by firms have declined since 1991, increased competition as a result of liberalization has forced many local Indian enterprises to rationalize their R\&D activity and to make this activity more cost-effective (Kumar and Aggarwal, 2005).

\footnotetext{
${ }^{133}$ India's foreign trade to GDP ratio has more than doubled from $15 \%$ in 1991 to better than $30 \%$ at the present time (Varshney 2007, p. 2).

${ }^{134}$ However, it is noted later that the critics of India's liberalization program contend that the competition and consumer benefits are less than predicted and promised by economic theory and liberalization supporters in government, and the business and academic communities.
} 
The Indian academic and policy literatures have especially emphasized the impacts of external liberalization and domestic industrial policy reforms on the country's growth performance and productivity. Often, this research involves comparisons between the growth performance of the Indian economy before and after the start of economic reforms in 1985 (Dholakia 2002). India's GDP growth rate in real terms averaged about $3.6 \%$ per annum from 1950 to 1985 , whereas the GDP growth rate from 1985 to 2008 averaged $6.2 \%$ per annum.

Two of the more important reasons for higher growth after 1985 are: higher growth in labour and total factor productivity (TFP) in the non-agricultural private sector (Ramaswamy 1999 and Hulten and Srinivasan $(1999)^{135}$; and the significant impacts of liberalization on equipment investment by private firms, which responded in a positive manner to both lower capital goods prices and to the financial deepening that resulted from the incomplete but still quite significant financial market reforms that have been implemented since 1991 (Sen 2002).

Based on the field mission interviews and other sources, an important indicator of the progress and impacts of liberalization on the Indian economy was the economy's ability to absorb the 2005 to mid-year 2008 shock of record high oil, gas and other energy prices. India's continuing high growth and strong export performance over the past four years, and the modest impact of the oil price shock on India's trade balance, can be compared with the three earlier oil crises at the start of the 1970s, 1980s and 1990s.

\footnotetext{
${ }^{135}$ Higher TFP growth in the non-agricultural private sector, which implies some reduction in the high incremental capital-output ratios that India suffered from since independence (see Debroy 2004) is consistent with the anticipated outcomes from liberalization based on economic theory. These would include: (i) improved and less expensive access to imported capital goods, foreign technology and foreign capital, and (ii) increased competition in the domestic market resulting from less import protection including lower tariffs and the relaxation of barriers to entry faced by both domestic and foreign firms (Dholakia 2002).
} 
These three earlier oil price shocks had severe impacts on India's external account and economic performance and forced India to go to the IMF for loans. The Indian economy now has more resilience, flexibility, depth and room to manoeuvre, and therefore is better able to absorb major external shocks.

Some studies however have emphasized the ambiguous effects of liberalization on import and export intensity and export performance. Some business groups and other companies have not yet made systematic efforts to adapt to imports in domestic markets and to respond to greater export opportunities in foreign markets. External reforms started later and progressed more slowly than the industrial policy reforms, and therefore some business groups may have believed up to the end of the 1990s that the Government of India was more deeply committed to domestic industrial reforms than to external reforms and liberalization (Driffield and Kambhampati 2003, and Ramaswamy 2006).

Therefore, while India's export performance has improved significantly particularly in the current decade ${ }^{136}$, this is largely the result of the country's traditional export strengths, its competitive advantages in information technology (IT), computer software and related professional, technical and R\&D-based services, and the devaluation of the Indian Rupee ${ }^{137}$ which especially benefited India's traditional exporters. In contrast,

\footnotetext{
${ }^{136}$ Over the five-year period from 2003-2007, export growth has averaged about $20 \%$ per year or more than double the rate of GDP growth, based on US dollar data from the Indian Ministry of Commerce website. The high growth export sectors include gems and jewellery, precious stones, diamonds, information technology (IT) and related services (business process outsourcing), computer software, pharmaceuticals, chemicals, spices, leather and leather products, and textiles and apparel.

Export growth is based largely on high growth in the Asia Pacific economy and the establishment of the ASEAN trading group. Japan also continues to be an important market, as does the United States particularly for IT/software. As well, export sales to China have increased dramatically during the current decade from very low levels. Asia is passing the EU as a major market for India's exporters, as EU enlargement has shifted the EU's focus to its new members.

${ }^{137}$ The value of the Indian Rupee over the past 17 years has declined from 17 to the dollar in the early 1990 s and the 21-28 range during the managed exchange rate period of the mid to late 1990s, to Rs 44-46 in 2005-2007. The current value (early December 2008) is Rs. 49.5 to the US dollar (compared with 39.8 a
} 
while some business groups are increasing their export sales, the traditional manufacturers by and large continue to emphasize the domestic market in their corporate strategies, and participate in other country markets mainly through direct investment, both greenfield and acquisition, rather than through export sales (Kochhar et al 2006).

One issue that continues to be debated in India's liberalization discourse is whether external trade liberalization or domestic industrial policy reforms have progressed further and had a greater impact on Indian businesses, markets, competition, consumers and economic performance ${ }^{138}$. The research participants and other sources indicated that external liberalization and domestic policy reforms are both incomplete "works in progress". While significant progress has been made since the 1980s, the limitations and gaps in each work together ${ }^{139}$ to: add to production and transaction costs and thus make Indian business groups and other large companies less efficient, productive and competitive; make Indian markets less competitive and "contestable"; and, provide continuing opportunities for well-established and well-connected business groups and other larger companies to strengthen their market positions and discourage entry by potentially more efficient domestic and foreign competitors.

year earlier see the Economist, 2008:2, p. 98). The nominal exchange rate when compared with India's purchasing power parity continues to provide India's exporters with an important competitive advantage.

138 The business lobby and business supporters in the academic community and business media have argued since 1991 that trade liberalization has gone further and is "locked in" because of India's WTO obligations. Trade and competition specialists in the academic community and research institutes often adopt the opposite stance - by focusing on the growing use of trade remedy law, the impacts of Rupee devaluation, rates of effective protection which often are higher than nominal protection rates, and continuing "soft" constraints to foreign direct investment (Henley 2004).

${ }^{139}$ As footnoted earlier, effective rates of protection are lower for intermediate and capital goods compared with consumer goods. This benefits current and potential manufacturers of consumer goods. On the other hand, the remaining domestic regulatory constraints on other key intermediate inputs - land, labour, financial services etc. - hurt these and other manufacturers as well as companies considering entry into industrial markets for intermediate and final consumer goods. 


\subsection{Summary of the Current Discourse on the Benefits and Costs of Liberalization}

Despite India's economic progress over the past two and a half decades, the post1991 liberalization program has been criticized by many commentators for being too modest, cautious and half-hearted; and by other critics for being too ambitious and for providing too much benefit to some businesses, industries and Indian states, and too little benefit to most Indian workers, households, consumers, the urban and rural poor, and the interior and other less developed provinces especially in East India. These debates are summarized in this section because of their significant implications for future interactions, conflicts and accommodations between the competition regime and informal business institutions (see Chapter 8).

\subsubsection{Arguments that Liberalization Has Been Too Modest, Cautious and Half- Hearted}

On the first side of the debate are the critics who argue that the liberalization program has been hesitant, reluctant, uneven and incomplete ${ }^{140}$. These critics state that, while there have been quite extensive reforms in the areas of trade, investment, and industrial licensing, there has been little or no change in bankruptcy, labour market and land use legislation. Reforms and progress in agriculture and the rural economy, and in the health and education sectors have also been very limited (Khanna 2007, Srinivasan 2003, Chand 2005 and 2006 and Debroy $2004^{141}$ ). And while reforms in the financial,

\footnotetext{
${ }^{140}$ See for example Lewis (2004, Chapter 8), Das (2002), Ganesh-Kumar et al (2003), Khanna and Palepu (1999), Mehta (2005 and 2006), Debroy (2004), Srinivasan (2003), Ahluwalia (2002) and Khanna (2007).

${ }^{141}$ For example, under the Industrial Disputes Act and the Act's Chapter V-B, a company in the modern (or organized/formal) sector cannot restructure, downsize, layoff some of its work force, or shut down without the permission of the government. For obvious political reasons, government permission is often not granted (although some "under-the-table" relaxation and flexibility reportedly is taking place -- see Chapter 8). As a consequence, India continues to have a large number of "sick enterprises" that are financially insolvent but continue to operate.
} 
telecommunications, energy and other previously regulated sectors have been quite significant, they fall short of what is required to support higher private business investment and sustainable economic growth (Mehta 2006, Kambhampati 2006, Pentecost and Moore 2006, Farrell and Lund 2006). Significant distortions remain in many intermediate input and final product markets (Lewis 2004 and Anant and Goswami 1995).

Some aspects of India's gradual and incomplete liberalization are particularly important to the analysis in the later evidence chapters. While government imposed entry barriers are much lower, the barriers to exit remain very high - which impedes entry by more efficient and better managed companies. Financial sector reform has made some progress, leading to somewhat greater competition and choice, and lower costs of intermediation (Bhaduri 2005). However, critics argue that more is needed to complete financial sector reform. India's capital account has not been fully liberalized (Kletzer 2004). Significant restrictions remain in some financial sectors such as in the insurance industry where major reforms began only after 2000. India's commercial and development banks ${ }^{142}$, which continue to be largely government owned, do not conduct appropriate due diligence before lending and effective monitoring of the financial performance of their customers after lending (Khanna and Palepu 1999, p. 277). India's equity markets require further development and modernization (Banerjee etc. 2003).

In March 2001, the number of sick enterprises that had obtained loans from the scheduled commercial banks was 252,947 , of which 249,630 belonged to small-scale industry. The remaining 3,317 sick enterprises of larger size can be further divided as follows: private sector $-2,942$, public sector undertakings (PSUs) -255 , joint sector - 106, and cooperative units - 14 (Debroy 2004, pp. 172 and 178). Later chapters will explore the importance of rapid and relatively inexpensive exit to strong market competition and inter-firm rivalry.

${ }^{142}$ These are called development finance institutions in India (Ahluwalia 2002, p. 86, and Farrell and Lund 2006). 
Privatization in both the financial and non-financial sectors, and efforts to open up the infrastructure sectors to private investment, management and operation through e.g. public-private partnerships, have been tentative and have lost momentum in the current decade, with few major successes (Business Standard 2007). At the start of the current decade, state-owned companies still accounted for about $35 \%$ of industrial value added, $43 \%$ of the country's capital stock and $15 \%$ of its non-agricultural employment (Ahluwalia 2002, p. 83; McKinsey \& Company, 2001) ${ }^{143}$. Foreign investment rules have been reformed considerably, but foreign investment review processes are still in place, adding to delays and transactions costs and discouraging some foreign investors. Furthermore, FDI is still prohibited from entering certain key sectors such as the retail sector, which in other countries has played a key role in promoting competition, lower prices, greater consumer choice, and higher product quality among consumer goods manufacturers (Lewis 2004). While foreign direct investment (FDI) entering India has expanded many times over since 1991, India's recent inward FDI is still much lower than the amounts entering China ${ }^{144}$.

\footnotetext{
${ }^{143}$ The 2006 field mission interviews indicated that the government had lost interest in privatization since about 2000 , and therefore the role of state-owned enterprises in the Indian economy has likely declined very little during the current decade.

144 UNCTAD's World Investment Reports for 2007 and 2008 outlined that, in 2006 and 2007, the ChinaIndia gap for inward FDI has closed considerably. In 2006, FDI into China was at \$US 73 billion compared to \$US 72 billion in 2005, while FDI into India had increased quite dramatically from \$US 7.6 billion in 2005 to \$US 19.7 billion in 2006 (which was approximately equivalent to the combined inbound FDI of the previous three years - UNCTD 2007, p. xviii). The inward FDI figures for 2007 are \$US 84 billion for China and 23 billion for India.

Preliminary estimates from another source indicate that FDI into India was estimated at about \$US 25 billion in 2007-08, and is projected to further increase to \$US 35 billion in 2008-09 (IBEF 2008). One unanswered question is whether the 2008 and 2009 inflows will in fact be much lower because of slower global economic growth and the very real possibility of a serious global economic recession as of December 2008, given the recent news that the American economy technically has been in recession for a year.
} 
Government bureaucracies remain too large, influential, complicated, centralized and too focused on process rather than outcomes (Das 2002, p. 284); and employment in government owned commercial undertakings is still at very high levels (Debroy $2004^{145}$ ). Government fiscal reform has barely started and government fiscal discipline remains problematic at all government levels (Varshney 2007). The result is that government subsidies and other current expenditures, government deficits and debt are still too high; unproductive current expenditures are limiting badly needed government investments in infrastructure services, health, education, other public goods, and the agricultural and rural sectors; and large government borrowings are crowding out private business investment (Ahluwalia (2002).

Improvements in the investment climate are uneven across Indian states. Greater advances have occurred in some of the already more industrialized, developed and prosperous states such as Maharashtra, Gujarat, Karnataka, Tamil Nadu and Andhra

\footnotetext{
${ }^{145}$ Encarnation (1989, especially Chapters 1 and 2), provides an excellent summary of the expanding role of the Indian state in the country's economy from the early 1960s to the late 1980s, as a central planner, regulator of domestic and foreign owned private businesses, an employer, an investor, owner and manager of key enterprises and other public sector undertakings (PSUs), and as a provider of debt and equity financing to private enterprise through the state-owned commercial banks and development finance institutions. In addition, his treatment of state-private business relations, bargaining, transactions and interactions are quite similar to the approach applied in this dissertation.

Debroy (2004), Lewis (2004), and other critics of India's liberalization program emphasize that the Indian state is still heavily involved in the country's economy, and that the state's economic role has declined comparatively little despite liberalization. In the early years of the current decade, central government employment was at 3.5 million, and this figure had changed very little over the previous decade despite liberalization and proposals for government downsizing from commissions and politicians (Debroy 2004, p. 155).

At the same time, there were 240 central government public sector undertakings (or PSUs - called stateowned enterprises in China and other transition economies), and an additional 1,000 PSUs were owned by the Indian states. These PSUs employed about six million people. Therefore, government including PSUs account for about 3\% of India's total employed work force and better than one-third of employment in the country's organized sector, since the organized sector constitutes only $8 \%$ of India's total work force (Debroy 2004, pp. 160-170 and 179). Less than 50\% of these Indian PSUs are reported to be profitable and this figure likely would be even lower if all PSUs published proper financial accounts. The current evidence is that, despite liberalization, India's business groups and state-owned enterprises make roughly similar contributions to employment, gross output, and assets in India's formal sector.
} 
Pradesh. These regional states have comparatively more pro-growth formal and informal institutions and are operating closer to their technological frontiers compared with less developed states such as Uttar Pradesh, Bihar, Orissa and West Bengal (Ahluwalia 2002, pp. 72-73, Aghion et al, 2003, 2005:1, and 2005:2, and Sinha 2005:1).

Growth has also become significantly more uneven across the major sectors. During the 1990s, the tertiary sector recorded the highest growth in GDP closely followed by the secondary sector. In contrast, growth in agricultural GDP, production and yields was much lower during the 1990 s compared with the previous decade. Slower agricultural growth since liberalization is the result in part of reduced public investment in the farm and rural sectors. In addition, higher farm prices and the hoped for improvements in access to foreign markets as a result of the Uruguay Round have not yet had a significantly positive impact on farm production and incomes (Bhalla 2001, p. 15) ${ }^{146}$.

Because final product markets have been deregulated more than key intermediate markets for e.g. labour, land, financial services, and infrastructure services ${ }^{147}$ and India continues to be a high transaction cost economy particularly for intermediate markets and

\footnotetext{
${ }^{146}$ Varshney (2007 brings an interesting political economy perspective to why the Indian liberalization program has been gradual and is still incomplete. He makes a distinction between elite and mass politics. Surveys conducted in the mid-1990s indicated that comparatively few people were aware of the 1991 liberalization program, indicating that these industrial and external trade policy reforms were mainly of interest to India's political, bureaucratic and private business elites.

In contrast, reforms and progress have been much more limited and in some cases non-existent in: the agricultural sector, small-scale industry, fiscal policy, and government downsizing; the privatization of state owned enterprises; and, in the modernization of e.g. land, labour, factory inspection, and bankruptcy laws.

Deeper reforms in these areas are more likely to raise broader political concerns; directly affect more people; have negative impacts at least initially; and thus, result in mass opposition among industrial workers, farmers and voters and their spokespeople and advocates in the labour movement, civil society and among left-leaning and more populist political parties. It is argued in Chapters 7 and 8 that debates on competition policy and law since 1995 have also mainly involved elites located for the most part in northern India.

${ }^{147}$ See e.g. Fisman and Khanna, 2004, Lewis 2004, Farrell and Lund 2006, and International Monetary Fund 2008:1 and 2008:2.
} 
inputs ${ }^{148}$, the intermediation role played by India's traditional business groups have continued to provide value to the quasi-independent companies that comprise each business group (Khanna and Palepu 1999). Reserving certain sectors for smaller firms that cannot grow past a certain size threshold continues to hinder India's manufacturing and export performance (Ganesh-Kumar et al 2003, chapters four and five ${ }^{149}$ ), and is likely the major reason why light industries never experienced "take-off" in India compared with other Asian countries such as Japan, Hong Kong, Taiwan, South Korea and of course most recently China.

Incomplete liberalization is resulting in both under-regulation of competition and in some other policy fields which increases market distortions and promotes the growth of highly protected and monopolistic private entities; and, over-regulation in other fields that result in the continuation of high transactions and production $\operatorname{costs}^{150}$. Competition, higher productivity and innovation in information technology, biotechnology, pharmaceuticals and other high-growth technology-intensive industries represent important Indian accomplishments and building-blocks for the future, but the critics emphasize that the new economy sectors will never account for more than a small portion of aggregate employment and production in India's total economy.

\subsubsection{Unflattering Comparisons with China}

For India's domestic and foreign critics, hanging like a dark cloud over India's economic performance is the reality that, even with economic growth rates that averaged

\footnotetext{
${ }^{148}$ In addition to the high costs of transacting with government, which are emphasized in other parts of this analysis. The reasons for and empirical evidence on why India remains a high transactions cost economy are provided in section 3.4 .

${ }^{149}$ See as well Government of India, the "Raghavan Committee" Report, 2000.

${ }^{150}$ Egypt over the past three decades has gone through a similar process of incomplete, partial, step-by-step ("two steps forward and one step back") liberalization with similar consequences (Handoussa (1997, p. 143).
} 
better than $6 \%$ per annum since 1980 , India each year is falling further behind a nominally Communist and clearly non-democratic country, China, that has achieved annual growth rates in the $8-10 \%$ range nearly every year over the same period.

The table on the next page compares GDP growth rates in the two countries from 1980 on based on time series developed from World Bank and the Economist Magazine data. There has been some convergence in growth rates between the two countries from about 1995 on, and this is expected to continue for the foreseeable future. Nonetheless, India continues to fall behind China in terms of GDP per capita based on purchasing power parity ${ }^{151}$.

Unfavourable comparisons with China are having some influence on policy formulation in India (Srinivasan 2004). Mumbai is using Shanghai as its benchmark of success. La Croix et al (2000, p. 187) offers the somewhat ironic conclusion that the non-government enterprise sector has made a more important contribution to growth in "socialist China" than in "capitalist India". Compared with China, the non-state enterprise sector in India, especially in the formal sector, faces more costly, intrusive and time-consuming economic regulation in terms of taxes, labour, land, restrictions on entry and in particular exit, restrictions on the inflow of foreign capital and technology, and factory, environmental and other forms of enterprise inspections. At the same time, stateowned enterprises in China have generated more global success stories than those in India.

\footnotetext{
${ }^{151}$ In 1990 , India was $6 \%$ above China in this measure of per capita income, whereas by 2000 India was $37 \%$ behind and by 2007 this gap between India and China had further increased to 49\% (World Bank 2009, Table I). Over this 17-year period, growth in GDP/capita in China was $8.8 \%$ per annum compared with 4.4\% in India. India's slower (but still quite impressive) growth in GDP/capita is the result of both higher population growth and lower growth in real GDP.
} 


\begin{tabular}{|l|c|c|}
\hline Time Period & \multicolumn{2}{|c|}{ Real GDP Growth Rate (\%) } \\
\hline & India & China \\
\hline $1951-1960$ & 3.9 & NA \\
\hline $1960-1970$ & 3.9 & NA \\
\hline $1970-1980$ & 3.0 & NA \\
\hline $1951-1980$ & 3.6 & NA \\
\hline $1980-1990$ & 5.8 & 10.2 \\
\hline $1990-2000$ & 6.0 & 10.3 \\
\hline $1995-2000$ & 7.4 & 7.8 \\
\hline $2000-2007$ & 8.0 & 10.4 \\
\hline 2005 & 8.4 & 10.0 \\
\hline 2006 & 9.2 & 10.6 \\
\hline 2007 & 9.0 & 11.7 \\
\hline 2008 projection ${ }^{152}$ & 6.3 & 9.6 \\
\hline 2009 projection & 6.1 & 8.0 \\
\hline Total Period 1980-2007 & $\mathbf{6 . 3}$ & $\mathbf{1 0 . 2}$ \\
\hline $\mathbf{1 9 9 5 - 2 0 0 7}$ & $\mathbf{7 . 8}$ & $\mathbf{9 . 3}$ \\
\hline 2000-2009: Actual and & $\mathbf{7 . 6}$ & $\mathbf{1 0 . 0}$ \\
Projected & \multicolumn{2}{|c|}{} \\
\hline
\end{tabular}

\subsubsection{Arguments that Liberalization Has Moved Forward Too Rapidly and Is Still Too Pro-Business}

Critics from the other side ${ }^{153}$ are arguing that India's liberalization reforms have moved forward too rapidly, with too little public consultation, and with too much benefit for the business groups and other larger companies and too little benefit for other socioeconomic groups especially the rural and urban poor. These critics are raising serious and well substantiated concerns that liberalization since 1991: opened up too few markets and industries to foreign competition; is increasing the already large gaps in

\footnotetext{
${ }^{152}$ The 2008 and 2009 projections are based on the GDP growth rates provided in the Economist magazine (Nov. $29^{\text {th }}-$ Dec. $5^{\text {th }} 2008$, p. 97), and thus reflect the much lower growth predictions being made at the end of 2008 because of the American recession. The pre-1980 GDP growth rates for India are also included in the Table to provide a context for later empirical analysis on India's longer term growth performance in Chapters 6-8). The Indian growth rates up to 1980 are taken from the website "India Economy". Because China's pre-1980 growth rates are controversial and likely not comparable to those for India in terms of methodology, China's pre-1980 growth rates are not included in the table.

${ }^{153}$ There is a temptation to categorize these as critics from the right and the left. However, critics from both sides of the political spectrum emphasize many of the same inadequate outcomes of liberalization such as the decrease in government investment in public goods, the still limited competition in many domestic markets especially for consumer goods, and the growing gaps between rich and poor households, cities and Indian states. The two sides however differ somewhat on the reasons for and the best means for addressing these problems and gaps.
} 
productivity and competitiveness across production units, companies and sectors (Aghion et al 2003, 2005:1 and 2005:2); is widening the already large disparities in production, productivity and living standards between socioeconomic groups, districts, states and regions (Topalova 2005, Datt and Ravallion 2002 and Sinha 2005:1), between urban and rural areas, and within the same urban region ${ }^{154}$. They argue as well that liberalization has had comparatively little impact on reducing poverty particularly in the poorer states (Jha 2001 and Datt and Ravallion 2002); and is placing too much reliance on markets and thus reducing government investments in public goods and government services especially for the rural and urban poor.

When compared with the predictions from economic theory and the promises from liberalization advocates, economic reforms have provided relatively limited competition and consumer welfare benefits, especially for the urban and rural poor, in the form of: reductions in market power, industry concentration and concentration ratios in specific markets ${ }^{155}$; higher productivity and innovation (Das and Pant 2006, and Balakrishnan et

\footnotetext{
${ }^{154}$ Benjamin (2000) for example highlights the major differences in living standards, quality of life and political influence between the more and less prosperous socioeconomic groups in Bangalore. This city is often referred to as India's Silicon Valley and therefore as one of the Indian success stories of the postliberalization period. He particularly relates the low incomes of the poor to their lack of political influence within a complex multi-scalar political system where the political access and influence of the poor are largely limited to local governments which are politically much weaker than the state- and national-level governments. Harriss (2006) and Fernandes and Heller (2006) raise similar concerns for other Indian urban regions.

155 Indian competition analysts continue to employ concentration ratios to determine the extent of concentration and competition in Indian industries and markets. Beyond the data challenges identified in the competition analysis literature (see e.g. Church and Ware Chapter 12), Chapter 2 points out some of the theoretical dangers of applying concentration ratios based on the Structure-Conduct-Performance model of traditional industrial organization economics to the case study comparisons in this dissertation.
}

The SCP model assumes that market structure determines business conduct, performance and the extent of market competition, and thus ignores the independent influences of business conduct and strategy, and of political economy and other external factors, on competition. Concentration ratios thus provide ambiguous and often contradictory and misleading evidence on competition, and therefore need to be supplemented by additional information on business strategy and actual market outcomes. 
al 2006); lower prices, business profits, and price-cost margins (Pant and Pattanayak 2005); and higher quality products. Research participants and other sources indicated that domestic industrial reforms and external trade liberalization are not sufficient to promote greater competition in India's manufacturing industries. Regulatory interventions by government to promote more competitive and fairer markets are also needed (Pant and Pattanayak 2005, p. 4226), through an effective competition regime and further capital market reforms to increase the opportunities for business entry and expansion, particularly by smaller and medium-sized companies (Das and Pant 2006).

\subsubsection{Implications of these Arguments for the New Competition Regime and Its Interactions with Business Groups and other Informal Business Institutions}

Criticisms from both sides are being made by, and continue to resonate with, politicians, governments, voters and other key stakeholders, despite India's very impressive growth performance during the current decade. The result has been a cautious, gradual and what some critics term an "ad-hoc" approach to liberalization in India (Lewis 2004, Das 2002, Debroy 2004, and McKinsey \& Company 2001) ${ }^{156}$.

This can be particularly true when comparing market structure, business conduct and competition in the pre- and post-1991 periods in India. The elimination of the $25 \%$ market share limit rule and other aspects of the License Raj after 1991 mean that many Indian domestic markets now have higher concentration ratios than before liberalization. This is the result of the post-1991 merger wave and the strategies of business groups and other larger companies to concentrate on fewer core markets where they can achieve sustainable competitive advantage (see Chapter 8).

At the same time, eliminating the License Raj and the reform of India's import and foreign direct investment regulations mean that many of these same Indian markets are becoming more contestable in the sense that entry is now much easier and therefore the threat of entry better disciplines the price and nonprice strategies of the smaller number of incumbent suppliers in these markets (see e.g. Baumol 1982).

Higher concentration ratios and greater competition and contestability in the same markets cannot be explained by the SCP model, but is readily explained by the new industrial organization economics (see Chapter 2). As a result, this author in the rest of this dissertation has tended to use with care secondary sources that depend on concentration ratios to explain increases and decreases in competition in India's post-liberalization markets (see Chapters 8 and 9 ).

${ }^{156}$ However, such an approach may be both necessary and even desirable in a functioning and raucous multi-party democracy where multiple voices are heard and have to be listened to by Indian governments at all spatial scales. 
India's new competition regime will need to develop and promote pro-competition ideas, arguments and ultimately results that can satisfy the critics on both sides of the liberalization debate.

The new competition regime is therefore facing a very ambitious and even daunting agenda. This agenda goes beyond effective enforcement of the new competition law to include competition policies and advocacy to complete the pro-business and pro-market reforms in the many areas outlined in sub-section 5.6.1, and ensure that the benefits from liberalization are more equitably distributed ${ }^{157}$. The ability of the new competition regime to address these challenges will strongly influence the quality of its future interactions with the traditional business groups, the new economy informal business arrangements, and a wide range of civil society and other stakeholders. The research participants and other sources raised serious questions about whether the new competition law, agency and regime will have the autonomy, resources, and political support to take on this dual challenge.

\subsection{Conclusions}

Together with the previous historical chapter, this analysis and comparison of the broader economic policy regimes and discourse in the pre- and post 1991 periods set the stage for the more detailed empirical analysis of interactions and accommodations in Chapters 6-9. India's broader economic policy discourse and regime are more favorable to competition in domestic markets after 1991 compared with the previous case study period. Having said that, the current economic policy regime still encompasses a mix of pro-competition, ambiguous and anti-competition components. Liberalization initiatives

\footnotetext{
${ }^{157}$ These and other competition and consumer issues are explored in some detail on the chapter on consumer protection and the need for a national competition policy in the Government of India's Five-Year Plan from 2007 to 2012 (Government of India 2007:1, pp. 282-289).
} 
to reduce barriers to entry by domestic firms since the mid-1980s, and by imports and foreign firms after 1991, are generally consistent with competition goals. The Indian economy on many fronts is now more dynamic, innovative, diversified and pluralistic compared with the first four decades after independence.

However, other developments described in this chapter are less favorable to domestic market competition after 1991 and to vigorous enforcement of India's new and still evolving competition regime. Incomplete liberalization combined with the country's large population and geographic size, complex society, and current stage of economic, institutional and social development, mean that India remains a high transactions cost economy (see section 3.4). Business groups and other firms will continue to search for informal business institutions and arrangements and other instruments in order to reduce these costs and capitalize on the remaining "institutional voids" in the Indian economy (Khanna and Rivkin 2001 and Khanna and Palepu 2004:1, 2004:2 and 2004:3). Some of these strategies could raise competition issues. Furthermore, incomplete liberalization, when combined with large and still active governments at all geographic scales, increases the danger that some business groups and other companies will make only partial commitments to liberalization, for fear that the License Raj could return in a modified form through e.g. an overly legalistic and market structure based enforcement of the new competition law (see Chapter 8). This reduces the potential benefits from liberalization for efficiency, competition and competitiveness (Denoon 1998, p. 48) and will further complicate interactions with the new competition regime.

The final roadblock to completing India's broader liberalization program and to strong enforcement of its new competition regime is ironically the high economic growth 
rates achieved by partial liberalization during the current decade. Higher growth means less pressure from the private business sector, consumers, voters and other stakeholders to complete the politically more difficult policy reforms identified earlier ${ }^{158}$. When comparing the pre and post 1991 periods, economic policy discourse in India has changed more than the economic policies themselves, and the economic policies have changed more than the day-to-day interactions, conflicts and accommodations between the broader economic policy regime (within which the competition regime is embedded) and India's informal business institutions. The post-1991 domestic and external reforms, the remaining deficiencies in India's liberalization program, continuing contestation on liberalization, and their implications for the evolution of and interactions between the country's competition regime and informal business institutions, are explored in greater detail in the empirical chapters to follow, especially Chapter 8 .

\footnotetext{
${ }^{158}$ Even though arguably many of these reforms, in such areas as small enterprises, land, labour market and bankruptcy laws and regulations, are exactly what are needed to bring about greater competition and consumer welfare, more pro-poor development, and a more equitable distribution of the benefits from liberalization (Mehta 2007).
} 


\section{Chapter 6: Interactions, Conflicts and Accommodations Between India's Competition Regime and Informal Business Institutions From 1965 to 1991}

\subsection{Purpose}

This chapter analyses the interactions, conflicts and accommodations between India's competition regime and its business groups and other informal business institutions and arrangements from 1965 to $1991^{159}$. The chapter represents the first of two time dependent case studies that are central to the empirical analysis for this thesis. The next two sections explore these interactions, conflicts and accommodations mainly from the perspective of the 1965-1991 competition regime, while sections 4 and 5 complete the 1965-1991 empirical story by adopting the perspective of India's informal business institutions. Section 6 summarizes the MRTPA legacy for the still evolving post-1991 competition regime and its post-1991 interactions with the country's informal business institutions, and the concluding section presents the major implications for the later empirical chapters. This chapter illustrates that the comparatively simple and unidimensional 1965-1991 argument (see Exhibit II and section 3.3.) becomes a more complex and richer narrative when: first, the MRTPA of 1969 is embedded within a broader competition regime that essentially acts as an impediment to business entry and competition; and second, appropriate attention is given to the strategic responses of India's traditional business groups to both the law and the broader competition regime.

\footnotetext{
${ }^{159}$ Most of the analysis in this Chapter focuses on the regime's interactions with India's traditional family based business groups which dominated the country's private business sector and discourse on competition policy and law throughout the pre-1991 case study period. As indicated in the Introduction (pp. 7-8), the traditional business groups of India and other Asian and developing countries are a particular form of informal business institution that are less "bound together" than the divisions legally consolidated within a single corporation, and more "bound together" than short-term strategic alliances and R\&D partnerships. The generic definition used by most business group scholars is that a business group is a set of legally independent affiliated companies that are linked together by a variety of economic and social instruments that allow them to operate in a coordinated and mutually beneficial manner over an extended period of time (Chung 2001 p. 721 and Granovetter 1995, p. 95).
} 


\subsection{Interactions, Conflicts and Accommodations from the Perspective of the 1965- 1991 Competition Regime}

\subsubsection{Limited Business Influence on the Design of the MRTPA and the Overall Competition Regime}

Research participants and other sources indicate that the business groups and other larger private companies (that became the MRTPA monopoly companies) had little or no influence on the competition regime that emerged in the late 1960s. While some protests were made by business groups during the 1960s through their trade associations (Mahadevan 1992), these were largely stated "for the record" after the policy change was enacted (Tirumalai 1986), and were subsequently ignored by the government of the day.

As a result of the Mahalonobis, Hazari, Monopolies Inquiry Commission and Dutt Committee Reports of the mid to late 1960s (see Appendix 5), there was consensus across government and key non-business stakeholders and elites that industrial concentration and inequalities in income and wealth had to be addressed through strong government policy interventions ${ }^{160}$. These reports documented that the extent of concentration in the Indian private sector had become much greater since independence. Increased concentration in specific industries and markets and across the entire private business sector were the combined result of the License Raj; the license pre-emption and hoarding strategies of business groups and other large companies; and their preferred access to financial resources from privately owned banks (that until 1969 were often owned by the larger business groups) and from development finance institutions that

\footnotetext{
${ }^{160}$ In fact, this consensus goes back to the time of independence. The 1969 MRTPA was consistent with the Constitution of India adopted in 1950, the licensing regime first established in 1951 and the subsequent GOI policies to reserve some industries for state owned companies and other industries for smaller firms. All of these policy instruments were intended, for the most part, to reduce economic concentration in India's private economy and the market, business and political power of large, typically family owned, business groups and other large companies (see Appendix 5).
} 
were owned by the government (Encarnation 1989, Chapter 2). The MRTP Act and Commission and related measures of business control discussed later were seen as the solution to this concentration problem in the late 1960s.

There are a number of reasons why these populist measures ${ }^{161}$ were adopted with strong political consensus and little effective business protest. At that time, the larger business groups and other private companies had little knowledge of and virtually no direct experience with competition law enforcement. Nearly all of their sales were to the highly protected domestic market and exports to the American and other more advanced OECD markets with competition laws in 1969 were very limited. The 1969 MRTPA and MRTPC resulted in an additional layer of investment approvals for business groups and larger firms that were either "large" by exceeding a certain threshold size or "dominant" because their market share was greater than one-fourth. However, at the outset, relatively few private companies in 1969 - estimated at less than one percent - would become MRTPA monopoly firms and thus be directly affected by the Act when enforcement began in $1970^{162}$.

The private business sector remained highly dependent on government for licenses, government contracts and continuing protection from imports, foreign direct investment and new potentially more efficient domestic competitors. At that time, the Government

\footnotetext{
${ }^{161}$ Generally speaking, business writers and academics apply the term "socialist" to these policies, while the academic community prefers the term "populist" (see e.g. Chibber 2003:2). This author prefers and therefore uses the term "populist" in this dissertation.

${ }^{162}$ This number however would increase greatly through time as the asset thresholds for determining a monopoly firm and business group did not change until the mid-1980s - despite quite significant inflation as well as some private sector and economic growth over this period. At the outset, a company or business group with assets of more than Rs. 200 million was considered an MRTPA company/monopoly firm. This was later raised to Rs. 1 billion in the mid 1980s. By that time and before the threshold was raised, nearly all of the business houses, including the smaller family owned groups and the larger unaffiliated companies, were under the purview of the MRTPA.
} 
of India clearly dominated all aspects of economic decision-making, had major economic and business interests to protect and advance, and was concerned that large business groups would become an alternative source of economic and political power within India ${ }^{163}$. Finally, the private business sector indicated little enthusiasm and support for the modest policies of market liberalization and export promotion that were tentatively put forward and then quickly withdrawn by the GOI in the mid-1960s (Mukherji $2000)^{164}$. This lack of business support for policies, which on the surface appeared to favour the private business sector through reducing government intervention in the economy and promoting exports, compromised the ability of business groups and other larger companies to lobby against the MRTPA and the new competition regime established later in the 1960 s.

The business groups and other larger companies, which had excellent government and bureaucratic contacts, recognized in 1969 the government's strength and resolve and their own dependence and relative weakness. They decided therefore that, rather than publicly

\footnotetext{
${ }^{163}$ This dissertation focuses on India's private economy. However, Indian governments played a very important and growing role in India's non-agricultural economy over most of the period covered by this chapter (and continue to be important as discussed in the previous chapter). Through its state-owned enterprises and other public sector undertakings, the public sector's contribution to GDP expanded from $10 \%$ in $1960 / 61$ to over $25 \%$ in the last years of the 1980 s, and the state's contribution to gross capital formation approached $50 \%$ in the 1980s compared to $23 \%$ just after independence in 1950/51 (Dutt 1997, p. 63). In short, the state had major industrial and other commercial assets to protect from private enterprise competition, and the MRTPA was seen by the GOI as a major instrument in providing this protection (see as well Encarnation 1989).

164 The response of the private business sector in the mid-1960s was not too different from the business groups' initial response to the post-1991 liberalization program described in Chapter 7. The major business associations which represented these business groups were either ambivalent or indicated no or tepid support for these reforms, while the business groups and other larger companies worked behind the scenes with considerable success to maintain the status quo. Even the Associated Chambers of Commerce (ASSOCHAM), the business association, which represented most of the foreign owned companies operating in India at that time, was largely silent on this issue (Mukherji 2000, p. 386-388). Once profitably established behind India's formidable trade barriers, foreign companies had as little interest in economic reform and market opening as the business groups and other domestic companies that were benefiting from the License Raj (Chibber 2003:2, Vachani 1997, and comments from many of the participants in the summer of 2006 field work).
} 
opposing the new business regulations prior to their implementation, they would continue to work behind the scenes with their pro-business political and bureaucratic connections in order to undermine, neutralize or make the MRTPA and other new regulations work to their advantage - as clearly took place for the original licensing system from the early 1950s on (Chibber 2003:2). Similar to the broader licensing/competition regime within which the MRTP Act and Commission was embedded, this augmented and even more complex competition regime was seen at the outset to provide additional advantages to larger incumbent firms. This was particularly true for the larger business groups who could afford the fully staffed New Delhi offices and the major lobbying and other transaction costs needed to constantly interact with the numerous government agencies and their bureaucrats that comprised the 1965-1991 competition and broader economic policy regimes (see Chapter 5).

\subsubsection{The Political Economy Context in the 1960s and Its Implications for Interactions, Conflicts and Accommodations between 1965 and 1991}

These changes and additions to India's competition regime need to be placed within the country's broader political economy context of the 1960 s and early 1970 s. These were difficult years for the GOI under the Congress Party. Major geopolitical developments included: wars with China in 1962 and with Pakistan in 1965 and 1971 (when Bangladesh became independent); serious droughts for three years in the mid1960s; the death of Jawaharlal Nehru, India's first and only Prime Minister from 1947 to 1964; and the early death of his chosen successor, Lal Bahadur Shastri, after less than two years in office. These events culminated in 1966 with the coming to power of Nehru's daughter, Indira Gandhi, who from 1969 on implemented a more populist regime of land reform and increased state planning, government intervention and regulation of 
the economy, which was more rigid, arbitrary, political and bureaucratic than the regime under her father.

When added to economic growth rates that were well below expectations and fiveyear plan projections (see sections 5.5 and 5.6.2) and the lack of business support for the GOI's short-term efforts in the mid-1960s to introduce modest economic reforms and promote exports (Chibber 2003:2, Denoon 1998, and Mukherji 2000), the government was under serious pressure to "do something" to address India's mounting geopolitical and economic problems. Even greater state planning, intervention in the economy, and regulation of the business groups and other larger privately owned companies through further expanding the "License Raj" was the political response at that time.

The GOI was able to neutralize the economic reformers within and outside government by pointing to the failure of the modest mid-1960s market reforms, which: had little or no support from business, labour, and political elites, including the Prime Minister of the day, Indira Gandhi (Mukherji 1997); and, was strongly associated among elites and the media with international pressures from the World Bank and IMF to devalue the Indian currency and introduce domestic and external reforms in order to maintain foreign aid at the high levels required by India's trade, balance of payments and fiscal deficits. Another consideration, which further reduced support for comprehensive liberalization in the mid-1960s, is that international evidence on the relative advantages of export promotion over import substitution strategies was just starting to emerge in the case of Japan (generally seen as a special case), South Korea and Taiwan. This evidence became much stronger in the 1970s and 1980s (Lucas 1993, the World Bank 1993 and Singh 2004). For these and many other reasons explored in the coming chapters, the 
political economy conditions for substantial economic reform were much less favorable in the mid-1960s than in the mid-1980s and early 1990s.

\subsubsection{Other Major Components of the 1965-1991 Competition Regime}

In addition to the MRTPA and MRTPC, the broader competition regime established in the late 1960s and early 1970s encompassed: (i) the nationalization of 14 major commercial banks (many owned by the largest business groups) in 1969; (ii) the formal elimination of the managing agency system in 1970 - this was clearly intended to further weaken the economic and political power of the major business groups ${ }^{165}$; (iii) the announcement in February 1970 of a new more rigorous licensing policy whereby previously granted exemptions from licensing were withdrawn from 41 industries, and applications for licenses from large business groups were subject to special screening (Sinha 2005:1, p. 80); and, (iv) the passage and start of implementation of the Foreign Exchange Regulation Act (FERA) of 1974, which provided the legal framework for regulating the commercial and manufacturing activities of foreign companies, and limited the equity of foreign companies operating in India to $40 \%$.

When placed in this broader context, the Monopolies and Restrictive Trade Practices Act and Commission of 1969 are best perceived as components of the GOI's broader competition regime to regulate and control the business groups and other large privately owned businesses, rather than as socioeconomic instruments to reduce industrial concentration, and promote competition and the consumer interest in India's domestic markets (Chaudhuri 1973). At least on the surface, the MRTPA was designed, expected

\footnotetext{
${ }^{165}$ However, eliminating the system had little or no real impact, as the managing agencies of the past were simply converted into the business groups of today while retaining the same or similar objectives, functions, routines, rules of business conduct, informal business arrangements and governance structures, and consequences for competition and market outcomes
} 
to be enforced by its proponents, and at times actually enforced, as a textbook application of the Structure-Conduct-Performance model of traditional micro-economic and industrial organization theory (see Chapter 2). Under this uni-directional model, a large business group or company (structure) was presumed to be anti-competitive (conduct) and be making monopoly profits and hurting economic efficiency and consumers (performance).

Therefore, consistent with the SCP approach, a business group or company could not have more than $25 \%$ of any one industry's production or market sales under the licensing regime and MRTPA - even when a high market share was the result of superior competitive performance. Moreover, the MRTPA went beyond this traditional IO model by defining large size in terms of the asset size of companies and their business groups, not based on market shares and market power in specific product and geographic markets. The MRTPA was the only competition law in the world that applied asset size in this manner. This asset-size approach was seen by its critics as even more primitive and interventionist than a structure-based approach to competition law. However, since the MRTPA was intended to be a major GOI instrument for learning about, monitoring, regulating and when necessary controlling the activities of large privately owned business groups and other larger companies, defining economic power based on asset size rather than market share and concentration probably made good sense from the GOI's perspective.

The design of the MRTPA of 1969 generally received a passing grade from outside observers of competition law and policy in India, who concluded that the Act was in many respects a fairly modern and even ambitious competition statute (see e.g. Till and 
Fulda 1968 and Fulda and Till 1968). The Act therefore was generally consistent with the design and enforcement of competition laws then in place in the OECD countries, which were also largely based on the Structure-Conduct-Performance model. However, enforcement of the MRTPA and the broader 1965-1991 competition regime generated a great deal of controversy and criticism. This is the subject of the next section.

\subsection{Reasons Why the 1965-1991 Interactions, Conflicts and Accommodations Did Not Reduce Industrial Concentration and Promote Competition}

For those competition analysts and proponents who believed that the purpose of the MRTPA was to promote competition through reducing industrial concentration and the dominant position of the large business groups within India's private economy, the MRTPA is seen as a complete failure. Industrial concentration and the position of the business groups and other larger companies were just as strong if not stronger within the Indian private economy of the late $1980 \mathrm{~s}$ as in the mid-1960s. A large number of interrelated reasons and conjectures explain the MRTPA failure to reduce industrial concentration and promote competition in the Indian private business sector. One conjecture supported by many sources is that the MRTPA and the rest of the post-1965 competition regime were mainly intended to deflect criticism away from the broader economic policy regime that was established in the 1950s and was designed to discourage business entry and competition.

A second factor was that many sections of the MRTPA were highly information and analysis intensive, which took scarce MRTPC resources away from the more structural investigations and cases needed to directly address industrial concentration. A third factor was the ability of the large business groups and other larger companies to use the broader economic policy regime, especially the "License Raj", to avoid the MRTPA 
and/or offset any negative impacts that the MRTPA might have on their strategies and performance. The result of these and other factors explored in the following sub-sections was that few cases investigated by the MRTPC directly affected the strategic interests of business groups and other larger companies.

\subsubsection{A Competition Regime that was Designed to Fail -- While Deflecting Criticism from the Broader Economic Policy Regime That Discouraged Business Entry and Competition}

Many research participants contended that the MRTPA was not intended to achieve its objective of reducing industrial concentration and promoting greater competition and consumer choice in the Indian private economy (Bhattacharjea 2003:1, p. 24). Given the historically close links between the GOI, the right wing of the Congress Party and India's large business groups, the role of the MRTPA arguably was to justify the leftist and populist turn of the Indira Gandhi government and deflect criticism away from the broader competition regime of: protection and entitlements to Indian state owned and privately owned companies; and state planning and Indian self-reliance and selfsufficiency; that was resulting in higher prices and less consumer choice in India's domestic markets and that at that time was benefiting India's traditional business groups and other larger companies at the expense of consumers, farmers, workers and medium sized businesses.

The MRTPA represented a compromise between the right and left wings of the Indian Congress Party at a time when the Indian federal government under Indira Gandhi was taking a populist turn (Bhattacharjea 2003:1, p. 24). The right wing and its business supporters may have reluctantly accepted an additional layer of business regulation as the price to be paid for continuing the broader competition regime, which clearly protected 
and promoted the interests of the traditional business groups and other larger business incumbents.

\subsubsection{Emphasis on Business Conduct and Other MRTPA Provisions That Were Information and Analysis Intensive}

While MRTPA design emphasized asset size and market structure, the Act included as well provisions on monopolistic trade practices and business conduct more generally. These provisions were given some priority in enforcing the MRTPA during the 1970s. This emphasis on business conduct over market structure and structural remedies such as forced divestiture, while consistent with recent advances in new industrial organization economics (see section 2.2) and current competition law enforcement in OECD countries, was also consistent with the GOI's reluctance to break up India's business groups and other large companies, which had their supporters within the Congress Party, the federal and state governments, and the bureaucracy (despite the strong anti-business rhetoric of the period).

The priority given to these conduct based provisions greatly complicated the early enforcement of the new competition law and the analysis and decision-making of the new Commission. MRTPC investigations of monopolistic and restrictive trade practices, as well as: mandatory MRTPC review and approval of the merger and acquisition, capacity expansion, product diversification, and other strategies of the so-called MRTPA monopolies as defined under Section 3 of the Act; and the mandatory registration and review of agreements involving restrictive trade practices; were highly resource and time intensive for both sides.

These investigations required detailed information, analysis, predictions, projections and conjectures on the future implications of the company's strategy and trade practices 
for market structure, business conduct, efficiencies, and performance, and consumer and social welfare -- including the potential for future collusion in more concentrated industries and markets. These investigations therefore required all of the analytical skills and tools of modern merger review and abuse of dominance (AOD) investigations that are now only found in the most experienced competition regimes in the OECD countries -

- without the necessary data, expertise, analytical experience, resources and political support in either India's public or private sectors at that time.

While these mandatory reviews required significant time and resources for both the Commission and the business groups and other companies, they rarely identified a competition problem that could be remedied by the Commission. The Commission's limited financial and technical resources and political clout, when combined with the administration of the mandatory review provisions and the investigation of complex business conduct cases in the early years, meant that the MRTPC had few resources available to address industrial concentration and the market, economic and political power of the larger business groups.

\subsubsection{Few MRTP Commission Decisions that Directly Hurt the Strategic Interests of the Business Groups and Other Larger Companies}

Comparatively few investigations and decisions of the Commission were directly contrary to the interests of business groups and other larger companies in India. One reason noted above was the emphasis on conduct over structure and structural remedies in many of the Commission's early enforcement cases during the 1970s. Another was that the MRTPA was embedded within a broader competition and economic policy regime of industrial, trade and investment controls that the business groups and other large businesses had learned to manipulate to prevent entry by potentially more efficient 
domestic and foreign competitors. Therefore, favorable decisions from the broader regime that e.g. granted multiple licenses to business groups were available to offset the effects of any unfavourable decisions from the MRTP Commission (Chaudhuri 1973).

The Dutt Committee of 1967 reported that the multiple capacity licenses granted to the same business group in the same industry often involved production capacities that were well beyond the levels that could be justified based on economic and technological factors. Moreover, monopoly and market power concerns did not enter the equation when a license was granted. The number of licenses that had been hoarded and not yet utilized was particularly high among some of the largest business groups in particular the Birla and Tata groups. Capacity licenses that were granted and hoarded before 1969 were available to prevent entry and competition after 1969. In addition, throughout the 1965-1991 period, the business groups and other larger firms continued to manipulate the capacity licensing system to pre-empt competition and prevent entry - and thus to help counteract any negative effects of the MRTPA on their market positions and power.

\subsubsection{Evidence on the Direct and Indirect Impacts of MRTPA Merger Review}

Chapter III of the MRTP Act (sections 20 to 30) was designed to ensure that the operation of the economic system did not result in concentrations of economic power to the detriment of the public interest. This section, which was unique among the antimonopoly laws at that time ${ }^{166}$, could be applied to either single companies called undertakings, or to groups of inter-connected undertakings (i.e. business groups), and could be applied to either large undertakings/business groups (based on asset size) or dominant undertakings/business groups (based on market share). Undertakings and

\footnotetext{
${ }^{166}$ This was because the MRTPA contained features of both modern competition law of the 1960s and of the Indian licensing regime within which the Act was embedded.
} 
business groups that passed a certain size threshold had to register with the central government under section 26 of the Act. As of December 1978, 1,428 undertakings had registered themselves as either dominant undertakings or large business groups (Rao 1982).

Over the period from 1970 to 1978 , the MRTPC received only 48 merger and amalgamation proposals from the 1,428 undertakings registered under Chapter $\mathrm{III}^{167}$, made decisions on 36, and approved 33 and rejected only 3. Moreover, none were rejected after 1971. Data on takeovers and acquisitions, which were reviewed under another section of the MRTPA, tell a similar story. From 1972 to 1978 , the MRTPC made decisions on 40 takeover and acquisition proposals and 34 were approved and six were rejected. However, only two of the rejected proposals involved major investments by one of India's business groups (Rao 1982).

Therefore, while few merger applications were disallowed by the MRTPA, the very existence of the merger and takeover provisions, and the high transaction costs and uncertainties of securing merger and takeover approvals, discouraged merger and acquisition activity by business groups and other privately owned companies. Instead, the business groups and other "MRTPA monopoly" companies preferred expansion of existing facilities and investments in new undertakings and facilities based on approvals under the licensing system and the "monopoly firm" provisions of the MRTPA (Rao 1982, pp. 508-509, and Agarwal and Bhattacharjea 2006) ${ }^{168}$.

\footnotetext{
${ }^{167}$ This means that in a typical year only 0.7 of one percent of the registered undertaking had a merger proposal reviewed by the Commission.

${ }^{168}$ In their comparative analysis of merger activity in India before and after 1991, Agarwal and Bhattacharjea (2006, p. 16) found that the elimination of the MRTPA merger review system remained statistically important in their econometric results even when other non-regulatory variables were included in their estimated equations. In contrast, delicensing in the 1980s and the 1990s had a positive but not statistically significant impact on merger activity in India. Therefore, their analysis confirms that, before
} 
The business groups concluded that, with appropriate influence, connections and lobbying in the right places and support from the beneficiary Indian state and other stakeholders (Sinha 2005:1, chapter 3), expanding existing facilities and investments in new facilities required less time, cost, risk and government intrusion than formal merger and takeover review by the MRTPC. Even though the MRTPC rejected very few mergers (which to some critics means it was ineffective), the Act had an indirect but still important impact on the corporate strategies of India's business groups and other large companies over the two decade period up to 1991 -- when merger review was eliminated from the competition law as part of the government's liberalization program.

\subsubsection{Case Evidence on Direct and Indirect Impacts of the Mandatory Registration System for Restrictive Trade Practices (RTPs)}

The provisions on the mandatory registration and review of all restrictive trade practices (RTPs) under the MRTPA were similar to the restrictive trade practices provisions in the UK competition law at that time (Rao and Sastry 1989). Under the MRTPA, such agreements were assessed, and then approved or not approved through evaluating the agreement in relation to a set of eleven gateways that addressed e.g. protecting the public, benefits to buyers, competition, employment, exports, maintaining supply of an essential good, and explicit authorization and approval by the central

1991, merger activity was more constrained by the MRTPA's merger provisions than by the licensing regime.

These findings indicate that the licensing regime was seen as more permissive and/or easier to manipulate by business groups and other larger businesses than MRTPA merger review. The relatively few mergers reviewed by the MRTPC before 1991 and the merger wave after 1991 provide additional evidence that the transactions costs, delays and risks incurred in the MRTPC merger review process (including the risks of sharing commercially confidential information with the state that had their own economic and business interests) were seen to be very high, and in some cases prohibitively high by the business groups and other larger companies, even though few mergers were in fact ultimately rejected by the MRTPA. The implications of these findings for the pre-1991 business group accommodations and strategies are further explored in the next section, while chapters 7 and 8 analyse the implications for business groups' lobbying on and strategic responses to the reintroduction of merger review under the amended Competition Act 2007. 
government. Similar to competition laws in other countries at that time, these gateways did not directly address the ability of vertical restraints and other RTPs to generate efficiencies and economize on transactions and production costs (see section 2.7.2 of Chapter 2 and Williamson 1975 and 1985).

The MRTPC registration and review of these practices that took place from 1970 to 1984 indicated that restrictive trade practices were used quite extensively in the Indian economy at that time. Most of the 499 inquiries on restrictive agreements conducted by the MRTP Commission from 1970 to 1984 led to "cease and desist" orders which required that the company or companies stop using these practices. However, very few of these cases and orders were directed against the larger business groups. Enforcement of the RTP and related provisions of competition laws is often based on complaints from one of the two business parties to the agreement. Vertical restraints and other restrictive trade practices involving two affiliated companies within the same business group, that may hurt competition and consumer welfare, would not generate complaints from one of the two affiliated business group companies. Moreover, compared with RTPs between independent companies which are more transparent, it would be much more difficult for the MRTPC to secure information on RTPs between affiliated group companies from e.g. competitors and consumer groups.

The need to register also may have led to the abandonment of some restrictive agreements in order to avoid the requirement to register and the cost and risk of MRTPC review (Rao and Sastry 1989, p. 430). This is another example where business groups and other private companies adopted strategies in order to avoid the MRTPC whenever feasible. The RTP provisions therefore were for the most part applied to agreements 
between smaller companies that were not members of business groups, and in a manner that typically ignored the reduced transactions costs and other efficiencies of these practices and agreements between these smaller independent firms (Bhattacharjea 2003:2, p. 210).

\subsubsection{Summary of the Debates and Evidence on the MRTPA's Effectiveness}

The role and effectiveness of the MRTPA were criticized from both sides of the economic and political spectrum, and to some degree both sides were correct in their criticisms (Dasgupta and Sengupta 1981, Chapter 5). Business advocates criticized the MRTPA and the 1965-1991 competition regime for being anti-business and for adding to the private sector's production and transactions costs; and argued that the Act inhibited private enterprise expansion, the establishment of larger plants and companies of efficient scale ${ }^{169}$, industry competitiveness and economic growth, and was unnecessary or irrelevant to the current stage of India's economic development.

Critics from the other side believed that the 1965-1991 competition regime failed to effectively address the growth in monopoly capital and economic concentration in the Indian economy (Datt 1971 and Dasgupta and Sengupta 1981, p. 93). These competition advocates were particularly concerned that, despite the anti-business rhetoric of the 1970s, the enforcement of the MRTPA and the broader competition regime failed to address the growing inter-relationships between the larger business groups, elected officials and bureaucrats, and was applying what would now be called "rule of reason" rather than structural approaches to the competition analysis of business groups and other larger companies (Paranjape 1980, p. 72).

\footnotetext{
${ }^{169}$ See the discussion of the implications of the $25 \%$ market share limit rule at the end of section 3.3, pp. 102-106.
} 
Criticism of this more flexible and sophisticated approach to competition law enforcement during the 1970s is one of the reasons for the adoption of more legalistic, rigid and doctrinaire approaches to enforcing the MRTPA from about 1980 on. The irony was however that this more legalistic approach was applied for the most part only: to consumer protection type cases with few if any competition implications, under both the unfair trade and restrictive trade practices provisions (Bhattacharjea 2008); and to vertical agreements and restraints and other non-standard contracting practices between smaller firms that had the potential to economize on transactions costs and generate other efficiencies (Fingleton et al 1996) ${ }^{170}$. In sharp contrast, this more legalistic and structural approach was almost never applied to hard-core cartels, monopolies, monopolistic trade practices, abuses of dominance, and other more obvious abuses of market power, that would be associated with business groups and other larger firms that were and are both economically powerful and politically well connected (see Appendix 8).

The debate on the MRTPA's effectiveness partly reflected confusion over the Act's intent and scope (Dasgupta and Sengupta 1981). The consensus among research participants and other sources was that the 1969 Act was not intended to promote competition, reduce industrial concentration and prevent India's business groups and other larger corporations from surviving and expanding. The MRTPA's intent was simply to monitor and regulate their growth and to ensure that expansion of the "MRTPA monopoly" business groups and companies was in the "public interest" - and in particular did not place at risk the government's substantial economic and business interests.

\footnotetext{
${ }^{170}$ Particularly given the limited development of India's wholesale, distribution and retail sectors at that time.
} 
Therefore, the MRTPC diverted its already very scarce enforcement expertise and personnel and financial resources from mergers, monopolies, cartels, and monopolistic trade practices ${ }^{171}$ involving business groups and other larger firms, and gave greater attention to the vertical restraints and similar business practices involving smaller firms that in many cases may have been pro-competitive and were needed to offset the "institutional voids" in the Indian economy ${ }^{172}$. For this reason, the Commission developed a reputation for being legalistic, meddlesome, and costly to transact with; and for failing to do its main job of curbing market and economic power (Government of India, 2000, Debroy 1997).

The failure of the MRTPA to reduce industrial concentration and control restrictive trade practices and related anti-competitive conduct was based not only on the provisions of the Act. This failure was as well the result of systemic problems with administration, enforcement, priority setting and case selection, which resulted from the Commission's small staff and enforcement resources, its inexperience, and government influence and interference on how its limited enforcement resources should be allocated. Research participants indicated that enforcement of the Act was a shared responsibility between the MRTP Commission and the Government of India, which weakened accountability and provided greater opportunities for business groups and their political and bureaucratic supporters to avoid or influence enforcement of the MRTPA.

\footnotetext{
${ }^{171}$ For example, Bhattacharjea (2003:1, p. 35) reported that only one per cent of MRTP cases investigated between 1991 and 1998 involved Section 33(1) (d), which covers price-fixing and bid rigging." Moreover, the three 2002 MRTPA cases under that section did not involve the "unsuccessful uncovering of a conspiracy". There were a few cases of price parallelism under the MRTPC against the tire companies, but these cases were not successful because of a lack of cartel evidence ("no smoking gun").

${ }^{172}$ This is consistent with interaction three in Exhibit II.
} 
Most importantly, the experience of the MRTPA demonstrates how difficult it is for a new competition law to achieve its industrial concentration, competition and related objectives when the statute is embedded within a broader competition and economic policy regime that essentially functions as a barrier to business entry and competition. The failures of the MRTPA and the 1965-1991 competition regime to reduce concentration and promote competition are the result as well of the accommodations and strategic responses of the business groups and other informal business institutions. These accommodations and responses, which have received less attention in the Indian competition literature, are addressed in the following section.

\subsection{Interactions, Conflicts and Accommodations From the Perspective of India's Business Groups and Other Informal Business Institutions and Arrangements}

While the MRTPA failed to reduce industrial concentration and promote competition in the Indian private business sector, it is wrong to conclude that the Act and 1965-1991 competition regime had no or little impact on India's business groups and private sector. The MRTPA and the overall competition regime made some contributions to meeting the political economy objectives of Indian governments of the 1970s and 1980s, through: knowing, influencing and when absolutely necessary blocking the groups' merger, expansion, diversification and other plans and strategies in a manner that protected stateowned enterprises and other state industrial and commercial interests; and helping to achieve the GOI's regional development and other broader socioeconomic objectives.

Furthermore, accommodating and whenever possible avoiding the MRTPA and the competition regime had significant ramifications for business group structure, rules of business conduct, strategies and performance over this period. The evidence on this business group perspective is further explored in the following sub-sections. 


\subsubsection{Impacts of MRTPA Design and Implementation on Business Group Structure, Conduct and Strategy}

The Act and Commission added another and unfamiliar layer of bureaucratic decision-making to the already complex competition regime - and thus added to the already high costs of transacting with and lobbying government. Only the larger private business groups and their affiliated companies could easily afford these additional costs. The MRTP Act and Commission as well significantly delayed the merger, expansion and diversification plans of these groups and companies, which further added to their transaction, governance and strategy implementation costs. With a few important exceptions, most merger, expansion, and product diversification applications were ultimately approved under the MRTPA and the "License Raj ${ }^{173}$.

Nonetheless, the 1965-1991 competition regime forced business groups to establish new (duplicate) companies of less than optimal size, rather than: expanding existing production units or companies; or merging or acquiring other firms, in order to expand their production capacity, gross revenues and profits. A totally new production unit or company typically represented a less efficient expansion option from a production cost perspective. However, it was more likely to receive central (GOI) and regional state government support ${ }^{174}$, and thus avoid the transactions costs, delays and uncertainties of

\footnotetext{
${ }^{173}$ One of the best known exceptions was the failure of the Tata Group over an extended period to receive a license to produce automobiles until the 1990s when the licensing regime was being dismantled. For part of this period, the Tata Group was reportedly less favoured by and popular with the government than its large business group rivals starting with the Birla Group (Das 2002, p. 170). Regardless, these delays and uncertainties cost time and money, and are remembered with considerable bitterness by business leaders (Das 2002) - leading to negative attitudes regarding the new competition regime and law.
}

\footnotetext{
${ }^{174}$ Sinha (2005:1, especially chapters 3-5) makes a convincing case that regional state-level lobbying and support from state politicians and senior government officials, directed at the responsible GOI approval agencies, played a major role in assisting private companies in securing a license and other approvals, and had a significant influence on the allocation of private and state enterprise investments across Indian states up to 1991 and to a lesser degree after liberalization. Regional state support as well was needed then and now to receive clearances for land, connections to power, environmental and other approvals (Sinha
} 
MRTPC review, and of sharing with government sensitive proprietary information on the group's and company's long-term expansion plans.

The business groups therefore favoured the older "License Raj" over the MRTPA when they conducted the "regulation shopping" made possible by the complex multilayered pre-1991 competition regime. The MRTPC was less open to business, political and bureaucratic lobbying compared with other parts of the 1965-1991 competition regime. The non-MRTPA components were in place before 1969, and were well known to and better understood by the Indian private sector compared with the new competition law and commission based on unfamiliar and largely foreign concepts of competition and business regulation. These components as well were clearly more open to lobbying for licenses and other approvals and entitlements from well-connected and well-financed business groups and companies and their national and state level government supporters $^{175}$.

Accommodations with the non-MRTPA components of the competition regime were also required, such as locating new companies or production units at less desirable, higher cost sites in under-developed states and urban regions. These sub-optimal business accommodations were made in order to maintain and strengthen the business groups' political and bureaucratic connections and support; and to help (and to be seen to

2005:1, pp. 215-216). The need for regional state support and approvals added significantly to the costs of transacting with government, which only the larger business groups could easily finance.

${ }^{175}$ Compared with more general competition regime policies that often are not facilitated by and embedded within a law, even a flawed competition law can act as a benchmark and "code of conduct" that influence and discipline the behaviour and decisions of competition agency officials, other bureaucrats and government agencies, politicians, and businesses. As noted in the previous section, this business group preference for the non-MRTPA components particularly affected merger review. The business groups concluded that, with appropriate influence, connections and lobbying in the right places and support from the beneficiary Indian state and other stakeholders (Sinha 2005:1, chapter 3), expanding existing facilities and investments in new facilities required less time, cost, risk and government intrusion than formal merger and takeover review by the MRTPC. 
help) Indian governments to achieve their regional development, poverty reduction and other broader socioeconomic objectives. Despite higher production costs, these accommodations were preferred to interactions with the MRTPA because of their lower transactions costs, less delay and risk, and the requirement to build political and bureaucratic support for future investments.

The MRTPA and MRTPC had other largely indirect impacts on the strategy, performance and efficiency of business groups and other larger private companies. After 1980, the MRTPC's emphasis on and legalistic approach towards vertical restraints and other restrictive trade practices that potentially can be efficiency enhancing not only discouraged arrangements between smaller companies. This approach as well discouraged business group affiliates from establishing mutually advantageous vertical and other arrangements with affiliates of other business groups and independent companies ${ }^{176}$. The author's review of specific MRTPA cases from the 1980s and 1990s indicated substantial variation in how the MRTPA was applied to vertical restraints and other restrictive and monopolistic trade practices (see Appendix 8). This variation in analysis led to unpredictable outcomes, which added to the risks of being an MRTPA defendant company and to the merits of avoiding the MRTPA whenever possible.

In those relatively few instances when the MRTPA could not be avoided, business groups (as well as other companies) typically decided to not contest the charges against them before the Commission. The case law review in Appendix 8 indicates that there were few MRTPA contested cases that applied a competition test and generated good

\footnotetext{
${ }^{176}$ As noted earlier, vertical restraints and other RTPs between affiliates of the same business group are less obvious and transparent, would not generate a complaint from one of the parties to the arrangement, and are less likely to generate complaints by outsiders even when the impacts on competition are negative.
} 
case law ${ }^{177}$. When the case was not contested, the MRTPC normally decided against the defendant based on the legalistic determination that the business practice was a restrictive trade practice (RTP) as defined under the Act.

There are a number of reasons why business groups and other companies normally did not contest an MRTPA restrictive trade practices case. The competition law remedy was relatively costless for the defendant. The remedy typically was an injunction or cease and desist order, which ordered the business to remove the RTP from agreements with suppliers and customers or otherwise modify or eliminate the business practice ${ }^{178}$. In these instances, the court costs were generally waived, since they were so small. As well, monitoring of business compliance with the injunction or "cease and desist" order by the MRTPC was weak or non-existent; and compliance therefore was dependent on future complaints from the plaintiff or other businesses. The defendant as well likely found other ways, such as "tweaking" the agreements with partner firms in the supply chain, to achieve the same business objective -- while appearing to comply with the order at least in law (if not in the spirit of the law). Nonetheless, while these enforcement and compliance costs were limited, the strategic response of the business groups (and other Indian businesses) was first to avoid the MRTPA whenever possible because of the delays, risks and uncertainty, and to not contest the MRTPC's charges when avoidance was no longer possible.

177 The case review in Appendix 8 indicated as well that the quality of the competition analysis and Commission decisions varied significantly depending on the MRTPC members on the panel and whether the defendant contested the case based on competition arguments. Inconsistent rulings when the case facts appear similar, mean that the Commission failed to develop good consistent case law that could be meaningfully employed in future cases with similar facts (including under the new Competition Act -- see as well section 6.6).

${ }^{178}$ Rather than a large monetary fine or possible imprisonment. In addition, there were few if any instances where companies had to pay for the harm caused to competitors and consumers (as takes place in the United States through class action suits and triple damages). 
The next section goes beyond the MRTPA in order to address the interactions, accommodations, conflicts and strategic responses to the broader competition regime from the perspective of India's traditional business groups and other larger privately owned companies.

\subsubsection{Interactions, Conflicts and Accommodations with the Broader Competition Regime and Their Implications for Business Group Strategy}

A surprising and perhaps unanticipated consequence of the overall competition regime is that its interactions and accommodations with India's traditional business groups had some deterrent effect on the more obvious forms of anti-competitive conduct during the pre-1991 period. Or less charitably, the competition regime made such anticompetitive conduct unnecessary. MRTPA business groups and other larger firms deemed as "monopolies" under the Act were under the government and media microscope, and government possessed a great deal of information regarding their market shares, plans, strategies and performance. Government access to this information, in combination with the continuing importance of state entitlements, discouraged anticompetitive conduct by business groups and other larger MRTPA monopoly firms. Protection from entry provided by the state through the broader competition regime, including the MRTPA, meant as well that anti-competitive corporate strategies to deter entry by potential competitors were unnecessary.

Price controls in many key sectors meant that cartels intended to raise prices were neither feasible nor necessary in many markets ${ }^{179}$. In other sectors not under formal price control, business groups were reluctant to make major and highly visible increases in their prices for fear of attracting unwanted media, political and regulatory scrutiny,

${ }^{179}$ Consistent with the concept of "regulatory capture", price controls can and in fact often did result in government protected cartels in India that significantly benefited the private company participants. 
including from price control agencies. With high government-imposed barriers to entry, little threat of entry and virtually no threat of "hit and run" entry under the "License Raj", business groups and other firms operating in oligopoly markets, where tacit collusion/price leadership is relatively easy, could maintain prices at well above competitive levels for extended periods. Fear of regulatory intervention (e.g. through rejecting the next request for a capacity license), not fear of entry, is likely what disciplined prices under the pre-1991 competition regime. Stable prices, even at high oligopoly levels, were less likely to attract regulatory and media attention.

In addition, cartels and other anti-competitive agreements are high cost and risky longer term initiatives that are difficult to monitor and discipline by private companies ${ }^{180}$ - and perhaps easier to detect when conducted by MRTPA monopoly firms that are already under government, media and academic scrutiny. Therefore, in most other markets with no price controls that were characterized by scarcity, and very little price, product quality or other forms of competition ${ }^{181}$, implicit price leadership by a major supplier affiliated with a business group and with deep pockets was often the preferred strategy. "Follow the leader pricing", implicit economy-wide market-sharing agreements and other forms of tacit collusion and "softer" anti-competitive practices are typically more difficult to detect and prove.

Such strategies as well can be easier to apply, monitor and police by incumbents in stable, slow-growth oligopoly markets with the following four characteristics. There are

\footnotetext{
${ }^{180}$ Especially when they involve companies that are affiliated with different business groups with different ethnic, religious, and/or caste backgrounds and corporate cultures.

${ }^{181}$ Because of market scarcity, highly protected markets, and government imposed barriers that prevented entry through imports, FDI, or domestic start-ups, there was little need for: (i) inter-firm competition based on price, product quality or product differentiation, (ii) corporate strategies that emphasized meeting customer needs, or (iii) company (corporate governance) scrutiny by shareholders, lenders or other stakeholders (Harriss 2003, p. 766).
} 
relatively few major suppliers. There is one acknowledged industry leader supported by a strong family/brand name, which supplies to this and other related product markets in the same industry. Little industry churning takes place - which implies virtually no threat of entry, and modest and infrequent changes in market share, and therefore in the negotiating positions and capabilities of incumbents (Williamson 1986, pp. 214-225). And finally, incumbents are required to secure government licenses and other approvals before they can expand and/or enter new markets; this information was public knowledge or at least readily available to other incumbents through their government connections.

There is considerable evidence that many Indian markets prior to 1991 were structured in this manner, with: (i) one industry leader at the $25 \%$ market share limit that set the price, quality and other characteristics, (ii) a comparatively few other larger but less efficient suppliers that benefited from the oligopoly price set by the industry leader, and (iii) a number of smaller suppliers that did not discipline the price, quality and other decisions of the industry leader. This evidence is developed from the research participants, other sources cited in this Chapter and Chapter 5, and the post-1991 responses of industry leaders and followers after the $25 \%$ rule, other aspects of the License Raj, and MRTPA merger review and control of "monopoly companies" were eliminated (see the end of section 3.3. and sub-sections 8.2.1 and 8.2.2 of Chapter 8).

Other factors that deterred more overt anti-competitive conduct by business groups and larger unaffiliated companies included: the embarrassment and media exposure from being caught; nationalism and patriotism of business leaders who wanted to be identified with nation building and be perceived as India's business elite; and the short term risk averse nature of the corporate strategies of many business groups. A final factor likely 
was the continuing influence of traditional Indian economic thought in support of fair trading and against price-fixing, and other forms of collusion, usury, price gouging and exploitation (see Chapter 4).

For these and other reasons such as business solidarity and the many economic and social instruments available to the larger business groups to discipline actual and potential competitors, there is little publicly reported "hard" evidence of cartel and other more overt anti-competitive behaviour and strategies by the business groups and other larger companies over this period. Rather, such anti-competitive behaviour appears to be simply presumed in the economic literature, policy analysis and anti-business rhetoric of the day, based implicitly on the traditional industrial organization Structure-ConductPerformance model that "if you are big you must be bad".

Instead, under this tacit economy-wide market sharing arrangement, India's business groups used the pre-emption and hoarding of licensable capacity (Fulda and Till 1968, Debroy 2004) and other aspects of the licensing regime, to "privately" regulate the system, keep out "outsiders", and discipline non-compliance by any renegade business groups and other companies. Business groups, compared with single independent companies, were better able to benefit from the misuse of capacity, technology ${ }^{182}$, import and other licenses, subsidies and other entitlements. This was because of "fungibility", that is, their ability to move licenses and subsidies around within the business group to maximize profit rather than to achieve government goals (Chibber (2003:2, pp. 189-191).

\footnotetext{
${ }^{182}$ Licenses for importing technology and establishing foreign collaborations were used at times to entrench dominant positions in domestic markets rather than to promote domestic R\&D and innovation. Research participants noted that, in addition to license pre-emption and mis-use, business groups and other larger companies found other ways to manipulate the "License Raj" to their benefit. For example, groups would import products with high tariffs, claim the export benefit which returned the duty to the company (called in Canada the export duty drawback), and then not export. Some business groups and other larger companies therefore paid lower duties than other companies that were either more honest or had weaker bureaucratic and political connections.
} 
Single companies did not have the same flexibility. This problem was exacerbated by little or no monitoring and limited bureaucratic and political will to discipline business groups and their affiliated firms that were misusing licenses and subsidies - for fear of being blamed for a slowdown in investment and production ${ }^{183}$.

This "live-and-let-live" strategy was supported by a number of other structural and corporate conduct factors that varied with the industry and market. Implicit price leadership by key business group suppliers to major markets was often effective because the competitive fringe of smaller suppliers in these markets avoided price competition. This was because small firms benefited from the higher prices; sometimes supplied to the larger producers during periods of high demand and were afraid of losing this valuable business; and knew that the large companies affiliated with business groups had the financial resources needed to successfully fight a price war and conduct predatory pricing strategies. Most importantly, small firms would lose their small firm entitlements if low prices led to significant company expansion.

Other strategic accommodations and responses of India's traditional business groups to avoid and/or minimize the cost and risk of a negative interaction with the pre-1991 competition regime include: splitting one company into two nominally independent firms when maximum capacity, production and market share limits had been reached (Das 2002, p. 263 and Bhattacharjea 2003:2, p. 204 ${ }^{184}$; conducting too little product

\footnotetext{
${ }^{183}$ In fact, Indian businesses quite effectively used the threat of an investment strike on two occasions, the first time prior to the First Five-Year Plan and the second in the late 1970s in order to place pressure on the GOI to adopt more pro-business policies (Chibber (2003:2, pp. 142-145). The licensing regime made the threat of an investment strike more credible.

${ }^{184}$ Since a business group would normally not be allowed to have two affiliated companies supplying to the same market, company splitting would require hiding the business group affiliation of the new company or lobbying the regulator to ignore the business group affiliation of the second company.
} 
specialization and too much diversification into unfamiliar products and markets ${ }^{185}$; avoiding the "License Raj" and pre-1991 competition regime by expanding through acquisitions and greenfield investments in other country markets - rather than expanding domestic production and exports from India (Das 2002); and, using backward and forward vertical integration to e.g. ensure the supply of essential intermediate inputs and to ensure that an essential input, customer or distribution system was not available to an actual or potential competitor. The business groups as well continued to use their political, bureaucratic and financial connections in order to offset the high costs of government transactions by receiving more than their "fair share" of subsidies, government subsidized credit, other government controlled and subsidized inputs, and other entitlements (including placement on the "sick companies" list) (Bardhan 1984, pp. 60-74, Sinha 2005:1, and Encarnation 1989, Chapter 2).

The successful implementation of these and other strategic responses required a fulltime office in New Delhi as well as some kind of presence in the larger, better developed and more industrialized Indian states. Operating these offices and transacting with the MRTPA, the licensing authorities and other government ministries at the national, state and municipal government levels were very costly. For the most part, these high costs of transacting with government and of developing and implementing corporate strategies in response to the many, complex, unstable, non-transparent, and arbitrarily enforced government regulations and restrictions, could be afforded only by the companies affiliated with the larger business groups. Business groups were able to distribute and share these transaction costs - and the resulting contacts and networks with bureaucrats

\footnotetext{
${ }^{185}$ This was the result in part of the regulation noted earlier under the licensing regime and MRTPA that a business group or company could not have more than $25 \%$ of any one industry's production and/or market revenues.
} 
and politicians -- across their affiliated companies. In this manner, the scale and scope economies in transacting with government in India were obvious and significant. In addition, for groups and companies operating in oligopoly markets with relatively stable prices and little threat of entry and "churning", significant portions of these costs would be passed on to their business customers and final consumers.

\subsection{Broader Consequences of the Interactions, Conflicts and Accommodations for Competition, Market Structure, Business Conduct and Performance From 1965 to 1991}

\subsubsection{Consequences for Business Group Costs, Strategy and Performance}

The interviews and other sources emphasized that, either fairly or unfairly, the MRTP Act and Commission are strongly identified at the present time with the much greater government regulation, intervention, and interference in private business - and a more bureaucratic and rigid approach to applying the rules - that took place through the 1970s and early 1980s (Das 2002). This is a reflection of the direct and indirect impacts of the MRTP Act and Commission on the costs and strategies of the "MRTPA monopoly" business groups and companies. In some respects, the addition of the MRTPA to the existing "License Raj" represents a perceived "tipping point" for India's traditional business groups, when the net benefits from before 1965 and the early years of the 19651991 competition regime were reversed to become perceived as net costs by the end of the 1970s.

While the "License Raj" established in the 1950s led to higher transaction and production costs, the licensing, import controls, and FDI regulations also added to the profits of business groups and other larger companies through preventing entry by potentially more efficient domestic and foreign firms. The business group benefits from 
the regime were perceived to exceed the costs at least up to 1970; and the business groups expected this to continue indefinitely despite the additions of the MRTPA and MRTPC to the competition regime. However, in fact, this situation was reversed by the end of the 1970s as on balance, the MRTPA and MRTPC ${ }^{186}$ added more to transaction costs and to production costs (e.g. because of inefficient plant scales ${ }^{187}$ and locations) than to the profits of the business groups. Furthermore, there was less political stability and greater political pluralism at the national level after the late 1970s as the dominance of the Congress Party began to recede. Some companies, industries, academics and government officials as well started to see threats from import competition in the near or mid-term future, particularly from the Asian Tigers ${ }^{188}$. Not surprisingly, higher costs and lower and more contingent benefits from the $1965-1991$ competition regime ${ }^{189}$ resulted by 1980 in quiet business group lobbying to relax domestic market controls - while keeping the import and FDI controls in place and having them strengthened if possible.

Until the late 1970s, the regime was consistent with and reinforced some of the business groups' tendencies, preferences and informal rules of business conduct. Business groups had little interest in innovation and large R\&D expenditures, and the

\footnotetext{
${ }^{186}$ Combined with the more bureaucratic, political, rigid, arbitrary, and adhoc nature of the broader competition regime from 1969 on (see section 6.2.2).

${ }^{187}$ Most companies operated their plants at well below minimum efficient scale because of the combined result of the $25 \%$ market share limit rule, India's small and highly fragmented markets, and limited competition and therefore pressure to become more cost competitive and efficient (see e.g. Chibber 2003:2, Das 2002, Debroy 2004, especially Chapter 4 and the conjectures and hypotheses at the end of section 3.3).

${ }_{188}$ But not yet from China which started to be seen as a major threat only in the early 1990s. Greater import competition in domestic markets would reduce the ability of business groups and other MRTPA monopoly companies to pass on their higher transaction and production costs to their business customers and final consumers.

${ }^{189}$ The high and increasing costs of transacting with government through the 1970 s have to be added to the high transaction costs resulting from the country's underdeveloped and fragmented markets for final products, financial services, infrastructure, labour and other services and information. Because of the slow pace of India's economic, market and institutional development through the 1970s, these transactions costs also remained very high - with the result that India continued to be (and probably still is) one of the highest transactions cost economies in the world (see section 3.4 above).
} 
competition regime made such innovation unnecessary - unless R\&D spending and a technology license could be used to increase domestic market dominance and prevent entry.

Because the business groups and affiliated companies are family owned, they preferred smaller companies and smaller-scale production units, even if economies of scale and scope were not fully realized. Finally, like the merchant firms of the past that were the foundation for many of the business groups of the present, the groups and their affiliated companies preferred smaller and less capital and technology intensive investments that generated quicker and more certain returns (Tripathi 2004). The License Raj and the 1965-1991 competition regime discouraged size, innovation and capital and technology intensity, and - through impeding entry - minimized inter-firm rivalry and guaranteed a quick and certain return to a license holder even when product quality and service were inferior.

\subsubsection{Consequences for the Total Indian Economy Through the 1970s and 1980s}

Chapter five provided a summary of the economic literature, discourse and debates on the impacts of the MRTPA and more generally the pre-1991 competition, licensing and broader economic policy regimes for India's economic performance through to the mid1980s. The consequences of the pre-1991 competition regime for the Indian economy are closely associated with the strategic responses and outcomes of business groups and other larger "MRTPA monopoly" corporations.

The consequences for the Indian economy of these business group accommodations with and responses to the MRTPA and the 1965-1991 competition regime more generally were: too many products; too much product differentiation into both nominally different 
and unfamiliar products; too little product specialization; business fragmentation resulting from too many companies and production units with sub-optimal plant capacities; few if any economies of scale; and higher production, transactions, and corporate governance costs ${ }^{190}$.

The 1965-1991 competition regime, and its interactions and accommodations with and the strategic responses of, the business groups, greatly favoured incumbents over new entrants, favoured large and small companies over medium-sized firms, and in particular, favoured business groups over medium-sized enterprises in the allocation of licenses and financing (Datt 1971, Ghosh 1970, Mookherjee 1995 and Kathuria 1995). The result was that relatively few medium-sized companies at the start of the period had achieved greater size and market prominence by the end of the period (Tripathi 2004). The regime provided trade protection to all industries and companies, regardless of the implications for cost, efficiency, market competition and comparative advantage; and restricted entry and expansion of more efficient small and medium sized firms that were not members of business groups. The result was higher costs and inefficiency in the formal industrial sector (Ganesh-Kumar et al 2003, pp. 24-26), supra-competitive profits in protected and uncompetitive domestic markets, and little incentive for most business groups and other larger firms to export.

In sum, while the 25\% market share limit rule and other aspects of the 1965-1991 competition regime and its interactions with business groups did not promote greater competition and reduce industrial concentration and business group dominance in the

\footnotetext{
${ }^{190}$ For the reasons discussed in the text, the affiliated firms and other larger companies were for the most part able to pass on these higher costs to their domestic industrial customers and final consumers through higher prices. At the same time, higher costs and prices in domestic markets discouraged business groups from competing in foreign markets where inter-firm rivalry was stronger.
} 
domestic economy (Bhattacharjea 2003:2, p. 204), the competition regime added significantly to business group costs and inefficiency and reduced their interest in and ability to compete in foreign markets ${ }^{191}$. Slower industrial and private sector growth in the 1960s and 1970s further added to industrial concentration since entry into an industry is typically easier when industry demand and production are growing rapidly. The lack of competition in product markets was exacerbated by almost no competition in the financial sector after the government nationalized the 14 largest commercial banks in 1970.

The pre-1991 competition regime combined with the strategic responses of business groups impeded innovation through: restricting access to foreign technologies and more advanced foreign machinery and equipment (within which higher technology is often embedded); export pessimism, which limited exports and thus further constrained market contact with more innovative foreign firms; and limited protection of intellectual property rights. These and other forces limited the capacity and incentives for innovation diffusion and the commercialization and adoption of more advanced technology; and restricted domestic market competition especially quality competition based on product innovation ${ }^{192}$ (Encarnation 1989, Chapter 3, Van Dijk 2003, Bowonder 1998 ${ }^{193}$ ). Lack of market competition and contestability channelled the technology development that did

\footnotetext{
${ }^{191}$ These results are fully consistent with the conjectures and hypotheses on the $25 \%$ market share limit rule that are described at the end of section 3.3 on pp. 102-106, and that were developed prior to the field work in India based on the economics conceptual literatures reviewed in Chapter 2. These results as well point out the limitations of traditional industrial organization economics based on the uni-directional StructureConduct-Performance model, which would have predicted that the $25 \%$ rule would be sufficient to generate reasonable levels of competition in most Indian domestic markets.

192 Limited competition, the limitations on production contained in capacity licenses, and the maximum $25 \%$ market share allowed under the MRTPA meant that business groups and other companies had no incentive to expand sales through producing a higher quality product.

${ }^{193}$ As a consequence, from independence to at least 1991, India failed to capitalize on its relatively good scientific and technological development infrastructure including a quite large number of governmentowned labs and industrial R\&D units (Bowonder 1998).
} 
take place into less efficient activities ${ }^{194}$. Research participants emphasized that the consequence was shoddy products supplied to protected domestic markets, where industrial customers and final consumers had few or no alternative sources of supply.

The combined result of these inter-related trends and developments was lower industrial and economic growth through to the early 1980s (see Chapter 4), and lost development, technology and innovation opportunities as the Indian economy moved further away from the technological frontier (Aghion and Howitt 2006). The pre-1991 empirical evidence therefore provides a fascinating story of how informal business institutions and a competition regime. which includes both formal and informal components (see Exhibit I), can interact together and make accommodations to each other in a manner that had significant negative consequences for: competition law enforcement; business conduct and strategy; market structure and outcomes; and the growth trajectory of a developing economy over an extended period. Informal business institutions and arrangements, led by India's traditional business groups, were largely successful in circumventing and/or undermining India's first competition law, the MRTPA. Their strategic accommodations and responses were costly and resulted in suboptimal outcomes for the groups themselves and the total Indian economy. However, they did allow the business groups to survive, often grow and prosper, and to maintain their strong position through a difficult period for India's private sector.

The reasons for the existence and continuing strength of large diversified familybased business groups in India through to 1991 and beyond continue to be debated in the Indian literature (e.g. Ghemawat and Khanna 1998). One strand, which was the major

\footnotetext{
${ }^{194}$ Such as technologies needed to accommodate the inferior quality of local raw materials and intermediate inputs (Kathuria 1995, 174-177), and technology transfer and sharing agreements with foreign companies designed to foreclose entry by a domestic competitor.
} 
driver of the pre-1991 competition regime, emphasizes their market, economic and political power, their monopolistic trade practices and their ability to abuse their dominant positions. A second strand, which is consistent with the economic literatures and conceptual framework described in Chapters 2 and 3, argues that business groups are a relatively efficient business institution response (compared to the available alternatives) to the country's stage of economic and institutional development and to the License Raj and other largely state imposed constraints to their survival and growth in postindependence India.

From this perspective, the business groups' existence and continuing success in India are better explained by their relatively successful responses to the high transactions costs, information imperfections, entrepreneurial scarcity, coordination failures ${ }^{195}$, and other "institutional voids" and policy distortions of the pre-1991 period, which continue in a somewhat reduced form up to the present day (see sections 8.3 and 8.4). In minimizing costs and coordination failures and maintaining revenues, profitability and shareholder value in a very complex political economy environment, business groups and their affiliated companies generally were able to survive and prosper - while making smaller contributions (than anticipated and desired by other elites) to capital accumulation, exports, productivity, innovation, job creation, and other broader development goals ${ }^{196}$.

\footnotetext{
${ }^{195}$ Business groups are better positioned than smaller unaffiliated companies to minimize coordination and related failures in investment planning, financing, capital investments, and $R \& D$ and innovation programs. These kinds of failures occur especially in developing economies with fragmented markets, information gaps and asymmetries, high transaction costs, limited management and entrepreneurial resources, and highly interventionist but not always knowledgeable (boundedly rational) governments.

${ }^{196}$ Particularly in comparison with the expectations of their Indian economic and political critics and the performance of business groups in e.g. Japan and South Korea (Chibber 2003:2, Bardhan 1984, pp. 71-74, Dore 1983, and Porter 1990). As well, as noted earlier, economic concentration in Indian industries was as high if not higher in 1991 than before the MRTPC was introduced in 1969 (Kathuria 1995, p. 172). At that
} 
The longer-term consequences of India's "anti-competitive" competition regime of 1965 to 1991 and the responses of India's business groups and other larger firms to that regime are less favorable. Many of India's traditional business groups and companies were poorly positioned to respond to the pressures of market opening, globalization and rapid technological change when the post-1991 liberalization program resulted in more meaningful competition and more contestable markets in the Indian economy.

\subsection{The MRTPA Legacy for the New Post-1991 Competition Law and Regime}

For the reasons described earlier and in Appendix 8, from 1980 to the present day, the MRTPC applied a more legalistic approach to enforcing the MRTPA which emphasizes case quantity over quality. One consequence of the MRTPC's inconsistent rulings and inconsistent application of a competition test is that the MRTPA's case law will not be helpful to the new Competition Act in providing competition law guidance to businesses, promoting competition, and investigating and adjudicating cases.

According to some critics, the MRTPA's weak case law could even hinder the enforcement of the new competition law if commissioners and judges were to use inappropriate MRTPC rulings as important precedents. Therefore, the early efforts of the MRTPC during the 1970 s to build its reputation and credibility by means of enforcement cases that applied sound competition analysis and provided good case law, were badly undermined by the much more numerous cases later in the case study period of questionable quality, validity and credibility. These more problematic cases often represented attempts by competitors to injure another competitor or resolve contractual disputes, and by the government to achieve non-competition objectives.

time, the Monopolies Inquiries Commission estimated that the assets of India's 75 largest business concerns in 1964 accounted for $47 \%$ of total private corporate assets. 
Even after 1980, there were a few instances when good competition analysis from the MRTPC investigative staff and panel members, and good competition arguments from the company defense, led to sound application of the competition test and the analysis of market power consistent with vertical restraint and abuse of dominance cases in more experienced competition law jurisdictions. Therefore, in fairness, the MRTPC members were prepared to consider competition and consumer welfare issues when such evidence was available, but these competition arguments were only rarely presented.

The adoption of a more legalistic approach was perhaps necessary or was clearly expedient because of the MRTPC's limited financial and human resources and competition law experience and expertise, the Commission's even more limited political, bureaucratic and business influence and support, and the difficult and complex Indian political economy of the period. Regardless, the good case law from these rare cases indicate that the years of MRTPA implementation represent a missed opportunity to develop the competition skills, expertise and case law that will be needed by India's new competition law, agency and post-1991 competition regime ${ }^{197}$.

Based on the interviews and other sources, criticism of the pre-1991 competition regime by businesses, their trade associations, business media and other business advocates was more often directed at the MRTPA and MRTPC than at the broader licensing/competition regime from $1970 \mathrm{on}^{198}$. In addition to the MRTPC's impacts on

\footnotetext{
197 The challenge for the new Competition Commission of India and India's academic, legal and business communities is to pick through the MRTPA cases and separate the good from the bad case law. Unfortunately, competition agencies and the competition law defense bar rarely agree on what constitutes good case law. Moreover, the Indian judiciary is reluctant to employ case law from other countries (Rampilla 1989). The new Commission and the legal community therefore may be "starting from scratch' in building good competition case law in India.

${ }^{198}$ Within which these formal competition law institutions were embedded and which arguably greatly influenced and undermined the effectiveness of the Act and Commission (Chaudhuri 1973, Debroy 2003, Das 2002).
} 
the already high cost of transacting with government, research participants and other sources also described the additional opportunities the Act and Commission provided to government and the bureaucracy to further interfere in the corporate strategies, investment plans and day-to-day decisions of big business. Finally, with all its limitations and flaws, the MRTPC was probably less open to political and bureaucratic interference and business manipulation than many other parts of the 1965-1991 competition regime. Regardless of whether these judgements are deserved and fair, the MRTPA's difficult history is adding greatly to the challenges to be faced by the still evolving post-1991 competition regime, especially when enforcement of India's new competition law begins in 2009 .

Exhibit XV: Summary of the 1965-1991 Interactions and Accommodations And Their Outcomes and Consequences 
Competition Regime Perspectives

- MRTPA and broader competition regime largely a government project

- Complicated and overly ambitious MRTPA design that included both structural and business conduct provisions

- And mandatory review of all alleged restrictive trade practices and expansion plans of all MRTPA "monopoly companies" and business groups

- Number of MRTPA "monopoly companies" expands greatly from 1969 to mid-1980s

- Enforcement under both kinds of provisions - including regulation of large business groups and other MRTPA monopoly companies -- was information and analysis intensive

- Mandatory review of RTPs and investment plans of MRTPA monopolies was to promote government information, regulation and control objectives rather than competition and consumer welfare

- However, MRTPA was provided with limited financial and technical resources and India's government, business and academic communities had limited competition expertise.

- Leading to MRTPC adoption by the early 1980 s of a legalistic approach which privileged case quantity over quality and gave little emphasis to concentration, competition, consumer welfare, innovation, and competitiveness issues.
Business Groups/Informal Business Institutions Perspectives

- Limited influence on design of 19651991 competition regime

- Initial response was that, like the License Raj, the new competition regime could be used and manipulated to benefit the business groups

- But over time, more business groups and companies became MRTPA monopoly companies. And competitive threat from Asian Tigers and other developing country suppliers was increasing

- Plus growing recognition that interactions with MRTPC were information and analysis intensive and that an MRTPC enforcement case can be very expensive and result in loss of prestige (even when the probability of losing is low)

- Therefore, used other parts of the License Raj and various strategies to avoid the MRTPA and MRTPC

- Strategies included smaller scale plants, diversification into related and un-related product lines, and tacit economy wide market-sharing agreements between business groups

- And for the largest business groups, expansion through acquisitions and greenfield investments in foreign markets.

Leading to the Worst Possible Outcome - High Concentration, Limited Competition, High Production and Transactions Costs, Too Many Inefficient Plants and Companies (the 25\% market share limit rule) and Limited Innovation and Competitiveness (limited Schumpeterian efficiencies)

- Accommodations made by the competition regime and the informal business institutions are for the most part equally favorable and unfavourable, mainly unfavourable, to the two sides

- Comparatively few enforcement cases that directly affected the interests of business groups and other larger privately owned companies. Leading to limited if any reduction in industrial and market concentration and little increase in domestic market competition.

- Most business groups and other informal business institutions survived and prospered - in part through "MRTPA avoidance" strategies.

- But business fragmentation, small duplicate plants, too much product diversification, and limited exports and technology creation and adoption, further reduced the competitiveness of business groups, industries and the Indian economy.

- Transaction costs remained high and often offset India's many production-based competitive advantages

- Resulting in pressures from the private business sector for additional domestic market reforms to further reduce business regulation and the cost of transacting with government - and growing academic advice and government interest for more ambitious liberalization compared with the modest and adhoc 1980s reforms that were more pro-business than competition enhancing. 
The many interactions and accommodations between the 1965-1991 competition regime and India's traditional business groups and other informal business institutions that are most important to the post-1991 empirical story are summarized in Exhibit XV on the previous page ${ }^{199}$.

Exhibit XVI concludes this pre-1991 analysis and attempts to set the stage for the post-1991 case study through summarizing the enforcement history of the MRTPA and drawing out the implications for the new competition regime and in particular enforcement of India's new competition law scheduled to begin in 2009.

\footnotetext{
199 The two-way arrow in Exhibit XV illustrates that the interactions and accommodations take place through an extended period and that the accommodation of one side is often in response to an earlier accommodation of the other side, and to individual and joint learning by the different "players". In this manner, the interactions and accommodations approximate the moves and counter-moves of two or more players in dynamic game theory, when there are repeated games and incomplete information regarding for example: (i) the strategies of the players -- the competition regime has incomplete information on the current and future strategies of the business groups and visa versa); (ii) future payoffs/outcomes; (iii) when the game will come to an end -- e.g. when the government decides to change the competition regime or a business group goes bankrupt and "leaves the game"); and (iv) the timing and impact of external forces/shocks that are exogenous to the "game" (see Church and Ware 2000, Chapter 9).
}

For example, the existence of the merger and takeover provisions under the MRTPA, and the high transactions costs and uncertainties of securing merger and takeover approvals, discouraged merger and acquisition activity by business groups and other privately owned companies. In this case, (i) the competition regime established merger review that covered the larger business groups, (ii) the business groups interacted with the competition regime and learned by the early 1970s that merger review was expensive and risky, and (iii) therefore made the counter-move or accommodation of using other strategies instead of mergers and acquisitions to achieve their expansion objectives in a manner that minimized production and transactions costs combined together, and strengthened the potential for government support for future investments.

One of the insights from this analysis is that, because of path dependence and institutional inertia on both sides, the interactions, accommodations, moves and counter-moves, outcomes and individual and joint learning from the "first game" under the 1965-1991 competition regime (in Exhibit XV), have influenced and continue to influence the "second game" under the post 1991 competition regime (in Exhibit XVII in Chapter 8). These inter-period linkages are illustrated by the major attention given to the reintroduction of merger review in business group and industry association submissions and media reports on the new competition law (see Chapter 7). These intuitions, inferences and "heuristics" from dynamic game theory were applied implicitly by the author throughout the empirical chapters on interactions, conflicts and accommodations. 


\section{Exhibit XVI: Summary of the Enforcement History of the MRTPA and}

Implications for the New Competition Regime

\begin{tabular}{|c|c|c|}
\hline $\begin{array}{l}\text { 1970-1980: Some } \\
\text { significant high } \\
\text { profile } \\
\text { monopolistic trade } \\
\text { practices/AOD } \\
\text { cases which } \\
\text { applied the rule of } \\
\text { reason and } \\
\text { provided good } \\
\text { case law - leading } \\
\text { to criticisms that } \\
\text { the MRTPC } \\
\text { should do more } \\
\text { "group-busting" } \\
\text { through applying } \\
\text { more structuralist } \\
\text { and legalistic } \\
\text { approaches. }\end{array}$ & $\begin{array}{l}\text { 1980-1991: A few more } \\
\text { well analyzed and } \\
\text { adjudicated MTP, RTP } \\
\text { and AOD type cases that } \\
\text { provided good case law - } \\
\text { but most enforcement } \\
\text { effort on (often } \\
\text { uncontested) RTP and } \\
\text { UTP (consumer } \\
\text { protection) cases with } \\
\text { limited or at times } \\
\text { negative implications for } \\
\text { competition and } \\
\text { consumers. Misuse of } \\
\text { MRTPA to achieve other } \\
\text { government objectives and } \\
\text { adjudicate private } \\
\text { contractual disputes. }\end{array}$ & $\begin{array}{l}1991 \text { to Present Day: } \\
\text { Weakening of MRTPA } \\
\text { through 1991amendments } \\
\text { and of political will to } \\
\text { enforce the law against } \\
\text { business groups and other } \\
\text { large companies (now seen } \\
\text { as national champions). } \\
\text { Nearly all cases involve } \\
\text { the application of a } \\
\text { legalistic approach to } \\
\text { RTPs and UTPs that for } \\
\text { the most part have trivial } \\
\text { impacts on competition } \\
\text { but in some cases could } \\
\text { enhance efficiency. }\end{array}$ \\
\hline \multicolumn{3}{|c|}{$\begin{array}{l}\text { Implications for New Competition Law, Commission and Regime: Limited useful case } \\
\text { law and experience with competition cases. Negative attitudes among private } \\
\text { businesses, government elites and potential competition policy advocates regarding the } \\
\text { utility of competition law - attitudes that grow the longer the MRTPA is implemented } \\
\text { and the substantive enforcement of the new law is delayed (now more than six years). } \\
\text { Perhaps justified fears among businesses and their government and media supporters } \\
\text { that the new competition law will be enforced in the same way as the old one - leading } \\
\text { to higher business costs, re-regulation of business, and government interference and } \\
\text { meddling in business decisions and strategy, with little benefit to competition, } \\
\text { consumers and honest businesses that want to compete fairly. }\end{array}$} \\
\hline
\end{tabular}

\subsection{Conclusions}

The analysis in this chapter on the interactions, conflicts and accommodations between India's competition regime and its business groups and other informal business institutions from 1965 to 1991 broadly confirms the first time dependent argument in the conceptual framework. But in other ways, it also provides a more subtle and complex story than anticipated by this first argument. 
The business groups and other larger companies (that became the "MRTPA monopoly companies") had no significant direct influence on the design of the MRTPA which was enacted in $1969^{200}$, and on the related "populist" policies to regulate the business groups and other larger companies brought in by the Indira Gandhi government from 1969 to 1973 . The resulting interactions, conflicts and accommodations between the 1965-1991 competition regime and informal business institutions did little to reduce industrial concentration and the economic and market power of the country's traditional business groups, but did assist in achieving the government's broader political economy objectives. A comparatively modern competition law for that time $\mathrm{e}^{201}$, when embedded within a broader economic policy and competition regime which was essentially anticompetitive, became simply another instrument for business regulation and for impeding business entry and competition.

Nonetheless, the pre-1991 case study illustrates that competition regimes that do not achieve their proclaimed competition goals can still have major consequences for business and economic performance. The interactions, conflicts and accommodations between the regime and the country's business groups and other informal business institutions were multi-dimensional and complex, with many unanticipated and unintended consequences for both sides. These interactions and accommodations had major and largely negative consequences for the business groups' production and transactions costs and incentives, their corporate strategies, investment decisions and

\footnotetext{
200. The empirical evidence suggests as well that the business groups and business lobby had limited influence on subsequent amendments to the MRTPA through to 1991. Competition law design was very much a government project during the period covered in this Chapter.

${ }^{201}$ With a design that was not too different from and borrowed heavily from the models available in the United Kingdom and other OECD countries at that time.
} 
expansion and diversification plans, and their productivity, competitiveness, exports, and overall corporate performance.

Through their impacts on the performance of business groups and other MRTPA monopoly companies, the 1965-1991 competition regime also had a major influence on the structure and performance of India's private sector and total economy. The business group as an organizational form survived, most groups prospered, and many on balance benefited more from the 1965-1991 competition regime than the country's consumers and the total Indian economy. However, their contributions to the country's economic performance and development objectives were severely diminished.

The combination of high industrial and market concentration and too many inefficient manufacturing plants and companies of sub-optimal scale meant that the Indian consumer and economy had the worst of both worlds. The economy and its industrial customers and final consumers had to absorb the supra-competitive prices and profits of the business groups and other suppliers -- while receiving little or no benefit from the lower production and transaction costs and more innovative products that in the Schumpeterian growth model are associated with the economies of scale and scope and learning curve effects generated by large dominant firms and business groups (Aghion and Howitt 2006, Schumpeter 1976 and section 2.5). The complex trade and industrial policy controls and tax system of the License Raj meant that the limited entrepreneurial resources of business groups and other larger companies were diverted from activities that promote innovation, competitiveness, and wealth creation, to rent seeking, tax and regulatory avoidance and manipulation, entry deterrence, and government lobbying (Kathuria 1995, p. 176 and Dutz, Ordover and Willig 2000). 
Through to the early 1970s, the post-independence competition regime of India in some ways was consistent with and reinforced some of the strategies and preferences of the business groups. However, a subtle change in business group attitudes and benefitcost calculations is evident from the late-1970s on. The pre-1991 regime through the 1970s became more expensive and much less approachable, responsive, pliable, and predictable in meeting business group needs. Compared with before 1965, the 1965-1991 interactions and accommodations increased significantly in quantity but deteriorated in quality and outcomes for the business groups themselves and for the total Indian economy. The result was growing pressures for change from both government and the private business sector from the late-1970s on. This is the subject of the second case study in Chapters 7 and 8. 
Chapter 7: Interactions, Conflicts and Accommodations Between India's Still Evolving Competition Regime and Informal Business Institutions From 1991 to the Present Day

\subsection{Purpose}

This and the next chapter move the analysis forward in time by exploring the interactions, conflicts and accommodations between India's competition regime and its traditional business groups and other informal business institutions and arrangements from 1991 on. This chapter investigates interactions, conflicts and accommodations mainly from the perspective of India's post-1991 competition regime, while the next chapter adopts the perspective of India's traditional business groups and new economy companies and informal business arrangements. Chapters 7 and 8 combined together represent the second of the two time dependent case studies in Part II of the thesis.

Emphasis in this chapter is given to interactions, conflicts and accommodations associated with: the broader economic liberalization program from $1991 \mathrm{on}$; the design of India's new competition regime that led to the Competition Act 2002, the amended Competition Act of 2007, and the proposals for a "National Competition Policy" in India's $11^{\text {th }}$ Five-Year Plan; and, the now six year delay (as of December 2008) in beginning substantive enforcement of the new competition law. Conclusions are provided in the final section.

There are as a consequence three important differences between the two case study periods that should be noted at the outset. In contrast to the pre-1991 period analyzed in Chapter 6 , the post-1991 competition regime is characterized by a quite proactive competition policy under the liberalization program, but a seriously diluted, out-of-date and largely irrelevant competition law. Therefore, the empirical analysis in this and the 
next chapter gives comparatively greater weight to interactions involving broader competition policies, and less weight to interactions that involve competition law and India's competition agency.

Second, as described in the notes to Exhibit $I$ and in Chapters 5 and 6 (see in particular Exhibit XIV on p. 154), the pre-1991 competition regime was a comparatively coherent, albeit sub-optimal, anti-competition and arguably dysfunctional, set of quite well articulated competition policies, laws and regulations. These were designed to regulate business entry, expansion, diversification, and exit. In contrast, the post-1991 competition regime is characterized by the elimination of many but not all of these "anticompetition" policies, laws and regulations, the serious weakening of the MRTP Act and Commission, and the introduction of new policies and regulatory regimes in the areas of sectoral regulation, international trade, innovation and competitiveness. These new policies and regimes were designed to achieve other objectives, but have important and often positive implications and consequences for competition. The post-1991 competition regime also encompasses the design and passage of a new competition law and a National Competition Policy that had not yet been implemented at the time this dissertation was completed in late 2008 , but were already having some fairly significant impacts on corporate strategy.

The consequence is that, compared with the first case study period, the post-1991 regime is a work in progress with impacts that are less obvious, more conjectural, and more challenging to describe and explain based on currently available evidence. Finally, the business groups that dominated the pre-1991 period are now joined by new business 
voices and new kinds of informal business arrangements from India's rapidly expanding and more globally competitive information technology and other new economy sectors.

7.2 Limited Interaction with, Accommodation to, and Influence of Traditional Business Groups and Other Key Domestic and External Stakeholders Regarding India's Post 1991 Liberalization Program

Starting in the late 1970s, India's industry and trade associations, business groups, other larger companies and the business media were arguing in their published documents for domestic market reforms and less government regulation and interference in private business decision-making. By the early 1980s, consensus emerged among government, business and academic elites that selective "pro-business" reforms were needed to promote greater investment, growth and diversification of India's privately-owned companies and in particular the larger companies that are affiliated with India's business groups. The influence of the business groups and other business interests on these initial reforms is quite obvious from the literature and their pro-business intent. This influence includes the credible threat of a "private investment strike" in the late 1970s (Chibber 2003:2 and Chapter 6).

Critics of India's post-1991 more "pro-market" and "pro-competition" liberalization program argue in a similar manner that the business groups and other larger companies employed their extensive political connections with the Indian Congress Party, the Ministry of Finance ${ }^{202}$, and with other key political and bureaucratic participants, in promoting more comprehensive domestic and external reforms and ensuring that liberalization was consistent with their business interests. On the surface, the 1991 domestic, trade, and foreign investment reforms appeared to have much to offer the

\footnotetext{
${ }^{202}$ Which was and is the lead department in designing and launching the post-1991 liberalization program and implementing additional economic reforms.
} 
private business sector. These benefits would include: improved access to higher quality and/or lower priced imported inputs, foreign technologies, and foreign financial services; lower transactions costs from complying with fewer domestic regulations and other transactions with government; and more limited "unfair competition" from the government-favoured state sector through privatization of public sector undertakings (PSUs) and expanding the purview of the MRTPA to cover state-owned enterprises and other PSUs.

Less dependence on government and greater use of market forces under liberalization and the post-1991 competition regime would be anticipated to "empower" business groups and other privately owned companies by allowing them to take greater control of their day-to-day operations and future expansion plans. Therefore, many Indian economic analysts, political scientists and social activists believe that the country's private business sector benefited significantly from and helped to orchestrate and accelerate the liberalization program from 1991 through to the present day.

However, several research participants emphasized that India's traditional business groups and the private business lobby had very little influence on the timing and content of the 1991 liberalization reforms. The reforms were largely debated, prepared and finalized behind closed government doors, and their timing and comprehensive nature came as a surprise and shock to many business groups, other larger companies and their trade associations ${ }^{203}$. From the government's perspective, these reforms were badly

\footnotetext{
${ }^{203}$ Many economics and political science models, including those based on neoclassical economics and Marxist theory, presume that private business dominates the economy and society and that the state is structurally dependent on the private business sector. The political economy literature for India since independence has adopted a more nuanced approach. This approach recognizes the importance of the Indian state and the comparatively weaker position of the private business sector, which needs to negotiate with government and compete with other (government and non-government) business and economic
} 
needed to address the very serious balance of payments crisis of 1991 and India's poor growth performance since independence ${ }^{204}$. The government's argument that the balance of payments crisis made substantive liberalization reforms absolutely essential, was directed as much at the misgivings and potential opposition from the private business sector, as the potential concerns from other interest groups such as labour, civil society, and more left-leaning political parties. The message that "the government had no choice" was directed particularly at business preferences for the status quo - the modest domestic and pro-business reforms of the 1980 s that included very little trade liberalization and in some sectors provided market incumbents with even higher rates of effective protection from imports (Aksoy and Tang 1992).

As a consequence, there were no substantive consultations with, contributions from, and accommodations to business groups, other Indian owned businesses and trade associations before the 1991 reforms were announced ${ }^{205}$. Research participants and other sources indicated as well that external influences from e.g. the World Bank and the International Monetary Fund (IMF) and multinational corporations (MNCs) operating in

interests and agents for their "fair share" of state entitlements (see e.g. Bardhan 1984, Encarnation 1989, Sinha 2005:1 and Varshney 2007).

Moreover, as discussed in Chapter 6, up to the time of the MRTPA and the related populist reforms of the early $1970 \mathrm{~s}$, private businesses, including foreign invested companies, were quite comfortable with their positions of dependence within the broader political economy and society - in large part because they were rarely challenged to innovate, expand their horizons, export and compete, except for state licenses and other entitlements (see Chibber 2003:2). The conceptual framework developed and applied in this analysis is broadly consistent with this more nuanced approach, which based on the evidence was highly relevant up to 2000 and continues to resonate to the present day.

${ }^{204}$ Especially India's much slower growth compared with the East Asian economies during the 1970s and 1980s and with China starting in 1980 (see Chapter 5).

${ }^{205}$ Research participants and other sources indicate that the negative response of some business groups, larger companies and trade associations to the post-1991 liberalization program was the result of both the lack of business consultation as well as the more comprehensive nature of the reform program, especially the external liberalization reforms. 
India were also quite limited ${ }^{206}$. After over 40 years of strong FDI controls, the MNC presence and influence in India was quite weak in $1991^{207}$, and MNC interest in liberalization was also limited (see Chapter 6). The empirical evidence indicates therefore that, for the most part, the 1991 liberalization program was a Government of India project.

The initial reactions of India's private business sector to the post-1991 liberalization program were fairly positive, but these positions quickly turned more negative among some but not all business segments as seen in the protests of the Bombay Club in 199394. The major business groups voiced concerns that: external trade liberalization was happening too quickly; their companies were not yet ready for full foreign competition in domestic markets; and the loss of protection from imports and foreign investors would lead to lower market shares, revenues, profits and investments in their key domestic markets. In some ways, these business arguments had some merit. Based on the evidence from research participants and other sources, the Indian business groups and lobby in 1993-1994 employed the same "level-playing field and fair trade" arguments that are often made by American and other OECD country industries that now face strong import competition from low production cost manufacturers located especially in China.

Indian business groups and other companies questioned in particular the fairness of forcing companies to suddenly face global competition -- after these same companies had been prevented from expanding, diversifying and becoming more globally competitive

\footnotetext{
206 In particular, external influences on India's liberalization program were relatively insignificant compared with the structural adjustment programs of other developing and transition countries such as Indonesia where the IMF and the World Bank were very influential in the design and implementation of that country's liberalization program after the East Asian crisis of the late 1990s.

${ }^{207}$ The MNC presence in India remains fairly limited 17 years after the start of the liberalization program particularly in comparison with China and many other East Asian and emerging market economies (see Chapter 5).
} 
and innovative for over 40 years largely because of government imposed regulations. Business groups and other companies in the formal sector also complained that they faced much higher taxes and transactions costs (especially from their transactions with government), and more rigorous and costly labour, land use, environmental, factory, inspection and related regulatory regimes than: foreign competitors from China, Malaysia, Thailand, Indonesia and other developing countries; and, smaller Indian enterprises in the small firm reservation and informal sectors (Lewis 2004). However, these business arguments did not resonate with the media, consumers, voters, and senior government officials, who contended that there was no alternative to liberalization and integration into the global economy.

There were also important divisions between the various industry associations, which reflected the growing diversity and complexity of India's business interests. Among the major industries and associations, the Federation of Indian Chambers of Commerce and Industry (FICCI), the Associated Chambers of Commerce \& Industry of India (ASSOCHAM), and the Bombay (Mumbai) Chamber of Commerce and Industries, which had long histories and represented the more traditional industries, companies and business groups including the MNC incumbents, were the most opposed to market opening.

A third major industry association called the Confederation of Indian Industries (CII), which was established only in 1992, was less opposed to market opening - although some of its members joined the Bombay Club opposition to liberalization for purposes of business solidarity - and have been supporters of the liberalization program since then. The CCI is limited to manufacturing and related services (Sinha 2005:2) and represents 
the engineering, electrical and other "sunrise industries" and new economy interests. Many companies in these industries - especially the information technology (IT) companies located in South India -- were already moving forward with their own globalization strategies and in the process making the Bombay Club doubters look timid and non-progressive.

There were as well some important differences among the traditional business groups. For example, Reliance/the Ambani Group in its public pronouncements generally supported liberalization, the Tata Group provided "quiet support" only, and the Birla Group was concerned that the reactionary stance of the Bombay Club had gone too far. Over time, many major business groups deserted the Bombay Club because of its bad press and total lack of success in changing government policy. The result was that the Bombay Club opposition to liberalization basically disappeared by the end of 1994 . From that point on, accommodation and adaptation to the post-1991 liberalization program became the norm -- while the larger and better connected groups with deeper pockets and better political connections carried on the fight on their own in a less conspicuous and public manner on an issue by issue basis ${ }^{208}$. The result was that from the mid to late 1990s, most business groups, other larger companies and industries moved forward with corporate strategies to become more professional and innovative, meet foreign competition, and extend their global reach (see Chapter 8).

\footnotetext{
${ }^{208}$ Using e.g. anti-dumping and other trade remedy laws and their strong connections with central and regional state government and financial intermediaries to support and strengthen their positions in previously protected domestic markets.
} 


\subsection{Interactions and Accommodations with India's Traditional Business Groups and Other Non-Government Stakeholders in Designing the New Competition Law and Regime}

\subsubsection{Limited Business Influence and Interest up to the Raghavan (High-Level) Committee Report and Concept Bill in 2000}

At about the same time, there was growing consensus within the government that the MRTPA had to be either reformed or eliminated, and replaced with a more modern competition law consistent with the needs of an open, more rapidly expanding economy that was becoming a global player in information technology, biotechnology and other advanced technology sectors. Government interest in a more modern and effective competition law and regime was driven in part by concerns that, at that time, the success of its economic reform agenda was far from certain (Dutt, 1997).

Similar to the 1991 liberalization program and the broader competition regime that was emerging from the post-1991 industrial, trade and regulatory policy reforms, competition law reform from 1995 to 2000 was largely a government-led legal project. There was little interest among business elites, and there were no obvious contributions from the Indian business and law communities and from outsiders except for technical assistance through British $\left(\mathrm{DFID}^{209}\right)$ and other donors. Business and academic interest in competition policy and law in the 1990s was quite limited compared with previous decades (see Chapter 6). In addition, the competition law status quo after the 1991 liberalization -- with a weak and discredited MRTPC which had no merger review process and limited powers and political support to regulate the competition-related conduct of business groups and other larger companies -- was quite satisfactory to the

\footnotetext{
${ }^{209}$ DFID e.g. has provided financial and technical support to the competition law and policy research and advocacy work of CUTS - India's Consumer Unity and Trust Society based in Jaipur, Rajasthan state to the south and west of New Delhi - for over a decade. CUTS was the host for the author's field work in India in the summer of 2006.
} 
vast majority of Indian business groups and other companies. Finally, research participants in Southern India stated that competition law and related policy reforms were of little interest to information technology and other new economy sectors and companies that were already competing in global markets (see section 8.5).

Other government and related factors that helped place competition law reform on the Government of India's policy agenda after 1995 included the Singapore WTO Ministerial of 1996 which proposed preparatory work on the trade related aspects of competition policy and thus sent a strong message that the GOI should take a greater interest in competition law reform ${ }^{210}$. There were as well some high profile merger transactions in the mid-1990s, including several that involved foreign corporations ${ }^{211}$, which received generally negative political and media attention. Competition law reform would also send a clear signal to government ministries, political parties on both the left and the right, regional state governments, the private business sector and consumers/voters that the GOI was truly committed to the liberalization program.

\subsubsection{Business Group Preoccupation with the Re-Introduction of Merger Review From 2000 On}

Business groups, other large companies and their trade associations however became much more interested in competition law reform when the Raghavan (High-Level) Committee was established and published its first major report in 1999, and the

\footnotetext{
${ }^{210}$ By the time of the Seattle WTO Ministerial in 1999 , the Indian government had already made a commitment to reform its domestic competition law, while continuing to oppose the incorporation of the trade related aspects of competition rules into the WTO architecture. The GOI recognized India's limited experience with enforcing a modern competition law, and was looking for some form of reciprocity from other countries (see Government of India 1999:1 and 1999:2).

${ }^{211}$ One of these was the merger of TOMCO (a Tata consumer products company) into Hindustan Lever, which took place in the mid-1990s. Concerns that India no longer had a system to assess the competition impacts of mergers and other combinations often emerged when a large merger transaction received media attention.
} 
government began serious work on the Draft Competition Bill in 2000. Business concerns focused almost exclusively on the re-establishment of merger review.

The proposed new merger review process was seen by business as re-regulation, the reintroduction of structural features into Indian competition law, the return of the License Raj in a modified but potentially still dangerous form, and as a serious threat to corporate restructuring through mergers, acquisitions and divestitures that was being implemented then and now by most of the Indian business groups and other larger companies. They argued with some merit and considerable effectiveness that, based on the pre-1991 MRTPA experience, long delays, needless and costly adjustments in the merger transaction to satisfy regulatory authorities and political interests, and high legal, lobbying and other transactions costs would be the inevitable result of an overly restrictive merger law. As a result of these arguments, the business groups and lobby were successful in significantly raising the merger size thresholds ${ }^{212}$, and in significantly modifying how a merger transaction is defined, between the time of the Concept Bill of 2000 and the Competition Bill that was tabled in the Indian Parliament in 2001.

Raising the merger size thresholds addressed industry and government concerns that Indian firms had to restructure and become larger to meet global competition. The merger size thresholds in the Competition Bill 2001 were more than double the thresholds found in the earlier Raghavan Report and the Concept Bill 2000. The size

${ }^{212}$ In 2000-2001, the business lobby also was successful in turning mandatory into voluntary merger notification. However, as noted in Chapter 1 and Appendix 5, mandatory notification was reintroduced into the Competition Amendment Bill passed in September 2007. The private business sector argued strenuously against mandatory notification in a 2007 submission to the GOI (International Bar Association 2007:1), but without success. In the author's view, the high thresholds are much more important to businesses and competition than mandatory notification. With the high size thresholds, relatively few transactions will need to be notified by each business group or larger company each year or even each halfdecade. 
thresholds included in the Competition Act Amendment Bill approved by the Indian Parliament in September 2007 are described in the Table on the next page.

\begin{tabular}{|c|c|c|c|c|}
\hline \multirow[t]{2}{*}{$\begin{array}{l}\text { Type of } \\
\text { Combination }\end{array}$} & \multicolumn{2}{|c|}{$\begin{array}{l}\text { For the Merging Etc. Parties } \\
\text { Combined Together }\end{array}$} & \multicolumn{2}{|c|}{$\begin{array}{l}\text { For the Business Group for Which } \\
\text { a Party is a Member }\end{array}$} \\
\hline & In India & Worldwide & In India & Worldwide \\
\hline $\begin{array}{l}\text { Acquisition, } \\
\text { Dominant } \\
\text { Position, or } \\
\text { Merger and } \\
\text { Amalgamation }\end{array}$ & $\begin{array}{l}\text { Combined Assets } \\
\text { of Rs } 1,000 \\
\text { Crore (Cr): } \\
\text { which translates } \\
\text { into Rs } 10 \text { billion } \\
\text { or USD } 222 \\
\text { million }^{213} \text {; or, } \\
\text { Combined } \\
\text { Turnover of Rs } \\
3,000 \text { Cr: that is, } \\
\text { Rs } 30 \text { billion or } \\
\text { USD } 666 \\
\text { million. }\end{array}$ & $\begin{array}{l}\text { Combined Assets } \\
\text { of USD } 500 \\
\text { million; or } \\
\text { Combined } \\
\text { Turnover of USD } \\
1.5 \text { billion } \\
\\
\text { And in India } \\
\text { Combined Assets } \\
\text { of Rs } 500 \text { Cr: Rs } \\
5 \text { billion or USD } \\
111 \text { million; or } \\
\text { Combined } \\
\text { Turnover of Rs } \\
1,500 \text { Cr: } 15 \\
\text { billion or USD } \\
333 \text { million }\end{array}$ & $\begin{array}{l}\text { Combined Assets } \\
\text { of Rs } 4,000 \\
\text { Crore (Cr): that } \\
\text { is, Rs } 40 \text { billion } \\
\text { or USD } 889 \\
\text { million; or, } \\
\text { Combined } \\
\text { Turnover of Rs } \\
12,000 \text { Cr: that } \\
\text { is, Rs } 120 \text { billion } \\
\text { or USD } 2.7 \\
\text { billion. }\end{array}$ & $\begin{array}{l}\text { And in India } \\
\text { Combined Assets } \\
\text { of Rs } 500 \text { Cr: Rs } \\
5 \text { billion or USD } \\
111 \text { million; or } \\
\text { Combined } \\
\text { Turnover of Rs } \\
1,500 \text { Cr: } 15 \\
\text { billion or USD } \\
333 \text { million }\end{array}$ \\
\hline
\end{tabular}

Source: Minister of Corporate Affairs (2007:1) "Press Release: Shri Prem Chand Gupta Introduces Competition Amendment Bill 2007" August 29, 2007

Raising the merger transaction size thresholds ignores the fragmented nature of many Indian markets, which are divided into smaller local and regional markets because of e.g. high transport costs, inter-state barriers to trade and regional differences in consumer tastes. Based on the size thresholds and how mergers are defined in the current merger provisions in the new competition law, below-threshold mergers that lead to high degrees of concentration and serious competition issues in smaller local and regional markets will not be investigated and adjudicated by the new Competition Commission of India (Chakravorty 2006, pp. 62-63). Recent estimates are that only about 100 transactions per

\footnotetext{
${ }^{213}$ Based on the exchange rate of Rs $\mathbf{4 5}$ to the US dollar (the approximate average over the period from 2003 to 2006 when most of the information collection and analysis for this thesis were conducted). As noted before, as of early December 2008, the exchange rate was nearly Rs 49 to the US dollar, up from about 40 a year earlier. .
} 
year will be reviewable under the new Act's merger provisions (Agarwal 2005, p. 77). All of the remaining merger transactions will be completed without challenge by the CCI - regardless of their predicted impacts on competition, efficiency and consumer welfare in urban, state and/or smaller national markets ${ }^{214}$.

By limiting merger review to the largest mergers and allowing all others to proceed without review and possible challenge by the CCI, the merger provisions accept the traditional national champion strategy to global competitiveness, and thus ignore the past record and current international trade and competition realities ${ }^{215}$. In most competition law jurisdictions, the essential criterion for merger analysis is the extent of competition in the relevant market, not the size of the merging companies. Size thresholds simply muddy the issue and allow anti-competitive mergers of medium-sized firms to go unchallenged by the CCI. The large size thresholds, when combined with mandatory notification in the amended statute, will as well result in the mis-allocation of the CCI's limited investigation resources and expertise to mergers of two larger firms that do not raise competition issues because e.g. barriers to entry are low and/or the relevant antitrust market is national or global with a large number of actual and potential competitors $^{216}$.

\footnotetext{
${ }^{214}$ This means as well that two or more smaller companies (that is, companies below the size thresholds) that are operating a successful cartel in a smaller Indian market can avoid investigation and prosecution under the anti-competitive agreement provisions of the new Competition Act by simply merging their operations together (Ireland 2007:2).

${ }^{215}$ Competitiveness strategies that allowed dominant firms to enjoy high prices for extended periods in protected local markets before entering national and global markets did not work in the past in India, have rarely worked in other countries, and are now even more problematic because of the growing use of antidumping, countervail and other trade remedy laws among most WTO members, including by India.

216 Similar to mandatory review of RTPs and "monopoly companies" under the MRTPA, mandatory merger notification and review of large mergers that raise no competition issues provide non-competition information from merging parties that will help the GOI to advance and protect its own economic and business interests - while reducing the CCI resources available for other competition cases, education and
} 
The success of the business groups and lobby in having these merger threshold and related changes adopted before Parliamentary introduction and review of the Competition Bill in 2001 was particularly beneficial to the private business sector. This strategy minimized political and public debate at this critical stage - and greatly increased the difficulties faced by competition advocates from the academic community and civil society in arguing for a stronger competition law and merger review process before the Standing Committee that reviewed the competition bill in detail.

The author's detailed review of the Raghavan Committee Report and the subsequent competition bills and act indicates that the competition regime's accommodations to the business groups and lobby not only raised the size thresholds. They also significantly modified how a merger transaction was defined under the new competition law. The latter accommodation may prove to be more important than the former. The discussion of merger size thresholds in the Raghavan Committee Report was contained in subsection 4.7.4 entitled Pre-Notification (pp. 37-39).

After that, in its concluding merger section on page 39 , the Committee recommended that the test of whether a merger is to be permitted or not should be based on the expected impact of the merger on market power and competition in the relevant market. This recommendation is then followed by a number of indented sub-clauses regarding the additional factors to be considered in reviewing the merger ${ }^{217}$. The next recommendation then describes the thresholds for mandatory pre-merger notification. In this manner, the

advocacy; and resulting in higher transaction costs and needless delays for merging parties (The Economic Times 2008).

${ }^{217}$ These factors include a number of issues found in merger review in OECD countries such as: (i) size and growth of the market, (ii) presence or absence of entry barriers, (iii) assessment of how the market is to evolve, (iv) whether the markets of the merging parties overlap, and (v) whether the market is susceptible to collusive behaviour. 
Committee separated the definition of an anti-competitive merger, based on market power and a competition test, from the threshold for mandatory pre-merger notification.

Either by mistake or by design when drafting the Competition Bill 2001, the Committee's definitions of asset size for purposes of mandatory pre-notification became a merger definition in the 2001 Competition Bill based on the much higher asset and turnover size thresholds compared with the Raghavan Committee's recommendations. Only transactions above these very high thresholds are determined to be a merger, acquisition or combination for purposes of the amended Competition Act 2007. Smaller transactions are not deemed to be a merger, acquisition or combination under the Act. As a consequence, asset and turnover size thresholds for purposes of mandatory notification in the Raghavan Committee Report became much higher asset and turnover size thresholds for purposes of determining a merger, acquisition or combination under the Competition Act. The Raghavan Committee did not intend that smaller mergers, which were below the size thresholds for mandatory notification but raised competition concerns, should be exempt. Rather, the Committee's Report and the Concept Bill of 2000 that was based on that report proposed the exact opposite.

The success of the business groups and community in publicly lobbying for high size thresholds and for using those thresholds to define a merger or other combination dramatizes how interactions and accommodations between India's competition regime and traditional business groups and other informal business institutions have changed and are now on more equal terms -- compared with forty years ago when the MRTPA was established and a less self-confident and more government dependent private business sector decided to work behind the scenes to circumvent and neutralize the merger, 
acquisition and MRTPA monopoly company provisions of the old competition law (see Chapter 6).

Perhaps as an unintended consequence and benefit, reviewing only the largest mergers ensures that the Indian merger review rules and the CCI can be used to protect the global interests of the large business groups and other large Indian companies: when large MNCs are planning to merge with a competing Indian firm or conduct a hostile takeover of one of their own affiliated companies ${ }^{218}$; and when international cross-border mega-mergers that affect their interests -- either as global competitors or as one of the merging parties -- are taking place. Despite the large size thresholds, the CCI will still be in a position to review virtually all cross-border mega-mergers, including those that likely will have only a de minimus affect on India's competition, consumer, and business interests $^{219}$.

The business groups and the business lobby had some success on two related fronts which indirectly illustrate the private business sector's concerns that the new competition law should not be used to bring back the costly business regulation system that they associate with the MRTPA. First, all references to business groups, demergers, and undertakings based on MRTPA definitions, which were proposed by the Raghavan Committee, are absent from the Competition Bill 2001, the Competition Act 2002, and the Competition Amendment Act of 2007. Second, the Raghavan Committee Report on page 39 stated that the $\mathrm{CCI}$ should have the power to advise the government on a

${ }^{218}$ In light of India's merger wave since 1991 and the country's greater integration into the global economy, hostile takeovers are seen as a real threat to India's business groups, particularly when the group and its other affiliates own only a small portion of the shares of the affiliated company target (which is normally the case), and the target is a strong performer with a good cash position and other assets.

${ }^{219}$ And therefore will be in a position to promote India's interests and sovereignty and reduce the anticompetitive impacts on India of large cross-border mega mergers. 
demerger or severance of interconnection between undertakings or division of undertakings along the lines of Sections 27, 27A, and 27B of the MRTPA 1969 with suitable modifications - with the government to make the final decision ${ }^{220}$. This second reference to the MRTPA in the Raghavan Committee Report also does not appear in the Competition Bill 2001 or the subsequent Competition Acts. The only reference to divestiture in the amended Competition Act 2007 is in the abuse of dominance section ${ }^{221}$.

Business group and lobby success in increasing the merger size thresholds, redefining mergers and thus weakening -- and minimizing their interactions under -- the merger review section, could however lead to more difficult and costly interactions under the two other major enforcement sections of the new competition law. This is because below threshold merger transactions can be reviewed later under the abuse or anti-competitive agreement sections of the new law. This approach could easily be more expensive for the companies, the CCI and the economy more generally because of the high business, economic and social costs of unbundling a completed merger (Agarwal 2006:1, p. 72). Fear of later applying the abuse of dominance and anti-competitive agreement provisions could provide the basis for a program of business education and voluntary compliance, targeted on medium sized (below threshold) firms that are considering a possible merger. The merging firms should particularly recognize that business practices that were pro-

\footnotetext{
${ }^{220}$ This in many cases would have involved forcing an affiliated company to become totally independent from (and thus sever itself from) its business group. In light of the role of non-transparent informal business institutions and rules of business conduct in holding together a business group (see Chapter 4 , Exhibit XII), accomplishing such a severance and ensuring that it is maintained over the longer term would have been a major enforcement challenge for the $\mathrm{CCI}$.

${ }^{221}$ While the Competition Act 2002 required both $\mathrm{CCI}$ and government decisions to force a divestiture, the amended statute passed in 2007 allows the division of a dominant enterprise to be ordered by the CCI itself, without recommendation to and approval by the government (see e.g. CUTS International 2006). Regardless, whether political economy factors would allow the CCI to order the "demerger" of two merged companies remains an open question (see e.g. the competition law submission of the Bombay Chamber 2000, p. 14). In fact, this power was included in but not used under the MRTPA.
} 
competitive or neutral before the merger may become anti-competitive abuses of dominance after the merger -- once the merged companies have achieved a much stronger market position $^{222}$.

Once these merger review and related demerger and divestiture changes had been realized by the business groups and lobby, the remainder of the Competition Act 2002 was accepted by the private business sector with little comment and change. The weakening of the merger review rules may have been the compromise needed to ensure that a fairly major reform of Indian competition law, which included the reinstatement of some kind of (albeit limited) merger review process, was approved by Parliament -- with nominal and quiet support (or at least no loud objections) from the country's private business sector at the end of 2002. Furthermore, merger review is highly information, analysis and resource intensive, and involves high costs for the competition agency and high fees for defense lawyers and economists. Therefore, fewer merger transactions to investigate, review, discuss, negotiate and modify with the merging parties, and to monitor and regulate after the transaction is completed (Sims and Herman 1997), may mean that the CCI will have more resources available for abuse of dominance, cartels and

\footnotetext{
${ }^{222}$ The proposed Jet-Air Sahara passenger airlines merger, which was later dropped by the two companies, points out the challenges for a competition agency when merger review under competition law has limited scope. The MRTPC approved the merger, despite the combined high market share of approximately 50\% that the merger parties would have enjoyed after the transaction. In approving the proposed merger in 2006, the MRTPC statement noted that the proposed transaction did not violate any provision of the MRTPA.

The statement indicated as well that the MRTPC's capabilities were limited because merger review was dropped from the Act in 1991, and that the matter could be investigated again if the combined entity postmerger was found to be engaging in restrictive trade practices (The Tribune 2006). The CCI will have to adopt a similar position on mergers that raise competition concerns among politicians, civil society groups and the media, but fall below the new Act's size thresholds. These press releases, which point out the statutory limitations of the competition law and agency, can weaken support for and the credibility of the new law and agency among competition policy advocates and the general public.
} 
other horizontal arrangements that on balance may involve more serious harm to competition in Indian markets.

Nonetheless, the adoption of much higher size thresholds for defining a merger under the new competition law was a major success for the business groups and lobby, which could have important (intended and unintended) consequences for the credibility and effectiveness of the new law and commission once the merger provisions become fully operational and its statutory limitations become better known among competition policy advocates, the media and the general public - especially in light of the wide coverage given to merger transactions by the business and general media.

\subsubsection{Much Less Business Lobby Interest in the Sections on Cartels and Other Anti- Competitive Agreements and on Abuse of Dominant Position}

In sharp contrast, the business groups, other larger companies and their trade associations gave much less attention to the other two major sections of the Competition Bill on cartels and other anti-competitive agreements and on abuse of dominance ${ }^{223}$. This lack of interest results from a large number of interrelated factors. Business groups have less familiarity and direct experience with these sections of competition law and the actual anti-competitive business practices that these sections are intended to remedy ${ }^{224}$. A second consideration is the past and often current ability of business groups and other

${ }^{223}$ The preoccupation of the private business sector and their legal counsel with the merger review provisions has continued up to the present day (December 2008). Most of the media commentary and business lobby submissions since the Competition Amendment Act was prepared and then passed in September 2007 have concerned the "unfinished business" in merger control to be addressed through regulations and guidelines to be prepared by the CCI (see e.g. International Bar Association 2007:1 and 2007:2).

${ }^{224}$ A related consideration is that mergers and acquisitions are major generators of legal fees and other corporate costs throughout the global economy, and therefore private lawyers and corporate counsel within companies give major attention to and become highly knowledgeable about the merger review systems under competition laws in the more important competition law jurisdictions. Indian based law firms share in this interest and knowledge through their participation in global networks on competition, corporate, intellectual property and related marketplace laws. 
larger companies to use their market power to discipline the pricing and other strategies of their suppliers and to pass on the costs of any anti-competitive practices that remain to their industrial customers and final consumers.

India's business groups also to date have had limited exposure to strong inter-firm rivalry in many domestic markets and to international corporations, markets and business practices, including anti-competitive conduct, in Indian and foreign markets -- despite 17 years of liberalization. Finally, based on their past experience, the business groups may still have the expectation that, in enforcing the two sections on abuse of dominance and on cartels and other anticompetitive agreements, the CCI will be as flexible, pliable, open to government and business lobbying, and as inactive as the previous MRTPC.

This situation will likely continue until the market presence and power and political influence of the business groups are further reduced ${ }^{225}$; their affiliated companies are facing intense rivalry, stronger competitors, and anti-competitive practices in their key markets; and the CCI has successfully investigated and adjudicated a few high profile cases under the two non-merger sections, where the remedies clearly hurt the defendant company or companies, and result in improvements to competition, consumer welfare and the financial performance of the companies that were disadvantaged by these anticompetitive practices ${ }^{226}$.

${ }^{225}$ Through imports, inward direct investment by international corporations, domestic entry and the more rapid expansion of the new economy sectors and companies.

${ }^{226}$ More specifically, the efforts of the new Competition Commission to inform the private business sector and its supporters within government that the anti-competitive and abuse of dominance provisions of the new Competition Act are available to address non-reviewable but anti-competitive mergers that subsequently lead to a reduction or prevention of competition, would be more effective if they were supported by a few high profile, well investigated and successful cases under the anti-competitive agreement and abuse of dominance sections. These cases would illustrate and send the message that these two sections have real enforcement "teeth". Competition education, advocacy and voluntary compliance programs supported by good case law under the first two sections would then have a significant impact on 


\subsubsection{More Subtle but Still Potentially Important Changes to the Non-Merger Provisions from the Two Competition Bills 2000-2001 to the Competition Act 2002 and Amended Competition Act 2007}

Nonetheless, business groups and other larger companies benefited from more subtle changes made to the Competition Bill and Act that from their perspective made the anticompetitive agreement and abuse of dominance (AOD) provisions of the Act less effective, threatening and dangerous. These more subtle but still potentially important changes reportedly were driven by government ministries and officials rather than business lobbying ${ }^{227}$. Nonetheless, the benefits to the private business sector from these changes are quite obvious ${ }^{228}$. These changes could take on added importance in the future if they establish precedents in India's competition case law that impede future enforcement $^{229}$.

Most importantly, the preamble to the Act includes a modified "public interest" test that competition policy should be designed to support the country's overall development path. This development criterion was added as well to the new law's abuse of dominance and merger provisions. This development oriented public interest criterion could be used and at times misused by business groups and other special interests to lobby for specific

how Indian companies structure their future merger transactions and other business combinations (Ireland 2007:2).

${ }^{227}$ All of these pro-development and pro-business additions and changes have been carried over into the final Competition Act as amended and approved by the Indian Parliament in September 2007.

${ }^{228}$ Unlike the merger review changes, the author was not able to uncover any direct evidence of business lobbying to modify these non- merger provisions in favour of business. However, business groups and their associations have their supporters within government and the bureaucracy, and are very good at working with them behind the scenes.

The author therefore has employed two kinds of evidence for identifying the impact of business (or any other group) on a government policy, law or regulation: (i) direct evidence based on position papers, media reports of meetings and consultation sessions, and comments by knowledgeable participants in interviews; and (ii) indirect evidence based on who does and does not benefit.

${ }^{229}$ Given the MRTPA experience where bad precedents had the cumulative effect through time of restricting the purview and effectiveness of that competition statute (see Chapter 6 and Bhattacharjea 2003:1 and 2003:2). 
and more general exceptions and exemptions for certain kinds of anti-competitive business arrangements and conduct associated with e.g. the establishment of a "national champion" to dominate a key "industry of the future" ${ }^{\text {230 }}$. The additional danger is that this public interest criterion, combined with the 2002 amendment to the new Competition Act that allows the Competition Commission of India to stop imports from entering the Indian market (discussed further below), could be used by domestic businesses to protect themselves from import competition in the Indian market and thus maintain highly protected, concentrated, and profitable oligopoly markets for themselves (Bhattacharjea 2003:1, pp. 14 and 19) ${ }^{231}$. Businesses and their legal counsel could argue e.g. that imports would prevent the growth of a "national champion", or would lead to plant closures and job losses and thus would not promote India's economic development, job creation, and poverty reduction efforts.

Business groups and other private businesses will benefit from many other additions and amendments to the Competition Act. Clear definitions are provided for various anti-competitive practices and for the criteria to be applied for determining the relevant geographic or product market in competition law cases. These provide the "bright lines" in competition law that generally find favour in business circles, but may reduce the

\footnotetext{
${ }^{230}$ A more specific concern is that this development criterion in the Introduction/purpose clause of the new Act - when combined with the open ended joint venture exception and the under-developed intellectual property rights provisions with their positive tone - could dilute and seriously complicate the enforcement of the Act's per se provisions against "hard core cartels" in the areas of price fixing, quantity limiting, market sharing and bid-rigging. The danger is that over time the development criterion could turn these per $s e$ provisions into a more flexible hybrid rule of reason test that would greatly complicate the investigation, analysis and enforcement of these hard core cartel offences for a new and inexperienced competition agency, and would introduce a form of "national champion" defense into their analysis and the case law that would negate their per se aspect.

${ }^{231}$ In this respect, the new Competition Act represents a step backward compared to the MRTPA. As noted by Bhattacharjea (2003:1, p. 14): "Section 38 of the MRTPA at least listed specific circumstances - the socalled "gateways" -- that could be addressed to rebut the presumption that a particular RTP was against the public interest. The amended new Competition Act of 2002 leaves these determinations entirely to the Commission's subjective understanding of 'development'."
} 
flexibility needed to fully apply the rule of reason approach. The new Competition Act treats intellectual property rights in a positive manner and provides no recognition of the harm to competition that can be caused by the abuse of IPRs ${ }^{232}$. The final Act as well contains changes that arguably soften the abuse of dominance section. In the Competition Bill 2001, factors for determining a dominant position included specific reference to technical advantages including the advantages provided by IPRs and other commercial rights acquired by the enterprise. However, these specific references were removed from the Competition Act of 2002, which may add to the challenges of effectively applying the abuse section ${ }^{233}$.

The Competition Act includes a joint venture efficiency exception in the anticompetitive agreements section $^{234}$; while the definition of combinations for merger review does not include joint ventures, strategic alliances and other less formal forms of firm combination ${ }^{235}$. These changes to the final act provide greater flexibility to

${ }^{232}$ Even though such provisions are recommended in the TRIPs agreement of the World Trade Organization. This could mean that the authority to address abuses of intellectual property rights remains with the Patent Act, which likely would not apply competition and related tests (Bhattacharjea 2003:1, p. 26). Such IPR abuses potentially could still be addressed under the abuse of dominance provision, but formal recognition in the Act would have assisted investigation, adjudication, the design of appropriate remedies by the CCI, the Commission's business education and voluntary compliance efforts, and the generation of complaints from businesses and consumers.

${ }^{233}$ In manner proposed by Williamson (1975) and described in sub-section 2.7.2.

${ }^{234}$ This efficiency exemption is somewhat similar to many other competition law jurisdictions such as the block exemption applied in the EU since the mid-1980s and the rule of reason approach to R\&D joint ventures in the United States. Under the Indian Competition Act, efficiency-enhancing joint ventures are excluded from the new act's prohibition against horizontal anti-competitive agreements. In one respect, this exemption under the Indian Competition Act 2002 is much broader than in many OECD countries, since it is not limited to $R \& D$ and innovation based joint ventures and no other conditions are imposed. In other respects, the exemption is narrower than in other countries since it applies only to joint ventures, and not to e.g. strategic alliances and other kinds of informal business arrangements between two independent companies (Bhattacharjea 2003:1, p. 15-17).

${ }^{235}$ Industry argued that including these informal arrangements under merger review would discourage the establishment of pro-efficiency joint ventures which are becoming increasingly important in the national and global economy. This exclusion likely also protects informal arrangements within existing business groups. More generally, informal arrangements within business groups appear to be largely outside the 
traditional business groups and new economy economies in structuring their future informal business institutions and arrangements. Perhaps more significantly, as discussed in the footnote, these changes apparently removed from the purview of the Competition Act many of the informal rules of business conduct and arrangements that are employed by and between nominally independent companies within a business group.

The definition of a dominant position excludes the positions of strength enjoyed by enterprises in markets outside India. This arguably allows large MNCs that have dominant positions in global markets to have small operations in India without raising abuse of dominance issues under the Indian competition law. At the same time, this exclusion could assist and protect Indian business groups that establish dominant positions in foreign markets. This feature of India's new AOD provisions ignores the ability of large international corporations, as well as India's business groups with major foreign operations, to leverage market power in other jurisdictions in order to deter entry and hurt competition and consumers in Indian markets. It as well could impede India's participation in major, cross-border, multiple jurisdiction investigations of abuse of dominant positions that are established by very large international corporations.

A 2002 amendment to the new Competition Act allows for temporary injunctions to restrain imports that can be used and misused by domestic firms to eliminate import competition (Bhattacharjea 2004 pp. 342-344). This 2002 amendment allows the Commission to issue a temporary injunction that would restrain a party from importing goods, if the imports are likely to contravene the new Competition Act's provisions on cartels, other anti-competitive agreements, abuse of dominance, or combinations. These

purview of the competition law, just as similar institutions and arrangements within a conglomerate or multi-division company are normally not subject to a competition statute - unless their negative impacts on competition are very obvious. 
temporary injunctions can be provided without a hearing and can be in place for many years until a final determination is made. The injunction can be provided when prices are either too high, which arguably could be evidence of a foreign cartel or conspiracy, or too low which could be evidence of price predation (Bhattacharjea 2003:1, p. 19). Finally, the new law includes a "meeting the competition" defense for price discrimination. This test does not take account of the potential for price discrimination to be employed, especially by larger firms with significant financial resources, in order to support predatory pricing and other anti-competitive conduct, to prevent entry, and as a facilitating practice to support collusion (Bhattacharjea 2003:1, pp. 17-18).

These amendments and additions to the new Act could be difficult to interpret and operationalize by the new and inexperienced Competition Commission and Appellate Tribunal, and could in time result in case law and legal precedents that could complicate and weaken future enforcement (Bhattacharjea 2003:2, p. 223). They could as well lead to difficult future interactions between the competition regime and business groups and other informal business institutions that could be complex and costly and result in uncertain and unfortunate outcomes for both sides.

\subsection{Summary of the Major Interactions, Accommodations and Outcomes, and their Implications from the Competition Regime Perspective}

Because of successful industry lobbying and the changes made by government to meet perceived business and economic development needs, India's new Competition Act has some of the following attributes. Larger international and domestic transactions that are above the high thresholds but pose no threat to domestic competition will still need to be notified to and reviewed by the CCI. At the same time, the merger section of the new Act does not address the informal business institutions and arrangements of business 
groups, and the mergers and acquisitions of small and medium sized firms that often can raise competition issues in sub-national markets. Furthermore, larger mergers that are above the thresholds and raise competition issues may be able to apply/misapply the economic development (public interest) criterion to receive approval from the Government of India. The development criterion and the permissive treatment of intellectual property rights also could be misused over time to exempt anti-competitive cartels, abuses of dominant position and other anti-competitive agreements, arrangements and conduct from investigation and enforcement under the new competition law.

The mandatory notification and review of the largest (above-threshold) mergers will result in some costs and delays for the merging parties. This may lead to some of the same merger avoidance strategies that business groups and other larger companies used to circumvent the MRTPA (see Chapter 6). The weaker merger provisions as well place a greater burden on the two other substantive sections of the Act to ensure that competition is not significantly reduced and prevented, market power is not abused, and anti-competitive agreements and conduct are not promoted, in post-merger Indian markets.

While the new Competition Commission of India (CCI) is on balance more independent and better resourced that its predecessor, some important restrictions have been placed on its competition education, advocacy, voluntary compliance and other functions. Competition advocacy will typically take place only at the direct request of the national and state government. The Commission remains financially dependent on appropriations from the government to finance its operations, competition policy advocacy initiatives, and the investigation and enforcement of specific competition law 
cases. Competition policy advocates interviewed during the field work stated that the powers and independence of the CCI are more limited than those of some other economic regulators in India. This at best sends a mixed signal to market participants regarding the government's commitment to competition policy and law and to competitive markets and outcomes.

Beyond the pro-business changes and additions described above, there are other aspects of the new Competition Act that: should be viewed with favour by the private business sector, should lead to more positive interactions between the competition regime and the country's informal business institutions compared with the pre-1991 case study in Chapter 6 , and therefore should be emphasized by the CCI and GOI in their education, voluntary compliance and related competition advocacy activities directed at the private business sector. Through addressing domestic and foreign based cartels, price-fixing and other collusive practices, enforcement of the new competition law should lead to lower prices for intermediate goods purchased domestically and from foreign suppliers by Indian companies that wish to compete on more equal terms with international companies in Indian and international markets. The new Competition Act arguably applies a per se prohibition against so-called hard core cartels (Bhattacharjea 2003:1, p. 31), which could add to effective cartel enforcement ${ }^{236}$.

India's new competition law should allow for a more balanced treatment of vertical restraints and other non-standard forms of contracting, which would take greater account of their potential efficiency enhancements. Based on the 2002 Competition Act, the administration of the merger review provisions was to be delayed for three years from the

${ }^{236}$ While increasing the risk that the CCI like the MRTPC will apply a legalistic approach that will prosecute and otherwise discourage and prevent other kinds of potentially efficiency-enhancing horizontal agreements (interaction three in Exhibit II). 
start of the new law's enforcement, to provide time for Indian companies to complete their current merger and acquisition transactions and to fully adjust to the new merger review regime. If this three year "grace-period" is still applied under the amended statute that was passed by the Indian Parliament in September $2007^{237}$, this would mean that full merger review will not begin until at least 2011. The result would be that Indian business groups and other companies would not have been subject to merger review under competition law for two decades.

When these accommodations and related features of the new Competition Act are reviewed together by means of the conceptual framework in Chapter 3 , the danger of misusing the act to undermine pro-efficiency business arrangements has been reduced (interaction three in Exhibit II), at the expense of a more limited capability to proactively enforce the act to promote competition and a competition culture (interaction two). There is as well a greater risk that the new Competition Act will be subordinated to broader business, economic and social interests (interaction one).

\subsection{Role of Business Groups and the Business Lobby in Delaying Enforcement of the New Competition Law}

There is no empirical evidence (only conjectures and conspiracy theories) that business played a role in: the judicial dispute that began in 2003 a few months after the Act was passed by the Indian Parliament and delayed the start of substantive enforcement for six years; and the extended period of well over two years required by the Government of India and Parliament to respond to the Supreme Court judgment of January 2005 and finalize and approve the amendment package -- with final passage in September 2007.

\footnotetext{
${ }^{237}$ Based on the information available as of December 2008, the question of the three-year delay had not yet been resolved by the GOI and CCI; but there is evidence from media reports that the business groups and business lobby are continuing to argue for further delays before merger review begins.
} 
Nonetheless, the private business sector is a clear beneficiary of this delay of six years (and counting ${ }^{238}$ ) in fully enforcing the $\Lambda \mathrm{ct}^{239}$. The delay gave businesses more time to complete their merger, restructuring and divestiture strategies and to establish strong positions in their key domestic markets - which is a major component in the current strategies of many Indian business groups (see Chapter 8). Moreover, India's competition policy experts and advocates are concerned that the private business sector may benefit from further delays before the substantive provisions of the new act are fully enforced. The Supreme Court's judgment was not definitive; therefore the government's response and the amended statute may not meet the Supreme Court's concerns and may lead to another legal challenge (Agarwal 2006:2) 240.

There are other features of the amended Competition Act 2007 that may benefit the business groups and other larger businesses in the short run on specific enforcement cases, but as well have raised concerns among both business representatives and competition advocates. The 2007 amendments resulted in four different adjudication layers that will provide various appeal options to defendant companies; but could as well

${ }^{238}$ As noted in Chapter 1, expectations as of December 2008 are that the CCI will be fully operational in mid-year 2009 - or more than six years later than originally anticipated.

${ }^{239}$ Perhaps ironically, before the Competition Act was passed in December 2002, some business lobby groups called for a five-year delay before the start of full enforcement.

${ }^{240}$ Specific concerns are: (i) the CCI will still not be headed by a judge - only the Appellate Tribunal will be headed by a judge; (ii) the CCI still possesses judicial type powers such as the power to order a divestiture, to impose monetary and other penalties (rather than fines and imprisonment), and to issue orders to e.g. temporarily restrain a party from carrying out anti-competitive activity during a $\mathrm{CCl}$ inquiry; and (iii) compared to the original 2002 Competition Act which guaranteed that there will be judicial members on the benches, the amended act removed the benches and therefore these judicial guarantees.

Some research participants and other sources questioned why the role of the judiciary arose with respect to the Competition Commission. India has been establishing sectoral regulators with adjudicative powers for the past decade. For these sectoral regulators, the regulatory head and other members do not need to be members of the judiciary, and in fact the vast majority of these regulatory members are not representatives of the judiciary. This was generally accepted by various parties, but not in the case of the Competition Act. It is evident that competition regulation raises special concerns and sensitivities not only for business but as well for government, the judiciary and civil society - suggesting the new competition law and commission will be under particularly severe scrutiny during its first years of enforcement by business opponents and sceptics as well as by competition policy advocates, senior bureaucrats, politicians and civil society. 
further delay merger completion and related restructuring and the resolution of other competition cases. The four levels are: the Commission (even though arguably the CCI will be mainly an investigative body), the Competition Appellate Tribunal (CAT), the High-Level Court and on legal matters the Supreme Court. A related concern is that the CCI is now a collegium of up to seven members rather than a series of benches of two members. Therefore, decisions may take more time, be more contested among members and be more difficult to finalize.

As a consequence, more levels and people are involved in competition law decisions, particularly when the decision is appealed to the Appellate Tribunal and beyond. All of this will require more time to make a final competition decision and to address and solve a competition problem; will add to the administration costs of the CCI and the legal and other transactions costs of businesses and other parties; and will increase the potential for poor CCI, CAT and higher court decisions and case law until all participants become familiar with their new competition law responsibilities. The four layers as well provide additional avenues and decision points where business groups and other larger companies: can appeal and have a negative decision reversed in their favour, or can misuse the competition law to adjudicate contractual disputes or disadvantage a competitor $^{241}$.

The four layers and resulting strategic behavior of companies and other economic agents therefore will further increase the number and complexity of the interactions, conflicts and accommodations between the new competition regime and the country's business groups and other informal business institutions. The business response could be similar to the MRTPA, namely the deployment of sub-optimal economic and business

${ }^{241}$ As took place under the MRTPA - see Chapter 6 and Appendix 8. 
solutions that avoid the new law and commission and minimize the cost and risk of transacting with the competition regime.

Competition policy advocates question why the time from the Supreme Court decision to the introduction of the amendments to Parliament took 14 months, and why Parliament took so long to review and finalize the amendment package. One outcome from these delays that was emphasized by many research participants is that political, government, media, business, and consumer interest in and support for Indian competition policy and law has diminished greatly over the past six years. Continuing contestation on the new amended law especially benefits India's private business sector by default, stealth, happenstance or some combination of these three factors ${ }^{242}$.

\subsection{The Continuing MRTPA Legacy and its Implications for Current and Future Interactions, Conflicts and Accommodations}

The MRTP Act and Commission has continued to function over the past 17 years from 1991 on in a highly weakened and truncated form -- despite losing its major functions of controlling mergers and the growth and diversification of the "MRTPA monopoly" business groups and other larger firms. The government in 1991 therefore effectively "eroded" the mandate of and "converted" the MRTP Act and Commission (Hacker $2003^{243}$ ), so that the MRTPA could not impede implementation of the broader

\footnotetext{
${ }^{242}$ It is noteworthy that the interest of the business lobby and media in the new competition law became more evident in the first half of 2008 with publication in January 2008 of the Competition Commission's "Draft Regulations (For Comment) on Combinations" - that is, mergers and acquisitions. In commenting on these regulations, business lobby and media reports are proposing that: (i) the merger size thresholds should be raised even further (the CCI's response is that these thresholds are already among the highest in the world); (ii) certain merger transactions such as in regulated industries and within business groups should be exempted from CCI merger review; and (iii) the start of merger review should be further delayed until these issues and concerns of the private business sector are resolved (see e.g. The Economic Times 2008 and Moneycontrol.com 2008). The CCI and GOI were still considering these and other proposals at the time this dissertation was being completed in early October 2008.

${ }^{243}$ The MRTPA and MRTPC were further weakened and truncated through "layering" other competition related policies and regulatory regimes on top of them, including the establishment of sectoral regulators
} 
economic liberalization program including greater private sector investment and expansion and the establishment of "national champions".

Over this period, the MRTPC has largely adjudicated smaller cases under the UTP and RTP provisions with questionable competition impacts ${ }^{244}$, and gave very little attention to cases designed to control cartels, monopolies and monopolistic trade practices (see Bhattacharjea 2008 and Exhibit XVI in Chapter 6) ${ }^{245}$. Research participants stressed that the MRTPC's legalistic approach - combined with its preference for quantity over quality in selecting cases -- is hurting the reputation of modern competition policy and law among political, bureaucratic, business and academic elites and competition advocates in India. Continuing enforcement of the discredited MRTPA has therefore added to its negative legacy (see section 6.6 and Appendix 8).

The continuing enforcement of the truncated and discredited MRTPA influences the attitudes of groups on both sides of the competition regime debate. For potential supporters, the MRTPA experience has led to serious doubts regarding whether formal competition policies and law can be effective instruments in promoting competition, consumer welfare, innovation and pro-poor development, and for reducing economic concentration and the market, economic and political power of business groups and other large companies. The business groups and other larger companies that had direct,

with competition mandates. As noted in the next chapter, the weakening of the old competition law through erosion, conversion and layering adds to the challenges of the new competition law and commission:

${ }^{244}$ As noted in Chapter 6, recent research has indicated that, over the past 20 years, the MRTPC has adjudicated consumer protection type cases under both the unfair trade practices and restrictive trade practices sections (see Bhattacharjea 2008).

${ }^{245}$ This was the consequence in part of unfavourable Supreme Court decisions since 1991. For example, since 1994, the MRTPC had reached a decision in only four cartel cases. This is because the Supreme Court laid down a standard (including "meeting of minds") in a 1994 cartel case that reached it on appeal. This standard has been very difficult for the MRTPC to meet in subsequent cases (see as well Bhattacharjea 2003:1 and 2003:2). 
numerous and typically negative interactions with the MRTPA are concerned that the new competition law, like the old one, will provide opportunities for poorly resourced and badly informed government agencies and officials to arbitrarily regulate and micromanage their businesses in a manner that adds to their transactions and production costs, and reduces their competitiveness in domestic and foreign markets.

These negative interactions with the competition regime could in turn result in strategic accommodations and responses by traditional business groups and other informal business institutions that result in sub-optimal outcomes for business and economic performance similar to the pre-1991 period (see Chapter 6). Large business groups and other companies that are now responding to liberalization, globalization and rapid technological change are particularly worried that, similar to the MRTPA, the new competition law could be used inappropriately through effective lobbying by competitors and their government supporters to impede and block their modernization and restructuring efforts ${ }^{246}$.

\subsection{Conclusions}

This analysis of interactions and accommodations from the perspective of the competition regime indicates a major change between the 1990 s and the current decade. The design and timing of the 1991 liberalization program was essentially a Government of India project, with little interaction with and direct influence from key domestic and external stakeholders including India's large business groups and their trade associations. The business groups: preferred the more modest domestic liberalization reforms of the

\footnotetext{
${ }^{246}$ In arguing for a cautious step-by-step approach to enforcement, Agarwal (2005, p. 6) states as follows: "it should not be overlooked that half-baked so-called experts would do more harm to the competitive environment in India. It is certainly going to take time before India starts getting a regular supply of personnel trained in competition policy and law and who can handle merger control."
} 
1980s that privileged incumbents over new entrants, competition and consumers; and opposed many aspects of the 1991 liberalization program (especially external trade liberalization) up to 1995 . The result was that, for the most part, they provided only grudging acceptance of liberalization after 1995. In a similar manner, the business groups and lobby initially played little role in - and gave little attention to -- the early design of the competition bill. However in 2000 , the business groups and lobby became more active, transparent and successful participants in the competition law design process, particularly in successfully weakening the merger provisions and in encouraging the government to introduce other pro-development and pro-business wording into the new act.

The number of interactions between the competition regime and India's informal business institutions was much smaller after 1991 than under the pre-1991 competition regime. This was the result of the dismantling of the License Raj, the much weaker and essentially "toothless" MRTPA from the perspective of the business groups, and the business lobby's limited influence on the 1991 liberalization program and little interest in competition law reform until 2000. At the same time, the quality of and outcomes from the interactions that did take place have been more positive for the business groups and the private business sector more generally, particularly given their substantial influence on the merger and other provisions in the new Competition Act. In the meantime, the failure to begin enforcement of the new competition law six years after its approval by the Indian Parliament - while benefiting the private sector -- continues to raise questions about the longer-term effectiveness of the new competition regime and its future 
interactions and accommodations with the traditional business groups and other informal business institutions and arrangements.

India's post-1991 competition regime is clearly a work in progress and the full story on the interactions and accommodations between the regime and India's informal business institutions and arrangements has yet to be told. Despite the more permissive merger review system and other more subtle pro-business and pro-development changes that resulted in part from business lobbying, many of the traditional business groups, companies, and industries remain quite concerned about the re-introduction of merger review into the Indian economy, after a period of 17 years with no competition-based merger control process. Moreover, given the "truncated" nature of the MRTPA from 1991 on, the new competition law essentially involves the reintroduction of substantive competition law into the Indian economy.

Despite the many limitations and concerns described in this Chapter and by research participants and many other sources, the amended Competition Act of 2007 has the potential to be significantly more effective than the previous competition statute, and thus to have more substantive impacts on the conduct, strategies and performance of business groups and their affiliated companies. These and other questions are addressed in detail in the next chapter when the thesis assesses the post-1991 interactions and accommodations from the perspective of how the business groups, the new economy informal business arrangements, and other informal business institutions and arrangements have responded and accommodated themselves to the post-1991 competition regime. 
Chapter 8: Analysis of the Post-1991 Interactions, Conflicts and Accommodations From the Perspective of India's Traditional Business Groups and New Economy Informal Business Institutions

\subsection{Purpose}

The purpose of this chapter is to build on the analysis in Chapter 7 in order to investigate, in greater detail, the accommodations and strategic responses of India's traditional business groups and the country's new economy companies and informal arrangements to the post-1991 competition regime. Because full enforcement of the new competition law has not yet begun, the analysis focuses for the most part on interactions and accommodations that: are in response to the more pro-competition domestic and external policy reforms that are major components of India's much broader economic liberalization program (see Exhibit I and Chapter 5) (247 $^{24}$ and anticipate enforcement of the new competition law which is expected to begin later in 2009 .

Section 2 analyses the current and future accommodations and strategic responses of India's traditional business groups to the new challenges and opportunities provided by the more pro-competition policy environment that resulted from liberalization, while section 3 assesses the groups' accommodations and strategic responses to the remaining gaps and institutional voids that result from India's incomplete liberalization program. Section four assesses the implications of both sets of responses for the future of India's

${ }^{247}$ Until India's new competition law starts to be enforced and the National Competition Policy under the $11^{\text {th }}$ Five-Year Plan is fully prepared and begins to be implemented, these pro-competition domestic and external policy reforms comprise an important part of India's still evolving post-1991 competition regime, as defined in Exhibit I and the start of Appendix 1, and as further described in Chapter 5, which analyses the reform and often the elimination of many but not all industrial and trade policy constraints, including the "License Raj", that impeded competition and business entry and exit before 1991.

As noted elsewhere in this document, India's post-1991 liberalization program fully contains but is much broader than its post-1991 competition regime. Therefore, the competition regime is an important part of but still only one component of India's broader liberalization program. The terms "competition regime" and "liberalization program" are used consistently throughout the rest of this document in order to keep the two post-1991 entities separate. Appendix 1 provides a further description of the regime-related terminology used throughout this dissertation. 
traditional business groups, and section five conducts similar analysis for India's new economy informal business institutions and arrangements, with emphasis on how their accommodations and responses differ from the traditional business groups. The final section provides the conclusions to this chapter that are most important to the comparative case study analysis in chapter nine.

\subsection{Accommodations and Strategic Responses of the Business Groups and Other Informal Business Institutions to the Opportunities, Challenges and Pressures of the Post-1991 Competition Regime}

The most important and interesting part of the post-1991 empirical story is how the business groups and other large companies in traditional industries are responding to and interacting with the (comparatively) pro-competition liberalization program and post1991 competition regime, and are anticipating the notification and start of enforcement of the substantive enforcement sections of the amended Competition Act 2007. The resulting adaptations, responses and strategies vary depending on the business group but often include many of the following characteristics.

\subsubsection{Mergers and Acquisitions}

Mergers, acquisitions and divestitures have played a major role in business group strategies since 1991. The number of mergers is much higher after than before $1991^{248}$ and in recent years has hit historic highs, which is expected to continue at least until

\footnotetext{
${ }^{248}$ The post-1991 merger wave provides further evidence that the transactions costs, delays and risks of the old MRTPA merger review system were sufficient to deter merger activity, even though very few mergers were stopped or substantially altered under the old law (see Chapter 6). Post-1991 merger activity in India is positively related to: the removal of MRTPA merger control; higher sales growth (which likely provides both the motivation and the financial resources needed for corporate expansion through mergers and acquisitions); and, higher levels of capacity utilization, which would provide further corporate motivation for expansion through merger (Agarwal and Bhattacharjea 2006).

Expansion through mergers is proving to be a less expensive way to satisfy growing matket demand and relax a capacity constraint compared with investments in additional plant and equipment. As further described in section 6.3.4, Agarwal and Bhattacharjea (2006, p. 16) found that the elimination of the MRTPA merger review system remained statistically important in their econometric results, even when other non-regulatory variables were included in their estimated equations.
} 
merger review begins under the new competition statute (Agarwal and Bhattacharjea 2006). India's merger wave began after 1991, with the elimination of the MRTPA merger review process, and has increased after each round of industry liberalization and delicensing by government. Both within-industry mergers and within-business group mergers between affiliated companies are higher in the post-1991 period compared with before 1991. This illustrates the significant corporate adjustment and consolidation that is now taking place within industries, business groups and markets in response to domestic market liberalization and market opening.

The merger wave as well reflects the opportuntities for such consolidation that were made possible by the elimination from 1991 on of MRTPA merger review, the "MRTPA monopoly" control systems, the $25 \%$ market share limit rule, and the License Raj. The post-1991 competition regime has thus allowed two nominally independent companies within a business group that operate in the same or similar product markets to come together and become a single company, in order to lower production and transactions costs and achieve scale and scope economies in production, marketing and management. The expectation is that few of these within-group mergers would result in a lessening of competition, since two affiliated companies likely did not compete against each other in the same relevant antitrust (competition) market before the merger ${ }^{249}$.

The first stage of the merger wave, which as noted above largely involved restructuring within business groups, came to an end a few years ago. In contrast, the

\footnotetext{
${ }^{249}$ As emphasized in Chapter six, business groups normally did not establish affiliates that competed with each other. This would have been contrary to the $25 \%$ market share limit rule applied to business groups, would have reduced monopoly and oligopoly rents, and/or would have led to charges of overt collusion if competition was limited and prices and profits were deemed to be at supra-competitive levels.

However, domestic industrial policy reforms, market opening, transportation and telecommunications improvements, and technological advances and convergence, could mean that two affiliated companies that supplied to different geographic and/or product market "spaces" before 1991 could now be serving the same geographic or product market for purposes of competition law analysis.
} 
emphasis now and in the future will be on strategic horizontal mergers that require the acquisition of target companies outside the business group and are intended to improve market position, share and power. Compared with within-group restructuring, strategic horizontal mergers that are above the size thresholds are more likely to raise competition issues for the CCI. Recent horizontal merger activity in India, which included many mergers involving foreign firms, resulted at times in mergers that would have been challenged in other competition law jurisdictions with merger review systems (Bhattacharjea 2003:2, pp. 207-209) ${ }^{250}$.

\subsubsection{Restructuring, Downsizing, Modernizing and Focusing on Core Capabilities}

Therefore, the larger and more successful business groups are now accommodating and responding to the new competition regime through: restructuring and modernizing their production and management operations and capabilities; downsizing through removing unprofitable businesses from their portfolios and thus reducing the business fragmentation and over-diversification caused by the pre-1991 "License Raj" and MRTPA (Chapter 6); and expanding their scale of operations through mergers and internal expansion. These groups as well are increasing their global reach mainly through FDI in other countries and less often by expanding their export sales. These business groups therefore are exiting domestic markets where competing incumbent firms are stronger, and focusing more on key product lines and core businesses and

\footnotetext{
${ }^{250}$ Any further delays to the start of merger review and enforcement would likely be in response to successful arguments from the business groups and lobby that the business groups and other large companies need even more time to adjust to globalization and liberalization and to establish "national champions" without government interference and regulation - and that the CCI needs even more time to prepare, consult on and finalize the regulations for merger control. The drafting and consultation process for the merger review regulations were taking place during the first nine months of 2008 at the time this dissertation was being completed.
} 
competencies $^{251}$, where they can be major players in the domestic market and hopefully later in global export markets.

In contrast, some of the less efficient and successful business groups ${ }^{252}$ are being forced to diversify and change their priority product lines, because they have lost market share to stronger incumbents and new entrants in some of their traditional core markets. This and the following sub-section further investigate the competitiveness and competition implications of these various strategies and what they may mean for future interactions, conflicts and accommodations between the competition regime and the country's informal business institutions and arrangements.

Corporate strategists from western business schools emphasize the need for corporate restructuring, downsizing and focusing on a relatively few core businesses, product lines and markets where the Indian business group or larger company could be leaders in domestic or global markets. However, other writers, including many that specialize in Asian business strategy, argue in favour of product, market and industry diversification for business groups and other firms in emerging and transition economies. In their view diversification is needed in order to: reduce business risks; achieve economies of scope; and collect information and facilitate within-group and within-firm learning through participating on a selective basis in geographic and product markets that are on the periphery of their core business (Day and Schoemaker 2004).

\footnotetext{
${ }^{251}$ To cite just one of many examples, Tata is a market leader in tea and therefore purchased Tetley Tea in 2000 to consolidate its position of leadership in the Indian tea industry and market. On the other hand, Hindustan Lever is much stronger in consumer products and therefore Tata sold some its consumer product operations to that company. Both transactions are reported to be major successes for the acquiring companies.

${ }^{252}$ These groups before 1991 were able to survive as secondary and less efficient suppliers in pre-1991 markets because of the $25 \%$ market share limit rule and government imposed barriers to domestic and foreign entry under the MRTPA, the Foreign Exchange Regulation Act (FERA) of 1974, and other components of the License Raj.
} 
In addition, diversification helps to compensate for their home country's weaknesses in financial, labour, land and product markets and in formal business institutions, the court system, and the enforcement of contracts; and allows business groups and other larger companies to more fully capitalize on the group's and firm's information, entrepreneurial, technology and other resources, preferred access to financing and government, and other corporate assets that typically are in short supply in these economies (Ray 2004, and Khanna and Palepu 1997, 1999, 2000:2 and 2004:1).

Indian business groups are in fact conducting both diversification strategies as well as restructuring strategies that give priority to core competencies. Diversification is more often into related product and industrial lines compared with the pre-1991 period, when unrelated diversification was required to foster business group expansion while circumventing the $25 \%$ market share limit rule and other aspects of the pre-1991 competition regime ${ }^{253}$. Restructuring that promotes scale expansion and core competencies should have a positive impact on affiliated company and business group performance through allowing firms to achieve the economies of scale and scope that were denied to them under the pre-1991 competition regime and the License Raj. Scale expansion as well provides opportuntities to upgrade and modernize plant, machinery,

\footnotetext{
${ }^{253}$ To expand on this point, some strategic diversification at the present time is into unrelated but historically familiar product lines. Financial sector liberalization, modernization and rapid growth have allowed many of the business groups to re-enter the financial services field that they were forced to leave in 1969 because of the nationalization of the group's commercial banks by the first Indira Gandhi administration. Another form of unrelated diversification is the large number of Indian industrial business groups that in recent years have entered information technology and IT enabled and related services.
}

It is argued that over time better developed and more competitive financial and other product markets in post-1991 India will favour core competencies and related diversification over unrelated product diversification. This is partly because better developed markets make more specialized corporate assets more important than generalized corporate capabilities (Ray 2004, p. 254, and Porter 1990 and 1996). Nonetheless, at the present time, India's incomplete liberalization and the capabilities of business groups make unrelated diversification potentially more profitable than in e.g. the OECD economies and compared with other governance modes. 
and equipment and to adopt more advanced technology ${ }^{254}$. In addition, greater entry and competition in domestic markets reduce price-cost margins, force incumbent firms to become more productive, competitive and innovative, (Poddar 2004) and make exports and outward foreign direct investment relatively more attractive as well as necessary compared with the pre-1991 period ${ }^{255}$.

The competition issues arising from these restructuring and scale expansion strategies often will lead to interactions under both merger review and the abuse of dominance (AOD) provisions of the new competition statute. Competition issues could include foreclosure strategies that involve e.g. vertical mergers, vertical restraints, predatory pricing and/or non-price predation that are designed to raise rivals costs and discourage new entry (Scheffman and Higgins 2003). More concentrated markets with one major supplier could as well lead to actual or tacit collusion between the dominant supplier and the smaller number of remaining suppliers ${ }^{256}$.

However, these potential competition problems could be offset by the higher growth, increased product differentiation, greater turnover in shares among incumbents, greater uncertainty about future trends and outcomes, and the greater threat of entry by domestic and foreign suppliers in the post-1991 liberalization period compared with government regulated market conditions under the pre-1991 competition regime and "License Raj". All of these post-1991 considerations make it more difficult to sustain a dominant position and add to the information, monitoring, enforcement, and other transactions

\footnotetext{
${ }^{254}$ Since advanced technology is often embedded in machinery and equipment - see Ray, 2004.

${ }^{255}$ Nonetheless, the larger business groups are still oriented more to the domestic market as the export pessimism and prudence of the pre-1991 period continue to have some influence on their strategies (see Chapter 5).

${ }^{256}$ Cooperation including collusion is easier and more cost-effective when the number of cooperators is smaller.
} 
costs and risks of establishing and maintaining actual and tacit collusive agreements in oligopoly industries (Williamson 1986, pp. 215-225) ${ }^{257}$.

One unanswered question is whether liberalization and the business group response to the greater threat of domestic and foreign entry in domestic markets will force the business groups to set aside the "live and let live" and tacit economy-wide market sharing and price leadership strategies of the past in favour of fiercer inter-group rivalry in key domestic markets -- as occurred in Japan, South Korea and Taiwan during their high growth periods. The evidence on this question is mixed and far from decisive. On the pro-rivalry side, Tata in the last decade has entered the passenger motor vehicle market in a major way and is competing very successfully with Birla and the other traditional motor vehicle producers and with foreign invested incumbents and new entrants. As well, many of the business groups, including Reliance, Birla and Tata, have become major players and competitors in financial services and in the mobile telephone and other post-reform telecom markets.

On the other side, corporate restructuring strategies designed to make the business group one of the three or four major players in a smaller number of key domestic markets could further reduce the number of markets where business group affiliates are major participants and rivals. Because of history, path dependence and the continuing influences of pre-1991 business group investments and strategies on current conduct and performance, fierce inter-group rivalry in key Indian domestic markets probably will occur less often than in other Asian and developing countries unless the Government of

\footnotetext{
${ }^{257}$ For these reasons, oligopoly markets are preferable to monopoly markets, even when there are only a few suppliers. The new IO literature has extensive evidence of reasonably competitive duopoly and oligopoly markets with two or three suppliers. As long as there are two or three effective competitors in a market, the "entrepreneurial spirits" of Schumpeter can often dominate business conduct and strategy to the benefit of competition and the consumer.
} 
India implements explicit competition and competitiveness strategies designed to encourage such inter-group rivalry ${ }^{258}$. Stronger competition in Indian markets perhaps is more likely to result from foreign entry through imports and FDI and through smaller and medium-sized companies (the so-called competitive fringe) becoming larger and more competitive $^{259}$.

Many of the business groups with deeper pockets are increasing their equity holdings in their key affiliated companies in order to reduce the threat of hostile takeovers ${ }^{260}$. For business groups with more limited access to financing or a preference for internal financing ${ }^{261}$, there is likely a positive relationship between, on the one hand, restructuring, divesting, downsizing, and focusing on core competencies and, on the other hand, increasing their equity holdings in key business group assets in order to reduce the danger of hostile takeovers. The cash generated by restructuring and selling less highly valued affiliated companies is used to increase the group's equity holdings of key business group assets.

\footnotetext{
${ }^{258}$ For example, Das and Pant (2006) suggest that, despite liberalization, follow the leader pricing may still be important in many Indian manufacturing industries - in part because capital market imperfections continue to limit entry by medium-sized enterprises that could represent important competitors to larger well-established incumbents.

${ }^{259}$ However, as outlined in earlier chapters, more effective competition from smaller and medium-sized companies will require the relaxation of a number of constraints such as: (i) reform of the small enterprise reservation system which prevents most smaller companies from becoming larger because of the loss of their small firm protections and privileges; (ii) dependence of smaller firms on sales to and other benefits from business groups and other larger companies; and (iii) limited access of smaller and medium sized companies to commercial bank financing, other key intermediate inputs and government clearances and approvals, which now are more numerous at the sub-national government levels (Sinha 2005:1). Promoting the growth of India's small and medium sized enterprises is a major objective of the GOI's Eleventh Five-Year Plan (Government of India 2007:1).
}

\footnotetext{
${ }^{260}$ The threat of hostile takeovers, which is very new to India, means that the market for corporate control is now part of the post-1991 competition regime.

${ }^{261}$ Internal financing is often preferred in order to minimize interest and transaction costs and interference from the commercial banks and development finance institutions which in both cases are still largely owned by the government.
} 
Downsizing and restructuring is often accomplished through reducing payrolls. Research participants indicated that reducing payrolls was mainly achieved by voluntary or mandatory retirement programs and "benign neglect" by governments, whereby the existing labour and related rules are applied with flexibility and adhoc forbearance ${ }^{262}$. In response to rising labour and other costs, the affiliated companies of business groups are as well moving out of the central cities of major metropolitan regions (such as Mumbai and Chennai), selling their high-valued land, and establishing new facilities based on more modern technology and equipment in the suburbs and smaller Indian cities where land, labour and other production and transaction costs are much lower.

Business groups are moving in a limited way into higher technology industries and markets ${ }^{263}$, increasing their investments in $R \& D$ and innovation, updating their technology, importing more modern machinery and equipment, and establishing technology collaborations with new foreign partners, in ways that could not be done under the pre-1991 competition regime and License Raj. These strategies provide them with better access to information and knowledge on advanced technologies and product, process and managerial innovations; and increase their ability to create and absorb more advanced technology. The result is somewhat greater emphasis on technology and innovation than the family-owned business groups have displayed in the past.

\footnotetext{
${ }^{262}$ There is some anecdotal evidence however that downsizing through reducing payrolls has in some cases gone too far. Some business groups and other firms reportedly have been left with much less labour flexibility and therefore some companies are being forced to reverse course and begin adding to payrolls, during a period when appropriately trained industrial workers are in short supply. The result is increasing labour costs in the industrial sector for some business groups, regions and occupational groups. The current slowdown (as of December 2008) in India's economic growth rate, as a consequence of the American and global recessions, may however provide the opportunity for the supply of trained industrial workers in the formal economy to catch up with demand.

${ }^{263}$ At the same time, most information technology and other more advanced technology goods and service production in India is generated by the new post-1980 companies (see Chapter 4 and section 8.5 below).
} 
Business groups are developing "market creation" strategies that are designed to create new industries and market demands by capitalizing on technological change (Langlois and Robertson 1995 and Robertson and Yu 2001), and are working with government to remove the policy and regulatory constraints to market creation. Reliance did this in the past in creating a market for synthetic fibre, and many business groups and other companies "created" the market for mobile telephones. Reliance and other business groups are now planning to establish more modern rural distribution and retail networks and to modernize agro-processing through a vertically integrated "farm to final consumer" strategy. Finally, creating new industries and market demands are fundamental to current proposals for business groups and other private companies to establish and operate Special Economic Zones to attract inward FDI and promote exports $^{264}$. The last two responses involve forms of cooperation and collective action across business groups and between business, government and other groups that were rarely evident and may not have been feasible under the pre-1991 competition regime ${ }^{265}$.

Some business group company affiliates are establishing partnerships, joint ventures, and strategic alliances with non-affiliated companies and are starting to participate in global supply chains. The purpose of these informal business arrangements with new partners are to meet the strong increases in domestic demand since 1991 through e.g. purchasing key inputs and final products from smaller firms on an "as needed" basis when demand is high (Patibandla 1998); and to provide better access to foreign markets,

\footnotetext{
${ }^{264}$ Following a Chinese model which has been applied with considerable success for close to 30 years particularly in the PRC's coastal provinces. The major difference is that the Indian strategy will involve private company rather than government ownership and operation of these zones - which to this author is an important innovation that should capitalize on the ability of business groups to minimize transactions costs and coordinate investments.

${ }^{265}$ When government distrust of business and the competition between business groups for licenses and other state favours and entitlements may have ruled out more open and transparent forms of cooperation between different business groups and the business groups and other larger companies.
} 
technology and investment, and the complementary assets of these non-affiliated firms ${ }^{266}$. In this manner, affiliated companies in business groups and other larger companies are developing closer "supply-chain type" relationships with a fewer number of suppliers based on higher quality, mutual benefit, information sharing, extended trust, and cooperation (Humphrey and Schmitz, 1998 p. 47). This approach essentially involves the adoption of the Japanese supplier model to the Indian economy (Dore 1983, Bostock and Stoney 1997, and Sako and Helper 1998).

As noted earlier, strategies to increase competitiveness often encompass expanding the geographic scope of business groups (Ray 2004, p. 250) and increasing their participation in global markets. Research participants and other sources confirm however that this is being achieved less through exports and more from outward FDI into other Asian countries and other international markets. The Birla Group was the Indian leader in "going global" starting in the 1980s in order to circumvent the high costs of transacting with Indian governments and the restrictions to business expansion caused by the $25 \%$ market share limit rule and other aspects of the MRTPA and the License Raj. Many more Indian business groups are now embarking on global market strategies to expand their presence in other country markets ${ }^{267}$. One indication of the global strategies of

\footnotetext{
${ }^{266}$ These arrangements with new partners are being employed in many cases to address the remaining "institutional voids" in the Indian economy through strong inter-firm relationships with both affiliated and unaffiliated companies, including smaller Indian companies and foreign firms based in India and overseas (Khanna and Palepu 2004:2). For example, they often encompass greater outsourcing and sub-contracting to smaller firms (including in the remaining small firm reservation sectors) that have lower wages and taxes and more labour flexibility compared with larger firms in the formal sector.

${ }^{267}$ Outward foreign direct investment (FDI) data are a good indicator of the expanding participation of India's business groups and other larger companies in global markets. UNCTAD's World Investment Reports for 2001, 2007 and 2008 indicate that outward FDI flows from India to other countries expanded from an average of \$US 20 million per year from 1989 to 1994, \$US 119 million in 1995, and 300 million in 2000 to \$US 3.0 billion in 2005, 12.8 billion in 2006, and \$US 13.6 billion in 2007. (Another source estimated that outward FDI would rise to about \$US 15 billion in 2007-2008 - see India PRWire 2007).
} 
India's business groups and other larger companies is that many of them only proceed with a major investment in India if the investment is projected to generate a competitive return on investment, when all Indian trade barriers are removed and all tariffs are reduced to zero. When industrial projects fail to achieve this threshold ROI based on an Indian domestic investment, many business groups would likely explore the ROI of a similar project investment based on direct investment in another country, either through greenfield investment or merger/acquisition.

The preference for outward FDI over exports in the global strategies of many business groups results in part from the many remaining macroeconomic and structural/microeconomic barriers and "institutional voids" that add to production and transactions costs and thus continue to discourage exports by larger firms in the formal sector. As a consequence, the contribution of the business groups to India's rapidly expanding exports is lower than its contributions to domestic sales and production (see Chapter 5). Competing in foreign markets through exports and especially FDI will make India's business groups more familiar with the pro-competition and anti-competition strategies of foreign rivals, as well with the more experienced competition regimes in the more advanced developed and developing countries. This experience will likely influence the number and quality of their interactions, conflicts and accommodations with India's new competition regime, generally in a positive manner except when business groups "learn from and mimic" the anti-competitive strategies of foreign competitors.

Turning to India's outward stock of FDI, these stock figures were only \$US 235 million in 1980, 124 million in 1990, 496 million in 1995 and \$US 1.9 billion in 2000, and then increased sharply to \$US 13.0 billion in 2006 and 29.4 billion in 2007. These data are consistent with earlier conclusions that: the modest pro-business reforms of the 1980s improved business group and other private company performance, but had little impact on their corporate strategies; and that the business groups and other larger companies responded significantly to the post-1991 liberalization program and competition regime only after 1995 and to a significant degree only after 2000. 
Business groups are adopting more modern governance and management methods. They are focusing more on competitiveness and shareholder value, and less on maintaining family wealth, solidarity and peace in making their investment and other corporate decisions. The business groups as well are making important internal changes to their governance structures and management practices. Several of the larger business groups have divided up the business group assets among sons and other relatives (e.g. six Birla and two Ambani groups rather than one in each case) in order to: reduce family conflicts that result in higher transaction costs and less cooperation and coordination; provide appropriate management positions to the next generation of sons and relatives; and, add to shareholder value through reducing the high information, governance and other transaction costs of managing huge conglomerate type groups with many semiindependent companies and unrelated product lines. While adding to shareholder value is stressed in press releases and media reports that announce these business group divisions, reducing family tensions and conflicts is also an important consideration (Das 2002).

Therefore, the partnership based incentives of the past (see Chapter 4) are not as effective in an era of greater liberalization, competition, individualism, and modern management in India. More generally, some business groups have reached the point where they have become too large, complex and diversified to hold together and to operate efficiently through employing their traditional informal rules of business conduct. Affiliated companies within the different "sub-groups" of divided business groups continue to closely coordinate their activities and to share the same family and brand name and their government and financial intermediary connections. However, the inter- 
company relationships across these divided business groups are less based on family ties and the partnership system of the past, and more based on the requirements of individual affiliated companies and each newly divided business group ${ }^{268}$.

Most business groups reportedly are adopting other more modern and professional business practices, hiring more outside expertise, and therefore are no longer depending on relatives and close family friends to manage major affiliated companies. This may be one of the greatest challenges that the business groups will face in responding to the new competition regime, the broader liberalization program and globalization. For family owned companies and business groups that have operated on the basis of hierarchy, paternalism, personalism, centralization of decision-making and deference to the owner/head of family, providing middle level professional managers who are not members of the family with the authority they need to do their job effectively can be a difficult transition and challenge. Interference by and deferring to the family head/owner can easily undermine the authority of the middle manager who is not a member of the family (Redding 1993, pp. 158-159). Therefore, in many cases, new hirings remain within the business group's original business community, based on language, religion, ethnicity, social group, and occupational caste (Das 2002).

\subsubsection{Implications for Their Future Interactions with India's New Competition Regime}

The major challenge to be faced by the traditional business groups in interacting with the new competition regime is likely to involve their strategic mergers and other longer-

\footnotetext{
${ }^{268}$ The major exception to this trend is the Tata Group which has attempted to stay united through the 1990 s up to the present day. There were media and other reports in the late $1990 \mathrm{~s}$, which suggested that efforts to keep the Tata Group together as a single entity had led to internal conflicts within the extended/joint family. These conflicts were associated with weaker performance by some of their main businesses e.g. in steel, automobiles and chemical products (Vaugier-Chatterjee 2003, p. 73). More recent reports indicate that the Tata Group has rebounded during the current decade; but over the longer term Tata could still be difficult to manage in a transaction-cost economizing manner.
} 
term business relationships with other business groups and outside domestic and foreign non-affiliated companies. These mergers and informal business arrangements will raise competition issues and require new rules of business conduct, governance methods and trust-based relationships with which they are for the most part unfamiliar ${ }^{269}$. These mergers and non-merger vertical and horizontal relationships with outside parties are more subject to modern competition, corporation and other commercial laws ${ }^{270}$; and are more likely to attract the attention of Indian and other competition authorities compared with traditional relationships that were internal to the business group, less transparent to outsiders, and less likely to raise competition concerns. These new arrangements will involve complex provisions of competition law - in such areas as abuse of dominance, vertical restraints and integration (vertical mergers), and anti-competitive horizontal agreements - where the experience of traditional business groups, affected unaffiliated companies and the new Competition Commission is limited.

When moving into uncharted territory, business groups can make mistakes in structuring these new relationships with outside parties; and the competition authority can apply traditional microeconomic and industrial organization theories and thus assume anti-competitive structures and conduct, when the relationships on balance will add to economic efficiency. Similar to the MRTPC, the new competition law and commission

\footnotetext{
${ }^{269}$ Trust between individuals and trust between organizations become blurred and mutually reinforcing in relationships between affiliated companies within family-based business groups. The differences between these two forms of trust become much more important for relationships between affiliated and nonaffiliated companies - particularly when the two firms do not share a common ethnic, religious, language, social or cultural background (Nooteboom et al 1997, pp. 312 and 318).

${ }^{270}$ In fact, as described in Chapter 7, the new amended competition statute has been designed to minimize interference with informal business institutions, rules of business conduct, and arrangements within business groups - that often will be treated the same as institutions, rules and arrangements within a single firm. The third kind of interaction in Exhibit II indicates the danger that harsher treatment of arrangements between non-affiliated companies could discourage such efficiency enhancing arrangements and reinforce the business group preference for arrangements between affiliated companies.
} 
could misuse traditional economic theory, particularly the Structure-ConductPerformance model of traditional IO, and the experience and weak case law from the MRTPC, to discourage and prevent efficiency enhancing business relationships between business group affiliates and non-affiliated companies. Even a poorly enforced competition law can add to the transactions costs of business groups and their affiliated companies, and can result in sub-optimal business arrangements designed to avoid scrutiny by the competition authority (Chapter 6). This is particularly true when poor enforcement involves arbitrary, unpredictable and legalistic approaches which do not apply a competition test in a consistent manner and which misuse the new competition law to achieve the broader political and socioeconomic objectives of Indian governments $^{271}$.

In contrast, effective and proactive enforcement of the new competition law by the CCI and GOI would provide a mix of positive and negative impacts that will vary depending on the business group. To the extent that the major business groups continue to stay out of each others key markets and apply some variant of the tacit economy-wide market sharing agreement of the pre-1991 period, provisions on cartels and other more formal anti-competitive agreements will continue to be applied infrequently to business groups.

At the same time, proactive enforcement of the new provisions on abuse of dominance could place limitations on the strategies of business groups to become key players in fewer major markets ${ }^{272}$. Applied properly, the abuse provisions would not

\footnotetext{
${ }^{271}$ As arguably took place with the MRTPA in the 1970 s and 1980 s and has taken place more recently with the Monsanto Bt cotton case (see Chapter 6 and section 3 of Appendix 8).

${ }^{272}$ Expanding on this point, business group restructuring means that the larger groups will be competing in fewer markets, but will be major players with higher market shares and greater market power in more of the
} 
prevent affiliated companies of business groups from achieving higher market shares based on superior competitive performance; but could place limitations on the kinds of strategies and business practices that the business groups are allowed to employ in achieving and maintaining dominance in their key markets ${ }^{273}$.

Application of the merger review section could prevent business groups from completing some of their very large strategic merger transactions that are critical to achieving dominance in key domestic markets. Alternatively, proactive merger review could encourage business groups to avoid mergers with outside companies and use instead within-group mergers, internal expansion, and greenfield investments in domestic and foreign locations - even when mergers with outside companies may be more profitable to the group and more efficient for the Indian economy.

On the positive side, the application of the new law's provisions on anti-competitive agreements, abuse of dominance and "mergers to monopoly" to their competitors, and to outside non-affiliated suppliers ${ }^{274}$ and customers, could enhance the cost competitiveness and profitability of business groups and their affiliates. These enforcement cases could be particularly beneficial when they address the anti-competitive conduct of international corporations that are now active in or are planning to enter the Indian market.

To summarize, the expectation is that the new competition law will have some impact but will not be determinative of the groups' future survival and success. Other forces

markets where they are participants. As indicated by the Microsoft and other recent abuse of dominance cases in the OECD competition law jurisdictions, this brings abuses of dominant position into play in a manner that will be very unfamiliar to most Indian business groups and their legal and economic advisers (see e.g. Takigawa 2005 and Ireland 2007:1 and 2007:2).

${ }^{273}$ Including limitations on the deployment of intellectual property rights - see Ireland 2007:1.

${ }^{274}$ Enforcement cases and other activities of the new Competition Commission that increase competition among non-affiliated suppliers especially benefit those business groups that are expanding their purchases of goods and services from outside companies in order to reduce costs and place pressure on affiliated company suppliers to become more cost competitive. 
internal and external to India's business groups, including their interactions, conflicts and accommodations with the broader competition regime and liberalization program, will likely be more important.

\subsection{Interactions Designed to Respond to and Capitalize on the Remaining Deficiencies in the Post-1991 Competition Regime}

The previous section describes how India's traditional business groups are accommodating and responding to the new opportunities, challenges, pressures and uncertainties of the post-1991 competition regime and liberalization more generally. This section discusses how the business groups are responding to and continue to capitalize on the institutional voids and other market distortions that result from the gradual, incomplete and at times adhoc character of Indian liberalization (see e.g. Williamson 1998, p. 6 and Chapter 5).

Use of the pre-1991 competition regime to implement entry deterrence strategies of "capacity pre-emption" has been replaced to some extent by "financial pre-emption", whereby business groups and other well established companies continue to use their political and banking connections to reduce the access of potential competitors to commercial financing. India has implemented significant but still incomplete financial market and related corporate governance reforms. One consequence is that business groups continue to enjoy preferred access to project and other financing. When compared with medium-sized and smaller unaffiliated companies, their access to external finance may have increased with financial sector reform and reduced government involvement in allocating investment funds under the post-1991 competition regime. Information asymmetries in financial markets significantly favour business groups and other larger companies that are well known to financial intermediaries compared with 
young start-up companies and small to medium sized firms in the formal economy (Bhaduri 2005). The preferred access of business groups to external financing is the combined result of (i) their better access to internal financing, based on strong balance sheets and retained earnings and within-group loans and equity including risk equity; and (ii) their strong reputations with financial intermediaries for successful projects and past loan repayment, which result in reputational capital that is developed over an extended period. Firms with inside financing and reputational capital have better access to greater volumes of external financing at lower cost (Tirole 2001, pp. 5-9); and the managers of affiliated firms with stronger balance sheets ${ }^{275}$ are better positioned compared with unaffiliated companies to secure outside financing while relinquishing fewer control rights (Tirole 2001 p. 16, Khanna and Rivkin 2001, and Khanna and Palepu 2000:2). Continuing weaknesses in capital markets, corporate governance and the monitoring of business groups and other Indian companies by domestic (generally state-owned) banks further reduce competition in non-financial markets -- by discouraging profitable entry by potentially more efficient domestic and foreign firms (Khemani and Leechor 1999, and Khanna and Palepu 2001:1 and 2000:2 $)^{276}$.

\footnotetext{
${ }^{275}$ Stronger balance sheets are associated with significant retained earnings and cash positions, high initial equity, strong collateral, and large and predictable revenue and net income streams.

${ }^{276}$ Domestic state-owned banks have limited incentives to monitor Indian business groups and other firms that have good political connections, and have limited experience and skills in corporate governance and monitoring. Srinivasan (2004) reports that, despite some financial market liberalization, the nonperforming loans of the commercial banks are large and growing; the rolling-over of loans so that they are not classified as non-performing is substantial; the government role in the financial sector is still large and in some ways could be increasing; and regulatory forbearance is high. Slower Indian economic growth in the next few years could exacerbate these financial market problems.
}

However, improvements are now taking place through the entry of foreign owned banks and other financial intermediaries that have more experience with and greater incentives to conduct corporate monitoring. Khanna and Palepu (2000:1, p. 288) found that "domestic financial institutions in India are ineffective monitors, whereas foreign institutional investment is associated with significant monitoring benefits ..." 
In this manner, business groups and other larger firms continue to benefit from the economies of scale and scope associated with their government contacts, networks and lobbying efforts; and, compared with small and medium-sized independent companies, continue to benefit more from political favours, state entitlements, and the remaining "institutional voids" under India's incomplete liberalization, With the elimination of the "License Raj" and the MRTPA regulation of "monopoly firms", business group lobbying now emphasizes the acquisition of financing, land, infrastructure services, environmental approvals, approvals for downsizing, anti-dumping, countervail and other import relief, and related approvals at the national, regional state and municipal levels (Sinha 2005:1). While business group dependence on government is now lower, transacting with government is still expensive and time consuming, and in many ways the broader competition and economic policy regime is even more complex and contingent than before liberalization.

\subsection{Implications of Interactions and Accommodations for the Future of India's Traditional Business Groups}

A major question of this thesis is the implications of the post-1991 competition regime and its interactions, conflicts and accommodations with traditional business groups for the future survival and success of this uniquely Indian informal business institution and arrangement. This question has been contested quite significantly in the Indian business literature over the past 17 years; and was emphasized in the interviews conducted during the Indian field work conducted in the summer of 2006. These debates and the major implications and findings for this analysis are summarized in the next three subsections. 


\subsubsection{Considerations Favorable to Future Survival and Success}

The business groups have many areas of strength. They have shown great resilience and flexibility in the past in responding to external shocks and developments, including dramatic changes to competition and related regimes. The business groups have strong family and brand names that are well known in India and are becoming known in selected foreign markets - and are recognized by many in India for their nation-building efforts and good works. They represent India's old business elite; or in the case of the new economy companies such as Infosys and Wipro, the icons of the new modern Indian economy (Pani 2006). Corporate social responsibility is now playing an enhanced role in the corporate strategies of many business groups in order to further build their reputations and brand names (UN Volunteers et al, 2004) ${ }^{277}$. The business groups often have well developed domestic distribution systems, know the highly complex and increasingly sophisticated Indian market very well ${ }^{278}$, and are becoming much better at modern advertising and marketing.

\footnotetext{
${ }^{277}$ The Tata Group for example began their corporate social responsibility program in the 1970s, while the leaders of Infosys have played a major role in working with reform minded politicians in Bangalore and the State of Karnataka, through actively participating in and contributing to city and state initiatives designed to advance the economic reform agenda (Pani 2006). The Indian research on social corporate responsibility indicates that social investments are made by both traditional business groups and new economy companies and groups, in order to add to shareholder value as well as contribute to the social goals of their communities. For example, Pani (2006, p. 253) discusses the ways in which Infosys in Bangalore leveraged its good works in assisting the state and city governments in order to increase shareholder value and attract investment from Singapore.

${ }^{278}$ The Indian market is characterized by complex, distinct and highly variable consumer tastes, preferences and challenges in many product lines (such as serving the rural consumer) --with significant differences in consumer tastes and preferences depending on the region, location (e.g. rural versus urban), ethnic group, religious group, language and socioeconomic status. Tata, Reliance, Hindustan Lever and other Indian business groups, larger firms and long established MNCs in India have proven experience in serving lower income consumers and households in urban and rural areas at the "base of the pyramid", where significant market expansion is likely to take place in the future in India and many other developing and transition economies (Das 2002, Ricart et al 2004).
} 
They have a proven ability to succeed in lower-income developing and transition economy markets that are characterized by infrastructure gaps and the many "institutional voids" discussed earlier in the text. This ability potentially could provide them with important competitive advantages, compared with the MNCs from OECD countries, in India's domestic market as well as in other developing and transition country markets. For example, because of their more informal governance methods where affiliated companies remain nominally independent, target companies in India and other developing and transition economies may be more comfortable before the transaction and more profitable after the merger, when they are purchased by an Indian business group rather than by a multinational corporation based in the United States or another OECD country (The Economist 2008) ${ }^{279}$.

Business groups benefit from within-group management training programs and are capitalizing on the expanding management skills within India and among Indian expatriots working in other countries. Indian management skills are gaining worldwide recognition and fame. The new PepsiCo President is a woman from India, Mittel is becoming the world's most important steel maker, the creators and leaders of India's largest IT firms are now among the global business elite, and the Tata brand name in particular is appearing in a growing number of business media articles and markets in OECD country markets. ${ }^{280}$

\footnotetext{
${ }^{279}$ Where the acquired company will likely become a "subsidiary" of or a division within the acquiring company.

${ }^{280}$ The Western business media (see e.g. The Economist 2008) have discussed the recent success of Mahindra \& Mahindra in exporting their tractors, and of Bajaj in exporting their high quality motor cycles to advanced country markets; the major acquisitions of the Tata Group which include London-based Tetley Tea in 2000, the European steel company Corus in 2007, and Jaguar and Land Rover from Ford in 2008; and the strategy of Tata Motors to produce and sell a low-price fuel efficient sub-compact car to lower
} 


\subsubsection{More Negative Considerations Emphasized by Critics}

There are though influential critics who contend that the business groups' strategic responses to the post-1991 competition regime have been tentative and half-hearted, which arguably place the success of these strategies and the ultimate survival of business groups in question (Das 2002). In their view, some of the larger business groups waited too long before implementing their global strategies ${ }^{281}$. The traditional business groups were among the last to recognize that the GOI had made a credible commitment to liberalization, and were then slow to develop within group consensus around the "right" accommodation strategies. Many continue to be too cautious, rigid, bureaucratic, and risk averse; they still invest too little in R\&D, innovation and more advanced machinery, equipment and technologies - despite some recent improvements in these indicators ${ }^{282}$; and they continue to apply the low investment/low risk/quick return business model and merchant mentality of the past (Tripathi 2004).

Their critics further contend that the business groups produce too few products of international quality, in many cases have brand names that are only well known in domestic markets, and have been too slow and cautious to become more fully engaged in global markets through exporting ${ }^{283}$. Many have had problems with succession planning. Sons too often replace a successful "founding father"; or the successful second generation has to be replaced by a third generation with more questionable capabilities and interest.

income market segments in both developed and developing countries. Recent media reports suggest that this car could sell for less than \$US 3,000.

${ }^{281}$ For example, the largest and reportedly most modern and professional of the traditional groups, the Tata Group, announced its strategy only in 1999, eight full years after the start of the liberalization program.

${ }^{282}$ See for example, the National Knowledge Commission (2007, pp. 5-6), which conducted a comprehensive firm-level survey and analysis of innovation in India.

${ }^{283}$ Their harsher critics further argue that the business groups in the future will have limited success overseas because they have been protected for too long by government in their domestic markets and therefore have not learned how to compete against foreign competition - and are too traditional, inflexible and tied to the past to learn how to compete now. 
Accommodating the new competition regime will require business groups to face new and unfamiliar management, governance and trust issues, and to increase their business transactions and long-term contractual relationships with other business groups and nonaffiliated companies ${ }^{284}$. They will be managing joint ventures, partnerships and other cooperative relationships with unfamiliar domestic companies that are not part of the family business group. These arrangements will require greater time, transaction and other costs, risks, uncertainties and dangers of opportunism compared with negotiating, finalizing and executing similar arrangements within the business group (Ring and van de Ven 2004, and Osborn and Hagedoorn 1997).

New foreign joint ventures with international companies could be particularly problematic because of differences in national business practices, cultures, experiences and expectations (Park et al 1997, Greif $1994^{285}$ ). As noted earlier, many business groups intend to recruit high quality professional staff who are not "members of the extended family". These and other strategic initiatives will be widening the "radius of trust" from the selective personalized trust based on family, religion, occupation, kinship or caste groups ${ }^{286}$, to building longer term relationships with non-affiliated domestic firms and

\footnotetext{
${ }^{284}$ Increasing the number of transactions and longer-term contractual relationships with other business groups and non-affiliated companies is one component of the post-1991 strategies of many of India's more prominent business groups. However, media reports, the research participants, and other evidence indicate comparatively little progress to date for the reasons of limited trust and unfamiliarity and fears of opportunism that are discussed in Chapters 2 and 4 and in this sub-section.

${ }^{285}$ Grief (1994) emphasizes the problems that companies embedded in collectivist societies encounter when they conduct transactions and attempt to establish long-term relationships with businesses embedded in individualist societies. The Indian merchant houses and early managing agencies and business groups first encountered these problems in their efforts to adapt to the individualist cultural norms and beliefs and the "anti-competitive" regime and unfair trading under the British Raj (see Chapter 4).

${ }^{286}$ Where to an important degree, business group solidarity and success are based on patriarchy, hierarchy, and the power of the leading company within the business group and/or group leader/patriarch. Whereas for the broader ethnic, religion etc. based business communities, the political influence, economic power and prestige of the largest business group within the broader community become important to coordination
} 
foreign companies, that will need to be based on more generalized trust, reciprocity of trust, relational norms and contracting, and equality between partners (Harriss 2003, Heide and John 1992, Nee 1998, Artz and Brush 2000). To some degree as well, business groups will need to depend less on informal business institutions and more on formal institutions of corporate governance and related forms of institutionalized sanctions and incentives (Harriss 2003, p. 767) to discipline the opportunism and other strategic behaviour of their new partners. Traditional business groups are less experienced and comfortable with formal governance institutions.

These accommodations to the post-1991 competition regime will require the support and acceptance of a common code of generalized morality that is essential to the efficient functioning of a modern market economy but that has not yet been fully established in India (Platteau 1994:2, pp. 797-798. Some business groups may too readily accept the advice of western-trained business management consultants and move too quickly into this unfamiliar territory. As they attempt to become more modern, professional, "western" and even "American", business group structures, management methods and rules of business conduct could become less consistent and aligned with India's overall institutional environment, where formal institutions and organizations (courts, regulators etc.) are under-developed, and often not effective and trusted; and limited-group morality remains more entrenched than generalized morality (Platteau 1994:1 and 1994:2) 287 . This situation can lead to new tensions and frictions, unfamiliar and unanticipated transactions

across the business community, as illustrated by the important role played historically by the Birla Group within the Marwari business community (see Chapters 2 and 4 including Exhibit XII, Tripathi 2004 and Taknet 1986).

${ }^{287}$ The concepts of generalized and limited-group morality are linked to caste and other social differences, which weaken the dissemination and acceptance of generalized morality within India's private business sector, economy and society - where the business groups, other larger businesses and the Marwari and other business communities are still narrowly based on a shared language, religion, ethnicity, caste or other occupational group (see Chapter 4). 
and production costs, and new forms of opportunism (Platteau 1994:2 pp. 797-801).

Business groups face dangers therefore in moving both too slowly and too quickly in adopting more modern business institutions, rules of business conduct, arrangements and management techniques ${ }^{288}$.

Possible compensating factors could include: the continuing influence of traditional Indian economic thought, with its emphasis on fair competition and trading; and, the economic, political and social influence and power of the larger business groups and their leaders, which will continue to discipline and reduce the opportunism and shirking of smaller suppliers, customers and other companies and economic agents that are outside the business group ${ }^{289}$. Business group accommodations will require practical and positive experiences with the private ordering of contracts and "contract as framework" to establish long-term mutually beneficial relationships with other business groups and nonaffiliated companies (Williamson 2005:2 p. 30, and Williamson 1975, pp. 37-39) ${ }^{290}$.

${ }^{288}$ This is a theme that cuts across many of the articles in the bibliography on India's and other developing
countries' business groups that were prepared by Tarun Khanna and his colleagues. Placing these
adaptations and accommodations within the context of the Williamson (1975 and 1985) TCE model
(Chapter 2 particularly Exhibit VI), opportunism, shirking and related governance and transactions costs
are relatively lower within India's business groups -- because of fewer information asymmetries, shared
mental models, loyalty to the group and family, and hierarchy in particular the economic power of the
group leader; and, much higher in market transactions and in longer-term relationships across different
business groups and with unaffiliated companies (see Chapter 2). ${ }^{289}$ The larger business groups have at their disposal the credible threat of market retaliation and a large number of other economic and social penalties to carry out those threats. As noted earlier, the larger business groups will be focusing on fewer core capacities, products and markets in order to build strong market positions and power in their key domestic markets. Nonetheless, these same groups will still be competing in multiple Indian markets (in terms of both geographic and product space). Multimarket contact, strong market positions to protect, and information asymmetries and uncertainties among competitors about their future strategies, mean that business group threats of price wars and price and nonprice predation become even more credible and are not just "cheap talk" (see Farrell 1987, Farrell and Rabin 1996 and Weigelt and Camerer 1988).

${ }^{290}$ However, as noted in the text, acquiring this experience may be more problematic in India because of limited familiarity with and trust in "contract as framework", the litigious nature of Indian society, and the high costs, delays, and uncertain and questionable decisions of Indian courts. While businesses in most countries prefer the private ordering of contracts over the formal courts (Williamson 1975 and 1985), the 
For these and other reasons, their Indian critics argue that the traditional business groups will not be able to make the necessary adaptations and accommodations to the post-1991 competition regime; and therefore will lose ground to multinational corporations and especially to the new entrepreneurs and companies in information technology (IT), biotechnology, other new economy sectors, and the deregulating sectors, that often have younger and more dynamic leaders.

\subsubsection{Bringing Together the Arguments on the Accommodation Strategies and Their Implications}

Both sides of the debate have good arguments and the more negative perspectives have considerable merit that this analysis has addressed in preparing its findings and conclusions. However, on balance, most research participants and other sources stated that, while liberalization and the more open Indian economy will result in more "churning" among business groups ${ }^{291}$, most of them are responding well to the

formal court system is still important in providing the location for ultimate appeal when informal business institutions cannot resolve a contractual dispute.

Liberalization, greater inward foreign direct investment, the accommodations of traditional business groups to the post-1991 competition regime, and the growing number of informal business arrangements with and between unaffiliated companies require that the formal courts take on greater importance as the "formal institution of last resort". Debroy (2003 and 2004) and other critics of India's court system seriously question whether the country's formal court system is capable of providing the required support to informal business institutions, rules of business conduct, and governance systems that are established outside the traditional business groups.

${ }^{291}$ This means at least some new entrants, more changes in market positions and relative economic and perhaps political strength between groups, and the disappearance of the less competent groups that have less vision and adaptability - especially in comparison with the greater stability found in the pre-1991 competition regime (see Chapter 6). The business groups that reportedly are less prominent today than before include the Walchands (Premier Autos and Construction), the J.K. Singhania Group, the Kirkoskar Group, the Goenkas (RPG Group), the Thapar Group, the Modi Group and the Arvind Mafatlal Group. Research participants noted as well that some of the smaller family owned business groups have disappeared since 1991.

The decline and disappearance of individual business groups are the result of (i) succession problems, (ii) too much concentration on one or a few sunset sectors that are becoming unprofitable, (iii) failure to achieve a leading position in a key high-growth domestic market, (iv) being forced to diversify into less familiar and profitable products and markets in order to survive as a group, and (v) failing to adjust to the new post-1991 environment - - with of course the importance of each factor depending on the group. 
liberalization challenge and will continue to be major players in the domestic market and over time will be successful participants in global markets ${ }^{292}$. Many of the traditional informal institutions, rules of business conduct, business practices and arrangements that worked for the business groups in the past continue to be effective and important today as India moves into a more globalized, knowledge-based economy. These institutions, rules and arrangements are important to reducing the transaction costs and high risks of globalization and rapid technological change, especially within the context of a liberalizing Indian economy where reforms are gradual and incomplete, government remains important, and information and other transaction costs are still high.

The incomplete liberalization and deregulation of financial and other business services, infrastructure and other intermediate markets are especially important to business group strategies, performance, persistence and success. Group affiliated companies have access to both internal business group services and markets and "external markets" outside their business group, and can choose between them based on price, availability, and speed of delivery. In sharp contrast, independent companies are totally dependent on outside markets and non-affiliated infrastructure and other service providers, which are less developed in India compared with the OECD countries ${ }^{293}$, and as well vary greatly between Indian regional states ${ }^{294}$. Because company exit is still

\footnotetext{
${ }^{292}$ These perspectives are in line with the more positive views held by such researchers as Dobson (1998), Granovetter (2005), and Khanna and Palepu and their colleagues (1997, 1999, 2000:2, 2004:1, 2004:2 and 2004:3). These scholars note that business groups continue to be important in the more highly developed of the post-WWII developing economies such as Japan, South Korea, Taiwan and Chile; and that India's business groups will likely display similar characteristics, strengths and survival skills.

${ }^{293}$ As well as many other developing and transition economies starting with China.

${ }^{294}$ Because companies affiliated with the larger business groups have access to the higher quality infrastructure and other services provided by other group affiliated companies (Fisman and Khanna, 2004), these companies are better positioned to locate in less developed Indian regions where infrastructure and other services are of lower quality. This allows business groups to benefit from the lower labour, land and
} 
difficult, time consuming and expensive in India, business group affiliates have an additional advantage over unaffiliated companies - through sharing the costs of a financially troubled affiliated firm that is unable to exit, and providing the troubled firm with the financial and management resources, increased sales and lower-cost inputs required to assist with business recovery ${ }^{295}$.

Accordingly, one of the major reasons for the "optimism" of many analysts and field research participants is the gradual, incomplete and in some ways contingent nature of India's liberalization program ${ }^{296}$. Gradual and incomplete liberalization requires a gradual, cautious and flexible response by India's business groups and other traditional companies. The more successful business groups are adopting a middle course that attempts to take account of and capitalize on both the opportunities provided by liberalization as well as its remaining gaps and deficiencies.

The gradual accommodations and responses of business groups also reflect the business groups' understanding of the limitations inherent in this form of informal business institution. Informal business institutions are more difficult to maintain and govern as the membership grows in size and diversity in terms of backgrounds, interests

other costs and the higher development subsidies and tax incentives available in less industrialized states; and thus can play -- and build a reputation and political capital for playing -- a developmental role through locating new plants in less developed Indian states and regions.

${ }^{295}$ In this manner, the affiliated companies of business groups share the costs and risks of financial failure and the constraints to exit (Khanna and Yafeh 2005, pp. 302-303), as well as the costs and political influence and benefits from lobbying government to apply existing labour, bankruptcy, restructuring and "sick company" laws in a flexible/forebearance type manner.

${ }^{296}$ While most argue that liberalization in some form is now a permanent feature of India's political economy, there is still significant contingency surrounding if and when further reforms will be implemented and the contents of the liberalization program through time, which could become more or less "liberal" depending on future economic and political developments and pressures either in India or from abroad, (including internal and external pressures associated with the current -- December 2008 -- global financial crisis and economic downturn). This is the natural consequence of India's active and highly pluralistic democracy where fundamental and unanticipated changes in economic policy are both possible and probably likely based on the past track record analysed in this dissertation. 
and incomes (Bowles and Gintis $2002^{297}$ and Chapter 4$)^{298}$. Size, prosperity and diversity pose a difficult trade-off for traditional family-based business groups. Greater group size, revenues and diversity in membership and business relationships can lead to significant benefits from greater division of labour, product and industry specialization, economies of scale and scope, and positive externalities such as technological spillovers ${ }^{299}$. Nevertheless, at some point, once certain (likely unknown) size, diversity, revenue and profitability thresholds and boundaries are surpassed, business groups are faced with new pressures and challenges that are difficult and unfamiliar. The more successful informal business arrangements are likely the ones that recognize these limitations, thresholds and boundaries $^{300}$.

Consistent with these findings on business group accommodations and limitations, the business group affiliated companies in India - particularly the members of the larger business groups - have enjoyed in recent years higher profits and less variability in profits compared to non-business group companies (Khanna and Rivkin 2001, and

\footnotetext{
${ }^{297}$ See as well the many Ostrom references in the bibliography.

${ }^{298}$ The self-enforcing and self-perpetuating nature of informal business institutions and arrangements can be undermined by the growing size, complexity, diversity and prosperity of its members. Greif (2004 p. 23) states as follows: "each member of the community can become, over time, sufficiently wealthy so that the threat of communal punishment will no longer be strong enough to make past patterns of behaviour self-enforcing".
}

${ }^{299}$ Redding (1993) explores these same issues for Overseas Chinese companies and business groups, in a manner that would appear to be relevant to India's business groups as well. The analysis of Redding and other informal business institution specialists suggest that greater incentives and payoffs for group members, when combined with: (i) adequate informal monitoring and enforcement facilitated by information technology, (ii) willingness to apply appropriate financial and social sanctions against noncooperators, (iii) long time horizons and low discount rates among most members, (iv) high frequency of business and social interactions, and (v) joint efforts in building shared values, experiences, successes, social and political capital, and "mental models"; may mean that business groups and other informal business arrangements can over time become larger and more complex and diversified. Nevertheless, each group faces an ultimate size constraint that likely varies with the business group and the country.

${ }^{300}$ The family-based business groups in India are therefore careful to ensure that family influence and control remain in place, despite the overall growth in the business group (Ghemawat and Khanna 1998). 


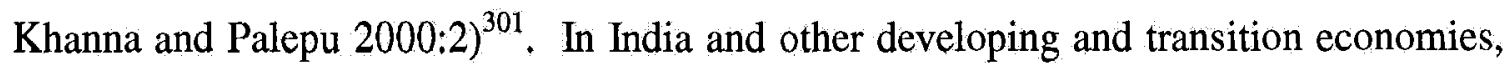
business group affiliation is just as important as industry sector in determining company profitability (Khanna and Rivkin 2001 and Khanna and Palepu 2004:1 p. 29).

\subsection{Responses of New Economy Industries, Companies and Informal Business Institutions and Arrangements}

\subsubsection{Implications for New Economy Sectors, Companies and Informal Business Institutions of the New Competition Regime}

India's new economy sectors, companies and informal business arrangements have brought new business voices and perspectives to the post-1991 debate on liberalization, market opening, competition, and competitiveness. Compared with the traditional business groups and their affiliated companies, these new economy companies in information technology, pharmaceuticals, biotechnology and related business services are: much more integrated into the global economy; more active participants in global supply chains, cross-border strategic alliances, long-term relational contracting and other informal business arrangements with companies in OECD and other countries; and, much more dependent on foreign capital, technology, expertise, and market access. For these reasons, the new economy companies and their informal business institutions and arrangements are much closer to their technological frontiers and have benefited more from the greater business entry and competition associated with India's post 1991 liberalization program (see Aghion et al 2005:1, 2005:2 and 2006).

The information technology sector, in particular computer software, business process services, other outsourcing, and related IT services, is the leading new economy sector in India. This sector experienced spectacular growth over an extended period starting in

\footnotetext{
${ }^{301}$ Less variability in profits is consistent with how the affiliated companies share the costs and benefits of group membership and come to the assistance of affiliated companies in financial difficulty (Khanna and Rivkin 2001, p. 65).
} 
1984 , largely through exports. Nearly $80 \%$ of its sales were to foreign markets in both 2001-2002 and 2006-2007. The IT sector is built around the sale of customized software services, supplied by Indian-owned firms, rather than products ${ }^{302}$; and encompasses a comparatively large number of suppliers with considerable entry, exit and changes in market share among the leading IT players (Athreye 2005, pp. 396-398). As of 2002, India's software sales were \$US 10.2 billion, growing by more than $40 \%$ per year during the 1990 s, and its 2002 exports were $\$ 7.7$ billion which constituted better than $10 \%$ of India's exports of goods and services in that year ${ }^{303}$. Ranbaxy Laboratories and other major pharmaceutical and biotechnology companies and business groups are implementing similar global strategies and are enjoying similar international market success.

Accordingly, the market structure, business conduct, company performance, and informal business institutions and arrangements of the IT and other new economy companies diverge sharply from India's traditional business groups, industrial sectors and

\footnotetext{
${ }^{302}$ As of 2000-2001, industry revenues were distributed fairly evenly between foreign firms (which include firms owned by US-based expatriates), new Indian owned entrepreneurial firms/relatively recent start-ups, and India's traditional business groups. Among the top twenty software exporters in 2000-2001, only seven were associated with India's business groups: Tata Consultancy Services (ranked ${ }^{\text {st }}$ ), Satyam Computer Services Ltd. $\left(5^{\text {th }}\right)$, Pentasoft Technologies $\left(10^{\text {th }}\right)$, Pentamedia Graphics $\left(11^{\text {th }}\right)$, Mahindra British Telecom Ltd. $\left(13^{\text {th }}\right)$, DSQ Software Ltd. $\left(15^{\text {th }}\right)$ and Tata Infotech Ltd. $\left(18^{\text {th }}\right)$ (Athreye 2005, pp. 398-399).

${ }^{303}$ A report prepared a few years ago by McKinsey for the National Association of Software and Service Companies (NASSCOM) projected that the Indian software industry would have sales of $\$ 77$ billion by 2008 , and would account for $7 \%$ of the country's GDP, 33\% of India's inflows of foreign exchange, and for four million jobs (Khanna and Palepu 2004, p. 24). This author was not able to identify a later report, using the same industry definitions, which would provide evidence on whether these projections are likely to be achieved in 2008.

However, less comprehensive evidence from Economist articles and other sources suggest the IT sector has continued to enjoy strong growth up to the time of writing. For example, media reports indicated that India's exports of software and related IT services reached US\$ 23.6 billion in 2005-2006, were expected to be \$US 31.4 billion in 2006-2007, and are projected by the GOI to be \$US 80 billion by 2011. In 200607 , exports accounted for nearly $80 \%$ of total Indian production of software and related IT services. These export figures are broadly in line with the McKinsey data and projections. Moreover, Varshney (2007) reported that India's information technology sector accounts for less than $0.5 \%$ of employment but contributes about $5 \%$ to the country's GDP.
} 
markets. The new economy sectors and companies were generally (albeit quietly) supportive of the 1991-liberalization and market opening program. Some research participants contended that the quiet support of these generally smaller newcomers played an important role in embarrassing the larger business groups and their trade associations into providing reluctant support to liberalization and market opening from 1995 on after the Bombay Club of 1993-94 became irrelevant ${ }^{304}$.

Research participants in South India stated that the new economy sectors and companies were also quietly supportive of the new competition law; but for the most part have ignored the competition law debate as irrelevant to their interests. Their perspective was coloured by three factors. The competition law debate was led by the national government and took place largely in the more northerly regions of India ${ }^{305}$. Competition law and other policy debates taking place in northern India have little resonance in southern India where most of the new economy sectors and companies are located; and where business dependence on and interest in the national government in New Delhi are more limited. These new economy companies sell relatively little of their goods and services in domestic Indian markets, and generally are smaller suppliers and junior partners in global markets, supply chains and strategic alliances.

\footnotetext{
${ }^{304}$ The new economy industries particularly information technology (IT), which were first based in and have grown rapidly in southern India, are now located in many other parts of the country. For example, West Bengal and other states in Eastern India that are less developed and prosperous are making efforts to establish their own IT clusters in order to accelerate economic growth and development.
}

The participation of West Bengal and other less developed but politically important northern and eastern regions in the new economy sectors could alter the institutional and political economy factors that are now dampening their economic growth performance (see Aghion et al 2003, 2005:1 and 2005:2), and could as well contribute to changing the national political and business discourse in favour of competition and market outcomes. These changes have already occurred in the southern states and major cities led by Karnataka (Bangalore), Tamil Nadu (Chennai) and Andhra Pradesh (Hyderabad).

${ }^{305}$ Between bureaucrats, competition law experts and advocates, politicians, civil society and other "elites" located for the most part in New Delhi, and the business groups, larger companies and their trade associations located in the major northern industrial cities and states. 
India's information technology (IT) industry looks to Silicon Valley and other foreign IT clusters for (i) leadership, funds, expertise, markets, informal networks and other arrangements, (ii) their competition, intellectual property, corporate governance rules and other rules of business conduct ${ }^{306}$, and (iii) for new entrepreneurs for Indian IT start-ups, which often are owned and managed by Indian nationals returning to India from Silicon Valley and other high-tech locations. In a similar manner, India's major pharmaceutical and biotechnology companies and business groups place much greater importance on foreign sales, informal business arrangements, expertise, and intellectual property, competition and other rules of business conduct.

These new economy companies live for the most part in their own global business world, and in many ways are insulated from and have separated themselves from the mainstream Indian economy, business culture and rules of business conduct. Therefore, a new and more modern competition law designed to promote greater competition in domestic markets would appear to have few implications for and to pose little threat to their corporate interests and strategies - especially their strategies to establish informal business institutions and arrangements with domestic and foreign partners.

Still, through time, the new competition law could have some impact on the new economy's corporate strategies and informal business institutions. Because of changes noted earlier to the Concept Bill of 2000, the new competition law encourages highly permissive treatment of the competition issues that can be raised by intellectual property

\footnotetext{
${ }^{306}$ These new economy companies and arrangements currently hold subordinate positions within global alliances and supply chains and therefore have simply adopted the informal and formal rules of competition and business governance of the major partner or customer headquartered in the home (generally OECD) country. Mainland Chinese companies - including state-owned companies, private and cooperative firms, and foreign joint ventures - that are now participating so successfully in global supply chains, have also accepted this "extra-territorial" application of informal and formal competition and other business governance rules of their Hong Kong, Taiwan or OECD country-based partners and customers.
} 
rights (IPRs) and IPR based informal business arrangements ${ }^{307}$. Permissive treatment of IPRs helps to advance the interests of the new economy companies in southern India and other parts of the country. Having said that, all that is needed is one important and successful abuse of dominance case with an important IPR dimension to develop new rules regarding the appropriate application of intellectual property rights to serve both competition and innovation objectives (Ireland 2007:1 and 2007:2, Werden 2001, Bresnahan 2003 and Takigawa 2005). The new economy sectors of southern India would have an important stake in such an AOD case; while in the near term, these new economy companies could be participants in global supply chains and strategic alliances that are investigated by e.g. the US and EU competition authorities ${ }^{308}$.

These Indian based new economy industries and companies currently are relatively small players striving to expand and achieve profitable and sustainable positions within global markets. With some important exceptions such as pharmaceuticals, entry barriers are generally low, government intervention is modest, access to risk capital is relatively good from international sources and ex-patriot Indian entrepreneurs and investors working overseas, and relevant competition law markets are multi-country and even global. However, as the Microsoft case indicates and Google is now demonstrating, the "fringe global player" of today can become with a little luck, significant business acumen, and aggressive marketing and corporate strategies, the dominant player of the

\footnotetext{
${ }^{307}$ Despite the very serious concerns raised by civil society and other competition policy advocates regarding the potential harm that the misuse of domestic and foreign owned IPRs can inflict on domestic competition and the consumer interest (see e.g. Mehta 2006, chapters 15, 21 and 22). The new economy sectors, companies and informal business arrangements will also benefit from the weaker merger review process and other changes to the new competition law that resulted from the lobbying of business groups and their trade associations.

${ }^{308}$ These companies will want to work with the Competition Commission of India (CCI) in order to ensure that India's competition, consumer, technology and new economy producer interests are not unduly hurt by the remedies proposed and enforced by the major competition law jurisdictions.
} 
not-too-distant future. India in fact is hoping that one of its (globally) smaller IT companies and bio-pharmaceutical producers can in fact become a major global producer in a comparatively few years. This will mean jobs, exports, royalty income and prestige for the Indian economy, but as well could pose competition dangers for the domestic industrial purchasers and final consumers of these products. At that point in time, the new Competition Commission of India (CCI) could have its own home-grown Microsoft type case.

\subsubsection{New Economy Responses to the Post-1991 Competition Regime}

Particular emphasis in this sub-section is placed on the major differences in accommodations and strategic responses between the new economy companies and arrangements and the traditional business groups. India's new economy companies and sectors are testing and developing new business models and products and expanding their sales in these new product lines, such as in "business process outsourcing" (also called "offshoring") in the IT sector ${ }^{309}$. They are aggressively expanding their foreign operations and their ability to manage their global operations (Athreye 2005, p. 412), through: diversifying their markets, selling more to European and Asian markets and reducing their dependence on the American market ${ }^{310}$.

New economy firms are increasing their company size to meet growing demands and to realize the benefits from specialization, a better division of labour (more precise splitting of tasks - Athreye 2005, p. 414) and scale and scope economies (particularly the

\footnotetext{
${ }^{309}$ These product lines range from call centres and services to financial institutions, to managing back office functions and other forms of content management services of large firms that can be conducted from a remote location (Van Dijk 2003, p. 96, and Athreye 2005, p. 393).

${ }^{310}$ This is in response to both the downturn in the US high tech sector in 2000-2001 - Van Dijk 2003, p. 104; as well as the higher growth and improved access to many Asian markets starting with Mainland China. This diversification will prove particularly beneficial in light of the recent news in December 2008 that the American economy technically has been in recession for a year.
} 
latter). They are investing more in $\mathrm{R} \& \mathrm{D}$, and in related human resource and software process management capabilities, in order to create and apply their own product and process innovations to be protected in many cases by intellectual property rights.

Many are moving up the value chain from low-margin to higher value goods and services in response to growing experience and capabilities as well as higher personnel and other costs (Athreye 2005, p. 412). These sectors and companies are placing greater emphasis on attracting, training and retaining high quality personnel in key management and technical positions - leading to the explicit introduction of human capital management strategies in some high technology companies (Athreye 2005, p. 414). Many of these firms are placing greater emphasis on building their brand name; increasing their efforts to attract offshore investment through e.g. NASDAQ listings; and further expanding their links with ex-patriot Indian nationals in the Silicon Valley and other locations.

Growth and further development of India's IT and other new economy sectors will require stronger interrelationships among related enterprises within and between e.g. India's growing number of IT clusters located in Bangalore, Chennai (Madras), Hyderabad, Pune and now many other cities. These stronger inter-firm and inter-cluster linkages would include both vertical sub-contracting as well as various forms of horizontal cooperation between independent companies in the same or highly related product lines in order to share R\&D, innovation and related product development and commercialization costs. Further growth and development will require as well the establishment of closer links between new economy companies and universities, research institutes, R\&D labs, technical training institutions, and government agencies responsible 
for promoting high technology development (Van Dijk 2003, and National Knowledge Commission 2007), and greater recognition and more proactive development and use of technology cluster resources (Prashantham 2004, p. 18).

Because the new economy companies have shorter histories; are less often based on a single family and ethnic, religious, occupational or other social group; and more often apply global rules of corporate governance and business conduct, their expansion, technology development, innovation, global, relationship building and related modernization strategies will face less severe internal thresholds, boundaries and other constraints compared with the traditional family based business groups reviewed in section 8.4. The strategic responses of the new economy companies to the still evolving post-1991 competition regime will as well less often raise serious competition issues. Research participants and other sources however are still concerned that the new Competition Commission will apply the same legalistic approach with no competition and efficiencies test ${ }^{311}$ as applied by the MRTPC. This would result in serious legal constraints to the establishment of mutually beneficial and efficiency enhancing nonmerger vertical and horizontal arrangements and networks with domestic and foreign partners that are so central to the new economy company strategies summarized above (Jorde and Teece (1992, Van Dijk 2003, p. 106) ${ }^{312}$.

\footnotetext{
${ }^{311}$ Consistent with the third kind of interaction in Exhibit II, this legalistic approach could be directed at e.g. vertical restraints and arrangements, non-merger horizontal agreements between competitors to promote R\&D and innovation, and other so-called anti-competitive agreements and practices. As noted in Chapter 7, the legalistic approach could result in the misapplication of the per se prohibition against hard core cartels to efficiency and innovation enhancing informal horizontal arrangements. Such new economy arrangements could be especially at risk if the new competition law is used to adjudicate non-competition based disputes between companies and by Indian governments to achieve non-competition objectives - as occurred under the MRTPA (see Chapter 6 and Appendix 8).
}

312 Therefore, the country's IT and other new economy sectors have an important stake in interacting with the new Competition Commission in order to better understand the new competition law and the 
The growing importance of these new economy/network industries within the Indian economy, and these more modern innovation based informal business arrangements and networks could also be a potentially important source of tension between competition law, innovation policy and intellectual property rights in India in the years ahead (Church and Ware 1998, Ireland 2007:1 and 2007:2). While India's new competition law and regime has adopted a permissive rule of reason approach to the competition issues associated with intellectual property and network and related high technology industries (Jorde and Teece 1992), India will be a net importer of IP protected technology, and a net exporter of IP royalties, for a long time to come; and therefore will continue to be sensitive to the ways in which domestic and international corporations can and do use and misuse their IPRs to achieve and maintain dominant positions in national and global markets; and to the harm to competition, consumers, farmers, small businesses, and the urban and rural poor that can result from (alleged or actual) misuse of IPRs for anticompetitive purposes (Ireland 1998, 2007:1 and 2007:2). In the coming years, this could be the basis for some difficult, complex, unanticipated and highly politicized interactions and frictions -- that neither side is currently prepared for -- between the post-1991 competition regime and the new economy/network industries and their informal business institutions and arrangements ${ }^{313}$.

\section{Exhibit XVII: Summary of Post-1991 Interactions and Accommodations And Their Anticipated Outcomes and Consequences}

enforcement practices of the CCI, and to exchange information with the CCI so that both sides better understand each others' mandates, requirements, and future plans and strategies.

${ }^{313}$ In fact, one such case involving the Monsanto patent and Bt cotton has already emerged and been addressed by the MRTPC and other GOI authorities in the past three years - see section 3 of Appendix 8 . 


\section{Competition Regime Perspectives}

1991 liberalization program and the design of the new competition law and policy were largely Government of India projects up to 2000. When for the first time the business groups/lobby successfully argued for -- in a highly public manner -- major changes in the draft competition bill before it was reviewed in detail and passed by the Indian Parliament in 2002.

With this business lobby success, the GOI is now taking greater account of business views in designing the competition regime and related economic policies and programs.

However, political economy factors can still "trump" business views and requirements as indicated by the incomplete nature of liberalization and the need for further "probusiness" reforms in land, labour, restructuring, bankruptcy, "sick company", infrastructure services, the informal economy, small firm, and related markets and regulatory regimes.

The business groups/lobby almost totally focused on and continues to emphasize merger review and ignored the other two major sections on cartels and other anti-competitive agreements and on abuse of dominance. Weakening of merger review means that the new competition law and regime will need to be more proactive and successful in enforcing the other two sections - to ensure e.g. that a merger or acquisition that falls below the size thresholds do not result in the future in a cartel or abuse of dominant position that hurts competition and consumers in smaller markets.
Business Groups and New Economy Informal Business Institutions Perspectives

Business groups not consulted on 1991 liberalization program, and first opposed it and then offered grudging acceptance. Leading to slow responses of up to a decade for most business groups and other larger more traditional companies. And ignored government work on a new competition law and policy from 1995 to 2000 when the business groups/lobby succeeded in a highly transparent manner in weakening merger review and were assisted by other pro-business and pro-development changes sponsored by government. In contrast, new economy sectors, institutions and arrangements were quietly supportive of liberalization and the new competition regime from the outset. Liberalization was consistent with their globalization and technology focus, and the new competition regime was seen as a threat only to the business groups and other traditional companies, sectors and markets.

Business group accommodations encompass a mix of strategic responses to address the opportunities, threats and risks resulting from liberalization and the new competition regime - e.g. mergers, acquisitions, downsizing, restructuring, emphasizing core capabilities, strategic product diversification, higher equity in key affiliate companies. And continuing to avoid, manipulate and/or benefit from the remaining gaps and deficiencies in the incomplete liberalization program and competition regime. Which still result in many complex interactions with government at all spatial scales and thus high transaction costs for business.

Current and Anticipated Outcomes and Consequences - and Outstanding Questions for the Future Compared with the pre-1991 regime, interactions are fewer in number, on balance higher in quality and more often result in positive outcomes for Indian business and economic performance. And accommodations made by the competition regime and informal business institutions more often favour the latter.

Strategic accommodations and responses of traditional business groups more often favour competition over anti-competitive conduct and rent seeking. Despite their slow response to liberalization and greater churning post-1991, current accommodations and responses of business groups appear sufficient to ensure their survival and success in aggregate as a "governance mode". Compared with traditional business groups which are still largely concerned with domestic market positioning, the strategic accommodations and responses of the new economy sectors, and their informal business institutions and arrangements are more focused on globalization, exports, technology creation and adoption, innovation, competition and long-term competitiveness. With some influence on the traditional business groups through demonstration effects, potential loss of moral leadership within India's private business sector, and business group participation in the new economy sectors and markets. Business group and new economy strategies and outcomes are not likely to be markedly different with full enforcement of the new competition act. But there remain many contingencies, risks, dangers and unknowns for the business groups, new economy informal arrangements and the competition regime itself as all three move into unfamiliar territory including: enforcement of the new competition law in 2009, the National Competition Policy under the $11^{\text {th }}$ Five-Year Plan, and the emerging more pro-competition attitudes and culture in India. 
Exhibit XVII on the previous page brings together the major findings from Chapters 7 and 8 in order to summarize and compare the post-1991 interactions, accommodations and outcomes analysed in the past two chapters from the perspective of the competition regime and India's informal business institutions.

\subsection{Conclusions}

This analysis of the interactions, conflicts and accommodations from the perspective of the country's informal business institutions indicates major differences: through the 17-year case study period; between the traditional business groups and the new economy informal business institutions; and based on whether the accommodations are in response to the positive attributes or remaining deficiencies of the new competition regime and liberalization program.

Compared with the pre-1991 regime, the interactions and accommodations of India's business groups and other informal business institutions with the country's new and still evolving competition regime are fewer in number but higher in quality, and on balance are more favorable to competition, innovation, competitiveness and business and economic performance. Especially since 2000, these interactions, conflicts and accommodations have resulted in significant changes to the competition regime, as well as to the corporate strategies of the traditional business groups. Their responses to the more positive aspects of the current competition regime and ability to capitalize on its remaining deficiencies are both important to their future strategies, survival and success.

In contrast to the business groups, the new economy companies are responding more to global developments and international rules of business conduct, and assume that India's new competition regime is for the most part irrelevant to their business decisions, 
strategies and informal business arrangements. The new economy sectors, companies and informal business arrangements could be ignoring the current competition regime "at their peril".

India may be approaching a "tipping point" ${ }^{314}$, where the business culture that was essentially anti-competition for a period of close to 200 years may return to the procompetition orientation of the pre-colonial period (Das 2002 and Chapter 4). India's informal business institutions and rules of business conduct (the right hand side of Exhibit I) are becoming better aligned with the formal and informal dimensions of the country's competition regime (the left hand side).

Such a pro-competition culture would be supported by India's traditional economic thought that favoured fair competition over collusion, exploitation, usury and rent seeking, and India's middle/consuming class which is growing rapidly in size, purchasing power and political influence. Perhaps most importantly, pro-competition policies, laws, and attitudes are starting to become more integral to the economic development models now being applied at the national, regional and local levels in India (see Aghion, Burgess et al 2003, 2005 and 2006, Sinha 2005:1 and Government of India 2007:1315). While full integration will take many years, this process still represents a major departure from the

\footnotetext{
${ }^{314}$ The concept of the "tipping point" as used in industrial organization economics and other fields is that small trends, that appear relatively unimportant in themselves, can have cumulative and inter-related impacts that at some point can result in major and even fundamental changes that are sustainable and therefore cannot be easily reversed without a similar cumulative trend that results in a new "tipping point" in the opposite or totally new direction (see e.g. Gladwell 2000). The business, competition and consumer culture of India may be going through this kind of "tipping point" process (Das 2002).

${ }^{315}$ One indication of this process is the many references to competition, consumer protection and related marketplace issues in Volume I on "Inclusive Growth" of the GOI's Eleventh Five Year Plan for the period 2007-2012 (Government of India 2007:1). In particular, this document recommends on pp. 287-288 that Indian governments should adopt "a comprehensive National Competition Policy". While five-year plans are less important today than before 1991 liberalization, they still play a useful role in signalling the government's priorities and intentions to the private business sector, regional state and municipal governments, consumers/voters, and civil society.
} 
1965-1991 competition regime, when the competition law was embedded within a broader "anti-competition" regime, the "License Raj".

Informal business institutions in India have the potential to generate significant efficiency gains as well as substantial anti-competitive conduct and harm to competition. The post-1991 competition regime is generally permissive and supportive of informal business institutions and arrangements. Nonetheless, the future interactions and accommodations will be complex and difficult, and will provide considerable scope for misunderstandings and sub-optimal decisions from both sides. Some traditional business groups could under-estimate the importance of the new pro-competition culture now emerging in India; and the competition regime may continue to apply the legalistic approach and anti-business biases of the past and ignore the efficiency, competition and competitiveness benefits of informal business institutions. In the early months and years of enforcing the new law, India's competition regime and informal business institutions will need to learn a great deal more about each others plans, strategies and requirements in order to reduce these dangers. 


\section{Chapter 9: Comparing the 1965-1991 and Post-1991 Case Studies}

\subsection{Purpose}

This chapter compares and contrasts the 1965-1991 and post 1991 periods in relation to the central question and two time dependent arguments (Exhibit II). Emphasis is given to how the interactions, conflicts and accommodations between India's competition regimes and informal business institutions have differed between the two case study time periods. Section two assesses the differences largely from the perspective of the competition regime, while section three analyses these differences largely from the perspective of India's traditional business groups and other informal business institutions. Concluding comments are provided in the final section.

\subsection{Comparing the Interactions and Accommodations Between the Two Time Periods from the Competition Regime Perspective}

Exhibit VVIII below indicates that the time period differences are the consequence for the most part of the major differences between the two competition regimes. The two competition regimes are markedly different in terms of rhetoric, attitudes, intentions, design, outcomes and the divergences between intentions and outcomes. The 19651991 competition regime, which was intended to control and regulate the business groups and other large "MRTPA monopoly" companies, in fact deterred business entry; privileged anti-competitive market structures and outcomes over competition; and through a combination of design, opportunistic behaviour and unintended consequences, favoured well established business groups and other larger firms over medium-sized companies and new entrants. The 1965-1991 competition regime was thus characterized by a sharp divergence between intentions and outcomes. 
Exhibit XVIII: Comparing the Interactions and Accommodations Between the Two Time Periods

\section{5-1991 Period and $\quad$ Post-1991 Period and Still Evolving Competition Regime \\ Competition Regime \\ Accommodations of the Competition Regime to Traditional Business Groups and Other Informal Business Institutions}

\section{In designing the pre- \\ In designing the new 1991 competition regime as a key component of India's liberalization program, there was virtually no}

1991 competition law

(MRTPA) and regime in

the late 1960 s, there was

virtually no consultation

with and thus

accommodation of the

competition regime to the

interests of informal

business institutions.

\section{In implementing the}

1965-1991 competition

regime and enforcing the

MRTPA, there were some

(largely indirect)

accommodations of the

regime to informal

business institutions

through case selection, the

priorities placed on

different sections of the

MRTPA, and how these

different sections were

interpreted by the consultation with the business groups and community. Liberalization, including the post-1991 competition regime, was a government project designed behind "closed doors". The GOI made some accommodations to the "perceived" needs of informal business institutions - through e.g. eliminating merger review and mandatory review of the "MRTPA monopoly companies" from the old Act, applying the old competition law to state-owned enterprises for the first time, and pushing the MRTP Act and Commission even more to the sidelines. The GOI likely expected that these accommodations would generate more business support for the liberalization program than in fact it received in the first half of the 1990 s.

In discussing and designing the new competition law from 1995 to 2000 , the competition regime made virtually no accommodations to India's informal business institutions -- as the private business sector essentially ignored the competition law reform project during this period. However, this situation changed abruptly, significantly, dramatically and (in some cases) transparently in 2000 with the publication of the Raghavan Committee Report and the Concept Competition Law based on the Report.

At that time, the competition regime had to make major accommodations to informal business institutions through e.g. (i) weakening the merger review provisions and the provisions associated with intellectual property, (ii) incorporating an explicit development oriented public interest test into the law's purpose clause and its key sections on e.g. abuse of dominance, and (iii) other pro-business and pro-development changes and additions made by the GOI. These accommodations of the competition regime and the new competition law to the country's informal business institutions benefited both the traditional business groups and India's current and future new economy informal business institutions.

In implementing the new 1991 competition regime as part of the liberalization program, there was some accommodation to India's informal business institutions - as seen in the gradual, incremental, stop/go approach to liberalization through the 1990s. However, some economic reforms that are deemed to be very important to the business groups and community remain incomplete. The liberalization of financial markets was slower than in many other markets; and many of the other most important reforms from the perspective of the largest business groups and businesses -- e.g. labour and land market reforms, bankruptcy law reform, and removal of the small enterprise preferences and reservations -- have still not been implemented.

MRTPC and the courts.

These business-friendly accommodations were greater in the 1980 s than the $1970 \mathrm{~s}$.

Because full implementation of the new competition law will not begin until 2009 , only preliminary evidence is available on the future accommodations of the competition regime to India's informal business institutions. Current evidence based on e.g. the influence of informal business institutions and the private business sector more generally on the competition law regulations that are now being prepared by the Commission and Government is that the competition regime and law will continue to make accommodations in response to the perceived needs and stated positions of India's business groups and other informal business institutions and business interests. 


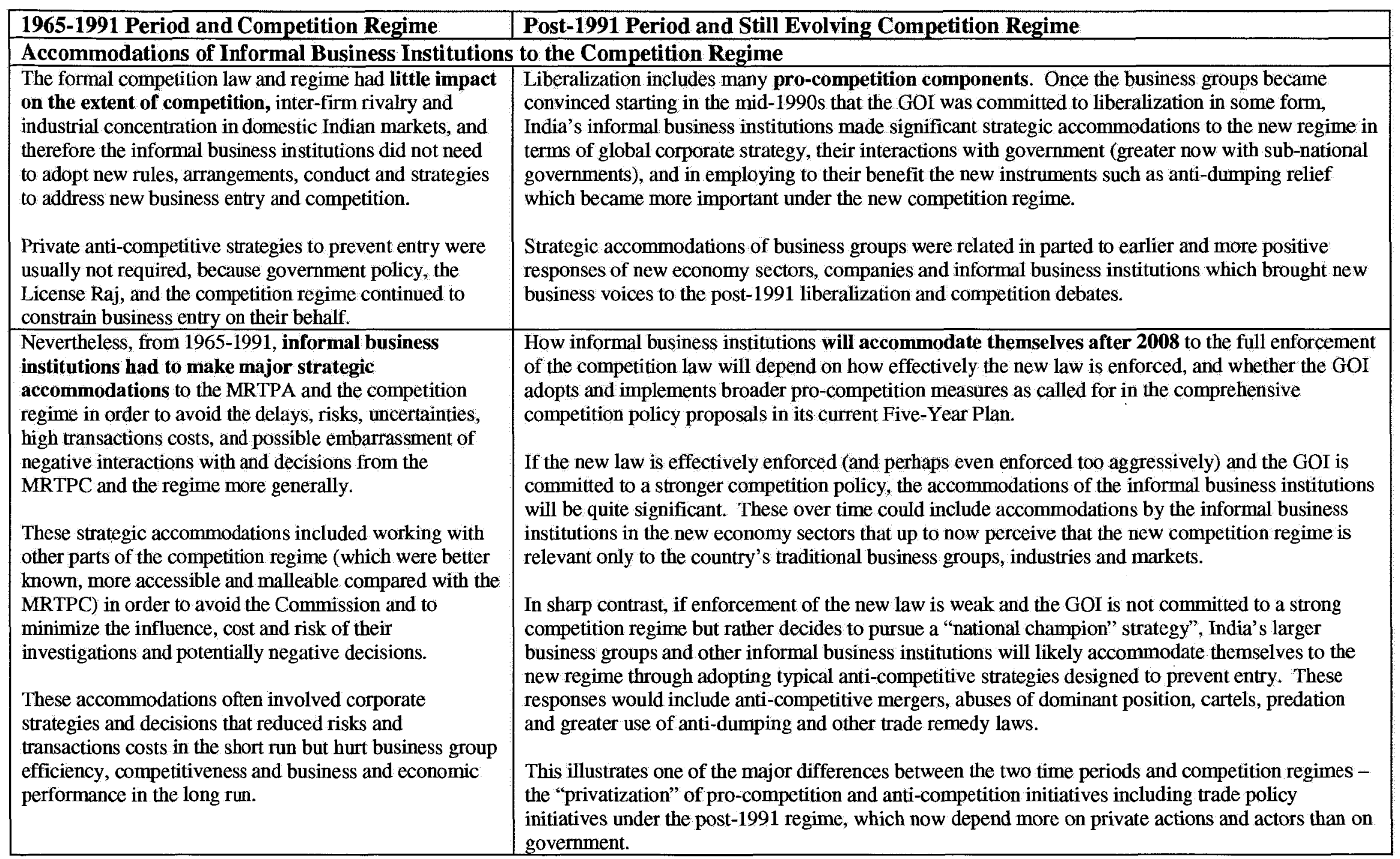


The post-1991 competition regime is still a work in progress, since full enforcement of the amended Competition Act 2007 has not yet begun. Based on the 1991 liberalization reforms which significantly weakened the MRTPA and eliminated many but not all barriers to entry and exit in the License Raj, the accommodations made by the GOI in designing merger review and other sections of the new competition statute (see Chapter 7) and the National Competition Policy objective in the $11^{\text {th }}$ Five-Year Plan, the post-1991 competition regime is intended to balance and provide appropriate trade-offs between competition, international competitiveness, economic growth and other socioeconomic development objectives, and the promotion of "national champions" in the Indian private sector ${ }^{316}$. The record to date indicates that the actual outcomes from 1991 through to 2008 are fairly close to these intentions.

Despite the concerns, limitations, and flaws noted by its critics and this author in earlier chapters, this still evolving competition regime could well be appropriate to the current stage of India's economic and institutional development, where many but not all companies, business groups, other informal business arrangements, industries and regional states are some distance from their technological frontiers (see the Aghion et al references in section 2.6 on pp. 76-77 and in the bibliography). However, this conjecture depends on the quality of enforcement and other factors that cannot be predicted at this time; and should be the subject of more detailed analysis through applying the

\footnotetext{
${ }^{316}$ Appropriate trade-offs in this context mean that, when compared with the competition regimes in the larger OECD competition law jurisdictions, the Indian competition regime is placing greater weight on: longer term producer and other dynamic efficiencies; and government policies and business investments, conduct and arrangements that promote innovation, poverty reduction, market integration (a stronger Indian common market), and other longer-term development objectives.

In contrast, India's evolving competition regime is placing less emphasis on static short-term consumer welfare gains and producer efficiencies, which are not ignored but are given relatively less weight in India's new competition regime than in e.g. the United States and the European Union; (see e.g. the discussion of the development oriented public interest test in India's new competition law in Chapter 7 and the proposals for a National Competition Policy, Government of India 2007:1, pp. 286-289).
} 
competition and institutional insights provided by new endogenous growth theory and related literatures.

\section{The position of competition law within the competition regimes of the two}

periods is markedly different. The $1965-1991$ period is characterized by an ambitious, but fundamentally flawed and poorly resourced and enforced, competition law and agency embedded within a broader competition regime that discouraged business entry and competition. The post-1991 period is characterized by an incomplete but, on balance, pro-competition regime embedded within India's liberalization program, which to date has had virtually no support from competition law enforcement because of the significant weakening of the MRTPA in 1991 and the failure to begin enforcement of the Competition Act passed in December 2002 up to the present day (December 2008).

In sum, the pre-1991 competition regime was essentially "anti-competitive" in all respects except perhaps government rhetoric, and the post-1991 regime on balance favours competition - while still including elements that are either ambiguous for competition or clearly negative in intent and impact. The trade policy and FDI reforms and financial market liberalization from 1991 on and the slow elimination of the licensing regime that started earlier in the 1980 s clearly favour competition. The devaluation of the Rupee and the liberalization of the foreign exchange regime from 1991 on had mixed and ambiguous effects on domestic competition ${ }^{317}$. On the negative side, beyond weakening the MRTPA and delaying the new law, India's liberalization program has

${ }^{317}$ Devaluation encouraged more companies to export, which can have positive albeit indirect effects on competition in some domestic markets (Thompson 2000). At the same time, devaluation: (i) increases the prices of imported goods in Indian markets -- offsetting to some degree the competition benefits from lower trade barriers, (ii) increases the Rupee cost of imported technology, machinery, equipment and business services, (iii) encourages Indian firms to compete in domestic and foreign markets on the basis of lower production costs and prices rather than product quality and product innovation, and (iv) can fuel general price inflation. These forces can reduce domestic competition and the incentives for Indian firms to be more innovative, competitive and responsive to consumer needs. 
failed to modernize bankruptcy, labour, land use and other laws that are important to business entry, exit and restructuring. These "anti-competition" elements provide new opportunities for rent-seeking and anti-competitive conduct especially by business groups and other large companies, employing strategies that are not too different from the pre1991 period (see Chapter 6 and section 8.3).

The relative importance of government and private business actions and actors for competition attitudes and outcomes has changed greatly between the two regimes. Before 1991, entry deterrence, foreclosure and other anti-competitive strategies by business were typically not needed by incumbents to deter entry and prevent competition. Government did the job for them through high import and FDI barriers and the "License Raj”. In contrast, private strategies to discourage and prevent business entry and decrease competition have become more important and effective after liberalization (Athreye and Kapur 2004). The government imposed entry barriers of the pre-1991 competition regime have now been replaced to a significant degree (albeit not completely) after 1991 by business imposed entry barriers through using trade remedy laws ${ }^{318}$, anti-competitive business strategies, financial pre-emption, and manipulating the remaining regulatory regimes particularly at the sub-national levels. Private actors and actions are now the major determinants of industrial concentration, market structure and

\footnotetext{
${ }^{318}$ What some trade experts call the "privatization" of trade law. Trade liberalization in most countries is accompanied by greater use by enterprises of anti-dumping, countervail, and safeguards, the so-called trade remedy laws, to prevent imports (National Board of Trade Sweden 2005). India since 1991 is consistent with this pattern.

India had its first antidumping case in 1993 and the number of Indian cases from 1995 to 2000 numbered 176 , which constituted $12 \%$ of the total number of cases initiated by all WTO members over that period (Aggarwal 2002, p. 6). India is now one of the most active users of anti-dumping and other trade remedy laws in the international economy. The potential to use anti-dumping as part of an anti-competitive business strategy is magnified because, consistent with most other countries under the WTO, antidumping law in India does not address competition factors (such as concentration in the domestic market and predatory behaviour by the importer) and does not require the application of a consumer welfare test (Aggarwal 2002).
} 
the extent of competition in India's domestic markets. Perhaps the most important difference between the two periods is this "privatization" of both pro-competition and anti-competition initiatives and instruments.

Compared with the pre-1991 competition regime, there is evidence of stronger competition in some Indian markets and industries after 1991 (see Chapter 5). Nonetheless, incomplete liberalization has led to less than anticipated and perhaps desired outcomes for competition, economic efficiency, productivity, innovation, industrial concentration, reductions in market power and consumer welfare at least over the short to medium term (see e.g. Balakrishnan et al 2006, Das 2003, Das and Pant 2006, and Athreye and Kapur 2004). Institutional and political economy factors, which were decisive under the pre-1991 competition regime (Bardhan 1984), still help to explain the less than anticipated competition benefits from liberalization. These factors, which have resulted in "political economy traps" for some traditional industries and markets despite liberalization, are slowing India's transition to a new economic growth model and development path (Acemoglu 2002, pp. 43-44) ${ }^{319}$.

Comparing the pre- and post 1991 competition regimes illustrates that industrial, trade and competition reforms are complements rather than substitutes for each other (Sharma 2005 and 2006). All three need to be deployed effectively for a liberalization project to have its maximum impact on domestic competition, innovation, international competitiveness and other indicators of economic performance and success. Earlier

\footnotetext{
${ }^{319}$ Accordingly, despite liberalization (and as a reflection of its incomplete character), the strong lobbying efforts and political influence of: the traditional business groups, government owned enterprises, existing foreign invested enterprises, other well-entrenched incumbents in domestic markets, trade unions in the modern sector, small firms benefiting from the reservation system, and business and non-business elites in the larger regional Indian states continue to have a stronger influence on government and business decisions and business and economic performance compared with e.g. the OECD economies (Sinha 2005:1).
} 
industry de-regulation in the 1980s made trade policy reforms in the 1990s more effective - even though the 1980s industrial reforms were modest (Sharma 2005 and 2006). Trade and industrial policy reforms likely would have been even more effective if they had been complemented by the earlier establishment and enforcement of a modern competition policy and law (The Financial Express 2008).

The major differences between the two competition regimes are associated with the significant differences in industrial and enterprise structure that are evident between the two periods. From 1965 to 1991, India's private economy, and the country's discourse on industrial concentration, competition and competitiveness, were dominated by India's traditional family based business groups and other larger traditional companies. During the post-1991 period, there are many new entrants, voices and major players in India's private business economy. These new voices are found in the information technology and other new economy sectors, and within the country's small but rapidly expanding foreign investment sector. They are also found in such service activities as telecommunications, passenger air and other transportation, banking and insurance, and the energy sectors, which in the past were dominated by public sector undertakings but recently have been partially deregulated and opened up to private investment.

As a result, India's industrial and enterprise structure is now more complex and diverse compared with the earlier pre-1991 period. These new voices, which typically are more oriented towards competition, technology and global markets, are influencing the competition regime, India's economic performance, and the strategies and lobbying efforts of the traditional business groups, industries and trade associations. One 
consequence of these new economy sectors and voices and their demonstration effects

(see below) is that India is slowly starting to move closer to its technological frontier, after moving away from this frontier under the 1965-1991 competition regime ${ }^{320}$.

A major change from the pre-1991 competition regime is the expanding prosperity, experience and market and political influence of India's consumers and voters in the

post-1991 period. The post-1991 period has seen the emergence and rapid growth of the middle class, called in the Indian literature the consuming class ${ }^{321}$. India's consuming class is still small in relative terms, comprising less than $20 \%$ or at most 200 million

\footnotetext{
${ }^{320}$ This is the combined result of: (i) the rapid growth of the new economy companies and sectors, which largely employ international competition, intellectual property, corporate governance and related rules and have had significant demonstration effects on the traditional business groups and industries and impacts on government policy; (ii) the more pro-business and pro-competition economic policy regimes at the national level and in many regional states and larger urban regions, and (iii) the more pro-competition accommodations of the traditional business groups compared with the pre-1991 competition regime and period.
}

All three factors are associated with the more pro-competition regime after 1991, This includes the first factor, the new economy expansion. The modest domestic reforms in the 1980s and the competition regime after 1991 provided the greater policy and regulatory space needed to allow the new economy sectors to become firmly established and to expand rapidly. These three factors are making important contributions to India's greatly improved growth performance over the past two decades compared with the first four decades after independence. See e.g. the various Aghion et al references especially in section 2.6, as well as Morris (2005) and Sinha (2005:1).

${ }^{321}$ This term is used because this class now has discretionary income to purchase non-essential goods and services. This new middle/consuming class is becoming more dominated by managers, professionals and other knowledge workers especially in the country's rapidly expanding private sector. This consuming class, which is replacing to some degree the old bourgeoisie of India that included teachers, government officials, other professionals such as doctors, merchants and industrialists, is based more on access to human, social and cultural capital and less on access to property and physical and financial capital (Das 2002, Chapter 19).

Recent research in economic sociology suggests that, on balance, this Indian consuming class would favour competition, innovation, merit, social and occupational mobility and market outcomes over state planning, protection and state entitlements and privileges based on political connections and social position. The term "on balance" is included on purpose in this phrase.

This is because of the major differences within India's middle class which includes: (i) professional and technical employees of government agencies and state owned enterprises that have lost some power and prestige because of liberalization, and (ii) the most prosperous and influential "fraction" of India's middle class (which as noted above is called the "new middle class" by some writers), which favors liberalization and modernization in large part because they facilitate higher consumption at lower cost, allow them to better capitalize on their advantages of caste, religion and language (particularly their English language skills), and thus promote their class interests at the expense of other classes and groups where the lower castes are more highly represented (see in particular Harriss 2006 and Fernandes and Heller 2006). 
people out of India's population of over a billion ${ }^{322}$. The poor and near poor still dominate the country's economic, demographic and voting structures. However, if India's GDP growth rate continues to approach the government target of $8 \%$ per year, the consuming class is expected to account for well over 50\% of the Indian population within the next two decades (Das 2002, p. 287, Nijman 2006 p. 768). The emergence of a strong, well educated and demanding consuming class could be critical to the establishment of a stronger competition and consumer culture in India and to future competition and related liberalization reforms. These and many other developments noted above are coming together to have a cumulative and fundamental impact on the Indian economy and society. The consequence is that India is approaching - and according to some commentators may have already reached -- the "tipping point" (Gladwell 2000) where a return to the statist, anti-competition and highly interventionist economy of pre-1991 will become virtually impossible ${ }^{323}$.

The success of the country's information technology and other more technology intensive sectors and business arrangements is generating important demonstration effects. These effects are encouraging some of the more traditional business groups and industries to become more innovative and competitive $\mathrm{e}^{324}$; and are forcing some of the more interventionist government agencies and more backward regional states to adopt policies that are more favourable to private business investment, competition, and competitiveness. Because of these new business voices and demonstration effects, the expanding market and political influence of India's consuming class, and the many pro-

\footnotetext{
${ }^{322}$ Based on World Bank data, India's population as of May 2006 is estimated to be about 1.1 billion.

${ }^{323}$ For similar reasons, China may have reached a "tipping point" in the mid-1990s, when a return to the command and control economy prior to 1978 became impossible.

${ }^{324}$ These demonstration effects are transmitted in part because many of the larger business groups now participate in both the traditional and more technology intensive sectors.
} 
competition accommodations of business groups, competition is starting to become more integral to consumer decisions, business strategy, market outcomes, the policies and economic development models of Indian governments at all spatial scales, and the attitudes about competition and markets of most economic agents. This development, and the privatization of pro-competition and anti-competition initiatives, represent the most fundamental differences between the two competition regimes and case study time periods; and are the two developments that will most influence the interactions, conflicts and accommodations of the post-1991 competition regime with India's informal business institutions in the coming years.

\subsection{Comparing the Interactions and Accommodations Between the Two Time Periods from the Perspective of India's Informal Business Institutions}

The final major difference between the two time periods is that, after a slow response to liberalization, the strategic accommodations and responses of India's traditional business groups and other informal business institutions and arrangements have been different in the second case study period especially since about 2000. These differences in business group responses are more the result of the differences between India's preand post- 1991 competition regimes, than of fundamental modifications to the business groups' rules of business conduct, routines, corporate culture and the variables they consider in finalizing their goals and objectives (see in particular the "Comments and Qualifications" column in Appendix 9) ${ }^{325}$.

\footnotetext{
${ }^{325}$ Appendix 9 employs a conceptual model of business group strategy and decision-making that was developed by the author for this thesis in order to compare and contrast the interactions, accommodations and responses of business groups to the very different competition rhetoric and the quite different competition regimes of the pre- and post-1991 periods. The Appendix compares the two periods in terms of their implications for some of the key business group related economic and financial indicators.

This conceptual model attempts to bring together insights from new industrial organization economics, new institutional economics, and political economy theories in order to explain how business group strategies
} 
The reluctance of India's traditional business groups to make these fundamental changes is consistent with the new economics institutional concepts of path dependence and institutional stability and inertia. Path dependence in this context means that, once a traditional business group with a long and successful history has achieved consensus among its company affiliates and senior officials regarding the fundamental requirements and reasons for success, institutional change takes place in a slow, careful and incremental manner. This reluctance as well is associated with and in response to the incomplete and in some respects contingent nature of Indian liberalization, and the continuing influence of India's past economic policies and political economy factors on current industrial structure, business conduct and economic performance (Kochhar et al 2006, pp. 4 and $24^{326}$ ).

The empirical evidence in Chapter 8 (and summarized in Appendix 9) indicates that, while the same financial and social variables are considered in preparing their strategies, goals and objectives, the business groups' interactions, conflicts and accommodations with India's new competition regime are requiring them to give different weight to some variables over others in the post-1991 period. The goals and objectives of business groups are now placing greater emphasis on financial variables and indicators of success, including: profits and shareholder value; higher equity holdings in major affiliated

towards, interactions with and accommodations to the competition regime can be expected to vary depending on the two time periods employed in this analysis.

${ }^{326}$ The two authors conclude on p. 24 that many of the distinctive features of India's economy that set the country apart from other developing countries in 1981 have not changed significantly despite the probusiness reforms of the 1980s and the pro-market reforms since 1991. They note as follows. "Part of the explanation for this continuity of trends may be that the reforms have not been completed ... But part of the explanation may be that there is hysterisis in growth paths, perhaps as a result of the acquisition of organizational capabilities and specific human capital. So the specializations induced by distortions may indeed be accentuated as reforms progress, rather than reversed." Many of the organizational capabilities and specific human capital noted by Kochhar (2008) are embodied within India's traditional business groups and other informal business institutions and arrangements. 
companies; and, larger size through internal growth, mergers, acquisitions, and greenfield investments to generate economies of scale and scope and establish a major presence in key domestic markets and in the future in foreign markets. Nonetheless, social considerations, obligations and preferences related to family solidarity, building social connections and networks, and investing in good works/corporate social responsibility are still given quite significant weight. Satisficing, rather than trying to maximize a single financial or social variable, is still the norm among business groups and other informal business institutions. In many cases, the business group responses to the competition regime of today are modifications to rather then radical departures from the corporate strategies of the past (Tripathi 2004).

Consistent with the hypotheses and conjectures provided in section 3.3, pp. 102$106^{327}$ on the business groups' strategic responses to the competition regime changes in the post-1991 period, some restructuring, downsizing, and re-focusing on core capabilities and key markets is taking place and will likely accelerate for many business groups. These strategic responses, which were made possible by the elimination of the $25 \%$ market share limit rule and the rest of the License Raj and the removal of merger review from the MRTPA, could raise some difficult competition issues under the nonmerger sections of the new competition act once enforcement begins in 2009.

Nonetheless, India's business groups continue to be more diversified than business groups and multi-division corporations in most other countries, and will continue to diversify into related and unrelated product lines for economic and family reasons and

\footnotetext{
${ }^{327}$ Which as noted earlier were developed prior to the Indian field work based on the economics conceptual literatures in Chapter 2, particularly the recent advances in new institutional economics and new industrial organization, and the conceptual framework in Chapter 3, especially the final paragraphs in section 3.3 on pp. 102-106.
} 
because the groups continue to enjoy preferred access to within-group and external financing ${ }^{328}$. The continuing preference for diversification may lead to missed opportunities for the business groups, the Indian economy and the country's industrial customers and final consumers ${ }^{329}$. Similarly, the tacit economy-wide market sharing arrangements of the past are still important in many markets where foreign entry has been limited, and potentially can be even more profitable since market shares can now be much greater than $25 \%$. Sustained supra-competitive profits in the groups' core markets depend on the success of business group strategies to discourage potential domestic and foreign entry, and whether, after 2008 , high market shares and dominance will attract the enforcement scrutiny of the new competition law and agency.

Business group strategies that favour consolidating their positions in core domestic markets -- while expanding in foreign markets through greenfield investments and mergers and acquisitions - are consistent with the export pessimism of the pre-1991

\footnotetext{
${ }^{328}$ Footnote 89 on p. 106 in Chapter 3 provides the hypothesis that, other things being equal, medium-sized unaffiliated companies would benefit more from the elimination of the $25 \%$ market share limit rule than the affiliated companies of business groups. However, while medium sized companies may capitalize on these opportunities in the future, there is little evidence to date that they have benefited more than affiliated companies since 1991 . Other things are clearly not equal.
}

Factors that continue to provide advantages to affiliated companies include the economies of scale and scope and lower transactions and production costs provided by business group membership, their preferred access to both within-group and external financing, other advantages associated with India's incomplete liberalization, and the other internal and external business group advantages discussed in Chapter 8 , including path dependence. In this context, path dependence indicates that the advantages provided by the pre-1991 formal business rules continue to provide benefits after the rules are modified or eliminated. This suggests that a theory intended to explain the establishment, existence, evolution, and expansion of the business group as a governance mode should go beyond the formal business rules and other external factors to include the internal institutions and rules of business conduct of business groups which, as discussed in Chapters 2 and 3, encompass an interesting mix of economic, social and cultural considerations (see the end of Chapter 10).

${ }^{329}$ For example, over diversification may mean that too much attention is given to managing affiliated companies operating in unrelated markets and too little attention is paid to innovation, the adoption of more advanced technologies, and business group expansion that capitalizes on core capabilities in new geographic and product markets that resulted in part from India's membership in the WTO and other trade arrangements. 
period. Because of these strategies, business groups and their affiliated companies based in India will have less opportunity to learn and benefit from: directly competing against more capable international companies in non-Indian markets; producing in India and then marketing higher quality products that serve the needs of higher income and more demanding industrial customers and final consumers in more prosperous OECD, Asian and other countries; and thereby moving up the value added chain through learning by doing and competing directly in foreign markets (see Lucas 1993) ${ }^{330}$. Still on balance, these gradual and prudent business group responses to the post-1991 competition regime have merit when external uncertainty, the limitations inherent to the family business group form, and the endogenous factors important to business group governance are added to the analysis (see section 8.4).

Exhibit XIX on the next page summarizes the accommodations and responses of India's traditional business groups to the changes in India's competition regime over the period covered in this dissertation. The dotted lines between the past and current situations attempt to capture the theme that elements of past interactions, conflicts and accommodations are still important to and found in current interactions, accommodations and responses. As predicted by institutional scholars, history and path dependence are important to understanding business strategy, market outcomes and economic performance in present day India.

\section{Exhibit XIX: Accommodations and Responses of India's Traditional Business Groups to Changes in the Competition Regime}

\footnotetext{
${ }^{330}$ The result could be lower export sales for India and greater Indian market opportunities for MNC joint ventures and fully owned foreign operations that are better prepared and more interested in making the investments and taking the risks needed to meet the demands of India's rising middle class compared to domestic competitors with little global market exposure and experience (Patibandla 2002).
} 


\begin{tabular}{|c|c|c|c|}
\hline $\begin{array}{l}\text { License Raj up to } \\
1965 . \text { Supported by } \\
\text { business groups } \\
\text { which believed with } \\
\text { justification that the } \\
\text { complex approval } \\
\text { system could be } \\
\text { manipulated to their } \\
\text { benefit. }\end{array}$ & \multicolumn{2}{|c|}{$\begin{array}{l}\text { The 1965-1991 Competition } \\
\text { Regime with MRTPA and other } \\
\text { additions to the License Raj. } \\
\text { Business groups at first believed } \\
\text { this regime could also be } \\
\text { manipulated to their benefit, but } \\
\text { concluded in the } 1970 \text { s that the } \\
\text { transaction costs were too high } \\
\text { and foreign competition was } \\
\text { becoming too strong. }\end{array}$} & $\begin{array}{l}\text { Modest and } \\
\text { Adhoc Domestic } \\
\text { Reforms of the } \\
\text { 1980s that } \\
\text { clearly favoured } \\
\text { and were } \\
\text { supported by the } \\
\text { business groups. }\end{array}$ \\
\hline \multicolumn{2}{|c|}{$\begin{array}{l}\text { Current and Still Evolving Competition Regime. } \\
\text { More positive and sustained accommodations and } \\
\text { strategy changes after the late } 1990 \text { s because: (i) } \\
\text { government displayed the required commitment to } \\
\text { liberalization; (ii) changes to merger and other } \\
\text { provisions in the draft competition bill were made } \\
\text { to meet business group needs; and (iii) new } \\
\text { economy sectors, businesses and informal } \\
\text { institutions and arrangements were responding } \\
\text { successfully to the new competition regime. } \\
\text { However, pre-1991 accommodations still influence } \\
\text { current strategic responses - and likely future } \\
\text { responses when full enforcement of the new } \\
\text { competition law begins. }\end{array}$} & \multicolumn{2}{|c|}{$\begin{array}{l}1991 \text { Domestic and } \\
\text { External Liberalization. } \\
\text { Opposed by business } \\
\text { groups as "too much too } \\
\text { fast" especially on the } \\
\text { external side, who } \\
\text { believed for a few years } \\
\text { that they could change or } \\
\text { circumvent the external } \\
\text { reforms while continuing } \\
\text { to benefit from the } 1980 \mathrm{~s} \\
\text { domestic reforms. }\end{array}$} \\
\hline
\end{tabular}

\subsection{Conclusions}

This case study comparison indicates that the interactions, conflicts and accommodations between India's competition regimes and the country's business groups and other informal business institutions and arrangements differ significantly between the two case study time periods. The interactions of the post-1991 period are smaller in number, more of them take place below the national government level, and their quality and outcomes are on balance better for the business groups, for India's business and economic performance, and for domestic competition. The evidence from the two time dependent case studies indicates that changes in the number and quality of and outcomes from these interactions, conflicts and accommodations made an important contribution to 
improvements in the performance of India's private business sector and total economy after 1991.

Changes to the two sets of institutions and to the interactions, conflicts, and accommodations between them, are all important to explaining the major differences in business and economic performance between the two case study periods. On balance, these differences result more from the fundamental changes to the competition regime, under which: the private business sector are now less dependent on government and more dependent on markets, their suppliers, industrial customers, and the final consumer for their survival and success; and, private not government actors and actions largely determine market structure, business conduct and the extent of competition in India's domestic markets. Fundamental changes to India's traditional business groups and other informal business institutions are taking place at a slower pace, but will likely accelerate in the years ahead as the competition regime becomes more firmly established.

Developments in the past 8-10 years have accelerated the trend towards greater equality and complexity in the interactions between the competition regime and the country's informal business institutions that began with the modest domestic reforms of the 1980s. Looking ahead, enforcement of the new competition law and the government's formulation and implementation of a comprehensive competition policy under its $11^{\text {th }}$ Five-Year Plan (Government of India 2006:2, 2007:1 and 2007:2) will add further complexities to these interactions. This story will need to be addressed in future research. 


\section{Chapter 10: Conclusions}

This final chapter presents the major conclusions from this analysis on the interactions, conflicts and accommodations between India's competition regimes and its informal business institutions. Conclusions are presented regarding the main contributions of the research, its overall purpose, the central research question posed, and the two time dependent arguments as set out in the Introduction and developed further in subsequent chapters. The chapter and dissertation closes with a brief discussion of research implications and areas for future research that are indicated by the earlier analysis.

\subsection{Contributions of the Dissertation}

The dissertation contributes to future research and analysis in three ways. Comparatively little academic research has been conducted on competition policy, law and related business practices in India, and on the formal and informal institutions and other forces that have both shaped and been influenced by the country's competition regimes over the past forty years. In particular, India's academic and policy communities have given much less attention to competition policy and law since 1991 compared with the three previous decades. This thesis contributes to filling this analytical gap.

A second contribution is that it adds to our understanding of the evolution of modern competition regimes in developing and transition economies. Unlike many other developing and transition countries that adopted more modern competition regimes over the past two decades, discourse on and development of more modern competition regimes in India over the past four decades are driven by domestic pressures, ideas, informal and formal institutions, and business and government interests, not by foreign 
influences and interests such as multinational corporations, IMF and World Bank requirements for structural reform, or obligations in trade agreements.

India's opposition to incorporating the trade related aspects of competition rules into the World Trade Organization (WTO) architecture could have inhibited domestic competition policy and law reform since $1991^{331}$. This in fact did not happen. However, discourse on international competition rules added to and enriched domestic debates within India on the country's new competition regime and better ensured that domestic pressures, ideas, institutions and interests dominated these debates, which continue up to the present day. This focus on how competition regime reform can serve domestic business, economic, social, poverty reduction and related objectives, requirements and interests makes the Indian research, analysis and debates, and the resulting competition regimes, relevant to other developing and transition economies,

More specifically, the emphasis in the two case studies on the interactions, conflicts and accommodations between two very different domestic institutional entities: competition regimes that include both formal and informal components (see Exhibit I); and, informal institutions of business rules, conduct and arrangements; represents a significant departure from previous research and studies on India and virtually all other competition law jurisdictions. The analysis indicates that interactions between these two very different sets of domestic institutions generate not only private and social transactions costs. They also result in accommodations and responses by both sides, which are important to the performances of both sets of institutions and to competition, competitiveness, innovation, efficiency and performance in the total national economy.

${ }^{331}$ In contrast, the author's research on competition policy and law in Malaysia over the period from 1995 to 2005 indicated that opposition to WTO competition rules greatly impeded domestic competition policy and law reform in that country. 
In addition, compared to other institutional analyses, the emphasis in this analysis on the interactions between two very different sets of institutions better ensures that the findings give appropriate weight to not only history and path dependence, but as well as to the actions and agency of business and government leaders and officials in their efforts to both adapt to and to influence their external environments.

In contrast to this analysis, the previous research on competition policy and law interactions has emphasized for the most part the interactions of formal competition regimes with other formal economic institutions and government policy regimes in such areas as trade, industrial policy, innovation, intellectual property rights, regulatory reform and the legal system (see e.g. Anderson and Gallini 1998, Doern and Wilks 1996, Graham and Richardson 1997, and Mehta 2006). About 80 developing countries now have some kind of competition law, but comparatively few of them are actively and effectively enforcing their current competition statutes (see Chapter 1). While this thesis involves analysis of a single country, India's domestic discourse and experience on the interactions between competition regimes and informal business institutions provide insights and areas for future research that are relevant to other developing and transition countries that are designing and enforcing new competition laws and regimes.

The third contribution of the analysis centres on the fact that, by applying a competition regime approach, new institutional economics (NIE) and the transactions cost economics (TCE) model, the dissertation offers further conceptual insights that are relevant to future competition research and competition policy and law formulation in developing and transition economies. Past analysis has largely focused on the legal design and economic rationale for the new competition law and agency, and has given 
little attention to existing policies, informal business and other institutions, and past and current attitudes towards competition and fair trading. In contrast, this analysis goes beyond law and economics and industrial organization economics, which currently dominate competition analysis, in order to encompass new institutional economics and related advances in the fields of behavioral, information and innovation economics and new endogenous growth theory. Employing these additional conceptual literatures increases our understanding of the evolution of competition regimes and the enforcement of modern competition policy and law in India and other developing and transition countries.

\subsection{Purpose of the Dissertation}

The dissertation analyses the evolution of India's competition regimes over the past four decades - through the prism of their interactions with India's business groups and other informal business institutions. Informal business institutions proved to be an excellent prism for analysing the evolution of India's competition regimes over the country's long and complex economic and business history (Chapter 4) and the two case study periods (Chapters 5-9). India's business groups and other informal business institutions dominated the Indian private economy prior to independence in 1947; continue to be very important to non-agricultural production and employment in the formal sector; and have dominated discourse on, the evolution, design and administration of, and outcomes from India's competition regimes from before independence through the two case study periods up to the present day.

Particularly important is the changing rhetoric and discourse on business groups and other informal business institutions over the two case study periods. Over this four decade period, there has been considerable contestation on whether India's business 
groups and other informal business institutions -- with their: large asset size, major presence in many key Indian industries and markets, and strong political and bureaucratic connections -- have on balance had a positive or negative influence on India's economic development and performance, competition in domestic markets, and ability to compete in foreign markets. This debate, and the rhetoric associated with the debate, has shifted greatly over the 40 -year period covered in Chapters 5-9.

Controlling the expansion, market, economic and political power, and supracompetitive profits of business groups that allegedly result from their large asset size, was a major objective of the licensing regime established in the $1950 \mathrm{~s}$, and was the dominant reason for the MRTPA and related competition regime changes from 1969 to 1973 . Starting in the early 1980 s, the dominant discourse changed quite abruptly to concerns that the business groups and their affiliated companies were international "minnows" and therefore too small to successfully compete in the global economy (Moore 1997, p. 344). Discourse since 1991 has added some pro-competition and pro-market elements, resulting in what can be called "a liberalization model with Indian features". However, discourse on the need for business groups and other larger privately owned companies to expand, prosper and become "national champions" is still prominent.

These two competing discourses on business groups and their interactions with the competition regime have been present among the country's elites from the 1960s to the present day. The major difference between the pre- and post 1991 competition regimes is the extent to which one of the two competing discourses has dominated policy rhetoric and formulation and by how much ${ }^{332}$. While liberalization, globalization and support to

\footnotetext{
${ }^{332}$ Comparing the two periods, discourse on the role of privately owned business groups and the private sector more generally has changed dramatically; the competition regimes have changed quite a bit but not
} 
private business now dominate Indian economic discourse, debate, and rhetoric, the alternative discourses have not disappeared and continue to influence and complicate the evolution of the post-1991 competition regime and its various interactions, conflicts and accommodations with informal business institutions that are addressed in this dissertation $^{333}$.

\subsection{The Central Question and Three Kinds of Interactions}

The central question of the thesis addresses how India's competition regimes have interacted with, conflicted with and accommodated themselves to the country's informal business institutions. All three kinds of interactions displayed in Exhibit II in the Introduction proved to be important to the analysis in ways that vary through the two time periods and that are often unanticipated. Causation is in both directions; and accommodations, moves, counter-moves, perceptions, misperceptions and learning by both sides combine together through time to result in important and often unintended consequences for business strategy and performance, competition and India's economic performance - leading to more complex and intriguing answers to and richer empirical narratives for an apparently quite simple central question.

Chapters 6 and 7 give significant attention to the first kind of interaction - the influence of informal business institutions on the design of India's competition regimes

by as much as the discourse; and the realities, transactions costs and outcomes of the interactions, conflicts and accommodations between the competition regime and informal business institutions have changed as well but by much less than the discourse and the competition regime. The interactions and accommodations continue to be difficult, complex, full of misunderstandings for both sides, and contingent on the issue, time, Indian state, ministry/agency, policy or regulatory regime, government official, and business group or company.

${ }^{333}$ These alternative discourses are particularly important among the pro-labour, leftist members of government coalitions at the central and state government levels, as well as among Hindu nationalist parties and other political and social activist groups that continue to favor self-sufficiency (called "swadeshi" in India) over integration into global markets (Jenkins 2003). 
over the forty-year period. While traditional business groups and other informal business institutions dominated the evolution of and discourse on competition regimes in India, the direct influence of the business groups and other larger companies on those same regimes was very limited up to 2000 . The MRTPA, other elements of the 1965-1991 competition regime, and the 1991 liberalization program were essentially imposed on them from above. In addition, the business groups and their trade associations paid little attention to competition law reform from 1995 to 2000.

All of this changed with the Raghavan Committee Report and the publication of the Competition Concept Bill by the Department of Company Affairs in 2000. These two documents proposed the reintroduction of merger control into India's competition law. This caught the attention of India's business groups, other larger companies and their trade associations in a major way. Their objective, which was clearly stated in their press releases, submissions and in pro-business media articles, was to have a competition law, and in particular a merger review process, that would represent the least hindrance possible to their expansion, merger, acquisition, divestiture, restructuring and downsizing plans and strategies. Despite the return of mandatory merger notification in the amended competition statute passed in September 2007, this business objective has been largely achieved. This was a major business lobbying success that in some ways was without precedent across the 40-year history of India's formal competition regimes -- when previously business groups and other firms had little interest in and influence on regime design and preferred to lobby (after the fact) behind closed doors to avoid, reduce the impacts of and/or manipulate the competition regime to their benefit. ${ }^{334}$

\footnotetext{
${ }^{334}$ The more transparent involvement of the country's private business sector in the design of India's competition regime continued with the establishment of the Working Group on Competition Policy for the
} 
Analysis of the other two kinds of interactions also provided some surprises. The pre-1991 competition regime had little influence on industrial concentration and the extent of competition in India's domestic markets; and, therefore, had little direct influence on the competition, anti-competitive, and related strategies of business groups and other informal business institutions (the second interaction in Exhibit II). At the same time, the MRTPA and the broader pre-1991 competition regime had important indirect impacts and consequences for the strategies and performance of the "MRTPA monopoly" business groups and other larger companies. For example, the MRTPA's legalistic approach to vertical restraints and other trade practices privileged such practices within business groups and discouraged potentially efficient vertical and other informal business arrangements across different business groups and unaffiliated companies (interaction three in Exhibit II).

While the influence of the post-1991 competition regime on the strategies of the business groups and other informal business arrangements has on balance been more favorable to competition and economic efficiency, concerns remain among business advocates and competition specialists that the new Commission's enforcement practices in the future will be similar to the MRTPC practices of the past - resulting in more instances of the third kind of interaction in the future.

\subsection{The Two Time Dependent Arguments and Case Studies}

The central question and three different kinds of interactions provide the foundation for the more detailed analysis of the number and quality of interactions, conflicts and

Eleventh Five-Year Plan in June 2006. Six of its 29 members represented the private business sector, including members from the three major trade associations: the Confederation of Indian Industries, the Federation of Indian Chambers of Commerce and Industry, and the Associated Chambers of Commerce and Industry. 
accommodations between India's competition regimes and informal business institutions and how these differed between the pre- and post-1991 case study periods. As predicted by the two time dependent arguments in Exhibit II, the number, quality and outcomes from these interactions, conflicts and accommodations differed significantly between the two time periods (see Chapter 9). The number of interactions between the competition regime and business groups and other informal business institutions are less numerous in the post-1991 period, and on average are of higher quality with more favorable outcomes for the competition regime, business performance, and the total Indian economy. The differences between the two periods are more the result of major (albeit still incomplete) changes to the competition regime, and less the consequence of fundamental changes in informal business institutions, rules of business conduct, and arrangements that have been relatively more stable.

Similar to the previous section on the central question, the empirical story in each period, and the differences between the two periods, are more complex, richer and more subtle than assumed by the two time dependent arguments in the conceptual framework. In the first period, a uni-directional argument (consistent with the first kind of interaction) that well established informal business institutions would prevent the competition regime from achieving its concentration and competition objectives was expanded and enriched. This was accomplished by assessing: the complex interactions, conflicts, and accommodations between the two sets of domestic institutions; and the strategic responses of traditional business groups to avoid the high transactions costs and risks of dealing with the MRTPC and to avoid or capitalize on other parts of the 1965-1991 competition regime. 
As predicted in the second time dependent argument, interactions, accommodations, and outcomes during the post-1991 case study period are even more complex, nuanced, and contingent. This is the result of many interrelated factors. The competition regime is still evolving; the traditional business groups were slow to respond to the broader liberalization program and the new competition regime; and the emergence of information technology and other new economy sectors added to the business voices which favour globalization, innovation and competition.

The major unanswered question for the second period is how business groups and other informal business institutions will interact with the new competition law, once full enforcement begins in 2009. The current expectation is that these interactions and accommodations will reinforce the comparatively positive contributions of the post-1991 competition regime to business and economic performance. However, Chapters 7 and 8 describe some of the dangers posed by the new competition law for traditional business groups, informal business institutions and arrangements in the new economy sectors, other informal business institutions, and the competition regime itself. In particular, the application by the new CCI of the MRTPA's legalistic approach with a limited competition test could result in the third type of interaction in Exhibit II, where the regime would discourage and in some cases prevent informal business institutions and arrangements that economize on transactions and production costs, promote innovation, and on balance are beneficial to business participants, competition, consumers and the overall economy ${ }^{335}$.

\footnotetext{
${ }^{335}$ For the reasons described in Chapters 7 and 8 , the risk of discouraging efficiency enhancing informal business arrangements is much higher for arrangements that involve two or more business groups or encompass business group affiliates and independent companies.
} 
The 1965-1991 case study illustrates that a competition regime does not have to achieve its competition and related objectives in order to have major impacts on business strategy and performance, and on the performance of the total economy ${ }^{336}$. The post1991 interactions with the competition regime are less numerous and of higher quality for both competition and business performance. Nonetheless, business groups and other larger companies are still incurring high costs in their transactions with government compared with the OECD countries and the more developed Asian nations. These high transactions costs still influence business group strategy, investment decisions and performance, competition in domestic markets and national competitiveness particularly of manufacturers in external markets.

India's competition regime has experienced more dramatic changes than the country's traditional business groups and other informal business institutions over the past four decades, which have changed their tactics and strategies much more than their fundamental business cultures and rules of business conduct and arrangements. Path dependence, continuity and small, cautious and incremental adjustments in the midst of political economy turbulence and uncertainty best capture the story of the Indian business groups and other informal business institutions over the past forty years and even longer - including under the post-1991 competition regime.

Despite the strategy improvements reported in Chapter 8, low cost, quick gestation, and risk averse investment strategies are still important; and imitation rather than innovation, and the adoption of tried and true technologies from familiar sources, are still

\footnotetext{
${ }^{336}$ Competition experts contend that, at the very least, a competition regime should do no harm. India's competition regime failed that test up to 1980; and there are concerns among both business critics and competition advocates that it could fail that test again once the new competition law begins to be fully enforced.
} 
given priority. Business group governance structures change slowly, and while professional management methods are being introduced to some degree, business groups continue to hire more often from their traditional ethnic, religious, caste or other social groups and communities. The business groups are now more outward looking and are making direct investments in other countries, but export pessimism and prudence and securing dominance in domestic markets before exporting still dominate business group strategy. Business groups are entering the new economy sectors and re-entering financial services markets, but their core capabilities are still found in traditional markets and products. Investments in transacting with government at all spatial scales are still important to the strategies and performance of business groups and other informal business institutions.

A major reason for the persistence and continuing success of India's business groups is that, compared to alternative governance structures, the business groups are in a better position to accommodate and capitalize on the risks and uncertainties caused by a volatile external environment - and to minimize their impacts on production and transactions costs and overall financial performance. These strengths remain important because of the challenges and uncertainties of globalization, liberalization, rapid technological change, and the incomplete nature of India's post-1991 competition regime and broader liberalization program.

Business groups and other informal institutions in the past have taken great care to not over-commit to a new economic policy regime that at times has been more rhetorical than substantive. This prudent and gradual approach to change and restructuring that emphasizes long-term survival over short-term profits continues to influence and in some 
ways diminish their contributions to the Indian economy and will shape their current and future interactions with the competition regime, including their interactions with the new Competition Act and Commission after enforcement begins in 2009.

\subsection{Research Implications and Areas for Future Research}

The dissertation's emphasis on domestic pressures for competition regime reform suggests that a more balanced approach that gives more equal weight to domestic and external pressures could be helpful to competition regime research in other developing and transition countries. The thesis as well demonstrates the importance of investigating the total competition regime (see Exhibit I). The evolution of India's competition regimes and its interactions with the country's informal business institutions over the two case study time periods could not be understood through focusing solely on India's competition law. Competition law is only one aspect of a broader competition regime (Doern and Wilks 1996, and Evenett 2005:1 and 20052); and in India it has often been one of the less important components, especially since 1991.

The conceptual framework employed in this dissertation - encompassing the competition regime approach, new institutional economics and the transactions cost economics model -- may be particularly relevant to China, which has been drafting a modern competition law for well over a decade. China's new Anti-Monopoly Law was adopted in August 2007, and came into effect a year later in August 2008. Similar to India, competition law has been the source of prolonged debate particularly within the PRC government. Another parallel is that China has established an increasingly procompetition regime over the past quarter century, culminating in the PRC's re-entry into the WTO in 2001, without the benefit of a modern, well-enforced competition law. 
In both countries, gradual and comparatively modest changes in competition and related policies have allowed private investment, entrepreneurship and risk-taking to flourish over the past two decades, after being discouraged in India and forbidden in China for the previous forty years. A final similarity is that informal business institutions, information and transactions costs, and the transaction related initiatives of business groups and other informal business institutions and enterprises are important to both countries' development models, and therefore should be given significant attention in the analysis, design and enforcement of modern competition regimes in the two countries.

Similar to future applications in India (see e.g. footnote 145 on pp. 174-175), applying the conceptual framework to China would require the analyst to go beyond privately owned business groups to include business groups and networks, strategic alliances and other informal business arrangements that involve state owned enterprises, foreign invested companies, and cooperative enterprises including smaller township and village enterprises.

The more specific areas for future research are as follows. Future research could employ the conceptual framework to explore why developing and transition economies have had little success in enforcing their relatively new competition regimes. Poor alignment between formal and informal business institutions - and the negative consequences of the interactions, conflicts and accommodations between them -- may provide important explanations for and solutions to these enforcement problems. Special attention would be given to the difficult, complex and sub-optimal interactions, conflicts and accommodations between the new formal competition regime and the country's 
business groups and other informal business institutions that were established well before the formal competition regime was introduced. Future analysis along these lines could include greater use of the dynamic game theory applications that are referenced briefly in this dissertation.

The conceptual framework and major findings from this thesis could also be employed in future research on international competition rules (see e.g. Singh 2004). The establishment of more modern competition regimes over the past $15-20$ years in developing and transition economies, where business groups and other "non-western" informal business institutions and arrangements continue to be important, are raising new issues, challenges and potential conflicts for the multi-jurisdictional investigation and enforcement of cross-border mergers, abuses of dominant position, cartels, predation and other competition cases. Based on past and current experience with the Korean chaebol and Japanese keiretsu (see Chapter 1), allegations from the major competition law jurisdictions regarding the anti-competitive conduct of business groups and other informal business institutions headquartered in the developing and transition economies, could play an important role in these inter-jurisdictional misunderstandings and conflicts.

The conceptual framework and major findings from the dissertation could be extended to apply the Varieties of Capitalism (VoC) approach of Hall, Soskice, Schmidt and their colleagues to India's political economy and stage of development (see e.g. Hall and Soskice 2001 and Schmidt 2003) ${ }^{337}$. The analysis suggests that India's

\footnotetext{
${ }^{337}$ The VoC approach of Hall and Soskice (2001) is actor-centered (i.e. it stresses agency) and describes a firm-centered political economy, which recognizes that companies are the crucial actors in a capitalist economy. The approach involves integrating game-theoretic perspectives on the firm into the analysis of the macro economy through investigating the kinds of institutions that alter the outcomes from the strategic interactions of companies and other economic actors.
} 
emerging capitalism has features of both liberal market economies (LMEs) and coordinated market economies (CMEs). There is cooperation, coordination and a more collectivist orientation within business groups and across the business communities that share a common ethnicity, language, religion and/or home location (consistent with CMEs).

However, the analysis indicates much less coordination, cohesion and cooperation, more individualist norms and beliefs, and much greater competition and conflict with other business groups, unaffiliated companies, and with key non-business actors such as trade unions and governments at different spatial scales. This situation results in a more individualist, contentious and litigious orientation outside business groups that has more in common with LMEs. On balance, India would appear to be more of an LME than a CME at its present stage of capitalist development and given current state-private business relations and the current interactions and relationships within the private business sector ${ }^{338}$. At the same time, $\mathrm{VoC}$ analysis of India would have to take account

These two authors compare capitalism in the US and UK and to some degree other Anglo-Saxon countries, with capitalism in continental European countries and to some degree Japan. The United States and Germany at times represent the two extreme points in this VoC continuum. The Anglo-Saxon economies are described as liberal market economies (LMEs), where firms coordinate their activities with other economic actors largely through hierarchies, formal contracts and competitive market arrangements. In contrast, the European continental economies are characterized as coordinated market economies (CMEs), where firms place greater dependence on less formal arrangements and non-market relationships (linked to institutions, organizations and culture) to coordinate their activities with other economic actors and to develop core competencies.

On the other hand, Schmidt (2003) argues for a "Third Variety of Capitalism" based on the past experience and current political economy of France. She summarizes this third variety as follows in her abstract (p. 526). "While France's state capitalism has been transformed through market-oriented reforms, it has become neither market capitalist nor managed capitalist. Rather, it has moved from 'state-led' capitalism to a kind of 'state-enhanced' capitalism, in which the state still plays an active albeit much reduced role, where CEOs exercise much greater autonomy, and labour relations have become much more marketreliant." This third variety could also be relevant to this analysis and creation of a VoC type that best fits the Indian experience and current stage of development.

${ }^{338}$ For example, similar to the United States, Indian business groups, larger companies and their trade associations have had some recent successes in coordinating their lobbying efforts on a single time specific 
of the continuing importance of the Indian state as business regulator, employer, investor, owner and manager of key enterprises and other public sector undertakings (PSUs), and as financier of private enterprise through the state-owned commercial banks and development finance institutions (Debroy 2004).

However, these are initial ideas only. A VoC analysis for India should be the subject of future research, which would require a more comprehensive application of the "Varieties of Capitalism" model, and a more detailed identification of its many implications, to India's quite unique historical, institutional, business and political economy conditions, state-business relations, and development trajectory. The analysis as well would address the differences between India's broader regions (that is groupings of regional states) and between individual regional states that: are at different stages of economic, market and institutional development; and have different economic and business histories and differing experiences during the pre-colonial period, under the British colonial regime and during post-independence India (see e.g. Sinha 2005:1 and the Aghion et al references in the bibliography).

The conceptual framework and major findings demonstrate the need to better tailor new industrial organization economics and competition analysis to the special requirements, conditions and realities of developing and transition economies and to the challenges faced by their governments in designing and enforcing modern competition rules and regimes. New industrial organization economics based on non-cooperative

issue, such as in 2000 when they successfully weakened merger review in the new competition law (see Chapter 7). In a similar manner, major American corporations in the pharmaceutical, chemicals, information technology and entertainment industries had great success from the mid-1980s to the mid1990s in lobbying collectively for stronger intellectual property rights first in the Free Trade Agreement (FTA) with Canada and then in the NAFTA and WTO trade agreements. In contrast, economy or private sector wide cooperation and negotiations with e.g. governments and/or labour unions in the formal sector over an extended period, which take place quite often in CMEs, have rarely been successful in India - as illustrated by the total failure of the Bombay Club in 1993-1994 (see Chapter 7). 
game theory has been developed for, tested in, and applied with some success in the most advanced OECD countries, especially the United States. In contrast, very little work has been conducted on how the new industrial organization economics can be modified to meet the competition needs of developing and transition economies. The major weakness of the new industrial organization economics is that it takes little account of history, time, place, the stage of economic and institutional development, and in particular the unique conditions faced by developing and transition economies.

These factors and conditions include: the continuing importance of government; the slow, problematic and often contingent transition towards more liberal and open economies; the greater importance of dynamic Schumpeterian efficiencies over shortterm static efficiencies; and the vulnerability of most consumers and households particularly the urban and rural poor. Also important to competition analysis in India and other developing and transition economies are their often highly fragmented markets across both product and geographic space; high barriers to business entry that may be lower than before liberalization but are still important in many sectors; and, the continuing importance of business groups and other informal business institutions in many of these economies.

Modifying the new IO for developing countries will require taking greater account of recent advances in new institutional economics and the related economic literatures and theories of the firm described in Chapter 2. NIE and its various extensions are particularly important to better understanding: the existence, evolution, continuing success and boundaries of business groups and networks and related informal business institutions in developing and transition economies; and, the competition dangers as well 
as the potential efficiency and innovation benefits associated with the various kinds of informal business institutions and arrangements found in India and many other developing and transition economies.

Finally, the conceptual economics literatures and framework applied in this dissertation and the empirical findings in Chapters 5-9 indicate the need for and some of the parameters of a distinct "theory of the business group", which would help to explain the establishment, existence, evolution, persistence, continuing success and boundaries of the business group as a business governance mode. The analysis suggests that a distinct theory of the business group would encompass and bring together elements of the economics conceptual literatures and theories of the firm reviewed in Chapter 2, These theories would include the production cost minimizing firm of neoclassical economics; the transactions costs minimizing firm of new institutional economics; the strategic firm of the new industrial organization economics; and the entrepreneurial, resource-based, innovation/knowledge based and evolutionary theories of the firm that has developed through time based on the work of several theory of the firm scholars ${ }^{339}$.

The analysis in this dissertation also suggests that a more comprehensive and coherent theory of the business group would need to go beyond the economic theories of the firm to incorporate the insights provided by: endogenous growth theory (see the Aghion et al references Chapter 2, pp. 76-77 and the bibliography); the political economy literature of ideas, interests and institutions that was employed selectively in the empirical chapters (see e.g. Bardhan 1984, Encarnation 1989, and Sinha 2005:1);

${ }^{339}$ These scholars would include Penrose (1959), Nelson, Winter (Nelson and Winter 1982 and Nelson 1991), Best (1990 as well as Best and Garnsey 1998), Madhok (2002), Langlois and Robertson (1995), Casson (2005 plus Casson and Della Guista 2007), and many other firm theorists and business group specialists (see e.g. the many Khanna et al references in the bibliography). 
economic sociology (see Granovetter 1995 and 2005); and, the theories of institutional change (see section 2.6, particularly sub-section 2.6 .6 and Exhibit VII). To be comprehensive, coherent and defensible, such a theory would bring together business, economic, social, cultural and institutional considerations with the action and agency displayed by business group founders, leaders and senior managers over extended periods in successfully accommodating, responding to and influencing their external environments. 


\section{APPENDICES}

\section{Appendix 1: Key Definitions Used Throughout the Dissertation}

The purpose of this section is to define some of the key policy, institutional and business organization concepts employed in this dissertation. As noted in the text (see Exhibit I), the term competition regime in this dissertation is defined to encompass: (i) the competition law itself, (ii) competition policies that are more directly related to enforcement of a country's competition law and other relevant policy activity (such as education, advocacy and voluntary compliance efforts) of the competition agency and its partners in and outside government, (iii) other formal policies and regulatory regimes that influence market competition, and (iv) the attitudes of economic agents towards competition, inter-firm rivalry and fair trading as captured in a country's "competition culture"; (this is the informal component of the competition regime in Exhibit I).

Defined in this manner, India's competition regimes are embedded and contained within but are smaller than and therefore subsets of the country's broader economic policy regimes. The broader economic regime before 1991 was the (largely) anticompetition "License Raj"; and after 1991 the broader regime was the country's more comprehensive and pro-competition, but still incomplete, liberalization program which remains a "work-in-progress".

The term "modern competition regime" is used in the text and is applied as a benchmark or point of reference in the competition literature, based on the more experienced competition law jurisdictions among the OECD countries, led by the US and the EU. Consistent with the competition laws and policies in these more advanced OECD jurisdictions, a modern competition regime would promote competition and efficiency, and would regulate and protect competition rather than individual competitors (including in India business groups as well as other companies). Stated in this manner, the post-1991 competition regime in India is "more modern" than the 1965-1991 competition regime. The following paragraphs expand on the concept of a modern competition regime.

Brooks (2007, p. 5) defines competition policy as follows. "Within markets, competition policy aims to ensure that an economy experiences the greatest potential net benefits from the efficiency induced by rivalry in contestable markets." Building on this more general definition, competition policy and competition law can be explained through exploring their more specific objectives. In most competition law jurisdictions, the main objectives of competition policy and in particular competition law are (i) to protect and regulate competition in domestic markets (rather than to protect and promote the interests of industries and competitors/companies which is the role of traditional industrial and trade policies), (ii) to promote economic efficiency (typically the static efficiencies of neoclassical micro-economics ${ }^{340}$ ), and (iii) to prevent increases in

\footnotetext{
${ }^{340}$ Recent literature suggests that four kinds of efficiency are important to competition policy and law: (i) allocative efficiency, (ii) productive efficiency, (iii) transactional efficiency - whereby "market participants design business practices, contracts and organizational forms to minimize transaction costs and, in
} 
consumer prices and reductions in product quantity and quality and consumer welfare that can result from: monopolies and abuses of dominant position; cartels, conspiracies, and bid rigging; anti-competitive horizontal, vertical and conglomerate mergers; product tying and other vertical arrangements/restraints; refusals to deal and boycotts; predatory pricing, raising rivals costs and other predatory and exclusionary conduct; misleading advertising and other forms of misrepresentation vis a vis business customers and final consumers; and, other anti-competitive practices and business conduct designed to raise prices and reduce competition, product choice and product quality in markets.

In addition, many competition agencies ${ }^{341}$ have proactive programs of competition advocacy that attempt to eliminate, prevent or at least modify other government policies and regulations (e.g. sectoral regulations, corporate governance and bankruptcy laws, and trade, industrial, innovation and regional development policies) that are expected to generate anti-competitive market outcomes (Evenett 2005:1 and 2005:2). Most competition law jurisdictions are moving towards a total efficiency objective under their statutes, whereby consumer welfare, promotion of small and medium sized enterprises, innovation and greater use of advanced technology, international competitiveness and other broader socioeconomic goals are achieved more or less indirectly through promoting competition and efficiency (OECD 2003).

In this dissertation, a distinction is made between competition law and competition policy. Typically, competition law (and the agency mandated to enforce a country's competition law) is only one component or instrument of a broader competition regime (Evenett 2005, p. 13) that can encompass both: (i) informal business institutions -- e.g. the extent to which business rules, norms and values in support of competition and fair trading, sometimes called a competition culture, have through time become well established within a society and economy; and, (ii) more formal institutions that can include the competition law and agency as well as competition related policies, laws,

particular, to mitigate information costs and reduce their exposure to opportunistic behaviour or [so-called] "hold-ups" " (Kolasky and Dick 2003 p. 43), and (iv) dynamic Schumpeterian type efficiencies that are associated with the creation and adoption of advanced technology and related product, process and organizational innovations. The first three efficiencies are essentially static in nature (Evenett 2005:1, p. 4). The fourth is being given increasing weight in competition analyses, but also poses many challenges for competition practitioners, agencies, tribunals and courts. These challenges are addressed in greater detail in chapter two and the empirical chapters.

Competition agencies in more advanced competition law jurisdictions contend that they address both static efficiencies (short term impacts on prices, quantities, production and transactions costs, and consumer and total welfare) as well as dynamic efficiencies (long term impacts on product quality and choice, product, process and organizational innovations and the generation and commercialization of new advanced technologies - that are often associated with Schumpeterian dynamic efficiencies, entrepreneurship and creative destruction). However, competition agencies, tribunals and courts typically are more comfortable with static over dynamic efficiencies, because dynamic efficiencies and related economic outcomes and benefits that may take place many years into the future are more difficult to identify, quantify and monetize (see e.g. Carlton and Gertner 2002 and Doern 2004). Addressing dynamic efficiencies in designing and enforcing competition law can be particularly problematic for less experienced competition agencies in developing and transition economies.

${ }^{341}$ Including the Competition Commission of India (CCI) and the new Competition Act (2002). 
regulatory regimes and institutions that can have significant impacts - both positive and negative -- on the state of competition in a national economy. In both case study periods, other policies, laws and regulations are incorporated into the competition regime based on their objectives and content, as well as their intended and unintended consequences for competition, business entry and the competitive strategies of business groups and other Indian private sector companies.

The competition advocacy programs of competition regimes to some degree define the other policies, laws and regulations that are added to the competition regime, as defined in Exhibit $I$ in the main text. These so-called secondary components of the competition regime can include such policy fields as industrial policy; science, technology and innovation policy; intellectual property rights; trade and foreign investment policies; financial market, corporate governance, securities and bankruptcy laws and regulations that influence business financing, entry and exit; business and industrial licensing regimes; consumer protection policy and law (often called unfair trading practices - see below); and sectoral regulatory regimes in such areas as telecommunications, transportation, energy, municipal utilities (e.g. water supply, wastewater treatment, solid waste management, and public transit) and financial services (Doern and Wilks 1996). The main text indicates that all of these policies and regulatory regimes influence competition in India.

The concept of fair-trading is also used as a reference point in the main text. This concept is found in the titles, objectives and content of many competition and consumer protection laws and agencies ${ }^{342}$ in developed and developing countries. The concept is used as well to describe and categorize business-to-business transactions over past decades and centuries in the new institutional economics literature. As defined by this author and as implied by the objectives of these laws and agencies, fair trading includes but goes beyond market competition to embrace the concepts of trust, fairness, reciprocity of trust, relational norms, and mutual obligations in business transactions and arrangements between producers and their suppliers and customers.

Fair trading is often applied to provisions of competition and consumer protection laws that prohibit misleading advertising, misrepresentation, deception, consumer frauds, exploiting a strong bargaining position to the detriment of the other party and the total economy, and related business practices; and that are caused by the information asymmetries and gaps, stronger financial and negotiating positions, the behavioral biases of final consumers and other economic agents, and other advantages that typically are enjoyed by vendors (e.g. larger manufacturers, retailers, banks and passenger airline companies) in their dealings with consumers and small businesses ${ }^{343}$. As stressed in

\footnotetext{
${ }^{342}$ For example, the major competition agency in the United Kingdom is called the Office of Fair Trading and the competition agency in Jamaica is called the Fair Trading Commission.

${ }^{343}$ A good example of fair trading found in competition law is the general prohibition against unconscionable conduct in Australia's Trade Practices Act, which prohibits the stronger party in a businessto-business or business-to-consumer transaction to exploit an evident special disability or disadvantage suffered by the other party.
} 
Chapter 4, the concept of fair trading is integral to traditional Indian economic thought first developed over 2000 years ago (Spengler 1971).

Transactions costs are essential to new institutional economics. Without transaction costs, institutional and governance choices would not be an issue (Coase 1937 and 1960, Williamson 1975 and Garrouste and Saussier 2005, p. 179). Transactions costs in the institutional literatures encompass the cost of exchange and more specifically the costs in money and time that are incurred in information collection and analysis, buyer-seller search, product and technology search by companies and consumers, the negotiation and enforcement of contracts (which generally are incomplete), and particularly in India and other developing and transition economies the cost of transacting with government including the costs of compliance with laws and regulation (which can be important in developed economies as well) and the costs of applying for and securing approval of licenses (which are more associated with developing economies).

The costs of transacting with government can involve corruption, that is, the payment of money, gifts etc. to government officials to turn a blind eye to non-compliance with regulations or to secure a license (Sharma 2006, p. 6). However, transacting with government can also involve the quite legitimate but still onerous costs of filling out regulatory and license approval forms (the paper burden), and of setting up meetings and negotiating with officials, which in a country like India with large and highly complex bureaucracies at all spatial scales, can be very time-consuming and expensive. This is because of the many layers of government agencies and regulatory regimes that need to be satisfied in a large and diverse federated state. In this dissertation, transacting with government will include both legitimate and non-legitimate (corruption related) costs, from the perspective that both kinds of government-imposed transaction costs are high in this country and influence business strategies and day-to-day decisions.

Throughout this dissertation, distinctions are made between informal and formal business institutions ${ }^{\mathbf{3 4 4}}$, informal and formal rules of business conduct, and informal and formal business arrangements. Informal business institutions and rules of conduct are those that are associated with business routines, conventions, customs, moral values and

\footnotetext{
${ }^{344}$ The reader should note that there are major differences between informal business institutions and the informal economy. The informal economy is defined in the literature to include all-income earning activities that are not covered by and are not under the protection of taxation and other formal laws and regulations. The informal economy is one aspect of the underground economy which also includes the illegal economy, the unreported economy and the unrecorded economy (Portes and Haller 2005, pp. 404405).
}

As defined for this dissertation, informal business institutions can operate: (i) between companies and other economic agents in the formal economy, (ii) between companies and other economic agents in the informal economy; in fact, by definition informal institutions based on social norms (trust, reciprocity of trust etc.), relationships, networks and penalties, are the only constraints to shirking, opportunism and fraud that are available to protect economic agents in the informal economy (Portes and Haller 2005, p. 407), as well as (iii) between companies/economic agents when one party to the transaction is in the formal economy and the second is in the informal economy. Because of the emphasis on business groups, this dissertation largely focuses on informal business institutions between companies and other economic agents within India's formal economy. 
ethical norms of trust, reciprocity, and cooperation more generally. These institutions/rules are developed informally or even evolve "spontaneously" within a business group, network or community; and are monitored and enforced by the community itself with no intervention by the courts or the state. Formal business institutions and rules of business conduct are those like competition rules in a competition law that are developed in an intentional manner by economic and political actors and that in most countries are monitored and enforced by a government agency and/or by competition courts, commissions and tribunals (see e.g. Williamson 1991:2, Dixit 1996 and Mantzavinos 2001).

The innovation, NIE, new IO and other economics conceptual literatures reviewed in chapter 2 are less clear on the distinctions between informal and formal business arrangements involving two or more companies. For purposes of this analysis, multidivision corporations and conglomerates and vertical and horizontal mergers, acquisitions and combinations are treated as formal business arrangements. Research partnerships, strategic alliances, long-term supply relationships, business networks and similar arrangements, which go beyond a simple (spot-market) contract but do not involve major equity investments by the parties, are considered to be informal business arrangements. Research and production joint ventures and specialization agreements that require major equity investments by the parties lie between mergers and non-equity based alliances, partnerships, and networks, but generally are considered as formal business arrangements because of the greater financial commitment by the parties (which to a degree may reduce the need for trust and reciprocity) and because such equity based joint ventures are often treated the same as mergers under competition law in many jurisdictions.

India's traditional business groups have elements of both formal and informal business arrangements but as explained in Chapter 4 of the main text, the informal elements are typically more important for India's business groups. The affiliated companies are treated as independent companies under corporate and other laws, the equity positions of the business group's leading company in its affiliates are often quite small, and governance of the business group is through informal institutions and rules of business conduct rather than formal rules adjudicated by a court or other third party.

Accordingly, as described in the Introduction (pp. 7-8), the traditional business groups of India and other Asian and developing countries are a particular form of informal business institution that are less "bound together" than the divisions legally consolidated within a single corporation, and more "bound together" than short-term strategic alliances and R\&D partnerships. The generic definition used by most business group scholars is that a business group is a set of legally independent affiliated companies that are linked together by a variety of economic and social instruments that allow them to operate in a coordinated and mutually beneficial manner over an extended period of time (Chung 2001 p. 721 and Granovetter 1995, p. 95)

${ }^{345}$ This definition for business groups is further discussed in Appendix A and the economic and social instruments used to bind together a business group are further discussed in Chapters 2 and 4 . 
One business group scholar developed a synthesis from previous studies to expand on this definition of a business group. "A business group is a set of firms which, though legally independent, are bound together by a constellation of formal and informal ties and are accustomed to taking coordinated action" (Khanna and Rivkin 2001, pp. 47-48). The two authors then stated in a footnote on p. 48: "Each firm is a distinct legal entity that publishes its own financial statements, has its own board of directors, and is responsible to its own shareholders. This is in contrast to conglomerates in the United States, for example, where individual lines of business do not have any of these properties."

In sum, while the conglomerate form is categorized as a formal business arrangement under e.g. corporate, competition, bankruptcy, and other laws, the business group is defined as an informal business arrangement that is not registered as a legal entity under corporate law but rather is bound together by a mix of formal and informal business institutions and rules of business conduct.

It is important to differentiate a business group from a business community. In the Indian business literature, the term business community is used at times to denote all (generally private) businesses in India in aggregate. As well, depending on the context, the term business community is applied to a group of (again mainly private) businesses that share the same ethnic, religious, caste, other occupational or locational characteristics, such as the Marwari business community, the Chettiar business community in South India, and the Gujerati business community. To avoid confusion, the term private business sector rather than business community is used in this dissertation to denote all privately owned business groups and unaffiliated companies.

In addition, the term business group is used to indicate a form of informal (generally privately owned) business institution and arrangement, and the term business and/or trade association is used to denote an association that lobbies government on behalf of its members and provides other services to their business members. The author's meetings with these trade associations indicated that these associations provide similar services as those in North America and the United Kingdom.

Finally, depending on the context, the term "state" is used to refer to the general concept of the state, to the nation state of India, and to the regional states of India under its federal structure, which are similar to the American states and to the provinces of Canada. To avoid confusion, the term "regional state" is sometimes employed when e.g. the relationships between business and government are being discussed (Sinha 2005:1, p. xvii). 


\begin{abstract}
Appendix 2
Specifications for the "Equations"

In the "Conceptual Model" on the

Interactions, Conflicts and Accommodations Between India's Competition Regimes and

Its Informal Business Institutions and Arrangements
\end{abstract}




\begin{tabular}{|c|c|}
\hline $\begin{array}{l}\text { Dependent } \\
\text { (Endogenous) } \\
\text { Variable (Y) }\end{array}$ & Is a Function of the Following Independent (Exogenous/X) Variables \\
\hline $\begin{array}{l}\text { 1. Design of } \\
\text { the Formal } \\
\text { Competition } \\
\text { Regime: } \\
\text { Competition } \\
\text { Law and } \\
\text { Policies - see } \\
\text { Exhibit I in the } \\
\text { text }\end{array}$ & $\begin{array}{l}\text { 1. Empirical evidence on and perceptions of elites, businesses, key government ministries, and citizens/consumers regarding: } \\
\text { (i) industrial and economic concentration and the market, economic and political power of business groups and other larger } \\
\text { companies; (ii) the extent of competition; and (iii) industrial and consumer prices, product quality, innovation and national } \\
\text { competitiveness } \\
\text { 2. Whether existing formal and informal business institutions, corporate culture, and policy, political and bureaucratic } \\
\text { environments support (and are perceived to support) market competition and inter-firm rivalry; and whether India has } \\
\text { established a pro-competition culture that has been so important to market competition and effective formal competition } \\
\text { regimes in e.g. the US } \\
\text { 3. Economic and political influence and power of business groups, industry and trade associations and other business interests } \\
\text { and elites - and their supporters in government and the academic and research communities - to influence the design of the } \\
\text { competition regime in their favour } \\
\text { 4. Particularly important are the interactions between (a) business groups and other major business interests and (b) the } \\
\text { government ministries, agencies and senior officials that were the major drivers of competition regime reform in the 1960s } \\
\text { and in the post-1991 liberalization period } \\
\text { 5. Extent to which competition, consumer protection and related issues and offences are being addressed (in a pro- } \\
\text { competition, anti-competition or neutral manner) by related policy regimes in the areas of foreign and inter-regional trade, } \\
\text { corporate law, business entry and exit (e.g. labour and bankruptcy law), industry, innovation, intellectual property, and } \\
\text { consumer protection; and in particular by the sectoral regulators (telecom, transportation, energy, financial services, urban } \\
\text { infrastructure etc.) given their overlapping mandates with the competition law and agency } \\
\text { 6. Current thinking of competition policy and law experts in India and other countries (i.e. trans-border competition } \\
\text { "epistemic communities" and networks) regarding the competition regime models most appropriate to the current stage of } \\
\text { India's development. }\end{array}$ \\
\hline $\begin{array}{l}\text { Effectiveness } \\
\text { of the } \\
\text { Competition }\end{array}$ & $\begin{array}{l}\text { 1. Quality of the design of the formal competition regime, including its consistency with, and ability to be effectively } \\
\text { administered, given India's current stage of economic, institutional and legal development } \\
\text { 2. Independence of and technical and financial resources provided to the competition agency -- including legal, economic and } \\
\text { policy expertise available from within the competition agency and from outside sources (the academic, legal, consulting, }\end{array}$ \\
\hline
\end{tabular}




\begin{tabular}{|c|c|}
\hline $\begin{array}{l}\text { Dependent } \\
\text { (Endogenous) } \\
\text { Variable (Y) }\end{array}$ & Is a Function of the Following Independent (Exogenous/X) Variables \\
\hline $\begin{array}{l}\text { Regime, } \\
\text { Especially } \\
\text { Competition } \\
\text { Law } \\
\text { Enforcement }\end{array}$ & $\begin{array}{l}\text { business and research institute communities) } \\
\text { 3. Enforcement, competition advocacy, education, information, voluntary compliance and related programs of the } \\
\text { competition agency and other government agencies with competition responsibilities } \\
\text { 4. Whether existing informal and formal business institutions, corporate culture, and policy, political and bureaucratic } \\
\text { environment are on balance pro- or anti-competitive } \\
\text { 5. Continuing perceptions and concerns of elites, businesses and citizens/consumer regarding concentration, competition, } \\
\text { prices, product quality etc. in the economy; perceptions can change in either a positive or negative direction after } \\
\text { competition law enforcement begins because of: the enforcement and education efforts of the competition agency and its } \\
\text { partners; their interactions with the competition law and regime; and changes in the external environment } \\
\text { 6. Extent to which companies, business groups and other business interests change their business strategies to be in } \\
\text { compliance with the new competition regime (or at least to avoid being investigated and embarrassed under the } \\
\text { competition law) } \\
\text { 7. Ability of business groups and other business interests to influence competition law enforcement (e.g. enforcement cases } \\
\text { that are selected for detailed investigation, how the competition analysis is conducted, and the decisions are made) and to } \\
\text { influence the related decisions of other policy regimes that can impact, support and/or undermine market competition and } \\
\text { the effectiveness of competition law enforcement (i.e. extent to which contestation continues after enforcement begins) } \\
\text { 8. Current thinking and advice of competition policy and law experts in India and other countries (i.e. trans-border "epistemic } \\
\text { communities" and networks) regarding competition law and policy analytical techniques and enforcement practices that } \\
\text { are appropriate to India's competition regime and to the current stage of India's economic and institutional development } \\
\text { 9. Cooperation with other competition law agencies in other jurisdictions in investigating transborder competition cases and } \\
\text { in the provision of technical assistance, advice and other support }\end{array}$ \\
\hline $\begin{array}{l}\text { 3. Persistence } \\
\text { and } \\
\text { Continuing } \\
\text { Strength, and } \\
\text { Market, } \\
\text { Economic and }\end{array}$ & $\begin{array}{l}\text { 1. India's business, social and cultural traditions, institutional inertia, path dependence, and pace of institutional change } \\
\text { 2. Ability of traditional business groups and other informal business arrangements based on trust, reciprocity of trust, } \\
\text { reputation and reciprocal obligations to economize on information, governance and other transaction and production costs } \\
\text {-including the high cost of transacting with government -- and to capitalize on their entrepreneurial, financial, } \\
\text { family/brand name and other resources that are generally in short supply in India }\end{array}$ \\
\hline
\end{tabular}




\begin{tabular}{|c|c|}
\hline $\begin{array}{l}\text { Dependent } \\
\text { (Endogenous) } \\
\text { Variable (Y) }\end{array}$ & Is a Function of the Following Independent (Exogenous/X) Variables \\
\hline $\begin{array}{l}\text { Political } \\
\text { Power of } \\
\text { India's } \\
\text { Business } \\
\text { Groups and of } \\
\text { Other } \\
\text { Traditional } \\
\text { Informal } \\
\text { Business } \\
\text { Institutions and } \\
\text { Arrangements } \\
\text { That Predate } \\
\text { India's 1969 } \\
\text { Competition } \\
\text { Law }\end{array}$ & $\begin{array}{l}\text { 3. High governance costs combined with the political visibility and risks associated with increasing the scale and market } \\
\text { positions of business group members and other large companies through mergers, acquisitions, expanding their existing } \\
\text { facilities and adding new production units. Especially before 1991, growth of business groups through establishing } \\
\text { another nominally independent affiliated company was less likely to attract the attention of a competition law agency, } \\
\text { other government regulators, and anti-business elites } \\
\text { 4. Ability of business groups to respond and adapt to economic, technological, policy and global changes through e.g. } \\
\text { economizing on transaction and other costs, capitalizing on their entrepreneurial, financial, family/brand name, and other } \\
\text { assets, and establishing mutually beneficial business arrangements with new companies and business interests } \\
\text { 5. Influence of business groups and other informal business institutions on the design and enforcement of India's competition } \\
\text { regimes and related policy regimes to ensure decisions and outcomes that support their business interests - related to their } \\
\text { ability to translate their economic, social, relational and institutional strengths and capital into political capital }\end{array}$ \\
\hline $\begin{array}{l}\text { 4. Emergence } \\
\text { and Strength } \\
\text { of New } \\
\text { Informal } \\
\text { Business } \\
\text { Institutions } \\
\text { and } \\
\text { Arrangements } \\
\text { and New } \\
\text { National and } \\
\text { Regional } \\
\text { Business } \\
\text { Interests }\end{array}$ & $\begin{array}{l}\text { 1. Ability to identify and capitalize on opportunities made possible by (i) rapid technological change and innovation, (ii) } \\
\text { globalization of markets, (iii) India's trade, foreign investment, domestic market reforms, and liberalization program since } \\
\text { 1991, and (iv) ex-patriot Indian financial, technical and entrepreneurial resources in e.g. Silicon Valley; opportunities } \\
\text { would involve e.g. business entry and expansion, advanced technology, innovation, exports, import substitution, national } \\
\text { and global supply chains, and new kinds of collaborations and arrangements with domestic and foreign firms } \\
\text { 2. Interest and ability of new players to establish mutually beneficial business collaborations and arrangements with business } \\
\text { groups and other well established business interests within India } \\
\text { 3. The influence of new business interests on the design and enforcement of competition and related policy regimes (such as } \\
\text { intellectual property rights and innovation and investment policies) to ensure decisions and outcomes that support the } \\
\text { emergence and ongoing profitability of new business institutions, arrangements and interests }\end{array}$ \\
\hline
\end{tabular}




\begin{tabular}{|c|c|}
\hline $\begin{array}{l}\text { Dependent } \\
\text { (Endogenous) } \\
\text { Variable (Y) }\end{array}$ & Is a Function of the Following Independent (Exogenous/X) Variables \\
\hline $\begin{array}{l}\text { 5. Number of, } \\
\text { Quality of, } \\
\text { and Outcomes } \\
\text { From } \\
\text { Interactions, } \\
\text { Conflicts and } \\
\text { Accommodati } \\
\text { ons Between } \\
\text { Formal }\end{array}$ & $\begin{array}{l}\text { 1. Highly related to and interrelated with the first four "dependent" variables and also many of the independent variables -- } \\
\text { since the "conceptual model" is simultaneous, and therefore most variables are endogenous; the model as well is dynamic } \\
\text { and therefore the variables and players change through time based on repeated interactions, continuous learning and } \\
\text { external developments } \\
\text { 2. For example, design of the competition law (determined under equation one) will influence the effectiveness of } \\
\text { competition law and policy enforcement (equation two) and both design and enforcement will influence the continuing } \\
\text { success of business groups (equation three), the success of new business interests (equation four) and the number, quality } \\
\text { and outcomes of interactions (equation five) }\end{array}$ \\
\hline $\begin{array}{l}\text { Competition } \\
\text { Regimes and } \\
\text { Informal } \\
\text { Business } \\
\text { Institutions and } \\
\text { Arrangements }\end{array}$ & $\begin{array}{l}\text { 3. Significant differences in the inter-relationships and therefore the interactions between the pre-and post- } 1991 \text { periods. } \\
\text { During the pre-1991 period, most of the interactions, conflicts, accommodations and interrelationships are associated with } \\
\text { the larger business groups - given their dominant role both in the private economy and in competition discourse - and } \\
\text { largely involved interactions with a poorly resourced competition law and agency that was embedded within a well } \\
\text { established, entrenched and quite stable broader competition regime that restricted entry and competition and thus often } \\
\text { allowed business groups and other business interests to circumvent the competition law. }\end{array}$ \\
\hline $\begin{array}{l}\text { Number, } \\
\text { quality, and } \\
\text { outcomes likely } \\
\text { to be much } \\
\text { different } \\
\text { between the } \\
\text { pre- and post } \\
1991 \text { periods. }\end{array}$ & $\begin{array}{l}\text { 4. After 1991, interactions, accommodations and interrelationships must take much greater account of: (i) the changing } \\
\text { strategies of traditional business groups - because of the "privatization" of pro- and anti-competition initiatives; (ii) new } \\
\text { informal business institutions, arrangements and interests, including new regional interests; and (iii) the potential for } \\
\text { collaborations across traditional business groups and between business groups, the new informal institutions and } \\
\text { arrangements, and other business interests. } \\
\text { 5. The post } 1991 \text { interactions are also different because, from } 1991 \text { to the present day (end of 2008), the competition law (the } \\
\text { old MRTPA of 1969) was weaker, while the overall competition regime embedded within the liberalization program is } \\
\text { more supportive of business entry and competition through imports, FDI, and new domestic competitors } \\
\text { 6. Therefore, the post-1991 interactions are expected to be more complex and contingent on e.g. (i) the continuing importance } \\
\text { of India's traditional business groups and their ability to survive and prosper within a different, less stable and rapidly } \\
\text { changing economic, social, policy, global and technological environment; (ii) whether the broader competition regime } \\
\text { (given the partial and incomplete nature of the liberalization program) will continue to move towards greater support of } \\
\text { competition in domestic markets and competitiveness in global markets; and (iii) whether the new competition law and } \\
\text { commission will be more effective than the MRTPA and MRTPC, when enforcement begins in } 2009\end{array}$ \\
\hline
\end{tabular}


Concluding Comment. Among all of the variables included in this conceptual model, the major drivers that are expected to have the greatest influence on the number, quality and outcomes of the interactions between competition regimes and informal business institutions are the quality of the design and enforcement of the competition law and related competition policies (the formal competition regime of Exhibit I in the main text), whether a competition culture has developed in the society, economy and private business sector (the informal competition regime of Exhibit I), and whether the informal business institutions and rules of business conduct favor competition and fair trading over collusion and rent-seeking.

For example, to the extent that the formal competition regime is poorly designed and enforced in a adhoc manner and informal business institutions are hostile to the formal regime and favor collusion over competition, the interactions, conflicts and accommodations between the competition regime and informal business institutions will be more numerous and contentious, of lower quality, and will have less favorable outcomes for the affected companies, business groups and other informal business institutions and arrangements, for the competition regime itself, and/or for the total economy (and often for all three). This would be consequence of the misalignment between the competition regime and the informal business institutions, and learning through time by the latter to avoid the regime whenever possible.

The model is both simultaneous and dynamic, which allows for complex interactions between variables and allows the "players" (business groups, other companies, competition and other government agencies and officials, civil society etc.) to learn through time from repeated interactions and the moves and counter moves of other players (see the reference to dynamic game theory at the end of section 6.6). 


\section{Appendix 3: Research Instrument and Questions Used for the Field Research Interviews and the Literature Review}

Role and Importance of Business Groups and Other Informal Business Institutions

1. What have been the role and importance of business groups (also called at different times managing agencies, and industrial and business houses) and other informal business arrangements during different periods in India's economic history: (i) before British East India Company and British colonial rule; (ii) during the British colonial period up to 1947 independence; (iii) after independence up to the 1991 liberalization program; and (iv) through the liberalization period up to the present day?

Interactions between Competition Regimes and Informal Business Institutions

2. What have been the role, influence and specific positions of India's business groups and other informal business arrangements (e.g. research partnerships and strategic alliances in the information technology (IT) and other high technology sectors) in shaping India's competition policy and law (i) before the MRTPA of 1969 was enacted and in the design of the MRTPA, (ii) with respect to the enforcement of the MRTPA up to the early 2000s; (iii) in designing and implementing the competition policy and related elements of India's liberalization program which started in the mid-1980s and accelerated with the balance of payments crisis in 1991; and (iv) in the design and early administration of India's new competition law of 2003 ?

3. Which government ministries, agencies, senior government officials, business groups and associations, and non-government groups played the lead role in, and thus were the major advocates and "drivers" of, competition policy and law reform: (i) in the 1960s leading up to the MRTP Act and Commission of 1969; and (ii) during the post-1991 liberalization leading to the competition policy changes embodied in the liberalization program and India's new competition law and commission of 2003? What were the major reasons for their advocacy of stronger competition policy and law during these different periods?

4. On the other hand, which government ministries, business groups and interests, and other government and non-government groups were less enthusiastic regarding and were more vocal in their opposition to more effective competition policy and law, and pro-market liberalization more generally, in the pre-1991 and post-1991 periods? What were the major reasons for their opposition?

5. The Indian competition policy literature indicates that the MRTPA of 1969 was mainly established to regulate India's large companies and business groups and to reduce their dominance in specific markets and in the country's total private economy? And yet, most commentators suggest that India's business groups continue to dominate the country's private economy up to the present day, despite the MRTPA, the liberalization reforms that began in the mid-1980s and India's increasing integration into the international economy? What in your view are the 
major reasons for the continuing importance and success of large companies and business groups within the Indian private economy?

6. On balance, do you believe that India's business groups and other informal business arrangements have played a positive or negative role in promoting competition, efficiency, lower prices, and better quality products in Indian markets, in encouraging greater competitiveness of Indian industries in foreign markets, and more generally in India's economic growth and development (i) before 1991; and (ii) after the 1991 liberalization program? What are the major reasons for your answers and for any differences in your answers between the two periods?

7. Do large companies affiliated with business groups very often compete against each other in the same product markets? When they do, are you aware of any examples of what some people may call anti-competitive, restrictive, or unfair business practices and conduct? Please provide specific examples, and in your view the reasons for these anti-competitive, restrictive, or unfair business practices and conduct.

8. More generally, are you aware of any other kinds of anti-competitive, restrictive, or unfair business practices and other forms of anti-business conduct by Indian firms (large or small, foreign or domestic, affiliated or not affiliated with business groups) in the country's product and other markets? Please provide specific examples, and in your view the reasons for these anti-competitive, restrictive, or unfair business practices and conduct.

9. Do you believe that, in the future, these business groups and other informal business arrangements will make a positive or negative contribution to promoting competition in domestic markets and India's ability to compete in international markets?

10. How have business groups and other informal business arrangements responded to the new competitive pressures resulting from India's post-1991 liberalization program? Please provide examples of the specific responses and measures taken of India's business groups and other informal business arrangements?

Evolution of Informal Business Institutions in the Years Ahead

11. More generally, do you believe that India's business groups will become more or less important to the Indian economy in the future as liberalization and integration with global markets continue and perhaps become further established and consolidated?

12. The Indian economics and business literatures largely assess the country's quite distinct business groups. Are other kinds of informal business arrangements now being established? Will other kinds of informal business arrangements - 
such as research partnerships and strategic alliances in higher technology industries - become more or less important in the future?

13. These new arrangements could take many different forms. These could include informal business arrangements between: domestic and foreign companies, smaller and larger firms, companies that are unaffiliated and affiliated with business groups, start-up companies and well-established firms, and between companies in the same and different industries etc. Which forms do you think are becoming most important now and will be most prominent in the future?

Links between Informal Business Institutions, Rules of Business Conduct and Arrangements

14. India's large business groups typically involve a conglomerate of family owned semi-independent companies that together produce many products and compete in many different domestic and foreign markets? What are the benefits to affiliated companies from their membership in these business groups and other arrangements? What are the major costs for affiliated companies?

15. What business rules and monitoring and enforcement methods are used within the largest business groups (such as Tata and Birla) to ensure that affiliated companies cooperate with each other and contribute to common goals and the overall success of the business group? Can you provide specific examples of how the larger firms in a business group secured cooperation from and otherwise disciplined e.g. a smaller affiliated company within the business group?

16. Do smaller business groups and other informal business arrangements use similar or different methods to secure cooperation from their affiliated and partner companies?

17. With regard to the above questions particularly questions 9-11, are there differences between the business groups based on a single extended family and other business groups and informal business arrangements where family connections are less important?

18. The Indian economics and business literatures indicate that, in the past, there were close connections and personal relationships between India's larger business groups, key government ministries at the national and state levels, and the stateowned banks which, prior to 1970 , in some cases were owned by these same business groups. Do you believe that these connections and relationships are as strong today as e.g. before the first steps towards domestic liberalization were made in the early 1980s? What are the major reasons for your answer and for any differences between the current and previous situations? What has changed? What has stayed the same? 
Treatment of Business Groups and Other Informal Business Institutions under the New Competition Regime

19. Do you believe that India's new competition law of 2003 should address business groups and other informal arrangements in a firm/rigorous way or in a flexible and permissive manner (using e.g. the "rule of reason")? What are the reasons for your answer?

20. India's competition policy experts have stated that the MRTP Act of 1969 closely followed the UK competition law model, particularly in terms of the registration and regulation of restrictive business practices. Turning to the new competition law of 2003, do you believe that the new law follows any particular advanced country model fairly closely, and/or that certain provisions of the new law were the result of foreign influences and pressures? If yes, where did these influences and pressures come from?

21. More generally, do you believe that the new Indian competition law was the result largely of domestic ideas, interests and pressures, or was for the most part the consequence of foreign ideas, interests and pressures?

22. Are there regional differences in India - e.g. between larger cities, different states and north and south India - regarding the kinds of business groups and other informal business arrangements that have been established, their role and importance in regional business communities, and their stated positions regarding India's liberalization program, competition policy and the new competition law of 2003? What are the major reasons for these regional differences?

These questions are quite general and open-ended. More specific questions were designed for specific participant groups (e.g. academics, government officials, industry and trade associations, other non-government organizations, leaders of companies and business groups) and even for specific individual research participants, depending on their anticipated expertise and interests. When allowed by the at times (limited) communications in India, these additional questions were shared with the research participant through attaching this research instrument, including the additional questions, to the letter of information.

Finally, research participants were asked to identify and when appropriate provide electronic or hard copies of published relevant academic research papers, policy papers, position papers or other documents that they may have written or co-written or that were prepared by their faculty, business, association, ministry, agency or group. 


\section{Appendix 4: List of Research Participants: From the Fieldwork in India During the Summer of 2006}

\begin{tabular}{|c|c|c|c|c|}
\hline No. & Name & Position and Agency & Location & $\begin{array}{l}\text { Date in } \\
2006\end{array}$ \\
\hline 1. & Manish Agarwal & $\begin{array}{l}\text { Senior Researcher, CUTS } \\
\text { International }\end{array}$ & Jaipur & June 23 \\
\hline 2. & Dr. Ramesh Chand & $\begin{array}{l}\text { Head, National Centre for } \\
\text { Agricultural Economics and } \\
\text { Policy Research }\end{array}$ & New Delhi & June 27 \\
\hline 3. & Ahmed (A.S.) Firoz & $\begin{array}{l}\text { Chief Economist, Economic } \\
\text { Research Unit, Joint Plant } \\
\text { Committee, Ministry of Steel }\end{array}$ & New Delhi & June 28 \\
\hline 4. & G.R. Bhatia & $\begin{array}{l}\text { Additional Director General, } \\
\text { Competition Commission of India }\end{array}$ & New Delhi & $\begin{array}{l}\text { June } 28 \text { and } \\
\text { Sept. } 1\end{array}$ \\
\hline 5. & $\begin{array}{l}\text { Aditya } \\
\text { Bhattacharjea } \mathrm{PhD} \\
\text { Boston } \\
\end{array}$ & $\begin{array}{l}\text { Reader (Associate Professor), } \\
\text { Department of Economics, Delhi } \\
\text { School of Economics }\end{array}$ & Nen & June 29 \\
\hline 6. & Shrawan Nigam & $\begin{array}{l}\text { Consultant, Planning } \\
\text { Commission, GOI }\end{array}$ & New Delhi & June 29 \\
\hline 7. & Dr. Mahesh Uppal & $\begin{array}{l}\text { Director, Com First (Private) } \\
\text { India Ltd. }\end{array}$ & New Delhi & June 30 \\
\hline 8. & Nitya Nanda & $\begin{array}{l}\text { Policy Analyst, CUTS } \\
\text { International }\end{array}$ & Jaipur & July 5 \\
\hline 9. & Archana Mahala & $\begin{array}{l}\text { Joint Director, Bombay (Mumbai) } \\
\text { Chamber of Commerce and } \\
\text { Industries (BCCI) }\end{array}$ & Mumbai & July 12 \\
\hline 10. & Larry A. D'Souza & $\begin{array}{l}\text { Executive Director, Bombay } \\
\text { (Mumbai) Chamber of Commerce } \\
\text { and Industries (BCCI) }\end{array}$ & Mumbai & July 12 \\
\hline 11. & Debjani Chowdhury & $\begin{array}{l}\text { Manager-Research, MVIRDC } \\
\text { World Trade Center (Mumbai) }\end{array}$ & Mumbai & July 12 \\
\hline 12. & Kiran Nanda & $\begin{array}{l}\text { Director, IMC (Indian Merchants } \\
\text { Chamber) Economic Research } \\
\text { and Trading Foundation }\end{array}$ & Mumbai & July 12 \\
\hline 13. & Sunil S. Bhandare & $\begin{array}{l}\text { Advisor, Economic and } \\
\text { Government Policy, Tata Strategic } \\
\text { Management Group }\end{array}$ & Mumbai & July 12 \\
\hline 14. & Pradeep Mehta & $\begin{array}{l}\text { Secretary General, CUTS } \\
\text { International; CUTS Institute for } \\
\text { Regulation and Competition }\end{array}$ & Jaipur & July 19 \\
\hline 15. & R. Subramanian & $\begin{array}{l}\text { Secretary General, The Madras } \\
\text { Chamber of Commerce and } \\
\text { Industry }\end{array}$ & Chennai & August 9 \\
\hline 16. & J. Prasad Davids & Advisor (and previously & Chennai & August 9 \\
\hline
\end{tabular}




\begin{tabular}{|c|c|c|c|c|}
\hline No. & Name & Position and Agency & Location & $\begin{array}{l}\text { Date in } \\
2006\end{array}$ \\
\hline & & $\begin{array}{l}\text { Secretary), The Southern India } \\
\text { Chamber of Commerce and } \\
\text { Industry (SICCI) }\end{array}$ & & \\
\hline 17. & $\begin{array}{l}\text { Dr. Subhashish } \\
\text { Gupta }\end{array}$ & $\begin{array}{l}\text { Associate Professor, Economics } \\
\text { and Social Sciences, Indian } \\
\text { Institute of Management } \\
\text { Bangalore }\end{array}$ & Bangalore & August 10 \\
\hline 18. & T. Ramappa & $\begin{array}{l}\text { Secretary-General, Bangalore } \\
\text { Chamber of Industry and } \\
\text { Commerce (Previously the } \\
\text { Greater Mysore Chamber of } \\
\text { Commerce) }\end{array}$ & Bangalore & August 10 \\
\hline 19. & Dr. S. Chakravarthy & $\begin{array}{l}\text { Indian Administrative Service } \\
\text { (Retd.) and Advisor/Consultant on } \\
\text { Competition Policy and Law }\end{array}$ & Hyderabad & August 11 \\
\hline 20. & K.K. Srinivasan & $\begin{array}{l}\text { Member, Insurance Regulator and } \\
\text { Development Authority of India } \\
\text { (IRDA) }\end{array}$ & Hyderabad & August 11 \\
\hline 21. & $\begin{array}{l}\text { Prof. (Dr.) } \\
\text { Ghanshyam Singh }\end{array}$ & $\begin{array}{l}\text { Professor of Law and Registrar, } \\
\text { NALSAR National Academy of } \\
\text { Legal Studies and Research), } \\
\text { University of Law Hyderabad }\end{array}$ & Hyderabad & August 12 \\
\hline 22. & $\begin{array}{l}\text { Dr. Vidyulatha } \\
\text { Reddy }\end{array}$ & $\begin{array}{l}\text { Professor of Competition and } \\
\text { Consumer Protection Law, } \\
\text { NALSAR National Academy of } \\
\text { Legal Studies and Research), } \\
\text { University of Law Hyderabad } \\
\end{array}$ & Hyderabad & August 12 \\
\hline 23. & Dr. Nalin Bharti & $\begin{array}{l}\text { Professor, Law and Economics, } \\
\text { NALSAR National Academy of } \\
\text { Legal Studies and Research), } \\
\text { University of Law Hyderabad }\end{array}$ & Hyderabad & August 12 \\
\hline 24. & $\begin{array}{l}\text { K.V. } \\
\text { (Krishnarajapet) } \\
\text { Ramaswamy } \\
\end{array}$ & $\begin{array}{l}\text { Associate Professor, Indira } \\
\text { Gandhi Institute of Development } \\
\text { Research }\end{array}$ & Mumbai & August 14 \\
\hline 25. & $\begin{array}{l}\text { Prof. Sebastian } \\
\text { Morris }\end{array}$ & $\begin{array}{l}\text { Chairperson, Post Graduate } \\
\text { Program in Public Management } \\
\text { and Policy, Indian Institute of } \\
\text { Management Ahmedabad }\end{array}$ & Ahmedabad & August 16 \\
\hline 26. & Bipin D. Patel & $\begin{array}{l}\text { Senior Deputy Secretary General, } \\
\text { Gujarat Chamber of Commerce } \\
\text { and Industry }\end{array}$ & Ahmedabad & August 17 \\
\hline
\end{tabular}




\begin{tabular}{|c|c|c|c|c|}
\hline No. & Name & Position and Agency & Location & $\begin{array}{l}\text { Date in } \\
2006\end{array}$ \\
\hline 27. & Arun Goyal & $\begin{array}{l}\text { Director, Academy of Business } \\
\text { Studies }\end{array}$ & $\begin{array}{l}\text { By } \\
\text { Telephone } \\
\text { in New } \\
\text { Delhi }\end{array}$ & August 28 \\
\hline 28. & Jyoti Vij & $\begin{array}{l}\text { Additional Director, Federation of } \\
\text { Indian Chambers of Commerce } \\
\text { and Industry (FICCI) }\end{array}$ & \begin{tabular}{|l} 
New Delhi \\
\end{tabular} & August 29 \\
\hline 29. & Dr. Nagesh Kumar & $\begin{array}{l}\text { Director General, RIS - Research } \\
\text { and Information Systems for } \\
\text { Developing Countries }\end{array}$ & New Delhi & August 29 \\
\hline 30. & S. Sundar & $\begin{array}{l}\text { Distinguished Fellow, The Energy } \\
\text { and Resources Institute (TERI) - } \\
\text { Participated in his Personal } \\
\text { Capacity not as a TERI } \\
\text { Representative }\end{array}$ & New Delhi & August 30 \\
\hline 31. & Sumit Malik & $\begin{array}{l}\text { Research Associate, The Energy } \\
\text { and Resources Institute (TERI) -- } \\
\text { - Participated in his Personal } \\
\text { Capacity not as a TERI } \\
\text { Representative }\end{array}$ & New Delhi & August 30 \\
\hline 32. & $\begin{array}{l}\text { Professor TCA } \\
\text { Anant }\end{array}$ & $\begin{array}{l}\text { Member-Secretary, Indian } \\
\text { Council of Social Science } \\
\text { Research (ICSSR) }\end{array}$ & New Delhi & August 30 \\
\hline 33. & Marut Sen Gupta & $\begin{array}{l}\text { Head, Economic Policy, } \\
\text { Confederation of Indian Industry }\end{array}$ & New Delhi & August 30 \\
\hline 34. & Sharmila Kantha & $\begin{array}{l}\text { Consultant, Confederation of } \\
\text { Indian Industry }\end{array}$ & New Delhi & August 30 \\
\hline 35. & Amit Kapur & $\begin{array}{l}\text { Partner, J. Sagar and Associates } \\
\text { (Law Firm) }\end{array}$ & New Delhi & August 31 \\
\hline 36. & Bibek Debroy & $\begin{array}{l}\text { Secretary General, PHD Chamber } \\
\text { of Commerce and Industry }\end{array}$ & New Delhi & Sept. 1 \\
\hline 37. & Anand S. Pathak & Advocate, P\&A Law Offices & New Delhi & Sept. 1 \\
\hline 38. & Ajay Sahai & $\begin{array}{l}\text { Director General, Federation of } \\
\text { Indian Export Organizations } \\
\text { (FIEO) }\end{array}$ & New Delhi & Sept. 1 \\
\hline
\end{tabular}




\section{Appendix 5 \\ Major Events and Milestones in the Evolution of India's Competition Regimes}

\begin{tabular}{|c|c|}
\hline Events & Year(s) \\
\hline $\begin{array}{l}\text { Establishment of High Levels of Protection Combined with Imperial } \\
\text { Preferences, which resulted in the Trade and Industrial Policy Regime of } \\
\text { "Discriminating Protectionism" }\end{array}$ & $\begin{array}{l}1920 \text { s and } \\
1930 \mathrm{~s}\end{array}$ \\
\hline Rationing Controls During the Second World War & $1939-45$ \\
\hline $\begin{array}{l}\text { Establishment of the First State-Owned Development Bank - the Industrial } \\
\text { Finance Corporation of India }\end{array}$ & 1948 \\
\hline $\begin{array}{l}\text { Directive Principles in the Indian Constitution -- which address the distribution } \\
\text { of material resources and requires that "the operation of the economic system } \\
\text { does not result in the concentration of wealth and means of production to the } \\
\text { common detriment" }\end{array}$ & 1950 \\
\hline $\begin{array}{l}\text { Industries (Development and Regulation) Act - which required an entrepreneur } \\
\text { to receive a license from the government (the Directorate-General of the } \\
\text { Technical Department) to establish a new unit, expand an existing unit or change } \\
\text { its product mix }\end{array}$ & 1951 \\
\hline $\begin{array}{l}\text { Establishment of India's Second State-Owned Development Bank, the Industrial } \\
\text { Credit and Investment Corporation of India. And the nationalization of India's } \\
\text { largest commercial bank, the British owned Imperial Bank of India, which was } \\
\text { merged with banks owned by the previous princely states, to create the State } \\
\text { Bank of India (Encarnation } 1989 \text { pp. } 41-42 \text { ) }\end{array}$ & 1955 \\
\hline $\begin{array}{l}\text { Nationalization of life insurance companies, which ere then merged into the Life } \\
\text { Insurance Corporation of India }\end{array}$ & 1956 \\
\hline $\begin{array}{l}\text { Industrial Policy Resolutions - which reserved } 17 \text { industries exclusively for the } \\
\text { public sector }\end{array}$ & $\begin{array}{l}1956 \text { and } \\
1959\end{array}$ \\
\hline $\begin{array}{l}\text { Establishment of India's Third Major State-Owned Development Bank - the } \\
\text { Industrial Development Bank of India (IDBI), which is currently India's fourth } \\
\text { largest bank }\end{array}$ & 1964 \\
\hline $\begin{array}{l}\text { Report of the Mahalonobis Committee on the Distribution and Levels of Income } \\
\text { in India }\end{array}$ & 1964 \\
\hline $\begin{array}{l}\text { Report of the Hazari Committee on Industrial Licensing - which emphasized } \\
\text { that licensing had increased the concentration of economic power in large part } \\
\text { because of the license pre-emption strategies that foreclosed capacity, which } \\
\text { were conducted by the Birla and Tata Groups and other business groups and } \\
\text { larger companies }\end{array}$ & 1965 \\
\hline $\begin{array}{l}\text { Report of the Monopolies Inquiry Commission (MNC) under Chair Das Gupta- } \\
\text { which stressed the high level of concentration in India's private economy and the } \\
\text { dangers posed to the public interest }\end{array}$ & 1965 \\
\hline $\begin{array}{l}\text { India's first, modest and "aborted" attempt at economic liberalization and export } \\
\text { promotion - which lasted less than two years. Similar export promotion efforts } \\
\text { of East Asian Countries at about the same time were much more successful }\end{array}$ & 1966 \\
\hline $\begin{array}{l}\text { Establishment of the Dutt Committee to Review the Functioning and Impacts of } \\
\text { the Licensing Regime Over its First Decade. }\end{array}$ & $1967-1969$ \\
\hline
\end{tabular}




\begin{tabular}{|c|c|}
\hline Events & Year(s) \\
\hline $\begin{array}{l}\text { The Committee Report in } 1969 \text { raised serious concerns about the expanding } \\
\text { concentration of market, economic, financial, and political power in the hands of } \\
\text { a relatively few family owned business groups; and stressed that no attempt over } \\
\text { the past decade had been made to use the licensing system to prevent further } \\
\text { growth by the large business groups; rather, the licensing system had favoured } \\
\text { the large business groups. }\end{array}$ & \\
\hline $\begin{array}{l}\text { Monopolies and Restrictive Trade Practices (MRTP) Act and Commission - } \\
\text { which is generally concluded to be overly ambitious, seriously flawed and } \\
\text { weakly enforced }\end{array}$ & 1969 \\
\hline $\begin{array}{l}\text { GOI's Nationalization of } 14 \text { Major Commercial Banks owned in some cases by } \\
\text { major business groups }\end{array}$ & 1969 \\
\hline $\begin{array}{l}\text { The last major British owned managing agency, Martin Burn, was taken over by } \\
\text { Indian interests - most in fact disappeared during the 1950s (Encarnation } 1989 \mathrm{p} \text {. } \\
\text { 64) }\end{array}$ & 1969 \\
\hline $\begin{array}{l}\text { Formal Elimination of the Managing Agency System - managing agencies were } \\
\text { then transformed (converted) into India's Business Groups, with similar } \\
\text { objectives, functions, routines, rules of business conduct, informal arrangements } \\
\text { and governance structures, and consequences for competition and market } \\
\text { outcomes }\end{array}$ & 1970 \\
\hline $\begin{array}{l}\text { New More Rigorous Licensing Policy that reversed the trend towards decontrol } \\
\text { of the mid-1960s e.g. withdrawal of licensing exemptions previously provided to } \\
41 \text { industries and special screening of license applications from large business } \\
\text { groups }\end{array}$ & 1970 \\
\hline $\begin{array}{l}\text { Nationalization (called a hostile takeover) of all property insurance companies, } \\
\text { which were reorganized as the General Insurance Corporation of India - which } \\
\text { largely completed the nationalization of India's financial industry and markets } \\
\text { (Encarnation } 1989 \text { p. } 42 \text { ) }\end{array}$ & 1971 \\
\hline $\begin{array}{l}\text { Foreign Exchange Regulation Act (FERA) - which limited the equity of foreign } \\
\text { companies in Indian companies to } 40 \%\end{array}$ & 1973 \\
\hline $\begin{array}{l}\text { Report of the High Powered Committee on Companies and the MRTP Act - } \\
\text { which led to some MRTPA amendments in } 1984 \text { (that fell far short of the } \\
\text { Committee's proposals and the desires of competition advocates -- see Chapter } 6 \\
\text { of the text }\end{array}$ & 1978 \\
\hline $\begin{array}{l}\text { Report of the Dagli Committee on industrial controls and subsidies, which } \\
\text { reported that many (WWII) war time controls were still in place, and others have } \\
\text { been added since independence. Controls are now overlapping, often negating } \\
\text { each other, and often are still in place long after their need has disappeared. }\end{array}$ & 1979 \\
\hline $\begin{array}{l}\text { Adoption of More Pro-Business Rhetoric and Policies by the Government of } \\
\text { India - with some "under-the-table" flexibility in applying the licensing regime } \\
\text { to incumbent business groups and other domestic businesses }\end{array}$ & 1980 \\
\hline $\begin{array}{l}\text { Amendments to the MRTPA to include five categories of unfair trade practices } \\
\text { (UTPs): false representation, misleading bargain prices, gifts and promotional } \\
\text { contests, product safety standards, and hoarding }\end{array}$ & 1984 \\
\hline
\end{tabular}




\begin{tabular}{|c|c|}
\hline Events & Year(s) \\
\hline $\begin{array}{l}\text { Start of More Formal (but still very partial) Domestic "Pro-Business" Industrial } \\
\text { Policy Reforms }\end{array}$ & 1985 \\
\hline $\begin{array}{l}\text { Passage of the Consumer Protection Act, which ostensibly addresses the same } \\
\text { consumer protection cases as the MRTPA UTP amendments in } 1984\end{array}$ & 1986 \\
\hline $\begin{array}{l}\text { Balance of Payments Crisis and Start of More Comprehensive and "Pro-Market" } \\
\text { Liberalization Program Involving Reforms in Industrial, Trade, Investment, and } \\
\text { Competition Policies - and later in the decade Competition Law (see below) }\end{array}$ & $\overline{1991}$ \\
\hline $\begin{array}{l}\text { As part of the Liberalization Program, Removal of the Licensing and Related } \\
\text { "Monopoly Company Control" Provisions from the MRTP Act, and Dilution of } \\
\text { the Merger Control Provisions - while the coverage of the Act was expanded to } \\
\text { include public undertakings/state owned enterprises }\end{array}$ & 1991 \\
\hline $\begin{array}{l}\text { Establishment of the High Level Committee on India's Competition Law - } \\
\text { Under Chairman Shri S.V.S. Raghavan }\end{array}$ & 1999 \\
\hline $\begin{array}{l}\text { Report of the Raghavan (High Level Committee) on India's Competition Law: } \\
\text { Volume I: which provided the foundation for the Competition Concept Bill of } \\
2000 \text {. }\end{array}$ & 2000 \\
\hline $\begin{array}{l}\text { The report was quite comprehensive; addressed both competition law and policy } \\
\text { issues (e.g. reservations for the small-scale sector, reform of labour, land ceiling } \\
\text { and "sick companies" laws to facilitate restructuring, entry and exit, and open, } \\
\text { non-discriminatory and rule-bound trade policies); and applied new industrial } \\
\text { organization principles. }\end{array}$ & \\
\hline $\begin{array}{l}\text { Competition Concept Bill drafted by the Department of Company Affairs and } \\
\text { placed on its Website. Which underwent major changes because of business } \\
\text { lobbying, particularly in the merger review provisions, before the Competition } \\
\text { Bill 2001 was introduced to the Indian Parliament }\end{array}$ & 2000 \\
\hline Competition Bill 2001 Introduced to Indian Parliament & $\begin{array}{c}\text { August } \\
2001\end{array}$ \\
\hline Report of the Parliamentary Standing Committee on the Competition Bill 2001 & $\begin{array}{l}\text { November } \\
2002\end{array}$ \\
\hline $\begin{array}{l}\text { Passage by the India Parliament of the New Competition Law and Commission, } \\
\text { entitled the Competition Act } 2002 \text { - which represents a significant improvement } \\
\text { over the MRTPA (see the comparison below). } \\
\text { But enforcement of the substantive provisions was delayed by a legal challenge } \\
\text { regarding the composition of the Commission. The Act was challenged on the } \\
\text { grounds that it did not adhere to the doctrine of the separation of powers between } \\
\text { the judiciary and the executive as set out in the Constitution of India. }\end{array}$ & $\begin{array}{l}\text { December } \\
2002 \text { and } \\
\text { January } \\
2003\end{array}$ \\
\hline $\begin{array}{l}\text { Establishment of the New Competition Commission of India (CCI) with a small } \\
\text { staff and limited mandate to conduct competition education and advocacy (until } \\
\text { substantive provisions can be enforced) }\end{array}$ & $\begin{array}{l}\text { Spring } \\
2003\end{array}$ \\
\hline Legal Challenge in the Indian Supreme Court re the Composition of the CCI & $\begin{array}{l}\text { October } \\
2003\end{array}$ \\
\hline Supreme Court Decision Requiring Competition Act Amendments & $\begin{array}{c}\text { January } \\
2005\end{array}$ \\
\hline $\begin{array}{l}\text { Tabling in India's Parliament of the Amendments Needed for Full } \\
\text { Implementation of the Competition Act } 2002 \text {. The Amendment Bill as well } \\
\text { sought the continuation of the MRTPC for another two years, and called for all } \\
\text { staff of the MRTPC to then be absorbed into the Appellate Tribunal or CCI after } \\
\text { the MRTPC is dissolved }\end{array}$ & $\begin{array}{l}\text { March } \\
2006\end{array}$ \\
\hline
\end{tabular}




\begin{tabular}{|c|c|}
\hline Events & Year(s) \\
\hline $\begin{array}{l}\text { Establishment by the Planning Commission, as part of its preparatory work on } \\
\text { India's Eleventh Five-Year Plan, of a Working Group on Competition Policy } \\
\text { with wide representation of professionals from government and non-government } \\
\text { organizations. } \\
\text { The Working Group identified the need for the government to adopt a broad } \\
\text { based, overarching and comprehensive National Competition Policy to promote } \\
\text { coherence in the reforms process, to establish uniform competition principles } \\
\text { across different sectors and to harmonize all other policies keeping in view the } \\
\text { competition dimension. The } 29 \text { members of the Working Group included six } \\
\text { business members and six members who represented other non-government } \\
\text { groups. }\end{array}$ & $\begin{array}{l}\text { Spring } \\
2006\end{array}$ \\
\hline $\begin{array}{l}\text { Substantive Comments from the Parliamentary Standing Committee to the } \\
\text { Government on the Amendment Bill } 2006 \text { - Including the Committee's own } \\
\text { Competition (Amendment) Bill tabled in Parliament in 2006, which proposed } \\
\text { reintroducing a mandatory merger notification scheme }\end{array}$ & $\begin{array}{c}\text { December } \\
2006\end{array}$ \\
\hline $\begin{array}{l}\text { Tabling by the GOI/Minister of Company Affairs of the revised Competition } \\
\text { Amendment Bill on August } 292007 \text {. The Bill provided for a three member } \\
\text { quasi-judicial body, the Competition Appellate Tribunal (CAT) to hear appeals } \\
\text { against any directions issued by the CCI. There is still some doubt about } \\
\text { whether the amendments will fully meet the Supreme Court's concerns. } \\
\text { See below for other amendments, which include important changes to the merger } \\
\text { provisions but no major changes to the sections on anti-competitive agreements } \\
\text { and abuse of dominance. Consistent with consultations before passage of the } \\
2002 \text { Act, these non-merger sections received little attention and debate from the } \\
\text { time of the Raghavan Committee Report in } 2000 \text { to passage of the amended } \\
\text { statute in September } 2007 \text {. }\end{array}$ & $\begin{array}{l}\text { August } \\
2007\end{array}$ \\
\hline $\begin{array}{l}\text { Proposal from the Competition Commission of India to establish a "Competition } \\
\text { Policy Oversight Council", which would be an autonomous body that would (i) } \\
\text { monitor the implementation of competition policy at the national and regional } \\
\text { state government levels, (ii) review laws and policies from a competition } \\
\text { perspective, and (iii) undertake competition impact assessments of new laws and } \\
\text { policies. } \\
\text { This recommendation was forwarded by the CCI to the Planning Commission } \\
\left.\text { for the } 11^{\text {th }} \text { Five-Year Plan ( } 2007-2012\right) \text {. The CCI at the same time announced } \\
\text { that the Commission would be conducting market studies to better understand } \\
\text { the state of competition in different sectors and to advise authorities on the } \\
\text { changes needed to promote competition. }\end{array}$ & $\begin{array}{c}\text { September } \\
2007\end{array}$ \\
\hline $\begin{array}{l}\text { Passage without debate by both the Lower and Upper Houses of the Indian } \\
\text { Parliament of the revised Competition Amendment Bill. Bill included: } \\
\text { (i) establishment of the CCI as an expert body that will function as a market } \\
\text { regulator and as well will play an advisory and advocacy role (no judicial }\end{array}$ & $\begin{array}{c}\text { September } \\
2007\end{array}$ \\
\hline
\end{tabular}

${ }^{346}$ However, since virtually all other competition law jurisdictions use the term "complaint" and the term "information" has an ambiguous meaning in a competition law context, the term complaint is used throughout the dissertation to denote a situation where a consumer, business, or other person or group 


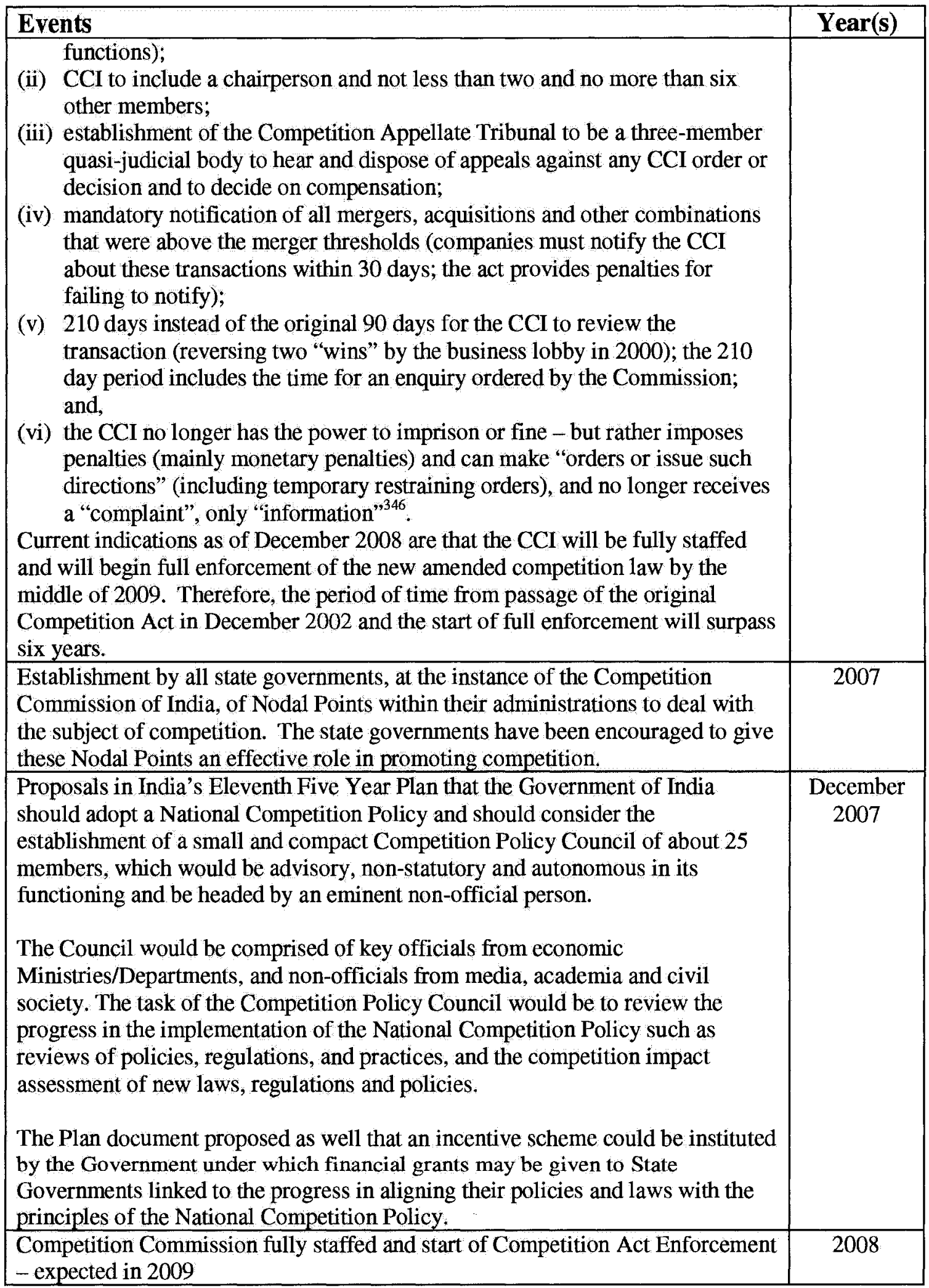

provides the CCI with information on and therefore complains about anti-competitive conduct or related competition problem. 
Sources: Compiled from the large number of references on Indian competition, trade, industrial, foreign investment and related policies and the liberalization programs of the 1980s and 1990s listed in the bibliography - including Encarnation (1989) and the Government of India's Eleventh Five-Year Plan (Government of India 2007:2).

The following provides a brief and incomplete thematic comparison of the MRTPA 1969 and the Competition Act 2002.

\begin{tabular}{|c|c|}
\hline MRTP Act 1969 & Competition Act 2002 \\
\hline $\begin{array}{l}\text { Based on the pre-liberalization } \\
\text { competition regime }\end{array}$ & $\begin{array}{l}\text { Based on the post-1991 more liberal but still incomplete } \\
\text { competition regime }\end{array}$ \\
\hline $\begin{array}{l}\text { Company and business group size } \\
\text { as the key factor (with tacit } \\
\text { assumption that large business } \\
\text { group and company size leads } \\
\text { almost automatically to anti- } \\
\text { competitive market structures, } \\
\text { conduct and performance) }\end{array}$ & $\begin{array}{l}\text { Market structure and conduct as key factors - with implicit } \\
\text { recognition that market structure, conduct and performance } \\
\text { are determined together (consistent with the new industrial } \\
\text { economics) }\end{array}$ \\
\hline $\begin{array}{l}\text { Competition offences that are } \\
\text { implicit or not defined }\end{array}$ & $\begin{array}{l}\text { Competition offences that are more explicit and better } \\
\text { defined }\end{array}$ \\
\hline $\begin{array}{l}\text { Complex in arrangement and } \\
\text { language }\end{array}$ & $\begin{array}{l}\text { Much simpler in arrangement and language and much } \\
\text { easier to understand for businesses, consumers and other } \\
\text { lay people who are not competition law specialists }\end{array}$ \\
\hline $\begin{array}{l}\text { Fourteen per se offences that } \\
\text { arguably negated the principles of } \\
\text { natural justice }\end{array}$ & Only four per se offences - rest are subject to rule of reason \\
\hline $\begin{array}{l}\text { Prohibition against dominance - } \\
\text { illustrating the importance of size } \\
\text { and structure }\end{array}$ & $\begin{array}{l}\text { Prohibitions again abuses of dominance rather than } \\
\text { dominance itself (company can dominate a market if based } \\
\text { on greater efficiency) - which illustrates importance of } \\
\text { conduct relative to structure in the design and possibly the } \\
\text { enforcement of the new Act }\end{array}$ \\
\hline $\begin{array}{l}\text { Compulsory registration of } \\
\text { agreements }\end{array}$ & $\begin{array}{l}\text { No requirement to register agreements - and voluntary not } \\
\text { mandatory notification of large merger transactions in } 2002 \\
\text { Act. But voluntary was changed to mandatory merger } \\
\text { notification under the Amendment Bill passed by the Indian } \\
\text { Parliament in September } 2007\end{array}$ \\
\hline $\begin{array}{l}\text { No explicit regulation of mergers, } \\
\text { acquisitions and other } \\
\text { combinations - which instead were } \\
\text { controlled through the regulation } \\
\text { of MRTPA monopoly business } \\
\text { groups and other larger companies }\end{array}$ & $\begin{array}{l}\text { Regulation of mergers, acquisitions and other combinations } \\
\text { but only for transactions that exceed very high threshold } \\
\text { limits. Smaller transactions are not deemed to be a merger } \\
\text { for purposes of merger review under the new competition } \\
\text { law. } \\
\text { When combined with mandatory notification, means that } \\
\text { small below threshold mergers that raise competition } \\
\text { concerns will not be reviewed, and large foreign and } \\
\text { domestic mergers - including large international mergers } \\
\text { that involve limited operations in India - will have to be } \\
\text { reviewed by the CCI }\end{array}$ \\
\hline
\end{tabular}




\begin{tabular}{|c|c|}
\hline MRTP Act 1969 & Competition Act 2002 \\
\hline $\begin{array}{l}\text { MRTPC appointed by the } \\
\text { Government of India }\end{array}$ & $\begin{array}{l}\text { Competition Commission (CCI) under the non-amended } \\
2002 \text { Act selected by a Collegium (a Search Committee). } \\
\text { Under the amended act, CCI selection to be conducted by a } \\
\text { Committee to be chaired by the Chief Justice of India or } \\
\text { his/her nominee, and would include the Secretary of Law } \\
\text { and Justice, the Secretary of the Ministry of Company } \\
\text { Affairs and two other experts (still to be determined). } \\
\text { (Many competition experts and advocates are still arguing } \\
\text { for the "Collegium" approach }\end{array}$ \\
\hline $\begin{array}{l}\text { Very little administrative and } \\
\text { financial autonomy for the } \\
\text { MRTPC }\end{array}$ & $\begin{array}{l}\text { Relatively greater autonomy for the Competition } \\
\text { Commission - but still not adequate independence } \\
\text { according to many competition policy advocates }\end{array}$ \\
\hline $\begin{array}{l}\text { No competition policy advocacy } \\
\text { role for the MRTPC }\end{array}$ & $\begin{array}{l}\text { Competition advocacy role for the CCI, but largely on } \\
\text { issues forwarded to the Commission by the central and state } \\
\text { governments. (Amended statute now allows a regional } \\
\text { state government in formulating a policy to make a } \\
\text { reference to the CCI for its opinion on the policy's possible } \\
\text { effects on competition). }\end{array}$ \\
\hline $\begin{array}{l}\text { No penalties for offences - only } \\
\text { cease and desist orders }\end{array}$ & $\begin{array}{l}\text { Penalties for offences. Under the amended act passed in } \\
\text { September } 2007 \text {, the power to impose fines and } \\
\text { imprisonment and to award compensation has been } \\
\text { transferred from the CCI to the Competition Appellate } \\
\text { Tribunal. } \\
\text { Also under the amended act, contravention of the CCI's } \\
\text { orders will lead to penalty proceedings by the Commission } \\
\text { in the first instance. If non-compliance still continues then } \\
\text { it shall be treated as a criminal offence and complaints are } \\
\text { to be filed before the Court (CMM, Delhi). }\end{array}$ \\
\hline Reactive, rigid and legalistic & $\begin{array}{l}\text { Potential for the Act and Commission to be more flexible } \\
\text { and proactive in identifying, investigating and adjudicating } \\
\text { cases (but questions remain on whether the CCI will in fact } \\
\text { employ these capabilities) }\end{array}$ \\
\hline $\begin{array}{l}\text { Unfair trade practices covered after } \\
1984\end{array}$ & $\begin{array}{l}\text { Unfair trade practices omitted - transferred to the consumer } \\
\text { fora under the Consumer Protection Act }\end{array}$ \\
\hline $\begin{array}{l}\text { Does not provide the MRTPC with } \\
\text { the powers to investigate cartels } \\
\text { and similar anti-competitive } \\
\text { arrangements of foreign origin }\end{array}$ & $\begin{array}{l}\text { New competition law seeks to regulate foreign based anti- } \\
\text { competitive arrangements and practices that have a material } \\
\text { effect on competition in Indian domestic markets }\end{array}$ \\
\hline $\begin{array}{l}\text { Concept of anti-competitive } \\
\text { activities of business groups was } \\
\text { emphasized in the MRTPA but } \\
\text { proved to be unworkable }\end{array}$ & $\begin{array}{l}\text { Concept has been simplified - largely through ignoring } \\
\text { business groups and the inter-connections between } \\
\text { affiliated companies in drafting the new law. Anti- } \\
\text { competitive activity of business groups likely to be } \\
\text { addressed in the same manner as the anti-competitive } \\
\text { activity of individual (affiliated and unaffiliated) companies }\end{array}$ \\
\hline
\end{tabular}




\begin{tabular}{|l|l|}
\hline \multicolumn{1}{|c|}{ MRTP Act 1969 } & \multicolumn{1}{c|}{ Competition Act 2002 } \\
\hline No criteria for defining markets & $\begin{array}{l}\text { Provides criteria for determining relevant geographical or } \\
\text { product market }\end{array}$ \\
\hline $\begin{array}{l}\text { No criteria for defining barriers to } \\
\text { entry and no listing of entry } \\
\text { barriers }\end{array}$ & $\begin{array}{l}\text { Listing of entry barriers under provisions that outline the } \\
\text { factors to be considered by the CCI in determining a } \\
\text { dominant position }\end{array}$ \\
\hline $\begin{array}{l}\text { Section 12(5) of MRTPA gave the } \\
\text { MRTPC search and seizure powers } \\
\text { to collect documents, records and } \\
\text { other evidence. }\end{array}$ & $\begin{array}{l}\text { CCI has no such powers under the Competition Act 2002 } \\
\text { and the amended statute 2007 }\end{array}$ \\
\hline
\end{tabular}

Source: Developed and modified from the comparison table in Singhi (2003), with expansions and additional interpretation by the author. 


\section{Appendix 6: Major Developments and Events in Indian History Relevant to This Thesis}

\begin{tabular}{|c|c|}
\hline Development and/or Event & $\begin{array}{l}\text { Time } \\
\text { Period or } \\
\text { Year }\end{array}$ \\
\hline $\begin{array}{l}\text { Development of Traditional Indian Economic Thought - called Arthashastra } \\
\text { Economics and Manu's Dharmashastra - which stressed continuity, stability and } \\
\text { fairness in business and economic relationships embedded within a comparatively } \\
\text { static caste-dominated society. Traditional Indian economic thought had } \\
\text { considerable influence up to the start of British colonial rule - and arguably has } \\
\text { continued to resonate in India's private business sector }\end{array}$ & $\begin{array}{l}\text { About } 200 \\
\text { BC-300 AD }\end{array}$ \\
\hline $\begin{array}{l}\text { Indian Ascendancy in Asian and Global Industry, Trade and Commerce-- } \\
\text { including Highly Capable Indian Merchants located e.g. in Surat (Gujarat), Madras } \\
\text { and Bengal. Many of these merchants - such as the Birlas based in Bengal and the } \\
\text { Tatas based in Western India and the Chettiars in Southern India -- later became } \\
\text { some of India's major industrialists and business groups in the late } 19^{\text {th }} \text { century and } \\
\text { the first half of the } 20^{\text {th }} \text { century. }\end{array}$ & $\begin{array}{l}1300-1750 \\
\mathrm{AD}, \text { and to } \\
\text { some degree } \\
\text { to } 1850\end{array}$ \\
\hline Portuguese Establish First Permanent European Coastal Settlement in India at Goa & 1510 \\
\hline Mughal Conquest of Delhi & 1526 \\
\hline Establishment of British East India Company & 1600 \\
\hline $\begin{array}{l}\text { Expansion of British Rule Through Establishment of Major British East India } \\
\text { Company Trading Posts at Surat in Gujarat in 1612, Madras (now Chennai) in } \\
1640 \text {, Bengal in } 1651 \text { and Bombay (Mumbai) in 1668. } \\
\text { These posts provided the foundation for establishing British colonial rule through } \\
\text { the British East India Company in many parts of India over a period covering } \\
\text { nearly } 250 \text { years up to Direct Rule in } 1857 \text { (see below) }\end{array}$ & $\begin{array}{l}1610 \mathrm{~s} \text { to } \\
1660 \mathrm{~s}\end{array}$ \\
\hline $\begin{array}{l}\text { Expanding Role of Dutch East India Company in Intra-Asian Trade - from Persia } \\
\text { through India and Indonesia ending in China and Japan }\end{array}$ & $1600 \mathrm{~s}$ \\
\hline Establishment of French Trading Post at Pondicherry & 1672 \\
\hline $\begin{array}{l}\text { Start of the Industrial Revolution in Britain - and the Beginning of the End of the } \\
\text { Mughal Empire in India }\end{array}$ & About 1750 \\
\hline $\begin{array}{l}\text { Battle of Plassey Establishes British Rule in Bengal largely through governance by } \\
\text { the British East India Company up to } 1857\end{array}$ & 1757 \\
\hline British Extend Power in Southern, Western, and Central India & $1790 \mathrm{~s}-1820 \mathrm{~s}$ \\
\hline $\begin{array}{l}\text { Elimination by the British Parliament of the India Trade Monopoly of the British } \\
\text { East India Company - which greatly facilitated growth in British owned managing } \\
\text { agency houses and other private merchants and "free traders" }\end{array}$ & 1813 \\
\hline $\begin{array}{l}\text { Initial Establishment of Mainly British Owned (and Some Indian) Companies That } \\
\text { Led to the Managing Agency System - which in turn were taken over by Indian } \\
\text { business interests after } 1947 \text { and thus added to the number and scale of Indian } \\
\text { business groups }\end{array}$ & $\begin{array}{l}1840 \mathrm{~s} \text { and } \\
1850 \mathrm{~s}\end{array}$ \\
\hline $\begin{array}{l}\text { Indian Mutiny, Dissolution of the British East India Company, and Rule of India } \\
\text { Directly from London }\end{array}$ & 1856-1858 \\
\hline
\end{tabular}




\begin{tabular}{|c|c|}
\hline Development and/or Event & $\begin{array}{l}\text { Time } \\
\text { Period or } \\
\text { Year }\end{array}$ \\
\hline Establishment of Indian National Congress & 1885 \\
\hline $\begin{array}{l}\text { Founding of the Muslim League - which later was the major political player in the } \\
\text { partition of } 1947\end{array}$ & 1906 \\
\hline $\begin{array}{l}\text { First World War - which led to significant expansion in Indian owned industry and } \\
\text { the Indian business class }\end{array}$ & 1914-1918 \\
\hline $\begin{array}{l}\text { Formation of the Federation of Indian Chambers of Commerce and Industry } \\
\text { (FICCI) - first major trade and industry association to lobby for Indian business } \\
\text { interests }\end{array}$ & 1927 \\
\hline $\begin{array}{l}\text { Government of India Act - Some local self-government but British power } \\
\text { remained largely in tact }\end{array}$ & 1935 \\
\hline $\begin{array}{l}\text { Second World War - which seriously weakened the British Empire and especially } \\
\text { the British colonial regime in India, and further increased Indian nationalism and } \\
\text { demands for the British to "Quit India" }\end{array}$ & $1939-45$ \\
\hline $\begin{array}{l}\text { Publication of the Bombay Plan - which outlined the objectives and wishes of the } \\
\text { Tata, Birla and other business groups and large industrialists regarding: rapid } \\
\text { industrialization, economic planning, a mixed economy with a large measure of } \\
\text { government control, considerable government ownership, limited government } \\
\text { regulation of sectors dominated by private industry where private enterprises } \\
\text { would be given a "free hand", and a strong central government in post-war and } \\
\text { post-independence India }\end{array}$ & 1944 \\
\hline $\begin{array}{l}\text { Industrial Policy Statement, which was the last significant economic measure of } \\
\text { the colonial government that transferred responsibility for most large-scale } \\
\text { industry from the provinces to the central government in Delhi - setting the stage } \\
\text { for nation-wide, highly centralized economic planning after independence }\end{array}$ & 1945 \\
\hline Independence and Partition into the Separate Nation-States of India and Pakistan & 1947 \\
\hline $\begin{array}{l}\text { Step-by-Step Establishment of Protectionist and Statist Industrial and Trade } \\
\text { Control Policy Regime based on Export Pessimism, Self-Sufficiency and } \\
\text { Significant Government Intervention - Appendix } 5 \text { for more detail }\end{array}$ & $1950 \mathrm{~s}-1970 \mathrm{~s}$ \\
\hline $\begin{array}{l}\text { India's Second Five-Year Plan, which emphasized import substitution, self- } \\
\text { sufficiency, and investments in state-owned companies, heavy industry, and } \\
\text { decentralized cottage industries - at the expense of export promotion, private } \\
\text { sector investment, and larger-scale consumer goods production }\end{array}$ & $1956-1961$ \\
\hline $\begin{array}{l}\text { Death of Jawaharlal Nehru, India's first and only Prime Minster from } 1947 \text { to } \\
\text { 1964. His death began the slow process during which the political hegemony of } \\
\text { India's Congress Party (INC) decreased and then disappeared, leaving in its place a } \\
\text { highly fragmented and much less predictable multi-party system at the both the } \\
\text { national and (regional) state levels. }\end{array}$ & 1964 \\
\hline $\begin{array}{l}\text { Declaration of the State of Emergency by the Indira Gandhi Government, Defeat } \\
\text { of that Government in 1977, and Re-election of the Indira Gandhi Government in } \\
\text { 1980. Result was a less certain and more contested, competitive and } \\
\text { heterogeneous political environment - leading to less economic policy certainty } \\
\text { and less certain protection and entitlements for large Indian firms and business } \\
\text { groups (private and state owned) }\end{array}$ & $1975-1980$ \\
\hline
\end{tabular}




\begin{tabular}{|l|l|}
\hline Development and/or Event & $\begin{array}{l}\text { Time } \\
\text { Period or } \\
\text { Year }\end{array}$ \\
\hline $\begin{array}{l}\text { First Steps in Pro-Business Domestic Liberalization - policy rhetoric in favor of } \\
\text { private business investment; leading to reduced constraints to entry and growth by } \\
\text { domestic firms on a selective ad-hoc basis, combined with continuing and even } \\
\text { higher protection and effective rates of protection in many Indian industries and } \\
\text { markets }\end{array}$ & $\begin{array}{l}\text { Early to Mid } \\
1980 \text { s }\end{array}$ \\
\hline $\begin{array}{l}\text { Serious Balance of Payments Crisis leading to More Fundamental and Accelerated } \\
\text { Pro-Market Industrial and Trade Policy Reforms. Reforms were led by Manmohan } \\
\text { Singh, the Finance Minister of the Congress Party government, who is currently } \\
\text { (as of December 2008) India's Prime Minister, Reform process is gradual and } \\
\text { incomplete and continues to the present day. }\end{array}$ & present day \\
\hline $\begin{array}{l}\text { Establishment of the Confederation of Indian Industry (CII) - which focused more } \\
\text { on sunrise than sunset industries and thus on balance was more open to domestic } \\
\text { and external liberalization compared with the traditional industry associations }\end{array}$ & 1992 \\
\hline $\begin{array}{l}\text { Threat of Nuclear War with Pakistan Averted through International Mediation. } \\
\text { Hindu and Muslim Troubles in Gujarat }\end{array}$ & 2002 \\
\hline $\begin{array}{l}\text { Closer Inter-Governmental, Nuclear and Trade Relations between India and the } \\
\text { United States, Quite Significant Improvements in Political and Trade Relations } \\
\text { with China, and Some, but Limited and Hesitant, Improvements in Relations with } \\
\text { Pakistan }\end{array}$ & $2004-2007$ \\
\hline
\end{tabular}


Appendix 7: Comparing The Gross Revenues of Major Business Groups With India's Gross National Income (GNI) for 2005

\begin{tabular}{|l|c|c|}
\hline Selected Business Groups & $\begin{array}{c}\text { 2005 Estimated } \\
\text { Gross } \\
\text { Revenues \$US } \\
\text { Billion }\end{array}$ & $\begin{array}{c}\text { Business } \\
\text { Group } \\
\text { Revenues as \% } \\
\text { of India's GNI }\end{array}$ \\
\hline Reliance Groups & 27.0 & 3.4 \\
\hline Birla Groups & 24.0 & 3.0 \\
\hline Tata Group & 21.9 & 2.8 \\
\hline Sub-Total: Top Three Groups & $\mathbf{7 2 . 9}$ & $\mathbf{9 . 2}$ \\
\hline Modi Group & 11.0 & 1.4 \\
\hline Mahindra \& Mahindra & 4.5 & 0.6 \\
\hline Essar Group & 4.0 & 0.5 \\
\hline Larsen and Toubro & 3.2 & 0.4 \\
\hline Dalmia Group & 3.0 & 0.4 \\
\hline Hindustan Lever & 2.6 & 0.3 \\
\hline Maruti Suzuki & 2.5 & 0.3 \\
\hline Sub-Total: Top Ten Groups & $\mathbf{1 0 3 . 7}$ & $\mathbf{1 3 . 1}$ \\
\hline WIPRO & 2.4 & 0.3 \\
\hline Goenka Groups & 2.3 & 0.3 \\
\hline Infosys & 2.2 & 0.3 \\
\hline Hero Cycle Group & 2.2 & 0.3 \\
\hline TVS Group & 2.2 plus & 0.3 \\
\hline Bajaj Industries (partial estimate) & 2.0 plus & 0.3 \\
\hline Thapar Groups (partial estimate) & 2.0 & 0.3 \\
\hline Murugappa Group & 2.0 & 0.3 \\
\hline TVS Group (partial estimate) & 2.0 & 0.3 \\
\hline Singhania Groups (partial estimate) & Up to 2.0 & 0.3 \\
\hline Kirloskar Group including JV with Toyota & Up to 2.0 & 0.3 \\
\hline Godrej Group & 1.3 & 0.2 \\
\hline Ranbaxy Group & 1.2 & 0.2 \\
\hline SPIC-MAC & 1.0 plus & 0.2 \\
\hline Escorts & Up to 1.0 & 0.2 \\
\hline Lalbhai Group & 0.5 & 0.1 \\
\hline Dr. Reddy's Laboratories & 0.5 & 0.1 \\
\hline Khaitan Group & 0.3 & -- \\
\hline Sub-Total of Above Groups (Partial Estimate & $\mathbf{1 3 2 . 8}$ & $\mathbf{1 6 . 7}$ \\
\hline Only) & $\mathbf{7 9 3 . 0}$ & $\mathbf{1 0 0 , 0}$ \\
\hline India's GNI \$US B ${ }^{347}$ & $\mathbf{6 3 4 . 0}$ & -- \\
\hline India's Non-Agricultural GNI \$US B & $\mathbf{4 8 8 . 0}$ & -- \\
\hline India's Non-Agricultural GNI in the Formal & \\
\hline Economy \$US B & \\
\hline & & \\
\hline & & \\
\hline
\end{tabular}

${ }^{347}$ From the World Bank's World Development Report 2007, Table 1, p. 288. 
Sources for Business Group Revenues and other information collected by the author on individual business groups: HR Folks International (2004), Dorin (2003), Tripathi (2004, in particular Appendix II of that book), Ghoshal et al (2001), Piramal (1996, particularly the Appendix), UN Volunteers et al, 2004, Das 2002, Ghemawat and Khanna (1998), Khanna and Palepu (1997, 2004:1, 2004:2 and 2004:3), Swaminathan (1992), Taknet 1986, Timberg (1969), and the various other Tripathi references in the bibliography. Plus the websites of the business groups, from Wikepedia, other material on the Internet and newspaper articles - including the list of Indian companies provided by Answers.com.

${ }^{348}$ Agricultural GDP/GNI is about $18 \%$ of total GDP, and the informal economy constitutes about $23 \%$ of total GDP. Therefore, the three largest business groups account for about $11 \%$ of India's GNI and $15 \%$ of non-agricultural GNI in the formal economy. For all of the business groups in the table, the percentages are $21 \%$ of non-agricultural GNI and about $27 \%$ of non-agricultural GNI in the formal economy. 


\section{Appendix 8: Analysis of Selected MRTPA Cases and Their Possible Impacts On Corporate Structure, Behaviour and Attitudes}

\section{1: MRTPA Cases Adjudicated by the Indian Supreme Court}

One source of evidence on the limited enforcement of and interest in the MRTPA is that, during its first two decades, very few MRTPA cases - seven in total -- came before India's Supreme Court (Rampilla 1989). Three of these cases concerned the concept of a business undertaking; three were concerned with restrictive trade practices, namely, territorial restrictions, price fixing and the per se rule versus the rule of reason; and one addressed the applicability of the principles of natural justice (Rampilla 1989, p. 667).

While the Indian Supreme Court was sceptical about applying American antitrust decisions, U.S. decisions that used the rule of reason received the approval of the Court, indicating that the Indian Supreme Court did not favor the per se rule in the Indian context. Rampilla (1989) concluded on p. 682 that the "wholesale incorporation of foreign mechanisms cannot work without due regard to the local circumstances. The mixed economy of India has special problems when compared to the private entrepreneurial system of the United States."

\subsection{Influence of MR'TPA Case Law on Corporate Structure and Behaviour}

The competition law literature from 1969-1991 as well as the author's review of a quite large number of MRTPA cases from the 1980s and 1990s indicated major variation in how the MRTPA was applied to vertical restraints and other restrictive trade practices.

The review of cases from 1985 to 1990 conducted by the author indicated that, even before the 1991 MRTPA amendments which seriously weakened the Act, the cases largely addressed restrictive trade practices (RTPs), such as territorial restrictions, retail price maintenance, and other vertical restraints, and unfair trade practices (UTPs) which largely involve consumer protection. There were as well a few collusive tendering/bid rigging cases, and a few cases on MRTPA "monopoly company" expansions. In contrast, there were no cartel cases involving non-government consumers, no mergers and no true monopoly investigations in the cases reviewed in the literature and case documentation.

Therefore, few cases directly addressed industrial concentration, monopolization, mergers to monopoly, and abuses of market power. Most cases appear to be quite trivial from a competition perspective -- essentially resolving contract disputes or providing another mechanism for government to achieve non-competition goals. However, some cases in the 1970s were more substantive and dealt with serious competition issues.

More specifically, the literature and other sources describe a few 1970s cases that were well investigated and analyzed and that involved monopolistic business practices, what we would now call abuses of dominant position. The literature and case review indicated as well that the quality of the competition analysis and Commission decisions 
varied depending on the MRTPC members on the panel and whether the defendant contested the case based on competition arguments.

One example of a contested case in the 1980s that provided good case law under the pre-1991 MRTPA was the August 1987 case against Hindustan Lever ${ }^{349}$. The company was charged under the RTP provisions with using its market dominance to conduct illegal tied selling -- whereby its retail customers were forced to accept slow-moving products if they wished to purchase the products for which demand was growing. Hindustan Lever threatened to refuse to sell, and actually refused to sell, to the retailers that would not accept the tied purchase of the slower moving product. Hindustan Lever was found guilty based on considerations of market power (the Hindustan Lever market shares varied between $21 \%$ and $70 \%$ in the affected product markets), business strategy and conduct (e.g. the threatened and actual refusal to supply), and negative competition effects.

The competition analysis particularly stressed the ability of Hindustan Lever to use tied selling to extend market power, where the company had a high market share, into a second market, where its market share was lower, its competitors were stronger, the company was less price competitive, and market demand was growing more slowly. The Commission argued that Hindustan Lever had the right to rationalize its retail sales network and selects its customers and to refuse to deal with other customers based on normal business considerations such as integrity and credit worthiness. However, these decisions and strategies should not be misused for purposes of manipulating and restricting competition in order to abuse and extend its market power into additional (currently competitive) markets. The good competition analysis and case law were developed in part because the defendant (unsuccessfully) contested the allegations.

A second and similar case where good competition analysis based on abuse of dominance and refusal to deal concepts were applied successfully by the Commission was the RTP case against Tata Iron and Steel Company Ltd. and M/S Indian Tube Company of 1984. These two companies were found by the MRTPC to be essentially abusing their dominant position through forcing wholesalers to purchase larger quantities of their products than previously agreed to and than were warranted by current demand. The distribution agreements of dealers who refused to accept these greater quantities were terminated. The competition analysis focused on the very strong monopolistic market positions of the two manufacturers.

Similar to the first case reviewed above, the Commission determined that manufacturers had the right to select their wholesalers based on commercial factors (creditworthiness, integrity etc.), but not in a manner that restricted competition or perpetuated a restrictive trade practice (RTP). The Commission in this case also decided that discounts for quantity purchases above agreed amounts were not an RTP (and therefore that. this practice did not involve price discrimination). As an aside, this is one

\footnotetext{
${ }^{349}$ Before the MRTPC Commission: Director General Of Investigation and Registration v. Hindustan Lever Limited; G.R. Luthra (Chairperson) and S.D. Manchanda (Member), August 4, 1987.
} 
of the few cases where the names of one of the larger business groups appeared as a respondent/defendant in the more than forty cases reviewed in some detail by the author. The two other major cases where a business group was the respondent involved Mahindra \& Mahindra and a smaller business group called Excel. Considering the major role played by the business groups in India's private economy over the four decade period of this analysis, this small proportion would appear to be both surprising and significant (see the main text).

A third RTP case involving United Brewing found in favour of the defendant, as the Commission argued that a trade mark holder had the right to place reasonable restrictions on franchise holders to protect the quality of their products and their investments in and the competitive strength of their trade mark. These restrictions are in the public interest and therefore are justified. This contested case, which rescinded an earlier MRTPC order against the defendant, provided good competition analysis and case law on the interactions between competition law and intellectual property rights.

As a final example of a contested case creating good case law, one of the better MRTPA cases reviewed by the author, the caustic soda case, involved one of the relatively few cartels that was successfully investigated and adjudicated under the MRTP Act. The case involved an industry association that attempted to extend the life of a government price control regime through establishing a private price control regime or cartel through directives, "helpful advice" and signalling to its members regarding the "appropriate" price.

This private cartel functioned for over a decade after the commodity had been removed from the list of items under formal government price control in 1963. Old habits learned under a government price control regime are hard to change (consistent with institutional continuity and path dependence); and obviously the association members wanted the private benefits of higher and more stable prices and profits, provided previously by a government imposed price cartel, to continue after government price control had been removed. The MRTPA, using modern competition law analysis, made strong arguments regarding why this was a cartel under the MRTPA that had to be eliminated in order to promote competition and the public interest ${ }^{350}$.

However, as noted above and in the main text, these contested cases that provided good competition case law were few and far between. The review as well indicated a few cases where the MRTPA was used by competitors to prevent entry, greater competition and greater supplier and product choice in the market. One case under the pre-1991 law, that involved a "monopolistic undertaking" as the complainant, was approved by the Central Government on the recommendation of the MRTPC, but was then appealed to the Supreme Court by an association of smaller competitors. The appeal was not successful but took 2.5 years and therefore competitors successfully used the courts and the MRTPA to stop entry of the successful applicant for that time period. Use of the MRTPA to deter

\footnotetext{
${ }^{350}$ Before the MRTP Commission: Registrar of Restrictive Trade Practices v. M/S Alkali Manufacturers Association of India, $29^{\text {th }}$ March, 1985.
} 
entry - probably even threats to go to the Commission and then the Supreme Court -could easily discourage some potential entrants with more limited financial resources.

\subsection{Government Use of the MRTPA to Achieve Non-Competition Policy Goals}

As noted in the main text, there were as well a fairly large number of cases where the government and bureaucracy tried to use/misuse the MRTPA to achieve other economic and political goals not related to competition and market power. The following provides five examples of government misuse of the MRTPA to achieve non-competition goals. Under the MRTPA, the Government was not bound to send a potentially anticompetitive merger to the MRTPC for review nor was it bound to accept the MRTPC's recommendation.

For example, in the mid-1980s, the government filed a merger case with the MRTPC for the purpose of breaking up the Indian Express group of newspapers and related businesses (Agarwal 2006, pp. 75-76, Wariavwalla 1988). Critics argue that this case (and other cases against newspaper undertakings) threatened freedom of the press and that politics not economics was the motive. Therefore, the Indian Express case was dropped when the government changed. This was one of the few major merger/divestiture cases under the MRTPA (see Chapter 6 of the main text).

In a 1987 case, the RTP provisions were used to try to prevent a company from "overcharging customers" during a period of short supply. The case review had no discussion of the state of competition in the industry at that time. This appears to be an attempt by the government of the day to reintroduce price controls through the "back door" of the MRTPA.

In a similar vein, there was another RTP case under the MRTPA, called the ethanol $\operatorname{case}^{351}$, when the MRTPC prevented a company from raising its prices even though their industrial customers were prepared to accept these price increases in order to ensure reliable supply of a high quality product. The MRTPC found against the company by arguing that the company was using its dominant position to coerce its customers into accepting a higher price.

Another case involved a 1985 decision by the Delhi High Court ${ }^{352}$. When a textile company attempted to register a dominant undertaking, the government attempted to use the dominant undertaking section of the MRTPA to force the company to sell its shares to the public, rather than continue the "monopoly holding" of shares by a few shareholders in the closely held company. The government's arguments therefore focused on fairness to shareholders - allowing more shareholders to enjoy the high profits from a dominant undertaking -- rather than the competition effects. The original reference and MRTPC

${ }^{351}$ Before the MRTP Commission: Director-General of Investigation and Registration v. All Gujarat Distillery Association and Others; G.V. Luthra (chairman) and S. D. Manchanda (Member), July 201988.

${ }^{352}$ In the Delhi High Court: Jiyajeerao Cotton Mills and others v. Deputy Secretary to the Government of India, Ministry of Law, Justice and Company Affairs and Others; Dalip K. Kapar and J.D. Jain Judges., August 9, 1985. 
decision was made in 1974, and the company and others challenged the original order under the MRTPA for eleven years, as the final judgment in favour of the company was not made until 1985.

At that time, the Court concluded (somewhat obviously) that a dominant undertaking under section 27 of the MRTPA had to be based on dominance in a product market, not monopolization of a company's shares by a small group of shareholders. The latter is not a legitimate concern of a competition law, the MRTPA. The final decision was the correct one, but the government's case resulted in a delay of 11 years and high legal and other transactions costs for the textiles company. This provides yet another example of the misuse of the MRTPA to achieve the non-competition objectives of government and places into doubt the independence of the MRTPC from the Ministry and overall government.

A 1984 case regarding Bengal Saws and Steel Products ${ }^{353}$ concerned the use of the MRTPA as an extension of the government's licensing regime, to prevent a company to diversify or to use their licensed capacity to produce a higher value and therefore more profitable product. In this case, the government's arguments against the proposal were largely legalistic and used competition arguments in a selective manner. For example, the government used dominant undertaking arguments because the new product was a close substitute with the company's previous product and those of competitors. However, the government then stated that the company's proposed new products and its previous products were separate products and therefore a new license under the licensing regime was needed.

More recently, the Indian regional states have been using the MRTPA in their disputes with Monsanto regarding the royalties on Bt cotton, arguing that Monsanto has a monopoly on the technology - which of course is true because of the Monsanto patent. In 2006, the MRTPC determined that the Government of India should fix a lower technology fee in line with the technology fee in China. While this MRTPC determination has been praised by some farmers' groups and NGOs (see e.g. GMWatch, 2006), it is questionable if the MRTPA has the remedies and other instruments needed to enforce such a judgment. This dispute is likely better addressed under patent law, agricultural policies, or through direct government intervention to establish the technology fee (similar to the price controls of the past). It is questionable whether the credibility of competition law is enhanced when the competition agency makes determinations that cannot be enforced and the problem remedied by the competition statute. Such issues are better addressed through competition policy advocacy by the agency working with its partners in government.

In a 1999 case, the Indian complainant attempted to obtain relief from alleged predatory pricing by an Indonesian company before the MRTPC after he failed to obtain

\footnotetext{
${ }^{353}$ In the Delhi High Court: Bengal Saws and Steel Products and Another v. Union of India R.N. Aggarwal Judge, November 15, 1984.
} 
relief under India's anti-dumping laws ${ }^{354}$. The Commission was divided in its judgment. The Chairman thought that the complainant made good arguments for predatory pricing. However, the other member believed that predatory pricing was not proved because the cost of production had not been determined, particularly given the recent devaluation of the Indian Rupee, and no evidence was presented that the Indonesian company had a strategy to eliminate competition. In fact, the sales of the Indian producers/complainant were increasing at that time.

This case, which ultimately was appealed to the Supreme Court, is a good example of "regulatory forum shopping" that will likely occur from time to time under the new competition law, and also illustrates how competitors can use competition law to achieve corporate rather than competition objectives (Bhattacharjea 2003:1 and 2003:2).

354 Before the Monopolies and Restrictive Trade Practices Commission: All India Float Glass Manufacturers Association v. P.T. Mulla Industries, Jakarta Indonesia and Others; A.N. Divecha Chairman and Dr. S. Chakravarthy Member, January 18, 1999. 


\section{Appendix 9:}

Comparisons of the Two Case Study Periods and Competition Regimes

In Terms of the Strategic Accommodations, Responses

And Outcomes of India's Traditional Business Groups 


\begin{tabular}{|c|c|c|c|}
\hline $\begin{array}{l}\text { Key Indicators } \\
\text { for Traditional } \\
\text { Business Groups }\end{array}$ & $\begin{array}{l}\text { 1969-1991 "Anti- } \\
\text { Competitive" } \\
\text { Competition Regime }\end{array}$ & $\begin{array}{l}\text { Post-1991 Incomplete but on Balance Pro- } \\
\text { Competition Regime }\end{array}$ & Comments and Qualifications \\
\hline $\begin{array}{l}\text { Costs from } \\
\text { Transacting } \\
\text { with } \\
\text { Government }\end{array}$ & $\begin{array}{l}\text { Very high because of } \\
\text { licenses, other permits, } \\
\text { entitlements, and } \\
\text { protection, constant } \\
\text { meetings with politicians, } \\
\text { bureaucrats, license and } \\
\text { approval providers, and } \\
\text { inspectors more often } \\
\text { from national agencies } \\
\text { (requiring permanent } \\
\text { offices in New Delhi) but } \\
\text { also to some degree from } \\
\text { sub-national } \\
\text { governments. }\end{array}$ & $\begin{array}{l}\text { Lower than before 1991, but still important } \\
\text { particularly in transactions with regional } \\
\text { states and cities given government } \\
\text { decentralization since } 1991 \text { (Kochhar et al } \\
2006 \text { ). } \\
\text { Other considerations are: (i) the continuing } \\
\text { importance of the "inspection raj", (ii) } \\
\text { transactions for special subsidies and } \\
\text { protection such as anti-dumping relief, (iii) } \\
\text { transactions on environmental regulations, } \\
\text { land assembly and to request government to } \\
\text { flexibly apply labour and related regulations } \\
\text { to allow corporate restructuring and } \\
\text { downsizing, (iv) more entrepreneurial } \\
\text { transactions with government to create new } \\
\text { product markets such as for enterprise } \\
\text { development zones and improved retail and } \\
\text { telecom services in rural areas, and (v) } \\
\text { transactions related to corporate social } \\
\text { responsibility to further build the group and } \\
\text { family prestige, contacts and brand name. } \\
\text { The result is fewer transactions with } \\
\text { government but transactions with more } \\
\text { agencies and levels of government - meaning } \\
\text { the complexity and cost per transaction have } \\
\text { increased (fewer economies of scale and } \\
\text { scope from repeated interactions and building } \\
\text { reputational capital with the same agency and } \\
\text { officials). }\end{array}$ & $\begin{array}{l}\text { In light of political fragmentation since } 1978, \\
\text { decentralization, and greater competition for } \\
\text { entitlements from new companies and economic } \\
\text { sectors, benefits to business groups from these } \\
\text { transactions -- in terms of lower production costs, } \\
\text { higher prices and revenues, and relationships based on } \\
\text { trust that are of lasting value -- are now relatively } \\
\text { smaller and more uncertain/contingent on a per } \\
\text { transaction basis. Leading to lower, more contingent, } \\
\text { and less predictable benefit/cost ratios for transaction } \\
\text { related investments intended to build lasting } \\
\text { relationships with politicians, government agencies, } \\
\text { senior bureaucrats, inspectors, state-owned enterprises } \\
\text { etc. at all spatial scales. } \\
\text { One consequence of incomplete liberalization, } \\
\text { combined with governments that continue to be large } \\
\text { and influential, is that government imposed barriers to } \\
\text { entry and related transaction costs are typically lower } \\
\text { for many service industries than for manufacturers. } \\
\text { Manufacturers are constrained by: (i) government } \\
\text { labour policies that affect wages, working conditions, } \\
\text { corporate restructuring and exit, (ii) policy and } \\
\text { regulatory impacts on land markets and acquisition, } \\
\text { which increase the time and cost needed to assemble } \\
\text { the required land, and (iii) the time needed for a } \\
\text { manufacturer to receive environmental and other } \\
\text { approvals. The delays, transaction costs, and start-up } \\
\text { costs in establishing a business are much lower for a } \\
\text { service firm. Full registration can take time, but the } \\
\text { service business can still operate in the meantime. }\end{array}$ \\
\hline
\end{tabular}




\begin{tabular}{|c|c|c|c|}
\hline $\begin{array}{l}\text { Key Indicators } \\
\text { for Traditional } \\
\text { Business Groups } \\
\end{array}$ & $\begin{array}{l}\text { 1969-1991 "Anti- } \\
\text { Competitive" } \\
\text { Competition Regime }\end{array}$ & $\begin{array}{l}\text { Post-1991 Incomplete but on Balance Pro- } \\
\text { Competition Regime }\end{array}$ & Comments and Qualifications \\
\hline $\begin{array}{l}\text { Other } \\
\text { Transactions } \\
\text { Costs with } \\
\text { Other } \\
\text { Businesses and } \\
\text { Non- } \\
\text { Government } \\
\text { Economic } \\
\text { Agents }\end{array}$ & $\begin{array}{l}\text { Major investments in } \\
\text { transactions with } \\
\text { affiliated companies in } \\
\text { the same business group } \\
\text { in order to maintain } \\
\text { family solidarity and the } \\
\text { survival, overall } \\
\text { effectiveness and } \\
\text { profitability of the } \\
\text { business group. }\end{array}$ & $\begin{array}{l}\text { Transactions with affiliated companies remain } \\
\text { very important, but transaction investments } \\
\text { and relationship building are being extended } \\
\text { to some degree into unfamiliar territory - with } \\
\text { non-affiliated companies including foreign } \\
\text { firms, lower-cost smaller companies (in e.g. } \\
\text { the informal sector and the small firms } \\
\text { reservation sector), and companies affiliated } \\
\text { with other business groups, as well as with } \\
\text { universities, research and technical institutes } \\
\text { and other non-business groups. }\end{array}$ & $\begin{array}{l}\text { Building new relationships and maintaining these } \\
\text { relationships with unfamiliar partners require time, } \\
\text { effort, patience and money - and the benefits are far } \\
\text { from certain. In general, these relationships involve } \\
\text { higher transactions costs (e.g. because of more formal } \\
\text { contracts and governance systems with unfamiliar } \\
\text { partners), greater risk and uncertainty such as less } \\
\text { timely payment by unaffiliated and unfamiliar } \\
\text { customers, and lower and less predictable benefit/cost } \\
\text { ratios from the business groups' transaction related } \\
\text { investments. }\end{array}$ \\
\hline Labour Costs & $\begin{array}{l}\text { Generally low } \\
\text { particularly for low and } \\
\text { medium skilled labour - } \\
\text { but much higher in the } \\
\text { organized than } \\
\text { unorganized sector. } \\
\text { Combined result of (i) } \\
\text { abundant low wage, low } \\
\text { to medium skilled, } \\
\text { labour, (ii) use of low } \\
\text { technology and low } \\
\text { capital intensive } \\
\text { production methods, and } \\
\text { (iii) labour laws in the } \\
\text { formal sector - with the } \\
\text { result that the need and } \\
\text { incentive for within- } \\
\text { company and within- } \\
\text { group training were }\end{array}$ & $\begin{array}{l}\text { Low and medium skilled labour still relatively } \\
\text { abundant and low cost compared with many } \\
\text { country competitors, and labour laws that } \\
\text { raise the worker costs of organized sector are } \\
\text { still in place (although administration of and } \\
\text { compliance with these laws are weaker than in } \\
\text { the past). } \\
\text { However, highly skilled labour, technical and } \\
\text { professional workers - especially knowledge } \\
\text { workers with good English skills -- are now in } \\
\text { high demand and becoming higher cost. } \\
\text { Because production inputs are in many cases } \\
\text { complementary, these skill shortages could } \\
\text { discourage use of more technology intensive } \\
\text { production methods, and could result in the } \\
\text { adoption of more capital intensive labour } \\
\text { saving technologies, leading to reduced } \\
\text { demand for less skilled workers (despite the }\end{array}$ & $\begin{array}{l}\text { Corporate responses include greater use of within- } \\
\text { company and within-business group training } \\
\text { programs, and relocation to lower cost locations } \\
\text { within India and other developing countries. But } \\
\text { these trends are just beginning, and are uneven across } \\
\text { business groups. } \\
\text { Constraining factors include old labour laws that } \\
\text { impede restructuring and relocation, problems in } \\
\text { securing the necessary land needed for relocation, the } \\
\text { high costs of transacting with less developed and less } \\
\text { institutionally sophisticated Indian states, and } \\
\text { unfamiliarity with alternative locations in both India } \\
\text { and in particular foreign countries (with result that } \\
\text { risk averse business groups are often cautious in } \\
\text { relocating their production facilities). }\end{array}$ \\
\hline
\end{tabular}




\begin{tabular}{|c|c|c|c|}
\hline $\begin{array}{l}\text { Key Indicators } \\
\text { for Traditional } \\
\text { Business Groups }\end{array}$ & $\begin{array}{l}\text { 1969-1991 "Anti- } \\
\text { Competitive" } \\
\text { Competition Regime }\end{array}$ & $\begin{array}{l}\text { Post-1991 Incomplete but on Balance Pro- } \\
\text { Competition Regime }\end{array}$ & Comments and Qualifications \\
\hline & limited. & $\begin{array}{l}\text { abundance of low cost labour in the lower } \\
\text { skill categories). }\end{array}$ & \\
\hline $\begin{array}{l}\text { Capital } \\
\text { Investment }\end{array}$ & $\begin{array}{l}\text { Selecting less capital and } \\
\text { technology intensive } \\
\text { technologies and } \\
\text { production methods in } \\
\text { order to economize on } \\
\text { limited financial, } \\
\text { investment, technological } \\
\text { and professional } \\
\text { resources, and because } \\
\text { of: a preference for low } \\
\text { cost, low risk, quick } \\
\text { return investments } \\
\text { (merchant mentality); and } \\
\text { the } 25 \% \text { market share } \\
\text { limit rule and other } \\
\text { License Raj constraints to } \\
\text { expanding production and } \\
\text { revenues. }\end{array}$ & $\begin{array}{l}\text { New capital investment and capital upgrading } \\
\text { as part of corporate restructuring, focusing on } \\
\text { core capabilities, and moving production from } \\
\text { high cost locations in central cities to lower } \\
\text { cost locations in suburbs and smaller cities } \\
\text { Some indication that capital-output ratios, that } \\
\text { were very high before 1991, are now coming } \\
\text { down - indicating that scarce capital is now } \\
\text { being allocated and employed more efficiently } \\
\text { under liberalization (Debroy 2004). }\end{array}$ & $\begin{array}{l}\text { While } 25 \% \text { market share limit rule and other } \\
\text { government-imposed capacity, market and revenue } \\
\text { constraints are gone, extent of capital investment and } \\
\text { upgrading are still constrained to some degree by } \\
\text { business group preference for smaller scale firms and } \\
\text { plants, limited competition in many markets, risk- } \\
\text { averse corporate strategies, and need to allocate scarce } \\
\text { financial and senior management resources to } \\
\text { "alternative" investments. } \\
\text { These "alternatives" include investments in social } \\
\text { "good works" to increase family and company } \\
\text { prestige; and transactions and relationships with } \\
\text { Indian and now foreign governments, affiliated } \\
\text { companies and new relationships with unfamiliar } \\
\text { (domestic and foreign) non-affiliated companies and } \\
\text { other entities. }\end{array}$ \\
\hline $\begin{array}{l}\text { Cost and Use of } \\
\text { Technology }\end{array}$ & $\begin{array}{l}\text { Technology investments } \\
\text { and upgrading } \\
\text { discouraged by licensing } \\
\text { regime, lack of market } \\
\text { competition, and the } \\
\text { merchant mentality and } \\
\text { skills of many business } \\
\text { groups. Norm was to } \\
\text { purchase the cheapest } \\
\text { technology available }\end{array}$ & $\begin{array}{l}\text { Somewhat greater emphasis on technology } \\
\text { investment and upgrading -- with purchases } \\
\text { from and partnerships with a wider range of } \\
\text { foreign suppliers, partners and country } \\
\text { sources. } \\
\text { Some evidence as well that technology is now } \\
\text { being deployed more efficiently compared } \\
\text { with before } 1991 \text {. }\end{array}$ & $\begin{array}{l}\text { But still constrained to some degree by limited } \\
\text { competition in some domestic markets, and limited } \\
\text { R\&D and innovation capabilities/absorptive capacities } \\
\text { and interest in many business groups that often } \\
\text { continue to be risk averse and technology followers } \\
\text { rather than leaders. }\end{array}$ \\
\hline
\end{tabular}




\begin{tabular}{|c|c|c|c|}
\hline $\begin{array}{l}\text { Key Indicators } \\
\text { for Traditional } \\
\text { Business Groups }\end{array}$ & $\begin{array}{l}\text { 1969-1991 "Anti- } \\
\text { Competitive" } \\
\text { Competition Regime }\end{array}$ & $\begin{array}{l}\text { Post-1991 Incomplete but on Balance Pro- } \\
\text { Competition Regime }\end{array}$ & Comments and Qualifications \\
\hline & $\begin{array}{l}\text { from familiar sources } \\
\text { mainly the ex-colonial } \\
\text { power (Tripathi 2004). }\end{array}$ & & \\
\hline $\begin{array}{l}\text { Entrepreneurial } \\
\text { Resources, } \\
\text { Activity and } \\
\text { Expertise }\end{array}$ & $\begin{array}{l}\text { Directed mainly towards } \\
\text { politicians, bureaucrats, } \\
\text { and government } \\
\text { regulators in order to } \\
\text { change, flexibly apply, } \\
\text { and/or convince } \\
\text { government to ignore } \\
\text { rules in order to expand, } \\
\text { diversify and promote the } \\
\text { entrepreneurs' "market- } \\
\text { making" activity that } \\
\text { benefits the group or } \\
\text { company. One example } \\
\text { is the success of the } \\
\text { Reliance group in } \\
\text { lobbying government to } \\
\text { change the rules to allow } \\
\text { the domestic market for } \\
\text { synthetic textiles to } \\
\text { become established. }\end{array}$ & $\begin{array}{l}\text { More directed towards the traditional } \\
\text { economic, market and investment } \\
\text { factors/environment - identifying, collecting } \\
\text { privileged information on, responding to and } \\
\text { developing strategy to capitalize on changes } \\
\text { and "shocks" in demand, supply, labour } \\
\text { availability, interest rates, competitor } \\
\text { strategies, consumer tastes, technology, } \\
\text { innovation, adaptation, demography etc that } \\
\text { provide "market-making" opportunities } \\
\text { (Casson 2005). } \\
\text { But with some activity still directed towards } \\
\text { government agencies, regulations and rules } \\
\text { for e.g. anti-dumping relief; more flexible } \\
\text { application of labour, land, environmental and } \\
\text { other rules that constrain restructuring and } \\
\text { relocation; and working with governments to } \\
\text { create new markets through e.g. rural } \\
\text { investments and private investment and } \\
\text { management of special development zones. }\end{array}$ & $\begin{array}{l}\text { Because liberalization is incomplete, and government } \\
\text { at all spatial scales remains important and influential, } \\
\text { more entrepreneurship is still directed towards } \\
\text { government compared with OECD and many other } \\
\text { developing countries. } \\
\text { With decentralization and devolution, entrepreneurial } \\
\text { activity towards government now gives greater weight } \\
\text { to sub-national entities: Indian states and major urban } \\
\text { municipalities and regions (Sinha 2005). } \\
\text { Compared to pre-1991, Indian business entrepreneurs } \\
\text { are now more highly valued -- receiving "movie-star" } \\
\text { type status in business books, the financial media and } \\
\text { the popular press, particularly the English language } \\
\text { press. }\end{array}$ \\
\hline Revenues & $\begin{array}{l}\text { Once a firm and group } \\
\text { are well established in a } \\
\text { product market (have the } \\
\text { necessary licenses and } \\
\text { ongoing relationships } \\
\text { with key ministries, }\end{array}$ & $\begin{array}{l}\text { While government trade, industrial and } \\
\text { procurement policies and government } \\
\text { transactions (e.g. to receive anti-dumping } \\
\text { relief) are still important, strong, sustained } \\
\text { and expanding revenues are now much more } \\
\text { dependent on inter-firm rivalry in markets and }\end{array}$ & $\begin{array}{l}\text { Corporate strategies that favor non-price over price } \\
\text { competition (see below) will often raise competition } \\
\text { issues and could lead to complaints to the Competition } \\
\text { Commission of India (CCI) from competitors, } \\
\text { suppliers, customers and other allegedly injured } \\
\text { parties. }\end{array}$ \\
\hline
\end{tabular}




\begin{tabular}{|c|c|c|c|}
\hline $\begin{array}{l}\text { Key Indicators } \\
\text { for Traditional } \\
\text { Business Groups }\end{array}$ & $\begin{array}{l}\text { 1969-1991 "Anti- } \\
\text { Competitive" } \\
\text { Competition Regime }\end{array}$ & $\begin{array}{l}\text { Post-1991 Incomplete but on Balance Pro- } \\
\text { Competition Regime }\end{array}$ & Comments and Qualifications \\
\hline Revenues Cont. & $\begin{array}{l}\text { bureaucrats, politicians, } \\
\text { and financial } \\
\text { intermediaries) -- and } \\
\text { given favorable } \\
\text { macroeconomic } \\
\text { conditions -- revenues } \\
\text { can be fairly certain and } \\
\text { predictable. } \\
\text { Expectations of slow but } \\
\text { steady revenue growth } \\
\text { were the result of: (i) few } \\
\text { well-known competitors } \\
\text { with deep pockets, (ii) } \\
\text { little threat of entry by } \\
\text { new domestic and foreign } \\
\text { competitors and products } \\
\text { (little product } \\
\text { innovation), (iii) } \\
\text { predictable sales to } \\
\text { government and other } \\
\text { regular customers, and } \\
\text { (iv) constraints on } \\
\text { internal firm ("organic") } \\
\text { growth of both your firm } \\
\text { and competitor firms - } \\
\text { the result of the licensing } \\
\text { regime. }\end{array}$ & $\begin{array}{l}\text { corporate strategies to address the competition } \\
\text { e.g. (i) charge competitive prices (meet the } \\
\text { competition), (ii) supply higher quality } \\
\text { products, (iii) product differentiation, (iv) } \\
\text { building the brand/family name, (v) entering } \\
\text { new export and other markets, and (vi) } \\
\text { strategies to deter entry and reduce the } \\
\text { growth, revenues and profits of competing } \\
\text { incumbents. } \\
\text { Entry deterrence strategies can include e.g. } \\
\text { threats of price predation or foreclosure of } \\
\text { supply through vertical restraints or mergers } \\
\text { which can be credible because of the business } \\
\text { groups: (i) financial resources and preferred } \\
\text { access to external financing, (ii) good access } \\
\text { to both affiliated and unaffiliated company } \\
\text { suppliers, and (iii) participation in multiple } \\
\text { markets which allows groups to make credible } \\
\text { threats of price wars and predation and thus } \\
\text { benefit from supra-competitive profits in } \\
\text { various markets. } \\
\text { For these and other reasons, conglomerate } \\
\text { mergers, vertical mergers and restraints, and } \\
\text { price and non-price predation can raise more } \\
\text { competition issues in India than in OECD } \\
\text { competition law jurisdictions. }\end{array}$ & $\begin{array}{l}\text { This however leads to two conflicting tendencies. On } \\
\text { the one hand, complaining to government about } \\
\text { another company is not part of India's corporate } \\
\text { culture and thus occurs quite rarely among traditional } \\
\text { business groups and companies. Disputes are } \\
\text { normally adjudicated and resolved informally, using a } \\
\text { mix of economic and social penalties. Courts are used } \\
\text { much less often and avoided whenever possible. } \\
\text { On the other hand, there may also be the tendency to } \\
\text { use the CCI to adjudicate contract and other company } \\
\text { disputes that have little to do with competition (a } \\
\text { problem for the MRTPC). This tendency could be } \\
\text { stronger among newer unaffiliated companies. These } \\
\text { conflicting tendencies have the same result - to } \\
\text { decrease the credibility and effectiveness of the } \\
\text { competition law and regime. }\end{array}$ \\
\hline
\end{tabular}




\begin{tabular}{|c|c|c|c|}
\hline $\begin{array}{l}\text { Key Indicators } \\
\text { for Traditional } \\
\text { Business Groups } \\
\end{array}$ & $\begin{array}{l}\text { 1969-1991 "Anti- } \\
\text { Competitive" } \\
\text { Competition Regime }\end{array}$ & $\begin{array}{l}\text { Post-1991 Incomplete but on Balance Pro- } \\
\text { Competition Regime }\end{array}$ & Comments and Qualifications \\
\hline Prices & $\begin{array}{l}\text { Many prices are either } \\
\text { controlled directly } \\
\text { through government price } \\
\text { controls, or semi- } \\
\text { controlled by government } \\
\text { through informal } \\
\text { monitoring and potential } \\
\text { pressure. } \\
\text { Large price increases } \\
\text { perceived as unjustifiable } \\
\text { could attract unwanted } \\
\text { attention and make it } \\
\text { more difficult to obtain } \\
\text { the next license or other } \\
\text { perceived entitlement. } \\
\text { Still, given oligopoly } \\
\text { markets and little threat } \\
\text { of entry, it was } \\
\text { comparatively easy for } \\
\text { business groups and other } \\
\text { larger companies through } \\
\text { time to pass on the high } \\
\text { costs of transacting with } \\
\text { governments and other } \\
\text { transactions and } \\
\text { production costs to their } \\
\text { industrial customers and } \\
\text { final consumers. }\end{array}$ & $\begin{array}{l}\text { Prices now largely established by: (i) the } \\
\text { market, (ii) market structure -- relatively } \\
\text { competitive, oligopoly or monopoly; (iii) } \\
\text { position of company within the market (price } \\
\text { leader or follower), and (iv) corporate } \\
\text { strategies of incumbents and entrants to } \\
\text { maximize monopoly and oligopoly rents, } \\
\text { prevent entry or the growth of incumbents, } \\
\text { meet the competition etc. (using prices as a } \\
\text { strategic competitive tool). } \\
\text { While oligopoly, market power, and barriers } \\
\text { to entry are still important in many Indian } \\
\text { markets, the threat of committed or "hit-and- } \\
\text { run" entry now disciplines prices more than } \\
\text { the threat of government price regulation. } \\
\text { In short, markets are now more contestable } \\
\text { than prior to } 1991, \text { but still much less } \\
\text { contestable than in the OECD countries and } \\
\text { many other developing and transition } \\
\text { economies - the result of incomplete } \\
\text { liberalization and no effective competition } \\
\text { law since } 1991 \text {. }\end{array}$ & $\begin{array}{l}\text { However, some moderation in setting and constantly } \\
\text { changing prices could still be required given the } \\
\text { information and other transactions costs of price } \\
\text { changes and the continuing importance of government } \\
\text { and anti-business media, political parties, civil society } \\
\text { groups, and other "elites" which can use "moral } \\
\text { suasion" to pressure high profile business groups to } \\
\text { moderate their proposed price increases. . } \\
\text { These considerations, the merchant mentality which } \\
\text { favors risk aversion, plus habit, custom and path } \\
\text { dependence likely mean greater emphasis on non- } \\
\text { price competition } \\
\text { Including continuing competition for the remaining } \\
\text { government subsidies and other entitlements that } \\
\text { increasingly are at the sub-national level. }\end{array}$ \\
\hline
\end{tabular}




\begin{tabular}{|c|c|c|c|}
\hline $\begin{array}{l}\text { Key Indicators } \\
\text { for Traditional } \\
\text { Business Groups }\end{array}$ & $\begin{array}{l}\text { 1969-1991 "Anti- } \\
\text { Competitive" } \\
\text { Competition Regime }\end{array}$ & $\begin{array}{l}\text { Post-1991 Incomplete but on Balance Pro- } \\
\text { Competition Regime }\end{array}$ & Comments and Qualifications \\
\hline Product Quality & $\begin{array}{l}\text { Little incentive to } \\
\text { improve product quality, } \\
\text { the result of: no foreign } \\
\text { competition, little threat } \\
\text { of entry, quantity } \\
\text { produced and sold } \\
\text { established by the license } \\
\text { and the } 25 \% \text { limit rule, } \\
\text { and the limited } \\
\text { purchasing power of most } \\
\text { urban consumers and } \\
\text { nearly all rural } \\
\text { consumers.. } \\
\text { Higher quality could not } \\
\text { result in greater } \\
\text { production (and at times } \\
\text { not even a higher price } \\
\text { because of low consumer } \\
\text { incomes and government } \\
\text { scrutiny). } \\
\text { India was a scarcity } \\
\text { economy where business } \\
\text { groups could sell all they } \\
\text { produced within their } \\
\text { capacity license. }\end{array}$ & $\begin{array}{l}\text { Much greater emphasis on product quality and } \\
\text { quality improvement in order to meet foreign } \\
\text { competition, increase market share in key } \\
\text { markets especially markets that serve the } \\
\text { rapidly expanding urban "consuming class", } \\
\text { and discourage entry into traditional core } \\
\text { markets. } \\
\text { Expanding and increasingly prosperous } \\
\text { consuming class is placing greater weight on } \\
\text { product quality and on well known Indian and } \\
\text { foreign brand names in making their } \\
\text { purchases. }\end{array}$ & $\begin{array}{l}\text { Strategies based on product quality and meeting } \\
\text { customer needs are new to many business groups. } \\
\text { But are growing in importance and effectiveness given } \\
\text { the emergence of a rapidly expanding } \\
\text { middle/consuming class in India and actual or the } \\
\text { threat of entry by experienced highly competitive } \\
\text { MNCs. }\end{array}$ \\
\hline Group Profits & $\begin{array}{l}\text { High and quite stable, } \\
\text { especially for larger and } \\
\text { more diversified business }\end{array}$ & $\begin{array}{l}\text { Probably still quite high, especially for } \\
\text { companies and groups competing in familiar } \\
\text { domestic markets with good distribution }\end{array}$ & $\begin{array}{l}\text { Greater profit variability and uncertainty at least for a } \\
\text { while, until the new entrants become well established } \\
\text { - which likely will then allow profits to return to a }\end{array}$ \\
\hline
\end{tabular}




\begin{tabular}{|c|c|c|c|}
\hline $\begin{array}{l}\text { Key Indicators } \\
\text { for Traditional } \\
\text { Business Groups }\end{array}$ & $\begin{array}{l}\text { 1969-1991 "Anti- } \\
\text { Competitive" } \\
\text { Competition Regime }\end{array}$ & $\begin{array}{l}\text { Post-1991 Incomplete but on Balance Pro- } \\
\text { Competition Regime }\end{array}$ & Comments and Qualifications \\
\hline $\begin{array}{l}\text { Group Profits } \\
\text { Cont. }\end{array}$ & $\begin{array}{l}\text { groups. This is the } \\
\text { expected result when: (i) } \\
\text { companies supply to } \\
\text { stable oligopoly markets } \\
\text { often with } 4 \text { or fewer } \\
\text { important suppliers firms } \\
\text { under the } 25 \% \text { rule; and } \\
\text { (ii) companies affiliated } \\
\text { with the larger business } \\
\text { groups are price leaders; } \\
\text { and (iii) other business } \\
\text { groups focus on other } \\
\text { industries and markets } \\
\text { under the tacit economy- } \\
\text { wide market-sharing } \\
\text { agreement. }\end{array}$ & $\begin{array}{l}\text { systems and limited foreign competition, } \\
\text { where their brand/family names are well } \\
\text { known. } \\
\text { But entry and threat of entry will make profits } \\
\text { more variable and less certain on a year-to- } \\
\text { year basis - which would place affiliated } \\
\text { company managers under greater pressure to } \\
\text { maintain and increase profits to maintain and } \\
\text { add to shareholder value and keep } \\
\text { minority/non-family shareholders happy (in } \\
\text { order to discourage hostile takeovers) }\end{array}$ & $\begin{array}{l}\text { more stable pattern. } \\
\text { Especially if the new entrants also prefer (i) non-price } \\
\text { competition, which is likely to be the case, and (ii) the } \\
\text { tacit economy-wide market sharing agreements. } \\
\text { Indian markets will rarely approach the perfect } \\
\text { competition ideal type of conventional economic } \\
\text { theory - or the "contestable market" ideal type of the } \\
\text { new IO theory (Baumol 1982). }\end{array}$ \\
\hline $\begin{array}{l}\text { Economies of } \\
\text { Scale and Scope }\end{array}$ & $\begin{array}{l}\text { Discouraged by the } \\
\text { licensing regime that } \\
\text { essentially prohibited } \\
\text { large firm size through } \\
\text { internal/organic firm } \\
\text { growth. } \\
\text { Limited competition also } \\
\text { leads to less pressure to } \\
\text { lower costs. Family } \\
\text { structure of business } \\
\text { groups and their affiliated } \\
\text { companies placed further } \\
\text { constraints on firm size. }\end{array}$ & $\begin{array}{l}\text { Government imposed capacity and size } \\
\text { constraints on business groups have been } \\
\text { removed, and entry and competition are } \\
\text { greater in many markets. The result is greater } \\
\text { pressure on managers to lower costs through } \\
\text { increasing production, realizing economies of } \\
\text { scale and scope, mergers and acquisitions, and } \\
\text { divesting less profitable assets. } \\
\text { Much stronger economic growth rates, } \\
\text { particularly during the current decade, also } \\
\text { allow greater scope for capacity expansions } \\
\text { by affiliated companies. }\end{array}$ & $\begin{array}{l}\text { But family basis of most business groups is still } \\
\text { important, meaning that scale and scope economies } \\
\text { are being pursued within the constraints provided by } \\
\text { the slowly changing family business group structure } \\
\text { and corporate culture (Redding } 1993 \text { and 1995). } \\
\text { This means greater emphasis on inorganic growth - } \\
\text { mergers and acquisitions - and purchasing from } \\
\text { smaller suppliers in the same product line when } \\
\text { demand increases faster than expected. }\end{array}$ \\
\hline
\end{tabular}




\begin{tabular}{|c|c|c|c|}
\hline $\begin{array}{l}\text { Key Indicators } \\
\text { for Traditional } \\
\text { Business Groups }\end{array}$ & $\begin{array}{l}\text { 1969-1991 "Anti- } \\
\text { Competitive" } \\
\text { Competition Regime }\end{array}$ & $\begin{array}{l}\text { Post-1991 Incomplete but on Balance Pro- } \\
\text { Competition Regime }\end{array}$ & Comments and Qualifications \\
\hline $\begin{array}{l}\text { Extent of } \\
\text { Product } \\
\text { Diversification } \\
\text { within the } \\
\text { Group }\end{array}$ & $\begin{array}{l}\text { Extensive and too much } \\
\text { diversification (often into } \\
\text { unrelated product lines) } \\
\text { was an important } \\
\text { business group response } \\
\text { to the pre-1991 } \\
\text { competition regime. } \\
\text { This was dictated by the } \\
\text { need to ensure adequate } \\
\text { business group growth } \\
\text { and family income and } \\
\text { wealth within the } \\
\text { constraints imposed by: } \\
\text { (i) the } 25 \% \text { market share } \\
\text { limit rule and other } \\
\text { aspects of the licensing } \\
\text { regime (including the } \\
\text { MRTPA), (ii) small and } \\
\text { fragmented domestic } \\
\text { markets, (iii) export } \\
\text { pessimism, and few } \\
\text { incentives to export, (iv) } \\
\text { risk averse investment } \\
\text { strategies, (v) limitations } \\
\text { of the family firm and } \\
\text { business group } \\
\text { governance structure, and } \\
\text { (vi) family cohesion and } \\
\text { solidarity including the } \\
\text { need to provide good }\end{array}$ & $\begin{array}{l}\text { Business group strategy statements in the } \\
\text { business media and on their websites } \\
\text { emphasize corporate restructuring, } \\
\text { downsizing and focusing on core capabilities } \\
\text { in line with the management philosophy of } \\
\text { western business advisors and business } \\
\text { strategy gurus - who emphasize the high } \\
\text { transaction and governance costs (and lower } \\
\text { shareholder value) of highly diversified } \\
\text { conglomerate type firms and business groups } \\
\text { that supply many products to many often } \\
\text { unrelated markets. } \\
\text { At the same time, there is strong evidence } \\
\text { from the business groups' websites, the media } \\
\text { and other reports that diversification still } \\
\text { holds considerable appeal to many Indian } \\
\text { business groups e.g. Tata's current emphasis } \\
\text { on steel and tea, two highly unrelated product } \\
\text { lines; and the expanding participation of many } \\
\text { business groups in information technology, } \\
\text { telecommunications and financial services. }\end{array}$ & $\begin{array}{l}\text { While some downsizing and restructuring may be } \\
\text { needed, economists and corporate strategists who have } \\
\text { focused on Asian business groups argue quite } \\
\text { persuasively that diversified business groups continue } \\
\text { to be a viable group strategy - particularly for the } \\
\text { larger groups. } \\
\text { This is because of the "institutional voids" that remain } \\
\text { in the Indian and other Asian economies and the } \\
\text { ability of business groups to use their capabilities and } \\
\text { resources to address, mitigate and benefit from these } \\
\text { voids (Madhok } 2002, \text { Khanna and Palepu } 1997 \text {, } \\
\text { Khanna and Palepu } 2000: 2 \text {, and Khanna et al 2005). } \\
\text { The result for many groups is restructuring to divest } \\
\text { less profitable companies and diversifying into the } \\
\text { new economy sectors, financial services, telecom etc. } \\
\text { where private business entry is now allowed and } \\
\text { encouraged and market growth rates and profits are } \\
\text { predicted to be much higher than in their traditional } \\
\text { products and markets. }\end{array}$ \\
\hline
\end{tabular}




\begin{tabular}{|c|c|c|c|}
\hline $\begin{array}{l}\text { Key Indicators } \\
\text { for Traditional } \\
\text { Business Groups }\end{array}$ & $\begin{array}{l}\text { 1969-1991 "Anti- } \\
\text { Competitive" } \\
\text { Competition Regime }\end{array}$ & $\begin{array}{l}\text { Post-1991 Incomplete but on Balance Pro- } \\
\text { Competition Regime }\end{array}$ & Comments and Qualifications \\
\hline & $\begin{array}{l}\text { management jobs to a } \\
\text { growing number of } \\
\text { relatives and loyal family } \\
\text { friends. }\end{array}$ & & \\
\hline $\begin{array}{l}\text { Market } \\
\text { Diversification } \\
\text { and Export } \\
\text { Orientation of } \\
\text { Business Groups }\end{array}$ & $\begin{array}{l}\text { Largely supplied to } \\
\text { highly profitable } \\
\text { domestic markets with } \\
\text { limited operations in } \\
\text { selected foreign markets } \\
\text { mainly through direct } \\
\text { investment not exports. } \\
\text { Approach based on } \\
\text { export pessimism which } \\
\text { contended that: (i) } \\
\text { exports provide limited } \\
\text { national economic } \\
\text { benefits; and (ii) in any } \\
\text { event Indian companies } \\
\text { could not compete head- } \\
\text { on with foreign producers } \\
\text { in their own markets. } \\
\text { Result was that India } \\
\text { received almost no } \\
\text { benefit from the rapid } \\
\text { growth in global trade } \\
\text { and FDI up to } 1991 \text {. }\end{array}$ & $\begin{array}{l}\text { Often still focused for the most part on } \\
\text { domestic markets based on the strategy of first } \\
\text { establishing strong positions in key domestic } \\
\text { markets before going global through exports } \\
\text { and direct investment. } \\
\text { Foreign operations are expanding but still } \\
\text { mainly through FDI, particularly mergers and } \\
\text { acquisitions, rather than through exports. } \\
\text { With result that business groups' participation } \\
\text { in foreign trade remains much lower than its } \\
\text { contribution to India's private business } \\
\text { economy. Therefore, learning-by-doing } \\
\text { benefits from exports are still limited. }\end{array}$ & $\begin{array}{l}\text { Export pessimism and prudence continues to some } \\
\text { degree among India's business groups, } \\
\text { Means that exposure of many key affiliate companies } \\
\text { of business groups to foreign competition is limited to } \\
\text { competing with imports and Indian-based foreign } \\
\text { producers in domestic markets, where the affiliated } \\
\text { companies still have many advantages. } \\
\text { Studies have shown that, compared with competing } \\
\text { against imports in your domestic market, directly } \\
\text { competing in foreign markets through exports } \\
\text { provides much greater benefits for company and } \\
\text { national competitiveness and for domestic market } \\
\text { competition. The same is probably true for exports } \\
\text { compared with direct investment in foreign markets. } \\
\text { This is because exports provide much more direct } \\
\text { intelligence and feedback to Indian producers, and } \\
\text { therefore greater potential to move up the value chain } \\
\text { (see Lucas 1993). }\end{array}$ \\
\hline
\end{tabular}




\begin{tabular}{|c|c|c|c|}
\hline $\begin{array}{l}\text { Key Indicators } \\
\text { for Traditional } \\
\text { Business Groups }\end{array}$ & $\begin{array}{l}\text { 1969-1991 "Anti- } \\
\text { Competitive" } \\
\text { Competition Regime }\end{array}$ & $\begin{array}{l}\text { Post-1991 Incomplete but on Balance Pro- } \\
\text { Competition Regime }\end{array}$ & Comments and Qualifications \\
\hline $\begin{array}{l}\text { Objective } \\
\text { Function of the } \\
\text { Affiliated } \\
\text { Company and } \\
\text { Business Group }\end{array}$ & $\begin{array}{l}\text { Very complex function } \\
\text { which involved a mix of } \\
\text { financial: profitability, } \\
\text { shareholder value, } \\
\text { appropriate scale of } \\
\text { operations; and social: } \\
\text { family solidarity, peace } \\
\text { and prestige, maintaining } \\
\text { social relationships, } \\
\text { investing in "good } \\
\text { works". } \\
\text { Satisficing rather than } \\
\text { maximizing behaviour. }\end{array}$ & $\begin{array}{l}\text { Greater emphasis on financial values -- } \\
\text { profits, shareholder value, higher equity } \\
\text { holdings in major affiliated companies, and } \\
\text { larger size through internal growth, mergers } \\
\text { and greenfield investments to generate } \\
\text { economies of scale and scope and establish a } \\
\text { major presence in key markets. } \\
\text { But social considerations e.g. (i) family peace } \\
\text { and solidarity, (ii) providing management } \\
\text { opportunities to sons and other relatives, (iii) } \\
\text { building social connections and networks with } \\
\text { affiliated and unaffiliated companies and } \\
\text { government and political elites, and (iv) } \\
\text { investing in good works/corporate social } \\
\text { responsibility are still given some weight - } \\
\text { including among new economy companies. } \\
\text { Social investments can add to shareholder } \\
\text { value but are also deemed to be important in } \\
\text { themselves. }\end{array}$ & $\begin{array}{l}\text { Satisficing behaviour, that is, achieving satisfactory } \\
\text { results in a number of financial, economic and social } \\
\text { variables, rather than trying to maximize a single } \\
\text { financial variable - e.g. profits, revenues, shareholder } \\
\text { value, and/or scale of operations - will likely continue } \\
\text { to be the norm. } \\
\text { Leading to criticisms from e.g. western trained } \\
\text { business analysts that groups and their affiliated } \\
\text { companies do not place sufficient weight on the share } \\
\text { price. } \\
\text { Could as well mean that cash rich affiliated companies } \\
\text { with share prices that are perceived to be lower than } \\
\text { their potential values, will be vulnerable to hostile } \\
\text { takeovers - which will force the target business group } \\
\text { to place greater weight on share value, dividends and } \\
\text { related financial variables. }\end{array}$ \\
\hline $\begin{array}{l}\text { Role and } \\
\text { Importance of } \\
\text { Business Groups } \\
\text { in Private Sector } \\
\text { Investment, } \\
\text { Production and } \\
\text { "Discourse" }\end{array}$ & $\begin{array}{l}\text { Dominated private sector } \\
\text { investment, production, } \\
\text { interactions with } \\
\text { government (on their own } \\
\text { or through traditional } \\
\text { trade associations), state- } \\
\text { business relations, and } \\
\text { discourse on government } \\
\text { policy to regulate private }\end{array}$ & $\begin{array}{l}\text { Business groups are still very important to the } \\
\text { Indian private sector, including to discourse } \\
\text { on the } 1991 \text { liberalization project and on the } \\
\text { design of the new competition statute, which } \\
\text { are implicitly intended to turn some of the } \\
\text { larger business group affiliates into "national } \\
\text { champions". } \\
\text { However, the traditional business groups now }\end{array}$ & $\begin{array}{l}\text { Could be argued that the traditional business groups } \\
\text { have an influence on private sector discourse and the } \\
\text { design of economic policies and regulations - } \\
\text { including competition policy and law - that exceed } \\
\text { their likely future importance to the Indian economy } \\
\text { over the medium- to longer-terms. } \\
\text { This is partly because the new voices and players are } \\
\text { less active because of their location (mainly in south }\end{array}$ \\
\hline
\end{tabular}




\begin{tabular}{|c|c|c|c|}
\hline $\begin{array}{l}\text { Key Indicators } \\
\text { for Traditional } \\
\text { Business Groups }\end{array}$ & $\begin{array}{l}\text { 1969-1991 "Anti- } \\
\text { Competitive" } \\
\text { Competition Regime }\end{array}$ & $\begin{array}{l}\text { Post-1991 Incomplete but on Balance Pro- } \\
\text { Competition Regime }\end{array}$ & Comments and Qualifications \\
\hline & $\begin{array}{l}\text { business. } \\
\text { Including design, } \\
\text { enforcement and } \\
\text { effectiveness of the pre- } \\
1991 \text { competition law, the } \\
\text { Monopolies and } \\
\text { Restrictive Trade } \\
\text { Practices Act (MRTPA) }\end{array}$ & $\begin{array}{l}\text { must share the stage with the new voices from } \\
\text { the new economy sectors and companies, as } \\
\text { well as recently deregulated and related } \\
\text { network sectors. } \\
\text { Situation is even more complex because many } \\
\text { of the larger traditional business groups - } \\
\text { Tata, Birla, Reliance, Goenka etc - are now } \\
\text { important participants in both the traditional } \\
\text { sectors and the new economy and recently } \\
\text { deregulated sectors - and therefore now have } \\
\text { more complex and mixed objectives in their } \\
\text { corporate strategies and interactions with } \\
\text { government. }\end{array}$ & $\begin{array}{l}\text { India until recently), and the greater importance of } \\
\text { foreign markets, investment sources, networks and } \\
\text { informal business institutions to their success. } \\
\text { Regardless, the new economy and other new voices } \\
\text { and players will take on greater importance in private } \\
\text { business discourse and policy formulation - in part } \\
\text { because the traditional business groups involved in } \\
\text { these sectors will more often join these new voices } \\
\text { rather than their traditional business group colleagues } \\
\text { of the past, in designing their market and government } \\
\text { lobbying strategies. }\end{array}$ \\
\hline $\begin{array}{l}\text { Scope for } \\
\text { Collective } \\
\text { Action Across } \\
\text { Business } \\
\text { Groups, With } \\
\text { Unaffiliated } \\
\text { Businesses, and } \\
\text { the Total } \\
\text { Private Business } \\
\text { Sector; and } \\
\text { Between the } \\
\text { Private Sector } \\
\text { and other Major } \\
\text { Groups in the } \\
\text { Indian Economy } \\
\text { and Society }\end{array}$ & $\begin{array}{l}\text { Limited scope because } \\
\text { individual businesses and } \\
\text { business groups were } \\
\text { competing among } \\
\text { themselves for the rents } \\
\text { and other spoils provided } \\
\text { by the "License Raj". } \\
\text { And scope for collective } \\
\text { action between the } \\
\text { private business sector } \\
\text { and other dominant } \\
\text { groups was limited for } \\
\text { the same reason, leading } \\
\text { to zero-sum games and } \\
\text { prisoners' dilemma type }\end{array}$ & $\begin{array}{l}\text { Partial liberalization - combined with higher } \\
\text { economic growth -- mean some reduction in } \\
\text { the available rents, rent-seeking opportunities, } \\
\text { and zero-sum games with prisoners' dilemma } \\
\text { type outcomes. } \\
\text { Liberalization should mean greater incentives } \\
\text { for collective action, to work together to } \\
\text { increase the "size of the pie" and reduce } \\
\text { coordination failures. } \\
\text { Liberalization as well is resulting in more } \\
\text { similar economic development and center- } \\
\text { regional state strategies across Indian regional } \\
\text { states (Sinha } 2005: 1, \text { p. } 271 \text { ) - which will } \\
\text { allow businesses to economize on the cost of }\end{array}$ & $\begin{array}{l}\text { But incomplete nature of liberalization combined with } \\
\text { decentralization to the Indian regional states and urban } \\
\text { regions mean that, to some degree, rent-seeking } \\
\text { opportunities and business competition in zero-sum } \\
\text { games continue but at a lower scale. } \\
\text { With the games more often being played at the sub- } \\
\text { national level - states, urban municipalities etc. } \\
\text { Collective action across business groups and with } \\
\text { other companies and groups outside the business } \\
\text { group also constrained by: limited comfort, familiarity } \\
\text { and trust with these broader arrangements, higher } \\
\text { information and other transactions costs, and limited } \\
\text { acceptance of a common code of generalized morality } \\
\text { in business and social transactions (the result of }\end{array}$ \\
\hline
\end{tabular}




\begin{tabular}{|c|c|c|c|}
\hline $\begin{array}{l}\text { Key Indicators } \\
\text { for Traditional } \\
\text { Business Groups }\end{array}$ & $\begin{array}{l}\text { 1969-1991 "Anti* } \\
\text { Competitive" } \\
\text { Competition Regime }\end{array}$ & $\begin{array}{l}\text { Post-1991 Incomplete but on Balance Pro- } \\
\text { Competition Regime }\end{array}$ & Comments and Qualifications \\
\hline & $\begin{array}{l}\text { outcomes (Bardhan 1984, } \\
\text { chapters } 6 \text { and } 7 \text { ). }\end{array}$ & $\begin{array}{l}\text { transacting with regional state governments } \\
\text { and in time could lead to greater collective } \\
\text { action involving several regional states and } \\
\text { the private business sector. }\end{array}$ & India's many social divisions). \\
\hline $\begin{array}{l}\text { Interactions } \\
\text { with and } \\
\text { Accomm- } \\
\text { odations to } \\
\text { Competition } \\
\text { Agency and } \\
\text { Broader } \\
\text { Competition } \\
\text { Regime }\end{array}$ & $\begin{array}{l}\text { Accounted for a major } \\
\text { portion of government } \\
\text { transactions, transaction } \\
\text { costs and business } \\
\text { frustrations - and major } \\
\text { source of delays, changes } \\
\text { in strategy, sub-optimal } \\
\text { accommodations, and } \\
\text { negative impacts on } \\
\text { business group } \\
\text { performance and } \\
\text { competitiveness. } \\
\text { Interactions and } \\
\text { accommodations with the } \\
\text { competition regime did } \\
\text { not threaten the overall } \\
\text { dominant position of } \\
\text { business groups within } \\
\text { the private economy. } \\
\text { But they did hurt business } \\
\text { and economic } \\
\text { performance and } \\
\text { competitiveness }\end{array}$ & $\begin{array}{l}\text { With weakening of MRTPA and removal of } \\
\text { licensing regime, transactions and interactions } \\
\text { with the competition regime have been less } \\
\text { numerous and important up to } 2008 \text {, and } \\
\text { transactions with state governments, with the } \\
\text { "inspection raj", with trade officials on tariffs, } \\
\text { anti-dumping and other non-tariff barriers } \\
\text { (NTBs), with government land authorities and } \\
\text { officials on land assembly, with labour } \\
\text { officials on downsizing etc., have become } \\
\text { more important. } \\
\text { Transactions and interactions with the new } \\
\text { CCI - in terms of quality, quantity and } \\
\text { outcomes - is the major unanswered question } \\
\text { of this dissertation. Business lobby was } \\
\text { successful in limiting the interactions on } \\
\text { mergers, but interactions on other provisions } \\
\text { will still be important (and even more } \\
\text { numerous and complex because of the weak } \\
\text { merger review system). } \\
\text { Interactions with the CCI could increase in } \\
\text { quantity and importance because of company } \\
\text { and business group strategies to focus on a } \\
\text { relatively few core capabilities and domestic }\end{array}$ & $\begin{array}{l}\text { The business lobby's success in weakening the merger } \\
\text { provisions of the amended Competition Act } 2007 \\
\text { could make interactions on the other provisions more } \\
\text { numerous, important and problematic for business } \\
\text { groups and other informal business institutions -- } \\
\text { particularly since anti-business rhetoric and elites } \\
\text { continue to be important to the political economy } \\
\text { discourse of India. } \\
\text { Merger review in other countries is a useful } \\
\text { instrument to deflect political pressure "to do } \\
\text { something" when a large merger takes place, and to } \\
\text { minimize the danger of political and competition } \\
\text { problems after the merger has been completed. The } \\
\text { business lobby has to some degree removed these } \\
\text { safety valves from the Indian competition regime. } \\
\text { Other changes to the new competition law, when } \\
\text { compared with the earlier competition bills, were } \\
\text { meant to favour business and economic development, } \\
\text { but could also lead to more numerous and costly } \\
\text { interactions with the CCI, the Competition Appellate } \\
\text { Tribunal and the courts. } \\
\text { This is because the CCI, Tribunal, courts and defense } \\
\text { bar will likely attempt to interpret these complex and }\end{array}$ \\
\hline
\end{tabular}




\begin{tabular}{|c|c|c|c|}
\hline $\begin{array}{l}\text { Key Indicators } \\
\text { for Traditional } \\
\text { Business Groups }\end{array}$ & $\begin{array}{l}\text { 1969-1991 "Anti- } \\
\text { Competitive" } \\
\text { Competition Regime }\end{array}$ & $\begin{array}{l}\text { Post-1991 Incomplete but on Balance Pro- } \\
\text { Competition Regime }\end{array}$ & Comments and Qualifications \\
\hline $\begin{array}{l}\text { Interactions } \\
\text { Cont. }\end{array}$ & $\begin{array}{l}\text { And at times these and } \\
\text { other government } \\
\text { interactions did influence } \\
\text { the relative positions of } \\
\text { business groups e.g. Birla } \\
\text { and Reliance became } \\
\text { stronger, while the Tatas } \\
\text { lost their relative position } \\
\text { in the business group } \\
\text { "hierarchy" during some } \\
\text { periods and political } \\
\text { regimes.. }\end{array}$ & $\begin{array}{l}\text { markets, and to establish strong positions in } \\
\text { these markets before going global. } \\
\text { These strategies can raise issues related to } \\
\text { abuse of dominance, anti-competitive } \\
\text { agreements, misuse of IPRs, and misuse of } \\
\text { anti-dumping and trade relief to prevent entry } \\
\text { by more efficient foreign competitors. } \\
\text { Interactions and accommodations with the } \\
\text { new competition regime and an effectively } \\
\text { enforced competition law could over time } \\
\text { have a more substantive impact on corporate } \\
\text { strategy and financial performance compared } \\
\text { with the pre-1991 MRTPA and competition } \\
\text { regime, when transactions were more } \\
\text { numerous and costly but much less } \\
\text { fundamental and substantive. } \\
\text { Globalization strategies should mean more } \\
\text { transactions and interactions with competition } \\
\text { agencies in other countries, especially the } \\
\text { more experienced competition law } \\
\text { jurisdictions in the OECD countries. The } \\
\text { resulting experience and learning should mean } \\
\text { higher quality interactions between India's } \\
\text { business groups and other informal business } \\
\text { arrangements and the country's new and still } \\
\text { evolving competition regime in the future }\end{array}$ & $\begin{array}{l}\text { often less than transparent additions and develop } \\
\text { "favourable" (from their perspective) case law. } \\
\text { The result could be costly and high risk litigation for } \\
\text { business groups and other larger companies under the } \\
\text { two non-merger sections of the Competition Act - } \\
\text { involving in some cases merged entities that fell } \\
\text { below the high size thresholds in the merger } \\
\text { provisions. } \\
\text { Also possible that greater exposure to external } \\
\text { markets will increase knowledge of the anti- } \\
\text { competitive strategies and successes of foreign firms. }\end{array}$ \\
\hline
\end{tabular}




\section{Bibliography}

Acemoglu Daron, Philippe Aghion, and Fabrizio Zilibotti (2002) "Distance to Frontier, Selection and Economic Growth" NBER Working Paper Series, Working Paper 9066, National Bureau of Economic Research, July 2002

Agarwal Anuran K. (2005), "Competition Law in India: Need to Go Slow and Steady", Indian Institute of Management, W.P. No. 2005-10-05, October 2005

Agarwal Manish (2006:1) "Mergers and Acquisitions in India: Implications for Competition" in Pradeep S. Mehta, Editor Towards a Functional Competition Policy for India CUTS International, Academic Foundation, New Delhi, pp. 71-84

Agarwal Manish (2006:2) "Off the Cuff: First, Set the House Right" Financial Express March 11, 2006

Agarwal Manish and Aditya Bhattacharjea (2006) "Mergers in India: A Response to Regulatory Shocks" Emerging Markets Finance and Trade, Vol. 42, No. 3, May-June 2006, pp. 47-66

Aggarwal, Aradhna (2002) "Anti Dumping Law and Practice: An Indian Perspective" Indian Council for Research on International Economic Relations, Working Paper No. 85 April 2002 (Available on the Internet)

Aghion Philippe and Peter Howitt (1992) "A Model of Growth Through Creative Destruction" Econometrica Vol, 60 No. 2 March 1992, pp. 323-351

Aghion Philippe and Peter Howitt (2006) "Joseph Schumpeter Lecture - Appropriate Growth Policy: A Unifying Framework" Journal of the European Economic Market Association April 2006 Vol. 4 No, 2-3 pp 269-314.

Aghion Philippe, Robin Burgess, Stephen Redding and Fabrizio Zilibotti (2003) "The Unequal Effects of Liberalization: Theory and Evidence from India", March 5, 2003 (Available on the Internet)

Aghion Philippe, Robin Burgess, Stephen Redding and Fabrizio Zilibotti (2005:1) "Entry Liberalization and Inequality in Industrial Performance" Journal of the European Economic Association April-May 2005 Vol. 3 No. 2-3, pp 291-302

Aghion Philippe, Robin Burgess, Stephen Redding and Fabrizio Zilibotti (2005:2) "The Unequal Effects of Liberalization: Evidence from Dismantling the License Raj in India", Development Economics Discussion Paper Series, London School of Economics and Political Science, December 2005 (Available on the Internet) 
Agrawal Ajay (2005) "A Survey of R\&D Governance in Canada and an Exploration of the Role of Social Relationships in Outsourcing R\&D" Prepared for the Industry Canada Workshop "Industrial Economics and Performance in Canada" held in September 2005

Ahluwalia Montek S. (2002) "Economic Reforms in India Since 1991: Has Gradualism Worked" Journal of Economic Perspectives Vol. 16, Number 3, Summer 2002 pp. 67-88

Akerlof, George (1970), "The Market for Lemons: Quality, Uncertainty and the Market Mechanism", Quarterly Journal of Economics, August 1970, Volume 84, Issue 3, pp 488500

Aksoy, M. Ataman and Helena Tang (1992) "Imports, Exports and Industrial Performance in India, 1970-1988" World Bank Policy Research Papers, WPS 969 August 1992

Amsden Alice H. and Ajit Singh (1994) "Growth in Developing Countries: Lessons from East Asian Countries; The Optimal Degree of Competition and Dynamic Efficiency in Japan and Korea" European Economic Review Vol. 38, pp 941-951

Anant T.C.A. and Omkar Goswami (1995) "Getting Everything Wrong: India's Policies Regarding 'Sick' Firms" in Dilip Mookherjee Editor Indian Industry: Policy and Performance Oxford U. Press Delhi, pp. 44-70

Anderson Robert D. (1998) "The Interface Between Competition Policy and Intellectual Property in the Context of the International Trading System" Journal of International Economic Law pp. 655-678

Anderson, Robert D. and Nancy T. Gallini (General Editors) (1998), Competition Policy and Intellectual Property Rights in the Knowledge-Based Economy, Industry Canada Research Series, University of Calgary Press

Anderson, Robert D. and Frederic Jenny (2005) "Competition Policy, Economic Development, and the Role of a Possible Multilateral Framework on Competition Policy: Insights from the WTO Working Group on Trade and Competition Policy" (A Version of this Working Paper Was Published in Competition Policy in East Asia, Erlinda Medalla Ed. Routledge/Curzon, 2005).

Annen Kurt (2003) "Social Capital, Inclusive Networks, and Economic Performance" Journal of Economic Behavior and Organization Vol. 50, Issue 4, April 2003, pp. 449463

Artz, Kendall W. and Thomas H. Brush (2000) "Asset Specificity, Uncertainty and Relational Norms: An Examination of Coordination Costs in Collaborative Strategic Alliances" Journal of Economic Behavior and Organization Vol. 41, pp. 337-362 
Aspers, Patrik (1999) "The Economic Sociology of Alfred Marshall" American Journal of Economics and Sociology Vol. 58 No. 4 October 1999, pp. 651-667

Athreye Suma S. (2005) "The Indian Software Industry and Its Evolving Service Capability" Industrial and Corporate Change Vol. 14 No. 3 pp. 393-418

Athreye, Suma S. and Sandeep Kapur (2004) "Industrial Concentration in a Liberalizing Economy: A Study of Indian Manufacturing" October 21, 2004 (Working Paper Available on the Internet)

Attwood, Donald W. (1991) "Does Competition Help Cooperation" McGill U.: Montreal and International Development Research Center: Ottawa (Available on the Internet)

Averitt, Neil W. and Robert H. Lande (1997) "Consumer Sovereignty: A Unified Theory of Antitrust and Consumer Protection Law', Volume 65, Antitrust Law Journal, p. 713, Spring 1997.

Axelrod, Robert (1984) The Evolution of Cooperation, New York: Basic Books

Axelrod, Robert (1986) "An Evolutionary Approach to Norms" The American Political Science Review Vol. 80 No. 4 December 1986 pp. 1095-1111

Bain Joseph (1956) Barriers to New Competition Cambridge Harvard University Press

Bain Joseph (1959) Industrial Organization New York John Wiley

Baker, Jonathan B. (2002) "Responding to Developments in Economics and the Courts: Entry in the Merger Guidelines", Washington College of Law, American University (Available on the Internet)

Balakrishnan, Pulapre, M. Parameswaran, K. Pushpangadan, and M. Suresh Babu (2006) "Liberalization, Market Power, and Productivity Growth in Indian Industry" The Journal of Policy Reform Vol. 9, No. 1 pp. 55-73, March 2006

Balasubramanyam V.N. and Ahalya Balasubramanyam (2000) "The Software Cluster in Bangalore" in John H. Dunning Editor, Regions, Globalization and the Knowledge-Based Economy Oxford U. Press, Oxford UK, pp. 348-363

Banerjee, Parthasarathi and Frank-Jurgen Richter Editors (2003) Economic Institutions in India: Sustainability under Liberalization and Globalization, Palgrave Macmillan, Great Britain

Bardhan Pranab (1984) The Political Economy of Development in India Basil Blackwell Publisher, Oxford 
Bardham, Pranab (2000), "The Nature of Institutional Impediments to Economic Development". From Mancur Olson and Satu Kahkonen eds. A Not-So-Dismal Science Oxford: Oxford U. Press.

Basant Rakesh and Sebastian Morris (2000) "Competition Policy in India: Issues for a Globalizing Economy" Economic and Political Weckly, July 29, 2000

Basu Kaushik (2003) "The Indian Economy: Up to 1991 and Since" BREAD Working Paper No. 052, Bureau for Research in Economic Analysis and Development, December 2003

Baumol, William J. (1982) "Contestable Markets: An Uprising in the Theory of Industry Structure" The American Economic Review Vol. 72 No. 1, March 1982, pp. 1-15

Bayly C.A. (1983) Rulers, Townsmen and Bazaar: North Indian Society in the Age of British Expansion 1770-1870 Cambridge U. Press, Trowbridge, Wiltshire, Great Britain

Benjamin, Solomon (2000) "Governance, Economic Settings and Poverty in Bangalore" Environment and Urbanization Vol. 12 No. 1 April 2000

Bernheim B. Douglas and Michael D. Whinston (1990) "Multimarket Contact and Collusive Behaviour" The RAND Journal of Economics Vol. 21 No. 1 (Spring 1990) pp. $1-26$

Benjamin, Solomon (2000) "Governance, Economic Settings and Poverty in Bangalore" Environment and Urbanization Vol. 12 No. 1 April 2000

Berkovitz Daniel, Katherina Pistor and Jean-Francois Richard (1999) "Economic Development, legality and the Transplant Effect" Working Paper (Available on the Internet) November 1999

Best, Michael H. (1990), The New Competition: Institutions of Industrial Restructuring, Cambridge Polity Press

Best, Michael H. and Elizabeth Garnsey (1998) "Edith Penrose (1914-1996) December 111998 (Available on the Internet)

Bhaduri Saumitra N. (2005) "Investment, Financial Constraints and Financial Liberalization: Some Stylized Facts from a Developing Economy, India" Journal of Asian Economics, Vol. 16 pp. 704-718"

Bhagwati Jagdish N. and T. N. Srinivasan (1975) Foreign Trade Regimes and Economic Development: India Columbia University Press New York and London 
Bhalla, G.S. (2001) "Political Economy of Indian Development in the $20^{\text {th }}$ Century: India's Road to Freedom and Growth" Indian Economic Journal Vol. 48 No. 3 JanuaryMarch 2000-2001, pp. 1-23

Bhattacharjea Aditya (2003:1) "India's Competition Policy: An Assessment" Delhi School of Economics (available on the Internet)

Bhattacharjea Aditya (2003:2) "Trade, Investment and Competition Policy: An Indian Perspective" in Aaditiya Mattoo and Robert Stern Editors, India and the WTO, A CoPublication of the World Bank and the Oxford U. Press, Washington D.C., pp. 197-234.

Bhattacharjea Aditya (2004) "Export Cartels - A Developing Country Perspective" Journal of World Trade Vol. 38 (2) pp. 331-359

Bhattacharjea Aditya (2006) "The Case for a Multilateral Agreement on Competition Policy: A Developing Country Perspective" Journal of International Economic Law Vol. 9 (2) May 2006, pp. 293-323

Bhattacharjea Aditya (2008) "India's New Competition Law: A Comparative Assessment" Journal of Competition Law and Economics Vol. 10 pp. 1-30 Bhattacharya, Dhires (1972), A Concise History of the Indian Economy: 1750-1950, Progressive Publishers, Calcutta

Birner Regina and Heidi Wittmer (2003) "Using Social Capital to Create Political Capital: How Do Local Communities Gain Political Influence? A Theoretic Approach and Empirical Evidence from Thailand" in Dolsak, Nives and Elinor Ostrom Editors, The Commons in the New Millennium: Challenges and Adaptation, The MIT Press, Cambridge Mass, and London England.

Blake Harlan M. (1973) "Conglomerate Mergers and the Antitrust Law" Columbia Law Review. Vol. 73, March 1975 pp. 555-592

Bombay Chamber of Commerce and Industry (2000) "Memorandum on Competition Policy and Law" Mumbai, India

Bostock Richard and Christopher Stoney (1997) "Japanese Corporate Governance: Governance for the Twenty-First Century or Model in Decline?" Asia Pacific Business Review Vol. 4 No. 1, Autumn 1997, pp. 63-82

Botti Simona and Sheena S. Iyengar (2006) "The Dark Side of Choice: When Choice Impairs Social Welfare" Journal of Public Policy and Marketing, Vol. 25 No. 1 Spring 2006, pp. 24-38

Bouchon, Genevieve (1999) "Trade in the Indian Ocean at the Dawn of the Sixteenth Century" in Chaudhury, Sushil and Michel Morineau Editors (1999) Merchants, 
Companies and Trade: Europe and Asia in the Early Modern Era Cambridge U. Press, UK, pp. 42-51

Bowles S. and H. Gintis (1998) "How Communities Govern: The Structural Basis of Prosocial Norms" in Ben-Ner, Avner and Louis Putterman Editors Economics, Values and Organization Cambridge University Press, Cambridge UK

Bowles, S., and H. Gintis (2002) "Social Capital and Community Governance" The Economic Journal 112 (November): 419-436

Bowonder B. (1998) "Industrialization and Economic Growth of India: Interactions of Indigenous and Foreign Technology" International Journal of Technology Management Vol. 15, No. 6/7, pp. 622-645

Bradach, Jeffrey L. and Robert G. Eccles (1989) "Price, Authority and Trust: From Ideal Types to Plural Forms" Annual Review of Sociology Vol. 15 pp. 97-118

Bresnahan Timothy F. (1989) "Empirical Studies of Industries with Market Power" in Richard Schmalensee and Robert D. Willig Editors Handbook of Industrial Organization: Volume II North Holland New York, pp. 1011-1057

Bresnahan Timothy (2003) Pro-Innovation and Competition Policy: Microsoft and Beyond", For Presentation at: Competition Policy Research Center, Fair Trade Commission of Japan Inaugural Symposium, November 20, 2003

Brooks Douglas H. (2007) "Industrial and Competition Policy: Conflict or Complementarity?" ADBI Research Policy Brief No. 24, Asian Development Bank Institute

Brooks Douglas H. (2005) "Competition Policy and Development" ADB, Economics and Research Department (ERD) Policy Brief Series, No. 39, October 2005

Business Standard (2007) "Competition and Privatization Policy" 21 March 2007

Business Line (2008) "'Selection Body for Competition Commission to be Notified Soon" January 10, 2008

Canadian Competition Bureau (2004) "Treatment of Efficiencies in the Competition Act: Consultation Paper", September 2004

Carlton Dennis W. and Robert Gertner (2002) "Intellectual Property, Antitrust and Strategic Behavior", National Bureau of Economic Research, May 2002

Carter Richard and Geoffrey M. Hodgson (2006) "The Impact of Empirical Tests of Transaction Cost Economics on the Debate on the Nature of the Firm" Strategic Management Journal Vol. 27 pp. 461-476 
Casson Mark (2005) "Entrepreneurship and the Theory of the Firm" Journal of Economic Behavior and Organization, Volume 58 pp. 327-348

Casson Mark and Marina Della Giusta (2007) "Entrepreneurship and Social Capital: Analysing the Impact of Social Networks on Entrepreneurial Activity from a Rational Action Perspective" International Small Business Journal Vol. 25 No. 3 pp. 220-244

Chakravorty Dr. S. (2006:1) "Competition Act, 2002: The Approach" in Pradeep S. Mehta, Editor Towards a Functional Competition Policy for India CUTS International, Academic Foundation, New Delhi, pp. 55-70

Chakravorty Dr, S. (2006:2) "Evolution of Competition Policy and Law in India" in Pradeep S. Mehta, Editor Towards a Functional Competition Policy for India CUTS International, Academic Foundation, New Delhi, pp. 39-54

Chakravorty Sanjoy (2003) "Industrial Location in Post-Reform India: Patterns of Interregional Divergence and Intra-regional Convergence" Journal of Development Studies, Vol. 40 No. 2, December 2003 pp. 120-152

Chand Dr. Ramesh Editor (2005) India's Agricultural Challenges: Reflections on Policy. Technology and Other Issues, Centad: Center for Trade and Development New Delhi

Chand Dr. Ramesh (2006) "Agricultural Markets in India: Implications for Competition" in Pradeep S. Mehta, Editor Towards a Functional Competition Policy for India CUTS International, Academic Foundation, New Delhi, pp. 139-154

Chand, Satish and Kunal Sen (2002) "Trade Liberalization and Productivity Growth: Evidence from Indian Manufacturing" Review of Development Economics Volume 6 No. 1

Chandrasekhar, C.P. (2003) "The End to Indian Anti-Trust" Frontline Volume 20 Issue 01, January 18-31, 2003 (Available on the Internet)

Chattopadhyay, Raghabendra (1991) Indian Business and Economic Planning (19301956)" in Dwijendra Tripathi Editor Business and Politics in India: A Historical Perspective Indian Institute of Management, Ahmedabad, Manohar Publications, New Delhi pp. 308-350

Chaudhuri, Asim (1973) "Anti-Monopoly Policy at Work" Social Scientist Volume 2, No. 1 August 1973 pp. 43-54

Chaudhuri Manas Kr (2005) "Proposed Competition Amendments Ignore Apex Court Intervention" (Available on the Internet at indlaw.com) 
Chaudhury, Sushil and Michel Morineau Editors (1999) Merchants, Companies and Trade: Europe and Asia in the Early Modern Era Cambridge U. Press, UK

Chen Tain-Jy (2003) "Network Resources for Internationalization: The Case of Taiwan's Electronic Firms" Journal of Management Studies Vol. 40 No. 5 pp. 1107-1130

Cheung Steven N.S. (1996) "A Simplistic General Equilibrium Theory of Corruption" Contemporary Economic Policy Vol. XIV July 1996

Chhauhan Pratapsinh (2003) "Role of Transaction Cost on Financial Performance of Sugar Industry of India" International Conference on Statistics, Combinatorics and Related Areas, October 3-5 2003, Southern Maine University, Portland Maine USA

Chibber, Vivek (2003:1) "Reviving the Developmental State: The Myth of the National Bourgeoisie", (Working Paper Available on the Internet)

Chibber, Vivek (2003:2) Locked in Place: State-Building and Late Industrialization in India, Princeton U. Press

Church Jeffrey and Roger Ware (1998) "Network Industries, Intellectual Property Rights and Competition Policy" in Anderson, Robert D. and Nancy T. Gallini (General Editors), Competition Policy and Intellectual Property Rights in the Knowledge-Based Economy, Industry Canada Research Series, University of Calgary Press, pp. 227-285

Church, Jeffrey and Roger Ware (2000) Industrial Organization: A Strategic Approach, Boston: Irwin McGraw-Hill

Coase Ronald H. (1937) "The Nature of the Firm" Economica November 1937, Volume 4 pp. 386-405

Coase Ronald H. (1960) "The Problem of Social Cost", The Journal of Law and Economics, Vol. III, October 1960

Confederation of Indian Industry (CII) (2000) Raghavan Committee Report on Indian Competition Policy and Law, and CII's Presentation National Seminar on Indian Competition Policy and Law, New Delhi

Conlisk John (1996) "Why Bounded Rationality" Journal of Economic Literature Vol. XXXIV, June 1996 pp. 669-700

Cooper Russell W. (1999) Coordination Games: Complementarities and Macroeconomics, Cambridge U. Press, United Kingdom and New York

Cooter, Robert D. (1994) "Structural Adjudication and the New Law Merchant: A Model of Decentralized Law" International Review of Law and Economics Vol. 14 pp 215-231 
Cooter, Robert D. (2000) "Law from Order: Economic Development and Jurisprudence of Social Norms". From Mancur Olson and Satu Kahkonen eds. A Not-So-Dismal Science Oxford: Oxford U. Press.

Crouch, Colin and Maarten Keune (2003), "Rapid Change by Endogenous Actors: The Utility of Institutional Incongruence", Third Revision August 2003 (Available on the Internet)

Culpepper, Pepper (2001) in "Employers, Public Policy and the Politics of Decentralized Cooperation in Germany and France" in P. Hall and D. Soskice, eds. Varieties of Capitalism: The Institutional Foundations of Comparative Advantage Oxford, 2001

CUTS International (2002) Reorienting Competition Policy and Law in India National Council of Applied Economics Research (NCAER) and CUTS Center for International Trade, Economics and the Environment

CUTS International (2003) Pulling Up Our Socks A Study of Competition Regimes of Seven Developing Countries of Africa and Asia: The 7-Up Project

CUTS International (2006) "Bill Blowup: The Competition (Amendment Bill) 2006 Whats To Be Done" Jaipur, India (Available on the Internet)

CUTS International (2007) "Old or New; The Road Ahead is Long: Competition Policy and Long in South and Southeast Asia" The 7-Up2 Project

Das, Deb Kusum (2003:1) "Manufacturing Productivity under Varying Trade Regimes: India in the 1980s and 1990s" Indian Council for Research on Economic Relations, Working Paper No. 107, July 2003 (Available on the Internet)

Das, Deb Kusum (2003:2) "Quantifying Trade Barriers: Has Protection Declined Substantially In Indian Manufacturing?" Indian Council for Research on International Economic Relations, July 2003 (Available on the Internet)

Das, Gurchuran (2002) India Unbound: The Social and Economic Revolution from Independence to the Global Information Age Anchor Books: A Division of Random House Inc. New York

Das, Samantak and Sanjib Pohit (2006) "Quantifying Transport, Regulatory and Other Costs of Indian Overland Exports to Bangladesh" The World Economy pp. 1227-1242

Das, Sandwip Kumar and Manoj Pant (2006) "Measuring Market Imperfection in the Manufacturing Sector: Theory and Evidence from India" Journal of International Trade and Economic Development Vol. 15, No. 1, March 2006, pp. 63-79

Das, Sanghamitra and Krishna Srinivasan (1997) "Duration of Firms in an Infant Industry" Journal of Development Economics Vol. 53 pp. 157-167 
Dasgupta A. and Dr. N. K. Sengupta (1981), Government and Business in India, Allied Book Agency, Calcutta and New Delhi

Datt, Gaurav and Martin Ravallion (2002) "Is India's Economic Growth Leaving the Poor Behind" Journal of Economic Perspectives Vol. 16 No. 3 Summer 2002 pp. 89-108

Datt, Ruddar (1971) "Industrial Licensing Runs Counter to National Industrial Policy" Economic Affairs Vol. 16 No. 4 April 1971 pp. 145-62

Day George S. and Paul H. Schoemaker (2004) "Driving Through the Fog: Managing at the Edge" Long Range Planning Vol. 37 pp. 127-142

Debroy, Bibek (1997) "Competition Policy - An Indian Perspective" LARGE: Legal Adjustments and Reforms for Globalizing the Economy, New Delhi

Debroy, Bibek (2003) Reforming the Legal System, Rajiv Gandhi Institute for Contemporary Studies

Debroy, Bibek (2004) India: Redeeming the Economic Pledge Academic Foundation New Delhi

DellaVigna, S. and Malmendier, U. (2004), "Contract Design and Self-Control: Theory and Evidence" Quarterly Journal of Economics Vol. CXIX Issue 2.

Denoon, David B.H. (1998), "Cycles in Indian Economic Liberalization, 1966-1996", Comparative Politics Vol. 31, No. 1, October 1998, pp. 43-60

Desai Ashok V., Marc Lautier and Hanumantha Charya (1999) "Machine Tool Industries in India and Chinese Taipei: A Comparison" in Lynn Krieger Mytelka Editor Competition, Innovation and Competitiveness in Developing Countries OECD Development Centre Studies, Chapter 2, pp. 33-76

Dholakia, Bakul H. (2002) "Sources of India's Accelerated Economic Growth and the Vision of the Indian Economy in 2020" Indian Economic Journal Vol. 49 No. 4 AprilJun 2001-2002, pp. 27-46

Dixit, Avinash (1996) The Making of Economic Policy: A Transaction-Cost Politics Perspective Cambridge Mass.: The MIT Press.

Djankov, Simeon and Peter Murrell (2002) "Enterprise Restructuring in Transition: A Quantitative Survey" Journal of Economic Literature Vol. XL, September 2002, pp. 739792 
Dobson Wendy (1998) "Business Networks in East Asia": Diversity and Evolution" in Rong-I Wu and Yun-Peng Chu Editors Business, Markets and Government in the Asia Pacific, 1998 Pacific and Trade Development Conference, Routledge London, pp. 24-47

Doern, G. Bruce and Stephen Wilks Editors (1996), Comparative Competition Policy: National Institutions in a Global Market, Clarendon Press, Oxford.

Doern, G. Bruce (2004), "Federal Competition Policy, Competitiveness, and the Canadian Pulp and Paper Industry", A Paper Prepared for Natural Resources Canada, February 2004

Dore Ronald (1983) "Goodwill and the Spirit of Market Capitalism" British Journal of Sociology Vol. 34 No. 4 pp. 459-482

Dorin Bruno Editor (2003) The Indian Entrepreneur: A Sociological Profile of Businessmen and Their Practices Manohar, A Publication of the French Research Institutes in India

Dow, Gregory K. (1987) "The Function of Authority in Transaction Cost Economics" Journal of Economic Behaviour and Organization Vol. 8 pp. 13-38

Driffield, Nigel L. and Uma S. Kambhampati (2003) "Trade Liberalization and the Efficiency of Firms in Indian Manufacturing" Review of Development Economics, 7(3) pp. $419-430$

Dutt, Amitava Krishna (1997) "Uncertain Success: The Political Economy of Indian Economic Reform" Journal of International Affairs, Summer 1997, 51, No. 1, pp. 57-83

Dutz Mark A. and Maria Vagliasindi (2000) "Competition Policy Assessment in Transition Economies: An Empirical Assessment" European Economic Review Volume 44, pp. 762-772

Dutz Mark A., James A. Ordover, and Robert D. Willig (2000) "Competition Policy and Development; Entrepreneurship, Access Policy, and Economic Development: Lessons from Industrial Organization" European Economic Review Vol. 44, pp. 739-747

Eastwood Robert and Renu Kohli (1999) "Directed Credit and Investment in Small-Scale Industry in India: Evidence from Firm-Level Data 1965-1978" The Journal of Development Studies Vol. 35 No. 4 April 1999 pp. $42-63$

The Economist (2006) “Can India Fly?” The Economist June $3^{\text {rd }}-9^{\text {th }} 2006$

The Economist (2006) "The Survey of Business in India" The Economist June $3^{\text {rd }}-9^{\text {th }}$ 2006 
The Economist (2008:1) "A Special Report on Globalization" The Economist September $20^{\text {th }}-26^{\text {th }} 2008$

The Economist (2008:2) November $29^{\text {th }}$-December $5^{\text {th }} 2008$

Eggertsson, T. (1990) Economic Behaviour and Institutions, Cambridge: CUP

Ellison Glenn (2006) "Bounded Rationality in Industrial Organization" MIT and NBER, January 2006

Encarnation Dennis J. (1989) Dislodging Multinationals: India's Strategy in Comparative Perspective Cornell University Press, Ithaca and London

Evenett Simon J. (2005:1) "What is the Relationship between Competition Law and Policy and Economic Development?" University of Oxford, March 15, 2005 (Available on the Internet)

Evenett, Simon J. (2005:2) "Would Enforcing Competition Law Compromise Industry Policy Objectives?" University of Oxford, February 7, 2005 (Available on the Internet)

Farrell Diana and Susan Lund (2006) "A Tale of Two Financial Systems: A Comparison of China and India" McKinsey Global Institute, September 2006

Farrell Joseph (1987) "Cheap Talk, Coordination and Entry" Rand Journal of Economics, Vol. 18, No. 1, Spring 1987, pp. 34-39

Farrell Joseph and Mathew Rabin (1996) "Cheap Talk", Journal of Economic Perspectives, Volume 10, Number 3, Summer 1996, pp. 103-118

Fernandes Leela and Patrick Heller (2006) "Hegemonic Aspirations: New Middle Class Politics and India's Democracy in Comparative Perspective" Critical Asian Studies Volume 34, No. 4 2006, pp. 495-522

Fingleton John, Eleanor Fox, Damien Neven, and Paul Seabright (1996), Competition Policy and the Transformation of Central Europe, Centre for Economic Policy Research, London.

Fisman Raymond and Tarun Khanna (2004) "Facilitating Development: The Role of Business Groups" World Development Vol. 32 No. 4 pp. 609-628

Foss, Nicolai J. (2003) "Bounded Rationality in the Economics of Organization: 'Much Cited and Little Used" Journal of Economic Psychology Vol. 24 pp. 245-264 
Fox Eleanor (2007) "Economic Development, Poverty and Antitrust: The Other Path" New York University of Law: Public Law and Legal Theory Research Paper Series, Working Paper No. 07-12, July 2007

Frankena Mark (1971) "The Industrial and Trade Control Regime and Product Designs in India", Economic Development and Cultural Change

Frenkel Stephen and Sarosh Kuruvilla (2002) "Logics of Action, Globalization, and Changing Employment Relations in China, India, Malaysia, and the Philippines" Industrial and Labor Relations Review Vol. 55 No. 3 April 2002

Friedman, Lee S. (2002) The Microeconomics of Public Policy Analysis, Princeton U. Press, particularly chapters $10-12$.

Fukuyama, Francis (1995) Trust: The Social Virtues and the Creation of Prosperity, The Free Press, New York and London

Fukuyama, Francis (1999) "Social Capital and Civil Society" prepared for Delivery at the IMF Conference on Second Generation Reforms, October 11999

Fulda Carl H. and Irene Till (1968) "An Antitrust Policy in India" Antitrust Bulletin Vol. 13 pp. 373-394

Gaastra, Femme S. (1999) "Competition or Collaboration? Relations between the Dutch East India Company and Indian Merchants Around 1680" in Chaudhury, Sushil and Michel Morineau Editors Merchants, Companies and Trade: Europe and Asia in the Early Modern Era Cambridge U. Press, UK

Ganesh-Kumar A., Kunal Sen and Rajendra R. Vaidya (2003) International Competitiveness, Investment and Finance: A Case Study of India, Routledge Studies in Development Economics, Routledge London and New York

Gans, Joshua S. (2005:1). "Protecting Consumers by Protecting Competition: Does Behavioural Economics Support This Contention?" Competition \& Consumer Law Journal, 13, 1-11.

Gans Joshua S. (2005:2), "The Road to Confusopoly," available on the Australia Competition and Consumer Commission (ACCC) Conference Website at http://www.accc.gov.au/content/index.phtml//itemId/658141/fromItemId/3765.

Garrouste Pierre and Stephane Saussier (2005) "Looking for a Theory of the Firm: Future Challenges" Journal of Economic Behavior and Organization, Volume 58 pp. 178-199

Gernet Jacques (2002) A History of Chinese Civilization Volumes I and II Translated by J.R. Foster and Charles Hartman The Folio Society: London 
Gerschenkron Alexander (1966) Economic Backwardness in Historical Perspective: A Book of Essays, The Belknap Press of Harvard U., Cambridge Massachusetts

Ghatak, Maitreesh and Raja Kali (2001) "Financially Interlinked Business Groups" Journal of Economics and Management Strategy Volume 10 No. 4, Winter 2001 pp. 591619

Ghemawat, Pankaj and Tarun Khanna (1998) "The Nature of Diversified Business Groups" The Journal of Industrial Economics, Volume XLVI March 1998

Ghosh, Alak (1970) "A Note on Industrial Licensing Policy” Economic Affairs Vol. 15, No. 6-8 156, August 1970 pp. $277-78$

Ghosh, Arabinda (1974:1) "A Critique of Antitrust Policy in India" Antitrust Bulletin Vol. 19 No. 4 Winter 1974 pp. 851-66

Ghosh, Arabinda (1974:2) "Japanese "Zaibatsu" and Indian Industrial Houses: An International Comparison" American Journal of Economics and Sociology Vol. 33 No. 3 July 1974 pp $317-326$

Ghosh, Arabinda (1974:3) "Role of Large Industrial Houses in Indian Industry, 19481968” Indian Economic Journal Vol. 21 No. 4-5, April-June 1974, pp. 317-45

Gladwell Malcolm (2000) "The Tipping Point: The Three Rules of Epidemics" (Available on the Internet)

GMWatch (2006) "Monsanto Indicted for Monopoly Practices" April 11, 2006 (Available on the Internet at GMWatch.org)

Goldar, Bishwanath (1986) "Import Substitution, Industrial Concentration and Productivity Growth in Indian Manufacturing" Oxford Bulletin of Economics and Statistics Vol. 48, No. 2

Goldar, Bishwanath and Suresh Chand Aggarwal (2004) "Trade Liberalization and PriceCost Margin in Indian Industries" Working Paper No. 130, Indian Council for Research on International Economic Relations, April 2004

Goldsmith Arthur A. (1999) "Slapping the Grasping Hand: Correlates of Political Corruption in Emerging Markets" American Journal of Economics and Sociology Vol. 58 No. 4 October 1999 , pp. 865-883

Government of India (1999:1) "India and the WTO", A Monthly Newsletter of the Ministry of Commerce, Vol. 1 No .9, September 1999.

Government of India (1999:2) Report of the Expert Group on Interaction Between Trade and Competition Policy Ministry of Commerce, New Delhi, January 1999 
Government of India (2000) Raghavan Committee Report: Report of the High Level Committee on Competition Policy and Law, Department of Company Affairs

Government of India (2001) The Competition Bill, 2001, Introduced into the Lok Sabha (the Lower House of the Indian Parliament) by the Minister of Law, Justice and Company Affairs on July 31, 2001

Government of India (2003) The Competition Act, 2002, The Gazette of India, January 14,2003

Government of India (2006:1) "The Competition Act, 2002, with Proposed Amendments of the Competition (Amendment) Bill 2006" (Available on the Internet)

Government of India (2006:2) "Towards Faster and More Inclusive Growth: An Approach to the $11^{\text {th }}$ Five Year Plan" Discussion Paper for Comment, Planning Commission, June 142006

Government of India (2007:1) Eleventh Five-Year Plan (2007-2012) Volume I: Inclusive Growth New Delhi December 2007

Government of India (2007:2) "Report of the Working Group on Competition Policy" Planning Commission, February 2007

Grabowski Richard (1999) "Market Evolution and Economic Development: The Evolution of Impersonal Markets" American Journal of Economics and Sociology Vol. 58 No. 4 October 1999 , pp. 699-712

Graham Edward M. (1997) "Contestability, Competition and Investment in the New World Trade Order”, Prepared for Industry Canada, January 71997

Granovetter, Michael (1985) "Economic Action and Social Structure: The Problem of Embeddedness" in (1992) M. Granovetter and R. Swedberg (Eds) The Sociology of Economic Life, Boulder Colorado: Westview Press.

Granovetter, Michael (1995) "Coase Revisited Business Groups in the Modern Economy" Industrial and Corporate Change Vol. 4 No. 1 pp. 93-130

Granovetter, Michael (2005) "Business Groups and Social Organization" in Neil J. Smelser and Richard Swedberg Editors The Handbook of Economic Sociology Russell Sage Foundation, New York, Princeton University Press, Princeton and Oxford, pp. 429450

Greif Avner (1993) "Contract Enforceability and Economic Institutions in Early Trade: The Maghribi Traders' Coalition” American Economic Review June 1993 
Grief Avner (1994) "Cultural Beliefs and the Organization of Society: A Historical and Theoretical Reflection on Collectivist and Individualist Societies" Journal of Political Economy Vol. 102 No. 5

Grief Avner (1996) "The Study of Organization and Evolving Organizational Form Through History: Reflections from the Late Medieval Family Firm" Industrial and Corporate Change Vol. 5 No. 2 pp. 473-502

Greif Avner (1997:1) "Cultural Beliefs as a Commons Resource in an Integrating World" in Partha Dasgupta, Karl-Goran Maler and Alessandro Vercelli (eds) The Economics of Transnational Commons Clarendon Press Oxford

Greif Avner (1997:2) "On the Social Foundations and Historical Development of Institutions That Facilitate Impersonal Exchange: From the Community Responsibility System to Individual Legal Responsibility in Pre-Modern Europe" Stanford U., Department of Economics Working Paper No. 97016, June 1997

Greif, Avner (2004) "Self-Enforcing Institutions: Comparative and Historical Institutional Analysis" Paper Prepared for Presentation in the European School of New Institutional Economics (ESNIE), May 2004

Gulati, Ranjay (1995) "Does Familiarity Breed Trust? The Implications of Repeated Ties for Contractual Choice in Alliances" The Academy of Management Journal Vol. 38 No. 1 Feb. 1985 pp. $85-112$

Hacker, Jacob S. (2003) "The Hidden Policies of Social Policy Reform: Uncovering and Explaining Retrenchment in America's Public-Private Welfare Regime". To appear in Wolfgang Streek and Kathleen Thelen eds. Continuity and Discontinuity in Institutional Analysis.

Hall, Peter and David Soskice (2001) "An Introduction to Varieties of Capitalism”, in P. Hall and D. Soskice eds. Varieties of Capitalism, Oxford: Oxford U. Press.

Harriss John (2003) "'Widening the Radius of Trust': Ethnographic Explorations of Trust and Indian Business" Journal of the Royal Anthropological Institute Vol. 9 Issue 4 December 2003 pp. 755-774

Harriss John (2006) "Middle-Class Activism and the Politics of the Informal Working Class: A Perspective on Class Relations and Civil Society in Indian Cities" Critical Asian Studies Volume 34, No. 4, 2006 pp. 445-465

Heide Jan. B and George John (1992) "Do Norms Matter in Marketing Relationships" Journal of Marketing Vol. 56, No. 2 April 1992, pp 32-44 
Heintzelman Martin D., Stephen W. Salant and Stephan Schott (2006), "Coordination and Free Riding: A Partnership Solution to the Common Property Problem" February 14 2006

Henley John S. (2004) "Chasing the Dragon: Accounting for the Under-Performance of India by Comparison with China in Attracting Foreign Direct Investment" Journal of International Development Vol. 16 pp. 1039-1052

Hirschman, Albert. (1982) "Rival Interpretations of Market Society: Civilizing, Destructive or Feeble" Journal of Economic Literature, Vol. XX, pp. 1463-1484

Hodgson, Geoffrey M. (1998) "Competence and Contract in the Theory of the Firm" Journal of Economic Behavior and Organization Vol. 35, pp. 179-201

HR Folks International (2004) "Corporate Houses - India" HR Management Consulting (Available on the Internet)

Huang, Yasheng and Tarun Khanna (2003) “Can India Overtake China?" Foreign Policy, July-August 2003

Hulten Charles and Sylaja Srinivasan (1999) "Indian Manufacturing Industry: Elephant or Tiger? New Evidence on the Asian Miracle" National Bureau of Economic Research, Working Paper No. 7441, Cambridge Mass., December 1999

Humphrey John and Hubert Schmitz (1998) "Trust and Inter-Firm Relations in Developing and Transition Economies" The Journal of Development Studies Vol. 34, No. 4, April 1998, pp. 32-61

IBEF (2008) "Foreign Direct Investment" India Brand Equity Foundation, October 8, 2008

India PRWire (2007) "India's FDI Outflow to Exceed Inflow in 2007-08 Study" March 16,2007

International Bar Association (2007:1) "Submission Regarding the Proposed Indian Mandatory Merger Notification Regime" Antitrust Committee: Working Group on India's Proposed Mandatory Merger Notification Regime, February 13, 2007

International Bar Association (2007:2) "Submission Regarding the Indian Merger Notification Regime and Necessary Implementing Regulations" Antitrust Committee: Working Group on India's Proposed Mandatory Merger Notification Regime, Autumn 2007

International Monetary Fund (2008:1) "India: IMF Country Report" February 2008 (Available on the Internet) 
International Monetary Fund (2008:2) "India: Selected Issues" January 4, 2008 (Available on the Internet)

Ireland Derek (1998) "Competition Policy, Intellectual Property and the Consumer", in Anderson, Robert D. and Nancy T. Gallini (General Editors), Competition Policy and Intellectual Property Rights in the Knowledge-Based Economy, Industry Canada Research Series, University of Calgary Press, pp. 293-338

Ireland, Derek (2006) "Evolution of Competition Policy and Law in India" in ReguLetter, CUTS International, Volume 7, No 3/2006, pp. 15-16

Ireland, Derek (2007:1), "Intellectual Property Rights and Competition Policy in the Knowledge-Based Economy: Compatible or Colliding Policy Regimes" Chapter 13 of Bruce Doern ed. Innovation, Science, Environment: Canadian Policies and Performance, 2007-2008, McGill-Queens U. Press

Ireland, Derek (2007:2) "The Agenda for Competition Policy and Law in India", Article to be Published as a Chapter in a Book by CUTS International/CCIER, Jaipur India (Forthcoming)

Jenkins Rob (2003) "International Development Institutions and National Economic Contexts: Neo-Liberalism Encounters India's Indigenous Political Traditions" Economy and Society Vol. 32 No. 4 November 2003 pp. 584-610

Jha, Raghbendra (2001) "Reducing Poverty and Inequality in India: Has Liberalization Helped?" Paper prepared for the WIDER Project "Rising Income Inequality and Poverty Reduction: Are They Compatible?" (Available on the Internet)

Jha, Saumitra (2005) "Trade, Institutions and Religious Conflict in India" Department of Economics Stanford University (Preliminary and Incomplete Draft Available on the Internet), December 24, 2005

Jolls Christine, Cass R. Sunstein and Richard Thaler (1998) "A Behavioral Approach to Law and Economics" Stanford Law Review May 1998 pp. 1471-1550

Jorde, Thomas M., and David J. Teece (1992), " Rule of Reason Analysis of Horizontal Arrangements: Agreements Designed To Advance Innovation and Commercialize Technology", Antitrust Law Journal, Vol. 61, No. 2, 1992, pp. 579-620.

Joskow Paul L. (2002) "Transaction Cost Economics. Antitrust Rules, and Remedies" The Journal of Law, Economics and Organization, Vol. 18, No. 1 pp. 95-116

Kahneman, D. (1994) "New Challenges to the Rationality Assumption" Journal of Institutional and Theoretical Economics, 150, 18-36. 
Kahneman, D., and Tversky, A. (1979) "Prospect Theory: An Analysis of Decision under Risk". Econometrica, 47, 263-291.

Kambhampati Uma S. (2006) "Financial Liberalization, Corporate Governance and the Efficiency of Firms in Indian Manufacturing" Structural Change and Economic Dynamics Vol. 17, pp 46-69

Kambhampati Uma S. and Ashok Parikh (2003) "Disciplining Firms: The Impact of Trade Reforms on Profit Margins in Indian Industry" Applied Economics Vol. 35 pp. $461-470$

Kathuria, Sanjay (1995) "Competitiveness of Indian Industry" in Dilip Mookherjee Editor Indian Industry: Policy and Performance Oxford U. Press Delhi, pp. 148-190

Khan, Mohsin U. (2004) "India's R\&D Policy and the Growth of the Software Industry in Comparison with China", National Institute of Science. Technology and Development Studies, New Delhi

Khanna, Tarun (2000) "Business Groups and Social Welfare in Emerging Markets: Existing Evidence and Unanswered Questions" European Economic Review, Vol. 44 pp. 748-761

Khanna, Tarun (2007) "China Plus India: The Power of Two" Harvard Business Review December 2007, pp. 60-69

Khanna, Tarun and Krishna Palepu (1997) 'Why Focused Strategies May Be Wrong for Emerging Markets” Harvard Business Review, July-August 1997 pp. 41-51

Khanna, Tarun and Krishna Palepu (1999) "Policy Shocks, Market Intermediaries, and Corporate Strategy: The Evolution of Business Groups in Chile and India" Journal of Economics and Management Strategy Vol. 8 No. 2 Summer 1999 pp. 271-310

Khanna, Tarun and Krishna Palepu (2000:1) "Emerging Market Business Groups, Foreign Intermediaries, and Corporate Governance" in: Randall K. Morck Editor, Concentrated Corporate Ownership, A National Bureau of Economic Research Conference Report, The University of Chicago Press, Chicago and London pp. 265-294

Khanna, Tarun and Krishna Palepu (2000:2) "Is Group Affiliation Profitable in Emerging Markets? An Analysis of Diversified Indian Business Groups" The Journal of Finance Vol. IV, No. 2 April 2000

Khanna, Tarun and Krishna Palepu (2004:1) "Emerging Giants: Building World Class Companies from Emerging Markets" Harvard Business School, October 17, 2004 (Available on the Internet) 
Khanna, Tarun and Krishna Palepu (2004:2) "The Evolution of Concentrated Ownership in India: Broad Patterns and History of the Indian Software Industry" NBER Working Paper Series, Working Paper 10613, National Bureau of Economic Research, June 2004

Khanna, Tarun and Krishna Palepu (2004:3) "Globalization and Convergence in Corporate Governance: Evidence from Infosys and the Indian Software Industry" Journal of International Business Studies Vol. 35 pp. 484-507

Khanna, Tarun, Krishna G. Palepu and Jayant Sinha (2005) "Strategies that Fit Emerging Markets" Harvard Business Review June 2005 pp. 63-76

Khanna, Tarun and Jan W. Rivkin (2001) "Estimating the Performance Effects of Business Groups in Emerging Markets" Strategic Management Journal Vol. 22 pp. 45-74

Khanna, Tarun and Yishay Yafeh (2005) "Business Groups and Risk Sharing Around the World" Journal of Business, 2005 Vol. 78 No. 1 pp. 301-340

Khemani, R. Shyam (2002), "Application of Competition Law: Exemptions and Exceptions", United Nations Conference on Trade and Development

Khemani, R. Shyam (2007) "Competition Policy and Promotion of Investment, Economic Growth and Poverty Alleviation in Least Developed Countries" Occasional Paper 19, World Bank

Khemani R.S. and W.T. Stanbury (1991) Historical Perspectives on Canadian Competition Policy The Institute for Research on Public Policy, Halifax N.S.

Khemani, R. Shyam and Chad Leechor (1999) "Competition Boosts Corporate Governance" (Available on the Internet)

Klemperer, Paul (1995) "Competition when Consumers have Switching Costs: An Overview with Applications to Industrial Organization, Macroeconomics and International Trade" Review of Economic Studies No. 62 pp. 515-539

Kletzer Kenneth (2004) "Liberalizing Capital Flows in India: Financial Repression, Macroeconomic Policy and Gradual Reforms" Department of Economics, UCSC (University of California, Santa Cruz, Paper 577 (Available on the Internet)

Kolasky William J. and Andrew R. Dick (2003) "The Merger Guidelines and the Integration of Efficiencies into Antitrust Review of Horizontal Mergers" Antitrust Law Journal Volume 71 No. 1 pp. 207-251

Kranton Rachel E. and Anand V. Swamy (1999) "The Hazards of Piecemeal Reform: British Civil Courts and the Credit Market in Colonial India" Journal of Development Economics Vol. 58 pp. 1-24 
Kreps, David M. (1990) "Corporate Culture and Economic Theory" in James E. Alt and Kenneth A Shepsle Editors, Perspectives on Positive Political Economy Cambridge U. Press, Cambridge

Krishna, Pravin and Devashish Mitra (1998) "Trade Liberalization, Market Discipline, and Productivity Growth: New Evidence from India" Journal of Development Economics Vol. 56, pp. 447-462

Kwotka, John E. Jr. and Lawrence J. White, (2000) "The New Industrial Organization and Small Business". Paper Presented at the Conference on Research Issues and Small Business, Office of Advocacy, Small Business Administration, Washington D.C. January 21,2000

La Croix Sumner J., Shelley M. Mark and Wing Thye Woo (2000) "Anatomy of Reform in Two Large Developing Countries: China and India" in Ulrich Hiemenz Editor Growth and Competition in the New Global Economy OECD Development Centre Seminars

Langlois Richard M. and Paul L. Robertson (1995) Firms, Markets and Economic Change Routledge, New York and London

Lawrence Robert Z. (1991) "Efficient or Exclusionist? The Import Behaviour of Japanese Corporate Groups" Brooking Papers on Economic Activity 1:1991 pp. 311-341

Lemoine Francoise and Deniz Unal-Kesenci (2007) "China and India in International Trade: From Laggards to Leaders?" CEPII: Centre D'Etudes Prospectives et D'Information Internationales, November 2007

Lensink Robert, Remco van der Molen and Shubashis Gangopadhyay (2003) "Business Groups, Financing Constraints and Investment: The Case of India" The Journal of Development Studies Vol. 40 No. 2 December 2003, pp 93-119.

Levenstein, Margaret, Valerie Suslow and Lynda Oswald (2003) “Contemporary International Cartels and Developing Countries: Economic Effects and Implications for Competition Policy" October 14, 2003

Levinsohn James (1994) "Competition Policy and International Trade" NBER Working Paper Series, Working Paper No. 4972, National Bureau of Economic Research Cambridge Mass. December 1994

Lewis William W. (2004) The Power of Productivity: Wealth, Poverty and the Threat to Global Stability The U. of Chicago Press, Chicago and London

Lindner, Johannes and Berthold Rittberger (2003) "The Creation, Interpretation and Contestation of Institutions - Revisiting Historical Institutionalism", Nuffield College, U. of Oxford (Available on the Internet) 
Lucas, Robert (1993) "Making a Miracle", Econometrica, March 1993

Madhok Anoop (2002) "Reassessing the Fundamentals and Beyond: Ronald Coase, The Transaction Cost and Resource-Based Theories of the Firm and the Institutional Structure of Production" Strategic Management Journal, Vol._23, June 2002, pp. 535-550

Mahadevan Raman (1992) "The Pattern of Industrial Control in Colonial Madras: Some Critical Observations on the Relative Position of Indian and Foreign Capital, 1930-1950" in Ghosh Arun and K.K. Subrahmanian, Mridul Eapen and Haseeb A. Drabu Editors Indian Industrialization: Structure and Policy Issues Oxford U. Press Oxford and New York pp. 333-359

Mahmood Ishtiaq P. and Chang-Yang Lee (2004) "Business Groups: Entry Barrier Innovation Debate Revisited" Journal of Economic Behaviour \& Organization, Vol. 54 pp. 513-531

Mantzavinos, C. (2001) Individuals, Institutions and Markets, Cambridge: Cambridge U. Press

McKinsey \& Company (2001) India: The Growth Imperative September 2001 (Available on the Internet)

Mehta Pradeep S. Editor (2005) Towards a Functional Competition Policy for India: An Overview CUTS International, Academic Foundation, New Delhi

Mehta Pradeep S. Editor (2006) Towards a Functional Competition Policy for India CUTS International, Academic Foundation, New Delhi

Mehta Pradeep S. Editor (2007) Competition and Regulation in India: 2007 CUTS Institute for Regulation and Competition, Jaipur India

Minister of Corporate Affairs (2007:1) "Lok Sabha: A Bill to Amend the Competition Act, 2002" August 22, 2007

Minister of Corporate Affairs (2007:2) "Press Release: Shri Prem Chand Gupta Introduces Competition Amendment Bill 2007” August 29, 2007

Moneycontrol.com (2008) "Will Competition Law Implementation Succeed in India" July 3, 2008

Mookherjee, Dilip (1995) "Introduction" in Dilip Mookherjee Editor Indian Industry: Policy and Performance Oxford U. Press Delhi, pp. 1-43

Moore Mick (1994) "How Difficult Is it To Construct Market Relations? A Commentary on Platteau" The Journal of Development Studies Vol. 30 No. 3, April 1994, pp. 818-830 
Moore Mick (1997) "Societies, Polities and Capitalism in Developing Countries: A Literature Survey" The Journal of Development Studies Vol. 33 No. 5, February 1997, pp. 287-363

Morineau, Michel (1999) "Eastern and Western Merchants From the Sixteenth to Eighteenth Centuries" in Chaudhury, Sushil and Michel Morineau Editors Merchants, Companies and Trade: Europe and Asia in the Early Modern Era Cambridge U. Press, UK, 116-144

Morris, Sebastian (2005) "Understanding Export Led Growth and Late Industrialization to Explain the Differences in the Post Reform Performance of India and China" Paper Presented at the India-China Conference at the Indira Gandhi Institute of Development Research Mumbai on February 24, 2005

Mukherji, Rahul (2000) "India's Aborted Liberalization - 1966" Pacific Affairs, Fall 2000, Vol. 73 , No. 3 pp. $375-392$

National Board of Trade Sweden (2005) "The Use of Antidumping in Brazil, China, India and South Africa - Rules, Trends and Causes" February 10, 2005 (Available on the Internet)

National Knowledge Commission (2007) "Innovation in India", June 2007

Nee Victor (1998) "Norms and Networks in Economic and Organizational Performance" The American Economic Review Vol. 88, No. 2 May 1998 pp. 85-89

Nelson Richard R. (1991) "Why Do Firms Differ, and How Does It Matter" Strategic Management Journal Vol. 12, Special Issue Winter 1991, pp. 61-74

Nelson Richard R. and Sidney G. Winter (1982), An Evolutionary Theory of Economic Change, The Belknap Press of Harvard University, Cambridge Mass. and London England.

Nijman Jan (2006) "Mumbai's Mysterious Middle Class" International Journal of Urban and Regional Research Volume 30, No. 4 December 2006, pp. 758-775

Nooteboom Bart, Hans Berger and Niels G. Noorderhaven (1997) "Effects of Trust and Governance on Relational Risk" The Academy of Management Journal Vol. 40 Bo. 2 April 1997 pp. 308-338

North, Douglas C. (1990), Institutions, Institutional Change and Economic Performance, Cambridge: Cambridge University Press.

North Douglass C. (1992) "The New Institutional Economics and Development" Washington U. St Louis (Available on the Internet) 
Olson, Mancur and Satu Kahkonen Editors (2000) A Not-So-Dismal Science Oxford: Oxford U. Press

Organization for Economic Cooperation and Development (OECD 2003) "OECD Global Forum on Competition: The Objectives of Competition Law and Policy" Note by the Secretariat, January 29, 2003

Osborn Richard N. and John Hagedoorn (1997) "The Institutionalization and Evolutionary Dynamics of Interorganizational Alliances and Networks" The Academy of Management Journal Vol. 40 No. 2 pp. 261-278

Ostrom, Elinor, James Walker and Roy Gardner (1992), "Covenants With and Without a Sword”, American Political Science Review, Vol. 86, No. 2 June 1992

Ostrom, Elinor, Gardner, Roy and James Walker, (1994) Rules, Games, \& Common-Pool Resources, Ann Arbor: The University of Michigan Press.

Ostrom, Elinor (2000) "Collective Action and the Evolution of Social Norms" Journal of Economic Perspectives Vol. 14 No. 3, Summer 2000 pp. 137-158

Ostrom Elinor and T. K. Ahn (2001) "A Social Science Perspective on Social Capital: Social Capital and Collective Action" Paper Presented to the European Research Conference on "Social Capital: Interdisciplinary Perspectives" September 15-20 2001.

Ostrom, Elinor and James Walker Editors (2003), Trust and Reciprocity: Interdisciplinary Lessons from Experimental Research, Russell Sage Foundation, New York

Oughton Christine and Geoff Whittam (1997) "Competition and Cooperation in the Small Firm Sector" Scottish Journal of Political Economy Vol. 44, No. 1 February 1997

Palat, Ravi Arvind and Immanuel Wallerstein (1999) "Of What World System Was Pre1500 'India' a Part?' in Chaudhury, Sushil and Michel Morineau Editors Merchants, Companies and Trade: Europe and Asia in the Early Modern Era Cambridge U. Press, UK pp. 21-41

Panagariya Arvind (2003) "India in the 1980s: Weak Reforms, Fragile Growth" University of Maryland (Available on the Internet)

Panagariya Arvind (2004) "India in the 1980s and 1990s: A Triumph of Reforms" IMF Working Paper WP/04/43, International Monetary Fund, March 2004

Pani Narendar (2006) "Icons and Reform Politics in India: The Case of S.M. Krishna" Asian Survey, Vol. 46, Issue 2, pp. 238-256

Paranjape, H.K. (1980) "India: Review of the Monopolies and Restrictive Trade Practices Act” Journal of World Trade Law Vol. 14 No.1 January February 1980 pp. 68-78 
Park, Seung Ho and Gerardo R. Ungson (1997) "The Effect of National Culture, Organizational Complementarity, and Economic Motivation on Joint Venture Dissolution" The Academy of Management Journal Vol. 40 No. 2 April 1997, pp. 279307

Parliament of India: Rajya Sabha (2002) Ninety-Third Report on The Competition Bill, 2001 Department-Related Parliamentary Standing Committee of Home Affairs, Rajya Sabha Secretariat, New Delhi, November 2002

Patibandla Murali (1995) "Firm Size and Export Behaviour: An Indian Case Study" The Journal of Development Studies Vol. 31 No. 6 August 1995 pp. 868-882

Patibandla Murali (1998) "Structure, Organizational Behaviour and Technical Efficiency: The Case of an Indian Industry" Journal of Economic Behavior and Organization Vol. 34 , pp. 419-434

Patibandla Murali (2002) "Product Differentiation and Market Demand for TNCs in an Emerging Economy: The Case of Indian Durable Goods Industries" Indian Economic Journal Vol. 49 No. 3 Jan.-March 2001-2002 pp. 74-81

Patibandla Murali and Bent Petersen (2001) "Role of Transnational Corporations in the Evolution of a High-Tech Industry: The Case of India's Software Industry" Department of International Economics and Management, Copenhagen Business School, Denmark (Available on the Internet)

Penrose Edith (1959) The Theory of the Growth of the Firm First Edition: Oxford: Basil Blackwell and New York: John Wiley and Sons.

Pentecost Eric J. and Tomoe Moore (2006) "Financial Liberalization in India and a New Test of the Complementary Hypothesis" Economic Development and Cultural Change pp. 487-502

Pierson Paul and Theda Skocpol (2003) "Historical Institutionalism in Contemporary Political Science" Harvard University (Available on the Internet)

Piramal, Gita (1996) Business Maharajas Penguin Books New Delhi

Platteau, Jean-Philippe (1994:1) "Behind the Market Stage Where Real Societies Exist Part I: The Role of Public and Private Order Institutions" The Journal of Development Studies Vol. 30 No. 3 April 1994, pp. 533-577

Platteau, Jean-Philippe (1994:2) "Behind the Market Stage Where Real Societies Exist Part II: The Role of Moral Norms" The Journal of Development Studies Vol. 30 No. 3 April 1994 pp. 753-817 
Poddar, Tushar (2004) Domestic Competition Spurs Exports IMF Working Paper WP/04/173, International Monetary Fund, Washington D.C., September 2004

Porter, Michael E. (1990) The Competitive Advantage of Nations, The Free Press New York

Porter, Michael E. (1996) "What is Strategy?" Harvard Business Review, NovemberDecember 1996

Porter, Michael E. (2001) Clusters of Innovation: Regional Foundations of U.S. Competitiveness, Council on Competitiveness, Washington D.C.

Portes Alejandro and William Haller (2005) "The Informal Economy" in Neil J. Smelser and Richard Swedberg Editors The Handbook of Economic Sociology Russell Sage Foundation, New York, Princeton University Press, Princeton and Oxford, pp. 403-425

Prakash Om (1985) The Dutch East India Company and the Economy of Bengal 16301720 Princeton U. Press, Princeton New Jersey

Prakash Om (1999) "The Portuguese and the Dutch in Asian Maritime Trade" in Chaudhury, Sushil and Michel Morineau Editors Merchants, Companies and Trade: Europe and Asia in the Early Modern Era Cambridge U. Press, UK pp. 175-188

Prakash, Om (2001) "The Transformation from a Pre-Colonial to a Colonial Order" (Available on the Internet)

Prashantham Shameen (2004) "Local Network Relationships and the Internationalization of Small Knowledge-Intensive Firms" The Copenhagen Journal of Asian Studies Vol. 19, pp. 5-26

Rabi Bimal (1997) “High Banking Transaction Cost are a 'Deadweight Loss': RBI Governor" Speech Given by the RBI Governor to the Symposium on Transformation of the Indian Banking and Financial System, Mumbai March 20-21, 1997

Ramamurthy Bhargavi (1995) "Small Industries and Institutional Framework: A Transaction Costs Approach" Stockholm School of Economics Working Paper Series in Economics and Finance, No. 83, November 1995

Ramaswamy K.V. (1999) "Productivity Growth, Protection and Plant Entry in a Deregulating Economy: The Case of India" Small Business Economics 1999, pp 131-139

Ramaswamy K.V. (2006) "State of Competition in the Indian Manufacturing Sector" in Pradeep S. Mehta, Editor Towards a Functional Competition Policy for India CUTS International, Academic Foundation, New Delhi, pp. 155-164 
Rampilla, Narayana Rao (1989) "A Developing Judicial Perspective to India's Monopolies and Restrictive Trade Practices Act" Antitrust Bulletin Vol. 34 No. 3 Fall 1989 pp. 655-82

Rao, Dr. P. V. Krishna (1982) "Restrictions in Large Industrial Houses Under the MRTP Act - An Analysis” Economic Affairs Vol. 27 No. 7-9 July-September 1982 pp. 507-511

Rao, Dr. P. V. Krishna and K.P. Sastry (1987) "Unfair Trade Practices Policy in India" Antitrust Bulletin Winter 1987 pp. 1051-1069

Rao, Dr. P.V. Krishna and K.P. Sastry (1989) "Restrictive Trade Practices Policy in India", The Journal of Industrial Economics Vol. XXXVII No. 4 June 1989

Ray, Sougata (2004) "Performance Implications of Corporate Strategic Behaviour of Firms in an Emerging Economy during Economic Liberalization" Problems and Perspectives in Management Vol. 2 pp. 246-256

Raychaudhuri, Tapan and Irfan Habib Editors (1982) The Cambridge Economic History of India; Volume I: c. 1200 -- c. 1750 Cambridge U. Press, Cambridge UK

Redding Gordon S. (1993) The Spirit of Chinese Capitalism Walter de Gruyter, New York and Berlin

Redding Gordon S. (1995) "Overseas Chinese Networks: Understanding the Enigma" Long Range Planning Volume 28 No. 1 pp. 61-69

Reur Jeffrey J., Maurizio Zollo and Harbir Singh (2002) "Post-Formation Dynamics in Strategic Alliances" Strategic Management Journal 23 pp. 135-151

Rey Patrick and Jean Tirole (2001) "Alignment of Interests and the Governance of Joint Ventures" February 8, 2001 (Available on the Internet)

Ricart, Joan Enric, Michael J. Enright, Pankaj Ghemawat, Stuart L. Hart, and Tarun Khanna (2004) "New Frontiers in International Strategy" Journal of International Business Studies Vol. 35, No. 3 may 2 pp. 175-200

Richter Rudolf (2002) "The New Institutional Economics - Its Start, Its Meaning, Its Prospects (Preliminary Version -- Available on the Internet)

Robertson Paul L. and Tony F. Yu (2001) "Firm Strategy, Innovation and Consumer Demand: A Market Process Approach" Managerial and Decision Economics, Vol. 22, No. 4/5, Strategy and the Market Process. June-August, 2001, pp. 183-199.

Robinson Kenneth (1986) "Maximizing the Public Benefits from the AT\&T Breakup" Journal of Policy Management and Analysis Vol. 5 No. 3 pp. 572-583 
Rodrik Dani (2001) "Development Strategies for the Next Century" Harvard U. August 2001 (Available on the Internet)

Rodrik Dani, Arvind Subramanian, and Francesco Trebbi (2004) "Institutions Rule: The Primacy of Institutions Over Geography and Integration in Economic Development" Journal of Economic Growth Vol. 9 No. 2 pp. 131-165

Rodrik Dani and Arvind Subramanian (2005) "From "Hindu Growth" to Productivity Surge: The Mystery of the Indian Growth Transition" IMF Staff Papers Vol. 52, Number 2, International Monetary Fund, pp. 192-228

Rothermund, Dietmar (1993), An Economic History of India: From Pre-Colonial Times to 1991, Routledge, London and New York

Roy, Tirthankar (2000), The Economic History of India: 1857-1947, Oxford U. Press, New Delhi

Rumelt Richard P., Dan Schendel and David J. Teece (1991) "Strategic Management and Economics” Strategic Management Journal Vol. 12, Special Issue Winter 1991, pp. 5-29

Sako, Mari and Susan Helper (1998) "Determinants of Trust in Supplier Relations: Evidence from the Automotive Industry in Japan and the United States" Journal of Economic Behavior and Organization Vol. 34 pp. 387-417

Sayer, Andrew (1984) Method in Social Science, Hutchinson, London.

Scheffman David T. and Richard S. Higgins (2003) "20 Years of Raising Rivals Costs: History, Assessment and Future" George Mason Law Review, Vol. 12:2, pp. 371-387

Schmalensee Richard (1989) "Inter-Industry Studies of Structure and Performance" in Richard Schmalensee and Robert D. Willig Editors Handbook of Industrial Organization: Volume II North Holland New York, pp. 951-1009

Schmidt Vivien A. (2003) "French Capitalism Transformed, Yet Still a Third Variety of Capitalism" Economy and Society Volume 32 Number 4 November 2003 pp. 526-554

Schmitz Hubert (1995) "Collective Efficiency: Growth Path for Small-Scale Industry" The Journal of Development Studies Vol. 31 no. 4 April 1995, pp. 529-566

Schumpeter, Joseph A. (1934) The Theory of Economic Development, Harvard U. Press

Schumpeter, Joseph (1976) Capitalism, Socialism and Democracy. 3d ed. New York: Harper Torchbooks

Scotchmer Suzanne (1998) "R\&D Joint Ventures and Other Cooperative Arrangements", in Anderson, Robert D. and Nancy T. Gallini (General Editors), 
Competition Policy and Intellectual Property Rights in the Knowledge-Based Economy, Industry Canada Research Series, University of Calgary Press, pp. 203 to 221

Schmidt Vivien A. (2003) "French Capitalism Transformed, Yet Still a Third Variety of Capitalism" Economy and Society Volume 32 Number 4 November 2003 pp. 526-554

Scott, James C (1998). Seeing Like a State: How Certain Schemes to Improve the Human Condition Have Failed. New Haven: Yale University Press.

Sen, Kunal and S. Chand (1999) "Competitive Pressures from Trade Exposure: Evidence from Indian Manufacturing" Indian Economic Review Vol. 34, No. 2 July-Dec. 1999, pp. 113-126

Sen, Kunal (2002) "Trade Policy, Equipment Investment and Growth in India" Oxford Development Studies Vol. 30, No. 3, 2002

Sharma Gunjan (2005) "Strategic Complementarities Between Trade and Industrial Policies" Department of Economics, University of Maryland, College Park, December 2005 (Available on the Internet)

Sharma Gunjan (2006) "Competing or Collaborating Siblings? Industrial and Trade Policies in India" Department of Economics, University of Maryland, College park, January 1, 2006 (Available on the Internet)

Sims Joe and Deborah P. Herman (1997) "Twenty Years of Hart-Scott-Rodino Merger Enforcement: The Effect of Hart-Scott-Rodino on Merger Practice: A Case Study in the Law of Unintended Consequences Applied to Antitrust legislation" Antitrust Law Journal Vol. 65 Issue 3, Spring 1997

Singh Ajit (2004) "Multilateral Competition Policy and Economic Development: A Developing Country Perspective on the European Community Proposals", UNCTAD Series on Issues in Competition Law and Policy

Singhi Surabhi (2003) "Competition Act, 2002, And Its Relevance" (Available on the Internet)

Sinha Aseema (2005:1) The Regional Roots of Developmental Politics in India: A Divided Leviathan Indiana University Press, Bloomington and Indianapolis

Sinha Aseema (2005:2) "Understanding the Rise and Transformation of Business Collective Action in India" Business and Politics Volume 7, Issue 2

Sivadasan Jagadeesh (2003) "Barriers to Entry and Productivity: Micro-evidence from Indian Manufacturing Sector Reforms" PhD Dissertation, University of Chicago 
Smith-Doerr, Laurel and Walter W. Powell (2005) "Networks and Economic Life" in Neil J. Smelser and Richard Swedberg Editors The Handbook of Economic Sociology Russell Sage Foundation, New York, Princeton University Press, Princeton and Oxford, pp. $379-402$

Spengler, Joseph J. (1971) Indian Economic Thought: A Preface to its History Duke U. Press, Durham N.C.

Srinivasan T. N. (2003) "The Costs of Hesitant and Reluctant Globalization" Revised and Expanded Version of the V. K. Ramaswami Memorial Lecture, Delivered at the Delhi School of Economics on 21 March 2003, and to Appear in the Indian Economic Review (Available on the Internet)

Srinivasan T. N. (2004) "China and India: Economic Performance, Competition and Cooperation: An Update” Journal of Asian Economics Vol. 15 pp. 613-636

Standing Committee on Finance (2006-2007); Fourteenth Lok Sabha (2006) "Ministry of Company Affairs: Competition (Amendments) Bill, 2006" Forty-Fourth Report. Lok Sabha Secretariat, New Delhi, December 2006

Stiglitz, Joseph E. (1999), "Promoting Competition Policy and Regulatory Policy: With Examples from Network Industries", The World Bank, July 25, 1999

Stiglitz, Joseph E. (2001), "Information and the Change in the Paradigm in Economics", Columbia Business School, Columbia U., New York, Prize Lecture, December 8, 2001.

Stiglitz, Joseph (2003), "Ethics, Markets and Government Failure" (Available on the Internet)

Streeck Wolfgang and Kathleen Thelen (2004) "Institutional Change in Advanced Economies" Chapter 1 in Change and Continuity in Institutional Analysis: Exploration in the Dynamics of Advanced Political Economies (Publication Pending - Available on the Internet)

Swaminathan, Padmini (1992) "Liberalization, Market Concentration and Growth: A Study of the TVS Group of Companies" in Ghosh Arun and K.K. Subrahmanian, Mridul Eapen and Haseeb A. Drabu Editors Indian Industrialization: Structure and Policy Issues Oxford U. Press Oxford and New York pp. 184-207

Takigawa, Toshiaki (2005) "A Comparative Analysis of U.S. EU, and Japanese Microsoft Cases: How to Regulate Exclusionary Conduct by a Dominant Firm in a Network Industry" The Antitrust Bulletin Vol. 50, No.2/Summer 2005, pp. 237-266

Taknet, Dr, D. K. (1986) Industrial Entrepreneurship of Shekhawati Marwaris Department of Business Administration, University of Rajasthan, Jaipur 
Teece David J. (1980) "Economies of Scope and the Scope of the Enterprise" Journal of Economic Behaviour and Organization, pp. 223-247

Teece David J. (1992) "Competition, Cooperation and Innovation: Organizational Arrangements for Regimes of Rapid Technological Progress" Journal of Economic Behaviour and Organization 18 pp. 1-25

Thompson, Aileen J. (2000) "Import Competition and Market Power: Canadian Evidence" Statistics Canada Analytical Studies Branch Research Paper Series, No. 139

Till Irene and Carl H. Fulda (1968) "Concentration and Competitive Potential in India" Antitrust Bulletin Vol. 13 pp. 999-1016

Timberg, Thomas A. (1969) "The Origins of Marwari Industrialists" in Paul Robert and Mary Jane Beech Editors (1969) Fifth Annual Conference on Bengal Studies: Bengal Change and Continuity Asian Studies Center, Michigan State U., East Lansing Michigan

Tirole, Jean (1988), The Theory of Industrial Organization, Cambridge: MIT Press

Tirole, Jean (2001) “Corporate Governance” Econometrica Vol. 69 No. 1, January 2001 pp. 1-35

Tirumalai R. (1986) The Voice of Enterprise: 150 Years of the Madras Chamber of Commerce and Industry Macmillan India Limited, Madras

Topalova Petia (2005) "Trade Liberalization, Poverty and Inequality: Evidence from Indian Districts" Department of Economics, Massachusetts Institute of Technology, August 2005 (Available on the Internet)

The Economic Times (2008) "Will the New Competition Law Lead to Slowdown in India's Corporate Deals" February 22, 2008

The Financial Express (2008) "Non-Implementation of Competition Policy Bars Growth, Says CCII" August 11, 2008

The Tribune (2006) "Probe May Clear Jet-Sahara Deal”" May 23, 2006

Tripathi Dwijendra (1987), State and Business in India: a Historical Perspective, Manohar Publications, New Delhi

Tripathi Dwijendra Editor (1991) Business and Politics in India: A Historical Perspective Indian Institute of Management, Ahmedabad, Manohar Publications, New Delhi

Tripathi Dwijendra (2004) The Oxford History of Indian Business Oxford University Press New Delhi 
Tripathi Dwijendra and Makrand Mehta (1990) Business Houses in Western India: A Study in Entrepreneurial Response, 1850-1956 Manohar Publications, New Delhi

UNCTAD (1997), "Empirical Evidence of the Benefits from Applying Competition Law and Policy Principles to Economic Development in Order to Attain Greater Efficiency in International Trade and Development", Report of the UNCTAD Secretariat, TD/B/COM.2/EM/10, 18 September 1997

UNCTAD (2001) World Investment Report 2001: Promoting Linkages United Nations Conference on Trade and Development, United Nations New York and Geneva

UNCTAD (2007) World Investment Report: Transnational Corporations, Extractive Industries and Development United Nations New York and Geneva

UNCTAD (2008) World Investment Report: Transnational Corporations and the Infrastructure Challenge United Nations New York and Geneva

UN Volunteers, TERI and the New Academy of Business (2004) "Enhancing Business Community Relations: The Role of Volunteers in Promoting Global Corporate Citizenship" National Research Report, New Delhi India, March 2004

Uppal, Mahesh (2006) "Competition Issues in Telecommunication Sector" in Pradeep S. Mehta, Editor Towards a Functional Competition Policy for India CUTS International, Academic Foundation, New Delhi, pp. 205-219

Vachani Sushil (1997) "Economic Liberalization's Effect on Sources of Competitive Advantage of Different Groups of Companies: the Case of India" International Business Review, Vol. 6, No. 2, pp. 165-184

Van Dijk, Meine Pieter (2003) "Government Policies With Respect to an Information Technology Cluster in Bangalore, India" European Journal of Development Research Vol. 15 No. 2 December 2003, pp 93-108.

Varshney Ashutosh (2007) "Democracy vs. Growth in India" Foreign Affairs March 9, 2007

Vaugier-Chatterjee (2003) "The Politics of Business: History and Strategies of Five Industrial Empires" in Bruno Dorin Editor The Indian Entrepreneur: A Sociological Profile of Businessmen and Their Practices Manohar, A Publication of the French Research Institutes in India, pp. 65-100

Virmani Arvind, and Surabhi Mittal (2006) "Domestic Market Integration" Working Paper No. 183, Indian Council for Research on International Economic Relations, July 2006 
Weigelt Keith and Colin Camerer (1988) "Reputation and Corporate Strategy: A Review of Recent Theory and Applications" Strategic Management Journal Vol, 9 pp. 443-454

Wilson Chris M. and Catherine Waddams-Price (2005), "Irrationality in Consumers' Switching Decisions: When More Firms May Mean Less Benefit", ESRC Centre for Competition Policy, School of Economics and School of Management, University of East Anglia, CCP Working Paper 05-4. Revised August 2005. Paper is available from the Web site at: www.ccp.uea.ac.uk/public_files/workingpapers/CCP05-4.pdf

Wariavwalla Bharat (1988) "India in 1987: Democracy on Trial" Asian Survey Vol. 28, No. 2, A Survey of Asia in 1987, Part II (Feb. 1988), pp. 119-125.

Werden Gregory J. (2001) "Network Effects and Conditions of Entry: Lessons from the Microsoft Case" Antitrust Law Journal Vol. 69 Issue 1

Williamson Oliver E. (1968) "Economies as an Anti-Trust Defense: The Welfare TradeOffs", American Economic Review 58, pp. 18-36.

Williamson Oliver E. (1975) Markets and Hierarchies: Analysis and Antitrust Implications The Free Press New York

Williamson Oliver E. (1980) "The Organization of Work: A Comparative Institutional Assessment" Journal of Fconomic Behaviour and Organization Vol. 1 pp. 5-38

Williamson Oliver E. (1985), The Economic Institutions of Capitalism, The Free Press, Collier Macmillan Publishers, New York and London

Williamson, Oliver E. (1986) Economic Organization: Firms, Markets and Policy Control Wheatsheaf Books, Brighton Sussex UK

Williamson Oliver E. (1991:1) "Economic Institutions: Spontaneous and Intentional Governance" Journal of Law, Economics and Organization Vol. 7 January 1991, pp. 159187

Williamson Oliver E. (1991:2) "Strategizing, Economizing and Economic Organization" Strategic Management Journal, Vol. 12, Special Issue: Fundamental Research Issues in Strategy and Economics (Winter 1991), pp. 75-94

Williamson, Oliver E. (1998) "Human Actors and Economic Organization" Paper for the 1998 Paris ISNIE Conference

Williamson, Oliver E. (1999:1) "Public and Private Bureaucracies: A Transaction Cost Economics Perspective" The Journal of Law, Economics and Organization Vol. 15 No. 1 pp. 306-342 
Williamson, Oliver E. (1999:2) "Strategy Research: Governance and Competence Perspectives" Strategic Management Journal Vol. 20 pp. 1087-1108

Williamson, Oliver E. (2000:1) "Economic Institutions and Development: A View from the Bottom." From Mancur Olson and Satu Kahkonen eds. A Not-So-Dismal Science Oxford: Oxford U. Press.

Williamson, Oliver E. (2000:2) "Empirical Microeconomics: Another Perspective" University of California Berkeley, September 2000 (Available on the Internet)

Williamson, Oliver E. (2000:3) "The New Institutional Economics: Taking Stock and Looking Ahead", The Journal of Economic Perspectives Volume 38, No. 3 September 2000 , pp. 595-613

Williamson, Oliver E. (2002:1) "The Lens of Contract: Private Ordering" The American Economic Review Vol. 92 No. 2 May 2002 pp. 438-443

Williamson, Oliver E. (2002:2) "The Theory of the Firm as Governance Structure: From Choice to Contract" Journal of Economic Perspectives Vol. 16, No. 3 Summer 2002, pp. $171-195$

Williamson, Oliver E. (2005:1) "The Economics of Governance" American Economic Review Vol. 95, No. 2 May 2005 pp. 1-18

Williamson, Oliver E. (2005:2) "Transaction Costs and Business Administration" Scandinavian Journal of Management Vol. 21 pp. 19-40

Wing Coady and Stephan Schott (2004) "Communications and Information Disclosure in Social and Commons Dilemmas" Carleton U., Work in Progress, Sept. 202004

World Bank (1993), The East Asian Miracle: Economic Growth and Public Policy, World Bank, Washington D.C.

World Bank (2002) World Development Report 2002: Building Institutions for Markets, The World Bank Washington D. C., September 2001

World Bank (2004), "Competition Law and Regional Economic Integration: An Analysis of the Southern Mediterranean Countries", World Bank Working Paper No. 35

World Bank (2007:1) "Doing Business in South Asia in 2007" pp. 29-36 (Available on the Internet)

World Bank (2007:2) World Development Report 2008: Agriculture for Development The World Bank, Washington D.C. 
World Bank (2008) "Doing Business 2009: Overview" The World Bank, Washington D.C.

Zhuang, Guotu (2006) "Trends of Overseas Chinese Business Network in East Asia: As Mirrored from Overseas Chinese Investment in Mainland China since 1978" Ritsumeikan International Affairs Volume 4, pp. 1-23 